
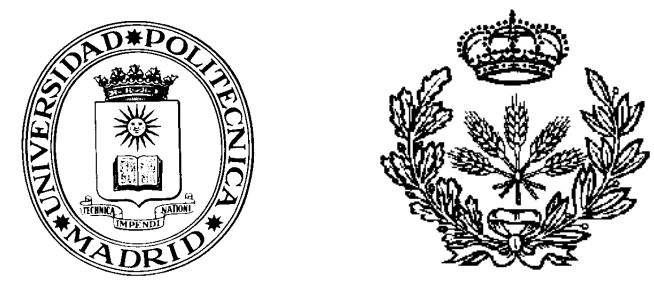

UNIVERSIDAD POLITÉCNICA DE MADRID

ESCUELA TÉCNICA SUPERIOR DE INGENIEROS AGRÓNOMOS

Departamento de Proyectos y Planificación Rural

\title{
Educación Superior de la Ingeniería \\ Industrial en el Perú: propuesta de un modelo educativo desde las competencias
}

\section{TESIS DOCTORAL}

Francisco Martín Palma Lama

Ingeniero Industrial

Madrid, abril de 2016 


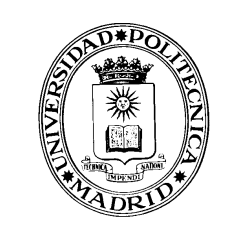

UNIVERSIDAD POLITECNICA DE MADRID

(D-16)

Tribunal nombrado por el Magfco. Y Excmo. Rector de la Universidad Politécnica de Madrid el día 14 de julio de 2014.

Presidente:

Vocal

Vocal:

Vocal:

Secretario:

Suplente:

Suplente:

Realizado el acto de Prelectura y defensa de la Tesis el día 14 de julio de 2014. En la ETSI Agrónomos.

EL PRESIDENTE

LOS VOCALES

EL SECRETARIO 
Departamento de Proyectos y Planificación Rural

Escuela Técnica Superior de Ingenieros Agrónomos

\section{UNIVERSIDAD POLITÉCNICA DE MADRID}

\section{Educación Superior de la Ingeniería Industrial en Perú: propuesta de un modelo educativo desde las competencias}

Francisco Martín Palma Lama

Ingeniero Industrial

Director: Ignacio de los Ríos Carmenado

Dr. Ingeniero Agrónomo

Madrid, 2016 
A Ricardo y Olga A Sandra

A Luciana y Joaquín 
Motivación 
Me inicié en la docencia universitaria hace 26 años. Entonces era un joven egresado de Ingeniería Industrial que iniciaba la enseñanza a jóvenes estudiantes universitarios, dirigido por profesores mayores con vasta experiencia académica. En aquel tiempo era un "Futuro Docente" formándose para ser Profesor. Especial gusto me producían las áreas de matemáticas y electrotecnia. Con el tiempo me convertí en Profesor Contratado y con ello llegaron los encargos administrativos: elaboración de Exámenes de Admisión de Ingeniería, miembro de la Comisión de Admisión, asistente del Laboratorio de Electrotecnia, esto en los primeros años de actividad académica. Pasados dos años estuve en la Università La Sapienza en Roma siguiendo una especialización en Accionamientos eléctricos de potencia por un año para luego retornar a la docencia.

Al convertirme en Profesor Auxiliar la necesidad de aplicar lo aprendido a problemas reales comenzó a inquietarme. Esto me llevó a pedir una licencia y trabajar como Especialista de Mantenimiento Eléctrico en EGENOR, una nueva e importante empresa de generación de energía eléctrica en el Norte del Perú, encargada de preparar este tipo de empresas para su privatización, ya que hasta mediados de los años 90 del siglo pasado eran estatales. Allí pude participar de muchos proyectos de generación de energía para la ciudad y toda la Región Piura y Tumbes; el principal objetivo era dejar un servicio suficiente para abastecer la demanda de energía al 100\% sin interrupciones, algo que en ese momento no se podía garantizar. Los objetivos se consiguieron con éxito en relativamente poco tiempo.

En esas circunstancias, fui convocado por el Ministro de Educación para cubrir el cargo de Director Regional de Educación de Piura. Hasta ahora no tengo claro cómo llegó hasta mí. Tengo entendido que pidieron referencias a la Universidad de Piura, de donde yo provenía y había trabajado, y por las referencias de allí obtenidas es que decidieron proponerme el cargo. Decisión difícil pues es un sector complejo, amplio y financieramente magro; decidí aceptar el reto y dirigirlo. Así, en 1996 fui Director Regional de Educación de Piura, una de las 24 regiones de Perú, hasta el 2001. Dado que a este tipo de funcionarios los designaba el Ministro, la duración de un director en el cargo era inferior a la del ministro en el suyo. Acompañé la gestión de tres Ministros de Educación por cinco años. Es el período más largo que ha permanecido en ejercicio un Director Regional de Educación en el Perú. En ese tiempo, de la Dirección de educación de Piura dependían 15,000 profesores, más de cuatro mil centros educativos y se gestionaba un presupuesto mayor a cinco millones de dólares mensuales. Esta experiencia marcó en mí una gran necesidad de mejorar las condiciones sociales para el desarrollo de mi región, por lo que luego me desempeñé como Director de Educación, Cultura y Deporte de la Municipalidad Provincial de Piura, por un año. Fue en estos cargos donde conocí las fortalezas y debilidades de la educación básica peruana y piurana. Los constantes viajes me permitieron interiorizar la realidad socio - económica de las ocho provincias de Piura en sus casi $36,000 \mathrm{~km}^{2}$ de superficie. Comencé entender sus necesidades en la costa, sierra y selva tropical; a comprender que sus problemas solo se resolverían desde dentro, cuando las personas que tenían las necesidades pudieran contar con los medios, recursos, conocimientos y ayuda para superar las dificultades. Hicimos muchas tareas propias y ajenas a la educación, varios proyectos de mejora social y educativa, siempre vinculando autoridades con profesores y padres de familia. 
La experiencia obtenida me enseñó que la poca o no apropiada formación de quienes toman decisiones, de quienes ejecutan tareas concretas o de los beneficiarios de estas, según sea el caso, puede hacer infructuosos los esfuerzos y los recursos que se depositen para resolver algún problema. No necesariamente se encuentra el origen del fracaso de un intento de solución en una mala intención, un mal planteamiento de la necesidad o discrepancias personales o de grupo; descubrí que en la mayor parte de los casos el fracaso se origina por no saber definir el problema, no saber acotar lo que se quiere abordar, no saber cómo resolverlo eficientemente o no saber cómo confirmar si lo que se hizo sirvió o no, y si vale la pena sostenerlo o eliminarlo.

El 2002 me reincorporé a la Universidad de Piura como Profesor Auxiliar a tiempo completo, en las Áreas de Matemática y de Investigación y gestión de operaciones. En el 2009 me convertí en Profesor Asociado C (existen tres niveles, el C es el más alto). En el 2016 he alcanzado el de Profesor principal. Volver a la vida académica me confirmó que desde allí se puede impactar significativamente la situación que había observado en los intentos de desarrollo social y económico, pues si los jóvenes ingenieros egresaran con conocimientos, formación humana y competencias apropiadas para superar las fallas que había observado, se evitarían pérdidas de dinero, esfuerzos y tiempo en el desarrollo de soluciones efectivas para los viejos y nuevos problemas que nuestra sociedad concentra.

En esos años de actividad académica he tenido cargos administrativos y de gobierno dentro de la Facultad de Ingeniería: Director del Programa Académico de Ciencias Básicas, Director del Programa Académico de Ingeniería Industrial, Coordinador de los Programas Académicos, Director de Estudios de la Facultad, Director de los Programas Académicos de la Facultad y ahora Vicedecano Académico de la Facultad de Ingeniería; fuera de la Facultad, Jefe de la Oficina de Admisiones de la Universidad. Durante estos años he tenido constante contacto con empresas, alumnos, profesores, padres de familia, autoridades políticas, colegas, y siempre me han hecho llegar sus comentarios, opiniones, objeciones, valoraciones, elogios y críticas a lo que hacía y lo que representaba.

Las experiencias y convicciones anteriores, unidas a estos mensajes de los grupos interesados en la tarea universitaria, acrisolaron mi convicción en que se han intensificado los requerimientos de contar con profesionales que sean capaces de dirigir el crecimiento económico, demográfico y social que experimenta el país; en que es necesario tener ingenieros capaces de responder no solo a las exigencias técnicas que les presenta un problema, si no también a identificarlo, acotarlo, planificar la solución, coordinar con las autoridades e interesados, resolverlo, y que permanezca en el tiempo, que sea suyo; y que tan persistente como las anteriores características, es imperiosa la necesidad de que estos nuevos profesionales sean íntegros, conocedores de su contexto, respetuosos de las localidades en que actúan y con conciencia social.

El país se ha inclinado hacia los proyectos de inversión, pero no ha dejado de lado los proyectos de desarrollo social, que cada vez son más y de mayor envergadura. De un lado el estado exige que solo se haga una inversión si se tiene un proyecto aprobado por el Ministerio de Economía y finanzas y el año 2012 adoptó oficialmente la metodología PMI como base de evaluación. Por otro lado, los empresarios reclaman la gestión de proyectos para ser competitivos, los alumnos 
y sus padres la reclaman su conocimiento para favorecer su inserción laboral, y la sociedad como un medio de escalar un peldaño hacia el desarrollo.

Por eso entendí que era conveniente fortalecer la formación que dábamos en Ingeniería Industrial y definir si la orientación que tenía era la apropiada respuesta a estas necesidades; si bastaba ser considerados cognitiva, ética y técnicamente entre los mejores del país. Todo indica, de acuerdo a la información que durante años he recogido, que los jóvenes egresados requieren una base sólida de proyectos y para lograrlo lo primero sería conocer los proyectos en su esencia, desde su concepción, desde dentro; sobre todo proyectos con enfoque social, de desarrollo; que no solo se midiera el resultado desde la óptica económica, que no debe evitarse y que es muy importante, sino también el impacto social y su permanencia en el tiempo. Sabiendo esto, decidí emprender un nuevo gran proyecto: formular una carrera de ingeniería industrial que respondiese a las solicitudes del rigor académico y las necesidades del entorno, tal como las he definido.

Supe del Doctorado de planificación y gestión de proyectos de desarrollo rural sostenible por un profesor amigo que lo acababa de seguir. Este doctorado me impactó pues su diseño se apoya en los pilares de la planificación y modelos de desarrollo, la evaluación socio económica y en los métodos y estrategias participativas de la gestión del desarrollo (dirección de proyectos). Consideré que el enfoque era el más apropiado para poder afrontar el problema que tenemos: diseñar un modelo educativo que favorezca la formación de ingenieros industriales en Perú, con rigor académico y que responda a los actuales requerimientos del entorno.

Con lo aprendido en el periodo lectivo, la experiencia de la búsqueda de información, las publicaciones hechas, la convivencia con experimentados investigadores, el grato y exigente ambiente de trabajo en la UPM, la calidad y calidez de los profesores y directores de trabajo, estoy convencido que este doctorado me permitirá alcanzar los resultados que tracé al inicio y el presente documento muestra el inicio un camino por recorrer. 
Resumen 
El objetivo del presente trabajo de investigación es diseñar un Modelo de Educación que permita formar ingenieros industriales en Perú que sean capaces de enfrentar los retos modernos de fuerte y sostenido crecimiento económico y social. Las necesidades que se han generado a lo largo de los últimos años llevan a identificar que una gran carencia es el poco dominio del concepto, naturaleza y gestión de un proyecto y la marcada ausencia de habilidades humanas y funcionales al momento de ejercer la profesión; entendiendo proyecto como "Un esfuerzo temporal que se lleva a cabo para crear un producto, servicio o resultado único. La naturaleza temporal de los proyectos indica un principio y un final definidos. El final se alcanza cuando se logran los objetivos del proyecto o cuando se termina el proyecto porque sus objetivos no se cumplirán o no pueden ser cumplidos, o cuando ya no existe la necesidad que dio origen al proyecto.... los proyectos pueden tener impactos sociales, económicos y ambientales susceptibles de perdurar mucho más que los propios proyectos."'1.

Entonces, formularnos la hipótesis que es posible tener un modelo educativo para la Ingeniería Industrial de Perú que permita y estimule alcanzar estas características tan reclamadas por la sociedad, confiando desde el inicio que su diseño y empleo tendrá fuerte repercusión tanto en el desarrollo personal de los estudiantes, como en el social y económico, por las habilidades y condiciones que serán capaces de desplegar los egresados en sus ámbitos de acción laboral.

Para lograr el objetivo se ha hecho una definición de la identidad de la universidad latinoamericana y una verificación de si es posible o no tomar modelos y experiencias de otros lugares y trasladarlos con éxito a escenarios nuevos y distintos. Luego, se han determinado las tendencias más fuertes en la formación de ingenieros industriales en los contextos más exitosos actualmente. Para definir esas habilidades tan reclamadas por el sector público y privado de la sociedad, se busca y define una codificación de competencias genéricas que permite tener un ingeniero moderno bien perfilado para las exigencias globales.

Los pasos finales son determinar el Modelo para la Educación Superior de la Ingeniería Industrial de Perú desde las Competencias (MESIC) a partir de novedosos enfoques para la educación como la contextualización, la gestión del conocimiento experto y experimentado, el enfoque socioformativo y la definición de Aspectos Clave del modelo antes de iniciar una planificación curricular de ingeniería. Al final se muestra una aplicación del modelo llegando a detalles de definición de competencias muy interesantes y a la necesidad de contar con un sistema de aseguramiento de calidad de la gestión curricular.

Al término de la investigación concluimos que es posible definir un modelo apropiado para formar ingenieros industriales en Perú desde las competencias, capaces de enfrentar los modernos retos locales y globales. También determinamos que el proceso no puede ser impuesto, debe pasar por un transitorio periodo de adecuación de docentes y alumnos y requiere de compromiso, pues se suele enfocar este cambio como una forma de desestimar todo lo

\footnotetext{
${ }^{1}$ Guía para los fundamentos de la dirección de proyectos (Guía del PMBOK®) Quinta Edición. Project Management Institute. 2013. Pensilvania. USA. Pp 3. ISBN 978-1-62825-009-1.
} 
anterior, cuando debe entenderse que son procesos complementarios, ya que los importantes logros con clases magistrales y resolución de problemas son evidentes y se trata de estilos diferentes de encarar la educación. El resultado de la imposición puede ser devastador para algunos estudiantes y frustrante para algunos docentes, consecuencias que no se desean y deben evitarse.

La aplicación se realiza en una universidad del norte de Perú, la Universidad de Piura, y puede observarse en el último capítulo de este trabajo. 
Summary 
The main objective of this research is to find an Educational Modell in order to train industrial engineers in Peru who are able to face modern challenges of strong and sustained economic and social growth. Over recent years the generated needs have led to understand that a major weakness in our professionals is the poor skills in project management and the marked absence of functional and human skills when exercising the profession.

This diagnose has led to formulate the hypothesis that it is possible to have an educational model for Peru Industrial Engineering that allows and encourages to achieve these features which are claimed by society. A project which we trust will have a strong impact from the beginning on both, personal development of students as well as in the social and economic conditions, considering the skills graduates will be able to deploy in their work fields.

To achieve the goal first it was defined the identity of the Latin American university and verified whether it is possible or not to take models and experiences elsewhere and move successfully to new and different scenarios. Then there were determined the strongest trends in the industrial engineers training in currently successful contexts.

In order to define these demanded skills by the public and private sectors of society, there are defined a set of generic skills that allows to have a modern engineer well profiled for global context.

Considering these elements, a Model for Higher Education in Industrial Engineering from Peru Competence (MESIC)is proposed considering novel approaches to education such as territoriality, skilled and experienced knowledge management, socio - formative approach and set the definition of Key aspects of the model before starting a engineering curricular planning.

Finally detailed records of an application of the model is shown through modern learning methodologies, development and assessment of skills and the need to have a quality assurance system for entire curriculum management.

Through this research it can be concluded that it is possible to determine an appropriate model to train industrial engineers in Peru from the skills, in order to meet the modern local and global challenges. Results show that the process cannot be imposed, instead it must go through a transitional period of adaptation from teachers and students and requires commitment, focusing that this change usually is a way to dismiss the above, and is important to address that there are obvious achievements on education lectures and problem solving, and it should be understood that they are complementary processes. The result of change imposition can be devastating for some students and frustrating for some teachers, unwanted consequences and they should be avoided.

The proposed model is applied at a university in northern Peru, the University of Piura, and the results can be seen in the last chapter of this work. 
Índices 


\section{Índice general}

Introducción

a._Preguntas de la investigación.

b._Objetivos e hipótesis de investigación.

b.1___objetivo general. 4

b. 2 Objetivos específicos. 4

b.3__Hipótesis. 4

c._Metodología general de la investigación 5

c.1.4_Esquema General de la Investigación 6

c.1.1._Etapa uno: Marco contextual y conceptual.___ 8

c.1.2._Etapa dos: Propuesta de modelo conceptual.___ 8

c.1.3__Etapa tres: Aplicación del modelo.__ 9

c.1.4._Etapa cuatro: Conclusiones._ 9

d._Producción científica asociada a la investigación.__ 9

e._Referencias de la Introducción.__ 10

Capítulo I_ 13

INDICE CAPITULO I

INDICE DE TABLAS CAPITULO I__ 16

INDICE DE GRÁFICOS CAPITULO I__ 17

1.1 INTRODUCCIÓN

1.2 EVOLUCIÓN DE LA UNIVERSIDAD LATINOAMERICANA: PERIODOS HISTÓRICOS

1.2.1 La universidad latinoamericana colonial (s. XVI - s. XVIII) _ 21

1.2.2 La Universidad Latinoamericana Republicana: el periodo napoleónico (s.XVIII - s. XX) ___ 24

1.2.3 La Universidad Latinoamericana del siglo XX: los procesos de reforma 26

1.2.3.1 La Primera Reforma: la autonomía y el cogobierno $(1918-1975) \_26$

1.2.3.2 La Segunda Reforma: la mercantilización y la educación binaria $(1975$ - 1995)___ _ 28

1.2.3.2.1 Incremento y diversificación de las universidades privadas __ 29

1.2.3.2.2 Masificación, feminización y nuevo perfil estudiantil __ 29

1.2.3.2.3 El agotamiento de la II Reforma Universitaria ___ 31

1.2.3.3 La Tercera Reforma: la internacionalización y el control de la calidad___ 32

1.3 TENDENCIAS DE LA EDUCACIÓN SUPERIOR LATINOAMERICANA — 36

1.3.1 Influencia de la universidad europea___ 36

1.3.1.1 Comparación entre la universidad europea y la latinoamericana 36

1.3.1.2 Implicancias del Proceso de Bolonia para América Latina___ 37

1.3.2 Influencia de la universidad norteamericana __ 40

1.3.2.1 La universidad norteamericana __ 41

1.3.2.2 Comparación entre la universidad norteamericana y la latinoamericana ___ 42 
1.3.2.3 La universidad latinoamericana __ 46

1.3.2.4 La universidad latinoamericana actual ___ 47

1.4 LA INFLUENCIA EN PERÚ ___________ 51

1.4.1 Principios y características de la educación superior universitaria en Perú __ 51

1.4.2 Relación entre el Espacio Europeo de Educación Superior y la educación superior peruana. _ 58

1.4.3 Proyecto de actuación peruano frente a los nuevos retos europeos__ 61

1.5 CONCLUSIONES DEL CAPÍTULO I ___ 64

1.6 REFERENCIAS DEL CAPITULO I____________ 67

Capítulo II_ 73

INDICE CAPITULO II__ 75

INDICE DE TABLAS CAPITULO II__ 76

INDICE DE GRAFICOS CAPITULO II__ 77

$2.1 \quad$ INTRODUCCIÓN DEL CAPÍTULO II___ 79

2.2 HISTORIA DE LA INGENIERÍA _________ 81

2.2.1 Antecedentes de la acción de la ingeniería en el tiempo __ 81

2.2.2 Inicio de la ingeniería en Europa __ 83

2.2.3 Inicio de la ingeniería en EE.UU __ 87

2.3 LA INGENIERÍA INDUSTRIAL EN EL SIGLO XX___ 90

2.3.1 La Ingeniería Industrial en Europa actual. _ـ 90

2.3.2 La Ingeniería Industrial en EE.UU actual___ 94

2.3.3 La Ingeniería Industrial en Perú ___ 97

2.4 TENDENCIAS DEL SIGLO XXI PARA LA INGENIERÍA INDUSTRIAL DE PERÚ

2.4.1 Enfoque de una Ingeniería Industrial para el Perú ___ 105

2.4.2 Características para un ingeniero industrial de Perú _ـ 107

2.5 CONCLUSIONES DEL CAPÍTULO II ___ 110

2.6 REFERENCIAS DEL CAPÍTULO II ___ 114

Capítulo III _ 121

INDICE CAPITULO III__ 123

INDICE DE TABLAS CAPITULO III _ 124

INDICE DE GRÁFICOS CAPITULO III__ 125

3.1 INTRODUCCIÓN DEL CAPÍTULO III ___ _ _ _ 127

3.2 Las Competencias Genéricas en el Ámbito de la IngenieríA __ 128

3.2.1 Competencias Genéricas en la Enseñanza de la Ingeniería. ___ 131

3.2.2 Codificaciones ABET y CDIO__ 131

3.2.3 Codificación IPMA_ 136

3.2.4 Codificación TUNING América Latina. __ 138

3.3 COTEJO DE CODIFICACIONES INTERNACIONALES DE COMPETENCIAS GENÉRICAS EN EL ÁMBITO DE LA INGENIERÍA. 
3.3.1 CDIO - ABET_ 141

3.3.2 Comparación CDIO - IPMA._ 142

3.3.3 Comparación TuningAL - IPMA._ 144

3.3.4 Selección de competencias genéricas para la Ingeniería en Latinoamérica __ 146

3.4 MÉTODOS DE ENSEÑANZA-APRENDIZAJE DE COMPETENCIAS

GENÉRICAS EN EL ÁMBITO DE LA INGENIERÍA____ 146

3.4.1 Métodos existentes. 148

3.4.2 Estrategia de aplicación de métodos a la Ingeniería Industrial de Perú. ___ 156

3.5 CONCLUSIONES DEL CAPÍTULO III _ 158

3.6 REFERENCIAS DEL CAPÍTULO III ___ 160

Capítulo IV 165

INDICE CAPITULO IV__ 167

INDICE DE TABLAS CAPITULO IV___ 168

INDICE DE GRÁFICOS CAPITULO IV___ 169

4.1 INTRODUCCIÓN DEL CAPÍTULO IV _ _ _ 171

4.2 BASES CIENTÍFICAS DEL MODELO ___ 173

4.2.1 Formación integral de la persona desde las competencias. _ 174

4.2.2 Modelos de planificación para la educación superior ___ 178

4.2.3 El conocimiento experto y experimentado y el enfoque territorial. __ 182

4.3 PROPUESTA DEL MODELO PARA LA EDUCACIÓN SUPERIOR DE LA INGENIERÍA INDUSTRIAL DE PERÚ DESDE LAS COMPETENCIAS — 184

4.3.1 Esquema conceptual del MESIC. 188

4.4 PROPUESTA DE ESTRATEGIA DE APLICACIÓN DEL MODELO _ _ 189

4.5 CONCLUSIONES DEL CAPÍTULO IV_____ 192

4.6 REFERENCIAS DEL CAPÍTULO IV __ 194

Capítulo $V+197$

INDICE DE CAPITULO V_r

INDICE DE TABLAS CAPITULO V_ 200

INDICE DE GRAFICOS CAPITULO V

5.1 INTRODUCCIÓN DEL CAPÍTULO V ___ 205

5.2 CONTEXTUALIZACIÓN ___ 207

5.3 ASPECTOS CLAVE: Principios, valores y plan a futuro _ـ 209

5.4 MODELOS DE PLANIFICACIÓN DE LA ENSEÑANZA___ 221

5.5 ENFOQUE EDUCATIVO _ 224

5.6 ESTRATEGIA DE PARTICIPACIÓN __ 232

5.7 CONTEXTUALIZACIÓN DE COMPETENCIAS ___ 233 


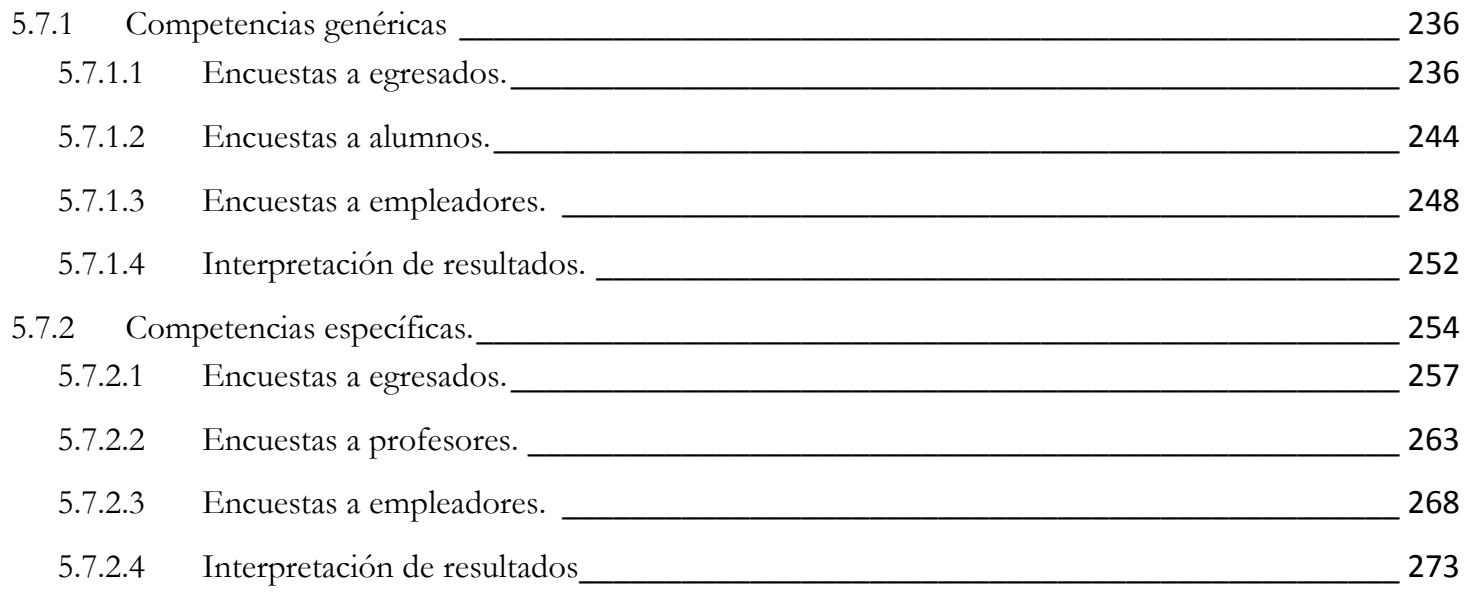

5.8 DISEÑO DEL PLAN DE ESTUDIOS ___ 274

5.9 ASEGURAMIENTO DE LA CALIDAD __ 287

5.10 CONCLUSIONES DEL CAPÍTULO V __ 287

5.11 REFERENCIAS DEL CAPÍTULO V _ 289

Capítulo VI. CONCLUSIONES 293

Capítulo VII. BIBLIOGRAFÍA _ 299

ANEXOS 319

INDICADORES _ 332 


\section{Índice de Tablas}

Tabla 1.7 Tasa de incremento de matrícula en América Latina por sector. 49

Tabla 1.8 Tasa de escolarización en educación superior en LA.

Tabla 1.9 Matrícula en educación superior por país en LA. ..........................................................50

Tabla 1.10 Universidades y población universitaria en Perú. ..............................................................55

Tabla 1.11 Universidades y población universitaria en Perú 1996 y 2010......................................55

Tabla 1.12 Evolución del número de Universidades. Fuente: (Censo universitario; 2010) ........56

Tabla 1.13 Total de alumnos de posgrado por sexo según tipo de estudio ....................................58

Tabla 1.14 Objetivos específicos de la Declaración de Bolonia........................................................59

Tabla 1.15 Comparación de los objetivos específicos del EEES con la gestión de la educación superior universitaria en el Perú

Tabla 2.1 Sub Ranking Ingeniería Industrial, Perú

Tabla 2.2 Carreras más demandadas en Perú en 2012.................................................................100

Tabla 3.1 Criterios ABET para Estudiantes que Terminan Ingeniería..........................................132

Tabla 3.2 Objetivos de Primer y Segundo Nivel del Syllabus CDIO.............................................135

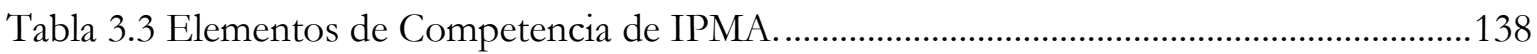

Tabla 3.4 Listado de Competencias Genéricas Acordadas para América Latina. .....................139

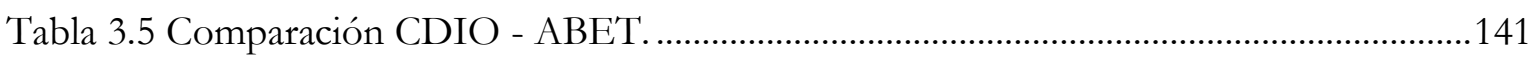

Tabla 3.6 Resultado de comparación de los elementos de competencia IPMA - CDIO..........143

Tabla 3.7 Comparación entre competencias genéricas de Tuning - América latina y los elementos de competencia de IPMA. Fuente: elaboración propia .................................145

Tabla 4.1 Aspectos clave del diseño de un Modelo Educativo de Educación Superior............185

Tabla 5.1 Dimensiones, factores, criterios y estándares para la acreditación de las carreras profesionales universitarias de Ingeniería. Fuente: CONEAU, 2010.

Tabla 5.2 Aspectos clave Modelo para la Educación Superior de la Ingeniería Industrial de

Perú desde las Competencias (MESIC). Fuente: Elaboración propia.

Tabla 5.3 Promoción por asignatura en Ciencias Básicas en Ingeniería Industrial de UDEP

Fuente: Elaboración propia, a partir de Información del Departamento de Ciencias

Básicas de UDEP

Tabla 5.4 Retención de alumnos por ciclo en Ingeniería Industrial de UDEP Fuente:

Departamento de Ciencias Básicas de UDEP 226

Tabla 5.5 Número de ingresantes por ciclo en Ingeniería Industrial en UDEP. .227 
Tabla 5.6 Número de egresados y titulados por ciclo en Ingeniería Industrial en UDEP.

Fuente: Secretaría de Facultad de Ingeniería

Tabla 5.7 Ranking incompleto de países que participaron en la PISA 2012.

Tabla 5.8 Valores de Alpha de Cronbach para determinar la confiabilidad de una encuesta.

Fuente: Elaboración propia

Tabla 5.9 Número de egresados por año y ciclo en Ingeniería Industrial en UDEP. Fuente:

Elaboración Propia

Tabla 5.10 Competencias genéricas más y menos importantes, y más y menos desarrolladas, según egresados de Ingeniería Industrial en UDEP.

Tabla 5.11 Competencias genéricas más y menos importantes, y más y menos desarrolladas, según Profesores de Ingeniería Industrial en UDEP.

Tabla 5.12 Competencias genéricas más y menos importantes, y más y menos desarrolladas, según alumnos de Ingeniería Industrial en UDEP. Fuente: Elaboración Propia......248

Tabla 5.13 Competencias genéricas más y menos importantes, y más y menos desarrolladas, según empleadores. Fuente: Elaboración Propia

Tabla 5.14 Competencias específicas propuestas por el grupo planificador. Fuente:

Elaboración Propia

Tabla 5.15 Resumen de resultados de la contextualización de competencias específicas a la

Ingeniería industrial de la UDEP. Fuente: Elaboración propia

Tabla 5.16 Asignaturas curriculares de la carrera de Ingeniería Industrial de UDEP. Fuente:

Elaboración propia.

Tabla 5.17 Malla curricular de Ingeniería Industrial de UDEP. Fuente: Elaboración propia. 279

Tabla 5.18 Asignación de competencias genéricas a asignaturas de la Malla curricular de

Ingeniería Industrial de UDEP. Fuente: Elaboración propia

Tabla 5.19 Asignación de competencias específicas a asignaturas de la Malla curricular de

Ingeniería Industrial de UDEP. Fuente: Elaboración propia.

Tabla 5.20 Diseño de actividad de Aprendizaje Basado en Proyectos. Fuente: Elaboración propia.

Tabla 5.21 Diseño de actividad de Aprendizaje Basado en Proyectos. Fuente: Adaptación de Tobón, 2013b. 


\section{Índice de Gráficos}

Gráfico 1.1 Porcentaje de población empleada en sector primario (minas y agropecuario) 34

Gráfico 1.2 Porcentaje de población empleada en sector secundario (manufactura e industria) 34

Gráfico 1.3 Porcentaje de población empleada en Sector Terciario (comercio y servicios). 35

Gráfico 1.4 Porcentajes de población ocupada por sexo y sector en la actividad económica, según país. 35

Gráfico 1.5 Ubicación de Perú 52

Gráfico 1.6 Evolución de la incidencia de pobreza total en Perú 2009-2013. 53

Gráfico 1.7 Evolución de la incidencia de pobreza extrema en Perú 2009-2013. 54

Gráfico 1.8 Evolución de la línea de pobreza y pobreza extrema en Perú. 54

Gráfico 1.9 Alumnos de pregrado por sexo según nuevas carreras en Perú. 56

Gráfico 1.10 Perú: docentes universitarios, por estudios de posgrado concluidos, 2010. 57

Gráfico 2.1 Empleabilidad de las especialidades de ingeniería en EE.UU. 96

Gráfico 2.2 Sueldo medio anual en ingenierías en EE.UU. 97

Gráfico 3.1 Fases del modelo de aprendizaje cíclico de cinco etapas. 147

Gráfico 3.2 Implicación de las competencias. 148

Gráfico 4.1 Integración de Modelos de Planificación. 179

Gráfico 4.2 Modelo de planificación mixto para el MESIC.

Gráfico 4.3 Propuesta de componentes del Modelo Educativo de Educación Superior. 185

Gráfico 4.4 Propuesta del Modelo Educativo para la Educación Superior desde las competencias. _186

Gráfico 4.5 Propuesta del Modelo para la Educación Superior de la Ingeniería Industrial de Perú desde las competencias. 188

Gráfico 4.6 Estrategia para el diseño de un modelo para la educación superior desde el enfoque socioformativo. 189

Gráfico 5.1 Localización de Perú. 208

Gráfico 5.2 Localización de Piura 208

Gráfico 5.3 Ideario de la Universidad de Piura. Fuente: UDEP, 1998. 210

Gráfico 5.4 Equipo Central del Plan estratégico de la Facultad de Ingeniería. 211

Gráfico 5.5 Etapa de consolidación con la Decana de la Facultad. 212

Gráfico 5.6 Representantes de alumnos y egresados en el diseño Plan Estratégico. 212

Gráfico 5.7 Anverso del Tríptico del Plan Estratégico de la Facultad de Ingeniería. 213

Gráfico 5.8 Reverso del Tríptico del Plan Estratégico de la Facultad de Ingeniería. 213

Gráfico 5.9 Publicación de los Estándares de calidad para las Ingenierías en Perú. 215

Gráfico 5.10 Modelo de Calidad para la Acreditación de las Ingenierías en Perú. 216

Gráfico 5.11 Situación laboral de egresados 236

Gráfico 5.12 Importancia de las competencias genéricas TuningAL según egresados. 237 
Gráfico 5.13 Desarrollo de las competencias genéricas TuningLA en Ingeniería Industrial de UDEP según egresados.

Gráfico 5.14 Comparación entre la importancia y nivel de desarrollo de las competencias genéricas TuningLA en Ingeniería Industrial de UDEP según egresados.

Gráfico 5.15 Formación recibida por alumnos de Ingeniería Industrial de UDEP según sus profesores.

Gráfico 5.16 Profesores conocen el concepto de competencias genéricas. 241

Gráfico 5.17 Importancia de las competencias genéricas TuningAL según los Profesores. 242

Gráfico 5.18 Desarrollo de las competencias genéricas TuningLA en Ingeniería Industrial de UDEP según los Profesores.

Gráfico 5.19 Comparación entre la importancia y nivel de desarrollo de las competencias genéricas

TuningLA en Ingeniería Industrial de UDEP según Profesores.

Gráfico 5.20 Formación recibida por alumnos de Ingeniería Industrial de UDEP según sus alumnos de último año. 245

Gráfico 5.21 Alumnos conocen el concepto de competencias genéricas. 245

Gráfico 5.22 Posibilidades de encontrar trabajo según alumnos. 246

Gráfico 5.23 Importancia de las competencias genéricas TuningAL según los alumnos. 246

Gráfico 5.24 Desarrollo de las competencias genéricas TuningLA en Ingeniería Industrial de UDEP según los Alumnos.

Gráfico 5.25 Comparación entre la importancia y nivel de desarrollo de las competencias genéricas

TuningLA en Ingeniería Industrial de UDEP según los alumnos.

Gráfico 5.26 Formación de egresados de ingeniería industrial de UDEP según los empleadores. 249

Gráfico 5.27 Dominio del concepto de competencias según empleadores.

Gráfico 5.28 Importancia de las competencias genéricas Tuning AL según empladores. 250

Gráfico 5.29 Desarrollo de las competencias genéricas TuningLA en Ingeniería Industrial de UDEP según empleadores.

Gráfico 5.30 Comparación entre la importancia y nivel de desarrollo de las competencias genéricas

TuningLA en Ingeniería Industrial de UDEP según los empleadores. 251

Gráfico 5.31 Situación laboral de egresados 258

Gráfico 5.32 Egresados conocen el concepto de competencia específica 258

Gráfico 5.33 Importancia asignada por los egresados a las competencia específicas propuestas para Ciencias Básicas.

Gráfico 5.34 Promedio de la importancia asignada por los egresados a las competencias específicas propuestas para Ciencias Básicas. 259

Gráfico 5.35 Importancia asignada por los egresados a las competencias específicas propuestas para

Operaciones.

Gráfico 5.36 Promedio de la importancia asignada por los egresados a las competencia específicas propuestas para Operaciones. 
Gráfico 5.37 Importancia asignada por los egresados a las competencias específicas propuestas para área Administrativa.

Gráfico 5.38 Promedio de la importancia asignada por los egresados a las competencias específicas propuestas para Administrativas. 260

Gráfico 5.39 Importancia asignada por los egresados a las competencias específicas propuestas para el Área de Sistemas. 261

Gráfico 5.40 Promedio de la importancia asignada por los egresados a las competencias específicas propuestas para Sistemas.

Gráfico 5.41 Importancia asignada por los egresados a las competencia específicas propuestas para los cursos Técnicos de Ingeniería.

Gráfico 5.42 Promedio de la importancia asignada por los egresados a las competencias específicas propuestas para Técnica. 262

Gráfico 5.43 Profesores conocen el concepto de competencia específica 263

Gráfico 5.44 Importancia asignada por los profesores a las competencias específicas propuestas para Ciencias Básicas. Fuente:

Gráfico 5.45 Promedio de la importancia asignada por los profesores a las competencias específicas propuestas para Ciencias Básicas.

Gráfico 5.46 Importancia asignada por los profesores a las competencias específicas propuestas para

Operaciones.

Gráfico 5.47 Promedio de la importancia asignada por los profesores a las competencias específicas propuestas para Operaciones.

Gráfico 5.48 Importancia asignada por los profesores a las competencias específicas propuestas para área Administrativa. 265

Gráfico 5.49 Promedio de la importancia asignada por los profesores a las competencias específicas propuestas para Administrativas.

Gráfico 5.50 Importancia asignada por los profesores a las competencias específicas propuestas para el Área de Sistemas. 266

Gráfico 5.51 Promedio de la importancia asignada por los profesores a las competencias específicas propuestas para Sistemas. 266

Gráfico 5.52 Importancia asignada por los profesores a las competencias específicas propuestas para los cursos Técnicos de Ingeniería.

Gráfico 5.53 Promedio de la importancia asignada por los profesores a las competencias específicas propuestas para Técnica.

Gráfico 5.54 Empleadores conocen el concepto de competencia específica 268

Gráfico 5.55 Importancia asignada por los empleadores a las competencias específicas propuestas para Ciencias Básicas.

Gráfico 5.56 Promedio de la importancia asignada por los empleadores a las competencias específicas propuestas para Ciencias Básicas. 
Gráfico 5.57 Importancia asignada por los empleadores a las competencias específicas propuestas para

Operaciones. 270

Gráfico 5.58 Promedio de la importancia asignada por los empleadores a las competencias específicas propuestas para Operaciones. 270

Gráfico 5.59 Importancia asignada por los empleadores a las competencias específicas propuestas para área Administrativa. 270

Gráfico 5.60 Promedio de la importancia asignada por los empleadores a las competencia específicas propuestas para Administrativas.

Gráfico 5.61 Importancia asignada por los empleadores a las competencias específicas propuestas para el Área de Sistemas. 271

Gráfico 5.62 Promedio de la importancia asignada por los empleadores a las competencias específicas propuestas para Sistemas. 272

Gráfico 5.63 Importancia asignada por los empleadores a las competencias específicas propuestas para los cursos Técnicos de Ingeniería 272

Gráfico 5.64 Promedio de la importancia asignada por los empleadores a las competencias específicas propuestas para Técnica. 273

Gráfico 5.65 Abordaje del Plan de estudios. Fuente: Adaptación de Tobón, 2013b. 275

Gráfico 5.66 Estructura de la Malla curricular para Ingeniería industrial de UDEP. 277 
Introducción 
Esta investigación parte de una premisa surgida y afianzada en años de experiencia de participación de proyectos y de actividad académica. La premisa es que para poder tener un desarrollo social sostenible en Perú, es indispensable contar con personas que tengan las capacidades necesarias para planificar, diseñar, dirigir, ejecutar, controlar, evaluar y sostener proyectos de desarrollo en distintos ámbitos económicos y sociales, y que sus capacidades se extiendan a un correcto actuar en el medio ambiente en que se desarrolle su acción, con integridad y sensibilidad. Esta afirmación pone de manifiesto la necesidad de formar personas con estas características en Perú. Elegir como medio la Ingeniería Industrial es porque los egresados de esta la titulación son los llamados a participar en proyectos de distinta índole, sean de desarrollo o de inversión, desde el inicio de su actuación profesional en Perú.

La meta es responder a las necesidades del norte del país con el fin de diseñar y experimentar un modelo que pueda luego replicarse en otras especialidades, ámbitos e instituciones. Los capítulos desarrollados y las investigaciones relacionadas, abordan la educación superior en Perú desde sus inicios, buscando un modelo apropiado que impulse a los alumnos de pregrado de Ingeniería Industrial a adquirir esas capacidades durante su formación.

La educación superior de Perú, particularmente la formación en ingeniería en Perú, ha estado fuertemente influenciada por corrientes extranjeras y esta es la razón por la que en los capítulos se hacen referencias y comparaciones con las realidades que más impactan en ella: Europa y USA. Esto no solo con el propósito de conocer sus orígenes y fundamentos, sino también para determinar las tendencias actuales y el futuro previsible en este nivel y especialidad. Luego se buscará las competencias necesarias para que un ingeniero tenga éxito en la dirección de proyectos y cuáles son las mejores estrategias metodológicas para que los alumnos las alcancen. La identidad provista por el análisis de su origen, las tendencias globales y latinoamericanas encontradas y el elenco de competencias pertinente, permitirán definir un modelo para la ingeniería industrial del norte del Perú que abarque. Este modelo podrá luego experimentar innovaciones y nuevas prácticas académicas que decanten en el diseño de un Plan de estudios aplicable a la titulación mencionada, en el territorio indicado.

\section{a. Preguntas de la investigación.}

La investigación se centrará en concebir el diseño de un modelo educativo que estimule la apropiada formación de jóvenes ingenieros industriales en el norte de Perú preparados para enfrentar las actuales exigencias sociales y empresariales de crecimiento con desarrollo e integridad. Esto con el fin de ser el soporte técnico de los grupos sociales que buscan la satisfacción de sus necesidades.

1. ¿La universidad peruana forma parte, formal o informalmente, de un sistema mayor que le ha conferido e incide en su identidad? ¿Cuáles son las características adquiridas y las soluciones adoptadas a problemas aún no resueltos en Perú?

2. ¿Cuáles son las tendencias a futuro y/o las estrategias que provienen del sistema universitario que contiene a la universidad peruana, que han resuelto o buscan resolver los problemas de pertinencia técnica, humana y social de los egresados de ingeniería? 
3. ¿Existe un elenco de competencias que permita la formación de ingenieros con sesgo a la dirección de proyectos?

4. ¿Es posible definir un modelo que estimule la formación de ingenieros industriales en Perú con capacidades técnicas, ambientales y conductuales para lograr el perfil buscado?

5. ¿Cuál sería un plan de estudios que refleje ese modelo en la práctica universitaria de Perú?

\section{b. Objetivos e hipótesis de investigación.}

Basado en las interrogantes planteadas, se definieron los siguientes objetivos de investigación.

\section{b.1 Objetivo general.}

Diseñar un modelo educativo para la ingeniería industrial de Perú que facilite a los estudiantes la adquisición de competencias que les permita, al egresar, desempeñarse profesionalmente suficiencia técnica, con integridad personal, respeto por el entorno y con competentes para la dirección de proyectos en un contexto internacional.

\section{b.2 Objetivos específicos.}

1. Compilar las características de los sistemas educativos que han influenciado la educación superior peruana. Ordenarlas en una relación priorizada que sirva para determinar las características ineludibles que debe tener el modelo educativo, que le confieren unos rasgos propios que le dan identidad.

2. Detectar y relacionar las tendencias actuales que han trazado y siguen los sistemas educativos que más han influenciado la educación superior de Perú. Proyectar las tendencias al espacio de la ingeniería en el Perú.

3. Distinguir un código de competencias holísticas que permita a los alumnos de ingeniería industrial de Perú, alcanzar el perfil requerido por los grupos de interés asociados a esa especialidad profesional.

4. Detallar un modelo educativo para la titulación de ingeniería industrial de Perú que resulte de la síntesis de los resultados obtenidos al alcanzar los tres objetivos anteriores.

5. Aplicar en un plan de estudios, a una universidad del norte del Perú, el modelo definido y evaluar, en lo que en el tiempo de evolución sea posible, los impactos de su aplicación.

\section{b.3 Hipótesis.}

Las interrogantes de investigación planteadas y los objetivos propuestos nos llevan a definir nuestras hipótesis de investigación:

1. Existen sistemas de educación superior que han modelado y dirigido el sistema de educación superior latinoamericano y peruano con características y problemática similares, por lo que sus tendencias y estrategias de solución son válidas para el sistema peruano. 
2. Es posible aplicar un código de competencias genéricas probado internacionalmente para la formación en ingeniería que permita una formación holística e incluya las competencias para la dirección de proyectos.

3. Se puede diseñar un modelo educativo efectivo para la formación de ingenieros industriales que incluya un código de competencias a desarrollar por los estudiantes, que permita el seguimiento y control y mejore el perfil de egresado en los aspectos técnico, de contextual y conductual en el contexto gestión de proyectos de inversión y de desarrollo rural.

4. Es posible aplicar el modelo y evaluarlo con métodos cuantitativos y cualitativos en cada una de las componentes que vayan desarrollándose.

5. La mejora del modelo repercutirá en una mejora de gestión de los procesos y de los proyectos de inversión y de desarrollo rural.

\section{c. Metodología general de la investigación}

La metodología seguida buscó dar solución al problema inicial que genera las hipótesis planteadas, esto apoyado en que según Russell L. Ackoff (Arquitecto y Filósofo norteamericano, 1919 - 2009) "la metodología cientifica puede ser considerada como un tipo especial de solucionador de problemas" (Ackoff, 1987: 28), complementado en la afirmación de Karl Raimund Popper (Filósofo austriaco, 1902 - 1994) "El conocimiento no comienza con percepciones u observación o con la recopilación de datos o de hechos, sino con problemas. No hay conocimiento sin problema pero tampoco bay ningún problema sin conocimiento. El entendimiento comienza con la tensión entre saber y no saber, entre conocimiento e ignorancia: ningún problema sin conocimiento - ningún problema sin ignorancia" (Popper, 1978: 10).

La importancia de tener precisión en la definición del problema radica en que a partir de él pueden plantearse las preguntas de investigación que por su naturaleza señalan el camino de investigación a seguir. Las interrogantes de investigación pueden, de manera general, ser enmarcados dentro de alguno de los siguientes tres tipos: descripción, explicación y predicción de resultados. Para el Dr. Raúl Valdéz (Sociólogo mejicano, 1955 -) "Un estudio que pretenda solo conocer las relaciones y aspectos de los fenómenos que suceden en la sociedad, será descriptivo. Si se apoya en las teorías pertinentes para explicar e interpretar diversos hechos y procesos significativos, la investigación se situará en el segundo nivel de la ciencia, es decir, la explicación. Cuando se requiere además de describir y explicar los fenómenos, lograr una predicción, la ciencia social cuenta con la posibilidad de diseñar experimentos para sacar conclusiones y predecir con cierto grado de error los fenómenos" (Valdéz, 2013: 37 - 38).

La metodología seguida llega a describir y explicar el fenómeno de formar ingenieros industriales para la realidad peruana desde una formación complementada por el enfoque desde las competencias respondiendo las cinco interrogantes de investigación propuestas: primero se ha realizado una exhaustiva revisión bibliográfica para definir la procedencia, identidad y características principales de la educación superior de Perú así como las principales fuentes de influencia; segundo, se determinaron las tendencias de los sistemas influenciadores de la educación peruana y se proyectaron hacia un nuevo modelo peruano que les involucra; tercero se buscó y encontró un código de competencias apropiado para la enseñanza de ingeniería que asegure que, al adquirirlas, se incorporan indubitablemente las capacidades necesarias para una 
correcta gestión de proyectos. En el primer y segundo paso se desarrolló el primer nivel de investigación de tipo cualitativa y exploratoria - descriptiva, en el tercero uno de tipo explicativa.

En un cuarto paso se procede a diseña un modelo educativo que integra las características, tendencias globales y del contexto, también el código de competencias genéricas más apropiado para la realidad de la ingeniería en la educación superior peruana; en este paso se incluyen las variables institucionales que resultan ser las más influyentes en la definición de una malla curricular, como la axiología, las expectativas de los grupos de interés, el talante del alumno y el grado de exigencia. En un quinto paso se hace el diseño del experimento que finalizará con la aplicación a una realidad concreta de un Programa académico, en una Facultad de Ingeniería de una universidad del Norte del Perú. En estos pasos la investigación es de tipo cuantitativa predictiva y de evaluación del modelo.

La secuencia general de la investigación se muestra en el gráfico siguiente:

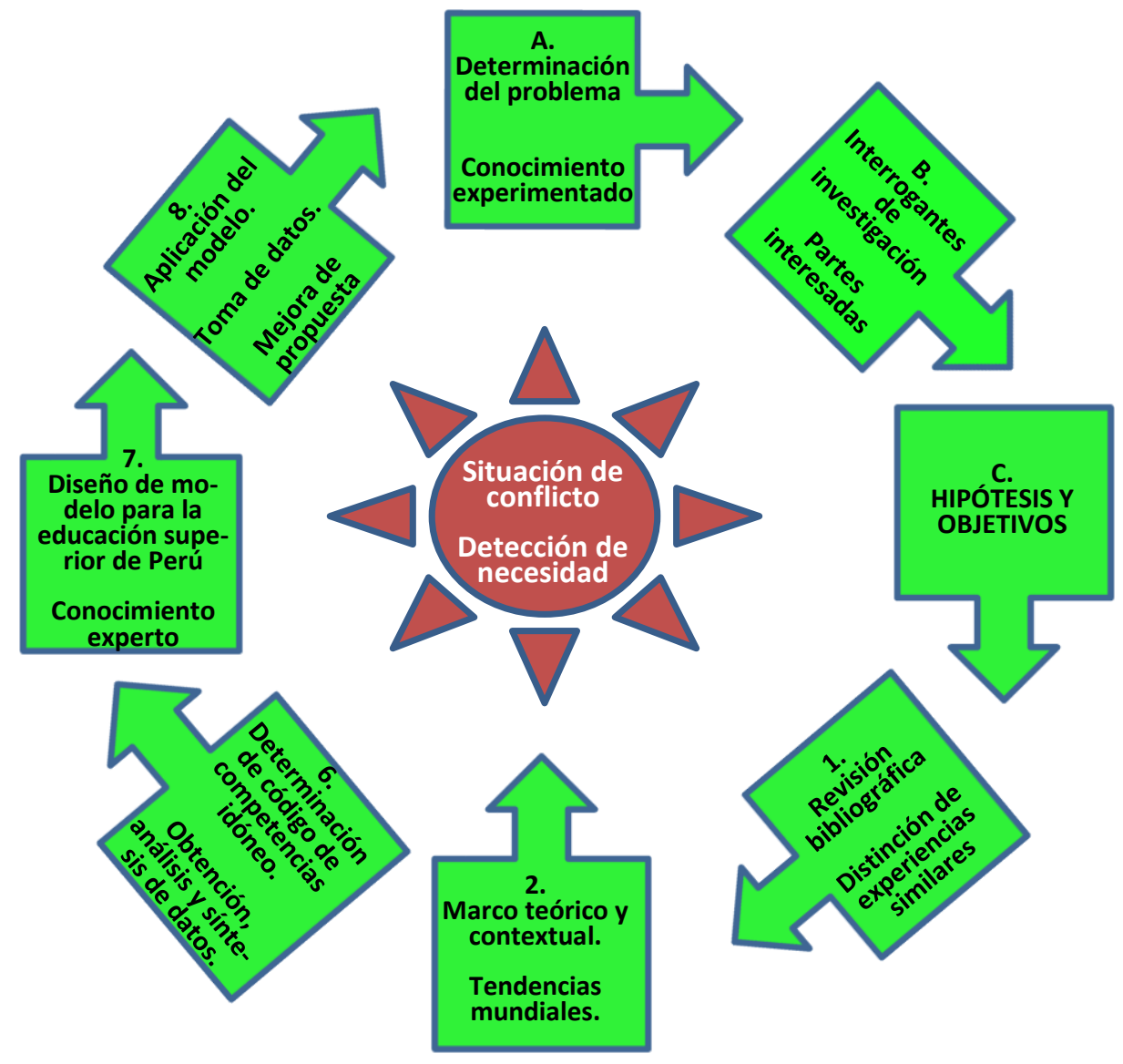

Gráfico. I.1: Metodología general de la investigación Fuente: Elaboración propia

\section{c.1 Esquema General de la Investigación}

Para poder responder a las preguntas de investigación, alcanzar los objetivos iniciales y confirmar las hipótesis se ha estructurado la investigación en las siguientes etapas: 
1. Etapa uno, marco contextual y conceptual.

2. Etapa dos, propuesta del modelo conceptual.

3. Etapa tres, aplicación de modelo.

4. Etapa cuatro, conclusiones.

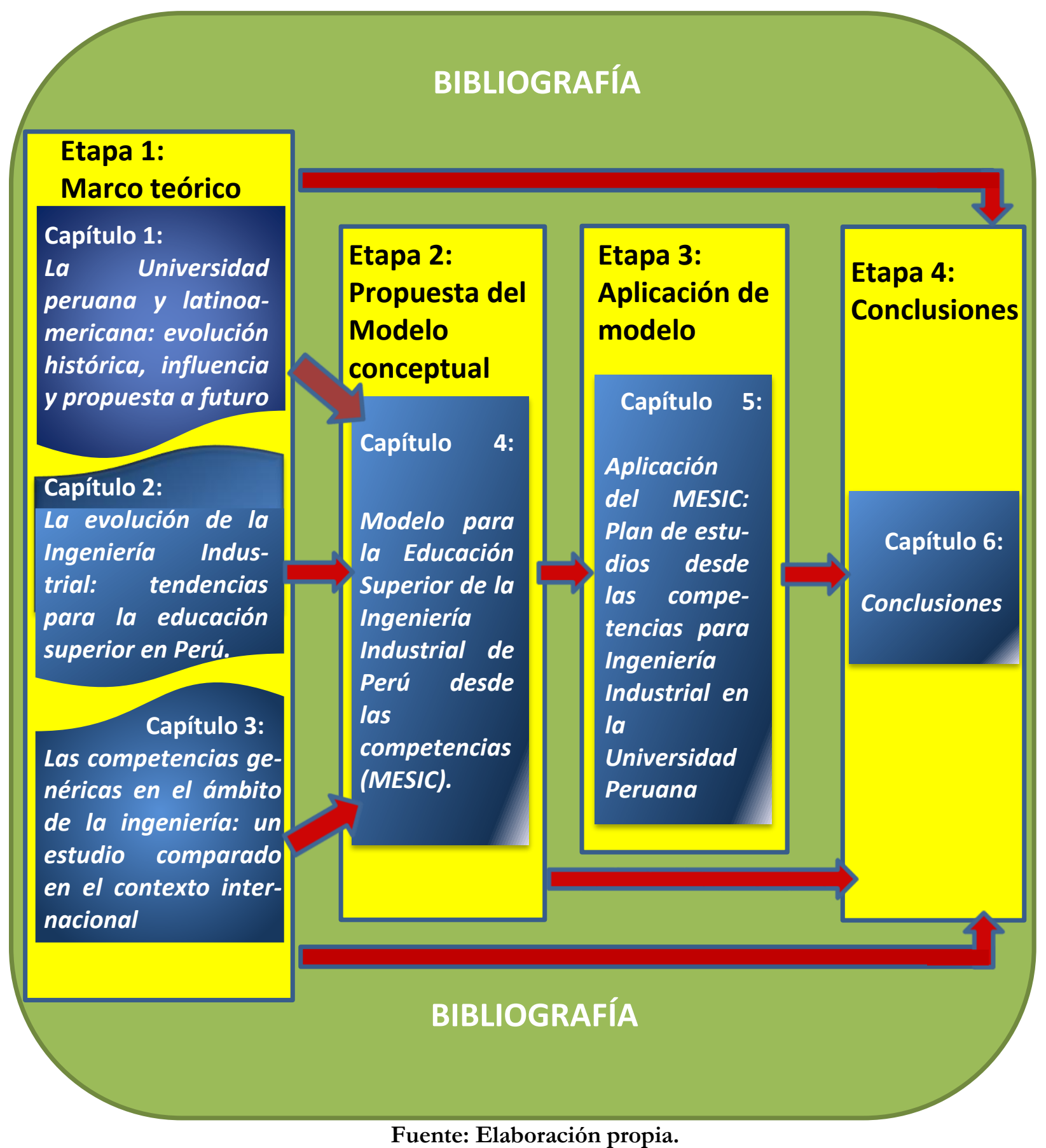

La estructura responde a la necesidad de vincular la investigación con la realidad de manera que el conocimiento hallado, el razonamiento y la aproximación a esa realidad, ordenen las acciones a emprender con de criterios de rigor científico. Para producir los constructos necesarios es fundamental recoger la evidencia teórica y empírica, lo que posibilita el diseño de un modelo a partir de una definición técnica, académica, humana, conceptual y de control pertinentes. 
El trabajo se soporta en revisiones bibliográficas sobre el estado del arte de las tendencias de la educación superior, de las competencias genéricas y de los modelos para ingeniería. También se realizaron encuestas y procesos participativos. Los procesos participativos incluyeron el conocimiento experto y el experimentado en los tres ámbitos que se involucran en la formación de ingenieros: alumnos-egresados, profesores y empresa-padres-sociedad. Se ha puesto atención en evitar sesgos por limitaciones de orden ambiental, técnico, estadístico y ético-moral del objeto de estudio. Estas estrategias soportaron las búsquedas documentales en torno a los ejes centrales y, a la vez, permitieron llegar a los productos finales.

\section{c.1.1. Etapa uno: Marco contextual y conceptual.}

En el capítulo uno se discute la entidad de la universidad Latinoamericana y su desarrollo hasta la actualidad; se determinan sus principales fuentes de influencia; se analiza los efectos que han tenido sobre ella el Espacio Europeo de Educación Superior y la educación superior anglosajona. Con estos resultados se define cuál ha sido el mayor impacto en la educación superior de Perú y las características más saltantes heredadas por el sistema educativo peruano. También, se selecciona el mejor quehacer educativo y se determina el mejor modelo que le lleve a él. Se concluye qué debe hacerse en el Perú para mejorar sus resultados en educación superior.

Capítulo dos, en este capítulo la investigación se centra en la evolución de la Ingeniería en el Perú, y cómo se ha visto influenciada por el desarrollo histórico en Europa y el mundo anglosajón. Se comparan las estructuras de las propuestas de formación, se define la tendencia actual de la ingeniería industrial en los espacios educativos más desarrollados y se detallan las tendencias que deben ser consideradas para un modelo en el Perú.

En el capítulo tres, se toman las tendencias y propuestas de los capítulos anteriores. Con estas se analiza y evalúan distintas codificaciones de competencias y se selecciona la mejor propuesta para el diseño de planes de estudios de ingeniería en Latinoamérica. Luego, se validan con encuestas a los cuatro grupos de interés alumnos, graduados, profesores y empleadores peruanos, para decidir la prioridad que deben tener y cuáles son las que mejor se ajustan a las necesidades peruanas. También contiene la definición de competencias específicas a partir de una búsqueda del estado del arte de cuáles son las más apropiadas en el medio de educación superior para la titulación de Ingeniería Industrial. Luego, se hacen encuestas a los grupos de académicos y empresarios para determinar la priorización, descarte o asimilación de competencias.

\section{c.1.2. Etapa dos: Propuesta de modelo conceptual.}

En el capítulo cuatro se perfila el modelo educativo para la titulación y se procesan los resultados de los pilotos aplicados para las estrategias de acción en la organización de horarios, evaluaciones, competencias, perfiles, contenidos, flexibilidad, mallas y vinculaciones con el exterior. También se vinculan a este modelo las nuevas metodologías de aprendizaje propuestas y se propone una estrategia de aplicación del modelo definido. 


\section{c.1.3 Etapa tres: Aplicación del modelo.}

En el capítulo cinco se diseña la aplicación del modelo a un programa académico de Ingeniería Industrial, de una Facultad de Ingeniería, en una Universidad de Perú: la Universidad de Piura. Se proponen herramientas concretas de aplicación y estrategias metodológicas para los docentes. Modularmente se aplica el modelo y exploran las consecuencias de su aplicación, dentro de lo posible dados los largos tiempos que en educación deben transcurrir para observar resultados.

\section{c.1.4. Etapa cuatro: Conclusiones.}

Esta etapa permite hacer el análisis de los resultados obtenidos en las etapas precedentes y compilar las conclusiones parciales que permitirán formar un cuerpo de experiencias y productos que respondan a las interrogantes iniciales y sustenten las hipótesis planteadas. Se define la estructura del Plan curricular más apropiado para la titulación.

\section{d. Producción científica asociada a la investigación.}

A continuación se detallan las comunicaciones a congresos y publicaciones científicas asociadas a la investigación.

\section{Capítulo 1: La Universidad peruana y latinoamericana: evolución histórica, influencia y propuesta a futuro}

"An approach of the European higher education framework to the management of higher education at university level in Peru". Publicado en Procedia Social and Behavioral Sciences Journal 15 (2011) 586-591 por Elsevier Ltd. 1877-0428 (C) 2011, se encuentra en Science Direct, Scopus and Thomson Reuters Conference Proceedings Citation Index (Web of Science). Coautores: Isabel Chiyón y Adolfo Cazorla.

\section{Capítulo 2: La evolución de la Ingeniería Industrial: tendencias para la educación} superior en Perú.

"Higher education in industrial engineering in Peru: towards a new model based on skills". Publicado en Procedia Social and Behavioral Sciences 46 (2012) 1570 - 1580 por Elsevier Ltd. 1877-0428 C 2012. Se encuentra en Science Direct, Scopus and Thomson Reuters Conference Proceedings Citation Index (Web of Science). Coautores: Ignacio de los Ríos, Dante Guerrero.

Capítulo 3: Las competencias genéricas en el ámbito de la ingeniería: un estudio comparado en el contexto internacional.

"Approaches and models of professional competence definition of competence in the training of engineers in Latin America". Ha sido publicado en el International Journal of Innovative Research in Advanced Engineering. Volumen 3, Issue-01 en enero de 2016. Autores Martín Palma, Dante Guerrero, Ignacio De los Ríos.

"Generic competences in engineering field: a comparative study between Latin America and European Union”. Publicado en Procedia Social and Behavioral Sciences 15 (2011) 576-585 Elsevier Ltd. 1877-0428 C 2011. ISSN: 1877-0428 Se encuentra en Science Direct, Scopus and 
Thomson Reuters Conference Proceedings Citation Index (Web of Science). Coautores: Ignacio de los Ríos, Erick Miñán.

ACCESIT DEL PREMIO de los Colegios oficiales de Ingenieros Agrónomos, Ingenieros de Caminos canales y puertos y de Ingenieros Industriales de Aragón y Rioja. Por la ponencia: "Generic competences in engineering field: a comparative study between Latin America and European Union”. En el 15th International congress on project engineering. Huesca 2011.

"Industrial Engineering in Peru in an International Context: Working towards a New Model from Skills", revisada y aceptada en el 2nd International Conference on Economic, Education and Management (ICEEM 2012) en Shangai, China, junio 2012. Publicado en ISI web of knowledge, Web of Sciences, ISBN: 978-988-19750-3-4.). Coautor: Ignacio de los Ríos.

\section{Capítulo 4: Modelo para la Educación Superior de la Ingeniería Industrial de Perú desde las competencias (MESIC).}

"Improving generic skills among engineering students through project-based learning in a project management course", en el 120th ASEE (American Society for Engineering Education) Annual Conference and Exposition. Se realizó en Atlanta, Georgia, USA, el 23 de junio de 2013. El artículo se encuentra en la base SCOPUS (Base de datos indexada) en "ASEE Annual Conference and Exposition, Conference Proceedings”. Código 99351, pag 21. Coautores: Dante Guerrero, Valeria Quevedo y Susana Vegas.

"Developing competences in engineering students: the case of project management course" International Conference on Education \& Educational Psychology 2013. Publicado en el Abstract Book, ISSN: 1986-3020. También aparece publicado en Procedia - Social and behavorial science, en la Base de datos indexada Science Direct. Publicado en octubre de 2013. Los coautores son Dante Guerrero y Gerson La Rosa.

\section{Capítulo 5: Aplicación del MESIC: Plan de estudios desde las competencias para Ingeniería Industrial en la Universidad Peruana.}

"Achievable competencies in project management during undergraduate engineering studies". Presentada en el 17th Congress on project management and engineering, organizado por la Asociación Española de Dirección e Ingeniería de Proyectos (AEIPRO) y la Universidad de la Rioja los días 17, 18 y 19 de julio de 2013 en Logroño. Coautores: Dante Guerrero, Valeria Quevedo y Susana Vegas. Ha sido considerado un Selected paper y será publicado en "Project Management and Engineering 2013. Selected papers from the 17th International Congress on Project Management and Engineering, held in Logroño (Spain)" en SPRINGER SCIENCE + BUSINESS MEDIA B.V.

\section{e. Referencias de la Introducción.}

Ackoff, Russel. 1987. Scientific method: optimizing applied research decisions. New York. Editorial Jhon Wiley and sons.

Popper Karl R., et al. 1978. La lógica de las ciencias sociales. México. Editorial Grijalbo. 
Rojas, Raúl. 2013. Guía para realizar investigaciones sociales. México. Editorial Plaza y Valdés, p.p. 37-38. 
Capítulo I

La universidad peruana y latinoamericana: Evolución histórica, influencias y propuesta a futuro 


\section{ÍNDICE CAPÍTULO I}

Capítulo I ¡Error! Marcador no definido.9

1. INTRODUCCIÓN ¡Error! Marcador no definido. 5

\subsection{EVOLUCIÓN DE LA UNIVERSIDAD LATINOAMERICANA: PERIODOS} HISTÓRICOS ¡Error! Marcador no definido.7

1.1.1 La universidad latinoamericana colonial (s. XVI - s. XVIII) ¡Error! Marcador no definido. 7

1.1.2 La Universidad Latinoamericana Republicana: el periodo napoleónico (s.XVIII - s. XX)30

1.1.3 La Universidad Latinoamericana del siglo XX: los procesos de reforma 32

1.1.3.1 La Primera Reforma: la autonomía y el cogobierno (1918 - 1975) _3iError! Marcador no definido.

1.1.3.2 La Segunda Reforma: la mercantilización y la educación binaria (1975 - 1995) iError! Marcador no definido. 4

1.1.3.2.1 Incremento y diversificación de las universidades privadas _iError! Marcador no definido.

1.1.3.2.2 Masificación, feminización y nuevo perfil estudiantil ¡Error! Marcador no definido. 6

1.1.3.2.3 El agotamiento de la II Reforma Universitaria _ ¿Error! Marcador no definido.7 1.1.3.3 La Tercera Reforma: la internacionalización y el control de la calidadiError! Marcador no definido. 8

1.2 TENDENCIAS DE LA EDUCACIÓN SUPERIOR LATINOAMERICANA 42

1.2.1 Influencia de la universidad europea ¡Error! Marcador no definido.

1.2.1.1 Comparación entre la universidad europea y la latinoamericana _ iError! Marcador no definido.

1.2.1.2 Implicancias del Proceso de Bolonia para América Latina ¡Error! Marcador no definido.

1.2.2. Influencia de la universidad norteamericana ¡Error! Marcador no definido.6

1.2.2.1 La universidad norteamericana ¡Error! Marcador no definido.

1.2.2.2 Comparación entre la universidad norteamericana y la latinoamericana ¡Error! Marcador no definido.

1.2.2.3 La universidad latinoamericana ¡Error! Marcador no definido.

1.2.2.4 La universidad latinoamericana actual ¡Error! Marcador no definido.

1.3 LA INFLUENCIA EN PERÚ ¡Error! Marcador no definido.

1.3.1 Principios y características de la educación superior universitaria en Perú ¡Error! Marcador no definido. 7 
1.3.2 Relación entre el Espacio Europeo de Educación Superior y la educación superior peruana. ¡Error! Marcador no definido.

1.3.3 Proyecto de actuación peruano frente a los nuevos retos europeos _iError! Marcador no definido.

1.4 CONCLUSIONES DEL CAPÍTULO I ¡Error! Marcador no definido. 0

1.5 REFERENCIAS DEL CAPÍTULO I ¡Error! Marcador no definido. 3

\section{ÍNDICE DE TABLAS CAPITULO I}

Tabla 1.1 Número de estudiantes universitarios en América Latina .306

Tabla 1.2 Tasa de matrícula en educación superior .306

Tabla 1.3 Producto bruto interno acumulado de América Latina.................................................................53

Tabla 1.4 Tasa de desempleo en américa Latina. ……………………………………………………….....53

Tabla 1.5 Crecimiento de salarios por región 2006 - 20011 ........................................................................48

Tabla 1.6 Número de universidades en América Latina...........................................................................49

Tabla 1.7 Tasa de incremento de matrícula en América Latina por sector.................................................495

Tabla 1.8 Tasa de escolarización en educación superior en LA.....................................................................49

Tabla 1.9 Matrícula en educación superior por país en LA. ........................................................................506

Tabla 1.10 Universidades y población universitaria en Perú. …………………………………………......551

Tabla 1.11 Universidades y población universitaria en Perú 1996 y 2010.....................................................55

Tabla 1.12 Evolución del número de Universidades. Fuente: (Censo universitario; 2010).........................62

Tabla 1.13 Total de alumnos de posgrado por sexo según tipo de estudio ..................................................584

Tabla 1.14 Objetivos específicos de la Declaración de Bolonia. ..................................................................595

Tabla 1.15 Comparación de los objetivos específicos del EEES con la gestión de la educación superior universitaria en el Perú .606 


\section{ÍNDICE DE GRAFICOS CAPITULO I}

Gráfico 1.1 Porcentaje de población empleada en sector primario (minas y agropecuario) 34

Gráfico 1.2 Porcentaje de población empleada en sector secundario (manufactura e industria) 34

Gráfico 1.3 Porcentaje de población empleada en Sector Terciario (comercio y servicios). 35

Gráfico 1.4 Porcentajes de población ocupada por sexo y sector en la actividad económica, según país.

Gráfico 1.5 Ubicación de Perú 52

Gráfico 1.6 Evolución de la incidencia de pobreza total en Perú 2009-2013. 53

Gráfico 1.7 Evolución de la incidencia de pobreza extrema en Perú 2009-2013. 54

Gráfico 1.8 Evolución de la línea de pobreza y pobreza extrema en Perú. 54

Gráfico 1.9 Alumnos de pregrado por sexo según nuevas carreras en Perú. 56

Gráfico 1.10 Perú: docentes universitarios, por estudios de posgrado concluidos, 2010. 57 


\subsection{INTRODUCCIÓN}

En este capítulo se determina que la educación superior del Perú puede ser capaz de asemejar a la norteamericana aspirando a alcanzar similares resultados en los indicadores de calidad de su nivel universitario, y que un camino apropiado para lograrlo es el ya iniciado por el Espacio Europeo de Educación Superior, puesto que la universidad de todo Latinoamérica, desde sus inicios, ha sido una extensión de la educación universitaria europea continental, fundamentalmente la hispánica, experimentando sus enfoques y cambios.

Para argumentar y explicar cómo se llega a tal afirmación, el capítulo se ha dividido en tres partes que le sustentan.

La primera de ellas define la identidad de la universidad latinoamericana, su origen, el modelo que siguió, la finalidad trazada desde su inicio y los cambios sustanciales a lo largo de su evolución. Los resultados permiten delimitar una división histórica, que sigue la universidad latinoamericana a lo largo de su evolución, en la que se observa la firme subordinación, desde sus inicios, de la universidad latinoamericana a la europea continental. También se muestra cómo le han afectado directamente los cambios que en aquella se produjeron. El mayor cambio reflejado en Latinoamérica fue el enfoque napoleónico de la universidad, constatándose en ese hecho la fuerte dependencia. Además, se definen los tres procesos de reforma que marcan el acontecer de la vida universitaria latinoamericana en el siglo XX y se marcan los resultados en cada una de ellas, determinando las tendencias al siglo XXI: la masificación, la globalización, la educación virtual y la oferta transnacional, como retos a futuro. Así, se consolida la afirmación que la universidad latinoamericana es similar a la europea, que le apetece ser como la norteamericana, y que tiene unas características a futuro trazadas pero no decididamente perseguidas ni mucho menos consolidadas.

En la segunda parte determino que las tendencias a futuro de la universidad latinoamericana se deben enmarcar en las corrientes norteamericana y europea siaspira a alcanzar sus índices de calidad. Se estudian estas realidades, su historia y su situación actual, y se concluye que las tendencias a seguir son las del modelo de la universidad norteamericana, por las características que tiene y los resultados que alcanza. Pero, puedo afirmar que, por la similitud en la secuencia de evolución y por la vinculación que han tenido en el tiempo, el sistema de la universidad europea es el camino que le permitirá a la latinoamericana llegar a la norteamericana. Un camino apropiado es seguir el ya diseñado con el Espacio Europeo de Educación Superior. Para el análisis de la influencia del Espacio Europeo de Educación Superior en la educación superior latinoamericana se han considerado los siguientes criterios: definición, principios y finalidades del espacio Europeo de Educación Superior, contrastar con las tendencias latinoamericanas y con esta contrastación se define el grado de vinculación que hay entre ambas. Para el análisis de la influencia norteamericana en la educación superior latinoamericana se consideran su estructura universitaria, los principios en que se sustenta y los resultados alcanzados empleando las estadísticas existentes y definiendo los desafíos que enfrenta. Del análisis realizado se desprende la dependencia que hay de una respecto de la otra.

La tercera parte coteja la realidad de la educación superior peruana con los objetivos del EEES planteados en la Declaración de Bolonia, y se define un proyecto de acción que permitirá que la 
Educación Superior Peruana aplique los postulados de tal declaración en su medio, para conseguir asemejarse a la norteamericana. Para eso se pone de relieve las similitudes de tendencias entre la educación superior peruana y la latinoamericana, y se definen las dificultades y fortalezas que existen al diseñar la estrategia. Se consultaron textos de expertos en la historia de la educación superior latinoamericana, historiadores, antropólogos, cronistas y sociólogos ampliamente versados, reconocidos, premiados y valorados: Luis Alberto Sánchez (1900-1994), Gonzalo Aguirre Beltrán (1908 - 1996), Darcy Ribeiro (1922 - 1997), Stephen Graubard (1922 - ), Carlos Tünnennann Bernheim (1933 - ), Águeda Rodríguez Cruz (1933 - ), Claudio Rama (1954- ) entre otros, quienes se han convertido en ineludibles e inconcusas fuentes secundarias en este tema. Se llega a establecer que hay acciones que se pueden emprender a nivel institucional y otras requieren del concurso del Estado para disponer políticas comunes en una realidad tan diversificada y con tanta autonomía institucional. También concluyo que es tanta la autonomía y la diversidad en las instituciones, que es altamente probable que al lanzar un proyecto único de proporciones nacionales, este genere reacciones que volverán muy lento, e incluso harían fracasar, el proceso. Por ello, establezco que dado el contexto la mejor opción es iniciar una experiencia piloto, con una titulación en una institución, de manera de poder monitorear el proceso, perfeccionar los procedimientos y difundir los resultados para generalizar a nivel institucional y luego nacional.

La principal conclusión de este capítulo, es que el mundo anglosajón ha logrado consolidar una universidad que por sus indicadores, acopia la mayor cantidad de lugares en los 20 primeros puestos en todas las listas clasificadoras (rankings) actuales y puede considerarse la mejor del mundo. Este modelo es apetecido por la universidad peruana y que una forma apropiada de llevarla a ese escenario, es seguir el modelo diseñado en la Unión Europea para el Espacio Europeo de Educación Superior puesto que los objetivos y procedimientos diseñados en la Declaración de Bolonia, acercan a la Universidad Europea Continental a la Anglosajona, que es lo que conviene y debe buscar también la universidad peruana, a partir de pilotos generalizables. 


\subsection{EVOLUCIÓN DE LA UNIVERSIDAD LATINOAMERICANA: PERIODOS HISTÓRICOS}

En todas las formas estables de sociedad, la educación ha sido siempre el medio de transmisión de los valores culturales, costumbres y modos de vida, y junto con su contribución, revela tanto la magnitud de su poder liberador y transformador cuanto sus impotencias y deficiencias. Esa complejidad pone de manifiesto que, para introducir cambios en una realidad educativa, es indispensable considerar las fuerzas que le han impulsado a través del tiempo y distinguir los principales argumentos que le dan sentido. Desde esta perspectiva, en la primera parte del capítulo se muestra la historia y actualidad de la educación superior latinoamericana para entender plenamente la problemática actual de las instituciones educativas superiores de América Latina. Éstas, incluidas las universidades, solo serán comprendidas cabalmente en lo que son actualmente si se toman en cuenta los hechos de mayor trascendencia de su desarrollo histórico. Entonces, es importante conocer el inicio, características, similitudes, estructura y funcionamiento de la universidad, por su influencia en el proceso evolutivo del hombre y en su mayor o menor proyección sobre la sociedad (Robles, 2006).

El término América Latina (AL) o Latinoamérica (LA) refiere a los países de América donde se habla lenguas latinas, específicamente español, francés y portugués (RAE, 2005). De acuerdo con esta definición, "América Latina" incluye a Hispanoamérica (países de habla española), Brasil (de habla portuguesa) y Haití (donde el francés es lengua oficial aunque el criollo haitiano es el idioma comúnmente utilizado). Forzando la definición, algunos autores incluyen a Quebec de Canadá y el estado de Luisiana de Norte América por ser el francés su lengua oficial. Otros incluso la extienden más e introducen a los estados norteamericanos de California, Florida y Nuevo México por el número de hispanohablantes que allí residen (Colburn, 2002). En este trabajo tomaremos la primera y más restringida agrupación, ciñéndonos a la definición.

La universidad en Latinoamérica ha pasado por un largo proceso de evolución desde la fundación de las primeras universidades en el siglo XVI hasta nuestros días. Se propone la siguiente división como la más natural, atendiendo a los hechos históricos relevantes que marcan el inicio y fin de cada periodo y a las repercusiones que tuvieron en las instituciones de educación superior de la región, hechos que se describirán en las hojas siguientes. Un primer periodo: el colonial, que inicia a mediados del siglo XVI y finaliza a mediados del siglo XVIII. El segundo que es al que llamaré Republicano que va de mediados del siglo XVIII a inicios del siglo XX. El tercero, de fines de la segunda década del siglo XX a inicios del siglo XXI y el cuarto que inicia a mediados de la primera década del siglo XXI.

\subsubsection{La universidad latinoamericana colonial (s. XVI - s. XVIII)}

La fundación de ciudades fue una importante expresión del dominio territorial durante la Colonia en América Latina, en las que se reproducía la organización social y las formas de vida de la metrópoli (entiéndase por Colonia, la extensión hispánica de orden imperial, social, político, religioso y cultural que se estableció en América durante los siglos XVI, XVII, XVIII e inicios del siglo XIX) (Quiroz, 2001). 
Como el proceso de penetración hispana buscaba justificarse culturalmente, surgió la necesidad de fundar establecimientos educativos conforme al modelo europeo. Como otras instituciones, municipalidades, cortes de justicia, iglesia católica, las universidades Latinoamericanas son instituciones instauradas en América por los ibéricos en el siglo XVI. Pero el cambio de espacio de las universidades no implicó la introducción de nuevas estructuras, nueva orientación, nuevos contenidos y nuevos métodos. Se repitió la tradición académica modelada durante la edad media europea en su espacio originario cuatro siglos antes de erigirse la primera universidad americana. Así que se puede afirmar que fue una prolongación del modelo universitario español (Robles, 2006).

A este punto cabe hacerse una pregunta ¿cuál fue el tipo de educación superior que los hispánicos instituyeron en Latinoamérica? La universidad de Bolonia debe origen a la necesidad de Italia medieval de poseer, difundir y aplicar normas jurídicas generales y estables. A ella fluyen desde diferentes partes de Europa, numerosos estudiantes que buscan formación en derecho e inician prácticas que posteriormente se consagran como esenciales de la institución universitaria. Es así como los alumnos contratan y pagan a sus maestros; eligen al rector o director de la comunidad; otorgan a sus maestros ciertos poderes disciplinarios, y logran con su unidad y trabajo organizado que la comuna o municipalidad de Bolonia, interesada en retener en la localidad una población que enriquecía y daba fama a la ciudad, conceda numerosos privilegios a maestros y estudiantes tales como el derecho a resolver internamente sus conflictos, la inviolabilidad del recinto universitario y la exención de impuestos municipales. La siguiente Universidad en constituirse en Europa es la de París. Ella nace a partir de una escuela de Teología y, por oposición a la Bolonia, surge por y para los estudiantes. Se convierte en el modelo de universidad creada y dirigida por una corporación de maestros. Hasta la primera mitad del siglo XII, existía en París gran libertad para la enseñanza. A partir de esta fecha el poder eclesiástico dispuso que para ejercer tal actividad era necesario poseer una licencia ("licencia docendi"), en 1213 se logra un acuerdo que es considerado como la primera constitución o estatuto de la Universidad de París. Allí se da por primera vez el nombre de Universitas a una institución de enseñanza superior, se definen los títulos y la duración de los estudios, e incluso se establecen las formas de enseñanza. El primer grado o nivel de estudio universitario es el de bachiller ("baccalaureatus"), término cuyo significado inicial era el de servicio preliminar; el segundo grado es la licenciatura ("licentia legendi” o "ubique legendi”) como permiso para enseñar fuera de la Universidad; el tercero es la maestría (para "magistri non regentes" o maestros honorarios, y "magistri acturegentes" o maestros efectivos), es decir, acto de aceptación de un individuo dentro de la corporación de maestros universitarios. Esta estructura universitaria, como es sabido, sirve posteriormente de modelo a muchas universidades, particularmente a las de Oxford y Cambridge, hijas famosas de la "Universitas Magistrorum" francesa (Menacho, 2007).

Así, en Europa se crean dos modelos de Universidad: una manejada por los estudiantes y la otra manejada por los maestros. La primera, proveniente de la experiencia de Bolonia, dominó el sur y occidente de Europa hasta la de Salamanca y Alcalá; era secular, se guiaba por los textos de los filósofos griegos o romanos, daban mucha importancia a la libertad de pensamiento y de ella parece nacer el proceso histórico de la Ilustración. Esta es la corriente que se sigue en el Sur de Europa y cuando la Universidad intenta apartarse de esta concepción, cuanto intenta señalar 
defectos en los conocimientos establecidos u oficiales, los poderes intervienen y la limitan en sus privilegios y derechos, y le restringen toda clase de apoyo. Aquí actúa con eficacia no solo la Santa Inquisición sino también la fuerza policial. La segunda, de la línea definida por la universidad de París, defendía su obediencia a la fe cristiana, se extendió al principio por el Norte de Europa y gozó de mayor apoyo de la Iglesia y del Estado. (Menacho, 2007).

La universidad traída a Latinoamérica por los españoles fue una copia de las Universidades de Salamanca y Alcalá. Los objetivos, los contenidos, los métodos pedagógicos memorísticos fueron trasladados al pie de la letra al Nuevo Mundo. El esfuerzo por repetir lo extranjero produjo una mentalidad colonial que se mantiene en la Universidad Latinoamericana con el método actual repetitivo y memorístico de la docencia (Pérez-Estevez, 2004: 97).

En Latinoamérica las universidades se han enfrentado, a lo largo de su historia, con la necesidad de ejercer una función crítica como característica distintiva de su quehacer. Surgidas con el fin de proporcionar a las elites (órdenes religiosas, hijos de peninsulares y criollos) instrucción de carácter teológico y educación en ciertas disciplinas como leyes, retórica, gramática y artes, las universidades hispanoamericanas tuvieron como meta principal garantizar la unidad religiosa y la vinculación con la cultura de la corona española. En cuanto a la formación profesional, se limitaba a la preparación del personal necesario para cubrir los puestos secundarios de la burocracia colonial; de esta manera, la universidad surge en América al margen de la realidad social de sus pueblos (Santamaría, 2001).

Eran manifestaciones de lo que hoy llamamos una cultura impuesta, como puede verificarse en los minuciosos estatutos de inspiración salmantina, que la tradición consolidaba. Todo esto contribuía a distanciar la institución universitaria del resto de la población y consolidaba así el papel de la educación formal como legitimadora de una sociedad rígidamente estratificada (Weinberg, 2001).

Entre los siglos XVI y XVII se fundan en el Nuevo Mundo alrededor de 32 universidades, con las de de San Marcos en Perú, Santo Domingo y de México como las primeras, cuya influencia fue decisiva para la creación de las restantes. Además de Perú y México en 1551, las universidades coloniales aparecen, principalmente, en Argentina, Bolivia, Colombia, Cuba, Chile, Ecuador, Guatemala, Venezuela y Nicaragua, esta última fundada ya en 1812 (Abarca, 2007).

Más allá de su existencia y desarrollo, la universidad latinoamericana como tal fue una institución completa durante el periodo colonial, según las normas de la época, y es en el siglo decimonónico cuando sobreviene su decadencia, al sustituirla por una simple yuxtaposición de escuelas profesionales, "las que han producido egresados diplomados incultos pero técnicos, si es posible una técnica cabal sin el ineludible trasfondo de una cultura general correspondiente" (Sánchez, 1969: 19). Y es en la comprobación del énfasis técnico que ha caracterizado a las universidades que podemos afirmar que “... en suma, ninguna universidad latinoamericana puede llamarse tal si no contribuye eficazmente a la cultura humanística mediante la investigación, la reflexión y la liberación de consignas” (Sánchez, 1969: 19). 


\subsubsection{La Universidad Latinoamericana Republicana: el periodo napoleónico (s.XVIII - s. XX)}

El ascenso de la casa Borbón en el siglo XVIII hizo que la ilustración francesa influyera fuertemente en la universidad Latinoamericana. La concepción universitaria napoleónica se caracteriza por el énfasis en la técnica, la desarticulación de la enseñanza y la sustitución de la universidad por una suma de escuelas profesionales, así como la sustitución de la investigación científica, que deja de ser tarea universitaria y pasa a otras instituciones (Academias e Institutos). La Universidad se somete a la tutela y guía del Estado, a cuyo servicio debe consagrar sus esfuerzos mediante la preparación de los especialistas requeridos por la administración pública y la atención de las necesidades sociales primordiales. Su misión es, por consiguiente, proveer adiestramiento cultural y académico a la élite burguesa, imprimiéndole un particular sello intelectual: promover la unidad y estabilidad política del Estado. El siglo XIX, caracterizado por la instauración de la República en la mayor parte de los países latinoamericanos, trae consigo el auge del modelo napoleónico, que fortaleció en las universidades las carreras de carácter técnico, como ingeniería civil, medicina y farmacia, en demérito del cultivo de las ciencias en sí mismas (Tünnermann, 2006).

En esta época la universidad se convirtió en la formadora de profesionales, preparados a un ejercicio técnico de su profesión. (Se denominaron así, por la vieja costumbre de profesar o guardar votos, guardando los secretos de la Congregación, mediante una ceremonia especial al ser recibidos al interior de un gremio y dedicarse a un determinado saber). Para lograr este fin, la Universidad Napoleónica dividió las actividades universitarias. Las antiguas Facultades siguieron siendo instancias de administración curricular, integradas por Escuelas Profesionales encargadas de elaborar los currículos de cada profesión. Casi todas las Escuelas se denominaron según aquello que los estudiantes aprendían a hacer en su paso por ellas y comenzaron a otorgar Licencias para ejercer legítimamente la profesión en la sociedad. Las Escuelas fueron atendidas por profesores, es decir, profesionales habilitados para enseñar, pero no necesariamente maestros (los antiguos Magistri), dedicados a la investigación y al cultivo del saber. El otro grupo de actividades, las de investigación, se agruparon en unas nuevas estructuras: los Institutos. Estos se formaron para quienes quisieran dedicarse a las labores de investigación científica, totalmente dedicados al estudio y a la investigación y solo eventualmente a la docencia (Mureddu, 1994).

De esta forma se salvaron dos escollos que los tiempos modernos habían erigido contra la acción de la universidad medieval. Por un lado, la docencia impactó directamente a la sociedad y contribuyó a solucionar los problemas prácticos que a ésta se le presentaban, éste fue el sentido social de la enseñanza profesionalizante; por otro, se rescató la actividad científica de investigación, a través de los institutos. Algunos de ellos, a través de la alta especialización, llegaron a constituir politécnicos y se dedicaron a formar expertos en algún campo específico de la práctica profesional. En estos casos, la ciencia pura quedó en manos de los institutos universitarios de investigación, mientras que la ciencia aplicada y la docencia técnica pasó a ser responsabilidad de los institutos tecnológicos (Mureddu, 1994) 
La trascendencia del modelo educativo napoleónico estriba no solo en el hecho de que con él se cierra el capítulo de la preminencia de la educación escolástica y su secuela selectiva, si no que el nuevo sistema abre nuevos paradigmas en distintos campos del saber y del trabajo; uno de ellos plantea por primera vez el vínculo de la educación y las ciencias aplicadas, particularmente aquellas que son, en ese momento, consideradas estratégicas para el progreso moderno de las sociedades: las ciencias experimentales y las ciencias exactas. Se diversifican además las carreras para hacer surgir dos modelos de profesionales: los que ejercían la profesión liberal de manera independiente y los que se insertarán en la vida profesional laica como cuerpo del Estado (Martínez, 2005).

En este periodo, se inauguran los emolumentos profesionales autónomos. Si bien la Universidad Colonial pagaba la cátedra impartida anualmente, de ella no vivían los catedráticos que eran por lo regular prebendados, funcionarios eclesiásticos o civiles. Se profesionalizó el magisterio, y se establece el nombramiento del profesor propietario remunerado. Al establecerse también los nombramientos de profesores honorarios o suplentes, se combatió el ausentismo docente que era tan frecuente en la universidad de la época. Solamente el Rector, que tenía que renunciar a todo para ser nombrado, el secretario, el maestrescuela y el bedel vivían del salario universitario (Martínez, 2005).

A fines el siglo XIX y comienzos del XX se observa una competencia entre la universidad francesa adoptada en Latinoamérica, rígida, pragmática y docente, por una parte, y por la otra, la anglosajona, más flexible y con docentes que investigan. La educación superior se extiende por todos los continentes y se incrementa significativamente. En los países coloniales se refuerzan los modelos de los países colonizadores. Pero este sector educativo ya no está conformado únicamente por las universidades, sino por una gama heterogénea de planteles superiores: institutos tecnológicos y pedagógicos; escuelas profesionales independientes o adscritas a ministerios; y academias científicas con funciones de investigación y docencia. Ante esta avalancha de nuevas instituciones educativas, la universidad trata de defender sus derechos tradicionales, y procura ampliar sus funciones, diversificar sus enseñanzas, y ligarse más a las demandas sociales (Menacho, 2007).

El crecimiento acelerado de las fuerzas productivas provoca un extraordinario empuje de la educación superior presionando constantemente con sus requerimientos científicos, tecnológicos y de personal cada vez más especializado, ponen de nuevo en crisis la institución universitaria y surgen hechos como los de Córdoba (1918) en los cuales los estudiantes toman la batuta para cuestionar la envejecida institución universitaria. Ante esta situación de crisis, se hace necesaria una nueva definición de la universidad para el siglo XX, y con ella también una reflexión de educación superior en que participen activamente los dirigentes de la política científica y educacional, y particularmente los de las grandes potencias mundiales que aparecen en el escenario académico: Estados Unidos (Menacho, 2007). 


\subsubsection{La Universidad Latinoamericana del siglo XX: los procesos de reforma}

Las dos primeras décadas del siglo XX, encuentran a Latinoamérica en un contexto político y cultural que se enfrenta con universidades anquilosadas, que no han sido capaces de dar respuesta a los cambios experimentados por la sociedad. Todo ello establece los antecedentes para que, en 1918, se inicien una serie de jornadas promovidas por estudiantes de la Universidad de Córdoba en Argentina, quienes denuncian el carácter aristocrático de la educación superior que se ofrece y tienen como propósito generar un nuevo tipo de universidad (Tünnermann, 1998).

Las Jornadas de Córdoba dieron lugar a diversos movimientos de reforma universitaria en diferentes puntos del subcontinente. De hecho, el movimiento de Córdoba representó solamente el punto de partida de un proceso destinado a definir el ser y el deber ser de la universidad latinoamericana por medio de la búsqueda de un modelo crítico adecuado a los problemas y necesidades de cada país en particular y de la región en general (Santamaría, 2001).

En la Universidad Latinoamericana se han suscitado muchos cambios a lo largo de su evolución desde la Colonia hasta el s. XX, como hemos descrito en las líneas precedentes, pero los cambios más significativos y radicales son los que se generan en las reformas de la educación superior latinoamericana producidas en el siglo XX. Son tres reformas las definidas, la primera inicia en 1918 con el Manifiesto de Córdoba, la segunda en las décadas de los 80 y 90 del siglo pasado; y la tercera marcada con el inicio del siglo XXI. (Rama, 2006a).

\subsubsection{La Primera Reforma: la autonomía y el cogobierno (1918 - 1975)}

América Latina inició durante el Siglo XX un modelo específico de Universidad, a partir de las Jornadas de Córdoba de 1918. Dichas jornadas culminan con la redacción del denominado "Manifiesto de Córdoba" cuyos postulados básicos fueron (Santamaría 2001):

1. El cogobierno de profesores y estudiantes.

2. La autonomía política, docente y administrativa de la universidad.

3. La elección de los dirigentes de la universidad por asambleas de profesores, estudiantes y egresados.

4. El fortalecimiento de la función social de la universidad.

5. La gratuidad de la enseñanza y ayuda social a los estudiantes.

6. La elección de profesores por medio de concursos públicos y la supresión de su autoridad incuestionable.

7. La renovación periódica de los nombramientos a los profesores.

8. La asistencia libre a clases.

9. La libertad de cátedra.

10.La inclusión de estudios humanísticos y de problemas sociales en los planes de estudio de las carreras profesionales.

Este modelo agregaba una excesiva rigidez de los marcos jurídicos, la ausencia de mecanismos institucionalizados de evaluación, una estructura institucional basada en facultades y un sistema 
de gestión donde lo legislativo, lo ejecutivo y lo judicial se integraba en los Consejos Universitarios. El modelo permitió el pasaje de la Universidad de las instituciones de elites del siglo XIX, para dar cabida a las nuevas clases medias y burguesas urbanas producto de las migraciones, la modernización, el cambio en el rol del Estado como redistribuidor y creador de un mercado interno y la industrialización sustitutiva. (Rama, 2006a).

Este es el modelo universitario que se generalizó con mayor o menor intensidad en todo el continente, como respuesta a demandas de las nuevas capas sociales, a la nueva inserción internacional de los países y a la introducción de un modelo de industrialización basado en la producción en masa. El modelo permitió a las Universidades públicas, la formación de los profesionales que requería la creciente industrialización y la transformación social que la región llevó adelante desde la década del 30 del siglo XX. Se permitió y propició la incorporación de alumnos de todos los estratos económicos y contribuyó enormemente a la movilidad social. El modelo de expansión interno basado en la industrialización sustitutiva coexistió con este nuevo modelo universitario gestado en Córdoba. Este escenario de la educación superior y del modelo industrial y social de América Latina duró más de 50 años y se caracterizó por tener como primer objetivo político la búsqueda permanente de una mayor autonomía universitaria. Las Universidades públicas se desarrollaron como estados dentro de los Estados Nacionales a partir del desarrollo de la normativa de la autonomía (Pérez, 2000).

Esta autonomía puso en evidencia la incapacidad de las Universidades de ajustarse en forma dinámica y ágil a las nuevas realidades y redujo su legitimación. El crecimiento desordenado de la matrícula condujo a un deterioro de la calidad de la educación impartida al no crecer los presupuestos y al carecer de mecanismos y procedimientos de aseguramiento de la calidad al interior de las Universidades o de todo el sistema. El peso desproporcionado de la matrícula en profesiones tradicionales y la baja presencia en las áreas tecnológicas, contribuyó a una mayor distancia, en términos de pertinencia, entre las universidades y un aparato productivo. La cantidad y calidad de los egresados comenzó a ser insuficiente frente a la demanda del mercado productivo que cambiaba. Finalmente la presión creciente de los docentes y empleados redujo sustancialmente los gastos de inversión y de funcionamiento de las Universidades, generándose un incremento de los gastos corrientes y restringiendo el propio desarrollo académico de las Universidades que se tornaron cada vez más, en centros de exclusiva docencia (Rama, 2006a).

A fines de los setenta irrumpió la crisis de la deuda externa en los países del cono sur de América. El incremento de las tasas de interés sobre el valor del débito, la reducción de los precios de los productos primarios y la retracción de la inversión productiva constelaron un panorama negativo en la dinámica de crecimiento, que gravitaba entonces en torno al mercado de crédito. Estas circunstancias auspiciaron fenómenos de fuga de capitales, devaluación e inflación, que muy pronto hicieron inviable el modelo macroeconómico gestado en la década anterior, llevando casi a la quiebra a los sectores productivos y financieros vinculados con el exterior y deprimiendo drásticamente la economía interna (Rodríguez-Gómez, 1999).

La crisis económica de los estados latinoamericanos fue la variable dominante que determinó el fin del modelo universitario exclusivista, porque el crecimiento de la demanda estudiantil no pudo ser cubierto por los limitados ingresos públicos. Sin embargo, además de las presiones 
financieras resultado de la demanda de nuevos estudiantes, el modelo presentó una crisis, dado que el radicalismo político de las universidades públicas en los sesenta aunada a la caída de los niveles de la calidad, incentivó a amplios sectores sociales a buscar otras opciones educativas. Se comenzó así a formar una nueva demanda de educación superior, cuya variable de decisión no estaba correlacionada con el precio sino con la calidad, la estabilidad o la desideologización de la educación superior (Rama, 2006a).

\subsubsection{La Segunda Reforma: la mercantilización y la educación binaria (1975 - 1995)}

En América Latina la transición económica de la época puso de manifiesto rasgos comunes con el proceso de cambio global, pero también expresiones particulares. Ante todo, las transformaciones en materia económica se han expuesto a través de una serie cíclica de momentos de crisis-recuperación. En las circunstancias que han sido apuntadas, las universidades latinoamericanas se vieron sujetas a la acción de fuerzas y demandas contrapuestas. Por un lado, la crisis económica y los subsiguientes programas de ajuste coartaron las posibilidades de un financiamiento público extensivo, pero, por otro, la caída de gobiernos autoritarios y la restauración democrática abrieron espacios para la recuperación de las instituciones universitarias por las comunidades académicas, al tiempo que suscitó nuevas expectativas sociales hacia ellas, sobre todo en aquellos casos en que el régimen autoritario respectivo había golpeado con rudeza al sector universitario (Rodríguez-Gómez, 1999).

Para entonces, un nuevo y radical movimiento estudiantil latinoamericano mostró claramente que nuevamente las universidades, tal como estaban estructuradas, no respondían a los nuevos escenarios políticos y económicos ni a las nuevas demandas sociales. El movimiento estudiantil expresaba tanto la necesidad de promover renovaciones en los sistemas universitarios como la de ampliar la cobertura de la educación superior. La respuesta fue el establecimiento de diversas restricciones al acceso automático de los bachilleres a las universidades públicas en casi todos los países de la región, y vía la libre acción del mercado se promovió una expansión desordenada de la educación superior privada. Este proceso constituyó el centro de la Segunda Reforma de la educación superior en el continente desde fines de los setenta y los ochenta: promovió un incremento de la cobertura dentro de una fuerte diferenciación de las instituciones y de la calidad de los servicios educativos, y terminó conformando un nuevo modelo universitario de carácter dual. El sistema dual muestra una educación pública cada vez más elitizada socialmente, con restricciones de acceso en base a cupos y exámenes de conocimiento asociados a las limitaciones del financiamiento público, y por el otro un sector privado pagante y con restricciones de acceso a consecuencia de los costos de las matrículas dada la desigual distribución de la renta en la región (Rama, 2006a).

La instauración de este complejo modelo binario (público y privado; de alta y baja calidad; universitario y no universitario) como resultado del contexto mercantil y heterogéneo, y que promovió modelos de calidad, de precios y de financiamiento diferenciados, conformó sistemas cuya diversificación mostraba fuertes mecanismos de exclusión y no garantizaban los niveles de calidad deseados. El modelo binario comenzó a encontrar límites políticos desde mediados de 
los noventa. Pero las que realmente fracasaron fueron las premisas de los 80 de que el mercado libre podía promover altos niveles de calidad en la educación superior. Se asumió que serían los usuarios-clientes (los estudiantes) los que seleccionarían las opciones de mejor calidad que, a su vez, serían las que el mercado de las remuneraciones aprobaría diferenciadamente, y que serían las propias universidades las que garantizarían elevados niveles de calidad (Arocena et al., 2000).

Ya a comienzos del siglo XXI, al terminar la II Reforma Universitaria del s. XX, el nuevo panorama de la educación superior en la región se caracteriza por cambios en la demanda como resultado de un incremento y diversificación de las universidades privadas y una masificación, feminización y nuevo perfil estudiantil.

\subsection{Incremento y diversificación de las universidades privadas}

No es un tema de solo nueva oferta, sino que remite demandas institucionales y de mercado. Interesa conocer cuáles son los factores que han determinado que la demanda social se haya ido inclinando por la opción de la educación privada. En el caso del Perú, la Comisión Presidencial designada para estudiar la reforma universitaria, ha apuntado tres causas como explicación de ese nuevo proceso (Rama, 2010):

a. El descrédito de la Universidad pública como resultado de una politización, un funcionamiento discontinuo, una saturación de las aulas y una caída de los niveles académicos, que condujo a que los sectores altos y medios prefirieran pagar su educación en instituciones que les ofrecieran orden y funcionamiento estable. En este caso la educación pública gratuita no se constituiría en términos económicos como una inversión rentable.

b. Las crisis fiscales que afectaron a la universidad pública en el rubro de inversiones y remuneraciones afectando negativamente su calidad y perdiendo imagen y efectividad como instrumentos de ascenso social.

c. La mayor dificultad de ingreso a la universidad pública por el establecimiento de cupos y restricciones administrativas, académicas o económicas.

Este proceso ha contribuido decididamente a la estructuración del modelo binario que se fue conformando con el desarrollo de la educación privada en el continente en los 80 y 90 . Para 1994 la región ya tenía 5.438 instituciones de educación superior de las cuales 2.515 eran públicas y 2.923 , o sea el $53.71 \%$, eran privadas. De ese total, 812 eran universidades que representaban el $14,9 \%$ del total y el restante $85.1 \%$ eran instituciones de educación superior no universitarias. En ambos tipos de instituciones el sector privado era mayoritario. La educación superior privada que en los 70's fue el 16\% de la matrícula total, superó el 50\% a fines del siglo. Ello, a pesar que el proceso se ha enlentecido en toda la región y en algunos países se ha revertido lentamente como en Colombia, Venezuela y Argentina. Aun así, el crecimiento de las instituciones privadas ha continuado en la región y el 2010 superó el 69\% (Rama, 2010).

\subsection{Masificación, feminización y nuevo perfil estudiantil}

En la década del sesenta la masa estudiantil no alcanzaba al millón de estudiantes. Hoy, estimado al 2010, con una tasa de crecimiento de 1.2\% al año, la población estudiantil universitaria en 
América Latina se calcula que ha superado los 20 millones de estudiantes (Tabla 1.1). La región se acercó al 38\% de su tasa de matrícula en educación superior, la más alta de su historia, pero comparativamente baja frente a otras realidades (Tabla 1.2). Más allá de la expansión violenta en la década del 70 y 80, el crecimiento de la matrícula se mantiene a una tasa muy superior al incremento poblacional de la región, estimada en 1.0\% para el periodo 2010 - 2015 y, por ejemplo, para el mismo periodo será de 1.12 para el Perú, (CEPAL, 2010). Tal incremento de la matrícula presiona por un aumento de la diversificación de oportunidades de estudio por parte los estudiantes, lo cual contribuye a su vez a una diversificación de la oferta educativa (López, 2011).

\begin{tabular}{|c|c|}
\hline Año & Número de estudiantes \\
\hline 1950 & 267.000 \\
\hline 1970 & 1.640 .000 \\
\hline 1980 & 4.930 .000 \\
\hline 1990 & 7.353 .000 \\
\hline 2000 & 12.000 .000 \\
\hline 2007 & 18.000 .000 \\
\hline 2010 & 20.000 .000 \\
\hline
\end{tabular}

Tabla 0.1 Número de estudiantes universitarios en América Latina (Fuente: Elaboración propia, a partir de: López, 2011)

\begin{tabular}{|l|c|}
\hline & Escolarización terciaria (\%) \\
\hline Europa & 94 Finlandia; 47 Suiza \\
\hline E.E.U.U. & 82 \\
\hline Australia & 77 \\
\hline América Latina & 88 Cuba; 19 Honduras \\
\hline Asia & 95 corea del Sur; 1 Afganistán \\
\hline Africa & 10 Nigeria; 3 Angola \\
\hline Estados Árabes & 54 Líbano; 4 Mauritania \\
\hline
\end{tabular}

Tabla 0.2 Tasa de matrícula en educación superior (Fuente: Elaboración propia, a partir de: UNESCO, 2010)

Uno de los cambios más marcados de la demanda está dado por el crecimiento de la matrícula femenina en la población estudiantil superior en la región. La matrícula femenina es superior a la de los hombres en casi todos los países y en casi todas las carreras, indicando que las viejas banderas que promovían la participación femenina, al menos en este ámbito, se alcanzaron, y que el perfil de la demanda estudiantil cambió radicalmente en los últimos años. Esta realidad de la demanda educativa, sigue constituyendo la variable de más rápida y directa incidencia en las Instituciones de Educación Superior (IES) de la región, más importante aún que la competencia interinstitucional (CEPAL, 2010). 


\subsection{El agotamiento de la II Reforma Universitaria}

La II Reforma Universitaria produjo una excesiva diferenciación de las universidades, no en términos de opciones profesionales, sino en términos de calidad. La expansión del modelo binario público-privado se produjo en el marco de la ausencia de políticas públicas y con gran libertad de mercado, lo que condujo a una fuerte diferenciación en términos de calidad sin mecanismos de su aseguramiento en la educación superior. La expansión de las instituciones contribuyó a un incremento de la matrícula con lo que se redujo la inequidad en el acceso, sin embargo se generó una nueva inequidad de proceso dadas las grandes diferencias de los niveles de calidad entre las instituciones (Rama, 2006a).

Un caso que debe diferenciarse es el de la universidad Brasileña. Si bien la universidad latiniamericana es una institución cuya trayectoria de más de cuatro siglos que se inicia con la Conquista misma, y se vio profundamente alterada por la revolución de Códoba, el Movimiento de la Reforma Universitaria se desencadenó cuando en Brasil la universidad, en sentido propio, todavía no existía. La creación de instituciones de enseñanza superior en el Brasil fue promovida, a partir de la instalación de la Corte portuguesa en Río de Janeiro, durante la primera década del siglo XIX. El impulso inicial fue vigoroso y con rasgos destinados a durar. La universidad propiamente dicha no surgirá en Brasil hasta el siglo XX (Arocena et al, 2000). Schwartzman abunda en las razones de esa aparición tardía que constituye una diferencia medular con la historia de la misma institución en la América Hispánica. Pese a que se plantearon diversas propuestas para la creación de la Universidad en Brasil, ello se demoró porque "al Imperio, como a la República en sus primeras décadas, le bastaban las escuelas profesionales" (Schwartzman, 1979).

En particular, a diferencia de Hispanoamérica, Brasil no tuvo universidad colonial; durante el siglo XIX, donde el llamado "modelo napoleónico" de la educación superior fuera implantado en una versión extrema con escuelas profesionales prácticamente sin vinculaciones entre sí; pero la brasileña tuvo la dimensión del modelo que atiende a la investigación, basado en institutos dedicados integralmente a esa actividad. Esto parece haber tenido bastante más éxito en el caso brasileño que en los países de habla hispana en su conjunto. En estos últimos, las tendencias dominantes apuntaban a desdibujar a la universidad como institución unitaria, mientras que en Brasil, partiendo del otro extremo, de un proceso de signo opuesto, vale decir, de agrupamiento de escuelas profesionales investigadoras, llevaría a un resultado comparable, la universidad como "confederación de facultades" (Arocena et al, 2000).

El hito mayor lo constituyó el surgimiento de la Universidad de Sao Paulo (USP), creada por ley 1934, Con la instalación de la USP puede decirse que empieza una nueva etapa en la historia de la enseñanza superior en el Brasil, cuyo eje central o célula mater sería una Facultad de Filosofía, Ciencias y Letras, donde sería promovida la investigación a tiempo integral. Así, el sistema creció con cierta rapidez: había 15 universidades en 1950, cuando la matrícula global alcanzaba 37 mil 548 estudiantes; en 1960 llegaría a unos 100 mil estudiantes y en 1965 a 160 mil (Ribeiro, 1971. 62-64). En la década de los 60 surgió el nuevo paradigma de la universidad brasileña, este periodo supuso un salto cualitativo, en el que se pasó de la investigación "desinteresada" y de la extensión como conjunto de cursos de "vulgarización del saber" a una concepción de universidad que 
tiene como foco el proceso social y como meta la investigación para la transformación de las estructuras sociales (Mazzilli, 1996. 95-107).

El s. XX finaliza con una verdadera conmoción en los sistemas universitarios latinoamericanos. A la alta diversidad, masificación y variada calidad se agregan la internacionalización de la educación superior, las nuevas tecnologías de comunicación e información, las nuevas demandas de acceso de la población y la presencia creciente de sociedades del conocimiento (Rama, 2010).

\subsubsection{La Tercera Reforma: la internacionalización y el control de la calidad}

A diferencia del pasado, a fines del s. XX no hay consenso popular sobre el prestigio que da un grado universitario o la educación universitaria. No existe un respeto incuestionado hacia la universidad como institución o hacia los hombres y mujeres altamente educados. Esto resulta irónico, pues habiéndose creado las sociedades más educadas de la historia, habiéndose asignado recursos económicos sin precedentes para la provisión de educación a todos los niveles, las universidades han perdido mucho del prestigio que antes gozaban. Parte del cambio se debe al propio éxito de la universidad en responder a las demandas de conocimiento más especializado y sofisticado. En el camino se perdió la base común de conocimiento y experticia. Se perdió la idea del rol educativo general, formativo, de la universidad, que se disuelve hoy en actividades especializadas. Ya no se habla de dos culturas, científica y humanística, ahora suele reconocerse la existencia de varias culturas incomunicadas en una misma institución, acompañando la profesionalización y especialización creciente de los saberes. Muchos de los problemas que enfrentan las universidades latinoamericanas son autoinfligidos y surgen de su interior, como resultado de su adaptación a procesos sociales previos y a desarrollos de su propia dinámica, que dificultan su adecuación a los cambios más recientes. Las estrategias deben ser diferentes para los distintos segmentos de la educación superior. Las instituciones de educación superior no universitaria deben mantener o alcanzar niveles adecuados de calidad atendiendo a nuevas demandas. Para evitar que los rasgos fundamentales de las universidades se vean aplastados por la amplia gama de actividades prácticas hacia las que pudieran inclinarse exageradamente, deben manejarse estrategias de equilibrio y flexibilidad, sin perder de vista sus objetivos esenciales básicos: producir conocimientos y formar a los futuros productores de nuevos conocimientos (Vessuri, 1996: 105-106).

Entre las nuevas estrategias tenemos la internacionalización de la educación superior. Directa e indirectamente esta estrategia promueve la movilidad estudiantil, el establecimiento de estándares internacionales de calidad, la presión hacia nuevas pertinencias globales y locales, y la vinculación de los ciclos y procesos educativos a escala global. Otra es el uso de las nuevas tecnologías de comunicación, que contribuyen a la globalización de la educación al generar la educación virtual, acortando las distancias, expandiéndola más allá de las fronteras, con nuevas prácticas pedagógicas de simulación, de autoaprendizaje y de praxis, en una realidad de educación no presencial. Este nuevo contexto favorece a la educación, al flexibilizarla y renovarla, y también da respuesta al problema de masificación y a las exigencias de las familias. En América Latina las familias están haciendo un gran esfuerzo expresado en los pagos a la educación superior y los costos de oportunidad de los tiempos de estudio. La matrícula de la educación privada más que se duplicó en la primera década del s. XXI. Esto marca el inicio de 
una nueva reforma que, con mayor o menor intensidad, están procesando y promoviendo las universidades, las sociedades y los gobiernos en todo el mundo y poniendo a los sistemas nacionales de educación en mayor sintonía e integración, y cuyos ejes fundamentales están dados por la masificación, la nueva regulación nacional e internacional, las nuevas tecnologías de comunicación, las nuevas fronteras de la educación y los nuevos saberes (Rama, 2006b).

Por educación internacional se entiende una práctica educativa cuyo objetivo es el fomento de la diversidad cultural, la movilidad de alumnos y docentes, y el respeto a la identidad y a la diferencia cultural. La educación transnacional reviste varias formas, mediante, por ejemplo, la operación con apertura de una filial de la universidad en otro país, siendo la mayor diferencia entre ambos conceptos los objetivos perseguidos. Sin embargo, actualmente la modalidad de la educación transnacional que empieza a predominar es la educación virtual, impartida a través de medios electrónicos, provocando que los aprendizajes devengan independientemente del lugar y del tiempo. El aprendizaje "virtual" o "en línea” representa para muchos una importante innovación educativa. El hecho de que la institución vaya en búsqueda del estudiante, y no a la inversa, se ve como un salto drástico. Súbitamente, la oferta educativa aparenta ser abundante y las posibilidades ilimitadas. El principal reto para los sistemas nacionales de educación es lograr establecer sistemas de aseguramiento de la calidad para proteger los intereses de sus usuarios. Sin embargo, este desafío se confunde a menudo con una conducta de proteccionismo de parte de los sistemas nacionales (Gacel-Ávila, 2006).

La educación virtual es una nueva forma de hacer, un proceso viable de enseñanza que suple precariedades propias de la educación tradicional. En la educación virtual, el proceso de enseñanza aprendizaje se trabaja con los alumnos sin horarios predeterminados, posee "entornos virtuales" sin paredes, no importa el tamaño, la vestimenta, el color, ni tampoco el nivel social de las personas. Además, por medio de esta enseñanza las personas recorren las dimensiones más lejanas, a través de las tecnologías de la información y las grandes redes de telecomunicación. La educación virtual ha experimentado un gran auge, puesto que cada día tenemos mayor cantidad de instituciones integrando sus programas académicos de educación "en línea" y más alumnos satisfechos que siguen estos aprendizajes (Rosario, 2006). Entre las innovaciones de los últimos años en este rubro están los MOC (Massive Online Courses) y los MOOC (Massive Open Online Courses); ambos son cursos colocados en internet para ser seguidos por alumnos de todo el mundo masivamente, en el primer caso a precios muy bajos y en el segundo de manera gratuita. Los MOOC's requieren de un fuerte financiamiento dada su gratuidad, y algunas universidades están apostando a esto (Harvard, Stanford invirtieron varias decenas de millones de dólares el año 2013 para este fin), por lo que se está intentando vincular a las empresas privadas a participar d esta modalidad.

La educación virtual configura una de las nuevas realidades de la Tercera Reforma a escala global, la educación transnacional. En el 2000, ya existían 164.000 estudiantes virtuales en 175 universidades de la propia región, lo cual representaba el 1,3\% de la matrícula. En el 2009 eran 1.2 millones, cerca del 6\% de la matrícula, un 28\% de crecimiento anual (Rama, 2010).

Otra de las características del inicio del s. XXI es que la globalización está cambiando muchos de los escenarios de la sociedad mundial. La disminución del empleo industrial en América 
Latina es parte de ese proceso. Es el empleo en el sector de servicios en la región, tanto el formal como el informal, el que sigue creciendo, mientras que el empleo industrial sigue reduciéndose (Gráfico 0.1, Gráfico 0.2, Gráfico 0.3). Pero, más allá de sectores, la flexibilización de los mercados laborales y la renovación tecnológica tornan difícil saber cuáles serán los conocimientos que se requerirán dentro de diez años. Esto plantea preguntas difíciles a la educación superior ya que ésta forma para mercados laborales y sociedades del futuro. Los desajustes en término de pertinencia con los volúmenes de la demanda de los mercados laborales se expresan hoy en un mundo global en las crecientes migraciones de profesionales.

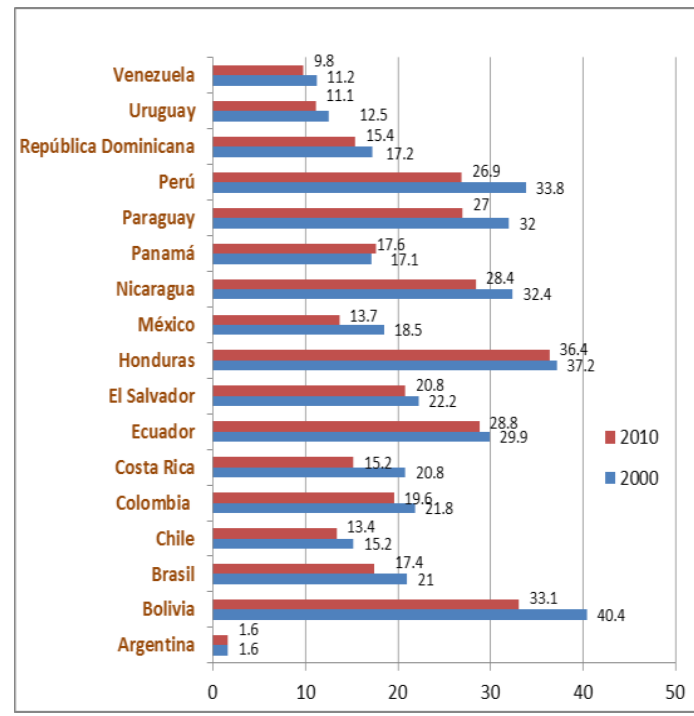

Gráfico 0.1 Porcentaje de población empleada en sector primario (minas y agropecuario) Fuente (OIT, 2011)

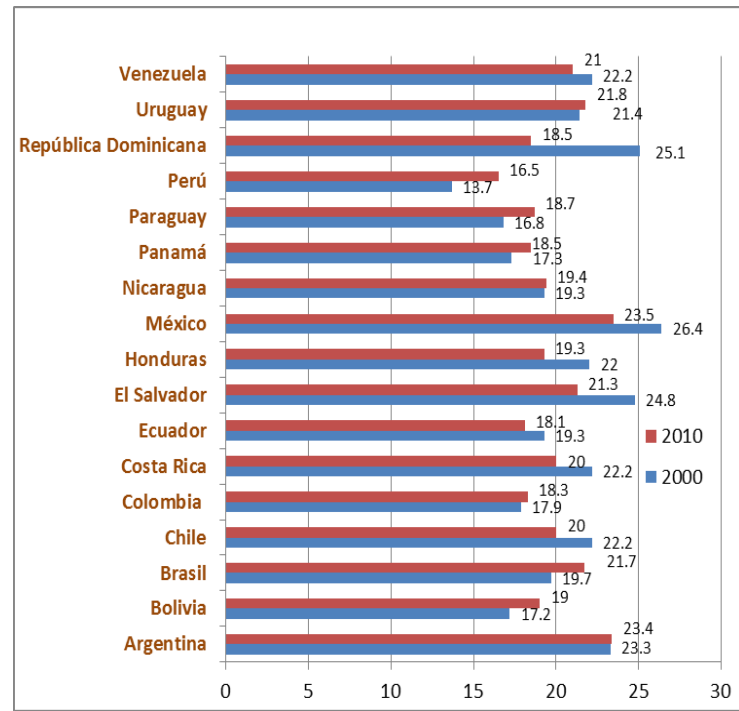

Gráfico 0.2 Porcentaje de población empleada en sector secundario (manufactura e industria) Fuente (OIT, 2011) 


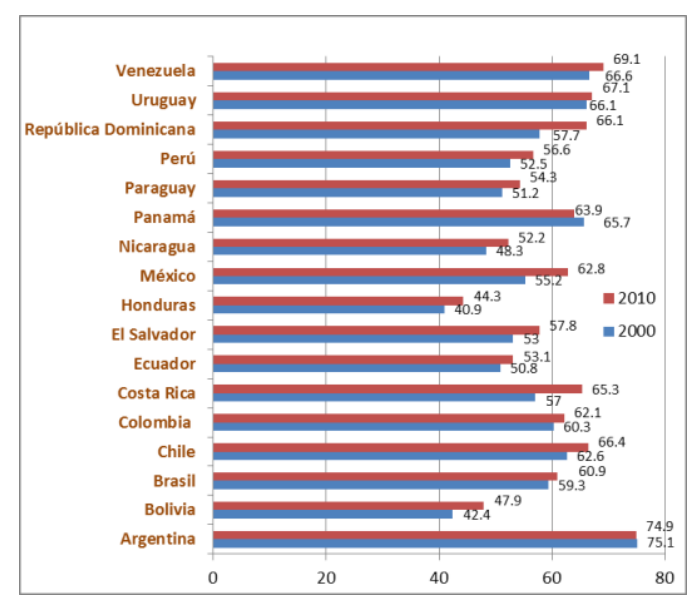

Gráfico 0.3 Porcentaje de población empleada en Sector Terciario (comercio y servicios). Fuente (OIT, 2011)

La generación de conocimientos, su diseminación y utilización, han llegado a ser un factor clave para el desarrollo y competitividad de las naciones, más importante incluso que los recursos naturales, el trabajo abundante o el capital financiero (Brunner, 2008).

Los países que ofrecen empleo, son aquellos que están pasando de ser sociedades industriales a sociedades del conocimiento, que exigen mayor capacitación laboral. La enseñanza de idiomas, el uso intensivo de las nuevas tecnologías y el ajuste de sus currículos a un escenario y una pertinencia global, platean fuertes desafíos y debates en relación a cuál es la demanda de los estudiantes de toda América y el tipo de respuesta que dan sus universidades. El sector servicios es el que mayor demanda de profesionales tiene y al que tanto hombres como mujeres están dando mayor preferencia (Gráfico 0.4).

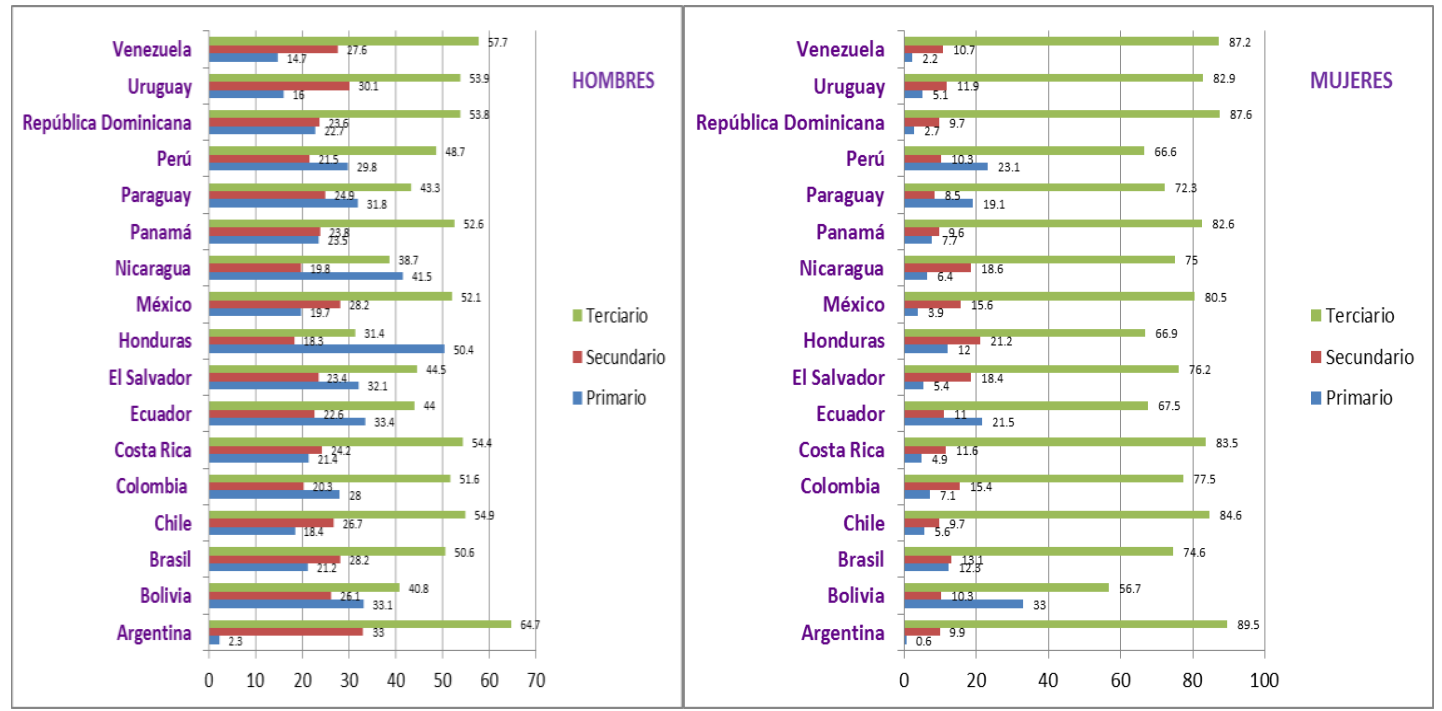

Gráfico 0.4 Porcentajes de población ocupada por sexo y sector en la actividad económica, según país. Fuente (OIT, 2011)

La tercera reforma nos deja esas dos grandes líneas de acción para las próximas décadas. La universidad enfrentará un nuevo modelo educativo transnacional que deberá adoptar, modificar o combatir, y debe decidir si el crecimiento económico cada vez más sesgado a los servicios debe hacerle repensar su oferta educativa. 


\subsection{TENDENCIAS DE LA EDUCACIÓN SUPERIOR LATINOAMERICANA}

Para poder entender cómo desde la Universidad Latinoamericana se pueden enfrentar los escenarios actuales y futuros planteados en los acápites anteriores, se requiere analizar cómo están haciéndolo y cómo les afecta a las principales fuentes de influencia que ha tenido y sigue teniendo: la Universidad Europea y la Universidad Norteamericana.

\subsubsection{Influencia de la universidad europea}

Los cambios que se suceden en el mundo y las fuerzas económicas que mueven a las naciones están generando profundas transformaciones en la educación superior. Palabras desdeñadas en el mundo de la educación superior hace 20 años: competitividad, globalización, fuerzas de mercado, clientes, parques tecnológicos, innovación industrial, educación trasnacional, desarrollo regional, son ahora frecuentes en los corredores, publicaciones y planes de desarrollo universitarios (Malo, 2004).

La percepción de esta realidad y de lo que ella significa - por ejemplo, que muchos de los mejores estudiantes del mundo prefieran quedarse en sus países de origen o irse a otros no europeos en vez de contribuir con su talento al desarrollo de Europa - fue lo que llevó a la Unión Europea a desarrollar programas para atraer a estudiantes extranjeros y para retener a los propios, y la llevó a crear el más importante espacio de educación superior del mundo y a tratar de convertir a la Unión Europea en la región más competitiva y dinámica del orbe en cuanto a investigación y desarrollo (Olvera, 2009).

Lo acontecido en Europa en el área de educación superior es punto de partida para el diseño de proyectos educativos en varias regiones del mundo. Este es el caso de Latinoamérica, que tiene en la Unión Europea un referente, por los vínculos sostenidos a lo largo de su evolución, y debe ser de su interés mantener y mejorar las relaciones entre las dos regiones y por ende el intercambio estudiantil y de profesionales. Sin embargo, es necesario conocer los efectos que el proceso de cambio emprendido en Europa tendría en Latinoamérica, ya que podría generar una gran transformación al sistema universitario que implique modificaciones en la estructura, ciclos, titulaciones, sistemas de evaluación y otros aspectos, que en la región no se podrían acometer ya que los países no están en las mejores circunstancias para afrontar este proceso tal como se plantea en el Europa. Ante esta situación, se han establecido una serie de proyectos de convergencia como el Proyecto Tuning, con la finalidad de acercar a ambas regiones. Se deben identificar los desafíos que deben enfrentarse para permitir estar en sintonía con lo acontecido en Europa, de lo contrario Latinoamérica será la representante de la educación europea del pasado (Olvera, 2009).

\subsubsection{Comparación entre la universidad europea y la latinoamericana}

Las diferencias y similitudes con la universidad europea quedan muy bien definidas en el estudio hecho por la Dra. Águeda Rodríguez Cruz, por lo que no se abundará en ella en este trabajo. La Dra. Rodríguez es profesora emérita de la Universidad de Salamanca y Directora del "Seminario 
de Historia de la Educación en América" de esa universidad desde su fundación. Podemos reseñar, a modo de resumen, algunas de las principales ideas del texto:

"La Universidad de Salamanca fue el modelo institucional de las universidades hispanoamericanas, más o menos directo e intenso, su denominador común, el bilo conductor de su historia, la raíz principal y vínculo de las mutuas relaciones, al menos en lo que constituye las líneas esenciales de la institución universitaria. La proyección de la Universidad de Salamanca en Hispanoamérica, especialmente en el aspecto educativo, y singularmente en el mundo universitario, forma parte de la identidad de los pueblos hispanoamericanos, donde la raíz educativa es uno de los principales cimientos de su historia cultural, y es en la historia cultural donde descubrimos la identidad de los pueblos. De modo que las universidades han sido un factor decisivo en la forja y cultivo de la identidad de los pueblos hispanoamericanos. Las lineas directas salmantinas de influjos copiosos van de Salamanca a: Lima, México y Caracas, fundamentalmente.

Salamanca está presente en Lima en su documento fundacional, que la crea a su imagen y le concede sus privilegios, aunque limitados. A través de algunos de sus primeros maestros, rectores y dirigentes y oficiales en general, formados en los claustros salmantinos... Los universitarios hispanoamericanos de boy continúan con esta conciencia de su filiación salmantina, que estiman grandemente como pertenencia a una estirpe sabia y a una alta alcurnia espiritual y académica." (Rodríguez, 2005: 75).

Se puede anotar la clara proyección institucional y pedagógica de la universidad europea sobre la latinoamericana en los siguientes párrafos:

"¿Qué proyectó Salamanca en América? ¿Qué tipo de universidad? Se trata de un tipo de universidad clásico, el modelo hispánico, que se encarna en Salamanca, por asi decirlo, heredero de la Universidad medieval, etapa histórica que dio a luz la institución universitaria con un perfil y estructura que han sido básicos. El sentido y organización de la universidad, con sus cursos regulares, maestros y discípulos, programas fijos y grados académicos con validez. universal (la licencia ubique docendi) es un producto típico de la Edad Media occidental. Estos estudios generales o universitas medievales, hispanizados, por asi decirlo, en Salamanca y demás universidades peninsulares de fundación temprana, con su incipiente organización, textos, métodos, grados, e incluso terminología básica, continuaron en la etapa moderna de la bistoria universitaria, aunque remozados con los aires renacentistas. $Y$, después de sufrir las reformas ilustradas del XVIII y las del centralismo del XIX, continúan siendo en nuestros días la base histórica remota de la estructura y sistema docente universitario" (Rodríguez, 2005: 175).

\subsubsection{Implicancias del Proceso de Bolonia para América Latina}

El 5 de mayo de 1998 con motivo del 700 aniversario de la Universidad de la Sorbona, los ministros de educación de Alemania, Gran Bretaña, Francia e Italia, redactaron un documento conjunto en el que solicitaban a los demás países de la Unión Europea un esfuerzo para la 
creación de un espacio dedicado a la educación superior. Los ministros de educación europeos firmaron el 19 de junio de 1999 una Declaración conjunta llamada “Área de Educación Superior Europea" pero se hizo más conocida como "Declaración de Bolonia" suscrita por 29 estados europeos, quienes en su momento abogaron por la creación, para el año 2010, de un Espacio Europeo de Educación Superior (EEES) coherente, compatible y competitivo, que sea atractivo para los estudiantes y académicos de la región, así como para los de otros continentes. El Comité de Dirección redactó un borrador de la declaración que se discutiría en Bolonia con un esquema de las divergencias y convergencias en las estructuras de aprendizaje. Al finalizar el Foro de Bolonia se adoptó una declaración conjunta, donde se enuncia que "la Europa del Conocimiento ahora ampliamente reconocida como un factor irremplazable para el desarrollo social y humano es un componente indispensable para consolidar y enriquecer la ciudadanía europea" (Toloza, 2006).

El Proceso de Bolonia sienta las bases para la construcción de un "Espacio Europeo de Educación Superior" (EEES), el cual estuvo organizado conforme a ciertos principios: Calidad, Movilidad, Diversidad y Competitividad. Bajo estos principios el Proceso de Bolonia fue orientado hacia la consecución de dos objetivos estratégicos: el incremento del empleo en la Unión Europea y la conversión del Sistema Europeo de Enseñanza Superior en un polo de atracción para estudiantes y profesores de otras partes del mundo. Los objetivos instrumentales o líneas de acción del Proceso de Bolonia son los siguientes (López, 2007):

- Adopción de un sistema fácilmente legible que haga posible el reconocimiento mutuo de las titulaciones, mediante la implantación, entre otras cuestiones, de un suplemento al Diploma.

- Adopción de una estructura educativa de ciclos.

- Adopción de un sistema de acumulación y transferencia de créditos que favorezca la movilidad, como el European Credit Transfer System (créditos ECTS)

- Promoción de la cooperación europea en materia de garantía de la calidad y desarrollo de criterios y metodologías comparables.

- Promoción de la movilidad y eliminación de obstáculos para el ejercicio libre de la misma por los estudiantes, profesores y personal administrativo de las universidades y otras instituciones de educación superior europeas.

- Fomento de la dimensión europea en la enseñanza superior con particular énfasis en el desarrollo curricular como condición necesaria para el logro de los objetivos del EEES.

Con el reconocimiento simultáneo y mutuo de las titulaciones, se pretende que los sistemas universitarios sean más compatibles y por ende, más comparables, sin que se pretenda una homologación total de las titulaciones, ni tampoco a que limite su número. Se podría describir como una especie de conversor de las modalidades académicas de cada país en un documento aceptado por todos los países miembros de la Unión Europea. El sistema ECTS establece las condiciones para que se logre el acercamiento entre las universidades y amplía las opciones que se dan a los estudiantes El sistema ECTS describe de un modo uniforme en toda Europa la carga de trabajo de cada estudiante, mediante este sistema, se presenta atención prioritaria al 
desarrollo de destrezas, capacidades y habilidades de los titulados, además de los contenidos específicos de las materias estudiadas (Cepeda, 2006).

En Latinoamérica (LA) existe una gran diversidad de titulaciones, cuando el estudiante pretende hacer válido su título para efectos de obtener un empleo o para continuar sus estudios profesionales en otro país de la región y si no existen convenios con la institución que lo expide, éste no es aceptado, lo que frena la movilidad del profesional. Esta situación además, es un obstáculo importante para establecer la cooperación con las universidades de Europa, la reestructuración o proceso de cambio y ajuste que se vive en Europa ya está reduciendo el número de carreras y la duración de las mismas. Esto implicará que en LA las titulaciones deban ser más acordes a lo que acontece en el EEES de tal manera que se logre la homologación de estudios y por ende se permita la movilidad entre los países de cada región y entre LA y el EEES.

Con referencia a la duración de las carreras en Europa los tres ciclos se precisan de diferente manera en los países involucrados en el EEES, aunado a la necesidad que existe de recortar el tiempo de estudio para que los estudiantes que culminen puedan acceder al mercado de trabajo con los conocimientos y competencias requeridas en el más corto tiempo y evitar que queden rezagados en virtud de la gran velocidad con que se genera actualmente el conocimiento. Se estima que para el año 2020 el conocimiento se duplicará cada 73 días (López, 2007).

Incorporar la educación superior al desarrollo económico y facilitar la empleabilidad de sus graduados, son retos para el EEES en todas las titulaciones. La creación de un espacio universitario común para todos los países europeos, orientado a fomentar su crecimiento económico, su competitividad internacional y su cohesión social a través de la educación y la formación de los ciudadanos a lo largo de la vida es la tarea que congrega a las universidades de la Unión Europea. Se convoca a los jóvenes europeos a la educación universitaria y se integran los estudios técnicos con los universitarios. Algunos critican haber tomado el modelo de Estados Unidos como meta, pues tiene primacía de criterios económicos y orientación a oficios o profesiones prácticas, pero aun así las universidades europeas han trabajado durante los últimos años para orientarse hacia ese nuevo modelo. Entre los desafíos que enfrenta la estrategia europea están: establecer un sistema común acumulativo de créditos por cada curso, ligados a horas de clase y a casi el doble de estudio independiente estudiantil fuera de clase; la identificación y adquisición de competencias laborales de los estudiantes y desarrollar una capacidad de aprendizaje independiente o autónoma que les acostumbre a actualizarse y a continuar educándose a lo largo de toda la vida (Ogliastri, 2008).

Todo esto requiere nuevos materiales educativos, como casos que permitan discusión en clase en lugar de la cátedra magistral, o el aprendizaje por Internet, lecturas y tareas en casa que obliguen al estudiante a preparar y responder sobre el tema de cada sesión de clase. Finalmente, se requiere la formación en el profesorado de una capacidad socrática de centrarse en el aprendizaje de los estudiantes en lugar de dictar cátedra y exigir memorización o precisión de cálculo. Hoy las mejores universidades del mundo son principalmente privadas, anglosajonas y todas sin ánimo de lucro. El éxito de la apuesta europea dependerá fundamentalmente de estandarizar y mantener la calidad de la educación y lograr puntuar en los indicadores de resultados como los mejores (Ogliastri, 2008). 
Si Latinoamérica pretende quedar dentro del espacio de movilidad estudiantil tienen que ofrecer un sistema evaluativo comparable con los estándares del sistema ECTS. Esto obliga a una profunda restructuración de todo el sistema de enseñanza, ya que el ECTS toma en cuenta la totalidad de las actividades del estudiante para otorgarle créditos, que son las competencias o capacidades que pueden desarrollar los poseedores de un título. Esto sugiere una transformación radical del sistema educativo que responde al cambio al que estamos asistiendo en las últimas décadas hacia una sociedad del conocimiento entendida también como una sociedad del aprendizaje (López, 2007).

No se trata de realizar una copia de lo acontecido en Europa sino de beneficiarse de la experiencia europea para provocar los cambios que se consideren pertinentes a la realidad latinoamericana. Debemos empezar iniciando reformas educativas que permitan homologar en una institución las estructuras de las diferentes carreras, los sistemas de evaluación, el proceso de movilidad y todas sus implicaciones en el rubro de la calidad, luego entre las universidades de su país de origen, posteriormente diseñar estrategias que permitan la compatibilidad, movilidad, calidad, en toda la región latinoamericana, para después contribuir al acercamiento regional y entonces ahora sí hablar de un proyecto transcontinental de tal magnitud como el de la UE y LA (Olvera, 2009).

La experiencia nos señala que la mejor estrategia para iniciar la transición de la aplicación del Acuerdo de Bolonia es estableciendo experiencias piloto institucionales, que luego sean replicables en un ámbito institucional, nacional y finalmente reproducirlos regionalmente, con las mejoras y ajustes que la evolución de la aplicación vaya señalando (Rubia et al, 2006).

\subsubsection{Influencia de la universidad norteamericana}

Otra fuente que ha influenciado la evolución de la educación superior latinoamericana ha sido la universidad norteamericana. La educación norteamericana proviene del mundo anglosajón y los países a los que generalmente se refiere esta denominación son: Australia, Canadá, Estados Unidos de América, Irlanda, Nueva Zelanda y reino Unido. través de la historia, este grupo de países han compartido, entre otras cosas, sistemas de gobierno democráticos, economías de mercado y el derecho anglosajón, que es utilizado por los integrantes de esta esfera a excepción de Quebec en Canadá y Luisiana en Estados Unidos, derivado de su herencia francesa. Estos países han tenido un crecimiento tan fuerte que han influenciado sobre el desarrollo de los mercados, la educación y la economía global (Bennett, 2004).

Los países anglosajones han tenido una posición de liderazgo, y no en pocas ocasiones han impuesto, sus objetivos sobre los de los demás. De cualquier manera, el empuje que como naciones tienen, es lo que en gran medida ha propiciado el desarrollo a nivel global de su cultura, ampliando sus fronteras más allá de sus límites físicos, su geopolítica está a la orden del día, siempre con el fin de seguir creciendo en poder y economía. De esta manera impactan directamente los rumbos de las demás naciones en las cuales surge la necesidad de equipararse apostando en gran medida con una educación respaldada por el aprendizaje de la lengua que marca la pauta en todas las actividades comerciales y de relaciones entre países (Narez, 2011). 
Esta no es una relación nueva y debemos revisar en la historia cómo es que la universidad latinoamericana se vinculó con la norteamericana y qué características saltantes mostraba ésta frente a aquella.

\subsubsection{La universidad norteamericana}

La universidad pública norteamericana ha tenido siempre como objetivos la enseñanza, la investigación y el servicio. La influencia de la universidad alemana de la última parte del siglo XIX continúa poniendo énfasis en los estudios de posgrado e investigación y los efectos del concepto de concesión de tierras siguen sintiéndose en la anuencia de la universidad para aceptar todo tipo de programas de educación técnica e investigación aplicada que el gobierno, los grupos de presión, los benefactores, etc., parecen necesitar. Está, además, el énfasis que se pone en el servicio y la extensión a todos los segmentos del público (Cuninggim, 1969).

"El resultado es la "multiversidad": tan inglesa como sea posible, por el bien de los no graduados todavia; tan alemana como sea posible, por el bien de los graduados y del personal de investigación, y tan norteamericana como sea posible por el bien del público en generaly, finalmente, tan confusa como sea posible, por el bien de la preservación de todo el difícil equilibrio" (Cuninggim, 1969: 39).

Sin embargo, en ningún lugar del mundo la universidad ha sido tan funcionalmente absorbente como en los Estados Unidos. Todas las otras naciones delegan algunas de las tareas de educación, entrenamiento e investigación, a otras instituciones. En ninguna otra parte se supone automáticamente que todo lo que todos quieren en lo que toca a experiencias educativas, o todo lo que todos quisieran ver resuelto en cuanto a problemas prácticos, recolección de datos, investigación del universo o limpieza del paisaje, fuera como cosa natural, una función de la universidad (Hutchins, 1967).

A lo largo de su historia, las universidades norteamericanas solo raramente se han interesado en la autonomía, entendiéndola como la libertad de la universidad como institución para llevar a cabo su papel de crítica de la sociedad y su objetivo de preservar y aumentar la verdad. La historia de la educación superior, sin embargo, ha tenido que enfrentarse amplia y frecuentemente con la libertad académica del intelectual. Naturalmente, la autonomía universitaria y la libertad académica individual de los profesores están relacionadas, pero no son idénticas. Una universidad que se gobierna a sí misma no garantiza necesariamente la libertad académica individual de los miembros del cuerpo de profesores, ni tampoco una universidad controlada por el gobierno, o por un personal ajeno a ella, infringe necesariamente los derechos individuales de los profesores. Un consejo de gobierno que delega a los miembros de la institución sus poderes sobre la institución académica (como ocurre con frecuencia), ciertamente cede una autonomía práctica a la universidad. En las mejores universidades estaunidenses públicas, sus consejos han delegado bastante, sin duda alguna, y han interferido poco. La suposición general debería ser que la sociedad es mejor servida por una universidad que esté en libertad de buscar y comunicar la verdad sin restricciones; el reconocimiento legal de la importancia de la autonomía no es de esencial significación, sin embargo, aun en un sentido pragmático, el 
reconocimiento de principios públicamente y por ley, puede ser preferible que el depender meramente de la práctica habitual (Waggoner, 1971).

Otro asunto importante en América del Norte (Estados Unidos y Canadá) es la evaluación de la calidad y ha constituido, desde hace décadas, una actividad permanente, en estrecha relación con la gestión de las instituciones educativas. En Estados Unidos, la evaluación institucional en el nivel superior se lleva a cabo a través de agencias regionales, y la acreditación de carreras la hacen agencias especializadas. En Canadá, la evaluación está a cargo de los consejos provinciales de las universidades, y la acreditación de carreras se hace con criterios similares a los de Estados Unidos.

Dentro de esta actividad de medición de calidad, la firma Ipsos Media (compañía global de investigación de mercado con sede central en París. Fundada en 1975 desde 1990 ha creado o adquirido numerosas empresas de investigación en todo el mundo. En octubre de 2011 se ubica como la tercera mayor agencia de investigación del mundo. Desde el 2014, Ipsos cuenta con oficinas en 87 países, empleando a 16.530 personas) realizó un relevamiento de información a partir de una encuesta entre trece mil trescientos treinta y ocho académicos de ciento treinta y un países, para tener una lista merituada de las mejores universidades del mundo en el 2010 y fue publicado 2011. En los resultados, los diez primeros muestran siete universidades norteamericanas y tres británicas. Para realizar la evaluación se tomaron en cuenta varios indicadores de desempeño, entre ellos la calidad de la enseñanza, la cantidad de citas que tienen los trabajos de investigación de cada entidad, innovación, cantidad de investigaciones, número de estudiantes por profesor, cantidad de estudiantes con doctorado y la mixtura internacional entre estudiantes y profesores. Existe un claro predominio anglosajón. Entre las doscientas mejores hay setenta y dos instituciones norteamericanas en la lista, veintinueve británicas, catorce alemanas, diez holandesas y seis chinas. Entre las primeras treinta solo aparecen, además de universidades de EE.UU. y Gran Bretaña, instituciones de Suiza, Canadá, Hong Kong, Japón y Corea del Sur. Ninguna universidad latinoamericana. Las universidades brasileñas Universidad Campinas y la Universidad de San Pablo estuvieron cerca de ser incluidas entre las doscientas mejores. Al referirse a América latina, el director del Centro de Educación Internacional del Boston College, Philip Altbach, dice que deben superarse las pesadas cargas de estructuras "burocráticas y a veces politizadas" y plantillas de profesores a tiempo parcial, que casi nunca pueden ser la base de una universidad que investiga (Thompson Reuters, 2011).

\subsubsection{Comparación entre la universidad norteamericana y la latinoamericana}

La universidad norteamericana y la latinoamericana tienen sus raíces en la universidad medieval. Estudios sobre educación superior tan diferentes como el de Luis Alberto Sánchez y el de Harold Benjamin concuerdan en especular que las diferencias entre las universidades de París y Bolonia todavía se reflejan en los contrastes que existen entre la organización universitaria norteamericana y la latinoamericana. La universidad medieval de París estaba controlada por los profesores, y su modelo influyó en las universidades del norte de Europa, que incluían Inglaterra y Escocia e influyeron en el modelo norteamericano. La universidad medieval de Bolonia, controlada formalmente por los estudiantes, influyó sobre las universidades del sur de Europa, que incluían Salamanca y Alcalá, las cuales fueron el modelo para las universidades españolas 
coloniales en el Nuevo Mundo (Sánchez, 1979). Los dos modelos cambiaron en el Nuevo Mundo pero, los conceptos básicos de una universidad de maestros que dirigían a estudiantes, por una parte, y una universidad de estudiantes en la que los profesores eran empleados, por la otra, siguieron persistiendo (Benjamin, Harold, 1965).

La universidad latinoamericana era autónoma en su organización, pero siguió las reglas estrictas trasmitidas por España, su papel era servir a las necesidades de la clase española gobernante. Luego de la influencia de la ilustración y la revolución francesa y americana, el nuevo estado independiente se hizo cargo de las universidades. El nuevo nacionalismo de independencia consideró a estas escuelas profesionales como escuelas nacionales, pero éstas sólo estaban unidas por débiles vínculos (Aguirre, 1961). Luis Alberto Sánchez hace notar que así como existen algunos países cuyas historias nacionales están puntuadas por constituciones nuevas, así también había universidades que con cada nuevo rector parecían adquirir un nuevo conjunto de estatutos (Sánchez, 1979).

Un asunto del gobierno universitario, incluso más controversial que la autoridad y la relación entre la universidad y el estado, es el que se refiere al gobierno interno de la universidad y a la participación de estudiantes en él. Después de 1918 y bajo presión de los estudiantes, se extendió a través de la mayoría de las universidades públicas de Latinoamérica el modelo llamado cogobierno, es decir, gobierno de los profesores, los alumnos y, ocasionalmente, los egresados. En casi todo el mundo, las autoridades universitarias son elegidas por profesores, y los profesores son el principal grupo de control. Los administradores de universidades latinoamericanas al estudiar la universidad estatal norteamericana, se sorprenden ante el hecho de que todo el control legal de la universidad esté a cargo de personas políticamente designadas y ajenas a la universidad. Sin embargo, quedan perplejos por el hecho de que el sistema parece funcionar sin conflictos aparentes. Suele concluirse que debe existir un extraordinario acuerdo general entre el estado y su universidad, al grado de que no hubiera problemas entre ellos (Waggoner, 1971).

El resumen de Stephen Graubard (Editor de Daedalus, Revista de la Academia Americana de las Artes y las Ciencias y profesor de Historia en la Universidad de Brown) sobre el desarrollo de la universidad, enfatiza la singularidad de este crecimiento, el cambio y la importancia que tuvieron las últimas décadas del siglo XIX en la formación de los modelos actuales de la educación superior en Norteamérica.

"Las universidades se desarrollaron en la edad clásica del capitalismo norteamericano. El mercado estaba abierto, la demanda condicionaba la oferta... La expansión de comodidades... parecía solamente incrementar la demanda de ellas... Casi todas las instituciones subordinadas que en conjunto definen el carácter de la educación superior norteamericana de boy en día, se desarrollaron en ese entorno. Las universidades que podían asegurar fondos para la construcción y el mantenimiento de bibliotecas y laboratorios, crecieron y prosperaron; las que no dieron importancia a estas instalaciones, casi sin excepción, limitaron sus ambiciones al papel tradicional de instrucción de alumnos y no pudieron ofrecer cursos de posgrado. La distancia entre los pequeños colegios y las grandes universidades se hizo mayor, no porque estas últimas fueran más prestigiosas (este no siempre era el caso), sino porque atrajeron cada vez más hacia sus cuerpos de profesores, individuos que se 
sentian a si mismos como miembros de comunidades académicas especificas y como miembros de cuerpos más grandes de profesiones intelectuales nacionalmente organizadas. Casi todas las principales sociedades profesionales e intelectuales que existen hoy en los Estados Unidos fueron fundadas en este periodo. A través de sus publicaciones y sus reuniones anuales, estas instituciones suministraron importantes redes de comunicación para quienes estaban comprometidos en buisquedas intelectuales comunes. La creación de una comunidad nacional de intelectuales (quizá más precisamente de muchas comunidades) dividida en líneas disciplinarias, dio impetu a la expansión de las universidades y a su organización, sobre líneas estrictamente departamentales. En esencia, pues, la universidad norteamericana actual... existió desde los primeros años del siglo XX." (Graubard, 1968: 16, 17)

A principios del siglo $\mathrm{XX}$, las principales universidades públicas latinoamericanas eran universidades nacionales y en ellas generalmente se dio por sentado que las escuelas secundarias cubrían el requerimiento de educación general, y los estudiantes entraban a las escuelas profesionales de su elección directamente después de la escuela secundaria, así, eran admitidos a la universidad sin conocer su verdadero potencial. Además, el trabajo que exigía el programa de una escuela profesional en disciplinas académicas específicas, era realizado sin que se diera ninguna o muy poca importancia al soporte de instalaciones de laboratorios o bibliotecas. En contraste, la universidad norteamericana exige el paso de los alumnos por un nivel llamado "High school" en el que se imparten asignaturas similares a las que llevarán en la universidad y luego se les evalúa con un examen nacional "SAT", (Scholastic Assessment Test) aplicado por el estado, para calificar los logros alcanzados en la educación básica antes de acceder a la educación superior (Waggoner, 1971).

Mientras que el modelo norteamericano del consejo de directores de muchas universidades estatales solo delega una parte de sus poderes legales a los programas y al personal, el modelo tradicional de la mayoría de las universidades del mundo ha sido el de investir al cuerpo de profesores con el control de estos asuntos. Sin embargo, durante más de cincuenta años en muchas universidades latinoamericanas los profesores y los estudiantes reunidos en consejos y comisiones mixtos han elegido a las autoridades universitarias, seleccionado el personal, elaborado los presupuestos y determinado las políticas académicas. En años recientes, la mayoría de las universidades públicas latinoamericanas han sido gobernadas por consejos y comisiones que incluían a estudiantes. El consejo universitario es el cuerpo que determina la mayor parte de la política de la universidad, en presupuesto, personal y currículo (Tünnerman, 2003).

Las diferencias que se presentan con la anglosajona se fundamentan en la adopción en el siglo XVIII por la universidad latinoamericana, del sistema universitario napoleónico, que le hace abandonar el sistema escolástico y le vuelve profesionalizante y controlada por el estado, siguiendo un patrón de normas que le alejan de la vocación investigadora y cuidado de su propia calidad. En tanto que la anglosajona, que se vincula más a la estructura propia de la universidad de París, soportando su sistema de gobierno en una corporación de profesores que son quienes configuran sus características esenciales, se vinculan más a la investigación, calidad y tecnología (Waggoner, 1971).

La universidad de Latinoamérica ha recibido presiones durante el siglo XX para el cambio, presión para un acceso más democrático a la educación superior, presión para el desarrollo de 
ciencia y tecnología modernas, para una mayor variedad de programas de carreras universitarias, y una preocupación para que la universidad contribuya realmente al desarrollo económico, industrial y social de sus países. Estimulado por profesionales liberales y por un gobierno también liberal. Fue después de la Segunda Guerra Mundial que se incrementó la presión en cambios internos estructurales y académicos, frecuentemente bajo la influencia de la universidad norteamericana, la cual había obtenido buenos resultados al hacer más amplio el acceso a la educación superior, al estimular la ciencia y la tecnología y al proporcionar importantes beneficios de la educación y la investigación a muchos aspectos de la sociedad (Tünnerman, 2003).

Por otro lado, en Latinoamérica se ha avanzado en la "cultura de la evaluación" de la educación superior, superando medianamente las tensiones planteadas en los primeros años de la década de los 90 por el antagonismo entre autonomía universitaria y evaluación. El mayor desarrollo se ha registrado en lo referente a la evaluación diagnóstica para el mejoramiento de la calidad y de la pertinencia institucional y no en lo que tiene que ver con fines de acreditación. Los procesos de acreditación de los postgrados cuentan con una amplia trayectoria en Brasil, y han sido aplicados de forma masiva en Argentina; también en Centroamérica a través del SICAR (Sistema de Carreras y Postgrados Regionales). Los procesos tendientes a la acreditación institucional, es decir, para la aprobación de nuevos centros universitarios privados o para la revisión de su funcionamiento, han posibilitado en varios países -como Argentina, Chile, Colombia y Uruguay- limitar la proliferación excesiva de nuevas instituciones universitarias, y tender a una mayor homogeneidad en cuanto a los niveles de calidad. Han sido significativos los avances producidos en los últimos años en materia de acreditación de carreras y de títulos en varias redes de facultades en las áreas de ingeniería, medicina y agronomía con procedimientos y con criterios similares a los vigentes en Estados Unidos y Canadá (Fernández, 2005). En el Perú se formó el Consejo de evaluación, acreditación y certificación de la calidad de la educación superior universitaria (CONEAU) con el fin de establecer los estándares que deberán cumplir las universidades para poder ofrecer el servicio educativo y, para promover y orientar procesos de autoevaluación para regularizar la práctica (Congreso del Perú, 2006). Luego, se ha definido el "Modelo de calidad para la acreditación de carreras profesionales universitarias" con el fin de promover el orden, la sistematización, la evaluación y la autorregulación de las carreras universitarias (CONEAU, 2012).

En resumen podemos afirmar que en la universidad latinoamericana, el movimiento de reforma académica ha sido ciertamente influido por la experiencia de las universidades norteamericanas. Sin embargo, pese a las dificultades de comunicación, la extrema sensibilidad de casi todos los latinoamericanos hacia una relación de dependencia, la amplia diferencia en lo que a recursos se refiere y la tradicional orientación de Latinoamérica hacia Europa, las universidades latinoamericanas tienen más que aprender del desarrollo que se lleva a cabo actualmente en sus propios países y los europeos que en Norteamérica (Waggoner, 1971).

Esto pone de relieve que la universidad norteamericana es un gran referente para la latinoamericana, como lo es para la universidad europea. La latinoamericana identifica los logros y trata de seguir las mejores prácticas norteamericanas, con, por ejemplo, los propedéuticos para mejorar los resultados de la secundaria al ingreso de la universidad. La europea ha diseñado el 
Espacio Europeo de Educación Superior para mejorar los indicadores educativos y la integración regional. La mejor posibilidad de mejora de la educación superior, en cuanto a indicadores de movilidad, logros de aprendizaje, para la Universidad Latinoamericana

\subsubsection{La universidad latinoamericana}

Vistas las características e influencias mencionadas, se descubre que las universidades latinoamericanas no tienen una estructura que corresponda a un esquema definido, lógico y racional, de acuerdo con la función que desempeña: "La universidad latinoamericana es un conjunto heterogéneo en que elementos de universidades europeas y norteamericanas se superponen o encajan en una trama tradicional heredada de la universidad española del siglo XVIII. El grado en que hayan podido modificar la estructura tradicional les confiere una apariencia de mayor o menor modernidad." (González, 1966. p 24).

En verdad es muy difícil tipificar la universidad latinoamericana, porque las universidades involucradas reflejan las enormes diferencias existentes entre los países latinoamericanos, aunque comparten por supuesto, las características de un continente subdesarrollado y dependiente, que todavía no ha alcanzado un grado total de avance científico ni tecnológico como para que sus universidades sean a la vez centros independientes de pensamiento (Albornoz, 1972).

Sin embargo, para Darcy Ribeiro, (antropólogo por la Universidad de São Paulo, fue consultor para la UNESCO y la OIT, fundador de la Universidad de Brasilia y ministro de educación en Brasil, murió en 1997), existe un tipo de universidad bien definida en Latinoamérica; y aun considerando que su estructura no responde a un conjunto uniforme de propósitos o a una decisión asumida deliberadamente en un momento dado, tiene características peculiares que, en general, se concretan en una división de facultades profesionales autosuficientes y cátedras autárquicas. "La característica distintiva de la universidad latinoamericana es su forma democrática de gobierno instituida a través de la coparticipación de profesores y estudiantes en todos los órganos deliberativos. Esta institución aseguró a las universidades que la adoptaron un grado alto de percepción de sus responsabilidades frente a la sociedad nacional, dio una mayor cohesión interna a sus cuerpos docente y estudiantil y es ella la que les brinda ahora la posibilidad de promover su renovación estructural." (Ribeiro, 1971: 132). También Ribeiro afirma que, “... a pesar de ser cientos las universidades latinoamericanas, todas se insertan dentro del mismo marco estructural básico el cual, cristalizado mejor o peor aqui o allá, alterado en todas partes por coloridos locales, configuran esencialmente el mismo modelo de México hasta Chile" (Ribeiro, 1971: 107).

El Dr. Gonzalo Aguirre Beltrán, (fue Director del Instituto Nacional Indigenista en México, Rector de la Universidad Veracruzana, Diputado Federal mexicano, Director del Instituto Indigenista Interamericano, Subsecretario de Cultura Popular) al analizar la evolución de las universidades latinoamericanas y la forma como ha cristalizado su organización académica y gobierno, concluye que es posible, no obstante las peculiaridades nacionales o regionales, enmarcarlas en un formato común que permite afirmar la existencia de una universidad latinoamericana que se diferencia de los modelos europeos y norteamericanos, que se ha constituido con un perfil propio en el curso de su particular desarrollo histórico, y que aunque 
constituyen parte de la cultura occidental tienen formas de vida y sistemas de valores distintos entre sí y distintos de los modelos euroamericanos, aunque ha sido influenciado por ellos (Aguirre, 1960).

\subsubsection{La universidad latinoamericana actual}

Conociendo los antecedentes y evolución de la Universidad Latinoamericana y las diferencias y similitudes que tiene con el EEES y la Universidad Norteamericana, se debe considerar el contexto actual, para saber cómo puede responder a las tendencias que le muestran estos dos sólidos referentes.

América Latina entre 2001 y 2011 acumuló un aumento del producto bruto interno del orden del 52\% (Tabla 0.3) en promedio, disminuyó la tasa de desempleo (Tabla 0.4) y los salarios reales se vieron favorecidos comparado con los países desarrollados (Tabla 0.5). La abultada demanda desde los mercados internacionales de las materias primas de la región, en particular desde los importantes mercados emergentes de China e India, ha generado un crecimiento sostenido (Desarrollo Peruano, 2012).

\begin{tabular}{|c|c|c|c|c|c|c|c|c|c|c|c|c|c|c|}
\hline \multicolumn{15}{|c|}{ América Latina } \\
\hline & País & 2001 & 2002 & 2003 & 2004 & 2005 & 2006 & 2007 & 2008 & 2009 & 2010 & 2011 & Acumulado & Promedio \\
\hline 1 & Panamá & 0.6 & 2.2 & 4.2 & 7.5 & 7.2 & 8.5 & 12.1 & 10.1 & 3.9 & 7.6 & 10.6 & 104.42 & 6.72 \\
\hline 2 & Perú & 0.2 & 5.0 & 4.0 & 5.0 & 6.8 & 7.7 & 8.9 & 9.8 & 0.9 & 8.8 & 6.9 & 85.44 & 5.77 \\
\hline 3 & Rep Dom & 1.8 & 5.8 & -0.3 & 1.3 & 9.3 & 10.7 & 8.5 & 5.3 & 3.5 & 7.8 & 4.5 & 75.32 & 5.24 \\
\hline 4 & Argentina & -4.4 & -10.9 & 8.8 & 9.0 & 9.2 & 8.5 & 8.7 & 6.8 & 0.9 & 9.2 & 8.9 & 66.72 & 4.76 \\
\hline 5 & Ecuador & 4.8 & 3.4 & 3.3 & 8.8 & 5.7 & 4.8 & 2.0 & 7.2 & 0.4 & 3.6 & 7.8 & 65.35 & 4.68 \\
\hline 6 & Chile & 3.4 & 2.2 & 3.9 & 7.0 & 6.2 & 5.7 & 5.2 & 3.3 & -1.0 & 6.1 & 6.0 & 59.57 & 4.34 \\
\hline 7 & Costa Rica & 1.1 & 2.9 & 6.4 & 4.3 & 5.9 & 8.8 & 8.0 & 2.7 & -1.0 & 4.7 & 4.2 & 59.25 & 4.32 \\
\hline 8 & Colombia & 1.7 & 2.5 & 3.9 & 5.3 & 4.7 & 6.7 & 6.9 & 3.5 & 1.7 & 4.0 & 5.9 & 57.89 & 4.24 \\
\hline 9 & Honduras & 2.7 & 3.8 & 4.5 & 6.2 & 6.1 & 6.6 & 6.2 & 4.2 & -2.1 & 2.8 & 3.2 & 53.70 & 3.98 \\
\hline 10 & Paraguay & 2.1 & 0.0 & 3.8 & 4.1 & 2.9 & 4.3 & 6.8 & 5.8 & -3.8 & 15.0 & 3.8 & 53.64 & 3.98 \\
\hline 11 & Bolivia & 1.7 & 2.5 & 2.7 & 4.2 & 4.4 & 4.8 & 4.6 & 6.2 & 3.4 & 4.1 & $5.1^{\mathrm{e}}$ & 53.19 & 3.95 \\
\hline 12 & Uruguay & -3.4 & -11.0 & 2.2 & 11.8 & 6.6 & 4.1 & 6.5 & 7.2 & 2.4 & 8.9 & 5.7 & 46.69 & 3.54 \\
\hline 13 & Brasil & 1.3 & 2.7 & 1.1 & 5.7 & 3.2 & 4.0 & 6.1 & 5.2 & -0.3 & 7.5 & 2.7 & 46.52 & 3.53 \\
\hline 14 & Guatemala & 2.4 & 3.9 & 2.5 & 3.2 & 3.3 & 5.4 & 6.3 & 3.3 & 0.5 & 2.8 & $3.8^{\mathrm{e}}$ & 44.29 & 3.39 \\
\hline 15 & Venezuela & 3.4 & -8.9 & -7.8 & 18.3 & 10.3 & 9.9 & 8.8 & 5.3 & -3.2 & -1.5 & 4.0 & 41.49 & 3.21 \\
\hline 16 & Nicaragua & 3.0 & 0.8 & 2.5 & 5.3 & 4.3 & 4.2 & 3.6 & 2.8 & -1.5 & 4.5 & 4.7 & 39.78 & 3.09 \\
\hline 17 & México & 0.0 & 0.8 & 1.4 & 4.1 & 3.2 & 5.2 & 3.3 & 1.2 & -6.2 & 5.5 & 3.9 & 24.16 & 1.99 \\
\hline 18 & El Salvador & 1.7 & 2.3 & 2.3 & 1.9 & 3.6 & 3.9 & 3.8 & 1.3 & -3.1 & 1.4 & 1.5 & 22.29 & 1.85 \\
\hline Fue & Ites: Bancos C & trale & Insti & de & adist & & & e: Est & hado & & & Elabora & on: Desarro & oPeruano \\
\hline
\end{tabular}

Tabla 0.3 Producto bruto interno acumulado de América Latina.

Fuente: Desarrollo Peruano, 2012

Esta realidad nos demanda no ser espectadores de una dramática presión en Latinoamérica: la clara necesidad de aumentar el número de profesionales que enfrenten este crecimiento.

\begin{tabular}{|l|c|c|}
\cline { 2 - 3 } \multicolumn{1}{c|}{} & $\mathbf{2 0 1 0}$ & $\mathbf{2 0 1 1}$ \\
\hline Argentina & $\mathbf{7 . 8}$ & $\mathbf{7 . 3}$ \\
\hline Brasil & 7.0 & 6.2 \\
\hline Chile & 8.5 & 7.3 \\
\hline Colombia & 12.9 & 11.8 \\
\hline Ecuador & 8.1 & 6.3 \\
\hline México & 6.5 & 6.1 \\
\hline Panamá & 7.7 & 5.4 \\
\hline Perú & 8.1 & 8 \\
\hline Uruguay & 7.3 & 6.4 \\
\hline Venezuela & 8.8 & 8.6 \\
\hline América Latina & 7.3 & 6.8 \\
\hline
\end{tabular}

Tabla 0.4 Tasa de desempleo en américa Latina.

(Fuente: Elaboración propia, a partir de: OIT, 2011) 

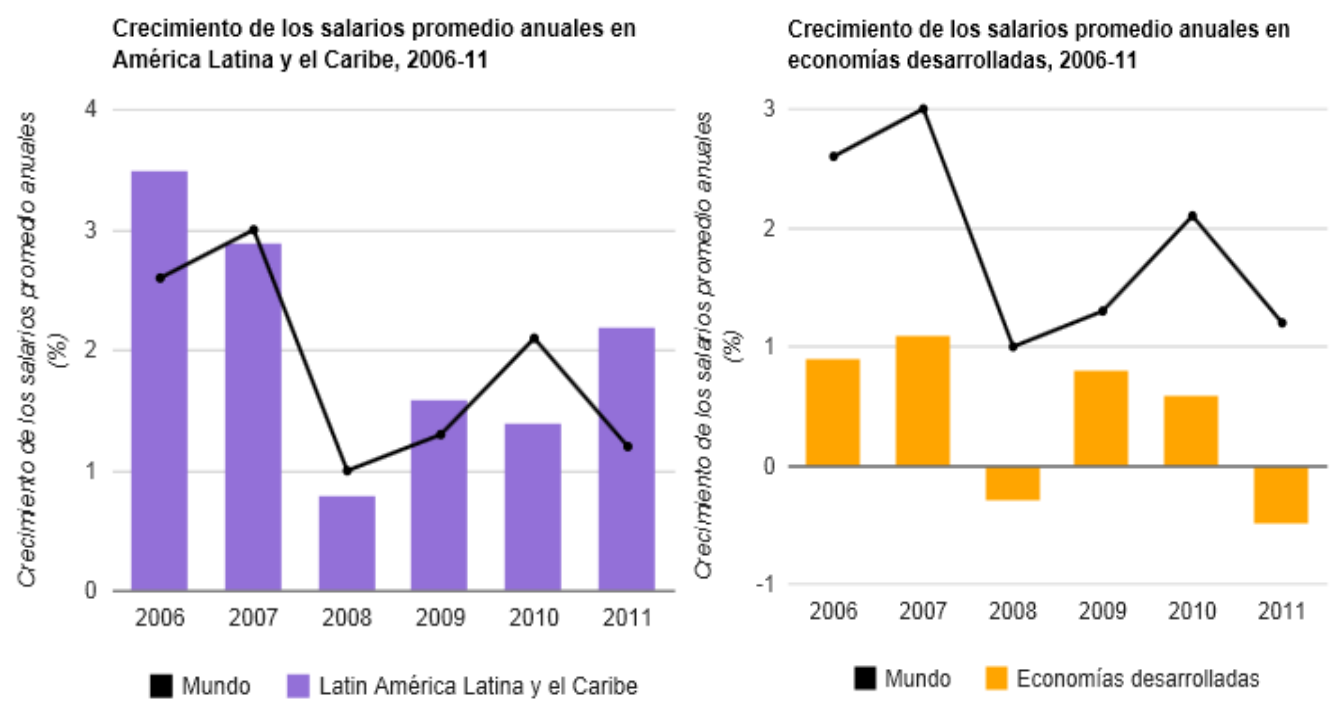

Tabla 0.5 Crecimiento de salarios por región 2006 - 20011.

(Fuente: OIT, 2012)

Los esfuerzos iniciales de la región con respecto a la educación superior se ven alterados por la irrupción de varios anhelos, una agresiva estrategia por cubrir la demanda de formación superior que comparten los proveedores trasnacionales, una competencia feroz entre los países desarrollados por el reclutamiento de los mejores talentos del mundo, la difusión de nuevas tecnologías y la difusión de programas tendientes a asegurar la provisión oportuna de personal calificado a las cadenas internacionales de producción, con visiones cortoplacistas e insuficientes para el logro de la capacidad intelectual estratégica de los países. Otro elemento que distingue al comienzo de siglo es la profunda erosión que ha sufrido el lenguaje referido a la educación superior. La perspectiva del nuevo "gestor" público, marcadamente economicista, ha penetrado en el lenguaje habitual de analistas y decisores universitarios. Vocablos, tales como "capitalismo académico", "transacciones en el mercado de estudiantes", "universidad emprendedora", "alumno cliente", "financiamiento discrecional", "diagnóstico del mercado", entre otros, han sido adoptados para interpretar la, prácticamente, totalidad de los fenómenos locales acerca de la educación superior. Y no es casual. América Latina es una de las regiones donde los procesos de mercadeo de variadas formas de producción cultural han adquirido enorme envergadura y múltiples formas de aparición (Gazzola et al, 2008).

En la última década se han producido innovaciones positivas y negativas. Entre las positivas podemos señalar (López, 2011):

$>$ reforzamiento y creación de redes de cooperación internacional,

$>$ incremento de programas de movilidad académica de profesores y alumnos,

$>$ los nuevos métodos de gestión, evaluación, acreditación y financiamiento,

$>$ la descentralización en las mega-universidades,

$>$ la diversificación de cursos, carreras y estudios de postgrado,

$>$ el énfasis en proyectos interdisciplinarios y transdisciplinarios,

$>$ la vinculación a la sociedad y al mundo del trabajo,

> la capacidad creciente de prospectiva, reforma e innovación, 
los modelos de triple hélice: universidad-industria-sociedad

Y entre las innovaciones negativas:

$>$ la consideración de la educación como un bien que se compra en el mercado y no como un derecho ciudadano,

la universidad deja de ser una institución social preocupada por la equidad y los valores éticos y ciudadanos y se convierte en una organización o empresa sólo preocupada por la ganancia

$>$ la progresiva eliminación de la gratuidad de la ES

$>$ la transición de una educación privada basada en valores, como la de las universidades católicas, a una educación "rentable" de dudosa calidad.

Las cifras muestran una educación superior creciente en Latinoamérica, que requiere de innovaciones para enfrentar las exigencias actuales. El cada vez mayor número de universidades en la región (Tabla 0.6) y del incremento de la matrícula (Tabla 0.7 y Tabla 0.8) llevan a un camino que ya está marcado y tiene características distintivas.

\begin{tabular}{|c|c|}
\hline Año & Número de Universidades \\
\hline 1950 & 75 \\
\hline 1975 & 330 \\
\hline 1985 & 450 \\
\hline 1995 & 812 (319 púb., 493 priv.) \\
\hline $2010 *$ & 2000 \\
\hline
\end{tabular}

Tabla 0.6 Número de universidades en América Latina. Fuente: (López, 2011). (*) Estimado.

\begin{tabular}{|c|c|}
\hline Sector & Incremento anual (\%) 2011 \\
\hline Público & 2.5 \\
\hline Privado & 8 \\
\hline General & 6 \\
\hline
\end{tabular}

Tabla 0.7 Tasa de incremento de matrícula en América Latina por sector. Fuente: (López, 2011)

\begin{tabular}{|c|c|}
\hline Año & Tasa escolarización $(\%)$ \\
\hline 1950 & 2 \\
\hline 1970 & 6.3 \\
\hline 1980 & 13.8 \\
\hline 1990 & 17.1 \\
\hline 2000 & 19.0 \\
\hline 2003 & 28.7 \\
\hline 2010 & 38.0 \\
\hline
\end{tabular}

Tabla 0.8 Tasa de escolarización en educación superior en LA. Fuente: (López, 2011)

Debe entenderse que en Latinoamérica existen realidades distintas y deben atenderse de manera diferenciada. Los sistemas difieren totalmente incluso por el tamaño o la cantidad de alumnos, lo que les hace definitivamente distintos. Hay megasistemas de educación superior con más de cuatro millones de estudiantes en Brasil (5.273.000) y con más de dos millones en México y 
Argentina. También los hay medianos -entre un millón doscientos mil y quinientos mil estudiantes, como son los casos de Chile, Colombia, Perú y Venezuela; pequeños, entre quinientos mil y ciento cincuenta estudiantes en Bolivia, Cuba, Ecuador, Guatemala y República Dominicana; y muy pequeños, como es el caso de los países centroamericanos y el Caribe anglófono y francófono. (López, 2011). Con un sesenta por ciento de la matrícula total regional de educación superior concentrada en tres países: Brasil, México y Argentina, Tabla 0.9 (Fundora, 2010).

\begin{tabular}{|c|c|c|}
\hline \multicolumn{3}{|c|}{$\begin{array}{l}\text { DESGLOSE MATRICULA TOTAL EDUCACION SUPERIOR } \\
\text { América Latina 2007-2008 }\end{array}$} \\
\hline No. & PAIS & Cantidad estimada \\
\hline 01 & BRASIL & 4802072 \\
\hline 02 & MEXICO & 2709255 \\
\hline 03 & ARGENTINA & 2384858 \\
\hline 04 & VENEZUELA & 1859943 \\
\hline 05 & COLOMBIA & 1260886 \\
\hline 06 & PERU & 909315 \\
\hline 07 & CUBA & 782040 \\
\hline 08 & BOLIVIA & 765955 \\
\hline 09 & CHILE & 663694 \\
\hline 10 & REP. DOMINICANA & 322311 \\
\hline 11 & ECUADOR & 312789 \\
\hline 12 & COSTA RICA & 202578 \\
\hline 13 & PARAGUAY & 149120 \\
\hline 14 & PANAMA & 140655 \\
\hline 15 & HONDURAS & 135832 \\
\hline 16 & SALVADOR & 124956 \\
\hline 17 & GUATEMALA & 114764 \\
\hline 18 & URUGUAY & 110288 \\
\hline 19 & NICARAGUA & 103577 \\
\hline 20 & JAMAICA & 45770 \\
\hline 21 & TRNIDAD Y TOBAGO & 16920 \\
\hline 22 & GUYANA & 11201 \\
\hline 23 & SURINAM & 6036 \\
\hline 24 & BELICE & 5760 \\
\hline 25 & GRANADA & 5097 \\
\hline 26 & SANTA LUCIA & 2617 \\
\hline 27 & ARUBA & 2032 \\
\hline 28 & ANTIGUA Y BARBUDA & 1617 \\
\hline 29 & SAN VICENTE Y LAS GRANAD. & 1544 \\
\hline 30 & DOMINICA & 1442 \\
\hline 31 & SAN CRISTOBAL Y NIEVES & 942 \\
\hline \multicolumn{2}{|c|}{ MATRICULA TOTAL 2007-2008 } & 17956866 \\
\hline
\end{tabular}

Tabla 0.9 Matrícula en educación superior por país en LA.

Fuente: (Fundora, 2010)

La educación superior ha tenido gran relevancia en el apoyo a los postgrados y en el desarrollo de la investigación científica. México y Brasil tienen una matrícula de cien mil estudiantes en cursos de postgrado. Las transformaciones recientes llevan a que el porcentaje de estudiantes en posgrados aumente del uno coma tres por ciento al tres coma seis por cien en la primera década del nuevo siglo. Fueron creadas doce de las veinte agencias de evaluación y acreditación de la región y, como novedad, se dio comienzo a un crecimiento sostenido de la educación trasnacional en todos los países de la región, hasta un doce por ciento de la matrícula en Bahamas o un siete coma cinco en Chile. Sin embargo, aunque la tendencia es alentadora, las cifras son bajas, en 2004 Latinoamérica recibió estudiantes extranjeros equivalentes al uno coma cinco por ciento de un total mundial de 2.450 .000 universitarios. En el 2009 de un total de 2.800.470 
estudiantes extranjeros, solo acudieron a América Latina y el Caribe cincuenta y tres mil, mientras que en USA y Europa Occidental eran 1.816.945 (UNESCO, 2009). Esto indica que los países latinoamericanos no constituyen destinos atractivos para los estudiantes internacionales. Ninguno de los países de Latinoamérica hoy en día aparece en la lista de los 23 destinos que atraen más estudiantes extranjeros (López, 2011).

\subsection{LA INFLUENCIA EN PERÚ}

\subsubsection{Principios y características de la educación superior universitaria en Perú}

El caso de Perú está inmerso en esa variopinta realidad latinoamericana que le contiene, que se replica en su interior y que está fuertemente influenciada por el Espacio Europeo de Educación Superior y el sistema educativo anglosajón.

La influencia europea se ha manifestado desde la creación de las primeras universidades peruanas y la réplica del sistema español ha sido largamente explicada líneas arriba. También la influencia francesa, con el sistema napoleónico, ha sido determinante. Si bien las reformas de la región afectaron el desarrollo de la educación terciaria en Perú, así como se instalaron, desaparecieron, debido a ese pernicioso quehacer educativo en el que cada autoridad define el sistema que se aplicará durante su mandato pudiendo tomar en cuenta o no la experiencia acumulada y las normas aprobadas con anterioridad.

El sistema norteamericano, anglosajón, también ha influenciado la educación superior peruana, pero no en lo profundo de sus sistemas, sino en las formas de hacer, y en las últimas décadas ha logrado definir un modelo que, por los resultados que muestran, parece el más apropiado a seguir.

Esto me lleva a conjeturar que el devenir de la educación superior de Perú y de Latinoamérica, será muy parecido al del Espacio Europeo de Educación Superior, pues ha nacido del mismo modelo de universidad europea, ha experimentado los cambios significativos que en ella se dieron y, ahora, mira el desempeño del mundo anglosajón, buscando un camino que le permita tener sus resultados de calidad, de movilidad, de aprendizajes, de investigación y de legitimación del entorno.

Por ello, en esta sección abordaré las líneas que Perú puede seguir para, aprovechando lo ya andado por el EEES, orientar vías apropiadas a considerar en el desarrollo de titulaciones, instituciones o estructura en la educación universitaria de Perú.

Iniciaré mostrando algunas particularidades de Perú y centrando algunos de los aspectos tratados en los acápites anteriores para el caso peruano. 


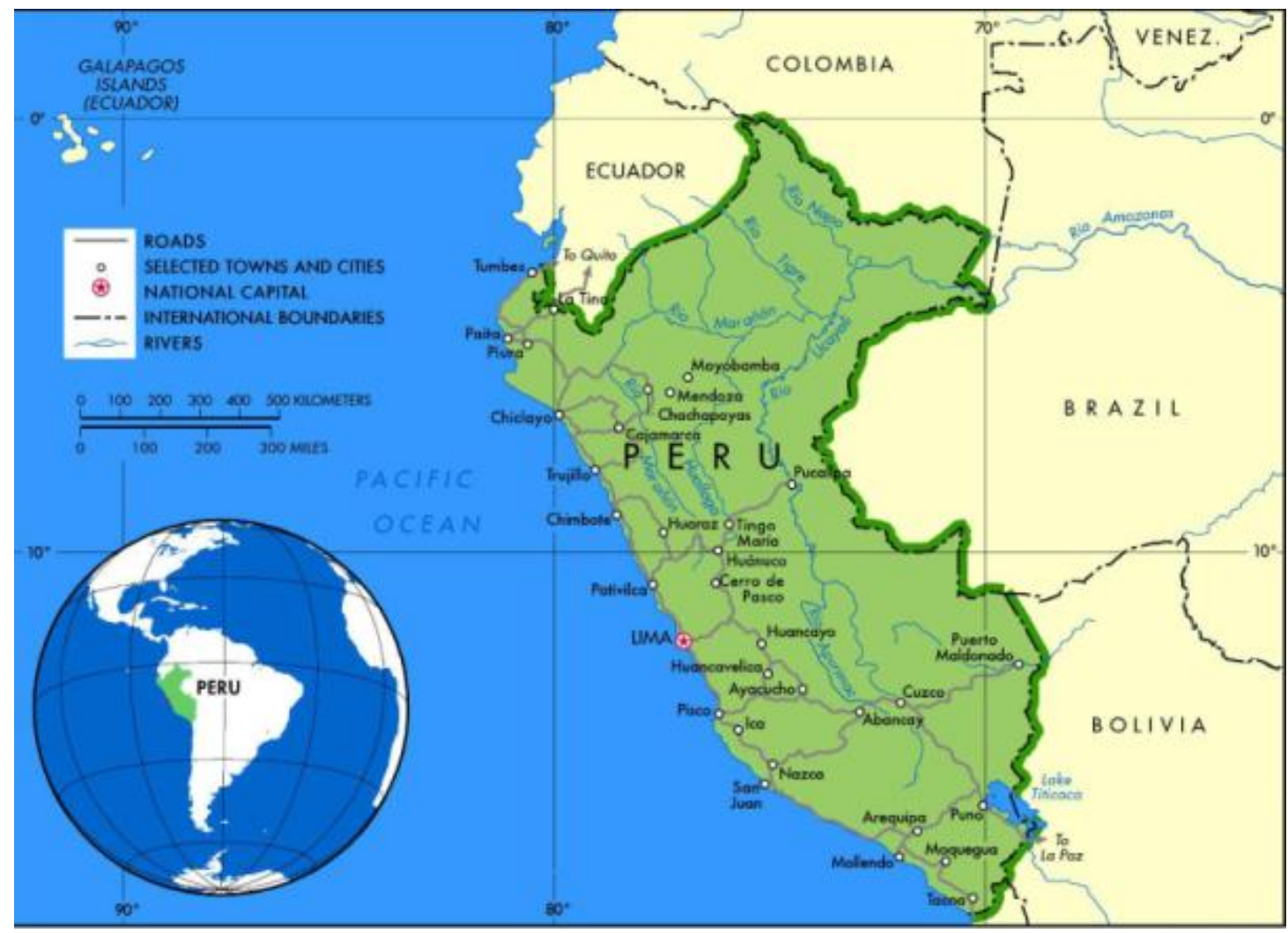

Gráfico 0.5 Ubicación de Perú

Fuente: World Bank, 2011

Perú es un país sudamericano de habla hispana, por tanto latinoamericano. El Perú está ubicado en la zona central y occidental de América del Sur (UTM N7970840.422; E552505.422; zona 19) comprendida entre la línea ecuatorial y el Trópico de Capricornio. Limita al norte con Ecuador y Colombia, al este con Brasil, al sureste con Bolivia, al sur con Chile, y por el oeste con el Océano Pacífico (Gráfico: 1.5). El territorio peruano abarca un espacio de 1.285.215,60 $\mathrm{km}^{2}$ de superficie, que representa el cero coma ochenta y siete por ciento de la superficie de todo planeta. Esta área se distribuye en tres regiones: región costeña ciento treinta y seis mil kilómetros cuadrados (diez coma seis por ciento), región andina de cuatrocientos cinco mil kilómetros cuadrados (treinta y uno coma cinco por ciento) y la región amazónica de setecientos cincuentaicuatro mil kilómetros cuadrados (cincuenta y siete coma nueva por ciento). En la costa vive el cincuenta y dos por ciento de la población peruana, la región andina alberga el treinta y siete por ciento, en tanto que en el llano amazónico vive el once por ciento de la población total. El pico más alto del Perú es el Huascarán en la Cordillera Blanca, con una altura de seis mil setecientos sesenta y ocho m.s.n.m. El río más largo de Perú es el río Ucayali, afluente del río Amazonas, con mil setecientos setenta y un kilómetros de longitud; el lago más grande es el Lago Titicaca en Puno/Bolivia con ocho mil trescientos ochenta kilómetros cuadrados y la isla más grande del litoral peruano es la Isla San Lorenzo en Callao con dieciséis coma cuatro kilómetros cuadrados. Perú es el tercer país más grande de Sudamérica. (INEI, 2012)

$\mathrm{Al}$ once de junio de 2011 los peruanos sumábamos veintinueve millones setecientos noventaiocho mil; en junio del 2015 la población peruana se estimó en treinta y un millones ciento cincuenta y un mil habitantes y se estima que en el año 2021, seremos treinta y tres 
millones habitantes. La pobreza (pobreza total) a nivel nacional se redujo en uno coma nueve por ciento al variar de veinticinco coma ocho a veintitrés coma nueve entre los años 2012 y 2013, esto indica que cuatrocientos noventa y un mil peruanos dejaron de ser pobres el 2013 (Gráfico 0.6 Evolución de la incidencia de pobreza total en Perú 2009-2013.), aunque se estima que aún siete millones doscientos mil peruanos se encuentran en dicha condición. La pobreza extrema en nuestro país disminuyó uno coma tres por ciento al pasar de seis en el año 2012 a cuatro coma siete el 2013, lo que equivale a que trescientos setentaicinco mil personas dejaron la pobreza extrema y que un millón cuatrocientos treinta y dos mil se mantienen en este sector socioeconómico (Gráfico 0.7 Evolución de la incidencia de pobreza extrema en Perú 2009-2013. Fuente:). Se entiende que una familia es pobre cuando, al sumar los ingresos de todos los miembros de la familia no se cubren las necesidades básicas de sus miembros, y la pobreza extrema, cuando no se llega a la canasta familiar mínima. El Instituto Nacional de Estadística e Informática del Perú (INEI) ha determinado los productos que componen estas canastas y los ha establecido sobre la base de los patrones de consumo real de los hogares del año base (2010), considerando el mínimo de energía requerida por el poblador peruano que efectúa actividades de acuerdo a su género, edad y lugar de residencia se determinó la canasta básica mínima mensual por persona y así se halló el valor de dicha línea cada año. En el Gráfico 0.8 Evolución de la línea de pobreza y pobreza extrema en Perú. Fuente: se aprecia la evolución de los indicadores de pobreza (pobreza total) y de pobreza extrema por persona. Para el año 2013 la línea de pobreza fue de doscientos noventa y dos nuevos soles por persona y por mes (setenta y seis euros aprox.) y de pobreza extrema ciento cincuentaicinco nuevos soles por persona y mes (cuarenta coma cinco euros aprox.).

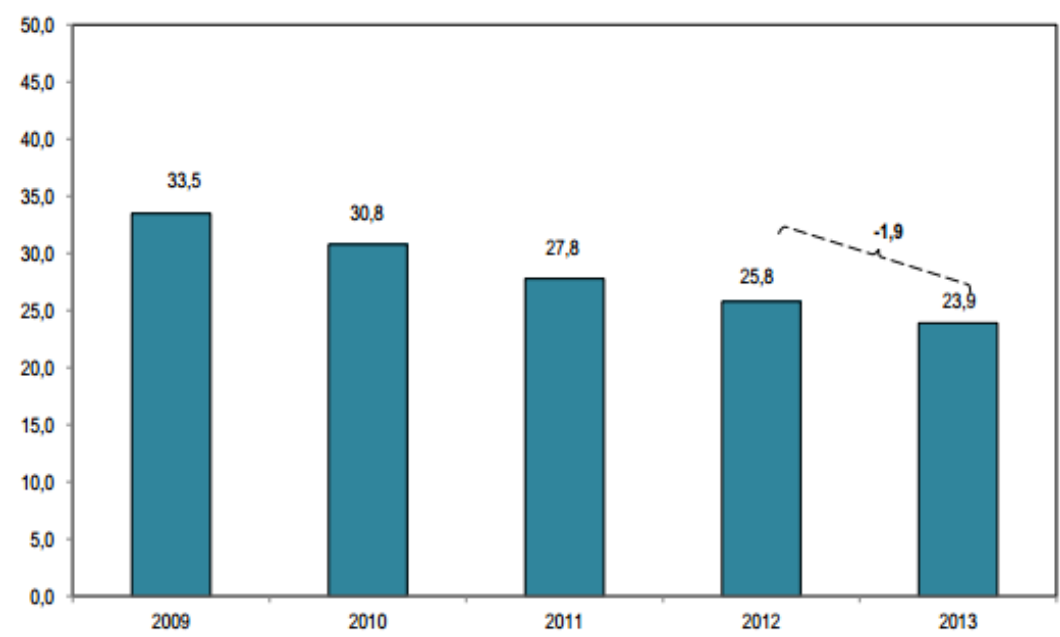

Gráfico 0.6 Evolución de la incidencia de pobreza total en Perú 2009-2013. Fuente: INEI 2014 


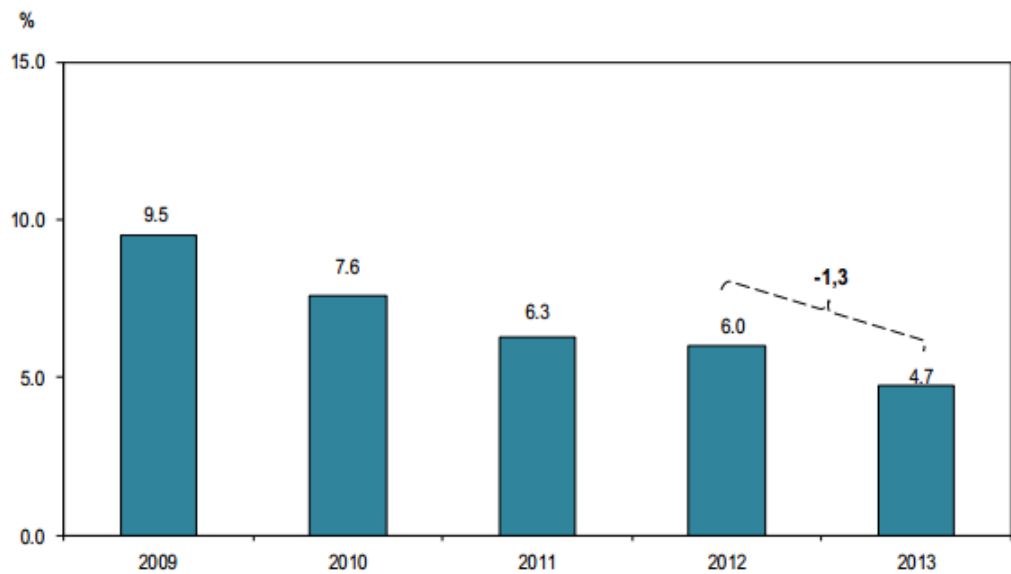

Gráfico 0.7 Evolución de la incidencia de pobreza extrema en Perú 2009-2013. Fuente: INEI 2014

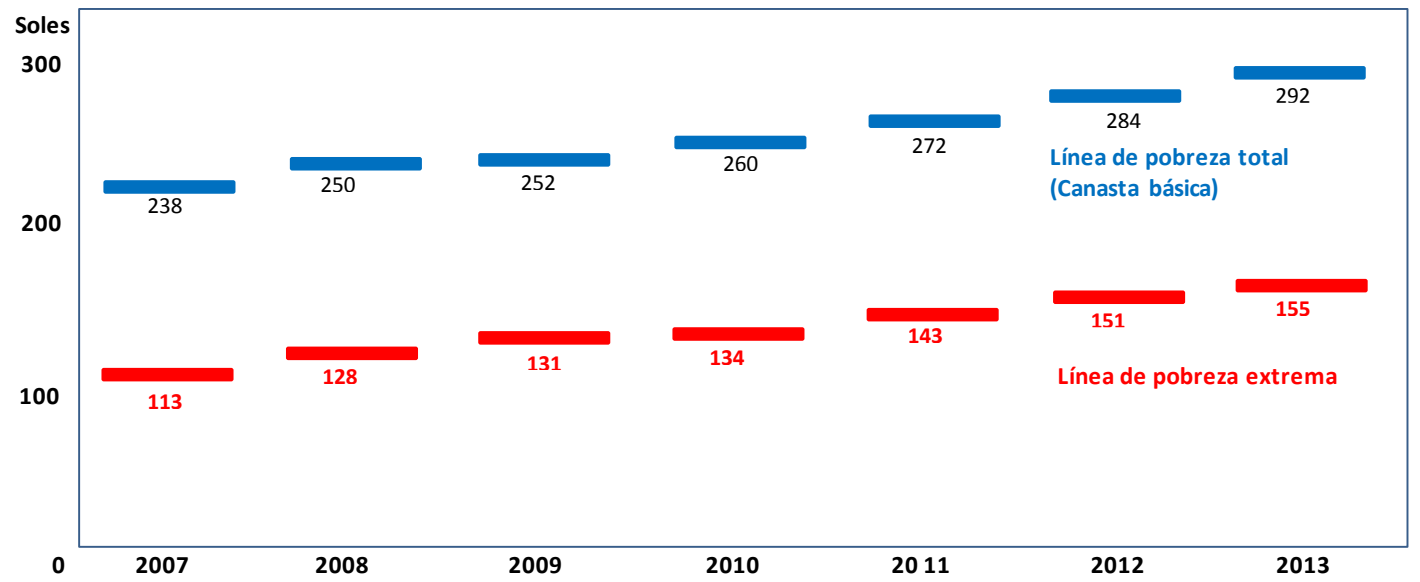

Gráfico 0.8 Evolución de la línea de pobreza y pobreza extrema en Perú. Fuente: Elaboración propia, a partir de, INEI, 2014.

La alta diversificación y masificación, la baja investigación, el aumento de demanda, y otras características mencionadas en la realidad educativa latinoamericana, están presentes en Perú. En el sistema de educación terciario peruano existe un numeroso conjunto de universidades y es posible identificar algunos rasgos importantes que le han regido en las últimas décadas para entender las limitaciones a las que se halla sujeta la gestión de la educación superior universitaria en el Perú. Describo las más saltantes:

Primero, una amplia proliferación de instituciones universitarias; de tamaños que van entre más de veinte mil alumnos y menos de un mil; estatales con más o menos dependencia financiera del estado, privadas con subsidios gubernamentales y privadas sin ningún tipo de apoyo estatal; instituciones con amplia cobertura de áreas del saber o, en el otro extremo, especializadas en una sola área; universidades dedicadas únicamente a la docencia de pregrado o con peso creciente del nivel de posgrado y la investigación, etc. En suma, sobre la geografía peruana se han multiplicado las instituciones de educación superior universitarias hasta alcanzar, según la última contabilidad disponible, un número de 100, incluyendo dentro de ellas 35 universidades públicas. Ver Tabla 0.10 y Tabla 0.11. (Censo universitario; 2010). 


\begin{tabular}{|c|c|c|c|c|c|}
\hline \multirow[t]{2}{*}{ UNIVERSIDADES / POBLACIÓN UNIVERSITARIA } & \multirow[t]{2}{*}{ TOTAL } & \multicolumn{2}{|c|}{ PÚBLICAS } & \multicolumn{2}{|c|}{ PRIVADAS } \\
\hline & & Absoluto & $\%$ & Absoluto & $\%$ \\
\hline Universidades & 100 & 35 & 35,0 & 65 & 65,0 \\
\hline Facultades & 628 & 359 & 57,2 & 269 & 42,8 \\
\hline Escuelas o carreras profesionalos & 1595 & 854 & 53,5 & 741 & 46,5 \\
\hline POBLACIÓN UNIVERSITARIA & 937430 & 375177 & 40,0 & 562282 & 60,0 \\
\hline Estudiantes de pre grado & 782970 & 309175 & 39,5 & 473795 & 60,5 \\
\hline Estudiantes de post grado & 56358 & 24591 & 43,6 & 31767 & 56,4 \\
\hline Docentes universitarios & 59085 & 21434 & 36,3 & 37651 & 63,7 \\
\hline Estudiantes por docente & 14,2 & 15,6 & - & 13,4 & - \\
\hline Personal administrativo y de servicios & 39017 & 19961 & 51,2 & 19056 & 48,8 \\
\hline
\end{tabular}

NOTA: Incluye todas las universidades que vienen funcionando formalmente en el Sistema Universitario Peruano Fuente : INEI - II Censo Nacional Universitario, 2010

Tabla 0.10 Universidades y población universitaria en Perú. Fuente: (Censo universitario; 2010)

\begin{tabular}{|c|c|c|c|}
\hline UNIVERSIDADES / POBLACIÓN & 1996 & 2010 & Variación \% \\
\hline Universidades & 57 & 100 & 75,4 \\
\hline Facultades & 485 & 628 & 29,5 \\
\hline Escuelas o carreras profesionales & 912 & 1595 & 74,9 \\
\hline POBLACION UNIVERSITARIA & 389316 & 937430 & 140,8 \\
\hline Estudiantes de pre grado & 335714 & 782970 & 133,2 \\
\hline Estudiantes de post grado & 10818 & 56358 & 421,0 \\
\hline Docentes universitarios & 25795 & 59085 & 129,1 \\
\hline Estudiantes por docente & 13,4 & 14,2 & 5,7 \\
\hline Personal administrativo y de servicios & 16989 & 39017 & 129,7 \\
\hline
\end{tabular}

Tabla 0.11 Universidades y población universitaria en Perú 1996 y 2010. Fuente: (Censo universitario; 2010)

Segundo, para Brunner existe una fuerte y creciente presencia de universidades privadas, no dependientes del financiamiento estatal, que conforman mayoría dentro de la plataforma institucional de provisión de educación superior universitaria, alcanzando una participación de alrededor de un cincuenta y ocho por ciento en la matricula total del Perú. La matrícula en universidades nacionales es inferior al de las privadas (Tabla 0.12) llegando el 2010 al 35\%. Se trata de una tupida red no gubernamental de instituciones e intereses, de profesores y alumnos, de inversiones y proyectos, de capitales económicos y sociales, de servicios masivos y de nicho social en el mercado de la enseñanza superior, que hoy se extiende de norte a sur y de este a 
oeste, otorgándole un carácter peculiar, mixto y heterogéneo a la provisión de educación superior universitaria en Perú (Brunner, 2008).

\begin{tabular}{|c|c|c|c|}
\hline AÑO & PUBLICAS & PRIVADAS & TOTAL \\
\hline 1960 & 8 & 1 & 9 \\
\hline 1965 & 17 & 8 & 25 \\
\hline 1970 & 21 & 10 & 31 \\
\hline 1975 & 22 & 10 & 32 \\
\hline 1980 & 25 & 10 & 35 \\
\hline 1985 & 27 & 15 & 42 \\
\hline 1990 & 28 & 24 & 52 \\
\hline 1996 & 28 & 29 & 57 \\
\hline 2000 & 32 & 46 & 78 \\
\hline 2002 & 33 & 42 & 75 \\
\hline 2006 & 36 & 56 & 92 \\
\hline 2009 & 35 & 63 & 98 \\
\hline 2010 & 35 & 65 & 100 \\
\hline
\end{tabular}

Tabla 0.12 Evolución del número de Universidades. Fuente: (Censo universitario; 2010)

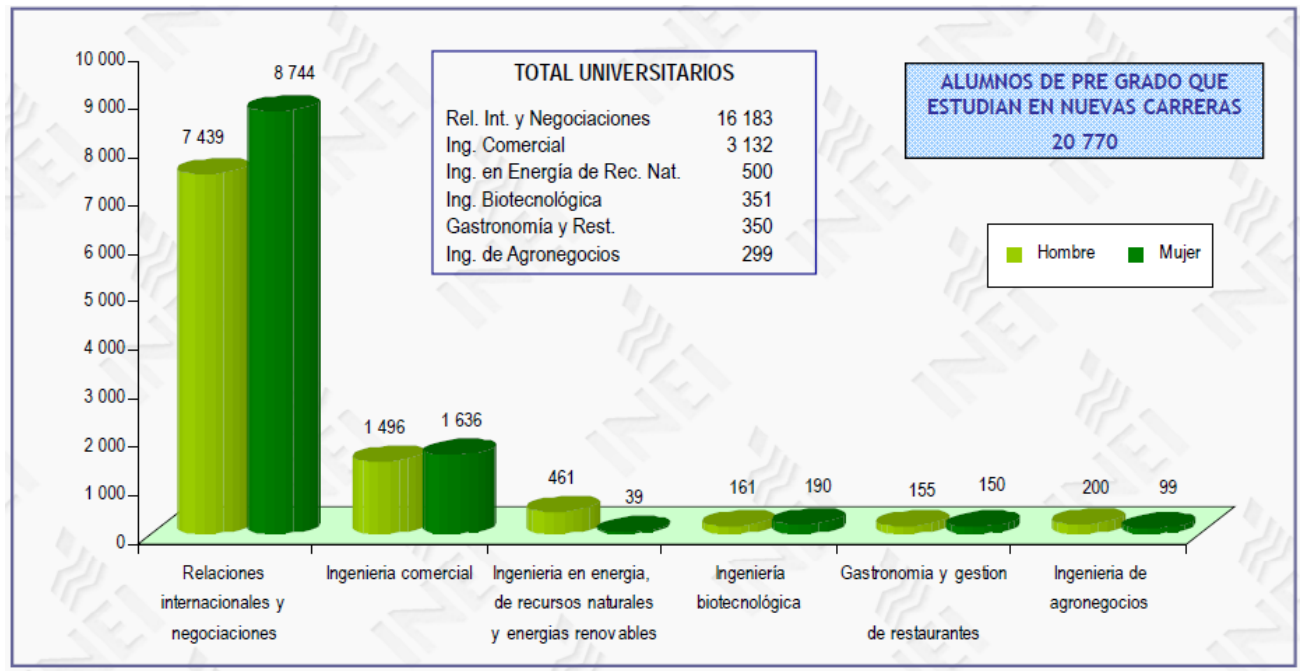

Gráfico 0.9 Alumnos de pregrado por sexo según nuevas carreras en Perú.

Fuente: (Censo universitario; 2010)

Tercero, y como resultado de las dos primeras, una educación superior universitaria intensamente diferenciada, cuya estructura y servicios se diversifican continuamente, en la misma medida que las instituciones buscan ampliar o profundizar sus espacios de reclutamiento estudiantil y expandir su cobertura de áreas del conocimiento, creando a tal efecto nuevos programas, nuevas sedes y nuevos certificados, muchos de ellos sin estudios previos serios y con poca posibilidad de permanecer en la oferta educativa por mucho tiempo. (Gráfico 0.79). Cuarto, producto de la evolución del sistema educativo y de las políticas nacionales, existe un predominio relativo de las principales universidades estatales, representada simbólicamente por la Universidad Nacional Mayor de San Marcos, la cual, puesta en la cúspide del subsistema 
estatal, ha acumulado a lo largo de su historia el beneficio de los subsidios fiscales y el prestigio asociado con su trayectoria como formadora de las profesiones de mayor reputación. Por ejemplo, "Como universidad pública, decana de América y primera universidad del país, San Marcos merece un tratamiento privilegiado, tanto en el aspecto presupuestal, como en su estatus académico y profesional, que le permita innovarse y continuar convirtiéndose en un centro científico-cultural que aporte a la solución de los principales problemas del país” (García, 2010: 276). En cambio, con escasas excepciones, están las instituciones privadas que pugnan aún por alcanzar reconocimiento social en un mercado que premia fuertemente las tradiciones y el capital.

Quinto, en general, existe un débil desarrollo de la investigación académica al interior de las universidades peruanas, hallándose concentrada en unas pocas, la mayoría estatales, aunque también en un pequeño núcleo de universidades privadas. El número de investigadores es bajo, (los doctorados son el 7\% de los docentes con segunda especialización, maestría o doctorado) en general los recursos humanos ocupados en labores de producción de ciencia y tecnología son escasos y se hallan concentrados, precisamente, en este grupo de universidades (Gráfico 0.810, Tabla 0.13). SIR-SCIMAGO Institutions Rankings es una institución que elabora periódicamente un listado de los países cuyas universidades están en condiciones de participar de proyectos de investigación científica de calidad El Perú se encuentra penúltimo a nivel de Iberoamérica, con solo dos universidades (contra 75 de Brasil, por ejemplo, o 14 de Chile) que se encuentran en estas condiciones: la Universidad Peruana Cayetano Heredia y la Universidad Nacional Mayor de San Marcos. (SIR - SCIMAGO; 2011)

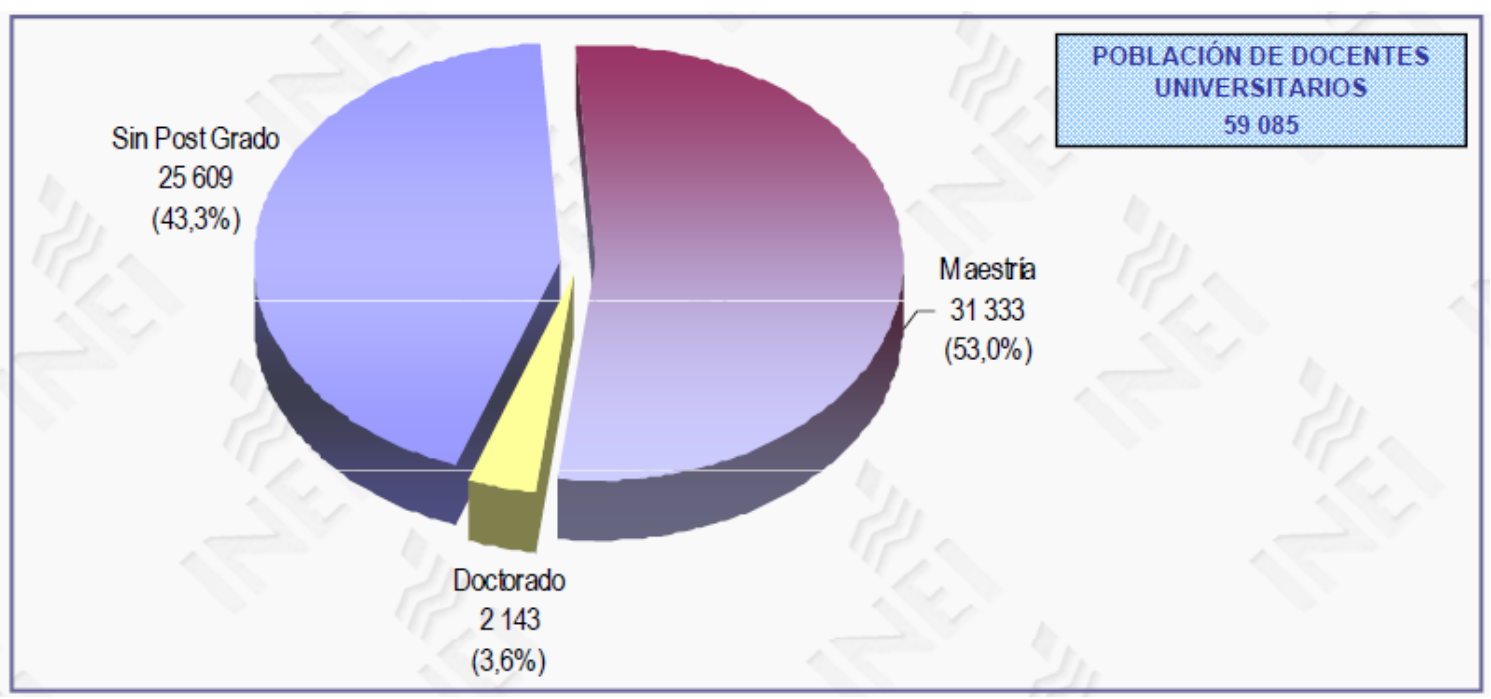

Gráfico 0.10 Perú: docentes universitarios, por estudios de posgrado concluidos, 2010. Fuente: (Censo universitario, 2010) 


\begin{tabular}{|c|c|c|c|c|c|}
\hline \multirow{3}{*}{ TIPO DE ESTUDIO } & \multicolumn{5}{|c|}{ SEXO } \\
\hline & \multirow{2}{*}{$\frac{\text { TOTAL }}{\text { ABS }}$} & \multicolumn{2}{|c|}{ HOMBRE } & \multicolumn{2}{|c|}{ MUJER } \\
\hline & & ABS & $\%$ & ABS & $\%$ \\
\hline \multicolumn{6}{|l|}{ TOTAL } \\
\hline II ESPECIALIZACION & 7726 & 3069 & 39,72 & 4657 & 60,28 \\
\hline MAESTRÍA & 44577 & 21660 & 48,59 & 22917 & 51,41 \\
\hline DOCTORADO & 4047 & 2423 & 59,87 & 1624 & 40,13 \\
\hline
\end{tabular}

Tabla 0.13 Total de alumnos de posgrado por sexo según tipo de estudio Fuente: (Censo universitario, 2010)

Sexto, mucha tensión entre legitimidad y efectividad del gobierno en las universidades peruanas, que a veces ha sido remarcado como una de sus características más resaltantes. En efecto, mientras en la mayoría de las universidades estatales predomina el modelo de gobierno inspirado en los principios de la reforma de Córdoba de 1918, consistente en la elección por votación (profesores, estudiantes, trabajadores no-académicos y, en ocasiones, graduados) del personal de los diferentes estamentos de los órganos de dirección unipersonal y colectiva de dichas instituciones, en las universidades privadas predominan, formas más bien empresariales de organización y dirección. Así, las universidades estatales suelen enfrentar problemas crónicos de efectividad por el lado de la gestión y, dependiendo de las coyunturas de contexto nacional, pueden verse confrontadas con problemas de hiper politización por el lado de la legitimidad. En cambio, el gobierno de las universidades privadas frecuentemente experimenta un déficit de legitimidad académica y, por el lado de la gestión, puede encontrarse frente a problemas de motivación de sus profesores.

\subsubsection{Relación entre el Espacio Europeo de Educación Superior y la educación superior peruana.}

Globalmente, las universidades se caracterizan hoy por sus vaivenes entre polos: tradición versus innovación, parálisis versus renovación, estatismo versus dinamismo. Estos binomios hacen de la educación superior universitaria un ámbito en proceso evolutivo constante. Los cambios socioculturales subyacentes a la "sociedad del conocimiento", unidos a las demandas implícitas que genera, han agilizado dicho proceso evolutivo. El resultado es una evolución cada vez más acelerada de la institución para adaptarse al cambiante entorno social, que supone un replanteamiento de su propia razón de ser, de sus objetivos y servicios, de los sistemas de organización, de los métodos e instrumentos de trabajo, de los planes de estudios, de la investigación que se realiza, de las competencias que debe tener su personal (Marquès, 2000).

La creación del Espacio Europeo de Educación Superior, desde 1998 con la Declaración de La Sorbona, no pasa inadvertida en la educación superior universitaria peruana, que también ve la necesidad de reformar la universidad para poder abordar, en el marco de la sociedad de la información y del conocimiento, los retos derivados de la innovación en la generación y transmisión de conocimiento. El EEES no es un camino hacia la estandarización o uniformización de la educación superior europea, sino que respeta los principios fundamentales 
de autonomía y diversidad y por ello permite un apropiado marco para iniciar la mejora de la universidad peruana.

Un punto crucial de la declaración de Bolonia es que se trata de un acto de compromiso a los principios de la educación superior europea a través de la cooperación creciente de las instituciones (Proyecto Tuning 2001).

Comparando los 6 objetivos específicos de la declaración de Bolonia (Tabla 0.14) con la situación actual de la gestión de la educación superior universitaria en el Perú, vemos que presenta algunos obstáculos estructurales, de organización y de funcionamiento, para converger como están haciéndolo los sistemas europeos bajo el impulso del proceso de Bolonia. Sin embargo, la universidad peruana no es ajena a esta realidad y para insertarse en un escenario tan competitivo es necesario un proyecto de actuación, un análisis acucioso de las limitaciones que se tienen en Perú para acometerla y una respuesta que nos permita pulsar las posibilidades de superar estos retos. Entonces, deben identificarse las limitaciones que presenta la universidad peruana para hacer frente a las claves de la convergencia europea y los medios o instrumentos que contamos o podemos contar para la conseguirlo. Estos resultados se muestran en la Tabla 0.15 (Brunner 2008).

\begin{tabular}{|l|l|}
\hline Item & \multicolumn{1}{|c|}{ Objetivo } \\
\hline a. & $\begin{array}{l}\text { Adopción de sistema de grados fácilmente comprensibles y } \\
\text { comparables, implementación de Diploma Suplementario, para } \\
\text { promover la empleabilidad, y la competitividad internacional de los } \\
\text { ciudadanos europeos del sistema de educación superior europeo }\end{array}$ \\
\hline b. & $\begin{array}{l}\text { Sistema basado en dos ciclos principales, de grado y posgrado. El } \\
\text { acceso al segundo ciclo requerirá la conclusión exitosa de los } \\
\text { estudios de primer ciclo, con una duración mínima de tres años. El } \\
\text { grado del primer ciclo debe ser relevante para el mercado laboral } \\
\text { europeo. El segundo ciclo conduce al grado de máster y/o doctor. }\end{array}$ \\
\hline c. & $\begin{array}{l}\text { Establecimiento de un sistema de créditos (ECTS), para promover } \\
\text { la movilidad estudiantil. Los créditos también podrán ser adquiridos } \\
\text { en contextos educacionales no universitarios, siempre que sean } \\
\text { reconocidos por las universidades. }\end{array}$ \\
\hline d. & $\begin{array}{l}\text { Promoción de la movilidad, prestando particular atención a: } \\
\text { - Para los estudiantes, acceso a oportunidades de estudio y } \\
\text { entrenamiento y servicios relacionados; } \\
\text { - Para los profesores, investigadores y personal administrativo, } \\
\text { reconocimiento y estatutarios. }\end{array}$ \\
\hline e. & $\begin{array}{l}\text { Promoción de la cooperación europea en aseguramiento de la } \\
\text { calidad, en perspectiva de desarrollar criterios y metodologías } \\
\text { comparables. }\end{array}$ \\
\hline f. & $\begin{array}{l}\text { Promoción de las dimensiones europeas en la educación superior, } \\
\text { particularmente en desarrollo curricular, cooperación } \\
\text { interinstitucional, esquemas de movilidad, programas integrados de } \\
\text { estudio, entrenamiento e investigación. (European Union, 1999) }\end{array}$ \\
\hline
\end{tabular}

Tabla 0.14 Objetivos específicos de la Declaración de Bolonia. Fuente: Bugarín, 2009 


\begin{tabular}{|c|c|c|}
\hline $\begin{array}{l}\text { Objetivos } \\
\text { estratégicos del } \\
\text { EEES }\end{array}$ & $\begin{array}{c}\text { Limitaciones en la Gestión de } \\
\text { la educación superior } \\
\text { universitaria en el Perú }\end{array}$ & Medios o instrumentos \\
\hline $\begin{array}{l}\text { Primer } \\
\text { objetivo: } \\
\text { Sistema de } \\
\text { grados } \\
\text { comprensibles y } \\
\text { comparables. }\end{array}$ & $\begin{array}{l}\text { El Estado no interviene directamente en el } \\
\text { sistema de educación superior universitario. } \\
\text { Las universidades peruanas tienen } \\
\text { autonomía universitaria, principio que } \\
\text { garantiza su independencia de los poderes } \\
\text { públicos. } \\
\text { Diferencias entre IES: Institutos } \\
\text { tecnológicos y Universidades, estatales y } \\
\text { privadas con fines o sin fines de lucro en } \\
\text { virtud de decreto legislativo } \mathrm{N}^{\circ} 882 \text { que } \\
\text { promociona la inversión en la educación. } \\
\text { Diferencias de títulos y grados concedidos a } \\
\text { nombre de la Nación. }\end{array}$ & $\begin{array}{l}\text { Leyes de Educación Superior Universitaria } \\
\text { Aspectos Generales: Ley Universitaria - 23733, } \\
\text { 09/12/1983 (Ultima modificación: 2007) } \\
\text { Universidades con fines de lucro Ley de } \\
\text { Promoción de la Inversión en la Educación. D.L. } \\
\text { 882, 09/11/1996. Creación de Nuevas } \\
\text { Universidades y filiales. Ley para la creación del } \\
\text { Consejo Nacional para la Autorización de } \\
\text { Funcionamiento de Universidades (CONAFU) N } \\
\text { 26439, 20/01/1995. Reglamento para la } \\
\text { Autorización de Funcionamiento de Universidades } \\
\text { y Escuelas de Postgrado 2004 - Resolución Na196, } \\
07 / 10 / 2004 \text { Reglamento de Filiales -Ley N 28564, } \\
\text { 18/07/2005 }\end{array}$ \\
\hline $\begin{array}{l}\text { Segundo } \\
\text { objetivo: } \\
\text { Adopción de un } \\
\text { sistema basado } \\
\text { en dos ciclos } \\
\text { principales, de } \\
\text { grado y } \\
\text { graduado. }\end{array}$ & $\begin{array}{l}\text { Es un sistema basado en el pregrado } \\
\text { principalmente de duración } 5 \text { años. El } \\
\text { post grado es opcional y no, } \\
\text { necesariamente, lo ofrece directamente la } \\
\text { universidad. } \\
\text { Diferencias de duración, pensiones y } \\
\text { preferencias por parte de los alumnos. }\end{array}$ & $\begin{array}{l}\text { Establecimiento en las universidades de dos } \\
\text { niveles académicos el pregrado de } 5 \text { años con } \\
\text { cualificaciones profesionales en el mercado } \\
\text { laboral y un segundo nivel de post grado, cuya } \\
\text { consecución implica la superación del primero, } \\
\text { pudiendo alcanzarse el título de Master y/o } \\
\text { Doctor con una duración de } 2+1 \text { años. }\end{array}$ \\
\hline $\begin{array}{l}\text { Tercer objetivo: } \\
\text { Establecimiento } \\
\text { de un sistema de } \\
\text { créditos. }\end{array}$ & $\begin{array}{l}\text { Sistema de créditos académicos, definida } \\
\text { por cada estatuto de universidad, se basa } \\
\text { en los contenidos y normalmente es por } \\
\text { las horas de teoría y práctica dictadas en la } \\
\text { asignatura. } \\
\text { Diferencias en las horas pedagógicas ( } 45 \text { ó } \\
50 \text { minutos) y duración mínima del } \\
\text { semestre (17 semanas) y número de } \\
\text { semestres por año. } \\
\text { La escala de calificaciones especialmente } \\
\text { en la mínima aprobatoria. }\end{array}$ & $\begin{array}{l}\text { Un plan de estudios que en lugar de valorar las } \\
\text { horas de clase recibidas por el alumno realmente } \\
\text { evalúe el "volumen global de trabajo" que el } \\
\text { estudiante debe realizar para alcanzar los } \\
\text { objetivos educativos. } \\
\text { Cambio de planes de estudios y en los programas } \\
\text { docentes que permitan la consideración del } \\
\text { propio aprendizaje de los alumnos. }\end{array}$ \\
\hline $\begin{array}{l}\text { Cuarto } \\
\text { objetivo: } \\
\text { Movilidad }\end{array}$ & $\begin{array}{l}\text { Sistema propio de cada universidad se } \\
\text { basa principalmente en la excelencia de su } \\
\text { enseñanza e investigación y de los } \\
\text { convenios internacionales que como } \\
\text { institución pueda acceder. }\end{array}$ & $\begin{array}{l}\text { Para potenciar la movilidad al EEES se puede } \\
\text { utilizar para conseguir una transparencia en las } \\
\text { titulaciones y permitir un mercado común } \\
\text { laboral, un documento acreditativo único } \\
\text { proporcionado por las universidades a instancia } \\
\text { del interesado y solo para aquellos títulos de } \\
\text { carácter oficial y con validez en todo el territorio } \\
\text { nacional. Este documento tendrá información } \\
\text { unificada, personalizada de cada titulado } \\
\text { universitario, sobre los estudios cursados, los } \\
\text { resultados obtenidos, las capacidades } \\
\text { profesionales adquiridas y el nivel de su } \\
\text { titulación. }\end{array}$ \\
\hline $\begin{array}{l}\text { Quinto } \\
\text { objetivo: } \\
\text { Aseguramiento } \\
\text { de la calidad }\end{array}$ & $\begin{array}{l}\text { Se basa en la autonomía de la universidad, } \\
\text { requiere cooperación de autoridades, } \\
\text { docentes y administrativos para una } \\
\text { educación transnacional y tiene efectos } \\
\text { sobre el financiamiento. Diferentes } \\
\text { sistemas de admisión y egreso. }\end{array}$ & $\begin{array}{l}\text { Alcanzar mayores niveles de calidad y } \\
\text { transparencia en la educación y gestión } \\
\text { universitaria. } \\
\text { Leyes sobre Calidad Universitaria } \\
\text { Ley del Sistema Nacional de Evaluación, } \\
\text { Acreditación y Certificación de la Calidad } \\
\text { Educativa SINEACE N }{ }^{\circ} 28740,19 / \mathrm{Mayo} / 2006 \\
\text { Reglamento de la Ley del SINEACE N } 28749 \text { - } \\
\text { Decreto Supremo } \mathrm{N}^{\circ} 018-2007-E D \text { - } 9 / \mathrm{Julio} / 2007 \\
\text { El órgano para las universidades es el CONEAU } \\
\text { quién normará la evaluación y certificación de la } \\
\text { calidad universitaria. }\end{array}$ \\
\hline
\end{tabular}

Tabla 0.15 Comparación de los objetivos específicos del EEES con la gestión de la educación superior universitaria en el Perú (Primera parte) 


\begin{tabular}{|c|c|c|}
\hline $\begin{array}{l}\text { Objetivos } \\
\text { estratégicos del } \\
\text { EEES }\end{array}$ & $\begin{array}{c}\text { Limitaciones en la Gestión de } \\
\text { la educación superior } \\
\text { universitaria en el Perú }\end{array}$ & Medios o instrumentos \\
\hline $\begin{array}{l}\text { Sexto objetivo: } \\
\text { Dimensión } \\
\text { europea de la } \\
\text { educación } \\
\text { superior. }\end{array}$ & $\begin{array}{l}\text { Responsabilidad de la educación superior. } \\
\text { Marco legal, la ley universitaria vigente } \mathrm{N}^{\circ} \\
23733 \text { es de } 1983 \text {. } \\
\text { ANR cuyos fines incluyen el estudio, } \\
\text { coordinación y la orientación general de } \\
\text { las actividades universitarias. Vigila el } \\
\text { cumplimiento de la legislación } \\
\text { universitaria. } \\
\text { Ministerio de educación coordina la } \\
\text { educación secundaria con los requisitos de } \\
\text { ingreso a la universidad. } \\
\text { El CONAFU creado por la ley } \mathrm{N}^{\circ} 26439 \text {. } \\
\text { Para la creación de nuevas universidades y } \\
\text { el decreto legislativo } \mathrm{N}^{\circ} 882 \text {. }\end{array}$ & $\begin{array}{l}\text { Establecimiento por el Congreso Nacional de la } \\
\text { República de una Comisión de Coordinación de } \\
\text { Reforma Universitaria CCRU, que se encuentra } \\
\text { trabajando en el proyecto de una nueva ley } \\
\text { universitaria que propone cambiar la gestión de } \\
\text { las universidades a un Sistema de Educación } \\
\text { Superior Universitaria en el Perú, teniendo en } \\
\text { cuenta la estructura universitaria de } 1983 \text { - Ley de } \\
\text { Sánchez-(Sánchez F., L. 1996) donde se proponía } \\
\text { una visión de conjunto y cooperación entre los } \\
\text { diferentes tipos de universidades. }\end{array}$ \\
\hline
\end{tabular}

Tabla 0.165 Comparación de los objetivos específicos del EEES con la gestión de la educación superior universitaria en el Perú

(Final)

En la Tabla 0.15 pueden leerse las limitaciones severas que se tienen en el sistema universitario peruano para poder seguir un camino claramente estructurado como el que propone el EEES. Esto complicará una propuesta de direccionamiento de la universidad peruana hacia un modelo más ordenado, contextualizado, moderno, legitimado y con resultados pertinentes y competitivos. Es fundamental contar con una propuesta de acción que permita iniciar un proceso de cambio paulatino y seguro.

\subsubsection{Proyecto de actuación peruano frente a los nuevos retos europeos}

La creación del Espacio Europeo de Educación Superior ha sido fundamental para fomentar y acelerar el cambio de la cultura universitaria en el Perú, sus propuestas aseguran un nivel de calidad pertinente estableciendo metodologías comparables al crear el espacio europeo en el desarrollo curricular (Sierra et al, 2009). Todas ellas han sido consideradas en la Tabla 1.15, con el fin de definir un plan y proponer una estrategia en Perú que permita precisar la posibilidad de adaptar los lineamientos de Europa para lograr una mejora de los indicadores peruanos de Educación Superior.

En el ánimo de fomentar esa influencia del EEES en Latinoamérica, se crea el Proyecto Tuning para Latino América. El Proyecto Tuning es un trabajo de más de 175 universidades europeas que desde el año 2001 quieren consolidar la búsqueda de puntos de acuerdo, de convergencia y entendimiento mutuo para facilitar la comprensión de las estructuras educativas en pos de la creación del Espacio Europeo de Educación Superior como respuesta al desafío planteado por la Declaración de Bolonia. Ha buscado identificar elementos de referencia necesarios para el reconocimiento de las titulaciones en todo el espacio europeo. Tuning había sido una experiencia exclusiva de Europa hasta finales de 2004 en que surge el proyecto Tuning - América Latina en un contexto de intensa reflexión sobre educación superior, tanto a nivel regional como interregional. El Proyecto Tuning - America Latina es uno de los trabajos más serios, que busca iniciar un diálogo para intercambiar información y mejorar la colaboración entre las instituciones de educación superior europeas y latinoamericanas, favoreciendo el desarrollo de la calidad, de la efectividad y de la transparencia (Proyecto Tuning América Latina, 2007). 
Conociendo a fondo la realidad de la educación superior universitaria en el Perú y su necesidad de contar con un sistema de calidad, efectivo y transparente se presenta un proyecto de actuación con una metodología basada en cinco objetivos considerados los más importantes: competencias (genéricas y específicas de las áreas temáticas), enfoques de enseñanza y aprendizaje, créditos académicos, calidad de los programas consolidación de la investigación.

En cuanto al primer objetivo, lo que se trata es de identificar competencias compartidas que pudieran generarse en cualquier titulación, y que son consideradas importantes por ciertos grupos sociales. Hay ciertas competencias, como la capacidad de aprender, la de análisis y de síntesis que son comunes a todas o casi todas las titulaciones. En esta propuesta las competencias genéricas y aquellas otras que se relacionan y se generan con cada área temática son de gran importancia y confieren la identidad y consistencia a cualquier programa (Proyecto Tuning América Latina, 2007).

Las competencias son diferentes para cada disciplina, por lo que es necesario definir resultados del aprendizaje y competencias para cada titulación. La definición de estas competencias es responsabilidad de los académicos, no sin antes consultarla con los interesados de la sociedad y del empleo. Al definir las competencias y resultados de aprendizaje de la manera indicada, se alcanzan puntos de referencia consensuados que sientan las bases para garantizar la calidad, y una evaluación que en primera instancia será interna luego nacional e internacional. Luego tendrán que definirse las competencias específicas de la titulación en la institución en la que se realice la experiencia.

Un segundo objetivo propone revisar los métodos de enseñanza, aprendizaje y evaluación más eficaces para el logro de los aprendizajes deseados y de las competencias identificados, y preparar una propuesta para el sistema universitario peruano. Esto lleva a la capacitación de los docentes universitarios de los diferentes enfoques de enseñanza para desarrollar las competencias que se diseñen en el perfil. Los cambios de enfoques y de objetivos de enseñanza y aprendizaje implican también las modificaciones correspondientes en los métodos de evaluación y en los criterios. Estos deben considerar no sólo el conocimiento y los contenidos, cómo se hace actualmente, sino las habilidades y destrezas generales. Cada estudiante debe experimentar una variedad de enfoques y tener acceso a diferentes contextos de aprendizaje, cualquiera que sea su área de estudio. Por supuesto, la transparencia y comparabilidad de los métodos y de los criterios para evaluar la realización son esenciales, si queremos incrementar la garantía de la calidad. Si el primer objetivo del proyecto busca la definición de las competencias genéricas y específicas, este objetivo se propone el modo más adecuado de aprenderlas, de enseñarlas y de evaluarlas. Se considera que lo más apropiado es iniciar con un proyecto piloto, en una titulación concreta y con una institución definida, para, dados los resultados, evaluar la generalización institucional y luego la nacional.

El tercer objetivo consiste en relacionar el sistema de competencias con el trabajo del estudiante, y la de su medida y su conexión con el tiempo resultante medido en créditos académicos. El actual sistema universitario peruano se encuentra estructurado en créditos que se definen en función de las horas de docencia impartidas (teóricas y prácticas). El ECTS (European Credit Transfer System) agrupa toda la actividad académica del alumno, y se mide en 
volumen de trabajo del estudiante (horas de clase, trabajos realizados dentro y fuera del aula, actividades académicas dirigidas, tiempo de estudio, etc.). El sistema de créditos europeos obliga a la universidad no solo a reconfigurar las materias que conforman el plan de estudios para estructurarse según esta nueva unidad de medida académica, sino también a replantear el papel y funciones docentes.

Se puede establecer una forma de cálculo de créditos similar a la definida en el EEES que pueda emplearse en Perú, y para una etapa de transición se puede plantear la coexistencia de ambos sistemas de créditos, hasta lograr el consenso en el sistema nacional.

El cuarto objetivo es la acreditación académica y calidad. Existe en los Estados Unidos de Norteamérica, Canadá y en países europeos una sólida y probada experiencia en cuanto a evaluación y acreditación universitaria. La experiencia en el Perú es limitada y reciente, aunque se aprecia un creciente interés por incorporar esta metodología a los sistemas nacionales de educación. La calidad constituye un elemento fundamental en la construcción de la educación superior. Supone la base y fundamento para el reconocimiento y comparabilidad de titulaciones. Para ello, las universidades han de desarrollar sistemas de garantía de la calidad y mecanismos de certificación y acreditación. En este proceso juega un papel el Estado a través del Consejo de Evaluación, Acreditación y Certificación de la Calidad de la Educación, que publicó en enero del 2009 en el diario oficial "El Peruano" el "Modelo de Calidad para la Acreditación de Carreras Profesionales y Estándares para la Carrera Profesional de Educación” y en diciembre de 2010 publicó en el mismo la "Separata Especial sobre los Estándares para la Acreditación de Carreras Profesionales de Ingeniería", pendiente de reglamentación a la fecha. La acreditación en el ámbito educativo, es un tema que recién está siendo atendido en nuestro país por las autoridades educativas competentes. El órgano operador encargado de garantizar la calidad universitaria es la Superintendencia dNacional de Educación Superior Universitaria (SUNEDU).

Debe considerarse la necesidad de asegurar la calidad del diseño de un currículo basado en competencias, por eso debe ser desarrollado desde Decanatos, Departamentos y grupos de investigación; por programas académicos o por facultades; participando en proyectos de innovación docente, en programas piloto o en planes estratégicos; no sólo para el diseño y acreditación académica como fin último y único, sino además como fomento de la movilidad del profesorado a universidades europeas, así como para el fomento de intercambio de alumnos, y mejora en los logros de aprendizaje, acciones fundamentales para garantizar la calidad.

El quinto objetivo plantea que la producción de conocimientos en modo de aplicación exige transformaciones organizativas pues la creación de conocimientos se manifiesta en las universidades pero no nace en ellas. Las circunstancias que lo hicieron posible en el mundo desarrollado están débilmente presentes en América Latina y la universidad debe entender que su razón de ser no se atiende cabalmente a menos que se propenda a cumplir un papel más directo en el ejercicio de su responsabilidad social en una acción que una la investigación y la docencia, en tanto productoras de conocimientos. Los fines explícitos de las universidades, de la contribución al crecimiento económico, desde esta perspectiva investigadora se hacen realidad a través de la incorporación de la universidad a la "triple hélice" universidad-empresa-estado. En esta realidad cada "hélice" asume nuevos roles, que antes eran de las otras, con lo cual en 
los espacios de interacción se crean nuevas instituciones. Se representa esta situación mediante tres conjuntos con intersección no vacía. Los vínculos entre las hélices son estrechos y la universidad se debe constituir en una "universidad investigadora" (Arocena et al, 2000) reforzándose el enfoque de seguir las tendencias europeas y norteamericanas en busca de la mejora universitaria.

Este esquema de actuación redundará en el fomento de la transparencia de los perfiles profesionales y académicos, en el de las titulaciones y en el de los programas de estudio, y favorecerá un énfasis cada vez mayor en los resultados. Así, la idea de que los estudiantes adquieran más competencias concretas afectará positivamente la transparencia en la definición de los objetivos fijados para un programa educativo específico, esos objetivos tienen que ser dinámicos acordes con las necesidades de la sociedad y del empleo. Tales cambios llevarán casi siempre a una transformación en el enfoque de las actividades educativas, puesto que proporcionarán la participación del estudiante, ya sea individual o como grupo, en la preparación de trabajos pertinentes, en presentaciones, etcétera (Proyecto Tuning América Latina; 2007).

El interés en el desarrollo de competencias en los programas educativos concuerda con un enfoque de educación superior universitaria centrado en el alumno y en su capacidad de aprender, exigiendo más protagonismo y cuotas más altas de compromiso, ya que es el estudiante el que debe desarrollar las capacidades, habilidades y las destrezas (Sierra et al., 2009).

Así mismo, se posibilitará la innovación a través de la elaboración de nuevos materiales de enseñanza, que ampararán tanto a los estudiantes como a los profesores, facilitando los procesos de enseñanza, aprendizaje y evaluación.

\subsection{CONCLUSIONES DEL CAPÍTULO I}

- La universidad latinoamericana nace europea, independiente, religiosa y centrada en atender las elites y transmitir esa cultura. Un cambio sustancial se experimenta en el s. XVIII y es reflejo de lo que sucedía en Europa: el enfoque napoleónico. En el s. XIX la universidad latinoamericana se vuelve laica, técnica, profesionalizante y con control estatal. En el siglo XX las reformas se suceden y desaparecen manteniéndose el esquema del siglo XIX. Queda establecido que el inicio y la evolución de la universidad latinoamericana está fuertemente vinculada a la universidad europea, hispánica, salmantina y boloñesa. Los rasgos y las tendencias son similares en las distintas etapas históricas.

- La universidad latinoamericana fue una institución completa que cumplió sus funciones de acuerdo a las normas de la época durante el periodo colonial. Es en el siglo XIX cuando sobreviene su decadencia, al sustituirla por una simple yuxtaposición de escuelas profesionales. Las dos primeras décadas del siglo XX encuentran universidades anquilosadas incapaces de dar respuesta a los cambios experimentados por la sociedad. El tiempo le va confiriendo personalidad y podemos encontrar que las características comunes a todas las universidades de la región, desde México hasta Chile, es tener Facultades autosuficientes y cátedras autárquicas, con un estilo propio, modelizado por el europeo y norteamericano, pero distinto a ellos. 
- La historia de la universidad latinoamericana podemos dividirla en la Universidad Colonial, de mediados del siglo XVI (1538), a mediados del siglo XVIII; la Universidad Republicana de mediados del s. XVIII a inicios del siglo XX (1918); la universidad del siglo XX y la del siglo XXI con la transeducación.

- La universidad latinoamericana vivió tres reformas en el s XX: la primera de 1918 a 1975 se caracteriza por la autonomía y el autogobierno, la segunda reforma que inicia en 1975 y finaliza en 1995, caracterizada por la mercantilización de la educación superior en un modelo público - privado, altamente diversificada y con dispar calidad, y la tercera reforma desde 1995 se caracteriza por la internacionalización, el establecimiento de sistemas de aseguramiento de calidad, la aparición de la educación virtual, la creación de universidades privadas, y la fuerte tendencia a la atención al sector servicios, en desmedro del sector industrial manufacturero.

- En el siglo XXI la universidad de latinoamericana debe encarar una masificación creciente, estudiantes que le ven solo como medio de mejora social, la necesidad de constante evaluación comparativa de calidad, nuevas tecnologías de comunicación, nuevas regulaciones y nuevos saberes. Además, compite con un agresivo desconocido, la educación virtual, que le despoja de alumnos y que en su consolidación, ha vuelto todo el sistema transnacional. La transeducación es el nuevo paradigma: la internacionalización de una educación que sigue un modelo económico global, con ventajas comparativas y exportación de intangibles (servicios). Esto está concretando el paso de la sólida sociedad industrial a la nueva sociedad del conocimiento.

- Queda manifiesta la semejanza entre el sistema universitario latinoamericano y el europeo por lo que es necesario conocer la actual propuesta de este último para el desarrollo de la universidad europea en los próximos años y obtener pautas posibles para el futuro de la universidad latinoamericana.

- El Espacio Europeo de Educación Superior (EEES) se ha organizado para alcanzar altos estándares de: calidad, movilidad, diversidad y competitividad, con dos objetivos estratégicos claros el incremento del empleo en la Unión Europea y la conversión del Sistema Europeo de Enseñanza Superior en un polo de atracción para estudiantes y profesores de otras partes del mundo. Busca que los sistemas universitarios existentes en Europa sean más compatibles y por ende, más comparables, sin pretender homologación de las titulaciones. Con variadas estrategias como los dos ciclos, créditos ECTS, y otros, definen y perfecciona una forma de mejora que marca un camino interesante a la universidad latinoamericana pues, siendo similares en origen y evolución, esta propuesta europea puede ser muy útil para alcanzar mejores estándares universitarios en Latinoamérica. No se trata de realizar una copia de lo acontecido en Europa sino de beneficiarse de la experiencia europea para provocar los cambios que se consideren pertinentes, a la luz de nuestras actuales circunstancias.

- En Latinoamérica existe una gran diversidad de titulaciones, que frenan la movilidad del profesional mientras que la restructuración y ajuste que se vive en el EEES reducirá el número de carreras y la duración de las mismas. Reducir ayudará a que en LA las titulaciones sean acordes al EEES logrando estudios comparables y permitiendo la movilidad intrarregional y entre LA y el EEES. La experiencia señala que una buena estrategia para la transición de la 
aplicación del Acuerdo de Bolonia es establecer experiencias piloto en titulaciones, replicables en ámbitos institucionales, nacionales y finalmente regionales.

- La universidad anglosajona desde su inicio, presenta significativas diferencias con la hispana continental: la forma de gobierno (de profesores o de alumnos), las formas de aprendizaje y su evolución. La europea continental siguió el formato francés - napoleónico, la anglosajona la influencia de las universidades francesas y alemanas. Eso muestra el porqué de la distancia entre LA y USA, pues la universidad de LA reprodujo la hispana continental.

- Una universidad que se gobierna a sí misma no garantiza necesariamente la libertad académica individual de los miembros del cuerpo de profesores, ni tampoco una universidad controlada por el Estado, o por un personal ajeno a ella, infringe necesariamente los derechos individuales de los profesores. En las mejores universidades públicas estaunidenses, sus consejos han delegado bastante, y han interferido poco. La garantía que debe darse es que una universidad esté en libertad de buscar y comunicar la verdad sin restricciones para que la sociedad sea mejor servida por ella, independientemente de la organización que legalmente se considere la mejor.

- Las universidades que pudieron asegurar fondos para la construcción y el mantenimiento crecieron y prosperaron, las que no dieron importancia a estas instalaciones, limitaron sus ambiciones a la instrucción de alumnos y renunciaron a la investigación, el servicio y posgrado.

- Una característica importante en América del Norte (Estados Unidos y Canadá) es la evaluación de la calidad, y ha constituido desde hace décadas, una actividad permanente en estrecha relación con la gestión de las universidades. Es clara la preeminencia de la universidad anglosajona sobre todas las demás existentes, comprobable con el uso de indicadores de desempeño. La universidad latinoamericana debe intentar llegar a esos estándares y buscar el mejor camino para lograrlo.

- Las universidades latinoamericanas tienen mucho que aprender de la trayectoria de las universidades norteamericanas y eurpeas y vencer la tendencia que traen de la extrema sensibilidad hacia una relación de dependencia y funcionamiento pseudo colonial, a las dificultades de comunicación y la amplia diferencia de recursos.

- La universidad latinoameicana debe dar un vuelco a un esquema de docencia.investigación fortaleciendo la la triple hélice de relaciones entre universidad, industria y gobierno a nivel del Estado si de desea fortalecer la innovación en la docencia, la mejora profesional de los profesores y el impacto en el desarrollo social y tecnológico nacional e internacional.

- Latinoamérica pasa por un período de crecimiento económico que configura sus sociedades, sus mercados y su educación. Este crecimiento obliga poner especial atención a la clara necesidad de aumentar el número de profesionales con calidad pertinente, que soporten ese crecimiento.

- En la definición de cualquier actuación que busque acercar la educación superior de LA al EEES o al anglosajón debe considerarse que el crecimiento acelerado actual define corrientes que deben tenerse en cuenta: cooperación internacional, incremento de movilidad académica, métodos de gestión, evaluación, acreditación y financiamiento, diversificación de titulaciones 
y posgrado, énfasis en proyectos interdisciplinarios y transdisciplinarios, vinculación a la sociedad y al mundo del trabajo, capacidad creciente de reforma e innovación, y considerar la triple hélice: universidad-industria-sociedad para la definición de modelos educativos.

- Ha comenzado un crecimiento sostenido de la educación trasnacional en todos los países de la región. Sin embargo, aunque la tendencia es alentadora, en LA las cifras aún son bajas. Esto indica que los países de la región no constituyen destinos atractivos para los estudiantes internacionales y la causa exhibida es la calidad. Ninguno de los países de América Latina hoy en día aparece en la lista de los 23 destinos que atraen más estudiantes extranjeros.

- La educación superior universitaria en el Perú tiene tendencia hacia la diversificación de la oferta, y estructura y organización competitiva. Se debe trabajar hacia una mayor homogeneidad. Los indicadores de estas tendencias coinciden con el entorno latinoamericano y permiten establecer una visión común hacia dónde se deben dirigir las universidades peruanas y es encaminarse al Espacio Europeo de Educación Superior con mira a lograr características de la universidad norteamericana.

- El cambio en el rol y funciones docentes, el alumno como centro y protagonista del aprendizaje, los nuevos métodos de evaluación, el conocimiento dinámico en continua actualización, el fomento del trabajo colaborativo, favorecen la convergencia y obligan a las universidades a actuar en pos de una integración real que le acerquen a la solución de su propia problemática, como ya se ha planteado en Europa y hacia donde se encamina el EEES.

- El proyecto de actuación debe encaminarse a fomentar y fortalecer la incorporación de un sistema universitario peruano partiendo de experiencias piloto en universidades donde se pueda controlar los cambios y medir los resultados. Las instituciones dirigidas a impartir educación superior universitaria, deben orientar la creación y producción de conocimiento hacia los requerimientos reales del país, considerando los avances acelerados o incidentes del mundo globalizado, creando confianza en la sociedad por su eficiencia, eficacia y calidad.

- La movilidad académica peruana es incipiente, pero ya muestra la importancia de las experiencias adquiridas por los estudiantes en otros países. La internacionalización de la educación superior incluirá necesariamente, procesos y criterios de acreditación, confianza en la cooperación, idénticos estándares de evaluación de calidad, reconocimiento de títulos y diplomas. Todos estos tópicos permitirán una mejor y mayor comparabilidad y compatibilidad entre los sistemas educativos.

\subsection{REFERENCIAS DEL CAPITULO I}

Abarca Fernández, Ramón. (2007). Modelos pedagógicos, educativos, de exelencia e instrumentales y construcción dialógica. Universidad Católica Santa María. Perú. pp 8.

Aguirre Beltrán, Gonzalo. (1960). Estructura y función de la universidad latinoamericana. Revista La Educación. Unión Panamericana Núm. 18. Año V, Washington, D.C. pp. 36-55. Aguirre Beltrán, Gonzalo. (1961). La universidad latinoamericana y otros ensayos. Xalapa, 1961. Editorial Universidad Veracruzana. pp. 2-3. 
Albornoz, Orlando. (1972. Ideología y política en la universidad latinoamericana. Instituto Societas. Caracas, 1972, pp. 113-118-119.

Arocena, Rodrigo; y Sutz, Judith. (2000). La Universidad Latinoamericana del Futuro: Tendencias - Escenarios - Alternativas. Unión de Universidades de América Latina, UDUAL. México 2000.

Benjamin, Harold R. (1965). Higher Education in the American Republics. N. Y. McGraw-Hill. pp. 12-13, 35 y 45-48.

Bennett, James. (2004). The Anglosphere Challenge: Why the English-Speaking Nations Will Lead the Way in the Twenty-First Century. Rowman \& Littlefield. 352 pp, ISBN 0-7425$3332-8$

Brunner, José Joaquín. (2008). Educación Superior en América Latina: elementos para un enfoque comparativo. Conferencia Regional de educación superior 2008. IESALC (Instituto Internacional para la Educación Superior en América Latina y Caribe). UNESCO. Cartagena de Indias 2008.

Censo universitario. (2010). II Censo Nacional Universitario 2010). Instituto Nacional de Estadística (INEI). http://www.coneau.gob.pe/noticias/ii-censo/Exposicion_Jefe _INEI.pdf

Cepal. (2010). Anuario estadístico de América Latina y el Caribe. Comisión económica para América Latina y el Caribe. ONU 2010. p 24.

Cepeda Juan; Sánchez Alfredo; Verástegui Jesús. (2006). Proceso de Bolonia: Enseñanzas y Cooperación entre las Instituciones de Educación Superior Mexicanas y sus Homólogas Europeas. Memorias del 3er Congreso Internacional sobre Docencia. p 376

Colburn, Forrest D. (2002). Latin America at the End of Politics. Princeton University Press. ISBN 0691091811.

CONEAU. (2012). Estándares de calidad para la acreditación de las carreras profesionales universitarias de ingeniería. Tomo IX. CONEAU

Congreso de la República del Perú. (2006). Ley 28740 Ley del Sistema Nacional de evaluación, acreditación y certificación de la calidad de la educación. Título II, Artículo 18. Cuninggim, Merriman. 1969. The Integrity of the University. Educational Record, Vol 2. p 39. Cita de Clark Kerr.

Cuninggim, Merrimon. (1969). The Integrity of the University. Educational Record. USA

Desarrollo peruano. (2012). El Perú en el Ranking Latinoamericano: Crecimiento Acumulado del PBI en el Siglo XXI. http://desarrolloperuano.blogspot. com.es /2012/04/el-peru-en-elranking-latinoamericano.html

Fernández Lamarra, Norberto. (2005). Hacia la convergencia de los sistemas de educación superior en América Latina. OEI - Revista Iberoamericana de Educación. Número 35. 
Ferrer, Thaís; Pelekais, Cira de. (2004) Tendencias gerenciales y la gestión universitaria”. Revista de Ciencias Sociales. Universidad del Zulia, Venezuela. Enero-abril 2004, vol X, número 001. pp. 148-163.

Fundora Herrera, Gilberto. (2010). La educación superior avanzada: Calidad, Equidad y Pertinencia: Tasas de Coberturas Terciarias en América Latina y el Caribe. Pedagogía Universitaria Vol. XV. N 1. 2010. Ministerio de Educación Superior, Cuba.

Gacel-Ávila, Jocelyne. (2006). Calidad y educación sin fronteras. Apertura pp 76- 91. Jalisco, México

García A., Lupe; Meza B., Aníbal; Sarria J., César; et al. (2010. Principios, lineamientos, y programa: propuesta para la gestión del gobierno 2004 - 2007 de la UNMSM, Lima, Perú. Revista IIPSI. Vol. 13. N 1. 2010. 273 - 282

Gazzola, Ana Lucía; Didriksson Axel. (2008). Tendencias de la Educación Superior en América Latina y el Caribe. IESALC-UNESCO. Caracas. ISBN: 978-958-98546-2-4

González G., Ignacio. (1966). Estructura de la universidad latinoamericana. Grupo Universitario Latinoamericano de Estudio para la Reforma y Perfeccionamiento de la Educación (GULERPE). Segunda Reunión. 1966. Universidad del Valle, Colombia. Carvajal y Cía. Colombia. 23-26.

Graubard, Stephen R. (1968). Notes on Higher Education. Mimeographed Boston, American Academy of Arts and Sciences. Abril de 1968. pp 16-17.

Hutchins, Robert M. (1967). The Issues. The University in America Congress. Santa Bárbara, Calif. Center for the Study of Democratic Institutions. 1967. p. 5.

INEI. (2012). Perú en cifras. Instituto Nacional de Estadística e Informática. http://www.inei.gob.pe/

INEI. (2014). Informe Técnico Evolución de la Pobreza 2009-2013. INEI Perú. Lima, mayo 2014

Lemasson, J.P. y Chiappe M. (1998). La investigación universitaria en América Latina, CRESALC, Caracas

López Segrera, Francisco. (2007). Transformación Mundial de la Educación Superior Universidad de Guadalajara. 26, 316

López Segrera, Francisco. (2011). Tendencias de la educación superior en América Latina y el Caribe: Un estudio comparado. Universidad de Guadalajara.

Malo, Salvador. (2004). El proyecto 6x4 UEALC. Seis profesiones en cuatro ejes. CENEVAL, México.

Martínez Moya, Armando. (2005). De la Universidad Colonial a la Universidad Napoleónica. Revista Historia de la Educación Latinoamericana - RHELA. Vol. 7, año 2005, 257 - 272

Marquès Graells, Pere. (2000). Los docentes: Funciones, roles, competencias necesarias, formación. Universidad autónoma de Barcelona. UAB 2000 
Mazzilli, Sueli. (1996): "Ensino, pesquisa, extensao: uma associaçao contraditótia", Tesis doctoral, Universidad Federal de San Carlos, Brasil.

Menacho Chiok, Luis Pedro. (2007). Historia de la educación superior y de posgrado. Oficina de Trámite Documentario y Archivo - OTDA. MIMDES. Perú.

Mureddu, César. (1994). Educación y universidad: el modelo francés de universidad moderna. ITAM, 1994.

Narez Melgoza, Erika. (2011). Influencia de los países anglosajones en el mundo globalizado. http://lessonplansandtips.blogspot.com.es/2011/09/influencia-de-los-paisesanglosajones.html

OECD. (2011). Education at a Glance 2011: OECD Indicators. Organization for Economic Cooperation and Development. 2011.

Ogliastri, Enrique. (2008). Tendencias en la universidad europea. Editorial Tiempo. Colombia

OIT. (2010). Políticas salariales en tiempos de crisis. Informe mundial sobre salarios 2010/2011. Santiago de Chile, Organización Internacional del Trabajo, 2010. p 16.

OIT. (2011. Panorama Laboral 2011: América Latina y el Caribe. Oficina Regional de la OIT para América Latina y el Caribe. pp 48, 49, 51

OIT. (2012). Informe Mundial sobre Salarios 2012-13: Los salarios y el crecimiento equitativo. Conditions of Work and Employment Branch (TRAVAIL). ISBN: 978-92-2-126236-7

Olvera, René B. (2009). Educación Superior en América Latina y el Proceso de Bolonia: Alcances y Desafíos. REMO: Volumen VI, Número 16 México, Enero-Abril de 2009. pp 50 $-58$

Pérez, Carlota. (2000. La reforma educativa ante el cambio de paradigma. Revista EUREKA, Pág. 61. Universidad Católica Andrés Bello, Caracas, 2000.

Pérez-Estevez, Antonio. (2004). LA universidad venezolana: de la colonia a la crisis actual Revista internacional de filosofía iberoamericana y teoría social. Año 9. $\mathrm{N}^{\circ}$ 27. Pp 97-101.

Proyecto Tuning. (2007). Reflexiones y perspectivas de la Educación Superior en América Latina. Informe Final. Proyecto Tuning - América Latina. 2004

Quiroz Chueca, Francisco. (2001). De la Colonia a la República independiente. Barcelona. Editorial Lexus. pp 165.

RAE. (2005). Diccionario Panhispánico de dudas. Real Academia Española. Asociación de academias de lengua española. Ed. Santillana. ISBN 9788429406238. Octubre 2005. Primera edición.

Rama, Claudio. (2006a). La Tercera Reforma de la educación superior en América Latina. Educación, Lenguaje y Sociedad. Vol. IV No 4 (Diciembre 2006). Fondo de Cultura Económica. pp 195-200 
Rama, Claudio. (2006b). La metamorfosis de la educación superior. Informe final sobre la educación superior en américa Latina y el Caribe 2000-2005. IESALC. UNESCO. pp 11 15.

Rama, Claudio. (2010). Seminario de doctorado. Doctorado de Ciencias de la Educación. Escuela de comando y Estado Mayor del Ejército de Bolivia. Universidad Militar de las Fuerzas Armadas de Bolivia. http://www.slideshare.net/claudiorama/historia-de-laeducacin-superior-tendencias-y-nuevos-retos-en-amrica-latina

Ribeiro, Darcy. (1971). La universidad latinoamericana. Editorial Universitaria, Santiago de Chile. p. 107.

Robles Ortiz, Elmer. (2006). Origen de las universidades más antiguas del Perú. Revista Historia de la Educación Latinoamericana, año 2006/vol. 8. Universidad Pedagógica y Tecnológica de Colombia. pp. 35-48

Rodríguez Cruz, Agueda María. (2005). La Universidad de Salamanca en Hispanoamérica". Salamanca, Ediciones Universidad de Salamanca, 2005.

Rodríguez-Gómez, Roberto. (1999). La universidad latinoamericana en la encrucijada del siglo XXI Revista Iberoamericana de Educación.21 (1999): 55-77.

Rosario, Jimmy. (2006). El Internet Herramienta de Innovación para la Educación a Distancia 5to. Congreso Internacional de Educación Superior. La Habana, Cuba.

Rubia Avi, Mariano; Marbán Prieto, José. (2006). El papel de las nuevas tecnologías en el desarrollo de proyectos piloto de innovación docente. Revista Latinoamericana de tecnología educativa. Vol 5. $\mathrm{N}^{\circ}$ 2. 301 - 308

Sánchez Ferrer, Leonardo. (1996). Políticas de reforma universitaria en España: 1983-1993. Tesis Doctoral. Univ. De Salamanca.

Sánchez, Luis Alberto. (1969. La universidad latinoamericana. Editorial universitaria de San Carlos de Guatemala. 6-11, 19.

Santamaría, Rocío. (2001). La Unión de Universidades de América Latina: 51 años en la historia de la educación superior latinoamericana. Revista universidades $\mathrm{N}^{\circ} 21$. UDUAL.

Schwartzman, S. (1979): Formaçao de comunidade científica no Brasil. FINEP. Río de Janeiro. Brasil.

SIR-SCHIMAGO. (2011). SIR World Report 2011: Regional Supplements. Revisado junio 2012. http://www.scimagoir.com/pdf/sir 2011 world report.pdf.

Sierra, Javier; Cabezuelo, Francisco. (2009). Post periodismo y formación en competencias digitales bajo el paraguas de Bolonia. I Congreso Internacional de la Sociedad Latina de Comunicación Social. Universidad de La Laguna.

Thompson Reuters. (2011). the world university rankings 2010-2011. Inglaterra. http://www.timeshighereducation.co.uk/world-university-rankings/2010-2011/top200.html 
Toloza, María del Pilar. (2006). Hacia la Movilidad Estudiantil en la Integración Latinoamericana a partir de la Experiencia Europea. OBREA/UELARO. Buenos Aires.

Tünnennann Bernheim, Carlos. (1998). La reforma universitaria de Córdoba. Educación Superior y Sociedad. Vol. 9, N 1, 103-127, 1998.

Tünnennann, Carlos. (2003). La universidad ante los retos del siglo XXI. Universidad autónoma de Yucatán. 42 - 48

Tünnermann Bemheim, Carlos. (2006). Desarrollo histórico de la Universidad en América Latina: Desde las primeras fundaciones universitarias hasta la universidad republicana. Buenos Aires. pp 64 - 72

UNESCO. (2009). Compendio Mundial de Educación 2009. Instituto de Estadística de UNESCO.

UNESCO. (2010). Compendio Mundial de Educación 2010, Instituto de Estadística de UNESCO. pp.160-170.

Vessuri, Henne. (1996). Pertinencia de la educación superior latinoamericana a finales del siglo XX. Revista Nueva Sociedad Nro. 146 Noviembre-Diciembre 1996, pp. 102-107.

Waggoner. George R. (1971). La educación superior en los Estados Unidos y en Latinoamérica. University Press of Kansas. Vol 2. 1971. Lawrence, KS.

Weinberg, Gregorio. (2001). Ilustración a la reforma universitaria. Ideas y protagonistas. Santillana, Buenos Aires. p 46.

World Bank. (2011). Perú Data. http://www.bancomundial.org/es/country/peru 


\section{Capítulo II}

La evolución de la Ingeniería Industrial: tendencias para la educación superior en 


\section{INDICE CAPITULO II} ¡Error! Marcador no definido. ¡Error! Marcador no definido.

2.2.1 Antecedentes de la acción de la ingeniería en el tiempo _ ¡Error! Marcador no definido.

2.2.2 Inicio de la ingeniería en Europa ¡Error! Marcador no definido.

2.2.3 Inicio de la ingeniería en EE.UU ¡Error! Marcador no definido.

2.3 LA INGENIERÍA INDUSTRIAL EN EL SIGLO XX _ _ ¿Error! Marcador no definido.

2.3.1 La Ingeniería Industrial en Europa actual. ¡Error! Marcador no definido.

2.3.2 La Ingeniería Industrial en EE.UU actual ¡Error! Marcador no definido.

2.3.3 La Ingeniería Industrial en Perú ¡Error! Marcador no definido.

2.4 Tendencias Del siglo XXI PARA LA INGENIERÍA INDUSTRIAL DE PERÚ —_Error! Marcador no definido.

2.4.1 Enfoque de una Ingeniería Industrial para el Perú ¡Error! Marcador no definido.

2.4.2 Características para un ingeniero industrial de Perú ¡Error! Marcador no definido.

2.5 CONCLUSIONES DEL CAPÍTULO II ¡Error! Marcador no definido.

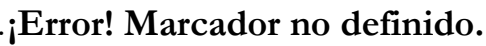




\section{INDICE TABLAS CAPITULO II}

Tabla 2.1 Sub Ranking Ingeniería Industrial, Perú.................................................................................99

Tabla 2.2 Carreras más demandadas en Perú en 2012 _...............................................................................100 


\section{INDICE DE GRAFICOS CAPITULO II}

Gráfico 2.1 Empleabilidad de las especialidades de ingeniería en EE.UU. 96

Gráfico 2.2 Sueldo medio anual en ingenierías en EE.UU. 


\subsection{INTRODUCCIÓN DEL CAPÍTULO II}

En este capítulo se determina la evolución histórica de la ingeniería industrial en Perú, analizando la incidencia que han tenido sobre ella las influencias desde la Unión Europea (U.E.) y desde los Estados Unidos de América (EE.UU.). Esto se hace para poder determinar las actuales peculiaridades de la formación de ingenieros industriales en Perú y, a partir de esto, y junto con las tendencias obtenidas del capítulo anterior, formular las características que debe tener un Ingeniero Industrial de Perú con posibilidad de desempeñarse satisfactoria e indistintamente en ambientes laborales o académicos europeos, norteamericanos $\mathrm{O}$ latinoamericanos, con las competencias técnicas, las habilidades profesionales y sociales, y la formación humanística necesarias en estos medios.

El capítulo se ha dividido en tres partes: la historia de la ingeniería, la Ingeniería Industrial del siglo XX y las tendencias de la Ingeniería Industrial en Perú del siglo XXI.

En la primera parte del capítulo se encuentran argumentos para afirmar que la técnica y el conocimiento pueden ser llevados de y hacia distintos lugares geográficos y que ello puede cambiar el balance de dominio técnico y académico en el mundo. Encontramos que el hombre lleva en su naturaleza modificar el entorno para mejorar su calidad de vida con el uso de la técnica y luego es capaz de portarla consigo para modificar otros entornos. La metodología empleada en esta parte destaca en la revisión bibliográfica de la historia de la ingeniería en el mundo de manera analítica-sintética, para relevar y comparar las aportaciones de las distintas culturas en la historia y así, seleccionar los hitos más importantes de la evolución de la ingeniería de manera cronológica y geográfica. De esta manera se llega a determinar que los inventos y la técnica se trasladaron de Asia a Europa y que, a pesar que las primeras máquinas aparecen en China, la industrialización florece en Europa por el impulso de comerciantes y navegantes, mientras que en China no sucede a pesar de haberse mecanizado antes. En EE.UU. sucede algo similar, reciben la técnica de Inglaterra, que en 1900 compartía la hegemonía industrial y de formación de ingenieros con Alemania; en EE.UU. la mejoran y es estimulada con fuerte financiamiento estatal. Entonces, sintetizo que el dominio del avance tecnológico puede migrar geográficamente por transmisión de conocimiento y experiencias de un lugar a otro y si bien la modificación del entorno por el hombre es espontánea, la innovación y mejora de la técnica requiere de estímulo social y respaldo financiero, por lo que, con el soporte apropiado, hoy en día, es posible formular estrategias de formación técnica a partir de tendencias foráneas exitosas y se puede aspirar a que se logren los mismos o mejores resultados que en su lugar de origen.

Conociendo que podemos trasladar el conocimiento y la técnica geográficamente, incluso entre culturas distantes y diversas, ahora necesitamos saber qué es lo que debemos trasladar y desde dónde, para la apropiada formación de ingenieros industriales en Perú.

En la segunda parte, se pone de manifiesto que la gran tendencia de la Unión Europea a fines del s. XX, por medio del Espacio Europeo de Educación Superior, es mejorar la convergencia de los modelos educativos que existen en Europa y diseña una estrategia que le permita alcanzar los resultados de la educación superior norteamericana, incluyendo los de la ingeniería industrial. Esto me llevó a revisar qué sucedía en Norteamérica. Luego de revisar la ingeniería industrial norteamericana, establezco que los modelos europeo y norteamericano tienen en el s. XX unas 
características comunes importantes: diseñan titulaciones con bases técnicas sólidas, robustecen el posgrado, forman para el liderazgo y motivación de personas, forman en competencias profesionales, hay un fuerte sesgo a los servicios y eso es lo que marcará el futuro de la educación en ingeniería. En Perú se observan iniciativas similares con retraso en el tiempo, pero en la misma dirección, aunque por ahora no hay experiencias de formación en competencias en ingeniería. También encontramos que dentro del mundo global, los requerimientos sociales a la ingeniería son similares, las tendencias de las repuestas de formación de ingenieros en Europa y Norteamérica son compatibles, y que en Perú no se han desarrollado aún. Por lo anterior, afirmo que se pueden emplear las tendencias del siglo XXI del EEES y de EE.UU. en Latinoamérica para perfilar una titulación apropiada a los tiempos futuros en Perú. En esta parte se ha analizado la información obtenida de fuentes secundarias relevantes para encontrar y argumentar afirmaciones sobre el estado de las tendencias de la Ingeniería Industrial en el Espacio Europeo de Educación Superior, Norteamérica, haciendo uso de las herramientas de investigación cualitativa - descriptiva, para llegar a generalizaciones aplicables al Perú.

En la tercera parte se establece que tal como procede de los acápites anteriores, el diseño actual de una formación en Ingeniería Industrial debe considerar apropiados contenidos técnicos muy sólidos, que sean básicos; además, deben darse habilidades y competencias pertinentes a la sociedad cercana; un currículo para satisfacer una decreciente demanda en manufactura y mayor aún en servicios; fomentarse la escritura reflexiva que estimula la toma decisiones; abundar en formación humanística, social y en artes liberales; y solidez en ejecución y dirección de proyectos con apropiado equilibrio teórico-práctico. Son muchas las variables a definir para perfilar la formación de ingenieros industriales en Perú y queda establecido que éste es el fundamento de un apropiado plan de estudios para una ingeniería industrial peruana.

En conclusión, puedo afirmar que es posible definir un perfil apropiado de ingeniería industrial de Perú que permita a los egresados desempeñarse indistintamente en un ambiente profesional europeo, norteamericano o nacional, con las competencias técnicas requeridas, con habilidades profesionales y sociales y con formación humanística suficiente para ejercer en Europa, Norteamérica o Latinoamérica. 


\subsection{HISTORIA DE LA INGENIERÍA}

\subsubsection{Antecedentes de la acción de la ingeniería en el tiempo}

El desarrollo de la ingeniería ha estado vinculado a la historia de los pueblos, ya que refleja cómo la humanidad ha adaptado el mundo a sus necesidades a partir de los logros técnicos que fue alcanzando. En la historia de la humanidad, esta inicial atención de necesidades se convierte en una profesión que, haciendo uso de la técnica, modela el entorno para mejorar la calidad de vida de las personas; así, la ingeniería es esa profesión en la que el conocimiento de las ciencias básicas se aplica al uso eficaz de los materiales y las fuerzas de la naturaleza con el fin de atender las crecientes necesidades del ser humano.

"La técnica es lo contrario de la adaptación del sujeto al medio, puesto que es la adaptación del medio al sujeto. Esto ya bastaría para hacernos sospechar que se trata de un movimiento en dirección inversa a todos los biológicos. Esta reacción contra su entorno, este no resignarse contentándose con lo que el mundo es, es lo especifico del hombre. Por eso, aún estudiado zoológicamente, se reconoce su presencia cuando se encuentra la naturaleza deformada; por ejemplo, cuando se encuentran piedras labradas, con pulimento o sin él, es decir, utensilios. Un hombre sin técnica, es decir, sin reacción contra el medio, no es un hombre" (Ortega, 1964: 304).

Encontramos la importancia de la influencia la ingeniería desde la definición de las etapas del desarrollo de la humanidad en función de los hallazgos relativos a su actividad técnica, desde la "Revolución Agrícola", que contribuye a que el hombre se transforme de nómada a sedentario, hasta en el "ingenio" de dar solución a necesidades diarias con la artesanía, la actividad militar, la irrigación y las construcciones. Estos cambios se pueden identificar claramente desde el año 8,000 a.C. en Siria e Irán, según los historiadores (Eiroa, 1994).

Las migraciones también crearon necesidades. Las regiones que se encontraban en la ruta terrestre de China a España tuvieron una posición ventajosa. Recibieron muchos conocimientos que fueron aportes de los emigrantes, que al mismo tiempo servían de portadores del conocimiento de las especialidades que se veían obligados a desarrollar. Esas regiones fueron el Oriente Medio y el Mar Mediterráneo, que se destacan en la historia como las culturas con el desarrollo más antiguo de la ingeniería: la egipcia, la mesopotámica, la oriental, la griega y la romana. En ellas, las ciencias y las soluciones tecnológicas se desarrollaron puntualmente (García, 2010).

En Egipto se encuentran algunas de las obras de ingeniería más grandiosas y antiguas de todos los tiempos: la presa del año 4000 a.C., la ciudad de Menfis y las pirámides hacia el 2530 a.C., además de los conocimientos de dibujo en papiros, piedra y madera, auxiliares fundamentales en la ingeniería. Muy importantes los progresos en agrimensura cada vez que el río Nilo se desbordaba; complejos sistemas de irrigación desde el año 3200 a.C. Con los que por medio de diques, canales y el "shadoof”, cigoñal para elevar el agua, lograban la irrigación de plantaciones (Cotterrell, 2000).

En Mesopotamia desde el año 6,000 a.C. evoluciona la cultura de los sumerios. Por el año 3500 a.C. construyen las primeras ruedas en su forma más simple. Desarrollaron una agricultura con técnicas ingeniosas. Establecieron núcleos urbanos en medio de las llanuras. El barro abundante 
les permitió construir presas, canales y edificios en organizadas y fortificadas ciudades y fueron los primeros en usar armas de hierro. También trabajaron metales como el cobre, el oro y la plata, así como nácar y piedras preciosas en piezas más delicadas y en labores de incrustación Necesitaron organizar el ejército para la defensa y crearon armas para posteriores guerras de conquista. Inventaron la caballería. Esta región se conoce en la historia como la "cuna de la civilización” (Gonzáles, 1991).

En Asia, en el "lejano oriente", se han encontrado primitivos ábacos del 3000 a.C. Los vehículos de rueda aparecen en las estepas del Asia Central, (c.2500 a.C.) en la civilización del valle del Indo. Los antiguos indios eran diestros en el manejo del hierro y fabricaban buen acero antes que los romanos. Por el 260 a.C. surge el sistema de numeración arábigo en la India. El monje mesopotámico Severo Sebokhtdio lo dio a conocer a occidente cerca del 700 d.C., pero no llegó a Europa hasta el año 1200. Los chinos ya construían, antes que los romanos, canales de irrigación y como vías de navegación. El canal Yun-ho, tiene mil setecientos ochenta y dos km, va de Beijing a Hangzhou y se construyó desde el s. VI a.C. hasta el 1327 d.C. La Gran Muralla China, para defenderse de los ataques, es la única obra humana visible desde el espacio. Fueron constructores de puentes con características únicas, inventaron la pólvora, el mecanismo de escape en los relojes y el de la cometa hace más de dos mil años; también la brújula, que se convirtió en un artículo de uso común por el 1200 d.C. e incluso, el importante papel (Cotterrell, 2000).

En Grecia los mayores logros se dieron entre 500 y el 400 a.C., la "Edad de Oro de Grecia". Destacaron obras como el Propileo (pórtico de Acrópolis), templos e impresionantes estatuas religiosas. Aparecen los refuerzos de hierro a las vigas de mármol. Surge "Mecánica", primer texto conocido sobre ingeniería. El mayor aporte de los griegos a la ingeniería fue el descubrimiento de la propia ciencia. Surgen las condiciones de conocimiento y racionalidad para el establecimiento de una lucha entre matemáticos e ingenieros por la aplicación de la ciencia a la práctica. Escribieron "Hybris" (orgullo por sí mismo o desmesura en el ejercicio del poder), basado en la necesidad de leyes morales y físicas restrictivas en la aplicación de una técnica dominada. Desarrollaron la topografía como ciencia aplicada de la ingeniería. Doscientos años después, Arquímedes encontró la ley de la hidrostática. Hizo descubrimientos en geometría plana y sólida, calculó con más exactitud la constante "pi" y los centros de gravedad de figuras planas. Fue astrónomo y constructor de barcos e inventó el tornillo de Arquímedes (Sarton, 1970).

En Roma estuvieron los más expertos constructores de obras civiles de su tiempo; obras como carreteras, puentes, edificios públicos, acueductos. Los "architectus" eran populares y respetados y quizás se les pueda calificar como los mejores ingenieros de la antigüedad. Por el 1200 a.C. reinventaron la centralización de la calefacción indirecta Turca. Con quinientos cincuenta km; la Vía Apia, iniciada trescientos doce años antes de Cristo, fue la primera carretera recubierta importante en Europa. Diez acueductos suministraban a Roma unos ciento cuarenta mil metros cúbicos de agua al día; usaron tuberías de plomo hasta intuir su toxicidad. El Imperio Romano declina definitivamente en el 476 d.C. (Saravia, Amorim, 2009). 
El aporte ingenieril a la sociedad mengua entre los años 600 y 1000 d.C. en el continente europeo. No obstante, allí la técnica tiene su antecedente inmediato en los artesanos, soldados y constructores medievales. Además, la guerra siempre ha sido acicate para el desarrollo del ingenio humano, y ya sea por las invasiones o por la Ruta de la Seda, a Europa llegaron los aportes de Asia que luego fueron adaptados, aplicados y desarrollados. (Paoli, 1944).

Durante la Alta Edad Media, comprendida aproximadamente entre 350 y 1050 d.C., aunque en Europa cada pueblo formó su cultura, todos reconocían el tronco común del legado romanocristiano transmitido por la cultura escrita latina. Esta fue una época de renovada vitalidad artística e intelectual, donde crecen las instituciones educacionales y renace el interés por la cultura antigua. Esa necesidad de superación del intelecto tuvo sus antecedentes en diversos países y regiones en forma de escuelas de avanzada, que luego derivaron en universidades (García B; 2010).

\subsubsection{Inicio de la ingeniería en Europa}

En el año 900 d.C. existían cerca de veinte escuelas en Europa y en el 1000 d.C. había cerca de doscientas, incremento motivado por su obligatoria creación en ciudades con catedrales. Cada ciudad catedralicia se sentía obligada a establecer una. Las primeras fueron: en Italia, las de Bolonia y Salerno; en España, las de Palencia, Salamanca y Valladolid; en Francia, la de París, la de Chartres, Reims, Laon y Soissons. En el siglo XIII en Inglaterra, Oxford y Cambridge. Aunque el propósito principal de la escuela catedralicia era educar a los sacerdotes para ser hombres de Dios mejor preparados, también atrajeron a otros individuos que deseaban contar con alguna educación, pero no querían ordenarse sacerdotes. Muchos administradores universitarios tuvieron títulos como los de canciller, preboste y decano, originalmente utilizados para los funcionarios de los capítulos (órganos colegiados dotados de personalidad jurídica y de autonomía en el ámbito de su jurisdicción) de la catedral (García B; 2010).

La ciencia comenzaba a aceptarse en el siglo XII, era el escenario para una apertura intelectual exuberante. Hasta el siglo XIII, cuando comenzaron a convertirse en universidades, las escuelas eran monacales (anexas a una abadía) episcopales (anexas a una catedral) o palatinas (anexas a la corte). Antecedente muy importante es la escuela palatina creada por Carlomagno y confiada en el 781 a Alcuino de York. Fue la que más contribuyó a despertar la cultura. Alcuino, formado en la escuela episcopal de Jarrow, organizó la enseñanza en tres grados: (1) Leer, escribir, nociones de latín vulgar, comprensión de la Biblia y de textos litúrgicos; (2) Estudio de las siete artes liberales: en el trívium (gramática, retórica, y dialéctica) y el quadrivium (aritmética, geometría, astronomía y música); (3) Estudio profundo de la sagrada escritura. Alcuino se proponía formar una nueva Atenas, pero cristiana. La segunda generación carolingia con Escoto Eriúgena, intentó revalorar la dialéctica y la filosofía, integrando las artes liberales en el contexto teológico. Así las convirtió en instrumentos de investigación, de comprensión y de elaboración desde el interior de las verdades cristianas, configurándose la primera escolástica (Escobar, 1999).

A partir del siglo XIII, la escuela se configura como universidad, producto típico del medioevo. No hubo modelos para las universidades, como sí lo hubo para las escuelas que tomaron los de la edad antigua, intentándose su continuidad y renovación. "Universidad" en su origen no 
indicaba un centro de estudios sino una agremiación o "sindicato", una asociación corporativa que protegía intereses de las personas dedicadas al oficio del saber. Bolonia y París representan los modelos organizativos en los que se inspiran en mayor o menor medida todas las demás universidades. La antigüedad y el oriente no conocieron esas entidades corporativas que constituyeron las universidades medievales: libres asociaciones de maestros y alumnos, con sus privilegios y programas establecidos, sus diplomas y sus grados. En Bolonia prevaleció la universitas scholarum, es decir, la corporación estudiantil. En París prevaleció la universitas magistrorum et scholarum, corporación de maestros y alumnos. La universidad de París fue una ampliación de la escuela catedralicia de Notre-Dame, muy prominente durante el siglo XII y atraía estudiantes de toda Europa (Escobar, 1999).

En la Baja Edad Media, 1400 d.C. aproximadamente, se desplegó una genuina revolución técnica en diferentes disciplinas, como la minería, el correo, la cartografía, el censo poblacional, las vías para el desarrollo de carreteras, puentes, canales, esclusas y túneles. Mientras que en el Renacimiento se desata la vida intelectual en Europa, dentro de esa intelectualidad se desarrollan la ingeniería y las ciencias. Se inició en Italia antes de 1400 y se amplió al resto de Europa. Surgió el consumismo de Europa, con el intercambio de artículos de lujo y este comercio impulsó la mejora de la tecnología de navegación. En la Ilustración europea, luego del Renacimiento, entre el s.XVII y el final del s.XVIII, muchos intelectuales convinieron en que todo conocimiento puede alcanzarse por la mente, si ésta hace uso de la razón y los métodos científicos. Esto inspiró a memorables científicos como Newton y Pascal y todas las áreas del conocimiento experimentaron avances con las novedosas teorías ilustradas. Surgen más universidades en Europa, la de Ferrara (1391) en Italia, la de Wittenberg (1502), la de Ginebra en Suiza en 1559, la de Leiden en 1575 en los Países Bajos de hoy, entre otras (García B; 2010).

En América, se funda la de Lima, luego llamada San Marcos, y la de Méjico, en 1551. Existe discrepancia con la de Santo Domingo, algunos historiadores afirman que fue fundada en 1538 y por ello sería la primera universidad de América, sin embargo Carlos Daniel Valcárcel ha demostrado que se fundó la Universidad de Santiago de la Paz por Real cédula de 1558, suprimida al ser expulsados los jesuitas en 1767, siendo esta distinta a la de Santo Tomás, que careció de Real Cédula de creación y Bula de ratificación pontificia; la bula dada supuestamente por Paulo III en 1538 no tuvo aprobación del Consejo Real, nunca dejó de ser un proyecto, por eso el Rey Fernando VI prohibió en 1788 a la llamada universidad de Santo Tomás autoproclamarse la más antigua de América. En esta Universidad de San Marcos, en Lima, el Virrey Conde de Chichón crea las Cátedras de Prima y de Vísperas de Medicina el 11 de octubre de 1634, dando inicio al estudio académico de las ciencias en el Perú. A finales de 1691 se crea la Cátedra de Método de Galeno o de Arte Curativo; en 1711, la de Anatomía; y en 1792 se inaugura el Anfiteatro Anatómico en el Hospital San Andrés, complementando la formación con el ejercicio práctico y el desarrollo clínico en el manejo de enfermos. En 1813, durante la administración del virrey José Fernando de Abascal, fue establecida la Facultad de Medicina "San Fernando" en homenaje al rey Fernando VII de España, en la plaza de Santa Ana, hoy Plaza Italia (Valcárcel, 1975).

A fines del siglo XVI muchas ciudades poseían colegios universitarios, seminarios y universidades. En Norteamérica, en Estados unidos, Harvard es la más antigua, fue fundada en 
1636; le sigue Yale, fundada en 1701; Pennsylvania, en 1740; Princeton, en 1746; Columbia, en 1754; Brown, en 1764; Dartmouth, en 1769 y Cornell, inaugurada en 1865. Cada una de ellas tiene un lema, una o varias palabras que sintetizan su esencia misma: Harvard: Verdad; Yale: Verdad y luz; Pennsylvania: Leer sin moral es inútil; Princeton: Florece bajo el poder de Dios; Columbia: En tu luz veremos la luz; Brown: En Dios esperamos; Dartmouth: Una voz clama en el desierto; Cornell: Quería encontrar una institución en la que cualquier persona pudiese hallar el conocimiento sobre cualquier cosa. En EE.UU. se inician los estudios de ciencias a fines del siglo XVIII, fundándose en la Universidad de Yale en 1810 la Facultad de Medicina en y la Facultad de Posgrado de Artes y Ciencias en 1847, la que en 1861 otorgó el primer Ph.D. en los Estados Unidos (Kaplan, 1996).

Mientras el estudio organizado de las ciencias y las tecnologías se extendía por el Nuevo Mundo, comienza en 1780 en Gran Bretaña, un evento conocido como Revolución Industrial, cuyo punto de partida fue la aplicación en la industria de una máquina de vapor. La Revolución Industrial dio pie al desarrollo impetuoso de la enseñanza superior en Europa, destacándose las de Alemania e Inglaterra (García B; 2010).

Realmente una máquina industrial ya se usaba desde hacía mucho tiempo: los chinos ya habían inventado un proceso mecanizado giratorio para el devanado de la seda y el hilo de cáñamo, medio milenio antes que la Revolución Industrial comenzara en el oeste de Europa. En muchas otras formas, China estuvo a punto de propiciar una revolución industrial medio milenio antes que Inglaterra. Pero, a diferencia de la revolución industrial inglesa, nunca el dinamismo comercial y agrícola revolucionó la sociedad china. En su lugar, estos acontecimientos fueron contenidos y absorbidos. Los chinos también tenían la tecnología para navegar por los mares y colonizar otras tierras, pero carecían de los incentivos debido a que China era en gran parte autosuficiente y no tenía ninguna tradición misionera. Con una producción agrícola suficiente para alimentar a una población enorme, medios de transporte por agua a través de los canales, y muchos recursos naturales, los chinos no tenían gran necesidad de desarrollar otras tecnologías mecanizadas. La conquista por los mongoles pasado el año 1200, un clima más frío en el siglo XIII y la pandemia de la Muerte Negra en el siglo XIV, terminaron por socavar el dinamismo económico chino. Por último, la presión demográfica se convirtió en una carga cada vez mayor y la tierra disponible para la agricultura se saturó (Lockard, 2010).

Este comportamiento puede asimilarse a la frase de la antropología, "Nada fracasa tanto como el éxito" muy utilizada por Leften Stavros Stavrianos (1913-2004; distinguido historiador grecocanadiense licenciado en historia por la Universidad British Columbia, maestría y doctorado de la Universidad Clark en Worcester, Massachusetts; profesor de la Universidad de Queens en Kingston, Ontario, del Smith College en Northampton, Massachusetts, de la Universidad de Northwestern y de Universidad de California) quien basado en ella acredita la "Ley de la iniciativa de retardo".

En esta Ley Stavrianos sostiene que las sociedades mejor adaptadas y más exitosas tienen más dificultad para cambiar y mantener su ventaja, por lo que luego de un tiempo pierden su impulso dinámico. Por el contrario, las sociedades atrasadas y con menos éxito son más propensas a adaptarse y seguir adelante. Si bien gran parte de Europa estaba económica y políticamente 
menos desarrollada que las sociedades asiáticas más importantes durante este período, en el siglo XIV algunos países europeos mostraron un mayor dinamismo. Con incansable energía humana los artesanos y los comerciantes influyentes pusieron los cimientos para un cambio en el equilibrio mundial. Así, la globalización echó por vez primera sus raíces entre los siglos XI y XVI y permitió a los avanzados inventos orientales fluir hacia occidente, donde fueron asimilados gradualmente por Europa. Por lo tanto, después de 1450 o 1500 la ventaja poco a poco pasó a los europeos occidentales (Lockard, 2010).

El término "globalización" se refiere a la creciente interconexión de las naciones y los pueblos de todo el mundo a través del comercio, la inversión, los viajes, el diálogo, la cultura popular y otras formas de interacción. Muchos historiadores han identificado "globalización" como un fenómeno del siglo XX conectado con el surgimiento de la economía internacional dominada por Occidente. Sin embargo, una amplia interacción entre los pueblos, así como viajes a grandes distancias llegaron muchos siglos antes de estos acontecimientos, y en ellas se generaron grandes cambios en las distintas sociedades.

Hasta fines del siglo XVIII no existía la profesión de ingeniero como la conocemos hoy. Se construía intuitivamente, sobre la base de ensayo y error según la tradición heredada. Durante los siglos XVI y XVII, en Europa occidental se fomentaron verdaderas fábricas. La industrialización dio lugar, como principio básico, a la división del trabajo. También a la producción en serie, a la consecuente especialización de la mano de obra y a la interacción cada vez mayor entre la ciencia y la industria. Se inició el cada vez más acelerado e indiscriminado uso de los recursos naturales y también a serios problemas sociales que se derivaron del maquinismo industrial, apareciendo el hombre máquina, que es dar valor a la persona sólo como un recurso de producción. La industria quitó espacio a la agricultura, la tecnología desplazó al arado romano y los bueyes (García B; 2010).

En ese contexto, el Renacimiento (s. XV y s. XVI), la Ilustración (s. XVII y s. XVIII) y las exigencias de la Revolución Industrial (s. XVIII y s. XIX) obligaron a la creación de centros especializados para las ciencias y para diversas ramas de la técnica. Las primeras escuelas de ingeniería en Francia, inicialmente militares, defendían que los diferentes oficios exigían habilidades y destrezas bien elaboradas. En Inglaterra surgen asociaciones profesionales interrelacionadas y se afirma que la revolución industrial fue realizada por "cabezas duras y manos inteligentes". Se destacó la Institución de Ingenieros Civiles (en mil ochocientos dieciocho) y con el auge del ferrocarril los operarios se especializaron como la Institución de Ingenieros Mecánicos. Fue durante la segunda mitad del siglo XIX que la ingeniería llegó a universidades como Glasgow, Dirham y Londres (Ashby, 1958).

La educación francesa y alemana al inicio del siglo XIX perfilan características propias. En Francia, la universidad se convirtió en formadora de profesionales, dedicados a un saber hacer. Para lograr este fin, la universidad napoleónica francesa dividió las actividades universitarias. Las Facultades fueron instancias de administración curricular, integradas por Escuelas Profesionales encargadas de elaborar los currículos de cada profesión. Comenzaron a otorgar Licencias para ejercer legítimamente la profesión en la sociedad. Las Escuelas fueron atendidas por profesores, es decir, profesionales habilitados para enseñar, pero no necesariamente maestros (los antiguos 
Magistri), dedicados a la investigación y al cultivo del saber. Para agrupar a quienes quisieran dedicarse a las labores de investigación científica, se formaron nuevas estructuras, los Institutos, totalmente dedicados al estudio y a la investigación y sólo eventualmente a la docencia (Mereddu, 2006).

En Alemania Guillermo von Humboldt retoma las enseñanzas de Herder, Fichte y Schleiermacher, herederos a su vez de Kant y Hegel. Contrariamente a la propuesta francesa, von Humboldt postuló una universidad fincada en el cultivo de la ciencia pura, que implicó también un replanteamiento de los estudios preparatorios para el ingreso a la universidad, por lo que se puede decir que la reformulación alemana es profunda y total. La idea de universidad germana supone que la ciencia se cultiva en las Academias, entre los maestros ya consagrados a ella. Los estudiantes, apenas se han iniciado en los primeros ejercicios intelectuales, en el Gimnasium. Por tanto, la universidad se concibe como el punto de reunión de ambos contingentes. De esa forma la universidad encarna el ideal, que ninguna de las dos partes posee por separado. Este supuesto teórico hegeliano dio como resultado una nueva estructura del trabajo propiamente universitario y con ello, un nuevo modelo de universidad (Mereddu, 2006).

Hacia 1820 diversas escuelas politécnicas se crearon en Berlín, Karksruhe, etc. De ellas salían ingenieros en electricidad, mecánica, química, construcción. Realmente eran técnicos de grado medio que tuvieron gran influencia en el desarrollo industrial alemán. A finales del siglo esas escuelas ya tenían rango universitario y simultáneamente las universidades fueron incorporando las ingenierías. El fomento de tales escuelas se distinguió por combinar docencia, investigación, laboratorios y una constante relación con la realidad industrial, proceso que se hacía cada vez más complejo desde el punto de vista científico. Entre 1850 y 1900 Alemania e Inglaterra competían por la hegemonía industrial, lo que se reflejaba en la formación de sus respectivos ingenieros.

\subsubsection{Inicio de la ingeniería en EE.UU}

En el siglo XVII y principios del siglo XVIII, se establecen numerosas escuelas o colegios en las colonias de Norteamérica, primordialmente para una formación orientada al ministerio religioso: Harvard puritano, Yale congregacionalista, Princeton y Columbia anglicanos, Brown bautista; y en siglo XIX se establecen los primeros colegios de mujeres: Mt. Holyke en 1837, Elmir en 1853, Vassr en 1861, Wellesley en 1871, Smith en 1871. A partir de 1870 la difusión de los beneficios de la coeducación lleva a casi todas las universidades a admitir alumnos y profesores de ambos sexos. En el siglo XIX, a partir de los colegios, las universidades modernas se desarrollan sostenidas con los impuestos estatales resultantes de una ley dada en 1862, la Morrill Act; en virtud de esa ley se otorgan tierras públicas a los estados para la formación y sostén de escuelas de agricultura, ingeniería mecánica y economía doméstica y para áreas académicas tradicionales. La Hatch Act de 1887 expande el programa de dotación de tierras proveyendo fondos para estaciones de investigación y experimentación. La Smith-Lever Act de 1914 da apoyo federal a la extensión en agricultura y economía doméstica. Otra importante influencia empieza a surgir en el siglo XIX con la fundación de la Universidad John Hopkins conformada más según el modelo de universidades del norte de Europa que el de los colegios norteamericanos. Así, se comienza a poner más énfasis en los estudios e investigaciones de 
posgrado que en una instrucción colegial. Se da especial atención al ejemplo de las universidades alemanas con su separación entre escuelas de posgrado, para la investigación, y profesionales, cada parte dedicada a su área de estudio (Kaplan, 1996).

En los Estados Unidos de América, los primeros ingenieros en ejercicio procedieron del Imperio Inglés, hasta su independencia. Su guerra de independencia los acercó a Francia, a quien pidieron apoyo técnico. Así crearon la Academia Militar de West Point en 1802. Las primeras obras civiles y de minas fueron diseños europeos y de ingenieros militares de dicha academia. Las experiencias francesas, británica y alemana fueron recogidas por universidades e institutos tecnológicos en los que se implantó la educación técnica, por ley, terminada la Guerra Civil (1861-65). Con un fuerte énfasis en la práctica, una gran potenciación de los laboratorios y firme vinculación de los estudiantes de ingeniería con el trabajo (Half time schools) sin descuidar la importancia de la teoría (NRC, 1985).

Las universidades norteamericanas se relacionaron además con el hecho de que el desarrollo económico necesitaba una educación superior no tanto con "originalidad y sofisticación científica" -que podía tomar prestadas de Europa- como con la capacidad de captar y utilizar la ciencia: "desarrollo" con investigación. Las universidades norteamericanas y sus academias técnicas eran económica y académicamente superiores a las europeas porque proveían una educación sistemática para ingenieros tal como no existía aún en el viejo continente. Incluso eran superiores a las europeas porque producían altos números de ingenieros a nivel adecuado en vez de producir unos pocos soberbiamente inteligentes y bien educados (Hobsbawn, 1996).

La ingeniería civil fue la primera disciplina de la ingeniería en alcanzar el estatus profesional en los EE.UU. A mediados de 1800, surge la ingeniería mecánica en los talleres mecánicos de armas, herramientas y otros implementos más sofisticados. La demanda de bienes y servicios de ingeniería creció con la población y para responder a estas y otras necesidades educativas, el gobierno federal comenzó, en 1862, a apoyar la educación superior técnica. Un subsidio federal dio un mayor impulso a la educación en ingeniería, haciendo posible un acercamiento más científico a problemas técnicos. Como resultado, la profesión de ingeniería comenzó a diversificarse. (NRC, 1985)

Hasta 1880, la ingeniería fue civil o militar. De ingeniería civil aumentó a la ingeniería mecánica, creció a ingeniería de minas y a metalúrgicos. Luego la eléctrica, la química, la industrial. En 1880 se fundó la American Society of Mechanical Engineers, seguida de la American Society of Electrical Engineers en 1884 y el American Institute of Chemical Engineers en 1908. El American Institute of Industrial Engineers se fundó en 1948 y fue el último campo importante de la ingeniería en organizarse. La ingeniería industrial inicia como un área de la ingeniería mecánica, desarrollada para sistematizar aún más los procesos de fabricación. Para entonces, las cinco disciplinas de la ingeniería - ingeniería civil, mecánica, eléctrica, química e industrial - se habían establecido como los principales programas (Romero et al, 2006).

La carrera de ingeniería industrial tradicional americana que hoy conocemos nace de los estudios de Taylor publicados en 1911 The principles of scientific management. Frederick W. Taylor es considerado como el padre fundador de la Ingeniería Industrial. Sus trabajos en 1874 para mejorar la eficiencia de Midvale Steel, condujo al desarrollo de la "administración científica". 
Taylor, muy cuidadosamente cronometró las tareas programadas que realizaban los operadores exactamente como se especificaban. Gastó mucho tiempo y esfuerzo en hacerlo. Esto dio como resultado el nacimiento de los "estudios del trabajo": estudio de métodos y estudio de tiempos, base de la carrera de ingeniería industrial tradicional que hoy conocemos. Otros dos pioneros que han dado forma a la profesión de ingeniería industrial son Frank Gilberth y su esposa Lillian Moller Gilberth. Ambos trabajaron juntos para analizar los movimientos fundamentales de la actividad humana. Su trabajo condujo al desarrollo de los elementos básicos de movimiento, conocidos como "therbligs", para la búsqueda, comprensión, transporte, alcance, y más. Esto todavía se enseña hoy en día en muchos programas de estudio (Zambrano et al, 2011)

En Estados Unidos, también siguieron apareciendo algunos personajes que alimentaron la disciplina de la ingeniería industrial durante la segunda mitad del siglo XIX e inicios del XX como Henry Robinson Towne (1844-1924) quien estaba asociado con la Yale and Towne Manufacturing Company y con la ASME (Sociedad norteamericana de ingenieros mecánicos), enfatiza en la responsabilidad económica de los ingenieros y expresó que hacía falta un conjunto de profesionales que se preocupara por los problemas de la fabricación y la administración; Towne en sus diversas intervenciones ante la ASME insistía en la búsqueda de profesionales con ciertas características y conocimientos capaces de ser buenos administradores y buenos ingenieros, al respecto Towne decía: (Zambrano et al, 2011).

"Hay muchos buenos ingenieros mecánicos y también hay muchos buenos "bombres de negocios"; pero rara vez se combinan ambos en una sola persona. Pero ésta combinación de cualidades, junto con alguna babilidad como contador, en una persona o en más, es esencial para la administración próspera de establecimientos industriales, y abarca, personalmente o a través de ayudantes, el funcionamiento de todos los departamentos de un negocio, y para subordinar cada uno de ellos al desarrollo armonioso del todo".

Como el interés en la ingeniería industrial creció, otras áreas afines se han desarrollado y más tarde se convirtieron en componentes principales del campo de estudio de la ingeniería industrial. Por ejemplo, el desarrollo de la investigación de operaciones en el Reino Unido en 1940 y el interesante problema que investigó dando lugar a su adopción por parte del Ejército, la Fuerza Aérea y la Armada de los EE.UU. Una de las primeras asignaturas en la investigación de operaciones se ofreció en 1948 en el Instituto Tecnológico de Massachusetts (MIT). Case Western Reserve se convirtió en la primera universidad en ofrecer un programa de grado, y poco después las universidades como Northwestern y Johns Hopkins eran referentes de la investigación de operaciones. Otras áreas relacionadas incluyen la gestión y el comportamiento organizacional. Hacia fines del siglo XX esto se ha extendido a la gestión de la tecnología, a la gestión de operaciones, a la gestión de calidad y a la ingeniería de gestión. De hecho, la ingeniería de gestión creció a un ritmo alto y dio lugar a convertirse en una disciplina independiente en algunas universidades. Del mismo modo, la ingeniería industrial pone atención en el ser humano y se amplifica en cursos tales como la ergonomía o factor humano, que ahora se considera una subdisciplina de la ingeniería industrial, estrechamente relacionado con la psicología industrial y experimental. (Elsayed, 1999)

En el siglo XX las universidades de los EE.UU jugaron un papel cada vez más importante en la investigación científica y en la innovación tecnológica, en gran medida como resultado de las 
demandas de tales servicios provenientes de los gobiernos y las grandes corporaciones. Se han dado así procesos de nacionalización y burocratización de la innovación y la investigación, por una parte, y de su apropiación y aprovechamiento por las grandes corporaciones, por la otra. Diferentes agencias gubernamentales asignan grandes cantidades de dinero a universidades públicas y privadas para fines de investigación. El gobierno federal provee también ayuda directa a varias categorías de estudiantes, como los veteranos de guerra y los minusválidos. El triángulo constituido por el estado, la universidad y la gran corporación, se convierte en determinante del desarrollo científico y tecnológico de los Estados Unidos (Hobsbawn, 1994).

\subsection{LA INGENIERÍA INDUSTRIAL EN EL SIGLO XX}

\subsubsection{La Ingeniería Industrial en Europa actual.}

Europa de finales del siglo XX presenta fundamentalmente dos modelos educativos diferentes: el anglosajón y el continental.

Los sistemas del continente presentan gran similitud y siguen dos modelos básicos, que coexisten en paralelo: ciclo largo para las licenciaturas, ingeniería y arquitectura, y ciclo cortó para diplomaturas, ingeniería técnica y arquitectura técnica. Este modelo es muy diverso y plantea una gran confusión, y esa confusión y complejidad han ido incrementando con el paso del tiempo. El ciclo largo es de mínimo 5 años y, para el caso de las ingenierías, conduce a un título de Ingeniero de Diseño/Investigación. En él se adquiere una buena base de conocimientos matemáticos y científicos. El ciclo corto es de 3 a 4 años, conducente a un diploma, de Ingeniero Técnico por ejemplo. Con la aplicación del Acuerdo de Bolonia, se estructura un modelo universitario en: Grado, que suprime la división actual existente entre diplomaturas y licenciaturas con la intención de facilitar un acceso más ágil y adecuado al mercado laboral y al ámbito social, proporcionando la mayor parte de las competencias profesionales necesarias; Máster, con fuerte sesgo a la especialización; y Doctorado, cuyo objetivo es la investigación. Cada ciclo conduce siempre a la obtención de un título oficial y además, en todos los casos, la superación de un ciclo permite el acceso al siguiente (Canós, et al, 2009).

El sistema educativo del Reino Unido que actualmente se conoce, comenzó en el año 1988 cuando se introdujo la nueva ley de educación, Education Reform Act 1988. En el sistema anglosajón al aprobar la secundaria, primer ciclo, los estudiantes eligen dejar la escuela y empezar a trabajar, seguir programas de entrenamiento en escuelas técnicas o estudiar dos años más para los exámenes de ingreso a la universidad o "A-Levels". El equivalente británico a los estudios de titulación superior del sistema español, es decir, los estudios conducentes al título de Licenciado, Ingeniero o Arquitecto, se denominan Undergraduate studies, segundo ciclo. Su duración varía entre tres y cuatro años, aunque hay algunos de dos años, y el título al que dan lugar es el de Bachelor's Degree. Si el programa de estudios combina varias áreas de conocimiento, se obtiene un Bachelor's Honours Degree que según las calificaciones logradas podrá ser de primera categoría, segunda o tercera (First Class Honours, Second Class Honours o Third Class Honours). Los DipHE (Diplomas en educación superior) son otorgados luego de haber superado cursos de dos años de duración, tras los cuales se puede continuar estudiando para la obtención de una licenciatura, o no, puesto que se trata de titulaciones reconocidas, con 
valor por sí mismas. Algunas carreras incluyen un año de práctica laboral; aunque tienen exámenes al final de cada año, las calificaciones finales no están basadas únicamente en ellos, pues se trata de un sistema de evaluación continua, en el que la entrega de trabajos, los ejercicios de clase, etc. son también importantes. El grado de Maestría o Master, tercer ciclo, se concede después de uno o dos años de estudios especializados en un campo concreto, a continuación de la licenciatura; debe realizarse una memoria de estudios y en algunos casos debe aprobarse un examen escrito. MBA son las siglas de Master en Administración de Empresas, MA de Master de Arte, y MSC de Master de Ciencias. El Master de Filosofía se obtiene tras dos años dedicados a la investigación y la aprobación de una tesis; suele figurar en su forma abreviada Mphil. El Doctorate of Philosophy es el título al que se accede tras tres años de investigación, posterior a la consecución del Master's Degree, y la presentación de una tesis. Aparece con mayor frecuencia en sus dos formas abreviadas D.Phil. Y PhD. Existe además una titulación posdoctoral, Higher Doctorate, concedida a profesores universitarios tras una notable trayectoria investigadora (UNIVERSIA, 2013).

En el modelo continental o napoleónico el énfasis está en los contenidos, ya que el supuesto es que el conocimiento es lo más importante del proceso educativo y supone que el contenido incluido en las distintas materias del programa permite alcanzar indirectamente, además de los fundamentos básicos, las competencias, habilidades, aptitudes y actitudes necesarias para la titulación. El proceso se centra en un profesor que enseña y por ello la unidad de medida es el trabajo del profesor (crédito 10 horas). En general la metodología pivota sobre la presencia del alumno en aula, clases magistrales, con contenidos muy ligados a atribuciones o calificaciones profesionales. El modelo puede resumirse en "estudiar mucho pocos años para trabajar toda la vida" (Rivero, 2005).

En el modelo anglosajón o nórdico, lo importante en el primer grado es el aprendizaje: aprender a aprender. El contenido desarrollado en las distintas materias del programa tiene por objetivo desarrollar en los alumnos los fundamentos básicos, las competencias, habilidades, aptitudes y actitudes necesarias para la titulación. El proceso se centra en el estudiante que aprende y por ello la unidad de medida es el trabajo del estudiante: los planes de estudio derivan hacia planes de trabajo. La formación inicial debe complementarse con un proceso de aprendizaje a lo largo de la vida. El modelo puede resumirse en "estudiar toda la vida para trabajar toda la vida" (Rivero, 2005).

Independientemente de la opinión que se tenga del modelo adoptado por el Proceso de Bolonia o de la forma en que se haya intentado implantar en cada caso, es claro que propone uniformar las variantes existentes en la educación superior del modelo continental, tendiendo al modelo anglosajón. Es manifiesto que surgen aprensiones en el mundo académico basadas en las suposiciones que el proceso es una realidad lejana o ajena, que es una moda o que requiere muchos recursos que lo hacen inviable; también basadas en la experiencia, pues en algunos casos se comprueba la dificultad de compatibilizar lo normado con lo que sucede en la realidad; sin embargo, es un hecho que ha iniciado el cambio y trae oportunidades de reflexión y mejora: un modelo educativo nuevo. Modelo homologable y reconocible internacionalmente, más acorde con las demandas sociales y necesidades de los estudiantes, con la posibilidad de transformar el 
modelo de enseñanza en un modelo de aprendizaje utilizable a lo largo de toda la vida, y que tiende a un modelo que exhibe indicadores de éxito.

Como consecuencia de esta integración en el Espacio Europeo de Educación Superior, actualmente estamos asistiendo a un cambio en la organización del mapa de las carreras en la universidad europea. Uno de los estudios con mayor salida profesional, al estar la demanda de estos titulados en constante crecimiento, es la Ingeniería de Organización y nos centraremos en ella en adelante. Debemos aclarar que este ingeniero de organización es el Industrial Engineering en terminología americana (Canós, et al, 2009).

La aclaración anterior es porque en España, entre otras muchas, existen dos titulaciones con amplia tradición: la Ingeniería Industrial, desde1857, y la Ingeniería de Organización Industrial, desde 1964. El objetivo de ambas ha sido tradicionalmente la formación de profesionales en procesos de contenido tecnológico o de gestión de empresas industriales, con más énfasis en la formación científica y tecnológica en los Ingenieros Industriales, y con más énfasis en la formación en gestión para los Ingenieros de Organización Industrial.

Los términos también varían de país en país para estos ingenieros: en América se utiliza Industrial Engineering o Ingeniero Industrial; en Reino Unido, Management Engineering, Manufacturing and Management Engineering o Technology Management; en Alemania, Wirtschaftsingenieurwesen; en Francia, Ingenieur du Génie Industriel; en Italia, Ingegneria Gestionale; en Bélgica, Handelsingenieur (Ingeniería Comercial); en Holanda, Technology Management. Podemos resumir esta diversidad en las siguientes características (UVa; 2010):

1. La denominación de Ingeniero Industrial que se imparte en las Escuelas de Ingenieros de Suecia, Francia, y Norte, Centro y Sur América es la denominación original, con un reparto equilibrado de contenidos entre ciencias de la ingeniería, tecnologías de fabricación, y técnicas y sistemas de gestión. Con un claro énfasis hacia las ciencias de la decisión (o métodos cuantitativos de gestión) y la gestión de la producción.

2. La denominación de "Ingeniero de Gestión Industrial", a pesar de la inclusión de la palabra Ingeniero, se imparte de Facultades de Ciencias Económicas o en Escuelas de Negocios en Alemania, Bélgica, Francia, Italia, Reino Unido. En estos estudios desaparecen casi por completo los contenidos de tipo tecnológico y se refuerzan los de economía tanto política como de la empresa y de gestión general de la empresa.

3. Ingeniero en Gestión de la Fabricación, Ingeniero en Gestión de las Operaciones y la Tecnología, Ingeniero de Producción, en las Fachhochschules o Hogescholes de Alemania, Holanda y en los Departamentos de Ingeniería Mecánica del Reino Unido. En todos los casos se trata de estudios universitarios tanto de grado (Bachelor) como postgrado (Master) de orientación profesional. Eso significa que se reducen fuertemente los contenidos científicos en favor de los tecnológicos y de las estancias en empresas industriales.

Así, el nombre de la titulación Ingeniería Industrial puede llevar confusión, según se refiera a una formación impartida en un país u otro. Lo que fuera de España se conoce como Ingeniería Industrial, en España se conoce como Ingeniería en Organización Industrial. Por ello, a partir de este punto, unificaremos el término en aquel que se conoce como común a la mayoría de los 
casos anteriores. Ingeniería Industrial llamaremos a las titulaciones con las características definidas en las Escuelas de Ingenieros Industriales de Suecia, Francia, y Norte, Centro y Sur América y en las Fachhochschules o Hogescholes de Alemania, Holanda y en los Departamentos de Ingeniería Mecánica del Reino Unido y similares. Para el caso español, la ingeniería de organización.

La formación de un Ingeniero Industrial, con conocimientos de las diferentes técnicas, y capaz de integrar el pensamiento industrial en Europa requiere de una enseñanza óptima, de un ciclo integral en el que ya desde el inicio se obtengan los conocimientos básicos suficientes. Esa "buena cimentación", es necesaria para posteriormente poder asimilar las técnicas específicas con profundidad. Este proceso formativo asegura que no se escapen aquellas posibles innovaciones tecnológicas que requieren una visión de conjunto. Los ingenieros industriales han jugado y juegan un papel decisivo como transmisores e introductores de progreso. La combinación equilibrada de una sólida formación científica y técnica de base, de diferentes tecnologías aplicadas y de disciplinas pertenecientes al ámbito económico-empresarial y humanístico-social, junto con el entendimiento que se alcanza de la realidad del sector industrial y la capacidad de interrelacionar diferentes disciplinas participantes en sistemas complejos (crear, desarrollar y gestionar), hace de estos estudios un modelo sólido e innovador (Romero, F; 2003).

Los estudios de Ingeniero Industrial se consideran básicos para el desarrollo económico de nuestra sociedad y se deben componer de cuatro áreas básicas: mecánica, eléctrica, química y de gestión de operaciones (Elsayed, 1999), que le dan al ingeniero capacidad de: innovar, trabajar en un contexto interdisciplinar, ejercer como generalista o especialista, y adaptarse a las nuevas orientaciones y avances tecnológicos (Romero, 2003).

Con el devenir de la universidad en Europa y las necesidades de contar con una ingeniería industrial que es cada vez más demandada, podemos afirmar que el ingeniero industrial europeo es un profesional con unas sólidas bases matemáticas y estadísticas, y que conoce en qué consisten, para qué sirven y cómo se ponen en marcha en una empresa las herramientas de gestión de operaciones que permiten ofrecer productos y servicios en el menor plazo y con la mayor productividad, calidad, fiabilidad y eficiencia posible. Además, es capaz de diagnosticar problemas, analizarlos, proponer posibilidades de mejora y decidir cuál de las herramientas de gestión de operaciones conviene usar o no usar en su área de responsabilidad. Para tomar esta decisión, debe ser capaz de valorar las prioridades estratégicas de su empresa, los indicadores clave, los recursos disponibles, los beneficios y costos esperados, y las condiciones del sector. También debe dominar las limitaciones tecnológicas de los productos y servicios que ofrece la empresa, y de los procesos con los que los produce, así como su responsabilidad social corporativa. Una vez tomada la decisión, es capaz de colaborar en la implantación y seguimiento de las acciones propuestas haciendo los protocolos, cálculos, planes, programas, simulaciones, etc., que sean necesarios para ello. También tendrá un papel importante liderando y motivando a las personas que deben colaborar en la implantación (Marín -García et al., 2008).

Un ingeniero industrial tiene una característica diferenciadora, y es que requiere una base matemática y estadística mucho más amplia y sólida que las otras ramas de la ingeniería. También precisa de conocimientos de programación para automatizar el cálculo de algoritmos que 
personaliza. En contraste, y por mencionar algunos, los Mecánicos requerirán más física y los de energética fundamentar más química (Canós, et al., 2009)

En definitiva, los ingenieros industriales son necesarios en cualquier situación donde haya que utilizar recursos escasos de la manera más eficiente posible (Gallwey; 1992). Por lo tanto, en este entorno, una de las maneras de lograr cierta ventaja competitiva, es dotar a una sociedad de ingenieros industriales que sean capaces de trabajar en entornos complejos e independientes, aprovechando las tecnologías actuales y canalizando la energía de las personas a su cargo (Markes, 2006).

En España la carrera de Ingeniero de organización (compatible con el Ingeniero Industrial americano) es bien acogida por el mundo empresarial y por los estudiantes. Sus principales variables de satisfacción son el contenido de sus trabajos y las perspectivas de escalamiento empresarial. Por el contrario, están muy poco satisfechos de las habilidades adquiridas durante su formación universitaria. (Martínez Costa et al.; 2007). Aun así, muchos de los antiguos alumnos de la especialidad de Organización Industrial, que tardaron más o menos años en terminar la carrera, afirman que volverían a elegirla "si tuvieran que volver a empezar" (Figuera, J; 2007). También se establece que las instituciones universitarias no enfatizan la formación de post grado de los ingenieros de organización (Markes, 2006).

Las universidades tienen un papel limitado en el desarrollo de posgrado de los ingenieros industriales. Por la salud de todo el sistema, es vital que las universidades desempeñen plenamente su papel. Si las universidades persisten en la negligencia de no buscar maneras de colaborar con el aprendizaje de los profesionales más allá de la graduación, tendrán que aceptar que termina tempranamente su intervención en el desarrollo profesional. Y, con el tiempo, aceptar que pueden perder su condición de autoridad frente a otras instituciones en el campo del desarrollo profesional superior (Maffioli, et al, 2003).

La carrera de Ingeniero Industrial es imprescindible para un país que se preocupe por mantener o relanzar la ventaja competitiva de sus empresas; es necesaria una reflexión y actuar en este ámbito (Martínez Costa, et al.; 2007).

\subsubsection{La Ingeniería Industrial en EE.UU actual}

En este punto, es oportuno mencionar brevemente el desarrollo de la ingeniería industrial como una disciplina. En los últimos años en Estados Unidos de Norteamérica, el número de graduados de las cinco disciplinas básicas de la ingeniería, civil, mecánica, eléctrica, química e industrial, constituye el setentaicuatro por ciento del número total de ingenieros graduados por año (cálculo propio a partir de información obtenida del Centro nacional para las estadísticas de ciencia e ingeniería) (NCSES, 2012).

En Estados unidos de América el ingeniero industrial no es mecánico, eléctrico ni químico, sino la persona encargada del control y la optimización de los procesos productivos, tarea que normalmente no realizan las otras especialidades. Esto no representa una ventaja ni una desventaja, sino simplemente una característica de esta rama de la ingeniería y sus tareas dentro de la empresa. De esta forma, todas las actividades relacionadas con una industria son injerencia de la ingeniería industrial, con excepción de las tecnologías específicas que se emplean en los 
procesos productivos; así, el ingeniero industrial puede encargarse desde la determinación de la localización y ubicación óptima de la industria, la optimización de los procesos, la utilización de la maquinaria, y de la mano de obra, el diseño de la planta, la toma de decisiones para la automatización de procesos, hasta la planeación de la producción, lo cual implica controlar los inventarios tanto de materia prima como de producto terminado; también planea el mantenimiento de todos los equipos. La evolución de la ingeniería industrial sigue las nuevas tecnologías y avances en el conocimiento científico. Así, antes era la máquina mecánica después, la semiautomática, luego la automática, y ahora la cibernética y la robótica, actualmente agregadas a las nuevas formas de Producción y de Servicio en todos los campos de la ciencia. Teniendo esto claro, es la única manera en que podemos fijar por dónde irá el camino de la evolución de la carrera hacia el futuro (Elsayed, 1999).

En Norteamérica, más que nunca antes, la ingeniería industrial significa diferentes cosas para distintas personas. De hecho, uno de los medios para ir entendiendo la ingeniería industrial moderna es lograr la comprensión tanto de sus subdisciplinas como de la forma en que se relaciona con otros campos. Las que llamamos subdisciplinas de la ingeniería industrial o campos relacionados con ésta, en la actualidad son: administración, estadística, investigación de operaciones, ciencia de la administración, ergonomía, ingeniería de fabricación, ingeniería de sistemas y medio ambiental. La educación del ingeniero industrial norteamericano del siglo XXI implica cierta combinación de contenidos de todas las disciplinas que se acaban de mencionar. La combinación y ponderación depende del departamento académico de ingeniería industrial y de las compañías en las cuales los individuos obtienen su título o su experiencia laboral (Hicks, 2002).

Esta combinación de subdisciplinas es la que mejor responde a las necesidades del mercado norteamericano, aunque el uso de "industrial" en la "Ingeniería Industrial" puede ser algo engañoso, ya que ha crecido para abarcar cualquier enfoque metódico o cuantitativo para optimizar el funcionamiento del proceso, sistema o la organización. Anteriormente, el término se aplicaba originalmente a la fabricación y para evitar la confusión algunas universidades de ingeniería y organismos educativos en varias zonas del mundo han cambiado el término "industrial" a términos más amplios como la "producción" o "sistemas", lo que lleva a las extensiones típicas señaladas anteriormente. De hecho, la principal organización profesional de EE.UU. de Ingenieros Industriales, el Instituto de Ingenieros Industriales (IIE) ha considerado la posibilidad de cambiar su nombre a algo más amplio, como "Instituto de Ingenieros Industriales y de Sistemas", aunque la última votación sobre el tema, entre los miembros, considera que esto es innecesario por el momento (IIE, 2011).

La ingeniería de fabricación se asocia naturalmente con la ingeniería industrial en los planes de estudios de muchas universidades. Sin embargo, la introducción de asignaturas como estadística, probabilidad e investigación de operaciones ha dado lugar a la reducción o eliminación de la oferta de cursos en el área de ingeniería de fabricación. Cuando en la década de 1980 los productos japoneses capturaron segmentos importantes del mercado, el Gobierno y universidades de EE.UU. respondieron profundizando en la ingeniería de fabricación. En esa época, asignaturas relacionadas con los procesos de fabricación, ingeniería de fabricación, diseño de sistemas, sistemas de producción se añadieron a los planes de estudios de ingeniería industrial. 
Adicionalmente, las ciencias físicas, matemáticas, las humanidades y las asignaturas de ciencias sociales dan lugar a los 4 años de necesarios para obtener el grado. Afortunadamente, los programas no son idénticos. La inclusión o supresión de las asignaturas anteriores depende de la experiencia, la formación y los antecedentes del cuerpo docente. Algunos programas, tienden a ofrecer cada vez más cursos de gestión, de recursos humanos y de negocios y todo indica que en el futuro los planes de estudio de la ingeniería industrial van en esa dirección, aunque aún existen algunas universidades que ofrecen más cursos de procesos de fabricación, diseño y ciencias de la ingeniería (Elsayed, 1999).

En el informe de febrero de 2012 de la Oficina de Estadísticas Laborales de Estados Unidos se afirma que el número total de arquitectos e ingenieros empleados en los EE.UU. en mayo de 2010, fue de aproximadamente dos millones tres cientos mil, lo que representaba aproximadamente el dos por ciento del empleo en los EE.UU. En comparación, las dos ocupaciones más grandes, vendedores minoristas y cajeros, tenían empleados a cuatro y, tres y medio millones, respectivamente; más que todas las especialidades de arquitectura e ingeniería combinadas. Las más grandes titulaciones de arquitectura e ingeniería fueron: ingenieros civiles, con doscientos cuarenta y nueve mil empleos, ingenieros mecánicos con doscientos treinta y cuatro mil, y los ingenieros industriales con doscientos tres mil puestos de trabajo; estas tres titulaciones cubren el veintinueve coma siete por ciento de la demanda de ingenieros y arquitectos (Gráfico 2.1) (BLS, 2012).

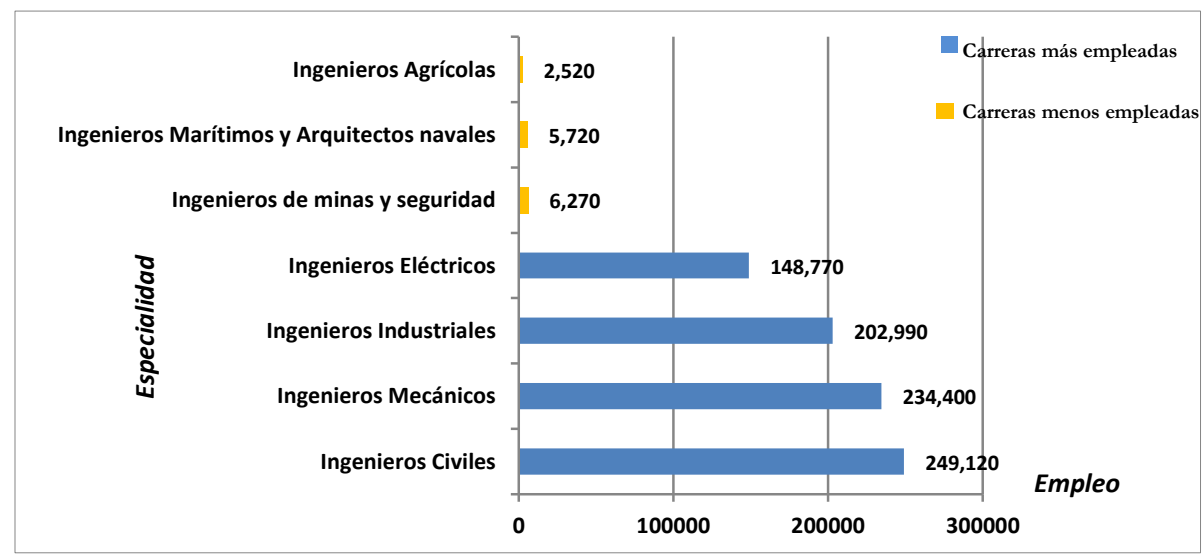

Gráfico 2.1 Empleabilidad de las especialidades de ingeniería en EE.UU. Fuente: U.S. Bureau of labor statistics (BLS, 2012). Elaboración propia.

En cuanto al ingreso medio anual en la fuerza laboral de EE.UU. a mayo de 2010, los ingenieros industriales perciben setenta y seis mil cien dólares, y la media del total de ingenieros y arquitectos es setenta y cinco mil quinientos dólares, cifra que está muy por encima de la media de todas las ocupaciones que es de cuarenta y cuatro mil cien dólares; superada solo por el salario medio para la gestión ("the management") de ciento cinco mil dólares, abogados noventa y siete mil dólares, y cómputo y matemática con setenta y siete mil dólares (Gráfico 2.2). Se espera que el empleo de ingenieros industriales crezca un seis por ciento desde 2010 hasta 2020, valor cercano y superior al promedio para todas las ocupaciones, debido a que es una ocupación 
versátil tanto en el tipo de trabajo que hace como en los sectores en los que su experiencia puede ser aprovechada (BLS, 2012).

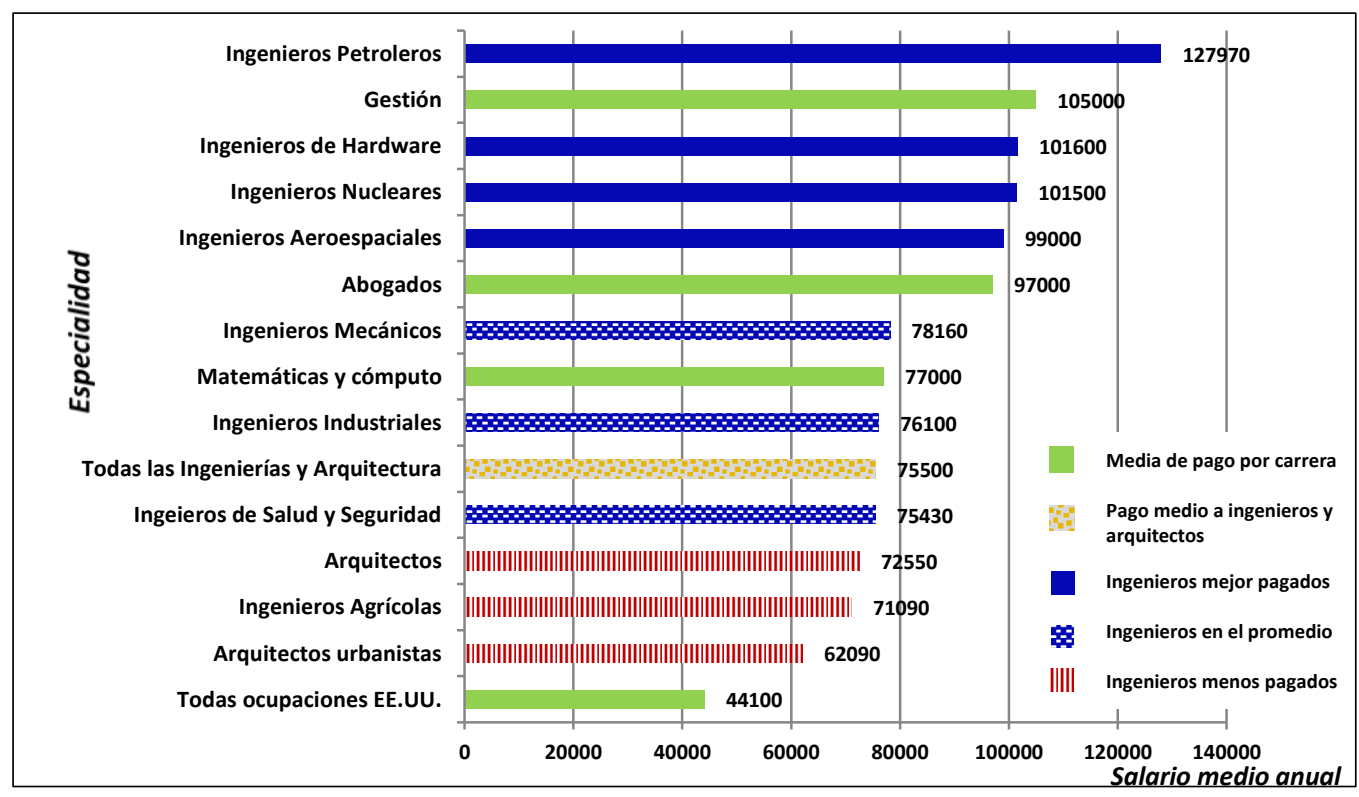

Gráfico 2.2 Sueldo medio anual en ingenierías en EE.UU.

Fuente: U.S. Bureau of labor statistics (BLS, 2012). Elaboración propia.

\subsubsection{La Ingeniería Industrial en Perú}

En Perú no se había consolidado aún el virreinato hispano, cuando surgió la primera universidad americana, "Universidad de Lima" creada por Real Cédula en 1551, llamada San Marcos desde 1574; es un caso singular en la historia de la educación, ya que en Lima (ciudad capital de Perú) de entonces, y demás ciudades peruanas, existían solo algunas escuelas elementales. Así, de un nivel de primeras letras, se dio un salto a la educación superior. La educación intermedia surgió después. La flamante institución universitaria se organizó, como se ha indicado en el capítulo anterior, con las mismas prerrogativas de la Universidad de Salamanca, y si bien cada universidad tenía sus propias normas o constituciones, su aparato académico y administrativo se guió por el modelo salmantino. Las formulaciones europeas se repetían con retraso en todas las materias, y durante el siglo XVIII San Marcos incorporó lentamente el estudio de las ciencias naturales (Robles, 2006).

La ingeniería industrial ingresó al Perú debido a las necesidades de mejora de diseño y funcionamiento de los procesos orientados a elevar la calidad y productividad de las industrias, y lo hizo con diferentes nombres. Esto motivó que las universidades de mayor importancia implementaran la enseñanza de esta nueva rama de la ingeniería, siendo el tiempo el que formalizó y unificó el nombre de ingeniería industrial en las universidades peruanas.

La primera universidad en ofrecer ingeniería industrial en el Perú fue la Universidad Nacional de Ingeniería (UNI). La Facultad nace en el año 1901 bajo el nombre de "Sección de Ingeniería Industrial", siendo la tercera sección creada en la UNI. En 1937 se cambia el nombre a "Sección de Ingenieros Químicos Industriales" y en 1946, se cambia nuevamente el nombre a 
"Departamento de Ingeniería Química Industrial". Luego, el 23 de Abril de 1959, el Consejo Universitario cambia el nombre por Facultad de Ingeniería Industrial, que rige hasta 1969, año en que se crea el Sistema Departamentalista, que hace nacer los Programas de Ingeniería Industrial y el de Ingeniería de Sistemas. Más tarde, en Abril de 1984, regresa nuevamente al Sistema Facultativo, organizándose en dos Escuelas Profesionales, la de Ingeniería Industrial y la de Ingeniería de Sistemas, el cual está vigente hasta la fecha (UNI, 2013)

La segunda universidad en instituir la carrera de ingeniería industrial en el Perú es la Universidad Nacional Mayor de San Marcos (UNMSM). En 1957 crea el Instituto de relaciones humanas y productividad, con el fin de investigar los problemas humanos más urgentes planteados por la realidad económica y social del país. El año 1960 el Instituto da lugar a la Escuela Superior de Graduados de la Facultad de Ciencias económicas, formando expertos en Relaciones públicas y publicidad, Relaciones industriales e Ingeniería Industrial de Producción y Gerencia. En octubre de 1965, se convierte en Escuela de Relaciones Industriales y Productividad. En 1969 esta Escuela se convierte en el Programa Académico de Ingeniería Industrial. Como consecuencia del cambio se estructuró el primer currículo de Ingeniería Industrial. En diciembre de 1983 se promulga la Ley Universitaria 23733 y en cumplimiento de ella la Universidad elige la Asamblea Estatutaria. En septiembre de 1984, el Programa Académico de Ingeniería Industrial se convierte en la Escuela Académico Profesional de Ingeniería Industrial integrando la Facultad de Ingeniería Industrial e Ingeniería Electrónica. Finalmente, el 7 de diciembre de 1988, la Asamblea Universitaria crea la Facultad de Ingeniería Industrial, que es la que existe hasta ahora (San Marcos, 2013).

En los años 60 varias otras universidades lanzan esta carrera tanto en la capital como fuera de ella. Estas universidades inician con el nombre ya formalizado de Ingeniería Industrial. Una de ellas es la Pontificia Universidad Católica del Perú (PUCP). La Pontificia Universidad Católica del Perú nació por iniciativa del sacerdote francés Jorge Dintilhac, de la Orden de los Sagrados Corazones, y fue autorizada por decreto supremo del 24 de marzo 1917. Comenzó con las Facultades de Letras y Jurisprudencia, que funcionaban en los mismos ambientes del Colegio de la Recoleta, de los religiosos mencionados, en el centro de Lima. En 1942 fue elevada al rango de Universidad Pontificia. Ahora cuenta con una moderna ciudad universitaria, levantada en el fundo heredado de José de la Riva Agüero y Osma, uno de sus docentes. Esta institución es tanto la primera Universidad de carácter privado como la primera fundada durante el siglo XX. La Facultad de Ingeniería inició sus actividades académicas en 1933. Un convenio de 1965 con la Fundación Ford propició un cambio significativo, pues facilitó el establecimiento de un Departamento de Ciencias Básicas que, a su vez, hizo posible incrementar la oferta de la Facultad y potenciar las áreas de Matemática, Física, Química, así como las ramas de Ingeniería Industrial, Mecánica y Minas. (Robles, Elmer; 2006).

La Universidad de Piura (UDEP) inicia el programa académico de Ingeniería Industrial en 1969 dentro de la Facultad de Ingeniería. La UDEP nace al impulso de San Josemaría Escrivá de Balaguer y es una obra corporativa del Opus Dei; se inspira en una concepción humanista y cristiana de la vida en un clima de total respeto a la libertad de los alumnos. Promueve que los egresados se distingan por su calidad humana y competencia profesional de primer nivel, traducidas en una actuación ética en el trabajo y rectitud de vida. La Facultad de Ingeniería 
incluye a los Programas académicos de Ingeniería Mecánica - eléctrica, Ingeniería Civil y Arquitectura.

Transcurridos los lustros, aparecieron nuevas universidades estatales y privadas, cuyo número se ha incrementado en forma explosiva en los últimos años. En la Tabla 2.1, puede observarse las cinco mejor clasificadas para la carrera de Ingeniería Industrial en Perú según la revista América Economía en el año 2013, también se observa las posiciones que ocuparon el año 2012. El ranking lo obtiene encuestando a los jefes de recursos humanos de las empresas que más facturan en el país y a los reclutadores de talentos, y analizando en: la percepción de calidad docente (15\%), internacionalización (15\%), investigación (25\%), empleabilidad (25\%), índice de prestigio (20\%) (América economía, 2013).

\begin{tabular}{|c|c|c|c|c|c|}
\hline $\begin{array}{c}\text { RK } \\
\mathbf{2 0 1 2}\end{array}$ & $\begin{array}{c}\text { RK } \\
\mathbf{2 0 1 1}\end{array}$ & $\begin{array}{c}\text { INGENIERÍA } \\
\text { INDUSTRIAL }\end{array}$ & $\begin{array}{c}\text { RECLUTADORES } \\
\text { Y } \\
\text { HEADHUNTERS }\end{array}$ & EMPRESAS & $\begin{array}{c}\text { ÍNDICE } \\
\text { FINAL }\end{array}$ \\
\hline 1 & 1 & $\begin{array}{c}\text { Universidad Nacional } \\
\text { de Ingeniería }\end{array}$ & 96.7 & 99.9 & $\mathbf{9 8 . 3}$ \\
\hline 2 & 2 & $\begin{array}{c}\text { Pontificia Universidad } \\
\text { Católica del Perú }\end{array}$ & 95.7 & 95.2 & $\mathbf{9 5 . 5}$ \\
\hline 3 & 3 & Universidad de Lima & 92.6 & 90.7 & $\mathbf{9 1 . 7}$ \\
\hline 4 & 4 & $\begin{array}{c}\text { Universidad Nacional } \\
\text { Mayor de San Marcos }\end{array}$ & 87.8 & 89.9 & $\mathbf{8 8 . 9}$ \\
\hline 5 & 5 & Universidad de Piura & 75.7 & 74.9 & $\mathbf{7 5 . 3}$ \\
\hline
\end{tabular}

Tabla 2.1 Sub Ranking Ingeniería Industrial, Perú Fuente: América Economía, 2013.

En sus inicios, la ingeniería industrial en el Perú no tuvo una fuerte acogida en la sociedad más allá de los desarrollos empresariales, que eran escasos. Sin embargo, al pasar los años, el mundo se iba globalizando, obligando a las pequeñas empresas a industrializase para sobrevivir en el mercado. En la actualidad la ingeniería industrial es una de las carreras más solicitadas por todo sistema y sobre todo por las empresas.

Se ha hecho un gran esfuerzo de homogenización de planes de estudios de la carrera de ingeniería industrial, pues con la autonomía universitaria cada universidad puede establecer el Plan más apropiado, según sus intereses. El Plan de cada universidad debe ser informado a los organismos del Estado, pero no existen directivas en cuanto a asignaturas o cantidad de horas por área de conocimiento, por lo que los planes difieren significativamente entre universidades.

En lo que sí hay uniformidad es que los planes tienen una duración de 5 años, con gran contenido de estadística e investigación de operaciones y también en la gestión y dirección de operaciones. Ninguno deja de lado la formación en ciencias básicas, mecánica, electrotecnia, energía y sistemas, aunque la profundidad con que se abordan varía notablemente. Algunos no contemplan la componente administrativa y organizacional y pocos muestran un serio interés en la formación humanística, social y ambiental. 


\begin{tabular}{|c|l|c|}
\hline No & \multicolumn{1}{|c|}{ CARRERAS } & PORCENTAJE \\
\hline 1 & Administración de empresas & 19,2 \\
\hline 2 & Contabilidad & 16,0 \\
\hline 3 & Ingeniería Industrial & 13,5 \\
\hline 4 & Ingeniería en informática / Sistemas & 5,8 \\
\hline 5 & Ingeniería Mecánica & 5,6 \\
\hline 6 & Economía & 5,0 \\
\hline 7 & Computación e Informática & 4,2 \\
\hline 8 & Secretariado & 3,3 \\
\hline 9 & Marketing / mercadotecnia & 3,2 \\
\hline 10 & Administración de negocios internacionales & 3,1 \\
\hline 11 & Ingeniería Electrónica & 2,6 \\
\hline 12 & Ingeniería en Alimentos & 2,5 \\
\hline 13 & Psicología & 2,4 \\
\hline 14 & Administración financiera & 2,3 \\
\hline 15 & Ingeniería Ambiental & 2,0 \\
\hline 16 & Ingeniería Civil Eléctrica & 2,0 \\
\hline 17 & Ingeniería Química & 1,9 \\
\hline 18 & Ingeniería Civil & 1,8 \\
\hline 19 & Administrción Industrial & 1,8 \\
\hline 20 & Agronomía / Agroindustria / Ing. Agrícola & 1,8 \\
\hline & & 2012 \\
\hline
\end{tabular}

Tabla 2.2 Carreras más demandadas en Perú en 2012. Fuente: Trabaja Perú, 2013

Con el fin de conocer cuáles son las tendencias laborales en el Perú en lo que va del siglo, Trabajando Perú realizó un estudio para determinar las carreras, cargos y las áreas más demandadas por las empresas en Perú. La investigación fue realizada en base a las ofertas de empleo de la comunidad laboral del país, desde enero a setiembre de 2012. El estudio evidencia que las carreras más demandadas por las empresas, se mantiene la tendencia de los últimos años, ocupando los tres primeros lugares Administración (19,2\%), Contabilidad (16\%) e Ingeniería Industrial (13,5\%). Lo anterior se explica en parte, indica el informe, porque son profesiones "versátiles", es decir, que se ajustan a distintas áreas de negocio e industria. En el cuarto lugar aparece Ingeniería de Sistemas (5,8\%), seguido de Ingeniería Mecánica (5,6\%) en el quinto. Tabla 2.2 (Trabajando Perú, 2013).

En los años anteriores, por ejemplo en 2007, el Grupo de Opinión Pública de la Universidad de Lima publica su Barómetro Empresarial, encuesta sobre la demanda de profesionales en las empresas. Esta encuesta tuvo por finalidad conocer la situación de la demanda de profesiones universitarias en las cuatro mil empresas de mayor facturación en el Perú en el 2007 según el ranking Perú: The Top 10.000 Companies of Perú (Grupo de opinión; 2007). En la encuesta se menciona que los profesionales más difíciles de encontrar son, en ese orden, ingenieros mecánicos (doce coma ocho por ciento), contadores (nueve coma seis por ciento), ingenieros industriales (siete coma seis por ciento). A la pregunta ¿qué profesional universitario demanda en mayor cantidad su empresa?, el más señalado es ingeniero industrial, con un veinte por ciento, luego administrador (diecisiete coma seis por ciento), y tercero, contador (doce por ciento). A la pregunta ¿qué profesionales universitarios cree que demandará su empresa en los próximos 10 años?, en primer lugar están los ingenieros industriales con dieciocho por ciento. A la 
pregunta ¿cuáles de las siguientes profesiones considera que son las que más necesita el país?, la primera preferencia es ingeniería industrial con quince coma seis por ciento (Grupo de opinión, 2007).

Entonces, en Perú, la Ingeniería Industrial es hoy una de las profesiones con mayor protagonismo. El ingeniero industrial peruano actual debe responder a las necesidades que le plantea el entorno empresarial y social. La responsabilidad de responder apropiadamente a la creciente demanda de ingenieros industriales en Perú, recae en las universidades, quienes deberán procurar entender el medio en el que se encuentran y los requerimientos para poder formar profesionales competentes que no se alejen de su propia esencia y que respondan a esas demandas.

\subsection{Tendencias del siglo XXI para la Ingeniería Industrial de Perú}

Desde fines del siglo XX se proclaman desde distintas fronteras la irrupción y dominio de la economía en la educación superior, y cómo los ciberespacios deshumanizarán la formación y el quehacer de los universitarios.

"Para los pregoneros de la globalización, la educación superior puede reducirse a un subsector de la economía, llamativo desde la perspectiva de los recursos involucrados y el volumen prácticamente ilimitado de su clientela. En los delirios de futuro trazados con el entusiasmo arrebatado de los tecnólatras, la educación superior será un alucinante entrenamiento perpetuo con imágenes compartidas por ciberusuarios universales, preservados de desvelos politicos, protegidos de amargos reatos de preocupación por la inequidad y la injusticia y sin primitivas sensaciones de compromiso con la sociedad" (Imbernón et al., 1999: 109).

Sin embargo, sabemos que la educación superior es más compleja y menos apocalíptica. Determinar qué dirección debe llevar la educación superior, o un plan de estudios de ingeniería industrial, en Perú no es imposible y requiere tomar en cuenta muchos aspectos, por ejemplo: el contexto mundial, las tendencias en ingeniería en el Espacio Europeo de Educación Superior y en Norteamérica así como las nacionales, entender la naturaleza del ser humano como un ser individual y social, con inteligencia, voluntad y libertad (Polo, 1993), analizar las deficiencias sociales y ambientales del entorno, conocer la demanda del sector productivo, entre otras.

En la visión del Espacio Europeo de Educación Superior sobresalen como líneas actuales y futuras claras: el aprendizaje centrado en el rol activo del estudiante, la movilidad, la relevancia del postgrado y doctorado, la acreditación, las asociaciones profesionales y la contextualización de profesionales. Esto se acompaña de la necesidad de pasar de una educación basada en la enseñanza a otra basada en el aprendizaje: en el nuevo espacio, el pregrado debe buscar que el estudiante aprenda a aprender como paso imprescindible para posibilitar el aprendizaje continuo (Suarez, 2004); consolidar el segundo nivel o posgrado con titulaciones oficiales, es un objetivo estratégico en el afán de dar relevancia al proceso formativo y de dar mayor visibilidad internacional a la educación superior en el espacio europeo; facilitar la movilidad, el desarrollo científico-tecnológico y la acreditación permite que los sistemas educativos sean vitales y contrastables; y el crédito europeo (ECTS) considera el trabajo integral del alumno dimensionándolo más allá de la sola transferencia de información. Entonces, los objetivos de 
este modelo educativo van a pivotar sobre una formación orientada a las profesiones e investigación, garantizando que se realice en un ambiente académico con sólida formación, en la que se consoliden los fundamentos técnicos, y las capacidades, aptitudes, actitudes y competencias (Zambrano et al; 2009).

Así, Europa busca su propia definición de la convergencia. El desarrollo europeo requiere de la conjunción de tecnologías diversas e intervenir en esos campos es una garantía de competitividad para la ingeniería en el Espacio Europeo de Educación Superior, que al mismo tiempo debe orientar su desarrollo hacia la mejora del funcionamiento de la sociedad. Es necesario diseñar planes de trabajo científico y técnico para enfocar mejor los esfuerzos de investigación y desarrollo, con el fin satisfacer las principales demandas sociales (Roco, M., et al; 2002). Esta convergencia debe recorrer un largo camino aún.

El cambio de dejar una educación centrada en la enseñanza por otra centrada en el aprendizaje, en Europa, requiere que los procesos educativos propicien el aprendizaje constante y perseverante del estudiante. La etapa en la que era necesario estudiar mucho durante pocos años para trabajar toda la vida ya está superada y sustituida por otra en la que es necesario estudiar toda la vida para poder trabajar. El analfabeto del siglo XXI no será quien no sepa leer y escribir sino quien no sea capaz de aprender, desaprender y reaprender (Zambrano et al, 2009).

Si observamos en el otro lado del mundo a quienes lideran los estándares de educación superior, en Estados Unidos se experimenta desde hace unos años el cambio del enfoque centrado en la práctica a uno más ligado a lo académico, a la "ciencia de la ingeniería". Aquello permitió que los graduados tuvieran marcadas capacidades técnicas, pero que estuvieran bien preparados para otras habilidades necesarias en la práctica de la ingeniería actual y en el desarrollo y gestión de tecnología innovadora. Por ello debe hacerse hincapié en el desarrollo de habilidades y capacidades generales para la ingeniería (Padros, 1998).

También debe considerarse otra parte de la realidad en Norte, Centro y Sudamérica: hay una disminución de la demanda de nuevos ingenieros en las industrias de manufactura. La investigación y desarrollo, área vista como glamorosa y que atraía a los alumnos más brillantes de ingeniería, ha ido disminuyendo su número de ofertas atractivas desde hace años. El sector de servicios ha mostrado un fuerte aumento en el número de puestos de trabajo ocupados por jóvenes ingenieros: medicina, salud, justicia, gestión empresarial, consultoría, ingeniería financiera, medio ambiente y seguridad. Algunos defienden que la educación en ingeniería debe preparar a los alumnos para la industria de manufactura, mientras que otros la consideran como preludio a carreras emocionantes. Es claro que cada vez más ingenieros trabajan en servicios que en industria.

Durante los primeros años de este siglo, en la Universidad de Princeton no más de una cuarta parte de los graduados de ingeniería tuvo su primer empleo en empresas de manufactura. La educación de los ingenieros ha sido tradicionalmente diseñada con el fin de capacitar a los estudiantes para empleos de manufactura y construcción, y los programas de estudio se diseñaron para enseñarles cómo fabricar artefactos útiles y cómo usarlos para el beneficio de la gente. Pero en las próximas décadas, las carreras de ingeniería estarán más vinculadas a los servicios que a bienes manufacturados. Los educadores de ingeniería deben reconsiderar la 
forma de educar a los estudiantes para el cambio de los mercados de los futuros puestos de trabajo. Los empleadores en el sector de servicios ya utilizan más de la mitad de todos los ingenieros por su capacidad de razonar cuantitativamente, aplicar el método científico para resolver problemas complejos, y para gestionar sistemas con múltiples objetivos y criterios. Los educadores de la ingeniería deben conservar todos los atributos positivos que son apreciados en los graduados de ingeniería por el sector servicios, pero también deberían considerar la posibilidad de aprovechar esta desindustrialización como una oportunidad para enriquecer su oferta (Wei, 2005).

Muchas de las asignaturas existentes en ingeniería industrial enseñan los conceptos y herramientas que son útiles en el sector servicios, estas deben complementarse con los desafíos que enfrentan ese sector y la resolución de sus particulares problemas. Para enseñar los conceptos y herramientas que son únicas en ese sector pueden desarrollarse otras asignaturas en la colaboración con ingenieros reflexivos del área de servicio. Los profesores de ingeniería deben formar alianzas educativas con los líderes del sector de servicios, invitándolos a dar conferencias e impartir asignaturas, y solicitar su ayuda en la creación de esas nuevas asignaturas y de materiales didácticos. Se debe empezar a pensar más ampliamente sobre "¿Cuáles son los mayores logros de nuestra profesión en formar e inspirar a nuestros estudiantes?”, en lugar de exclusivamente en "¿Cuáles son las nuevas técnicas que necesitan con mayor urgencia en sus maletines de herramientas?" (Wei, 2005).

Kevin O'Connor de la University of Rochester y otros profesores universitarios (O'Connor et al., 2008) han llamado la atención sobre la importancia de la identidad profesional como parte integral del marco para el aprendizaje de la ingeniería. Debe estimularse la escritura reflexiva sobre sus experiencias y fomentar las oportunidades de tomar decisiones, ambos son momentos únicos de estímulo de la propia identidad profesional (Eliot, M; Turns, J; 2011). En este mismo enfoque Nihad Dukhan, profesor del Departamento de Ingeniería Mecánica de la Universidad de Detroit (Dukhan, 2008), exploró el impacto de sostener experiencias aprendizaje-servicio en la formación de identidad de los estudiantes determinando que es la mejor forma de entender las necesidades sociales, mientras que Xiang-Yun profesor del Departamento de planificación y desarrollo de la Universidad de Aalborg (Xian-Yun, 2006), confirmó que una adecuada construcción de la identidad de un ingeniero se consigue en un ambiente de aprendizaje basado en proyectos.

Karen Tonso de la Universidad de Colorado-Boulder (Tonso, 2006a, 2006b) asevera la firmeza de los vínculos que existen entre la identidad del estudiante de ingeniería y el trabajo en equipo; Michael Loui del Departamento de Ingeniería eléctrica and computación de la Universidad de Illinois (Loui, 2005) vinculó la identidad profesional de ingeniería a los principios de la ética; en tanto que Downey y Lucena (2004) afirman que en la construcción de la identidad profesional las diferencias culturales ofrecen vías importantes para el entendimiento intercultural en el contexto cada vez más global para los graduados de ingeniería.

Para Larry Shuman del Departamento de Ingeniería Industrial y ex Decano de Asuntos Académicos de la Universidad de Pittsburgh, debe considerarse que la diversidad de los estudiantes: étnica, de género, racial, económica, y de discapacidad, se incrementará en los 
siguientes lustros y de hecho esta diversidad debe ser estimulada. Los estudiantes de las próximas décadas llegarán a la universidad con diferentes antecedentes y experiencias, y el contexto significativo para un estudiante puede no ser un contexto significativo para otro. El resultado de este desafío es que los formadores de ingenieros vamos a tener que trabajar más duro para asegurar que las necesidades de todos los estudiantes sean satisfechas (Shuman et al., 2002) y esto será un problema también global.

Es importante tener en cuenta, también que la tecnología y la ciencia se están desarrollando tan rápidamente que no puede enseñarse a los alumnos de ingeniería los fundamentos y resultados más recientes, así que no es posible lograr que sean capaces de saber y hacer todo lo que su profesión requiere en el momento de ejercer la profesión en un lugar determinado. Por ello es conveniente estimular el contacto internacional de alumnos en redes que les permitan saber cómo se abordan los problemas en otros países, en otras culturas. En un mundo global, como el que les tocará vivir a los actuales alumnos de ingeniería, es conveniente que tengan experiencias en las que entiendan que un problema de ingeniería no tiene una única solución, sino más bien, muchos enfoques y perspectivas distintas, y todas con soluciones eficaces y creativas (Hansen, 2004).

Cuando los estudiantes en un futuro próximo puedan elegir entre (a) asistir a las clases pasivas en determinados lugares y tiempos con un plan de estudios basado en el campus y (b) la realización de tutoriales interactivos multimedia en cualquier otro lugar y tiempo en una institución a distancia acreditada, es probable que los programas basados en el currículo tradicional que obliga a la asistencia al campus sea cada vez menos atractivo para los futuros estudiantes. El impacto potencial en los campus tradicionales que no cumplan con el reto no será agradable de contemplar (Felder et al., 2000). Deben estudiarse nuevas formas de enfrentar la presencia o ausencia del alumno en el salón de clase.

Hasta ahora, se ha creído firmemente que basta con que los graduados sean capaces de resolver problemas de diseño de ingeniería. Sin embargo, los programas de ingeniería tienen que empezar a satisfacer la creciente demanda de técnicos graduados que pongan en juego sus competencias para resolver problemas que antes se pensaba de dominio de las artes liberales. La enseñanza de la ingeniería debe continuar ampliando su alcance a las artes, las humanidades, las ciencias sociales o los negocios, tanto como los cambios tecnológicos influyan en el mercado. La enseñanza de la ingeniería de grado deberá ser más amplia, llena de estudios liberales, proporcionando a los graduados una base para estudios avanzados en ingeniería, al tiempo que abre las puertas para resolver problemas tecnológicos de ingeniería y aplicar este conocimiento a las necesidades generales de la sociedad como lo ha hecho antiguamente (Smith, Prados, 2000).

Para Charles Yokomoto, de Indiana University - Purdue University Indianapolis, los estudiantes deberán convertirse en más hábiles en los procedimientos de ingeniería básica, protocolos y métodos, pero también deberán lograr una mejor educación en las artes liberales y las ciencias sociales porque los problemas se vuelven más complejos debido a la inclusión de factores sociales y ambientales. Los profesores de ingeniería deberán tener una mejor comprensión de las metodologías de enseñanza, de cómo aprende la gente a nivel cognitivo, de la motivación del estudiante, del uso de la tecnología y de la creación de software (Shuman et al, 2002). 
La National Academy of Engineering ha publicado un informe titulado "The Engineer of 2020: Visions of Engineering in the New Century", que concluye en el resumen ejecutivo que "Los ingenieros deben adaptarse a las nuevas tendencias, y educar a la próxima generación de estudiantes armándolos con las herramientas necesarias para un mundo, que ya no será lo que es".

Con la tendencia actual de la globalización, la mayoría de los ingenieros en el curso de su carrera profesional serán requeridos para trabajar en proyectos internacionales relacionados con otras culturas y otras normas de ingeniería. La mayoría de las universidades conocen esta tendencia y se están moviendo hacia la búsqueda de una solución duradera. Parte del enfoque actual incluye la introducción en la ingeniería de los órganos consultivos, prácticas pre-profesionales obligatorias, experiencias de pasantías, la asociación con la industria, gestión de proyectos, programas de intercambio internacional y motivar a los estudiantes a tomar cursos no técnicos, de humanidades o dirección de empresas. Esto, con el fin de proporcionar estudiantes con una educación completa y tenerlos preparados para la práctica de la ingeniería mundial; su educación debe estar estructurada para proporcionar un equilibrio entre la teoría y la práctica, así como en las perspectivas globales de la ingeniería. Tiene que haber un cambio de énfasis dentro de la comunidad académica para utilizar enfoques orientados a la práctica y resaltar las necesidades de la profesión, como preparar la próxima generación de ingenieros para el mercado global. El nuevo objetivo de la ingeniería industrial debe ser satisfacer las necesidades de la industria mediante la producción de ingenieros con la técnica básica, conocimientos, habilidades analíticas, habilidades profesionales, y experiencia práctica considerada adecuada en un mundo globalizado (Jackson et al, 2010).

Cada vez más, las organizaciones consideran al potencial humano como el recurso más valioso con que cuentan, es así que el mercado laboral se caracteriza hoy día por exigir una sólida formación profesional y personal a los ingenieros. Si a esto le sumamos la característica cambiante del mercado, el papel de las universidades es todavía más significativo, pues para garantizar la competitividad de los profesionales la sólida formación académica debe ir acorde con las exigencias de este mercado cambiante (Álvarez, 2005). Dentro de este contexto las universidades necesitan retroalimentarse constantemente con las nuevas exigencias del mercado laboral y proyectarse para formar ingenieros hoy, que satisfagan las demandas del mañana.

Deben incluirse estrategias para infundir perspectivas globales en los programas de ingeniería. El apoyo institucional es necesario para que los programas puedan tener ese enfoque. Si se deja que en una universidad los profesores solos lo hagan, los esfuerzos serán menos eficaces y difíciles de mantener en el tiempo. Pueden darse las competencias técnicas y no técnicas con el balance adecuado, que junto con una exposición adecuada al mundo global, permitirá que la próxima generación de ingenieros esté bien preparada para enfrentar los retos del futuro (Jackson et al., 2010).

\subsubsection{Enfoque de una Ingeniería Industrial para el Perú}

Habiendo expuesto el trayecto de la ingeniería industrial a lo largo del tiempo y las tendencias que se están produciendo actualmente en la educación superior de ingeniería industrial marcadas 
por los modelos educativos más influyentes en la educación superior para Perú, definimos cómo debe enfocarse una ingeniería Industrial en Perú.

Primero observemos cómo está la educación superior y la ingeniería industrial en Perú.

Para Nicolás Lynch Gamero (1954 - ); licenciatura en sociología, magíster en Ciencias Sociales y Ph.D. en sociología en el New School for Social Research de New York, EE. UU.), ex Decano del Colegio de sociólogos, ex Ministro de Educación de Perú y ex Embajador de Perú, la Universidad Peruana atraviesa una crisis por una causa central: el abandono del Estado. Para él este abandono ha permitido una hipertrofia del conjunto, multiplicándose las universidades y los estudiantes, respondiéndose a la demanda por educación superior sin un proyecto y sin recursos. Afirma que dos han sido los actores en este proceso, los políticos irresponsables que han creado universidades públicas para mantener contenta a su clientela electoral y los amantes del negocio rápido que han encontrado en esta actividad un filón más para hacer dinero; el resultado es que salvo contadas excepciones hoy no se enseña, ni se investiga, ni menos se proyecta la universidad a la sociedad.

Se requiere cambiar nuestra Universidad Peruana y en este empeño, un punto primordial es la autonomía universitaria para que la institución pueda, efectivamente, cumplir sus fines. Sin embargo, aquí el actual concepto de autonomía data de la reforma de Córdoba de 1918 y se entiende como autonomía frente a un Estado Oligárquico que impedía el desarrollo de la Universidad. A esta realidad corresponde la Asamblea Nacional de Rectores (ANR), organismo coordinador director de todas las universidades peruanas, que es más representante de un colegiado que una autoridad del sistema. La realidad de la reforma de Córdoba ya no existe más y la Universidad ya no está, confrontada con el Estado, y debería buscar ser parte de la construcción de una sociedad democrática. Su autonomía no puede significar autarquía. La autonomía mal entendida ha permitido, en especial por el deterioro de los últimos años, que en las universidades públicas se desarrollen mafias expertas en usufructuar las pobrezas universitarias y que en algunas privadas proliferen las "universidades garajes" con carreras de "tiza y pizarra" para esquilmar la ingenuidad de la creciente demanda por educación superior. La ANR ha fracasado en cualquier empeño de poner orden en este concierto (Lynch, 2013).

La Universidad Peruana tiene que cambiar para establecer un nivel que la haga no solo idónea y capaz de competir, tiene que enfrentar retos hacia los cambios reconociendo los grandes errores de los últimos años. Reconociendo que actualmente existen tres tipos de universidad: la Universidad Pública, la Universidad Privada sin fines de lucro y la Universidad Privada con fines de lucro a la que hoy también denominan UNIVERSIDAD EMPRESA. Necesitamos que se asuma la necesidad de la relación de cada universidad con los requerimientos de su sociedad regional, con el país en su conjunto y con el exterior, y por ello se atreva a trascender los límites del claustro académico (Lynch, 2013).

Para el Dr. Luis Enrique Carpio Ascuña, Presidente del CONAFU (Consejo Nacional para la Autorización de Funcionamiento de Universidades, órgano autónomo), para el 2014 Perú con 140 universidades es, sorprendentemente, el segundo país con mayor cantidad de universidades en Sudamérica solo por detrás de Brasil, que posee 197 y tiene una población siete veces mayor (poco más de 200 millones de habitantes). De las 140 universidades en Perú, existen 76 que 
tienen autorización definitiva de funcionamiento; las otras 64 cuentan con autorización provisional. Sin embargo, las 140 pueden entregar títulos a nombre de la nación. Además, de todas las universidades del territorio peruano, solo siete carreras de algunas de ellas han sido acreditadas como de buena calidad por el Consejo de Evaluación, Acreditación y Certificación de la Calidad de la Educación Superior Universitaria (Coneau) hasta ahora (Monzón, 2014).

En Perú existen treinta y dos Universidades dedicadas a la formación de profesionales en Ingeniería Industrial, diez de gestión pública y veintidós de gestión privada. De estas treinta y dos universidades que enseñan Ingeniería Industrial en el Perú, catorce (44\%) se encuentran ubicadas en el Departamento de Lima (cinco de gestión pública y nueve de gestión privada). En Lima, la capital, la carrera de Ingeniería Industrial es una de las más ofertadas, pues casi la mitad de Universidades (48\%), tienen esa especialidad. Actualmente hay un incremento en el número de ingresos, lo cual hace muy competitivo el mercado laboral para estos profesionales (U. Perú, 2012).

En Perú, producto de la mal entendida autonomía universitaria existente, no hay una formal, organizada y uniforme propuesta del sistema universitario en conjunto. Esto obliga a que cada universidad establezca un modelo distinto y planes de estudios diferentes que pueden llegar a ser drásticamente diferentes. Esto determina la conveniencia de tomar como arquetipos, los modelos y tendencias europeas y norteamericanas para perfilar un modelo de ingeniería industrial apropiada en el Perú que responda a las exigencias modernas, contextualizándola a la realidad local.

La realidad de la educación superior peruana difiere diametralmente de la estaunidense pero es similar en cuanto a la mayor dedicación de los ingenieros industriales a los servicios. Desde los inicios de la ingeniería, en Europa, en Estados Unidos y Perú, los hombres y mujeres que se dedicaron a ella lo hicieron atendiendo a las necesidades del entorno, y en los tres casos, la ingeniería industrial nació por presión del entorno industrial y social, y ligada a la mecánica y la química.

Tomando esas tendencias y realidades determino que la Ingeniería Industrial en Perú deberá considerar necesario dar identidad profesional a los alumnos, que es integrar los logros de aprendizaje en aula con los acontecimientos externos locales y extranjeros. El desarrollo de la "identidad profesional" es el grado en que los estudiantes llegan a identificarse como ingenieros en su medio y es un aspecto clave del aprendizaje de los alumnos en ingeniería. Aquellos que cuenten con una mayor identificación pueden persistir más tiempo frente a la dificultad y pueden ser retenidos en la ingeniería en tasas cada vez mayores. Por lo tanto, los estudiantes deben participar de proyectos de aprendizaje en grupo y actividades como intercambios o pasantías, que son experiencias con atributos de integración de asignaturas, en un contexto profesional real.

\subsubsection{Características para un ingeniero industrial de Perú}

Para sentar las bases de un perfil apropiado para el ingeniero industrial en Perú podemos basarnos en las consideraciones hechas por Juan A. Marín-García et al, para los Ingenieros de organización españoles: 
"Entre los diferentes perfiles que se pueden proponer para el Ingeniero de Organización, hay dos interpretaciones del titulo bastante difundidas. La primera de estas interpretaciones, la gestión de operaciones, coincide con la visión del Industrial Engineering de USA, Reino Unido y Holanda y tiene una relación muy estrecha con el Manufacturing Engineer y con la rama industrial de la ingeniería. La otra visión, coincide con el Management Engineering de USA y ReinoUnido, el WirtshchaftIngenieur de Alemania o la Ingenieria Gestionale de Italia y está más asociada con la gestión y administración de empresas. Si el titulo queda enmarcado en la rama industrial, entendemos que el enfoque prioritario del título debería estar marcado por la dirección de operaciones, incluyendo algo de administración y dirección de empresas y, dejando campo para las otras visiones (gestión de la innovación o consultoría) en intensificaciones que se oferten como optatividad. Si queda enmarcado en las ciencias sociales, el enfoque prioritario sería la administración y dirección de empresas, dejando la dirección de operaciones como un complemento o como optatividad." (Marin-García et al, 2009).

En Perú, será conveniente que la formación de industriales siga el enfoque del Institute of Industrial Engineering, el British Engineering Council o el Libro blanco de titulaciones de grado de Ingeniería de la Rama Industrial, para quienes los ingenieros son capaces de analizar, modelizar, diseñar, implementar y mejorar sistemas complejos compuestos por personas, materiales, dinero, información, máquinas, tecnología y energía (ABET \& EUR-ACE, 2012), (ANECA, 2005), (Chen et al., 2005), (Elsayed, 1999), (Gallwey, 1992), (Maffioli, Augusti, 2003). Esto porque en Perú el acelerado desarrollo y crecimiento pone ante los ingenieros un panorama de complejos problemas nuevos, con recientes tecnologías, con alta variedad cultural y en tiempos cortos.

La velocidad de los cambios tecnológicos, la necesidad de actuar en ambientes multidisciplinarios y transculturales, el requerimiento de enfrentar y resolver los problemas del entorno, la inevitable contextualización de los conocimientos a la realidad, hacen que no sea suficiente dotar a los egresados de sólidos conocimientos técnicos, se les debe dotar de competencias suficientes para enfrentar los retos actuales. El dominio de competencias diseñadas para ejercer profesionalmente así como la capacidad para innovar, aportará un valor añadido suficiente para que los graduados de ingeniería industrial de Perú no caigan en obsolescencia técnica rápidamente y puedan continuar el desarrollo de habilidades laborales mediante el aprendizaje dentro de su mundo.

Para desarrollar las habilidades antes mencionadas es necesario definir un perfil profesional como el conjunto de competencias (conocimientos, habilidades, experiencias, aptitudes y actitudes) necesarias para el ejercicio de una profesión en un ámbito determinado (ANECA, 2005). Podemos distinguir entre las competencias generales, comunes para cualquier rama de la ingeniería, y las competencias específicas, propias de cada especialidad.

Así es importante considerar la división propuesta por Shuman para las genéricas: las habilidades de comunicación, trabajo en equipo, la capacidad de hacer el aprendizaje permanente y la capacidad de reconocer y resolver los dilemas éticos, y las aptitudes para la comprensión del impacto de lo global y factores sociales y el conocimiento de los problemas contemporáneos, 
llamadas como "habilidades de proceso", porque los estudiantes aprenden un proceso sólido para cada uno; por el contrario, las habilidades conductuales permiten a los alumnos aprender a ser conscientes de la importancia de cada receptor de su accionar y que los incluyan en sus actividades de resolución de problemas. (Shuman, L. et al; 2005).

Las específicas se fundamentan en las matemáticas, la física, la química, el diseño asistido por ordenador, la estadística, el derecho, la gestión de empresas, la economía, la informática, la electrónica, la mecánica, fundamentos de fluidos e hidráulica, el impacto energético y medioambiental, etc. Las competencias se concretan en el conocimiento de estas materias, además de en la capacidad para realizar mediciones, cálculos, valoraciones, tasaciones, peritaciones, estudios, informes, planos y otros trabajos análogos relacionados con la gestión de empresas y gestión de operaciones; la comunicación en contextos internacionales (mail, foros, chats, wikis, video conferencias, mooc's, redes sociales, etc.); la gestión de forma eficiente de documentos extensos (informes, memorias, dossiers y pósteres); técnicas de investigación; la gestión del conocimiento; el trabajo en equipo; el compromiso social y ético; la responsabilidad social corporativa; la comunicación interpersonal, lectura comprensiva y escucha activa; el espíritu emprendedor; el aprendizaje autónomo y el auto aprendizaje. (Canós et al., 2009).

La ingeniería, desde sus inicios, ha respondido a los requerimientos del entorno social, empresarial y ambiental. No debe renunciar a esto en el futuro, y por ello, en los programas de estudio, se deben balancear los contenidos propios del diseño de ingeniería con los de las artes liberales y humanidades, para poder armar a los egresados con herramientas que le permitan actuar en las complejas redes humanas que rodean a los problemas técnicos. Para ello, es imprescindible que un ingeniero adquiera identidad profesional, que conozca los principios antropológicos, reconozca, desde el pregrado, al hombre como el centro de todos los procesos y que contextualice su saber con la realidad del entorno. Esto requerirá de procesos formativos que construyan en los estudiantes la realidad del hombre como totalidad (unidad de la persona y de su actuar), estimulen la movilidad estudiantil, asimilen la transculturalidad, propugnen las diferencias entre alumnos y acerquen la realidad a los programas.

En otro ámbito, la tecnología cambia tan rápido y es tan abundante que los egresados de ingeniería no pueden dominar el estado del arte de su especialidad al salir de la universidad. El hombre - tecnólogo no será el que más profundamente domine un área específica, sino aquel que sea capaz de desenvolverse en un ambiente cambiante con comodidad y respetando al hombre, la sociedad y el ambiente. Los egresados deberán ser capaces de dominar las técnicas de su área mostrando competencias suficientes para gestionar los recursos asignados en ambientes propicios u hostiles.

Un programa de ingeniería industrial para el Perú de los próximos años tendrá que enfatizar la formación de competencias y habilidades más allá, y no en desmedro, del conocimiento de contenidos especializados. Los empleadores y la sociedad requieren de habilidades blandas para enfrentar los cambios acelerados, la competitividad, la tecnología y la innovación, sin embargo, no brindar la oportunidad de desarrollar competencias específicas profesionales sean fácilmente transformables en laborales a un alumno, pondrá en desventaja al egresado en a un medio exigente y cambiante. 
La ingeniería industrial ha cambiado su enfoque desde la revolución industrial, desde el hombremáquina y el enfoque tayloriano, al hombre-información, en el que todo conocimiento le es cercano. Esto corresponde a la realidad del medio pues ahora los alumnos tienen a su alcance toda información y le es posible todo conocimiento. Entonces, ya sucede que el estudiante del siglo XXI se pregunte si requiere acudir a un centro de formación universitario. La posibilidad de obtener instrucción en casa con información completa de instituciones acreditadas hace necesario evaluar la conveniencia de tener programas a distancia y si con estas se logran las competencias buscadas o si debemos potenciar el sistema actual actualizándolo a los nuevos requerimientos enfatizando en competencias y habilidades demandadas.

La ingeniería industrial moderna de Perú deberá poner atención a los aspectos mencionados en este capítulo y tendrá que hacerlo con rapidez y decisión. La posibilidad que instituciones distintas a la universitaria se acrediten y oferten esta opción de formación profesional con las características descritas, puede, en poco tiempo, atraer a los jóvenes estudiantes y llevar a un futuro incierto a la institución universitaria.

\subsection{CONCLUSIONES DEL CAPÍTULO II}

La ingeniería es una actividad no forzada, no impuesta al ser humano; es el soporte organizado y eficaz de una inclinación natural del hombre por satisfacer sus necesidades. Es justo lo contrario de la adaptación del sujeto al medio, es la adaptación que el sujeto hace del medio usando la técnica. El conocimiento de las ciencias básicas aplicado al correcto uso eficaz de los materiales y las fuerzas de la naturaleza, le han permitido atender sus crecientes necesidades, mejorando la calidad de vida de las personas; el uso incorrecto puede conducir a un detrimento de esa calidad de vida o del entorno.

Se puede afirmar que el conocimiento, los procesos, la ciencia y la técnica pueden trasladarse de un territorio a otro con posibilidades de alcanzar resultados exitosos en las nuevas regiones; como sucedió en la globalización que echó por vez primera sus raíces entre los siglos XI y XVI de China a Europa. En esas experiencias se ha verificado que las sociedades exitosas tienen más dificultad para cambiar y mantener su ventaja, y las sociedades atrasadas y con menos éxito son más propensas a adaptarse y progresar. Por esto es posible aplicar en Perú experiencias y tendencias exitosas en otros medios con altas posibilidades de éxito.

Desde sus inicios, existe una fuerte conexión entre los ámbitos universitarios europeo, latinoamericano y norteamericano, aunque las diferencias de enfoques se reflejan en los resultados de hoy. En Latinoamérica se replica el modelo de Bolonia y Salamanca, formador de profesionales dedicados a un saber hacer, y en EE.UU. el de las universidades de París y Alemania, donde se cultiva aprender a aprender y la ciencia pura en una cooperación de profesores y alumnos, y de separación de actividades. La Revolución Industrial europea le dio un impetuoso impulso a la enseñanza de las ciencias y al desarrollo de la ingeniería, que repercutió en Latinoamérica y Norteamérica.

En la historia, el desarrollo productivo, económico y social ha exigido que se generen respuestas serias de formación técnica de personas que enfrenten estos retos. La industrialización europea necesitó resolver problemas de producción masiva, de organización, de gestión, de uso de los 
recursos naturales, problemas sociales y poca consideración del hombre. Esto obligó a la creación de centros especializados para las ciencias y diversas ramas de la técnica. En el Perú de hoy, debe seguirse este proceder y establecer un modelo que responda a exigencias surgidas de esas mismas fuentes fuentes, y que debe responder la Ingeniería industrial de hoy, en lo que le competa.

La experiencia norteamericana del siglo XVIII, muestra que la acción de un ente proveedor de respaldo financiero a la educación superior técnica, es conveniente y alcanza contundentes resultados si es sostenido en el tiempo. Desarrollan un sólido enfoque pragmático: fuerte soporte a los laboratorios técnicos y la convicción que debían egresar grandes números de ingenieros con el "nivel adecuado", sin demasiada sofisticación científica ni soberbiamente inteligentes. Así, el triángulo constituido por el Estado, la Universidad y la Gran corporación, se convierte en determinante del desarrollo científico y tecnológico de los Estados Unidos. Esta experiencia que no debe pasarse por alto y remarcar la importancia de ese rol del Estado y la empresa.

El Ingeniero de Organización español es el Ingeniero Industrial (Industrial Engineer) americano y esta Ingeniería Industrial se considera básica para el desarrollo económico de una sociedad; se debe componer de cuatro áreas básicas: mecánica, eléctrica, química y de gestión de operaciones que le dan al ingeniero capacidad de: innovar, trabajar en un contexto interdisciplinar, ejercer como generalista o especialista, y adaptarse a las nuevas orientaciones y avances tecnológicos; perfil fundamental para el nuevo modelo.

Existen tópicos considerados fundamentales en la Ingeniería Industrial de Reino Unido y de EE.UU.: la investigación de operaciones, la gestión y el comportamiento organizacional; a fines del siglo se extendió a la gestión de la tecnología, gestión de operaciones, gestión de calidad y a la ingeniería de gestión, y le pone atención al ser humano amplificándose en cursos como ergonomía y factor humano, relacionados con la psicología industrial y experimental; todas, áreas de conocimiento fundamentales para una Ingeniería Industrial actual.

El modelo adoptado por el Proceso de Bolonia propone reducir las variantes existentes del modelo continental europeo encaminándose al modelo anglosajón. Hasta finales del siglo XX e inicios del XXI Europa presenta dos modelos educativos diferentes: continental o napoleónico y anglosajón o nórdico. En el primero se enfatiza en buenos cimientos de ciencias, en contenidos, y supone que las competencias necesarias se adquieren indirectamente con ellos; el proceso se centra en el profesor y la unidad de medida es el tiempo de trabajo de él, pivota en la presencia del alumno en aula y en clases magistrales muy ligadas a calificaciones profesionales. En el modelo anglosajón o nórdico, lo importante es el desarrollar los fundamentos básicos, el aprendizaje: aprender a aprender, y las competencias necesarias para la el ejercicio de la profesión; el proceso se centra en el estudiante que aplica y aprende, y la medida es el tiempo de trabajo del estudiante. Conviene tomar lo mejor de ambos sistemas para el caso peruano, encontrar un balance apropiado y plasmarlo en el modelo.

El ingeniero industrial tiene una característica diferenciadora en Europa, y es que posee una base estadística más amplia y sólida para la optimización de recursos que las otras ramas de la ingeniería. Otro objetivo europeo es dotar a la sociedad de ingenieros industriales que sean 
capaces de trabajar innovando en entornos complejos e independientes, aprovechando las tecnologías actuales y canalizando la energía de las personas a su cargo. Estas tres características deben considerarse claramente en el modelo peruano, pues son herramientas fundamentales para el desempeño laboral de los egresados.

En EE.UU. el ingeniero industrial es la persona encargada del control y la optimización de los procesos productivos, especializado en las decisiones estratégicas de preproducción, producción y posproducción. En el ejercicio del ingeniero industrial norteamericano existe la combinación de varias subdisciplinas, configurar el apropiado balance entre ellas depende del cuerpo académico y las empresas en las que obtengan su experiencia laboral. Es responsabilidad de los diseñadores de los planes de estudios lograr ese balance entre las asignaturas de "fabricación" y las de "formación" o "básicas", así como de incluir acertadamente los requerimientos de los empleadores.

Perú atraviesa un largo periodo de crecimiento económico y productivo que ha incrementado la demanda de ingenieros industriales apropiadamente formados para que respondan a las necesidades empresariales y sociales. En la actualidad la ingeniería industrial es una de las más solicitadas por el sistema laboral peruano; las encuestas muestran que en los próximos años el ingeniero industrial será uno de los profesionales más demandados. Por esto un modelo apropiado debe garantizar la idoneidad de la formación y favorecer el aumento de la retención y promoción de alumnos, para aumentar el número de egresados de buena calidad laboral.

Un buen modelo de estudios de ingeniería industrial en Perú requiere tomar en cuenta muchas variables: el contexto mundial, las políticas internacionales en currículos de nivel superior, las tendencias en ingeniería en el Espacio Europeo de Educación Superior, en Norteamérica y las nacionales, entender la naturaleza del ser humano como un ser individual y social, con inteligencia, voluntad y libertad, analizar las propias deficiencias sociales y ambientales, y conocer la demanda del sector productivo.

Deberá considerar que:

- La tecnología y la ciencia se están desarrollando tan rápidamente que no puede enseñarse a los alumnos de ingeniería todos los resultados más recientes, así que no es posible lograr que sepan y hagan todo lo que su profesión requiere al dejar las aulas ejercer la profesión en un lugar determinado; debe darse especial énfasis a lo básico.

- Del EEES podemos tomar para el modelo: el aprendizaje centrado en el rol activo del estudiante, la movilidad, la relevancia del postgrado y doctorado, la acreditación, las asociaciones profesionales, la contextualización de profesionales y el aprendizaje continuo; facilitará el desarrollo científico-tecnológico y la acreditación de los sistemas educativos; establecerá el crédito europeo (ECTS) que considera el trabajo integral del alumno estimulará y evaluará la investigación, garantizando que todo esto se realice en un ambiente académico en que se consoliden los fundamentos técnicos y las competencias.

- El sector servicios tiene un fuerte aumento en el número de puestos de trabajo y por ello se debe formar alianzas con los líderes del sector de servicios; se debe estimular la investigación y desarrollo en el pregrado y preparar a los estudiantes para el cambio: 
capacidad de razonar cuantitativamente, aplicar el método científico para resolver problemas complejos y para gestionar sistemas con múltiples variables y criterios.

- Debe dotarse de identidad profesional a los alumnos. La "identidad profesional" es el grado en que los estudiantes llegan a identificarse como ingenieros y aquellos que tengan mayor identificación pueden persistir más tiempo frente a la dificultad y pueden ser retenidos en la ingeniería en tasas cada vez mayores. Sostener experiencias de servicio social, la escritura reflexiva de sus experiencias, fomentar las oportunidades de tomar decisiones, el aprendizaje basado en proyectos, el trabajo en equipo, analizar casuística de principios de ética o experimentar las diferencias culturales entre estudiantes migrantes proporciona una adecuada construcción de la identidad de un ingeniero. Entender cómo se abordan los problemas en otros países, en otras culturas, la diversidad étnica, de género, racial, económica, y de discapacidad de los estudiantes, se incrementará, así que los formadores de ingenieros tendrán que asegurar que las necesidades de todos los estudiantes sean satisfechas: personalización.

- La enseñanza de la ingeniería debe continuar ampliando su alcance a las artes, las humanidades, las ciencias sociales o los negocios, porque los problemas serán más complejos debido a la inclusión de factores económicos, sociales y ambientales. Los nuevos planes deben dejar espacio para tomar cursos no técnicos. La ingeniería industrial peruana, deberá balancear los contenidos propios del diseño de ingeniería con los de las artes liberales y humanidades, para poder dotar a los egresados de herramientas que les permitan actuar en las complejas redes humanas que rodean a los problemas técnicos.

- No es suficiente proveer a los egresados de sólidos conocimientos técnicos, se les debe dotar de competencias específicas suficientes para enfrentar los retos actuales. Un apropiado código de competencias profesionales permitirá que los graduados del nuevo modelo de ingeniería industrial Perú no caigan en obsolescencia técnica rápidamente y puedan continuar el desarrollo de habilidades mediante nuevos aprendizaje.

- Al diseñar el nuevo modelo se debe pensar más en cuáles son las mejores formas de inspirar y encender en los nuestros estudiantes el deseo de aprender que en cuáles nuevas técnicas e instrumentos que necesitan con mayor urgencia en sus cajas de herramientas. Esto nos obliga a definir nuevas estrategias metodológicas para proyectar los procesos de enseñanza y aprendizaje.

La autonomía universitaria existente en Perú, no ha contribuido a una homogenización de planes de estudios en Ingeniería Industrial, ni a la creación de modelos a seguir en la educación superior, pues cada universidad puede establecer el Plan más apropiado, según sus intereses. La Asamblea Nacional de Rectores, que es la más alta jerarquía universitaria peruana, no tiene directivas en cuanto a asignaturas, contenidos o cantidad de horas mínimas por área de conocimiento y carrera, así los planes de estudio de una misma titulación pueden diferir drásticamente entre universidades y al no existir una formal y uniforme propuesta de formación desde el sistema universitario en conjunto, las empresas centran su atención en los egresados de pocas universidades. Entonces, convendrá elegir una universidad destacada en Ingeniería para aplicar el modelo y luego poder replicarlo en el resto de universidades peruanas que lo deseen; de encontrar resultados positivos proponerse al sistema universitario. 
Es posible definir un perfil apropiado que permita a los egresados de ingeniería industrial de Perú desempeñarse indistintamente en un ambiente profesional europeo, norteamericano y nacional, con las competencias requeridas, con habilidades profesionales y sociales, y con formación humanística suficiente para ejercer en los tres ámbitos. El modelo tendrá que enfatizar la formación de competencias y habilidades más allá, y no en desmedro, del conocimiento de contenidos especializados. No brindar a un alumno la oportunidad de desarrollar competencias específicas profesionales que sean fácilmente transformables en laborales, pondrá en desventaja al egresado en un medio exigente y cambiante.

Aunque se logre compatibilizar todas estas características en un modelo, no debe dejarse de lado que similares características pueden ofertarse desde sistemas distintos al universitario clásico y por ello deben explorarse nuevas formas de acercarnos a los alumnos. La formación profesional virtual es un complemento que debe explorarse. El impacto potencial en los campus tradicionales que no cumplan con el reto de lograr aprendizajes fuera de los claustros no será agradable de contemplar. Deben plantearse nuevas formas de enfrentar la presencia o ausencia del alumno en el salón de clase.

\subsection{REFERENCIAS DEL CAPÍTULO II}

Abarca Fernández, Ramón. (2007). Modelos pedagógicos, educativos, de excelencia e instrumentales y construcción dialógica. Universidad Católica Santa María. Perú. pp 8.

ABET; EUR-ACE. (2007). Criteria for Accrediting Engineering Programs. Engineering Accreditation Commission.abet. U.S.A.

Alvarez, María. (2005). Panorama laboral Del ingeniero industrial egresado de universidades ubicadas en el departamento de Lima - Perú. Tesis de grado. Universidad Nacional Mayor de San Marcos. Perú.

América economía. (2013). Ranking 2013 Perú: las mejores universidades. América economía http://rankings.americaeconomia.com/mejores-universidades-peru-2013/ingenieriaindustrial/. Visitado por última vez el 22 -05-2014

ANECA. (2005). Ingeniero De Organización Industrial. Libro blanco de titulaciones de grado de ingeniería de la rama industrial: Capítulo V. http://www.aneca.es/ activin/activin_conver_LLBB_indus.asp.

Ashby, Erick; 1958. Technology and the academics: An essay on universities and the scientific revolution. Última edición Macmillan, Londres y Nueva Yorew York). ID: 101-188-916.

BLS (2012).

Canós, Lourdes, García, José; García, Julio; Marin. (2009). Competencias profesionales y perfil del Ingeniero de Organización ante el Espacio Europeo de Educación Superior. Actas del Congreso. IV Congreso Cibersociedad, 2009. Visitado por última vez en junio de 2013 http://www.cibersociedad.net/congres2009/es/coms/eixos/ 
Chen, C.; Jiang, B. C.; Hsu, K. (2005). An empirical study of industrial engineering and management curriculum reform in fostering students' creativity. European Journal of Engineering Education, 30 (2): 191-202.

Cotterell, Arthur .2000. Historia de las civilizaciones Antiguas. Tomo 1. Editorial Crítica, Provenza. Barcelona.

De Miguel Fernández, E., (2005). Introducción a la gestión (management).Valencia: Editorial de la Universidad Politécnica de Valencia. ISBN 8497057503

Downey, G., \& Lucena, J. (2004). Knowledge and professional identity in engineering: Codeswitching and the metrics of progress. History and Technology, 20(4), 393-420.

Dukhan, N. (2008). Implementation of service-learning in engineering and its impact on students' attitudes and identity. European Journal of Engineering Education, 33(1), 21-31.

Eiroa, Jorge J. (1994). La prehistoria: paleolítico y neolítico. Ediciones Akal. Madrid

Eliot, Matt; Turns, Jennifer. (2011). Constructing Professional Portfolios: Sense-Making and Professional Identity Development for Engineering Undergraduates. Journal of Engineering Education. October 2011, Vol. 100, No. 4, pp. 630-654

Elsayed, E.A... (1999). Industrial Engineering Education: A Prospective. European Journal of Engineering Education, volumen 24, $\mathrm{N}^{\circ}$ 4, pp. 415-421.

Escobar, Jaime. (1999). Historia de las universidades. Revista Medicina. Academia Nacional de Medicina de Colombia. Vol. 21 No. 1 (49), Marzo 1999.

Felder, RM; Woods, DR; Stice JE; Rugarcia, A. (2000). The Future of Engineering Education II: Teaching Methods that Work. Chemical Engineering Education, v. 34, 1: 26-39.

Figuera, Juan Ramón, 2007. Análisis del pasado de la Ingeniería de Organización en España para mantener su competitividad en el futuro. International Conference on Industrial Engineering \& Industrial Management - CIO 2007. Innovation in Education and Professional Skills p.p 931- 940.

Gallwey, T. J. (1992). Europe needs Industrial Engineering degrees in order to enhance its conpetitiveness. European Journal of Engineering Education. 17(1): pp. 51-57.

García Borrajero, N.H. (2010). Breve cronología del conocimiento científico-técnico desde la antigüedad hasta la ingeniería industrial. Contribuciones a las Ciencias Sociales, octubre 2010. www.eumed.net/rev/cccss/10/

González Prats, Alfredo. (1991). "La edad del cobre en Mesopotamia (5500-3000 aC)". Universidad de Alicante. España.

Grupo de opinión. (2007). Encuesta sobre demanda de profesionales en la empresa. Grupo de opinión pública de la Universidad de Lima. Setiembre octubre 2007. http://www.ulima.edu.pe/webulima.

Nsf/default/4BE58345536E

B3BC05256E630017BCED/\$file/bemp9.pd 
Hansen, Joergen. (2004). International Engineering Students in Cross-cultural, Interdisciplinary Teams. International Conference on Engineering Education and Research "Progress through Partnership". Ostrava, pp 523 - 527.

Hicks Philips E. (2002) Ingeniería industrial y administración. CECSA, Editorial 27. México, Distrito Federal:

Hobsbawn, Erich (1994). The age of the extremes. History of de world, 1914 - 1941. Pantheon books. New York. USA.

Hobsbawn, Erich (1996). The age of the capital. 1848 - 1875. Vintage books. New York. USA.

IIE. (2011). Visitado en abril 2012. http://arisecenter.eng.fiu.edu/iie_latino/.

Imbernón, F.; et al. (1999). La educación en el siglo XXI. Los retos del futuro inmediato. 1999. Biblioteca de Aula, Barcelona, págs. 101 - 114]

Jackson, H.; Tarhini, K.; Zapalska, A.; Zelmanowitz, S. (2010). Strategies to Infuse Global Perspectives and Industrial Collaboration in Engineering Education. 40th ASEE/IEEE Frontiers in Education Conference. October2010 Washington, DC

Kaplan, Marcos (1996). Universidad nacional, sociedad y desarrollo. Asociación nacional de universidades e instituciones de educación superior, ANUIES. Dirección de servicios editoriales. México. ISBN 968-6297-98-7

Lynch, N. (2013). La autonomía universitaria. Otra mirada. Página web http://www.otramirada. pe/content/la-autonomía-universitaria, visitada por última vez el 20-05-2014.

Lockard, Craig A. (2010). The sea Common to All: Maritime frontiers, Port cities, and Chinese Traders in the Southeast Asian Age of Commerce, ca. 1400-1750. Journal of World History, Jun2010, Vol. 21 Issue 2, pp. 219-247.

Loui, M. C. (2005). Ethics and the development of professional identities of engineering students. Journal of Engineering Education, 94(4), 383-390.

Maffioli, Francesco; Augusto, Giuliano. (2003). Tuning engineering education into the European higher education orchestra. European Journal of the Engineering Education.

Marín -García, J.A.; Garcia-Sabater, J.P.; Miralles, C.; Rodríguez, A.; Andrés, C., (2008), La Ingeniería de Organización en un entorno educativo globalizado: reflexiones y propuestas para la Universidad Española. II International Conference on Industrial Engenieering and industrial management. XII Congreso de Ingeniería de Organización. Burgos, pp. 817-826.

Marin-Garcia, J.; Garcia-Sabater, J; Perello-Marin, R; Canos-Daros, L. (2009). Propuesta de competencias para el Ingeniero de Organización en el contexto de los nuevos planes de estudio. Intangible Capital, 2009

Markes, I. (2006). A review of literatura on employability skills needs in engineering. European Journal of Engineering Education. 31(6): pp 637-650.

Martinez, C.; Calvet P., D.; Pons, O.; Tura, M.; (2007). Inserción laboral de las titulaciones de la subárea de tecnologías avanzadas de producción. International conference on Industrial 
engineering and Industrial Management. II International Conference on Industrial Engenieering and industrial management. XII Congreso de Ingeniería de Organización. Burgos, pp 985-992

Mereddu Torres, César (2006). Pragmatismo, ética y carrera académica en la educación superior. Reencuentro 45, México. Pp. 8-16

Monzón, Ricardo. (2014). Perú segundo país de Sudamérica con más universidades. http://peru21.pe/noticias-de-conafu-105859?href=nota_tag, visitado el 20-05-2014

NCSES, (2012). National Center for Science and Engineering Statistics. Science and Engineering Degrees: 1966-2008. Detailed Statistical Tables NSF 11-316. National Science Foundation, 2011. Arlington, Virginia, USA.

NRC (1985). National Research Council. Engineering Education and Practice in the United States. National Academy Press. Washington DC.

O’Connor, K., Amos, D., Bailey, T., Garrison, L., Lichtenstein, G., Loshbaugh, H., \& ... Stevens, R. (2007). Sponsorship: Engineering's tacit gatekeeper. Proceedings of the 2007 American Society of Engineering Education Conference, Honolulu, HI.

Ortega y Gasset, José. (1964) Meditación de la Técnica. Obras Completas; Revista de Occidente, Madrid, 1964, 6 a ed., Vol. V, p. 304.

Paoli, Ugo Enrico. (1944). La vida en la Roma antigua. Iberia. Barcelona. España.

Polo, Leonardo. (1993). Quién es el Hombre. Servicio de Publicaciones de la Universidad de Piura. p. 112. Primera edición.

Prados, John. (1998). Engineering Education in the United States: Past, Present, and Future. International Conference on Engineering Education. Proceedings of ICEE’98, pp. 17 - 20.

Rivero García, Luis (2005). El crédito ECTS y la nueva estructura universitaria. Comisión Andaluza para el EEES. Universidad de Cádiz.

Robles O., Elmer (2006). Origen de las universidades más antiguas del Perú. Revista Historia de la Educación Latinoamericana, año 2006, vol. 8; pp 35-48. Universidad Pedagógica y Tecnológica de Colombia

Roco, Mihail; Tomellini, Renzo. (2002).Revolutionary Opportunities \& Societal Implications. 3rd Joint EC - NSF Workshop on Nanotechnology. Istituto Nazionale per la Fisica della Materia. Lecce (Italy), February 2002.

Romero, F. (2003). El perfil del ingeniero industrial generalista en el nuevo espacio europeo. Jornada: El Ingeniero Superior Industrial en el Nuevo Espacio Europeo. Universitat Jaume I. Mayo 2003. http://www.cinei.uji.es/estud_ perfil/docs/Jornada16mayo/Presentacion \%20F.Romero.pdf

Romero H., Omar; Muñoz, David; Romero H., Sergio (2006). Introducción a la ingeniería. Un enfoque industrial. International Thompsom editores. México. ISBN 9706865551 
San Marcos, 2013. Universidad Nacional Mayor de San Marcos. Facultad de Ingeniería Industrial. http://industrial.unmsm.edu.pe/es.resena_historica.php Visitado el cinco de junio de 2013.

Saravia G., Ana María; Amorim, Luisa F. (2009). Influencia de la ingeniería en el desarrollo comercial de la humanidad. Edad antigua. Revista Lámpsakos. Fundación universitaria Luis Amigó. No 2, 2009, págs. 79-89. ISSN 2145-4086.

Sarton, George. (1970). Historia de la ciencia: la ciencia antigua durante la edad de oro griega. Vol. 1. Eudeba.

Shuman, Larry J.; et al. (2002.) The future of engineering education. 32 ${ }^{\text {nd }}$ ASEE/IEEE: Frontiers in Education Conference. November 6 - 9,2002, Boston.

Shuman, Larry J.; et al. (2005.)The ABET Professional Skills - Can TheyBe Taught? Can They Be Assessed? Journal of Engineering Education, 94(1), pp. 41-56, 2005.

Smerdon, E., (2000). An Action Agenda for Engineering Curriculum Innovation. 11th IEEEUSA Biennial Careers Conference, San Jose, Cal., Nov. 2 and 3, 2000. Visitado por última vez en junio de 2013, http://www.ieeeusa.org/careercon/proceeding/esmerdon.pdf.

Smith, K.A.; Prados, JW. (2000) Academic Bookshelf. Journal of Engineering Education, v. 89, 4, October, 2000.

Suarez A., B. (2004). Las enseñanzas técnicas del espacio europeo de educación superior. Universidad Politécnica de Cataluña. http://www.porto.ucp.pt/feg/bolonha/docs/ Reflectir_bolonha/sems/c1/01_bs.pdf

Tonso, K. (2006a). Student engineers and engineering identity: Campus engineer identities as figured world. Cultural Studies of Science Education, 1(2), 273-307.

Tonso, K. (2006b). Teams that work: Campus culture, engineer identity, and social interactions. Journal of Engineering Education, 95(1), 210-229.

Trabajando Perú, 2013. Tendencias en el mercado laboral peruano en el 2012. htpp://trabajando.com/peru/382-tendencias-en-el-mercado-laboral-peruano-en-2012. trabajando.com. Revisado el 27 de mayo de 2013.

UNI, 2013. Universidad Nacional de Ingeniería. Facultad de Ingeniería Industrial y de Sistemas. http://www.uni.edu.pe/sitio/academico/facultades/industrial/. Visitado el cinco de junio de 2013.

UNIVERSIA, 2013. http://estudios-internacionales.universia.net/uk/sistema-educativo/ estructura.html. Consultado el 25 de mayo de 2013.

U. Perú: Universidad Perú, 2012. http://www.universidadperu.com/ingenieria-industrialperu.php Consultada en abril de 2012.

Uva: Universidad de Valladolid, 2010. Graduado en Ingeniería de Organización Industrial. Escuela de Ingenierías Industriales, Versión 2, 2010.7 - 9. Programa Verifica - ANECA.

Valcárcel, Carlos Daniel (1975). Historia de la educación. Lima. Editorial Educación, p 88. 
Wei, James. (2005). Engineering education for a post-industrial world. Technology in Society. Elsevier Ltd. Vol. 27 pp. 123-132.

Xiang-Yun, D. (2006). Gendered practices of constructing an engineering identity in a problem based learning environment. European Journal of Engineering Education, 31(1), 35-42.

Zambrano, J.; Velázquez, Rodrigo; Sáenz Fabiola. (2009). Tendencias de la educación en ingeniería. Avances investigación en ingeniería. Revista del Centro de Investigaciones. Facultad de Ingeniería de la Universidad Libre.

Zambrano, S. y Alvarado, F. (2011). Surgimiento y evolución de la ingeniería industrial. Revista In Vestigium Ire. Vol 4, 19-28 
Capítulo III

Estudio comparado de las competencias genéricas para ingeniería en el ámbito internacional: una contextualización y método de aprendizaje para Perú 


\section{INDICE CAPITULO III}

Capítulo III

¿Error! Marcador no definido.

3.1 INTRODUCCIÓN DEL CAPÍTULO III ¡Error! Marcador no definido.

3.2 Las Competencias Genéricas en el Ámbito de la IngenieríA ¡Error! Marcador no definido.

3.2.1 Competencias Genéricas en la Enseñanza de la Ingeniería. ¡Error! Marcador no definido.

3.2.2 Codificaciones ABET y CDIO ¡Error! Marcador no definido.

3.2.3 Codificación IPMA ¡Error! Marcador no definido.

3.2.4 Codificación TUNING América Latina. ¡Error! Marcador no definido.

\subsection{COTEJO DE CODIFICACIONES INTERNACIONALES DE COMPETENCIAS} GENÉRICAS EN EL ÁMBITO DE LA INGENIERÍA. ¡Error! Marcador no definido.

3.3.1 CDIO - ABET ¡Error! Marcador no definido.

3.3.2 Comparación CDIO - IPMA. ¡Error! Marcador no definido.

3.3.3 Comparación TuningAL - IPMA. ¡Error! Marcador no definido.

3.3.4 Selección de competencias genéricas para la Ingeniería en Latinoamérica ¡Error! Marcador no definido.

3.4 MÉTODOS DE ENSEÑANZA-APRENDIZAJE DE COMPETENCIAS GENÉRICAS EN EL ÁMBITO DE LA INGENIERÍA ¡Error! Marcador no definido.

3.4.1 Métodos existentes. ¡Error! Marcador no definido.

3.4.2 Estrategia de aplicación de métodos a la Ingeniería Industrial de Perú. ¡Error! Marcador no definido.

3.5 Conclusiones del Capítulo III ¡Error! Marcador no definido.

3.6 Referencias del capítulo III ¡Error! Marcador no definido. 


\section{INDICE DEL TABLAS CAPITULO III}

Tabla 3.1 Criterios ABET para Estudiantes que Terminan Ingeniería........................................................132

Tabla 3.2 Objetivos de Primer y Segundo Nivel del Syllabus CDIO. .......................................................135

Tabla 3.3 Elementos de Competencia de IPMA.........................................................................................138

Tabla 3.4 Listado de Competencias Genéricas Acordadas para América Latina......................................139

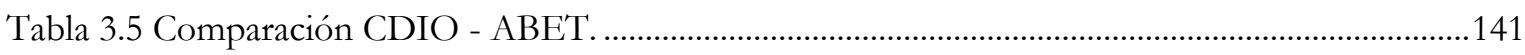

Tabla 3.6 Resultado de comparación de los elementos de competencia IPMA - CDIO.........................143

Tabla 3.7 Comparación entre competencias genéricas de Tuning - América latina y los elementos de

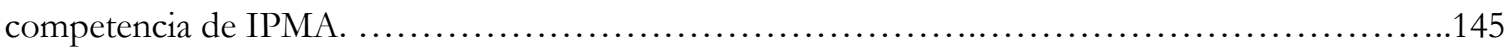




\section{INDICE DE GRAFICOS CAPITULO III}

Gráfico 3.1 Fases del modelo de aprendizaje cíclico de cinco etapas. 147

Gráfico 3.2 Implicación de las competencias. 148 


\subsection{INTRODUCCIÓN DEL CAPÍTULO III}

En los capítulos uno y dos se ha dejado establecido que en el mundo los sistemas universitarios mutan, migran, influyen unos sobre otros y tienden a la convergencia; que la formación en ingeniería sigue ese derrotero y que el gran desafío de formar ingenieros es lograr que tengan la base técnica y las competencias necesarias para enfrentar los retos de las próximas décadas en un mundo globalmente competitivo.

En este tercer capítulo se plantean tres objetivos: E1 primero es distinguir los códigos de competencias holísticas que permitan a los alumnos de ingeniería desarrollar competencias aceptadas internacionalmente. El segundo objetivo es detectar el código de competencias genéricas para la ingeniería Industrial de Perú que incluya las tendencias europea, americana y latinoamericana para favorecer la movilidad y correspondencia de titulaciones, el dominio de conocimientos técnicos, la identidad profesional, las habilidades sociales de relación con el entorno, la gestión de proyectos y la inserción laboral . Un tercer objetivo es encontrar una estrategia de aplicación de metodologías de aprendizaje que facilite la adquisición de esas competencias en el contexto peruano.

La hipótesis de inicio es que puede encontrarse una codificación de competencias genéricas que favorezca el desarrollo de competencias profesionales en los alumnos de ingeniería en el contexto peruano y que existe una metodología apropiada que facilita su aprendizaje.

La metodología de investigación empleada en la primera y segunda parte ha sido realizar revisiones bibliográficas de fuentes primarias para conocer el estado del arte de las codificaciones de competencias propuestas para el ejercicio y formación de competencias. Se compararon, y luego de procesos de análisis lógico inductivos e hipotético deductivos, se establecieron generalizaciones aplicables a un caso real. Se ha seguido un proceso de análisis y síntesis para lograr definir una codificación apropiada en la formación de ingenieros en Latinoamérica, teniendo en cuenta los objetivos de aprendizaje de Europa, EE.UU. y Latinoamérica. En la tercera se hará una búsqueda del estado del arte de las metodologías más empleadas y se seleccionará las que mejores resultados muestren de acuerdo a la experiencia disponible.

El capítulo se divide en tres grandes bloques: el primero es definir $\mathrm{r}$ las codificaciones de competencias genéricas para la ingeniería en al ámbito internacional. En el segundo bloque se comparan estas codificaciones y se selecciona las que mejor se pueden aplicar a la enseñanza de la Ingeniería. El tercero es proporcionar una estrategia de aplicación de métodos apropiados para la adquisición de estas competencias durante el proceso de formación superior en una ingeniería.

La primera parte, clarifica que las competencias holísticas son el mejor tipo de codificación para la formación en educación superior y se hace una revisión exhaustiva de las codificaciones de competencias genéricas más saltantes en Europa, EE.UU. y Latinoamérica (IPMA, Tuning, CDIO, ABET y TuningLA). En la segunda parte se determina que la más apropiada es Tuning para Latinoamérica y a con ella es que se construirá el modelo para la formación de Ingenieros Industriales de Perú. 
En conclusión, puedo afirmar que sí existe una codificación de competencias genéricas aplicable en Perú para la formación de ingenieros con el perfil descrito y que las metodologías más apropiadas para conseguir pertinentes logros de aprendizajes significativos son el Aprendizaje Basado en Proyectos y el trabajo en equipos, sin dejar de lado la Clase Magistral y la Resolución de Ejercicios y Problemas.

Los siguientes capítulos se abocarán establecer el modelo más apropiado para la formación de ingenieros industriales en Perú, a contextualizar estas competencias genéricas TuningAL al Perú, consolidar una propuesta de competencias específicas, y concluir con una aplicación del modelo.

\subsection{LAS COMPETENCIAS GENÉRICAS EN EL ÁMBITO DE LA INGENIERÍA}

Es importante recalcar, como se desprende de los capítulos anteriores, que desde mayo de 1998 en la Unión Europea (UE) se propuso un 'Espacio Europeo de Educación Superior' (EEES) a través de la llamada Declaración de La Sorbona, y un año más tarde, en junio de 1999, firmaron el Tratado de Bolonia los ministros de educación de 29 países de la UE y actualmente es respaldado por 47 de ellos: Alemania, Albania, Andorra, Antigua República Yugoslava de Macedonia, Armenia, Austria, Azerbaiyán, Bélgica, Bosnia y Herzegovina, Bulgaria, Croacia, Chequia, Chipre, Dinamarca, Eslovaquia, Eslovenia, España, Estonia, Finlandia, Francia, Georgia, Grecia, Hungría, Irlanda, Islandia, Italia, Kazajstán, Letonia, Liechtenstein, Lituania, Luxemburgo, Malta, Moldavia, Montenegro, Países Bajos, Noruega, Polonia, Portugal, Rumanía, Rusia, Santa Sede, Serbia, Suecia, Suiza, Turquía, Ucrania y Reino Unido (CE IP/12/394, 2012). El EEES propone algunas interesantes pautas en el accionar educativo de sus estados miembros:

El EEES propone una nueva metodología de enseñanza-aprendizaje e invita a la implantación de un modelo basado en el desarrollo de las competencias. La finalidad es dotar a los alumnos de unas competencias que les permitan seguir aprendiendo y encontrar por sí mismos los caminos del conocimiento y la resolución de problemas. Igualmente, busca proporcionar una educación técnica $y$ dotar de una capacitación a los futuros profesionales, dotándoles de habilidades combinables que sirvan tanto para la esfera académica como laboral. La educación por competencias, además de reconocer el resultado de los procesos escolares formales, también reconoce los conocimientos, habilidades y destrezas adquiridos fuera de las aulas. Entonces, el llamado Proceso de Bolonia se convierte en una gran oportunidad para mejorar la calidad de las universidades y la actividad docente en Europa (Sierra \& Cabezuelo, 2009).

La realidad que enfrentan los egresados europeos de la educación superior es muy compleja y requiere de estrategias y acciones eficaces. Para fines del año 2013 la tasa de desempleo juvenil se acercó al $23.7 \%$ en toda la Unión Europea y, sin embargo, existían más de uno coma siete millones de puestos de trabajo que no pudieron cubrirse. Europa se replantea de forma radical cómo los sistemas de educación y formación pueden proporcionar las capacidades que necesita el mercado de trabajo. Este reto presenta la máxima dificultad en el contexto de las medidas de austeridad y los recortes en los presupuestos de educación (European Comission, 2014). 
La Comisión Europea ha puesto en marcha una nueva estrategia, denominada Replantear la Educación, para animar a los Estados miembros a que tomen medidas inmediatas destinadas a garantizar que los jóvenes desarrollen las capacidades y competencias necesarias para el mercado de trabajo y para alcanzar sus objetivos en materia de crecimiento y empleo. La estrategia Replantear la Educación aboga por un cambio fundamental en la educación, con una mayor focalización en los "resultados de aprendizaje", es decir, los conocimientos, las capacidades y las competencias que adquieren los estudiantes. Ya no basta con haber estudiado satisfactoriamente durante un tiempo determinado, se debe desarrollar competencias concretas; deben mejorarse notablemente o reforzarse las competencias de emprendimiento y la capacidad de iniciativa. En definitiva, lo importante es dotar al alumno de unas competencias para la solución de problemas específicos más allá de dotarle solo de una preparación teórica y práctica que no le capacite para salir airoso de retos académicos y profesionales. Se trata de hacerle capaz ante las circunstancias de la vida laboral que le espera -con suerte- a la salida de las aulas. Del mismo modo, se espera que el alumno pueda compaginar formación y vida laboral. De hecho, el EEES considera acertadamente que la formación debe ser constante y se produce a lo largo de la vida (long-life learning) (CE IP/12/1233, 2012).

Todo indica que es indispensable formar en competencias, pero ¿de dónde vienen? ¿Qué son? ¿Cómo se organizan? ¿Cómo podemos abordarlas?

Hablar de competencia se ha convertido en una práctica usual y su aplicación al ámbito educativo parece fácil y automático, casi espontáneo, pues desde hace algún tiempo muchos las "aplican". Sin embargo, se encuentra que no se sabe mucho de ellas y su acometida en la educación superior ha traído tropiezos a docentes ya alumnos. Al indagar sobre ellas se descubren diferentes acepciones que responden a sendos enfoques. Se establecen definiciones de competencias desde el lugar de trabajo, el ámbito cognitivo, la motivación, el comportamiento empresarial, constructivista, humanista, holístico y laboral, unas más completas que otras (Guerrero et al.; 2013).

El colofón de la revisión de las diferentes definiciones de competencias, desde cada uno de sus enfoques, es que más allá del matiz específico que quiera dárseles, las competencias son un conjunto de elementos que integran los conocimientos, habilidades y valores, que vinculan los aspectos cognitivos, procedimentales y actitudinales que se esperan de una persona, en la búsqueda de desempeños eficientes relacionados a un entorno y campo laboral específico; entendida así es claro que un código de competencias debe ser integral e integrador.

De entre todos los enfoques es el holístico el que mejor refleja este carácter integral e integrador, "el enfoque holístico define la competencia como el resultado de una mezcla de aspectos personales subyacentes, como son la comunicación, el auto desarrollo, la creatividad, el análisis y resolución de problemas, a las cuales se denomina meta competencias, que son las que permiten la existencia de competencias cognitivas, funcionales, comportamientos y valores éticos que en su conjunto determinan la competencia profesional" (De los Ríos I. et al. 2008). Además, "el enfoque holístico de las competencias, considera la complejidad en la integración de conocimientos, habilidades, destrezas y la comprensión que realiza el individuo permitiéndole un desempeño exitoso. Incorpora la ética, los valores y la práctica reflexiva como elementos de un desempeño competente. El enfoque holístico es el menos reduccionista de 
Los modelos estudiados y analizados y contiene aspectos esenciales que facilitan su aplicación directa a las competencias profesionales". La aplicación directa de este enfoque a las competencias profesionales se observa en las condiciones y resultados de aprendizaje: personas críticas y reflexivas, aprendizaje significativo e innovador en condiciones de colaboración, coprotagonismo de quien aprende y enseña, desarrollo de competencias fundamentales, trasferibles y transversales, entre otros.

Sin duda puede afirmarse que "en la sociedad del conocimiento del nuevo milenio el perfil de un buen ingeniero debe basarse en la capacidad y voluntad de aprender, el conocimiento sólido de las ciencias naturales básicas y el buen conocimiento de algún campo de la tecnología, además de los valores humanos generales. Por otra parte, tiene que estar preparado para el aprendizaje permanente y también debe poseer una buena comunicación y trabajo en equipo. Las competencias técnicas no son suficientes en el mundo actual" (Maffioli, Giuliano; 2003). Esto convierte al enfoque holístico en el más apropiado para la codificación de competencias para titulaciones en la educación superior, incluso en las ingenierías.

Los modelos de competencias en general agrupan las competencias en al menos dos tipos: básicas, genéricas, laborales o transversales, y específicas. Las definiciones de estos tipos son (Díaz Barriga, 2006):

- Las competencias básicas, genéricas, transversales o laborales, también llamadas core skills, generic skills, professional skills, key competences, basic skills son las que permiten el ingreso al mundo laboral por lo que deben identificarse entre el sistema universitario, la empresa y la sociedad. Es lo que los empleadores consideran como requisitos mínimos necesarios no solo para el desempeño de una ocupación u oficio, sino, y prioritariamente, para desenvolverse adecuadamente en los espacios sociales y ciudadanos donde se encuentre. Aportan las herramientas demandadas por un trabajador profesional para enfrentarse a los problemas del mundo en el que se desenvolverá y poder darles solución, nueva o no.

- Las competencias específicas, son las definidas para el desempeño de una profesión o especialidad en concreto; están relacionadas con los puestos de trabajo y sus funciones y deben aportar los conocimientos, actitudes, habilidades y valores propios de cada profesión o actividad. En la educación superior se definen entre el centro de estudios y los empleadores.

Las competencias básicas o genéricas sirven fundamentalmente para definir los perfiles de egreso, las determinan las características que debe tener un profesional en un contexto, por lo que deberán ser definidas en primer término. Las específicas se requieren para una especialidad, por lo que se deben trabajar en el diseño del currículo, posteriormente.

Así, se convierte en una necesidad definir un cuerpo de competencias genéricas apropiado para emprender el diseño de un modelo educativo profesional universitario, pues sin él el alumno no podrá lograr la formación que la sociedad actual le requiere. En cambio, una correcta definición ofrecerá la posibilidad de una formación en la que los alumnos podrán obtener aprendizajes que no solo sirvan para conocer, resolver y comprender, sino también para 
comportarse de manera adecuada frente a los problemas que se suscitan en un contexto determinado.

Muchas listas de habilidades necesarias o competencias han sido propuestas: por ejemplo, por la norteamericana Accreditation Board of Engineering and Technology (ABET). Listas que son válidas para los ingenieros de ciclo corto y ciclo largo, y que presentan ponderaciones apropiadas (y diferentes) a cada competencia. Todas ellas consideradas por sus autores como listas de competencias "indispensables" para los profesionales de la ingeniería (Maffioli, Giuliano; 2003).

En las siguientes páginas se analizarán codificaciones de competencias que, desde un enfoque holístico, permitan elegir la lista de competencias más apropiada para una carrera de ingeniería. Luego, se comparará este listado con las competencias definidas para para los egresados de la educación superior de América Latina, posibilitando la selección de una apropiada lista de competencias genéricas para la formación profesional de ingenieros en América Latina.

\subsubsection{Competencias Genéricas en la Enseñanza de la Ingeniería.}

En esta sección se describen las necesidades de competencias que muestra el contexto de la práctica profesional de ingeniería y las codificaciones de competencias más empleadas en la actualidad.

Desde hace dos décadas, los académicos se han empeñado en reformular los objetivos de la enseñanza en ingeniería para vigorizar la relación universidad - empresa. Pister (1993) propuso que los objetivos de la enseñanza de la ingeniería deben incluir la adquisición de conocimientos, desarrollo de la comprensión, y la adquisición y aplicación de habilidades. Estos objetivos pueden ser descritos desde el desarrollo de la competencia técnica, la comprensión de la práctica de la ingeniería como un emprendimiento social, la adquisición de experiencia en la práctica, la preparación para los roles de gestión y liderazgo en la sociedad, y la construcción de bases para el aprendizaje permanente (Pister, 1993). Se hace evidente la necesidad de dejar la sola formación técnica y, sin abandonar la anterior, de lograr otros atributos en los egresados de ingeniería que hagan énfasis en su rol social.

En esos mismos años, la American Society for Engineering Education (ASEE) abunda en remarcar esta necesidad. La ASEE afirma que la formación en ingeniería no debe centrarse solo en la teoría y la experimentación técnica, debe tener programas relevantes, atractivos y conectados, preparando a los estudiantes para el aprendizaje permanente. En síntesis la formación en ingeniería debe proporcionar el conocimiento y capacidad técnica, y la flexibilidad y capacidad de comprensión del contexto social en que se encuentra. (Augustine, Vest; 1994).

\subsubsection{Codificaciones ABET y CDIO}

En la década de los 90s se ha observado cómo la necesidad de ser más competitivos ha transformado la industria mundial. Compañías internacionales empezaron a valorar los equipos flexibles con miembros de talentos múltiples, en lugar de aquellos con múltiples niveles de 
dirección. La industria reconoció este hecho y puso un gran énfasis en la gestión total de la calidad, la reducción de tiempo de ciclo y la eliminación de jerarquías con su personal. Las metas de equipo, las contribuciones del equipo, y las recompensas al equipo reemplazan a los objetivos y contribuciones individuales. (Black, 1994). Sin embargo, aplicar el aprendizaje cooperativo eficaz no es trivial. Se requiere el conocimiento de cómo formar equipos y capacitarlos para hacer frente a los problemas que suelen surgir en el trabajo en equipo. Existen estrategias de trabajo eficaces para lograr una correcta aplicación del aprendizaje cooperativo que puede dotar a los estudiantes de todos los resultados de aprendizaje requeridos por los criterios de ABET para Ingeniería. (Felder \& Brent; 2003).

En 1996, la junta directiva ABET aprobó la lectura final de la adopción de un conjunto totalmente nuevo de criterios para la acreditación de los programas de ingeniería. Al adoptar los nuevos criterios, conocidos como los Engineering Criteria 2000 (ahora se conocen como los Criterios de ingeniería ABET), la Junta también aprobó el diseño de un periodo de prueba de dos años y otro de aplicación, escalonado en tres años. En esos periodos no solo cambiaron los criterios de la junta, también cambió la filosofía de funcionamiento de ABET. La acreditación de ABET se había convertido en rígida y regida por muchas reglas, lo que resultaba en cerca de treinta páginas de letra pequeña con requisitos detallados para créditos de cursos y su distribución, para el personal docente su metodología y evaluación e instalaciones de laboratorio para prácticas (Prados; 1997).

(a) an ability to apply knowledge of mathematics, science, and engineering

(b) an ability to design and conduct experiments, as well as to analyze and interpret data

(c) an ability to design a system, component, or process to meet desired needs within realistic constraints such as economic, environmental, social, political, ethical, health and safety, manufacturability, and sustainability

(d) an ability to function on multidisciplinary teams

(e) an ability to identify, formulate, and solve engineering problems

(f) an understanding of professional and ethical responsibility

(g) an ability to communicate effectively

(h) the broad education necessary to understand the impact of engineering solutions in a global, economic, environmental, and societal context

(i) a recognition of the need for, and an ability to engage in life-long learning

(j) a knowledge of contemporary issues

(k) an ability to use the techniques, skills, and modern engineering tools necessary for engineering practice.

Tabla 1.1 Criterios ABET para Estudiantes que Terminan Ingeniería. Fuente: ABET, 2009

Luego de la aplicación, tres páginas fáciles de leer sustituyeron las treinta de letra pequeña. Se llega a un conjunto de once resultados que todo graduado de ingeniería debe poseer (ABET; 2003). Éstos se muestran en la Tabla 1.1. Y se pueden dividir en dos categorías: un conjunto de 
cinco habilidades "duras" y un segundo conjunto que llaman "habilidades profesionales". En la tabla se muestran en cursiva, los cambios introducidos el 28 de octubre 2004. Las habilidades duras son: a, b, c, e y k, mientras que las blandas o profesionales son: d, f, g, h, i y j (ABET, 2012). Las competencias llamadas duras no producen ninguna reacción entre los académicos de la ingeniería, existen acuerdos en la necesidad de insistir en ellos. Sin embargo, las competencias blandas llevan a discusiones sobre su pertinencia.

La Sociedad Americana para la Educación en Ingeniería (ASEE), en colaboración con la Mesa de Decanos de Ingeniería Corporativa y del Consejo, también analizó el cambio necesario en la educación en ingeniería y en 1994 publicó, "Formación del ingeniero para un mundo cambiante". $\mathrm{El}$ informe señaló que los programas de ingeniería deben ser relevantes, atractivos y conectados (Smerdon, 2000):

Smerdon (2000) también afirma que los pequeños equipos de diseño de ingeniería de hoy utilizan potentes herramientas de diseño. El número de ingenieros "desplazados" por el análisis de gran alcance y por las nuevas herramientas de diseño solo puede crecer. ¿Sugiere esto una menor necesidad de ingenieros en el futuro? Si los ingenieros del futuro hacen el mismo tipo de trabajo que los ingenieros del pasado, la respuesta sería "SÍ". Pero los ingenieros de este nuevo siglo deben cubrir una gama mucho más amplia de necesidades de la sociedad que en el pasado, y puede esperarse que la demanda siga aumentando. La "nueva industria" busca ingenieros con buena capacidad de análisis y con habilidades nuevas para la resolución de problemas, que sean expertos en modelización y el uso de computadoras y que entiendan la tecnología en el sentido más amplio. El ingeniero debe aprovechar estas nuevas oportunidades y la educación en ingeniería debe ser más integral. La educación técnica se ha basado en un modelo analítico (la ciencia) y la enseñanza de la ingeniería del futuro debe ser más integradora (Smerdon; 2000).

En este contexto en el Massachusetts Institute of Technology (MIT) surge el interés de contar con un soporte sobre el que se pueda construir un cuerpo de competencias genéricas apropiado para la ingeniería y planes de estudios que las desarrollen. Parten de la certeza que los ingenieros de hoy se involucran en todas las etapas del ciclo de vida de productos, procesos y sistemas, desde los más simples a los más increíblemente complejos, que requieren de nuevas tecnologías, empujan a nuevas fronteras y crean nuevas capacidades. La Propuesta CDIO (Conceive, Desing, Implement and Operate) se basa en la certeza de que la tarea de la educación superior, es formar estudiantes que lleguen a ser ingenieros modernos, capaces de participar y eventualmente liderar la concepción, diseño, implementación y operación de esos sistemas, productos, procesos y proyectos en los que desarrollan su actividad. Para hacer lo anterior los egresados deben ser técnicamente expertos, socialmente responsables e inclinados a innovar (Crawley et al.; 2007).

La propuesta CDIO se definió conociendo de la crítica creciente de que la enseñanza de la ingeniería prioriza la teoría de las ciencias básicas y la técnica, sin dar suficiente énfasis a poner las bases para la práctica. Por ello propone, a partir de la información de las partes interesadas, identificar las necesidades de aprendizaje de los estudiantes y construir una secuencia de experiencias de aprendizaje integradas, para compatibilizarlas con las necesidades planteadas. 
La propuesta afirma que el propósito de la educación en ingeniería es proveer a los estudiantes de los aprendizajes que requerirán, para ello se codifican resultados de aprendizaje concretos en una propuesta que define un racional, relevante y consistente conjunto de habilidades para un ingeniero (Crawley et al.; 2007).

El sistema CDIO, desarrollado inicialmente por el MIT y las universidades Suecas de Chalmers, Linköping y al que hoy se acogen más de 40 programas de la ingeniería de todo el mundo, define un listado de competencias (syllabus) en varios niveles. Establece el ciclo de vida de un producto como el entorno idóneo para el estudio de la ingeniería y promueve el aprendizaje de competencias como contexto para el desarrollo de asignaturas. Promueve además la adopción de metodologías activas de aprendizaje y la inclusión de diversas actividades de diseño e implementación a lo largo de los estudios (Bragós et al, 2010).

La iniciativa CDIO, propone construir un currículum integrado, con las competencias imbricadas en las asignaturas. CDIO también propone insertar asignaturas de proyectos en las que de manera natural se desarrollan diversas competencias, tanto personales como interpersonales, específicas de la ingeniería. En particular, se recomienda llevar a cabo una asignatura en primer curso en la que se realice una introducción a la ingeniería y un primer proyecto, a fin de que el estudiante pueda identificar el contexto en el que se desarrollará su formación y enfocar correctamente el resto de asignaturas del grado. Se trata, en resumen, de considerar las competencias genéricas como el contexto del aprendizaje de la ingeniería y no su contenido, que seguirá estando constituido por las competencias específicas de las distintas materias (Bragós et al, 2010). Así, los planes de estudio diseñados incluyen en su estructura un conjunto de asignaturas en las que se desarrollen proyectos, que no deben entenderse como contenedores de competencias sino que deben tener un triple impacto:

- Consolidar el aprendizaje de los contenidos de las materias que se cursan en paralelo y de las anteriores.

- Motivar al estudiante.

- Trabajar en el contexto de la ingeniería y, como consecuencia, ofrecer un marco para desarrollar de manera natural las competencias genéricas y específicas correspondientes.

Por lo tanto, la iniciativa CDIO tiene tres grandes objetivos generales:

- dominar un conocimiento profundo de técnicas fundamentales,

- liderazgo en la creación y operación de nuevos productos, procesos y sistemas y,

- entender la importancia y el impacto estratégico de la investigación y el desarrollo tecnológico en la sociedad.

Si nos basamos en el contexto de la práctica profesional de ingeniería, las implicaciones para la enseñanza de la ingeniería son relativamente claras. Debemos fijar firmemente la educación en los aspectos intemporales del contexto profesional: un enfoque a las necesidades de los clientes, entrega de productos y sistemas, incorporación de nuevas invenciones y tecnologías, un enfoque en la solución no en las disciplinas, trabajar con otros, comunicación efectiva y trabajar con los recursos (Crawley et al.; 2008). 
Debemos lograr que los estudiantes tomen conciencia de los nuevos y cambiantes elementos de contexto. Deben incorporar de manera apropiada la aparición de nuevos servicios de ingeniería y el ritmo de evolución de la tecnología, es decir, centrarse en la naturaleza de la práctica de la ingeniería. Esta es la idea que se manifiesta en CDIO.

Dicho de otra manera, los ingenieros graduados deben comprender el proceso de ingeniería, ser capaces de contribuir al desarrollo de productos de ingeniería y hacerlo al mismo tiempo que trabajan en organizaciones de ingeniería. Está implícita la expectativa adicional de que, como titulados universitarios y adultos jóvenes, los graduados de ingeniería deben desarrollarse en su conjunto como individuos honrados, maduros y reflexivos (Crawley, Edward F.; 2001).

CDIO define las competencias que deben poseer los alumnos al terminar su formación como ingenieros. Estas son el resultado de la conjunción de los intereses de todos los involucrados en la actividad de la ingeniería y en su definición usa como herramienta clave la participación a través de encuestas del cuerpo docente, la industria, antiguos alumnos, entre otras partes interesadas.

Éstas se organizan en cuatro áreas de formación, en el primer nivel:

1. Conocimiento técnico y razonamiento crítico.

2. Habilidades profesionales y personales.

3. Habilidades interpersonales.

4. CDIO (Nivel más alto: Concieve-design-implement-operate.

\begin{tabular}{|l|}
\hline 1. Conocimiento y razonamiento técnico \\
\hline 1.1 Conocimiento de ciencias básicas. \\
\hline 1,2 Conocimientos básicos del núcleo de la ingeniería \\
\hline 1,3 Conocimientos básicos de Ingeniería avanzada \\
\hline 2. Competencias y habilidades personales y profesionales \\
\hline 2,1 Razonamiento ingenieril y resolución de problemas \\
\hline 2,2 Descubrimiento de la experimentación y el conocimiento \\
\hline 2,3 Pensamiento sistémico \\
\hline 2,4 Habilidades y actitudes personales \\
\hline 2,5 Habilidades y actitudes profesionales \\
\hline 3. Competencias Interpersonales: trabajo en equipo y comunicación \\
\hline 3,1 Trabajo en equipo \\
\hline 3,2 Comunicación \\
\hline 3,3 Comunicación en lenguas extranjeras \\
\hline 4. Concebir, diseñar, implmentar y operar sistemas en contextos \\
empresariales y sociales. \\
\hline 4,1 Contexto exterior y social \\
\hline 4,2 Contexto empresarial y de negocios. \\
\hline 4,3 Concibiendo e "ingenierizando" Sistemas \\
\hline 4,4 Diseñar \\
\hline 4,5 Implementar \\
\hline 4,6 Operar \\
\hline
\end{tabular}

Tabla 1.2 Objetivos de Primer y Segundo Nivel del Syllabus CDIO. Fuente: (Crawley, E. F.; 2001) 
Examinando cada una de estas áreas con más detalle, podemos ver que un individuo maduro interesado en los esfuerzos técnicos debe poseer un conjunto de habilidades personales y profesionales, que son fundamentales para la práctica (1). Para desarrollar complejos sistemas de ingeniería de valor añadido, los estudiantes deben dominar los fundamentos del razonamiento y conocimiento técnico adecuado, así como las relaciones interdisciplinares (2). Para trabajar en un ambiente moderno basado en equipos, los estudiantes deben tener desarrolladas las habilidades interpersonales de trabajo en equipo y las comunicaciones (3). Por último, en para ser realmente capaces de crear y operar productos y sistemas, un estudiante debe entender algo de concebir, diseñar, implementar y operar sistemas en el contexto empresarial y social (4). Se verifica que el Plan de Estudios CDIO se organiza de manera consistente con lo explicado en los párrafos anteriores. En la Tabla 3.2 se encuentran las competencias de primer y segundo nivel definidas por CDIO.

El primer nivel descrito refleja la función de un ingeniero, que es un individuo bien desarrollado, que participa en un proceso y que está incrustado en una organización con la intención de construir productos. El segundo nivel refleja mucho de la práctica moderna y la erudición sobre la profesión de la ingeniería (Crawley, Edward F.; 2001).

La formación de un ingeniero debe contemplar, entre las competencias que logre un egresado, aquellas que se requieren para la gestión de proyectos. Esto nos lleva a la necesidad de contar con una codificación clara de estas competencias que un ingeniero requiere en su ejercicio profesional.

\subsubsection{Codificación IPMA}

Cada vez más organizaciones se están dando cuenta que los proyectos son tan buenos como las personas que los realizan y que es vital para el éxito que las personas relacionadas dominen las herramientas de gestión. Los educadores universitarios deben tomar este punto de vista e incrementar sus esfuerzos en mejorar las habilidades de los estudiantes para las prácticas de gestión de proyectos que incluyan habilidades blandas, habilidades duras y conocimiento tácito y explícito (Pant \& Baroudi; 2008).

El conocimiento tácito está por lo general en el campo del aprendizaje subjetivo, cognitivo y experiencial, mientras que el conocimiento explícito está con el conocimiento más objetivo, racional y técnico y es bien documentado y accesible. La gestión del proyecto comprende una amplia gama de funciones y responsabilidades y ello debe reflejarse en los programas educativos. Sin embargo, el foco de la mayoría, en el contexto de las universidades, ha estado en la formación de los conocimientos técnicos que son necesarios para lograr el éxito del proyecto, que está principalmente en el triángulo de hierro de tiempo, costo y calidad. Esto se debe a que las habilidades técnicas son más fáciles de tratar cuando se comparan con las habilidades blandas (Pant, Baroudi; 2008).

Es importante adquirir esas habilidades porque el número de proyectos, programas y carteras crece a un ritmo exponencial en el mundo. Cada día aumenta la variedad de proyectos que se gestionan de forma profesional. En el pasado dominaban los proyectos de construcción y 
defensa, actualmente siguen siendo importantes pero son minoría. Existen proyectos, por ejemplo, de tecnologías de información y comunicación (TICs), desarrollo de organizaciones, desarrollos de productos, cambios en el mercadeo, desarrollo de producción, investigación, eventos, proyectos políticos, legislativos, educativos y sociales, en muchos sectores económicos distintos (IPMA; 2009).

La International Project Management Association (IPMA) y la Asociación Española de Ingeniería de Proyectos (AEIPRO) a través del OCDP (Organismo Certificador de Dirección de Proyectos), seleccionan las competencias para la dirección de proyectos en tres ámbitos: técnicas, de comportamiento y contextual. Los elementos de competencia técnica describen lo que se requiere en el ámbito técnico para poner en marcha un proyecto, gestionar su ejecución y cerrarlo. Los elementos de competencia de comportamiento son relevantes para la forma en que interactúan los grupos interesados en el contexto de un proyecto. Los elementos de competencia contextual describen la promoción en la dirección de proyectos y las distintas funciones de apoyo que las organizaciones en línea deben conocer acerca de proyectos (IPMA; 2009).

En la

Tabla 1.3 se muestran los elementos de competencia codificados por IPMA.

\begin{tabular}{|c|c|c|}
\hline 1. Competencias Técnicas & \begin{tabular}{|l|} 
2. Competencias de \\
Comportamiento
\end{tabular} & $\begin{array}{l}\text { 3. Competencias } \\
\text { Contextuales }\end{array}$ \\
\hline $\begin{array}{l}\text { 1.01 Éxito en la dirección de } \\
\text { proyectos. }\end{array}$ & 2.01 Liderazgo & 3.01 Orientación a proyectos \\
\hline 1.02 Partes interesadas & 2.02 Compromiso y motivación & 3.02 Orientación a programas \\
\hline $\begin{array}{l}1.03 \text { Requisitos y objetivos del } \\
\text { proyecto. }\end{array}$ & 2.03 Autocontrol & 3.03 Orientación a carteras \\
\hline 1.04 Riesgo y oportunidad & 2.04 Confianza en sí mismo & $\begin{array}{l}\text { 3.04 Implantación de } \\
\text { proyectos, programas y } \\
\text { carteras. }\end{array}$ \\
\hline 1.05 Calidad & 2.05 Relajación & $\begin{array}{c}3.05 \text { Organizaciones } \\
\text { permanentes }\end{array}$ \\
\hline 1.06 Organización del proyecto & 2.06 Actitud abierta & 3.06 Negocio \\
\hline 1.07 Trabajo en equipo & 2.07 Creatividad & $\begin{array}{l}\text { 3.07 Sistemas, productos y } \\
\text { tecnología }\end{array}$ \\
\hline 1.08 Resolución de problemas & 2.08 Orientación a resultados & 3.08 Dirección de personal \\
\hline 1.09 Estructuras del proyecto & 2.09 Eficiencia & $\begin{array}{l}\text { 3.09 Seguridad, higiene y medio } \\
\text { ambiente. }\end{array}$ \\
\hline 1.10 Alcance y entregables & 2.10 Consulta & 3.10 Finanzas \\
\hline 1.11 Tiempo y fases del proyecto & 2.11 Negociación & 3.11 Legal \\
\hline 1.12 Recursos & 2.12 Conflictos y crisis & \\
\hline 1.13 Costo y financiación. & 2.13 Fiabilidad & \\
\hline 1.14 Aprovisionam. y contratos & 2.14 Apreciación de valores & \\
\hline 1.15 Cambios & 2.15 Ética & \\
\hline 1.16 Control e informes & & \\
\hline $\begin{array}{c}\text { 1.17 Documentación e } \\
\text { información }\end{array}$ & & \\
\hline 1.18 Comunicación & & \\
\hline 1.19 Lanzamiento & & \\
\hline 1.20 Cierre & & \\
\hline
\end{tabular}


Tabla 1.3 Elementos de Competencia de IPMA.

Fuente: (IPMA; 2009)

La demanda sobre las competencias de comportamiento de los directores y de los miembros de los equipos de las organizaciones es más exigente y pronunciada en la última década y son un elemento esencial adicional a las competencias técnicas. Son 46 elementos requeridos para una persona que actúa en beneficio del conjunto del proyecto para satisfacer las expectativas de los clientes, de los agentes que suministran las mercancías y servicios y demás partes involucradas (IPMA; 2009).

El enfoque dirigido a la gestión de proyectos y la naturaleza holística y minuciosa de esta definición de competencias, hace que esta codificación sea idónea para la determinación del conjunto de competencias requeridas para un egresado de ingeniería con capacidad de gestionar un proyecto.

Las codificaciones de competencias definidas en las páginas anteriores, tomaron como referencia la realidad norteamericana (ABET y CDIO) y la del Espacio europeo de Educación Superior (IPMA). Requerimos comprobar si son aplicables al contexto latinoamericano.

Dentro de la bibliografía revisada, uno de los trabajos más serios emprendidos en la definición de competencias genéricas para la formación de profesionales es el Proyecto Tuning.

\subsubsection{Codificación TUNING América Latina.}

El Proyecto Tuning es un trabajo de más de 175 universidades europeas que desde el año 2001 quieren consolidar la búsqueda de puntos de acuerdo, de convergencia y entendimiento mutuo para facilitar la comprensión de las estructuras educativas en pos de la creación del Espacio Europeo de Educación Superior como respuesta al desafío planteado por la Declaración de Bolonia. Ha buscado identificar elementos de referencia necesarios para el reconocimiento de las titulaciones en todo el espacio europeo. Tuning había sido una experiencia exclusiva de Europa hasta finales de 2004 en que surge el proyecto Tuning - América Latina (TuningAL) en un contexto de intensa reflexión sobre educación superior, tanto a nivel regional como internacional.

Tuning - América Latina es un trabajo conjunto que busca y construye mecanismos para la comprensión recíproca de los sistemas de enseñanza superior, que faciliten los procesos de reconocimiento de carácter transnacional y transregional. De esta forma, el inicio del proyecto está dado por la búsqueda de puntos comunes de referencia, centrados en las competencias. Se trabajó en identificar competencias compartidas, que pudieran generarse en cualquier titulación y que fueran consideradas importantes por ciertos grupos sociales. Hay ciertas competencias, como la capacidad de aprender y actualizarse permanentemente, la capacidad de abstracción, análisis y síntesis, etc., que son comunes a todas o casi todas las titulaciones. En una sociedad cambiante, donde las demandas tienden a hallarse en constante reformulación, esas competencias y destrezas genéricas son de gran importancia (Proyecto Tuning; 2007). 
Al definir competencias y resultados del aprendizaje, se desarrollaron puntos de referencia consensuados, que sentaron bases para la garantía de la calidad y contribuyeron con los procesos de evaluación nacional e internacional. Para la elaboración de las mismas, se tomó como punto de partida la lista de las 30 competencias genéricas identificadas en Europa, así como diferentes aportes realizados por varios participantes del proyecto. Esto permitió armar un consolidado, con los aportes de los 18 países participantes, que dio como resultado un listado de 85 competencias genéricas. Se consultó en las 62 universidades participantes de los 18 países latinoamericanos, así como a las partes interesadas y se tomó la decisión de presentar un listado definitivo de 27 competencias genéricas que se muestran en la Tabla 1.4.

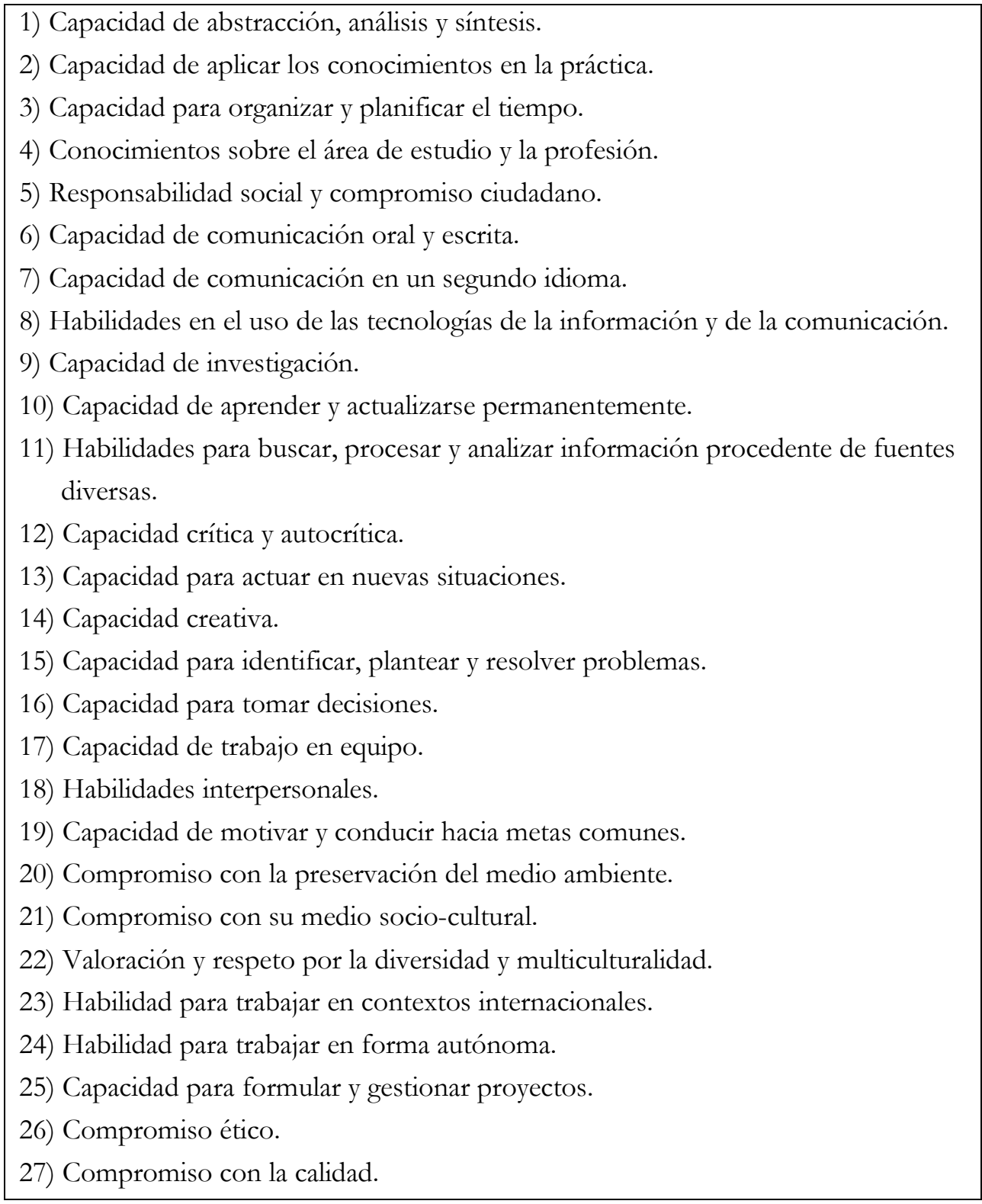

Tabla 1.4 Listado de Competencias Genéricas Acordadas para América Latina. Fuente: (Proyecto Tuning; 2007).

En el informe final del Proyecto TuningAL, se pone de manifiesto que entre las competencias definidas para Europa y aquellas de América Latina existen 22 competencias comparables, que en el listado latino americano se precisaron con más detalle. También se anota que 5 de las 
europeas se convirtieron en dos latinoamericanas y se incorporaron 3 nuevas al último listado: responsabilidad social y compromiso ciudadano, compromiso con la preservación del medio ambiente y compromiso con su medio socio-cultural.

En este informe final, Reflexiones y perspectivas de la Educación Superior en América Latina, se hacen encuestas a todas las partes interesadas y se analizan y valoran los resultados destacando, de entre todos, dos en particular: para los empleadores la competencia más importante es el compromiso ético; el segundo, se puede apreciar un alto grado de coincidencia en 5 de las 6 competencias consideradas como más importantes por los empleadores, tanto europeos como latinoamericanos, lo mismo sucede entre las 6 competencias menos importantes, coinciden en 4 de ellas (Proyecto Tuning; 2007).

Las competencias TuningAL se pueden agrupar en competencias técnicas, de comportamiento y contextuales.

Consideramos Competencias TuningAL Técnicas las siguientes:

1. Capacidad de abstracción análisis y síntesis

2. Capacidad de aplicar los conocimientos en la práctica

3. Capacidad de organizar y planificar el tiempo.

4. Conocimientos sobre el área de estudio y la profesión

6. Capacidad de comunicación oral y escrita

8. Habilidades en el uso de tecnologías de la información y de la comunicación

9. Capacidad de investigación

10. Capacidad de aprender y actualizarse permanentemente.

11. Habilidades para buscar, procesar y analizar información de diversas fuentes

15. Capacidad para identificar, plantear y resolver problemas.

17. Capacidad para trabajo en equipo.

25. Capacidad para formular y gestionar proyectos.

Consideramos Competencias TuningAL Contextuales las siguientes:

5. Responsabilidad social y compromiso ciudadano

7. Capacidad de comunicación en un segundo idioma

20. Compromiso con la preservación del medio ambiente.

21. Compromiso con su medio socio-cultural.

22. Valoración y respeto por la diversidad y multiculturalidad.

23. Habilidad para trabajar en contextos internacionales.

Consideramos Competencias TuningAL de comportamiento las siguientes:

12. Capacidad crítica y autocrítica.

13. Capacidad de actuar en nuevas situaciones.

14. Capacidad creativa.

16. Capacidad para tomar decisiones.

18. Habilidades interpersonales.

19. Capacidad de motivar y conducir a metas comunes.

24. Capacidad para trabajar en forma autónoma.

26. Compromiso ético.

27. Compromiso con la calidad.

Con la revisión del contexto hecha hasta aquí, se procederá a realizar comparaciones para determinar la mejor codificación de competencias para la enseñanza de ingeniería en América latina. 


\subsection{COTEJO DE CODIFICACIONES INTERNACIONALES DE COMPE- TENCIAS GENÉRICAS EN EL ÁMBITO DE LA INGENIERÍA.}

\subsubsection{Comparación CDIO - ABET}

Las competencias ABET han sido codificadas para servir como base de un sistema de acreditación homogéneo para las universidades norteamericanas. Ya ha sido aceptado por un gran número de ellas y eso las hace apetecibles por las universidades que desean tener estándares similares a los de las universidades norteamericanas. Si logramos determinar que existe un grupo de competencias más integrador, y holístico habríamos encontrado una codificación de competencias acorde con el perfil que hemos definido y que sea acreditable en el sistema norteamericano.

Compararemos las codificaciones descritas y buscaremos cuál de entre ellas reúne las características que buscamos de ser genéricas, holísticas, basada en la gestión de proyectos, y aplicable a la enseñanza de la ingeniería en Latinoamérica.

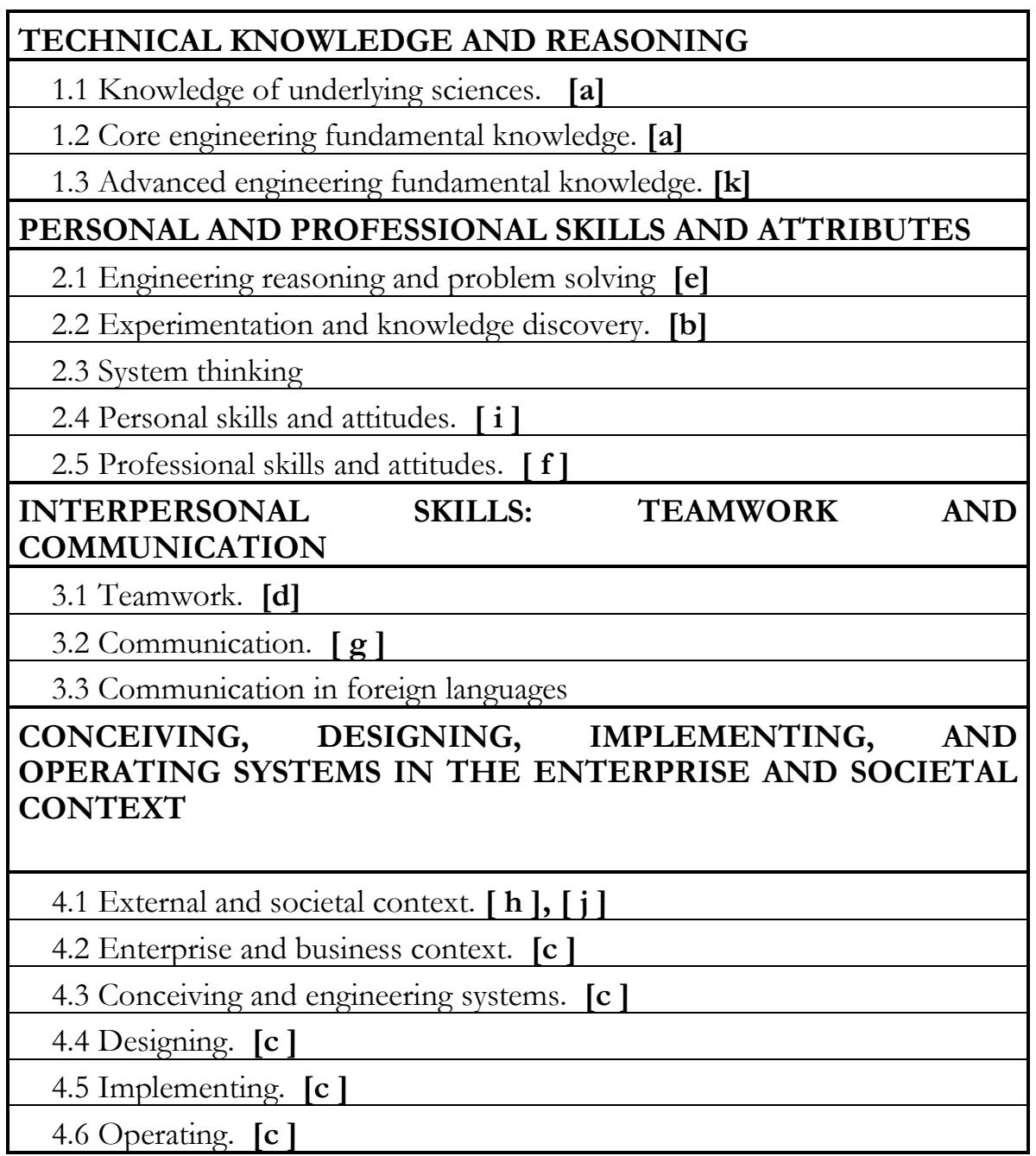

Tabla 1.5 Comparación CDIO - ABET.

Fuente: (Crawley, E. F.; 2001) 
En el libro "The CDIO Syllabus. A Statement of Goals for Undergraduate Engineering Education" (Crawley, Edward F; 2001), Edward Crawley analiza y compara los criterios que ABET establece para que un programa de ingeniería sea acreditado comprobando que sus graduados han desarrollado los conocimientos, habilidades y actitudes de la Tabla 3.1, con los definidos en el segundo nivel de CDIO. El resultado lo muestra en la Tabla $3 \mathrm{~b}$ de su libro y que reproducimos en la Tabla 1.5 .

Crawley afirma que la cobertura del syllabus CDIO, en segundo nivel (Tabla 1.2), con los puntos de ABET (Tabla 1.1) es fuerte, pero que la definición de CDIO es más completa que la de ABET. Por ejemplo, ABET omite cualquier referencia a un "Sistema de Pensamiento" (2,3 de CDIO) y lista solo, "reconocer la necesidad para y la habilidad de desarrollar un aprendizaje permanente" (punto i de Tabla 3.1); de entre los muchos atributos deseables personales (CDIO 2,4), ABET omite iniciativa, perseverancia, flexibilidad, el pensamiento creativo y crítico, etc. Asimismo ABET lista en la letra (f) solo "una comprensión de la responsabilidad profesional y ética”, entre varias importantes habilidades y aptitudes profesionales (CDIO 2,5).

En su libro Crawley dedica muchas páginas a explicar cómo los puntos 2.3 y 3.3 de CDIO no son abarcados por los de ABET y por ello le considera menos completa que la propuesta CDIO. En la Tabla 1.5, para facilitar la comparación directa con los Criterios para la acreditación de los Programas de Ingeniería (ABET, 2012), las competencias ABET de la Tabla 3.1 se denotan con las letras desde la [a] a [k], y se colocan al lado de las de CDIO para mostrar los elementos de correlación más fuerte entre los dos documentos.

Se puede afirmar que la propuesta CDIO está bien alineada con los criterios de ABET y además tiene dos ventajas. La primera es que puede afirmarse que están más organizados racionalmente, porque están más explícitamente derivados de las funciones de la ingeniería moderna, lo que crea una mejor comprensión de por qué implementar un cambio. La segunda y principal ventaja es que contiene más niveles de detalle que el documento de ABET; penetra en los detalles como para que las frases que son generales, como "buenas habilidades de comunicación", adquieran un significado sustantivo (Crawley; 2001).

Esto nos permite afirmar que el listado de competencias CDIO es un referente importante para la definición de las competencias pertinentes para un programa de ingeniería y que incluye en su malla, las competencias que busca ABET en la formación de ingeieros.

\subsubsection{Comparación CDIO - IPMA.}

Tenemos dos codificaciones importantes, CDIO e IPMA. Comparamos ambas seleccionamos la más útil para cubrir la necesidad de contar con ingenieros que respondan a tener sólidos conocimientos técnicos, respeto por el entorno social y empresarial, y habilidades en el comportamiento con las organizaciones y personas involucradas, con un apropiado dominio de la gestión de proyectos.

El resultado de la comparación se muestra en la Tabla 3.6. En ella se observa como las competencias de CDIO se encuentran incluidas en los elementos de competencia de IPMA. También se observa que los contenidos de CDIO excepto el 3.3, son tratados en los elementos de competencia de IPMA y que existen dos elementos de IPMA que no son tratados por CDIO: 
el elemento 3.11 y el 3.05. El punto 3.3 de CDIO "Comunicación en lenguas extranjeras" no se trata en los elementos de competencia de IPMA. Sin embargo en el 1.17 y 1.18 de IPMA se indica la actitud, oportunidad, eficacia, forma y acciones necesarias para una comunicación efectiva y la documentación requerida, lo que permite afirmar que el dominio de la lengua está implícito.

\begin{tabular}{|c|c|c|c|c|c|c|c|c|c|c|c|c|c|c|c|c|c|c|c|c|c|c|}
\hline & $\dot{-}$ & $\exists$ & ב & 3 & $i$ & $\bar{i}$ & तี & $\overrightarrow{3}$ & $\stackrel{+}{i}$ & $\stackrel{4}{4}$ & $\dot{r}$ & $\bar{m}$ & ले & $m$ & $\dot{+}$ & $F$ & Y & 9 & $\stackrel{+}{+}$ & & & $\bar{t}$ \\
\hline \multicolumn{23}{|l|}{ 1. Competencias técnicas } \\
\hline 1.01 Éxito en la dirección de proys. & & & & & & $\mathbf{x}$ & & $\mathbf{x}$ & $\mathbf{x}$ & $\mathbf{x}$ & & & $\mathrm{x}$ & & & $\mathbf{x}$ & $\mathbf{x}$ & & & & & \\
\hline 1.02 Partes interesadas & & & & & & & & & & & & & $\mathbf{x}$ & & & $\mathbf{x}$ & $\mathbf{x}$ & & & & & \\
\hline 1.03 Requisitos y objs. del proy. & & $\mathbf{x}$ & $\mathbf{x}$ & $\mathbf{x}$ & & $\mathbf{x}$ & & & & & & & & & & $\mathbf{x}$ & $\mathbf{x}$ & $\mathbf{x}$ & & & & \\
\hline \multicolumn{23}{|l|}{1.04 Riesgo y oportunidad } \\
\hline \multicolumn{23}{|l|}{1.05 Calidad } \\
\hline \multicolumn{23}{|l|}{1.06 Organización del proyecto } \\
\hline \multicolumn{23}{|l|}{1.07 Trabajo en equipo } \\
\hline \multicolumn{23}{|l|}{ 1.08 Resolución de problemas } \\
\hline \multicolumn{23}{|l|}{1.09 Estructuras del proyecto } \\
\hline \multicolumn{23}{|l|}{ 1.10 Alcance y entregables } \\
\hline \multicolumn{23}{|l|}{ 1.11 Tiempo y fases del proyecto } \\
\hline \multicolumn{23}{|l|}{1.12 Recursos } \\
\hline \multirow{2}{*}{\multicolumn{23}{|c|}{1.13 Costo y financiación. }} \\
\hline \multirow{2}{*}{\multicolumn{23}{|c|}{1.14 Aprovisionam. y contratos }} \\
\hline \multicolumn{22}{|l|}{1.15 Cambios } & \\
\hline 1.16 Control e informes & & & & & & & & $\mathrm{x}$ & & $\mathbf{x}$ & & & $\mathrm{x}$ & & & & & $\mathbf{x}$ & & & & \\
\hline 1.17 Documentac. e información & & & & & & & & & & $\mathrm{x}$ & & & $\mathrm{x}$ & $\mathbf{x}$ & & & & & & & & \\
\hline 1.18 Comunicación & & & & & & & & & $\mathbf{x}$ & $\mathrm{x}$ & & & $\mathbf{x}$ & $\mathbf{x}$ & & & & & & & & \\
\hline 1.19 Lanzamiento & & & & & & & & & & & & & $\mathrm{x}$ & & & $\mathbf{x}$ & & & & & & \\
\hline 1.20 Cierre & & & & & & & & $\mathrm{x}$ & $\mathrm{x}$ & & & & $\mathrm{x}$ & & & & & & & & & \\
\hline 2. Comps. de comportamiento & & & & & & & & & & & & & & & & & & & & & & \\
\hline 2.01 Liderazgo & & & & & & & & & & $\mathbf{x}$ & & $\mathrm{x}$ & & & & $\mathbf{x}$ & & & & & & \\
\hline 2.02 Compromiso y motivación & & & & & & & & & $\mathrm{x}$ & & & & $\mathrm{x}$ & & & & $\mathbf{x}$ & & & & & \\
\hline 2.03 Autocontrol & & & & & & & & & & $\mathrm{x}$ & & $\mathbf{x}$ & $\mathbf{x}$ & & & & & & & & & \\
\hline 2.04 Confianza en sí mismo & & & & & & $\mathrm{x}$ & & & $\mathrm{x}$ & $\mathrm{x}$ & & & & & & $\mathrm{x}$ & & & & & & \\
\hline 2.05 Relajación & & & & & & & & & $\mathbf{x}$ & $\mathbf{x}$ & & & & & & . & & & & & & \\
\hline 2.06 Actitud abierta & & & & & & & & & $\mathrm{x}$ & & & $\mathrm{x}$ & & & & $\mathrm{x}$ & $\mathrm{x}$ & & & & & \\
\hline 2.07 Creatividad & & & & & & & $\mathbf{x}$ & $\mathrm{x}$ & $\mathrm{x}$ & & & & & & & $\mathbf{x}$ & & & & & & \\
\hline 2.08 Orientación a resultados & & & & & & & & $\mathrm{x}$ & & & & & $\mathbf{x}$ & & & & & $\mathbf{x}$ & $\mathbf{x}$ & & & \\
\hline 2.09 Eficiencia & & & & & & $\mathbf{x}$ & & $\mathrm{x}$ & & & & & & & & $\mathbf{x}$ & $\mathbf{x}$ & & & & & \\
\hline 2.10 Consulta & & & & & & & & $\mathrm{x}$ & & & & $\mathbf{x}$ & $\mathbf{x}$ & & & $\mathbf{x}$ & $\mathbf{x}$ & & & & & \\
\hline 2.11 Negociación & & & & & & & & & $\mathrm{x}$ & & & & $\mathrm{x}$ & & & $\mathbf{x}$ & & $\mathbf{x}$ & & & & \\
\hline 2.12 Conflictos y crisis & & & & & & $\mathbf{x}$ & $\mathbf{x}$ & & $\mathrm{x}$ & & & & $\mathbf{x}$ & & & & & & & & & \\
\hline 2.13 Fiabilidad & & & & & & & & & & $\mathbf{x}$ & & & & & & $\mathbf{x}$ & $\mathbf{x}$ & $\mathbf{x}$ & & & & \\
\hline 2.14 Apreciación de valores & & & & & & & & & $\mathbf{x}$ & $\mathbf{x}$ & & & $\mathbf{x}$ & & & $\mathbf{x}$ & $\mathbf{x}$ & & & & & \\
\hline 2.15 Etica & & & & & & & & & & $\mathbf{x}$ & & & $\mathbf{x}$ & & & & & & & & & \\
\hline 3 Competencias contextuales & & & & & & & & & & & & & & & & & & & & & & \\
\hline 3.01 Orientación a proyectos & & & & & & $\mathrm{x}$ & & $\mathbf{x}$ & & $\mathbf{x}$ & & & & & & $\mathbf{x}$ & & $\mathbf{x}$ & & & & \\
\hline 3.02 Orientación a programas & & & & & & $\mathrm{x}$ & & $\mathbf{x}$ & & $\mathrm{x}$ & & $\mathrm{x}$ & & & & & $\mathbf{x}$ & $\mathbf{x}$ & & & & \\
\hline 3.03 Orientación a carteras & & & & & & $\mathrm{x}$ & & $\mathbf{x}$ & & $\mathbf{x}$ & & & $\mathbf{x}$ & $\mathrm{x}$ & & & & $\mathbf{x}$ & & & & \\
\hline 3.04 Implant. proys, progs y carts. & & & $\mathbf{x}$ & & & $\mathrm{x}$ & & $\mathbf{x}$ & $\mathbf{x}$ & & & $\mathbf{x}$ & & & & $\mathbf{x}$ & & & $\mathbf{x}$ & & & \\
\hline 3.05 Organizaciones permanentes & & & & & & & & & & & & & & & & & & & & & & \\
\hline 3.06 Negocio & & & & & & & & & $\mathrm{x}$ & $\mathrm{x}$ & & $\mathrm{x}$ & $\mathrm{x}$ & & & $\mathbf{x}$ & $\mathrm{x}$ & & $\mathbf{x}$ & & & \\
\hline 3.07 Sistms, prodtos y tecnología & & & $\mathbf{x}$ & $\mathbf{x}$ & & & & $\mathbf{x}$ & & & & & & & & & & $\mathbf{x}$ & $\mathbf{x}$ & & & \\
\hline 3.08 Dirección de personal & & & & & & $\mathrm{x}$ & & & $\mathrm{x}$ & & & $\mathbf{x}$ & $\mathbf{x}$ & & & & & & & & & \\
\hline 3.09 Segurid, higiene y med. amb. & & & & & & & & & & & & & & & & $\mathbf{x}$ & & & $\mathbf{x}$ & & & \\
\hline 3.10 Finanzas & & $\mathrm{x}$ & & & & & & & $\mathbf{x}$ & $\mathbf{x}$ & & & $\mathbf{x}$ & & & & $\mathrm{x}$ & $\mathbf{x}$ & $\mathbf{x}$ & & & \\
\hline 3.11 Legal & & & & & & & & & & & & & & & & & & & & & & \\
\hline
\end{tabular}

Nota: La letra $\mathrm{X}$ indica correspondencia entre los elementos relacionados.

Tabla 1.6 Resultado de comparación de los elementos de competencia IPMA - CDIO. Fuente: Elaboración propia. 
El elemento 3.11 "Legal" de IPMA se describe como "el impacto de la ley y las normas sobre proyectos". Se precisa que es importante saber limitar la exposición legal para reducir la posibilidad de demandas, tener la diligencia de saber operar dentro de la ley y ser capaz de reconocer y descubrir qué actividades tienen requisitos legales y cuáles principios legales son de aplicación a un proyecto (IPMA, 2009). La única mención de CDIO a este tópico está en del código 4.1.3 en el cuarto nivel de desarrollo, "Forma en que los sistemas legales y políticos regulan e influencian la ingeniería" (Crawley; 2001). Consideramos que no son comparables las descripciones de los requisitos, CDIO es más superficial.

Consideramos que el elemento de competencia de IPMA abarca una mayor y mejor El elemento 3.05 "Organizaciones permanentes". IPMA afirma que "para un proyecto es importante saber cómo están definidas las políticas y los resultados de las operaciones de una organización permanente, cómo se controlan y cuáles son los riesgos asociados. Es preciso entender bien los principios de planificación y dirección de una organización permanente y la contribución del proyecto a ellas, para establecer unas buenas condiciones previas y obtener resultados satisfactorios" (IPMA, 2009). En CDIO en 4.1.2 "El impacto de la ingeniería en la sociedad" trata este tema como "El impacto de la ingeniería en los sistemas sociales, del conocimiento, el medio ambiente y económicos en la cultura moderna”, y en 4.2.4 "Trabajando exitosamente en las Organizaciones" afirma que deben conocerse "Diferentes funciones y responsabilidades en una organización” y "El papel de las organizaciones funcionales y por programa”.

Descripción de la competencia que requiere un egresado de ingeniería en el tratamiento de las organizaciones involucradas en su desempeño profesional, que las que describe CDIO.

Consideramos que IPMA define un elenco de competencias apropiado para servir como base de diseño de los planes de estudio de un programa de ingeniería, pues aquella competencia que tiene CDIO adicionalmente, ya está contemplada en la apropiada comunicación que indica IPMA y, además, en la mayoría de universidades latinoamericanas ya se exige como una condición de egreso. Lo que necesitamos es saber si esta codificación de IPMA podrá responder a los requerimientos de América latina.

\subsubsection{Comparación TuningAL - IPMA.}

Con la codificación de los elementos de competencias de IPMA, seleccionada como aplicable para la formación de ingenieros, y las de Tuning para cualquier titulación de América Latina, podemos realizar una comparación y determinar si las primeras son aplicables para la formación de ingenieros en Latinoamérica. En la Tabla 3.7 se muestran los resultados de la comparación.

De los resultados de la comparación, se concluye que en los elementos de competencia definidos por IPMA para la Dirección de proyectos se incorporan las competencias genéricas definidas por Tuning para la educación superior de América latina excepto la competencia 7 de dominar un segundo idioma, que no se indica expresamente en IPMA y tendrá que ponérsele énfasis en el elemento de competencia 1.18, aunque de la misma manera que el caso anterior, puede entenderse que una correcta comunicación implica el dominio de la lengua. 
Por lo anterior, ambas codificaciones pueden emplearse en la formación de ingenieros en Latinoamérica con capacidad de gestionar proyectos pues puede afirmarse que una incluye a la otra y viceversa.

\begin{tabular}{|c|c|c|c|c|c|c|c|c|c|c|c|c|c|c|c|c|c|c|c|c|}
\hline & $\dot{\sigma}$ & & & & & & & & & 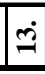 & $\dot{\square}$ & & & & & ते|त่ & & & & \begin{tabular}{l|l|} 
\\
\end{tabular} \\
\hline \multicolumn{21}{|l|}{ 1. Competencias técnicas } \\
\hline 1.01 Éxito en la direc de proys. & & & & & & & $\mathbf{x}$ & & & & & $\mathbf{x}$ & & & & & & & $\mathbf{x}$ & \\
\hline \multicolumn{21}{|l|}{ 1.02 Partes interesadas } \\
\hline 1.03 Reqstos y objs. del proy. & & $\mathrm{x}$ & $\mathbf{x}$ & & & & & & & & & & & & & & & & $\mathbf{x}$ & \\
\hline 1.04 Riesgo y oportunidad & & & & & & & $\mathbf{x}$ & & & & & & & & & & & $\mathbf{x}$ & & \\
\hline \multicolumn{21}{|l|}{ 1.05 Calidad } \\
\hline \multicolumn{20}{|l|}{1.06 Organización del proy. } & \\
\hline 1.07 Trabajo en equipo & & & & & & & & & & & & & $\mathbf{x}$ & & & & & & & \\
\hline \multicolumn{21}{|l|}{1.08 Resolución de problemas } \\
\hline 1.09 Estructuras del proyecto & & & & & & & & & & & & & & & & & & & $\underline{x}$ & \\
\hline 1.10 Alcance y entregables & $\mathbf{x}$ & & & & & & & & & & & & & & & & & & & \\
\hline \multicolumn{20}{|l|}{1.11 Tiempo y fases del proy } & \\
\hline \multicolumn{21}{|l|}{ 1.12 Recursos } \\
\hline 1.13 Costo y financiación. & & & & & & & & & & & & & & & & & & & $\mathbf{x}$ & \\
\hline \multicolumn{21}{|l|}{ 1.14 Aprovisionam. y contratos } \\
\hline \multicolumn{21}{|l|}{ 1.15 Cambios } \\
\hline \multicolumn{21}{|l|}{1.16 Control e informes } \\
\hline \multicolumn{21}{|l|}{ 1.17 Documentac. e inform. } \\
\hline \multicolumn{21}{|l|}{1.18 Comunicación } \\
\hline 1.19 Lanzamiento & & & & & & & & & & & & $\mathbf{x}$ & & & & & & & & \\
\hline 1.20 Cierre & & & & & & & & & & & & $\mathbf{x}$ & & & & & & & & \\
\hline \multicolumn{21}{|c|}{ 2. Competecias de comportamiento } \\
\hline \multicolumn{21}{|l|}{ 2.01 Liderazgo } \\
\hline 2.02 Compromiso y motivación & & & & & & & & & & & & & & \begin{tabular}{l|l}
$x$ & $x$ \\
\end{tabular} & & & & & & \\
\hline 2.03 Autocontrol & & & & & & & & & & & & & & & & & & $\mathbf{x}$ & & \\
\hline 2.04 Confianza en sí mismo & & & & & & & & & & & & $\mathbf{x}$ & & & & & $\bar{x}$ & $\mathbf{x}$ & & \\
\hline 2.05 Relajación & & & & & & & & & & & & & & & & & & & & \\
\hline 2.06 Actitud abierta & & & & & & & & & $\bar{X}$ & & & & & $\mathbf{x}$ & & & $\mathbf{X}$ & & & \\
\hline 2.07 Creatividad & & & & & & & & $\mathbf{x}$ & & & \begin{tabular}{|l|}
$\mathbf{x}$ \\
\end{tabular} & & & & & & & & & \\
\hline 2.08 Orientación a resultados & $\mathbf{x}$ & & & & & & & & & & & & & & & & & & & \\
\hline 2.09 Eficiencia & & & & & & & & & & & & & & & & & & & & \\
\hline 2.10 Consulta & & & & & & & $\mathbf{x}$ & & & & & & & & & & & & & \\
\hline 2.11 Negociación & & & & & & & & & $\begin{array}{l}x \mid x \\
\end{array}$ & & & & & $\mathbf{x}$ & & & & & & \\
\hline 2.12 Conflictos y crisis & & & & & & & & & $\underline{x}$ & & & & & $\mathbf{x}$ & & & & L & & \\
\hline 2.13 Fiabilidad & & & & & & & & & & & & & & $\mathbf{x}$ & & & & $\mathbf{x}$ & & \\
\hline 2.14 Apreciación de valores & & & & $\mathbf{x}$ & & & & & & & & & & $\mathbf{x}$ & & & $\mathbf{x}$ & & & \\
\hline 2.15 Etica & & & & & & & & & & & & & & $\mathbf{x}[$ & & & & & & $\mathbf{x}$ \\
\hline 3 Competencias contextuales & & & & & & & & & & & & & & & & & & & & \\
\hline 3.01 Orientación a proyectos & & & & & & & & & & & & & & & & & & & $\mathbf{x}$ & \\
\hline 3.02 Orientación a programas & & & & & & & & & & & & & & & & & & & $\mathbf{x}$ & \\
\hline 3.03 Orientación a carteras & & & & & & & & & & & & & & & & & & & $\underline{x}$ & \\
\hline 3.04 Implant. proys, progs, $c$ & & & & & & & & & & & & & & & & & & & $\mathbf{x}$ & \\
\hline 3.05 Orgs. permanentes & & & & $\mathbf{x}$ & & & & & & & & & & & & \begin{tabular}{c|c}
$\mathbf{x}$ & $\mathbf{x}$ \\
\end{tabular} & & & & \\
\hline 3.06 Negocio & & & & & & & & & & & & & & & & & & & & \\
\hline 3.07 Sistms, pdtos y tecnología & & & $\underline{\bar{x}}$ & & & $\underline{\mathbf{x}}$ & & & $\mathrm{x}$ & & & & & & & & & & & \\
\hline 3.08 Dirección de personal & & & & & & & & & & & & & & $\mathbf{x}$ & & & & & & \\
\hline 3.09 Segur, higiene y med. amb. & & & & $\underline{x}$ & & & & & & & & & & & & $\mathbf{x}$ & & & & \\
\hline 3.10 Finanzas & & & & & & & & & & & & $\mathbf{x}$ & & & & & & $\mathbf{x}$ & & \\
\hline 3.11 Legal & & & & & & & & & & & & & & & & & & $\mathbf{x}$ & & \\
\hline
\end{tabular}

Nota: La letra $\mathrm{X}$ indica correspondencia entre los elementos relacionados.

Tabla 1.7 Comparación entre competencias genéricas de Tuning - América latina y los elementos de competencia de IPMA. Fuente: elaboración propia 


\subsubsection{Selección de competencias genéricas para la Ingeniería en Latinoamérica}

Afirmamos entonces, que la codificación de competencias TuningAL incluye a las de IPMA totalmente y, de las comparaciones anteriores, también a las de CDIO y las de ABET, por lo tanto puede emplearse para la formación de competencias de los estudiantes de ingeniería de América Latina con énfasis en la gestión de proyectos.

Con las competencias genéricas de Tuning, el desarrollo de un modelo educativo para ingeniería industrial en el Perú permitirá que sus estudiantes tengan una sólida formación en el desarrollo de habilidades contextuales y de comportamiento, en un enfoque holístico, sin restarle importancia a las técnicas. Además, como las competencias TuningAL contienen a los elementos de competencia de IPMA, puede afirmarse que serán capaces de emprender una genérica formación en gestión de proyectos.

Para la carrera de Ingeniería Industrial en el Perú consideramos conveniente emplear las competencias genéricas establecidas por el Proyecto TuningAL para diseñar y complementar un modelo educativo cuyo currículo esté basado en ellas.

\subsection{MÉTODOS DE ENSEÑANZA-APRENDIZAJE DE COMPETENCIAS GENÉRICAS EN EL ÁMBITO DE LA INGENIERÍA}

La formación en competencias implica construir un currículum integrado, con las competencias imbricadas en las asignaturas. También implica insertar asignaturas de proyectos en las que de manera natural se desarrollen diversas competencias personales e interpersonales, específicas de la ingeniería. En particular, es conveniente que el primer año se imparta una asignatura en la que se desarrolle una introducción a la ingeniería y un primer proyecto, a fin de que el estudiante pueda identificar el contexto en el que se desenvolverá su formación y pueda enfocar correctamente el resto de asignaturas del grado (Crawley et al.; 2008).

Se trata, en resumen, de considerar las competencias genéricas como el contexto del aprendizaje de la ingeniería y no su contenido, que seguirá estando constituido por las competencias específicas de las distintas materias (Bragós et al, 2010).

En general, para lograr aprendizajes basados en competencias, la estrategia de enseñanzaaprendizaje debe asegurar la adquisición por los estudiantes de competencias genéricas de la carrera y específicas de las asignaturas. Es el profesor quien debe seleccionar una estrategia organizada en una metodología y unas actividades concretas (Yániz, 2003).

Las metodologías que pretenden formar en competencias deben favorecer el desarrollo del estudiante con aprendizajes significativos. Una forma general que da resultados es la cíclica de cinco pasos que se basa en partir de un contexto experiencial, luego una observación reflexiva, para pasar a la conceptualización, que da paso a la experimentación y termina en la evaluación, Gráfico 1.1 (Poblete y García., 2007). 
El contexto experiencial, es importante porque un aprendizaje se genera desde las ideas, concepciones y experiencias previas, es decir en su contexto personal académico y social. Por lo tanto para entender algo, un problema, debe comprenderse el contexto que lo alberga. Por esto es conveniente que, para que un aprendizaje nuevo sea acogido por un alumno, se presente a través de las experiencias y conocimientos ya adquiridos, contextualizarlo a la realidad del estudiante. Esto puede hacerse de modo colaborativo, intercambiando experiencias o puntos de vista sobre el problema en el contexto dado.

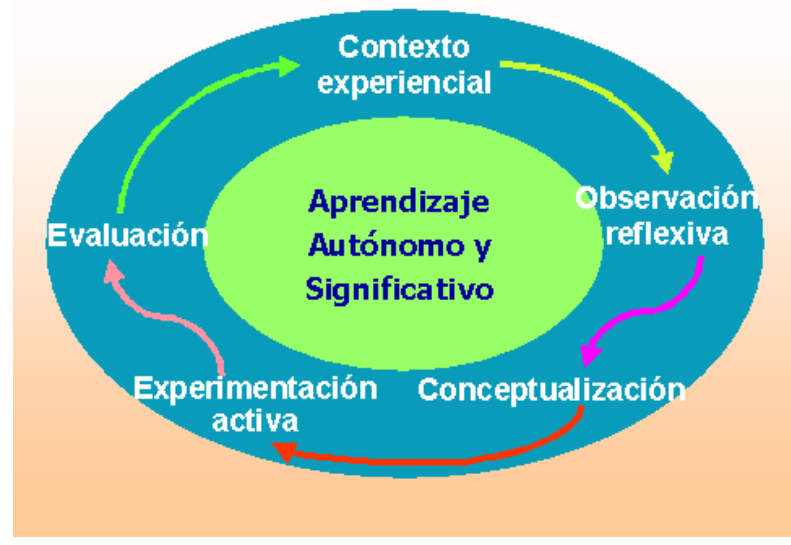

\section{Gráfico 1.1 Fases del modelo de aprendizaje cíclico de cinco etapas. Fuente: (Poblete, y García., 2007)}

La observación reflexiva expone que si bien la observación es un método natural de aprendizaje si no se acompaña de la reflexión no habrá aprendizaje significativo pues es en la reflexión cuando la memoria, el entendimiento, la razón y los sentimientos permiten captar el significado esencial de lo que se está estudiando. En esta fase es que el alumno se hace las preguntas y busca las respuestas.

La conceptualización, se busca que los aprendizajes incluyan conocimientos, hechos, métodos, estrategias y teorías que configuran el saber científico y técnico de la disciplina en cuestión. No se trata de aprender de manera repetitiva, debe ser el resultado del uso y aplicación de habilidades cognitivas como la comprensión, pensamiento analítico-sintético, juicio crítico y pensamiento divergente.

La experimentación activa, implica la acción, la vinculación entre la teoría y la práctica (ejercicios, prácticas, proyectos, trabajos de investigación, diseños, etc.), se trata de valorar el propio comportamiento personal y profesional desde la perspectiva de la necesaria coherencia entre lo que se hace, lo que se dijo que se haría y las creencias y valores del alumno. Esto dentro de los ámbitos técnico y humano o social, propios de la asignatura.

La última fase es la evaluación, y esta debe verificarse en tres niveles: personal, formativo y sumativo. El personal es la propia valoración del estudiante de su aprendizaje "¿qué has aprendido?”, “¿qué has aportado?”, “¿lo consideras importante?”. Esto permite determinar las capacidades puestas en juego, sus limitaciones y motivaciones, así como las técnicas empleadas. La formativa es dar la información al alumno de los resultados alcanzados para que progrese. La sumativa es hacer un juicio y valorar el rendimiento del alumno que lleva a una calificación y un nivel de competencia alcanzado. 
Para Poblete (2007), las competencias son parte esencial del desarrollo integral de la personalidad del estudiante, Gráfico 1.2. Se han de incluir en el aprendizaje como un elemento necesario. Las competencias, aunque se determinan y miden en el desempeño, adquieren sentido, al influir y ser influidas por actitudes y valores. El Aprendizaje Basado en Competencias implica establecer las competencias que se consideran necesarias en la sociedad actual y que no pueden ser determinadas unidireccionalmente por la universidad, sin tener en cuenta las entidades destinatarias como son las organizaciones laborales y profesionales. Consiste en desarrollar las competencias genéricas y las competencias específicas (propias de cada profesión) con el propósito de capacitar a la persona acerca de los conocimientos científicos y técnicos, de su aplicación en contextos diversos y complejos, integrándolos con sus propias actitudes y valores en un modo propio de actuar personal y profesionalmente.

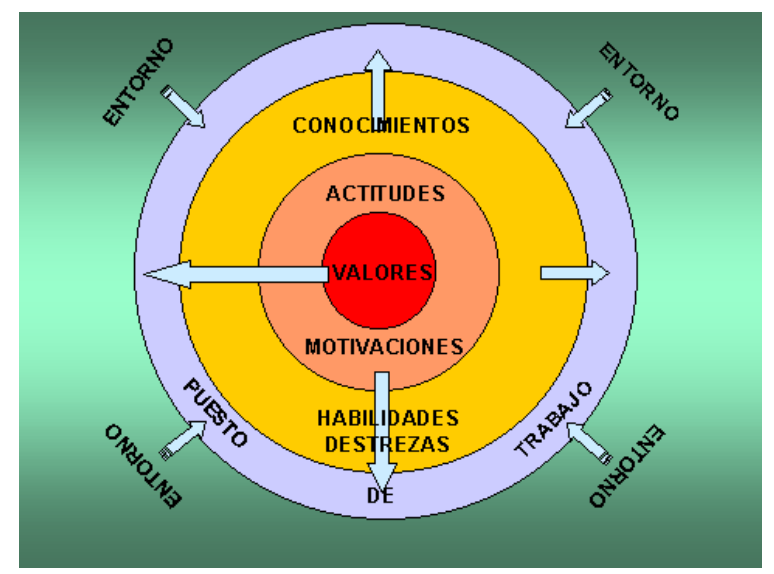

Gráfico 1.2 Implicación de las competencias. Fuente: (Poblete, 2007)

Las metodologías que se ajustan a este enfoque y se están usando en las universidades actualmente para lograr los aprendizajes en competencias son las que se muestran a continuación. Pueden ser empleadas en su forma pura o en una combinación de ellas en cada curso o en el currículo. Se muestran de una forma resumida pues no se intenta hacer una exhaustiva revisión de cada caso (Fortea M.A., 2009).

\subsubsection{Métodos existentes.}

\section{Método de lección magistral}

Método expositivo consistente en la presentación de un tema lógicamente estructurado con la finalidad de facilitar información organizada siguiendo criterios adecuados a la finalidad pretendida. Centrado fundamentalmente en la exposición verbal de los contenidos por parte del profesor sobre la materia objeto de estudio. La finalidad es transmitir conocimientos y activar procesos cognitivos en el estudiante

La clase magistral ofrece importantes ventajas frente a otros métodos docentes: es un método rápido, barato y eficiente de transmitir una gran cantidad información a un gran número de alumnos de forma simultánea. Es un método "conservador", porque es muy conocido tanto 
por los profesores como por los alumnos. Pero no es el mejor de los métodos docentes (y para ser justos, tampoco es el peor) (Luján Mora, 2013). Por ejemplo, está demostrado que la atención de los alumnos sólo se puede mantener por períodos cortos de 15-20 minutos separados por pequeños "lapsus" de 1-2 minutos en los que los alumnos "desconectan" y dejan de prestar atención; estos periodos de atención se van reduciendo, llegando a durar menos de cinco minutos al final de una clase magistral tradicional (Khan, 2012).

Por eso, importa más el tiempo de trabajo, de aprendizaje del estudiante que el tiempo de clase del profesor, importa más cómo funciona autónomamente el estudiante, buscando en las fuentes de información, que lo que importa cómo hace unos apuntes, fieles al dictado del profesor. La clase es un elemento más, un método de aprendizaje puesto a disposición del estudiante para que recorra el camino de su propio proceso (Poblete, 2007).

\section{Método de resolución de ejercicios y problemas}

Situaciones donde el alumno debe desarrollar e interpretar soluciones adecuadas a partir de la aplicación de rutinas, fórmulas, o procedimientos para transformar la información propuesta inicialmente. Se suele usar como complemento a la lección magistral. La finalidad es ejercitar, ensayar y poner en práctica los conocimientos previos.

El contenido procedimental es el conjunto de actividades y acciones que sirven para ir adquiriendo de forma gradual y mediante la práctica algunas destrezas para "saber cómo hacer" algo (conocimiento procedimental). El estudiante realizará los procedimientos para la resolución de problemas y ejercicios en forma secuencial y sistemática. Estos contenidos requieren de la repetición de las actividades y acciones, con la meta de llevar al estudiante a dominar la técnica, habilidad o destreza requerida (Villanueva, 2013).

Esto lleva a considerar que los estudiantes obtienen mayor nivel de rendimiento si se han preparado mejor en esta habilidad procedimental llamada operativa, la cual se va desarrollando y afianzando a lo largo de los niveles educativos. En el nivel superior, dicha habilidad se mide a través del éxito en la resolución de ejercicios y problemas. Es necesario que en los niveles anteriores se desarrollen los contenidos poniendo atención al desarrollo de habilidades operativas, que servirán como herramienta para el desarrollo posterior de la matemática superior. Se debe tener en cuenta que al principio, las habilidades operativas desarrolladas anteriormente pueden resultar irrelevantes, pero posteriormente, dichas habilidades se convertirán en una herramienta necesaria e indispensable para procurar la asimilación de nuevos conocimientos no sólo en Matemática sino también en otras áreas. (Villanueva, 2013).

\section{Método del aprendizaje basado en problemas (ABP)}

Método de enseñanza-aprendizaje cuyo punto de partida es un problema que, diseñado por el profesor, el estudiante en grupos de trabajo ha de abordar. De forma ordenada y coordinada los estudiantes enfrentan las fases que implican la resolución o desarrollo del trabajo en torno al problema o situación. La finalidad es desarrollar aprendiqajes activos a través de la resolución de problemas. 
Para De Miguel (2005), citado por Guerrero (2011), el ABP es un método de enseñanzaaprendizaje cuyo punto de partida es un problema que, diseñado por el profesor, el estudiante ha de resolver para desarrollar determinadas competencias previamente definidas. Parte de la idea de que el estudiante aprende de un modo más adecuado cuando tiene la posibilidad de experimentar, ensayar o, sencillamente, indagar sobre la naturaleza de fenómenos y actividades cotidianas; que el aprendizaje es más estimulante cuando se plantean preguntas que requieren del esfuerzo intelectual del estudiante y cuando no se brinda toda la información a los estudiantes para solucionar el problema; y que los problemas que entrañan cierta dificultad se resuelven mejor en colaboración con otras personas.

El aprendizaje basado en problemas no es un método fácil, se requiere una experiencia considerable del tema y flexibilidad por parte de los profesores, que pueden ser desplazados de sus áreas de especialización, cuando los equipos de estudiantes salen en direcciones imprevisibles y desconocidas. El ABP también hace que los estudiantes asuman niveles no acostumbrados de responsabilidad de su propio aprendizaje, y hace que surjan todos los problemas de gestión de proyectos y los conflictos interpersonales que comúnmente ocurren cuando los estudiantes están obligados a trabajar en equipo. Además, muchos estudiantes son hostiles al ABP cuando "tropiezan" con él por primera vez, lo cual puede ser intimidante para los profesores que no están preparados para esta reacción (Prince \& Felder, 2006: 130; citado por Guerrero, 2011).

\section{Estudio de casos (Case Studies)}

Análisis intensivo y completo de un hecho, problema o suceso real con la finalidad de conocerlo, interpretarlo, resolverlo, generar hipótesis, contrastar datos, reflexionar, completar conocimientos, diagnosticarlo y, en ocasiones, entrenarse en los posibles procedimientos alternativos de solución. La finalidad es adquirir aprendizajes mediante el análisis de casos reales o simulados (Fortea M.A., 2009).

El objeto es lograr un encadenamiento entre la teoría y la práctica a través de un proceso reflexivo que lleva a un aprendizaje significativo, al verse los alumnos obligados a detectar y analizar cómo los expertos han logrado resolver sus problemas, y las decisiones, valores, técnicas y/o recursos empleados en ese proceso. Buscar la comprensión e interpretación del conjunto del caso, de las alternativas que pueden surgir de él, así como de las decisiones y posiciones asumidas, desarrolla un aprendizaje activo, que trasciende el aula, y sirve para generar modelos de acción que pueden evocarse en situaciones posteriores similares (De Miguel 2005).

Los objetivos del método del caso son: formar profesionales capaces de encontrar para cada problema particular la solución experta, personal y adaptada al contexto social; trabajar desde un enfoque profesional los problemas de un dominio determinado, partir de un problema real, con sus elementos de confusión, a veces contradictorios, tal como en la realidad se dan; crear contextos de aprendizaje que faciliten la construcción social del conocimiento y favorezcan la verbalización de las ideas y de los conocimientos (UVa, 2006).

Las mayores ventajas que se generan son: retención de la información y el conocimiento adquirido al discutir y practicar acerca de los conceptos utilizados; el aprendizaje significativo, 
ya que el estudiante usa conocimientos previos para el análisis del problema y la propuesta de soluciones; desarrollo de diversos estilos de aprendizaje; aprendizaje en grupo y el trabajo en equipo; y que resolución de problemas genera conocimientos y promueve la creatividad. También algunos inconvenientes se generan: el autor es quien recoge los datos a los que se refiere el caso, por lo que la formación debe de ser complementada con la capacitación en recogida de datos (algo fundamental para tomar decisiones); las soluciones a los problemas que se plantean durante el estudio del caso, no se llevan generalmente a la práctica, por lo tanto, el método no sustituye la formación práctica; los estudiantes tienen que poseer ciertos conocimientos sobre el tema y no suelen estar acostumbrados al proceso de reflexión sobre problemas en grupo, elaboración de propuestas de solución y su defensa en público y una asignatura semestral no proporcionan suficiente tiempo para desarrollar esta cultura (Uva, 2006).

\section{Aprendizaje basado en proyectos (PBL)}

Método de enseñanza-aprendizaje en el que los estudiantes llevan a cabo la realización de un proyecto en un tiempo determinado para resolver un problema o abordar una tarea mediante la planificación, diseño y realización de una serie de actividades y todo ello a partir del desarrollo y aplicación de aprendizajes adquiridos y del uso efectivo de recursos. La finalidad es realizar de un proyecto para la resolución de un problema, aplicando habilidades y conocimientos adquiridos (Fortea M.A., 2009).

El aprendizaje basado en proyectos es un aprendizaje orientado a la acción, no se trata solo de aprender "acerca" de algo (como ocurre en el aprendizaje basado en problemas), sino en "hacer" algo (De Miguel, 2005).

Existen tres tipos de proyectos que difieren en el grado de autonomía de los estudiantes (De Graaff \& Kolmos, 2006, pág. 130, citado por Guerrero, 2011): Proyecto de tarea: los equipos de estudiantes trabajan en proyectos que han sido definidos por el instructor, utilizando los métodos dados por él. Proporciona la mínima motivación al estudiante y el desarrollo de habilidades, es parte de la instrucción tradicional en muchos programas de ingeniería; Proyecto de disciplina: el profesor define el área temática de los proyectos y especifica en términos generales los criterios que se utilizarán, pero los estudiantes identifican el proyecto concreto y diseñan el enfoque particular que tomarán para completarlo; y Proyecto del problema: los estudiantes disfrutan de una autonomía casi total para elegir su proyecto y su acercamiento a este.

Las mayores ventajas están en que los estudiantes aprenden a tomar sus propias decisiones y a actuar de forma independiente, mejora la motivación para aprender porque se apoya en la experiencia, permite aplicar los conocimientos, habilidades y actitudes adquiridas a situaciones concretas con la consiguiente mejora de las competencias correspondientes, favorece un aprendizaje integrador (aprendizajes cognitivos, metodológicos, sociales y afectivos). Su principal desventaja es la dificultad de actuar con estudiantes poco motivados, de bajo rendimiento académico, que carezcan de experiencias (De Miguel 2005). 


\section{Aprendizaje cooperativo}

Es un enfoque interactivo de organización del trabajo en el aula en el que los alumnos son responsables de su aprendizaje y del de sus compañeros, en una estrategia de corresponsabilidad para alcanzar metas e incentivos grupales. La finalidad es desarrollar aprendizajes activos $y$ significativos de forma conjunta y colaborativa (Fortea M.A., 2009).

En una estructura de aprendizaje cooperativo los alumnos y las alumnas están distribuidos en pequeños equipos de trabajo, heterogéneos, para ayudarse y animarse mutuamente a la hora de realizar los ejercicios y las actividades de aprendizaje en general. Se espera de cada alumno, no sólo que aprenda lo que el profesor o la profesora les enseña, sino que contribuya también a que lo aprendan sus compañeros y compañeras de equipo es decir, se espera de ellos que, además, aprendan a trabajar en equipo. Los alumnos consiguen este doble objetivo si y solo si los demás lo consiguen. Una estructura cooperativa lleva a los alumnos a contar unos con otros, a ayudarse. Todo lo contrario de un aula individualista donde cada quien va a lo suyo prescindiendo de los demás. Los alumnos y las alumnas que, por diversos motivos, tienen más dificultades a la hora de aprender tienen muchas más oportunidades de ser atendidos en un aula cooperativa. Este método se basa en la lógica de que los alumnos son heterogéneos y no que son homogéneos (Pujolàs, 2012).

Este método propone abandonar la lógica de la homogeneidad y avanzar decididamente hacia la "lógica de la heterogeneidad": Teniendo en cuenta que muchos entornos postescolares, domésticos, laborales o recreativos de la comunidad son de naturaleza fundamentalmente heterogénea, la lógica de la heterogeneidad postula que si esperamos que alumnos "diferentes" funcionen eficazmente en entornos comunitarios heterogéneos, es necesario que en la institución educativa tengan la oportunidad de llevar a cabo tantas experiencias como sea posible basadas en esta heterogeneidad. Esta nueva lógica lleva a la conclusión de que las personas con diferencias o disimilitudes deberían poder interactuar cuanto más mejor (Brown et al. 2007).

Debe tenerse cuidado, decir y recalcar que, en algunas ocasiones seleccionadas y con finalidades específicas, atender temporalmente al alumnado en grupos homogéneos o, incluso, de forma individualizada, puede ser defendible desde un punto de vista educativo, médico y social. Una cosa no quita a la otra y no podemos caer en el extremo totalmente opuesto. Es decir, rechazar completamente la lógica de la homogeneidad puede ser tan irracional como adherirse a ella ciegamente. Sin embargo, la lógica de la homogeneidad, en la medida que determina los servicios educativos previstos para los alumnos "diferentes", es generalmente negativa y debe ser rechazada a favor de la lógica de la heterogeneidad (Brown et al. 2007).

\section{Trabajo en equipos.}

Es un enfoque de trabajo cooperativo en el aula, en el que los alumnos se agrupan, designan un líder, se trabaja por acuerdos, se fijan normas y se respetan, se fijan objetivos, buscando que haya cohesión entre los miembros, surjan nuevos enfoques y se negocien las soluciones a los problemas. No es un aprendizaje del equipo, es un aprendizaje en equipo. La finalidad es mezclar las múltiples habilidades de los miembros del equipo para hacerlos más sociables, más 
respetuosos de las ideas de los demás, más solidarios, más eficaces y más productivos (Fortea M.A., 2009).

$\mathrm{El}$ aprendizaje en equipo es vital debido a que los equipos, no los individuos por si solos, son la unidad fundamental del aprendizaje en las organizaciones. La disciplina del aprendizaje en equipo inicia con un "diálogo", como la capacidad de los miembros del equipo a suspender suposiciones e iniciar una etapa genuina de "pensamiento en conjunto", permitiendo hacer descubrimientos que no se pudieran hacer en forma individual. El trabajo en equipo es considerado un punto clave y una ventaja competitiva, en la actualidad, debido a su gran importancia ha generado un cambio en la manera de trabajar, dando lugar a un incremento de los equipos de trabajo. Esta competencia participativa permite aumentar la productividad, la innovación y la satisfacción en el trabajo y por ello es tan necesaria en los egresados (Rousseau et. al. 2006).

Para el trabajo en equipo se determinan siete dimensiones necesarias para tener éxito con el método. La primera dimensión hace referencia a la planificación del equipo: el conocimiento de la misión, los objetivos, la asignación de roles, la planificación, entre otros lo incluyen dentro de la dimensión de autogestión. Para Baker et. al. (2006), esta dimensión es sobre todo, preparatoria, de planificación y toma de decisiones. La segunda dimensión es de coordinación-cooperación. Esa sincronización con los otros miembros y tareas es un requisito básico. Debe haber interdependencia entre los miembros del equipo. La tercera dimensión es la interacción reconocida en los diferentes estudios analizados como un componente necesario en el grupo para alcanzar sus metas de comunicación, que viene a reconocer como indispensable (Torrelles et al. 2011). La cuarta dimensión es el procedimiento de seguimiento y realimentación, tal como lo indican Stevens y Campion (1994). Las dimensiones quinta y sexta, hacen mención expresa a la Resolución de conflictos y la Resolución de problemas colaborativos. Queda una séptima dimensión que contempla Rousseau et. Al. (2006) denominada ajustamientos del equipo donde se trabajan los aspectos de apoyo, orientación dentro del equipo e innovación.

Torrelles (2011) concluye que la competencia de trabajo en equipo es una competencia viva, multidimensional, con múltiples categorizaciones dada su complejidad (por su eficiencia) y que abarca múltiples modelos de antaño.

\section{Contrato didáctico o de aprendizaje (Learning Contract)}

Alumno y profesor de forma explícita intercambian opiniones, necesidades, proyectos y deciden en colaboración como llevar a cabo el proceso de enseñanza-aprendizaje y lo reflejan oralmente o por escrito. El profesor oferta unas actividades de aprendizaje, resultados y criterios de evaluación; y negocia con el alumno su plan de aprendizaje. La finalidad es desarrollar el aprendizaje autónomo (Fortea M.A., 2009).

El contrato de aprendizaje es un acuerdo establecido entre el profesor y el estudiante para la ir tras unos aprendizajes a través de una propuesta de trabajo autónomo, con una supervisión por parte del profesor y durante un período determinado. Recibe el nombre de contrato porque 
es básico tener un acuerdo formalizado de aprendizaje, una relación de contraprestación recíproca, una implicación personal y un marco temporal de ejecución (Lobato, 2006: 219).

De esta definición se pueden destacar los siguientes aspectos: Acuerdo entre profesor y estudiante: negociación sobre los objetivos y competencias a lograr, los contenidos a estudiar, la metodología y evaluación. No todo es negociable, existen objetivos, competencias y contenidos que el estudiante tendrá que alcanzar sí o sí; Trabajo autónomo: el alumno es el que aprende. Él tendrá que desarrollar las habilidades y recursos necesarios para lograr sus aprendizajes. El profesor será un guía, un apoyo y un orientador. El alumno, en la evaluación acordada, demostrará que ha alcanzado los objetivos que fueron negociados; Supervisión del profesor: a base de un plan de tutorías, de encuentros para establecer una fluida comunicación entre el tutor y el alumno; Contraprestación recíproca: en el contrato de aprendizaje se fijan una serie de derechos y deberes del profesor y del alumno. Ellos se comprometen a cumplir lo acordado; Marco temporal de ejecución: el contrato ha de tener una fecha de inicio y una fecha de finalización (UPM, 2009).

De entre las ventajas del método hay unas que son más saltantes: promueve la autonomía y responsabilidad del alumno, incrementar la motivación e implicación del alumno en su propio aprendizaje (toma de decisiones), estimula la actividad del alumno en el proceso de enseñanzaaprendizaje, atiende las características personales de cada alumno, promueve la capacidad de autoevaluación y pensamiento crítico del alumno (García y Fortea; 2006)

Sin embargo también presenta inconvenientes: la baja motivación del alumno y la poca experiencia de aprendizaje autónomo dificultarán el proceso y corresponde al docente la motivación del alumno, así como ofrecerle que gradualmente se vaya responsabilizando de su aprendizaje; las barreras culturales y sociales basadas en mitos como profesores y alumnos no pueden debatir y llegar a acuerdos sobre el aprendizaje o que es un método que promueve el individualismo en vez del trabajo cooperativo y grupal; y el control y poder, porque en este método el control del aprendizaje lo tiene el alumno y para el profesor quizá sea una situación difícil de manejar al principio (Anderson y otros, 1996).

La evaluación del contrato de aprendizaje se realiza en función de lo acordado en dicho contrato entre el profesor y el alumno. No puede ser de otra manera. Los contratos, y este tipo particular que se elabora con el alumno directamente, deben cumplirse en las condiciones pactadas entre las partes.

\section{Seminario clásico}

Encuentros semanales de unos pocos estudiantes (10 o 15) y un profesor que actúa como experto y animador. El objetivo es explorar y estudiar un tema especializado en profundidad. Se compone de 4 partes: lecturas (iniciales comunes facilitadas por el profesor e investigación de ampliación a cargo del estudiante), redacción progresiva de textos tutorizada por el profesor, y discusión del seminario tras la lectura de todos los textos por todos los estudiantes. La finalidad es un aprendizaje cooperativo (Fortea M.A., 2009).

El seminario es un grupo de aprendizaje activo, pues los participantes no reciben la información ya elaborada, como convencionalmente se hace, sino que la buscan, la indagan por sus propios 
medios en un ambiente de recíproca colaboración. Es una forma de docencia y de investigación al mismo tiempo. Se diferencia claramente de la clase magistral, en la cual la actividad se centra en la docencia-aprendizaje. En el seminario, el alumno sigue siendo discípulo, pero empieza a ser él mismo profesor. Es importante implementar este aprendizaje en las aulas, los estudiantes aprenden a no hacer las cosas tan obvias cuando se pretende explicar algún fenómeno y aceptar explicaciones poco convencionales para lo que es su diario vivir. El cambio permanente implica adaptaciones fundamentales en el sistema educativo, en cada nivel "aprender", en este caso, se entiende como un proceso activo de construir su propio conocimiento con apoyo de profesores, que no presentan la materia de enseñanza, sino que aconsejan a sus estudiantes dónde y cómo se puede encontrar lo que quieren y tienen que aprender (Johnson et al. 1997).

Las ventajas de este método son, ejercita a los estudiantes en el estudio personal y de equipo, los familiariza con medios de investigación y reflexión, y los ejercita en el método filosófico. El seminario es fundamentalmente una práctica.

Desventajas: los participantes pueden tener intereses no comunes respecto al tema o un distinto nivel de información acerca del mismo; el tema del Seminario exige la investigación en diversas fuentes y los alumnos pueden no estar preparados para esto, un tema ya expuesto en un libro no justifica el trabajo de Seminario; los resultados o conclusiones son responsabilidad de todo el grupo de seminario y en ocasiones algunos alumnos pueden ocultarse en otros y no es fácil detectarlos; el profesor es un facilitador, es un miembro más que coordina las labores pero no resuelve de por sí.

\section{Aprendizaje a través del aula virtual}

Situación de enseñanza-aprendizaje en la que se usa un ordenador con conexión a la red como sistema de comunicación entre profesor-alumno y se desarrolla un plan de actividades formativas integradas dentro del currículo. Existen múltiples "entornos" ya diseñados no solo para "colgar información", sino para facilitar el "aprendizaje constructivo" por parte del estudiante (como por ejemplo el "Moodle" o los MOOC's).

Creemos que los entornos personales de aprendizaje (PLE, Personal learning enviroment), es un concepto que resume las ideas sobre cómo podemos utilizar las herramientas de comunicación que nos ofrece la Internet para aprender y desarrollarnos personal y profesionalmente junto otras personas, va a transformar en los próximos años no solo el ámbito del desarrollo profesional y la formación continua, sino también la enseñanza reglada en las aulas, combinándose con las fórmulas tradicionales y formando parte del bagaje de recursos y estrategias habituales del docente y muy especialmente del estudiante, del aprendiz (Adell \& Castañeda, 2010).

En la sociedad de la información, como afirma Attwell (2007) “...no podemos simplemente reproducir formas previas de aprendizaje, el aula o la universidad, encarnadas en software. Tenemos que mirar hacia las nuevas oportunidades para el aprendizaje posibilitadas por las tecnologías emergentes". Este es el reto, en la era de la información, en un tiempo tan complejo y cambiante como el que vivimos. Se trata de contribuir a desarrollar, con la tecnología que disponemos, una competencia básica: aprender a aprender (Attwell, 2007, p. 1). El aula virtual 
debe contener herramientas que permitan su correcto funcionamiento como: la distribución de la información, es decir al educador presentar y al educando recibir los contenidos para la clase en un formato claro, fácil de distribuir y de acceder; el intercambio de ideas y experiencias, en un ambiente amigable y estructurado; la aplicación y experimentación de lo aprendido, transferencia de los conocimientos e integración con otras disciplinas; la evaluación de los conocimientos; y el "safe heaven", que es dotar de seguridad y confiabilidad al sistema (Adell \& Castañeda, 2010).

Con lo que debe tenerse especial atención por parte de los docentes en esta estrategia es: el acceso al aula virtual, existen muchas categorías de acceso pero en todos los casos es importante que el personal técnico que administra el aula virtual conozca las necesidades de la clase para que pueda definir y aplicar los privilegios a los sistemas de acceso apropiadamente; la actualización y monitoreo del sitio se debe definir con qué frecuencia y quien estará a cargo de la actualización de las páginas del curso; el archivo de materiales, el profesor debe mantener copias del material presentado al inicio en el aula virtual para seguridad y también de los informes de avance y finales; y el tiempo en el que los materiales estarán en línea para el acceso, es importante que los alumnos sepan cuanto tiempo tendrán acceso al curso, y también que el instructor sea el que decida que pasará con los materiales de la asignatura una vez completadas cada una de sus etapas (Adell \& Castañeda, 2010)..

De entre estas metodologías, todas válidas, existen algunas que tienen una particular incidencia en la formación de ingenieros.

\subsubsection{Estrategia de aplicación de métodos a la Ingeniería Industrial de Perú.}

El rápido ritmo de desarrollo del conocimiento y la tecnología requiere un nuevo paradigma a desarrollar en los estudiantes de ingeniería: habilidades de trabajo en equipo. Los equipos cada vez son más exigidos y requerirán de competencias personales más desarrolladas. Se requiere que sean multidisciplinares con acceso instantáneo a la información y la comunicación, ya que los miembros no estarán en el mismo lugar o incluso ni el mismo país cuando trabajen juntos. Los equipos se forman de acuerdo a los conocimientos técnicos necesarios para el trabajo. Este estilo de trabajo futuro requiere que cambie la educación en ingeniería para facilitar aprender los conocimientos básicos necesarios, y que los profesionales se mantengan al corriente de los nuevos conocimientos en el campo de trabajo (Shuman, Larry, et al; 2002).

En este estilo de trabajo futuro sería necesario que los estudiantes de ingeniería se sientan cómodos y capaces de utilizar la tecnología más avanzada para acceder a la información y comunicarse con otros. También será necesario que la educación en ingeniería proporcione a los estudiantes una conciencia y comprensión mucho más profunda del trabajo en equipo, que lo que nuestros actuales planes de estudios ofrecen. El futuro de la ingeniería debe incluir todos los tipos posibles de personas como ingenieros, incluyendo el trabajo con personas en situaciones de aprendizaje interculturales y/o a distancia. Debe desarrollarse completamente un programa que ayude a un estudiante a apreciar y comprender las diferencias que la cultura, género, etnia, raza, estilos de aprendizaje, valores y ética aportan a la solución de problemas en equipo. Para desarrollar un plan de estudios, el profesorado y los estudiantes tendrán que 
analizar y/o cuestionar algunos de sus supuestos fundamentales sobre la naturaleza de la ingeniería, la naturaleza del trabajo en equipo y la naturaleza de trabajar con aquellos que son diferentes a uno mismo. Saber trabajar en equipo será fundamental (Shuman, Larry, et al; 2002).

Los estudiantes de ingeniería de hoy podrían experimentar en su carrera profesional que sus evaluaciones de desempeño dependan más de su capacidad para trabajar bien en los equipos que en sus habilidades técnicas. Uno de los resultados estipulados en los Criterios de Ingeniería ABET es la capacidad de trabajar en equipos multidisciplinarios. Es poco probable que los estudiantes adquieran conocimientos de alto nivel del trabajo en equipo si solo trabajan en equipos en una o dos asignaturas, pero también es cierto que cientos de estudios de investigación han demostrado que en comparación con los estudiantes que trabajan individualmente, los que en una asignatura trabajan en equipos que funcionan bien, aprenden más, aprenden a un nivel más profundo, son menos propensos a abandonar la asignatura, desarrollan actitudes más positivas hacia ella y una mayor confianza en sí mismos (Felder \& Brent; 2004).

También es cierto que el aprendizaje basado en proyectos (PBL Project-Based Learning) es una de las metodologías educativas más adecuadas para el desarrollo de competencias, vinculando la enseñanza con el ámbito profesional. Esta técnica de aprendizaje se basa en la cooperación, la participación activa y la interacción, ofreciendo múltiples posibilidades para el desarrollo de competencias técnicas, contextuales y comportamiento. La integración de modelos de aprendizaje basada en proyectos tiene su fundamento científico en la generación de procesos de aprendizaje en el que los estudiantes no son receptores pasivos de conocimiento. Exige que tanto profesores como estudiantes asuman un papel más activo, mayor compromiso compartido, y en el caso particular de los estudiantes, una mayor responsabilidad de su propio aprendizaje. (De los Ríos, Cazorla, Díaz-Puente, Yagüe; 2010).

Además, el PBL ayuda a los estudiantes a conectar la teoría con la realidad mediante el tratamiento de problemas que surgen en situaciones de la vida real. $\mathrm{Al}$ asociar el contenido con el contexto, el PBL está basando en la estructura fundamental de la memoria. Enseña conceptos a través de problemas reales, se crea una asociación entre la teoría y la práctica y esta asociación permite que los estudiantes evoquen mejor los conocimientos teóricos pertinentes cuando se enfrentan a problemas reales (Chinnowsky, et al., 2006).

Entonces, los planes de estudio de ingeniería deben incluir un conjunto de asignaturas en las que se desarrollen proyectos, que no deben entenderse como contenedoras de competencias sino el medio en el que éstas se desarrollan y que deben tener un triple impacto:

- Consolidar el aprendizaje de los contenidos y competencias específicas de las materias que se cursan en paralelo y de las anteriores.

- Motivar al estudiante.

- Trabajar en el contexto de la ingeniería y, como consecuencia, ofrecer un marco para desarrollar de manera natural las competencias genéricas correspondientes.

Un aprendizaje basado en proyectos, empujará a los estudiantes hacia niveles superiores de aprendizaje. Estos niveles superiores de aprendizaje son una manera de alcanzar la visión de 
aprendizaje de competencias por un ingeniero de ABET o para alcanzar los objetivos del ingeniero del futuro. Por supuesto, solo porque el aprendizaje es de alto nivel, no significa que los estudiantes (o los profesores) apreciarán los esfuerzos adicionales que esto demanda, pero los resultados lo ameritan (Barroso \& Morgan; 2009).

Esto nos lleva a afirmar que existen varios métodos de aprendizaje de competencias y que pueden ser empleados, en sus formas puras o entrelazados, dentro de una asignatura o en asignaturas distintas dentro de un currículo, pero existen dos que son particularmente apropiadas en la formación de ingenieros y son: el aprendizaje basado en proyectos (PBL) y el trabajo en equipos. También es necesario dejar claro que los métodos de la Lección Magistral y Resolución de Ejercicios y Problemas presentan unas bondades que no deben dejarse pasar desapercibidas o menospreciarles pues su potencia en los aprendizajes ya ha sido demostrado. Estos métodos permiten que el estudiante logre aprendizajes relevantes y significativos a través de su propia realidad o contexto, la observación reflexiva, la conceptualización, la experimentación y una evaluación personal, formativa y sumativa, actuando frente a problemas reales, conectando la teoría con la práctica y creando una asociación en las mentes de los alumnos, que al egresar, les permite evocar mejor los conocimientos teóricos pertinentes cuando se enfrentan a problemas reales. Por estas razones son los métodos a los que daremos mayor relevancia en el diseño del Plan de estudios a partir del Modelo para la educación superior de la ingeniería industrial de Perú desde las competencias.

\subsection{CONCLUSIONES DEL CAPÍTULO III}

La definición del Espacio Europeo de Educación Superior ha llevado a la necesidad de contar con una codificación de competencias genéricas que, sin restarle importancia a las técnicas, deben considerar el desarrollo de habilidades contextuales y de comportamiento, en un enfoque holístico, indispensable para el egresado de educación superior actual. Queda establecido que la codificación holística de competencias es una mezcla de aspectos de: resolución de problemas, comunicación, creatividad y análisis, que determinan el comportamiento profesional, cognitivo, actitudinal y ético de los egresados.

Los 11 criterios de ABET, muestran una codificación de competencias genéricas, 5 duras y 6 blandas, que sirven para la acreditación y son considerados indispensables en los egresados de la ingeniería norteamericana. ABET define un camino hacia una educación ingenieril profunda, integradora y responsable.

La Propuesta CDIO define un listado de competencias en varios niveles. Establece el ciclo de vida de un producto como el entorno idóneo para el estudio de la ingeniería y promueve el aprendizaje de competencias como contexto para el desarrollo de asignaturas. La propuesta CDIO está organizada racionalmente y tiene más niveles de detalle que la codificación de ABET, lo que facilita su comprensión y la aplicación al diseño de planes de estudios. Está bien alineada con los criterios de ABET, los absorbe, facilitando una posterior acreditación al usar CDIO en la formación de ingenieros. 
IPMA ha definido un conjunto de elementos de competencia para la dirección de proyectos con enfoque holístico y minucioso, que lo hace idóneo para servir de base en la determinación una codificación de competencias requeridas para un egresado de la educación superior.

Está demostrado que el listado de competencias CDIO es más amplio e incluye a la de ABET y demostramos que la codificación de IPMA contienen a las de CDIO con la comparación realizada entre ellas. Esto nos permite utilizar la codificación de IPMA en la definición de competencias de un estudiante de ingeniería y tener la confianza que superará la certificación de ABET.

El Proyecto Tuning ha desarrollado un elenco de competencias genéricas para América Latina: TuningAL validado por 62 universidades de 18 países latinoamericanos. Al compararlas con las de IPMA se encuentra que ambas tienen una gran similitud. Podemos afirmar que tanto las competencias IPMA como TunnigAL pueden aplicarse a la formación en educación superior de ingenieros en América Latina y lograr en los estudiantes los resultados esperados por las partes involucradas en el proceso.

La codificación de competencias TuningAL puede: satisfacer las exigencias de acreditación internacional, generar condiciones de gestión de proyectos, ser apropiadas para la formación en ingeniería y ser compatibles con los requerimientos de la educación superior latinoamericana.

Para aplicar las competencias Tuning a la formación de ingenieros industriales en Perú es necesario validarlas, contextualizarlas; dadas las características del sistema de educación superior de Perú, para hacerlo se elige una universidad con una titulación de Ingeniería Industrial esté considerada entre las cinco mejores del país: la Universidad de Piura. El proceso de determinar si pueden ser empleadas en Perú deberá considerar encuestas a los cuatro grupos de interés: alumnos, profesores, egresados y empleadores.

Existen varios métodos de aprendizaje de competencias y pueden ser empleados en sus formas puras o entrelazados dentro de una asignatura o en asignaturas distintas dentro de un currículo, pero afirmamos que existen dos que son particularmente apropiados para la formación de ingenieros y son el Aprendizaje Basado en Proyectos (PBL) y el trabajo en equipos, porque generan aprendizajes relevantes y significativos creando una asociación en las mentes de los alumnos, que al egresar, les permite evocar mejor los conocimientos teóricos pertinentes cuando se enfrentan a problemas reales.

No deben dejarse de lado los métodos tradicionales en el Modelo para la Educación Superior de la Ingeniería Industrial de Perú desde las competencias. Métodos como la Resolución de Ejercicios y Problemas y la clase magistral han demostrado ser útiles en determinados momentos de los procesos de enseñanza - aprendizaje y asignaturas.

Las competencias deben estar imbricadas en las asignaturas, y es conveniente insertar la acción en proyectos en asignaturas de primer año. Así, de manera natural en estas asignaturas se desarrollarán competencias, tanto personales como interpersonales, específicas de la ingeniería. Esta es la mejor forma de realizar una introducción a la ingeniería y a un primer proyecto, en el que el estudiante identifica el contexto en el que se desarrollará su formación y enfoca correctamente el resto de asignaturas del grado. 
Las competencias genéricas son un contexto del aprendizaje de la ingeniería y no su contenido, que seguirá estando constituido por las competencias específicas de las distintas materias

Para poder transmitir las competencias genéricas a los alumnos, debe diseñarse un modelo educativo que estimule su adquisición y un Plan de estudios para la formación de ingenieros que incluya unas competencias específicas para su especialidad y contexto.

\subsection{REFERENCIAS DEL CAPÍTULO III}

ABET (2009). Criteria for Accrediting Engineering Programs. Engineering Accreditation Commission. Effective for evaluations during the 2010-2011 accreditation cycle. See http://www.abet.org/forms.shtml\#For_Engineering_Programs Only

ABET (2012). Criteria for Accrediting Engineering Programs. Effective for reviews during the 2013-2014 accreditation cycle. Engineering Accreditation Commission. ABET 2012. Visto por última vez en mayo de 2014 en http://www.abet.org/uploadedFiles/ Accreditation/Accreditation_Step_by_Step/Accreditation_Documents/Current/2013__2014/eac-criteria-2013-2014.pdf

Adell Segura, J. \& Castañeda Quintero, L. (2010) Los Entornos Personales de Aprendizaje (PLEs): una nueva manera de entender el aprendizaje. En Roig Vila, R. \& Fiorucci, M. (Eds.). Stumenti di ricerca per l'innovaziones e la qualità in ámbito educativo. Le Tecnologie dell'informazione e della Comunicaziones e l'interculturalità nella scuola. Alcoy: Marfil Roma. Università degli studi

Anderson, G., Boud, D., Sampson, J. (1996). Learning contracts. A practical guide. RoutledgeFalmer. Londres.

Attwell, G. (2007). The Personal Learning Environments - the future of eLearning? eLearning Papers, Vol. 2 No. 1. ISSN 1887-1542. http://www.elearningeuropa.info/ files /media/media11561.pdf

Augustine, N.; Vest, C. (1994). Engineering Education for A Changing World. Joint Project by the Engineering Deans Council and the Corporate Roundtable of the American Society for Engineering Education. ASEE, 1994.

Baker, D.P.; Day, R.; Salas, E. (2006). Teamwork as an Essential Component of High-Reliability Organizations. HSR: Health Services Research. Vol. 41, No 4: 1576-1598

Barroso, Luciana; Morgan, Jim; (2009). Project Enhanced Learning: Addressing ABET Outcomes and Linking the Curriculum. Journal of professional issues in engineering education and practice. ASCE. Jan. 2009, pp $11-20$.

Black, K.M. (1994). An Industry View of Engineering Education. Journal of the Engineering Education, Vol, $83 \mathrm{~N}^{\circ}$ 1: $15-18$.

Bragós, R, Alarcón E., Cabrera M., Calveras A., Comellas J., O’Callaghan J., Pegueroles J., Prat L., Sáez, G., Sardá J., Sayrol, E. (2010). Proceso de inserción de competencias genéricas en 
los nuevos planes de estudios de grado de la ETSETB de acuerdo al modelo CDIO. IX Congreso de tecnologías aplicadas a la enseñanza de la electrónica. Madrid 2010.

Brown, L., Nietupski, J. y Hamre-Nieupski, S. (2007). Criterios de funcionalidad última. Suports. Vol. 11, $\mathrm{N}^{\mathrm{o}} 1$

CE IP/12/394. (2012). Comunicación a los Ministros del Proceso de Bolonia: la reforma de la educación superior es clave para el empleo y el crecimiento. Comisión Europea. Comunicado de prensa IP/12/394, del 25/04/2012.

CE IP/12/1233. (2012). "La Comisión presenta la nueva estrategia Replantear la Educación". Comisión Europea. Comunicado de prensa IP/12/1233. Bruselas, Estraburgo, noviembre 2012.

Chinnowsky, P., Brown, H., Szajnman, A. \& Realph, A. (2006) Developing knowledge landscapes through project-based learning. Journal of Professional Issues in Engineering Education and Practice, 132(2), (118-125).

Crawley, Edward F.. (2001). The CDIO Syllabus. A Statement of Goals for Undergraduate Engineering Education. http://www.cdio.org

Crawley, E. F; Malmqvist, J.; Östlund, S.; Brodeur, D. (2007). Rethinking engineering education: the CDIO approach. (2007) Springer Science.

Crawley, Edward; Jianzhong, Cha; Malmqvist, Johan; Brodeur Doris; (2008). The context of engineering education. Proceedings of the 4th International CDIO Conference, Hogeschool Gent, Belgium. June 2008.

De los Ríos, Ignacio; Cazorla, Adolfo; Díaz-Puente, José; Yagüe, José. (2010). Aprendizaje basado en la ingeniería del proyecto de educación superior: dos décadas de las competencias docentes en entornos reales. Procedia Social and Behavioral Sciences (2010), (1368 - 1378). Science direct, 2010

De los Ríos, I.; Guerrero, D. \& Díaz-Puente, JM. (2008). Las competencias profesionales: marco conceptual y modelos internacionales. Actas II Jornadas Internacionales UPM sobre Innovación Educativa y Convergencia Europea 2008 (INECE'08).

De Miguel, M. (2005). Modalidades de enseñanza centradas en el desarrollo de competencias: Orientaciones para promover el cambio metodológico en el Espacio Europeo de Educación Superior. Madrid: Ediciones Universidad de Oviedo.

European Commission. (2014). Vacancies, hirings and job prospects. Employment, Social Affairs \& Inclusion. European Vacancy Monitor. Volumen No. 12 / Febrero 2014. ISSN: 1977-3897

Felder, R.M.; Brent, R.; (2003). Designing and Teaching Courses to Satisfy the ABET Engineering Criteria. Journal of the engineering Education. 92(1), 7-25.

Felder, Richard; Brent, Rebecca. (2004) The ABC's of engineering education ABET, Bloom's taxonomy, cooperative learning, and so on. Proceedings of the 2004 American Society for Engineering Education Annual Conference \& Exposition. 
Fortea, Miguel Ángel. (2009). Metodologías didácticas para la Enseñanza/Aprendizaje de competencias. Formació professorat de la Unitat de Suport Educatiu. Universitat Jaume I.

García, F.J., y. Fortea, M.A. (2006). Ficha metodológica de contrato didáctico o contrato de aprendizaje. Coordinada por Universitat Jaume I. Generalitat Valenciana.

Guerrero, Dante. (2011). Modelo de aprendizaje y certificación en competencias en la dirección de proyectos de desarrollo sostenible. Tesis Doctoral. Universidad Politécnica de Madrid. ETSI Agrónomos.

Guerrero, Dante; De los Ríos, Ignacio. (2013). Modelos internacionales de competencias profesionales. DYNA: Ingeniería e industria, 88 (3), 266-270.

IPMA (International Project Management Association). (2009). Nacional Competence Baseline. V3.0, Revisión 3.1. Asociación Española de Ingeniería de Proyectos. Valencia (2009). AEIPRO.

Johnson, D; Johnson, R. y Smith, K. (1997). El Aprendizaje Cooperativo Regresa a la Universidad; Qué Evidencia Existe de que Funciona. Universidad de Minnesota.

Khan, Salman.. (2012). Why Long Lectures Are Ineffective?. Time Ideas, 2 de octubre. Visitado por última vez el 06 de junio de 2014 en http:/ /ideas.time.com/ 2012/10/02/why- lecturesare-ineffective/

Lobato F., Clemente. (2006). Estudio y trabajo autónomo del estudiante. En De Miguel D., Mario (coord.) Metodologías de enseñanza y aprendizaje para el desarrollo de competencias. Alianza Editorial. Madrid: 191-223.

Luján-Mora, Sergio. (2013) Revista de Docencia Universitaria. Vol.11 (Número especial, 2013), 279-300. ISSN: $1887-4592$

Maffioli, Francesco; Augusto, Giuliano. 2003. Tuning engineering education into the European higher education orchestra. European Journal of the Engineering Education. (251, 273)

Pant, Ira; Baroudi, Bassam. (2008). Project management education: The human skills imperative. International Journal of Project Management. 26 (2008). (124-128). Science Direct.

Pister, K.S.. (1993). A Context for Change in Engineering. Journal of Engineering Education, Vol. 82, No. 2: 66-69.

Poblete R., Manuel. (2007). Evaluación de competencias en la educación superior. Preguntas clave que sobre evaluación de competencias se hacen los profesores. Tentativas de respuesta. III Jornadas Universitarias de Innovación y Calidad “Buenas Prácticas Académicas”. Bilbao.

Poblete, M. \& Gracía, A. (2007). Desarrollo de competencias y créditos transferibles: experiencia multidisciplinar en el contexto universitario. Ediciones Mensajero. Universidad Deusto. Bilbao.

Prados, J.W. (1997). The Editor's Page: Engineering Criteria 2000-A Change Agent for Engineering Education. Journal of Engineering Education. Vol. 86, No. 4. 
Prince, M., \& Felder, R. (2006). Inductive Teaching and Learning Methods: Definitions, Comparisons, and Research Bases. Journal of Engineering Education , 123-138.

Proyecto Tuning (2007). Reflexiones y perspectivas de la Educación Superior en América Latina. Informe Final - Proyecto Tuning - América Latina. 2004-2007 http://tuning.unideusto.org/tuningal.

Pujolàs, Pere. (2012). Aulas inclusivas y aprendizaje cooperativo. Educatio Siglo XXI. Vol. 30 $\mathrm{N}^{\circ}$ 1: 89-112.

Rousseau, V., Aube, C., Savoie, A. (2006). Teamwork behaviors: A review and an integration of frameworks. Small Group Research. Vol. 37 No 5: 540-570.

Sierra, Javier; Cabezuelo, Francisco. (2009). Post periodismo y formación en competencias digitales bajo el paraguas de Bolonia. I Congreso Internacional de la Sociedad Latina de Comunicación Social. Universidad de La Laguna.

Shuman, Larry; Atman, Cynthia; Eschembach, Elizabeth; Evans, Don; FelderR, Richard; Imbrie, P. K.; Mc Gourty, Jack; Miller Ronald; Richards Larry; Smith, Karl; Soulsbi, Eric; Waller, Alisha and Yokomoto, Charles. (2002). The future of engineering education.. $32^{\circ}$ ASEE/IEEE Frontiers in Education Conference. pp T4A-1 - T4A-15

Smerdon, E., (2000). An Action Agenda for Engineering Curriculum Innovation. 11th IEEEUSA Biennial Careers Conference, San Jose, Cal., Nov. 2 and 3, 2000. Visto por última vez en junio 2013, http://www.ieeeusa.org/careercon/proceeding/esmerdon.pdf.

Stevens, M. J., \& Campion, M. A. (1994). The knowledge, skill, and ability requirements for teamwork: Implications for human resource management. Journal of Management. Vol. 20: 503-530.

Torrelles C., Coiduras, J., Isus, S., Carrera X., París, G. y Cela, J. (2011). Competencia de trabajo en equipo: definición y categorización. Profesorado, Revista de currículum y formación del profesorado. Vol. 15, No 3: 329-344

UPM. (2009). El contrato de aprendizaje. Guías rápidas sobre nuevas tecnologías- Servicio de Innovación Educativa. Universidad Politécnica de Madrid.

UVa. (2006). Método de casos. Universidad Politécnica de Valencia. Visitado el 16 de Junio de 2014, de Espacio interuniversitario de recursos para el EEES: http://www.recursos eees.uji.es/fichas/fm3.pdf

Villanueva P., María E. (2013). Evaluación del trabajo adicional de resolución de problemas de matemática. VII Congreso Iberoamericano de Educación Matemática CIBEM. Uruguay. Actas del VII CIBEM (ISSN 2301-0797).

Yániz, C. (2003). Sistemas y métodos de aprendizaje. Seminario Internacional: Orientaciones pedagógicas para la convergencia Europea de Educación Superioi. Universidad de Deusto. Bilbao 2003. 
Capítulo IV Modelo para la Educación Superior
de la ingeniería industrial de Perú
desde las competencias 


\section{INDICE CAPITULO IV}

4 Capítulo IV

iError! Marcador no definido.

4.1 INTRODUCCIÓN DEL CAPÍTULO IV ¡Error! Marcador no definido.

4.2 BASES CIENTÍFICAS DEL MODELO ¡Error! Marcador no definido.

4.2.1 Formación integral de la persona desde las competencias. ¡Error! Marcador no definido.

4.2.2 Modelos de planificación para la educación superior ¡Error! Marcador no definido.

4.2.3 El conocimiento experto y experimentado ¡Error! Marcador no definido.

4.3 PROPUESTA DEL MODELO PARA LA EDUCACIÓN SUPERIOR DE LA

INGENIERÍA INDUSTRIAL DE PERÚ DESDE LAS COMPETENCIAS ¡Error! Marcador no definido.

4.3.1 Esquema conceptual del MESIC. ¡Error! Marcador no definido.

4.4 PROPUESTA DE ESTRATEGIA DE APLICACIÓN DEL MODELO¡Error! Marcador no definido.

4.5 Conclusiones del Capítulo IV ¡Error! Marcador no definido.

4.6 Referencias del capítulo IV ¡Error!

Marcador no definido. 


\section{INDICE DE TABLAS CAPITULO IV}

Tabla 4.1 Aspectos clave del diseño de un Modelo Educativo de Educación Superior. 185 


\section{INDICE DE GRAFICOS CAPITULO IV}

Gráfico 4.1 Integración de Modelos de Planificación. 179

Gráfico 4.2 Modelo de planificación mixto para el MESIC. ¡Error! Marcador no definido.

Gráfico 4.3 Propuesta de componentes del Modelo Educativo de Educación Superior. 185

Gráfico 4.4 Propuesta del Modelo Educativo para la Educación Superior desde las competencias. 186 Gráfico 4.5 Propuesta del Modelo para la Educación Superior de la Ingeniería Industrial de Perú desde las competencias. 188

Gráfico 4.6 Estrategia para el diseño de un modelo para la educación superior desde el enfoque socioformativo. 189 


\subsection{INTRODUCCIÓN DEL CAPÍTULO IV}

En este capítulo se determina un Modelo para la Educación Superior de la Ingeniería Industrial de Perú desde las Competencias (MESIC) y una estrategia para su adecuada aplicación.

En un primer paso se argumentan las bases científicas sobre las que se apoya este modelo, en un segundo paso se propondrá el Modelo para la Educación Superior de la Ingeniería Industrial de Perú desde las Competencias (MESIC) para finalizar con el tercer paso que es definir una estrategia para su aplicación.

En las bases científicas se integran cuatro bases complementarias de la ciencia 1) los enfoques educativos de formación desde las competencias: parte en la que revisamos los enfoques más empleados y elegimos los más apropiados para este fin; 2) métodos existentes de planificación de proyectos: se encuentran las catalogaciones y una síntesis de ellas, de esa síntesis tomamos las que mejor se adaptan a nuestro caso; 3) el conocimiento experto y experimentado: en el que consideramos que la experiencia y la información acumulada por los distintos grupos involucrados en el proceso educativo es fundamental para la definición del modelo; Adicionalmente a estas bases científicas es importante atender la definición de los Aspectos Clave del modelo que son los que deben marcar su diseño de inicio a fin: ¿qué tipo de persona formar? ¿Para qué sociedad? ¿Con qué profesores? ¿En qué ambiente de investigación? Estos aspectos claves deben ser planteados en el modelo y se vuelven cruciales en las aplicaciones del mismo.

Estudiadas las bases científicas y determinadas las corrientes que se seguirán en cada caso, se determinan los componentes de modelo y se propone un Modelo para la Educación Superior de la Ingeniería Industrial de Perú desde las Competencias (MESIC). Consideramos que no es suficiente dejar la propuesta en el modelo en la base teórica, es necesario acompañarla de una propuesta de estrategia de aplicación a un caso concreto, y esto es lo que se desarrolla en la parte tres de este capítulo.

La metodología de investigación empleada es cualitativa del tipo Teoría Fundamentada. En este tipo de metodología se descubren y muestran hipótesis, conceptos, proposiciones y teorías partiendo de datos ya estudiados y probados de otras investigaciones o de marcos teóricos ya existentes, y no de supuestos a priori. Esta metodología permite desarrollar una nueva teoría durante la investigación, lo que se realiza a través de una continua interpelación entre el análisis de lo ya propuesto y probado, y la síntesis en un nuevo constructo a la luz de la nueva información recabada (Stauss y Corbin, 1994: 273). También se emplea la metodología de la Investigación-acción en su forma de búsqueda autoreflexiva de los participantes de un grupo social para perfeccionar las propias prácticas sociales y educativas que se efectúan (Kemmis, 1998: 42).

De este capítulo se obtienen dos productos: una clara propuesta de un Modelo para la Educación Superior de la Ingeniería Industrial de Perú desde las Competencias (MESIC) que parte del enfoque educativo socio-formativo elegido, el conjunto de Competencias Genéricas determinadas en el capítulo anterior y los Aspectos Clave que deben responder a territorio de 
aplicación elegido. El segundo producto, es una estrategia de aplicación del modelo a situaciones concretas.

Queda abierta la necesidad de hacer una aplicación donde se pongan de manifiesto los aspectos clave, se definan unas competencias específicas y se desarrolle el enfoque desde el socioformación en un Plan de Estudios definido y con una gestión curricular apropiada. 


\subsection{BASES CIENTÍFICAS DEL MODELO}

En la búsqueda de esa ansiada apropiada formación de personas capaces de atender el desarrollo de su localidad con proyectos eficaces, hemos recorrido un largo camino que debemos precisar para lograr un modelo educativo de educación superior para la ingeniería industrial de Perú desde las competencias. La precisión es necesaria porque hoy existe en la universidad latinoamericana una gran discusión alrededor acerca de si la formación debe girar hacia las competencias o mantener sus características tradicionales. En una sucinta revisión tenemos que en el Capítulo I concluimos que la universidad latinoamericana tiene vínculos fuertes con la europea, que persigue los resultados de la anglosajona y que es posible trasladar geográficamente con éxito las formas educativas superiores de hacer y de ser, si se tienen en cuenta la realidad del contexto de origen y la realidad del contexto de destino.

En el segundo capítulo puede verificarse que la realidad del entorno en el que se desenvuelve la universidad peruana tiene características muy particulares y confirmamos que el proceso de Bolonia intenta acercar la universidad europea continental a la universidad anglosajona con una interesante propuesta, en ejecución actualmente con el Espacio Europeo de Educación Superior, de la que podemos nutrirnos. También determinamos que la universidad anglosajona ha alcanzado los buenos resultados que hoy muestra con una propuesta distintiva, que involucra el financiamiento del estado y que tiene como fin de la ingeniería el desarrollo de la sociedad, de la industria y de la empresa. Esto les ha llevado a definir un ingeniero industrial que tenga unas capacidades cada vez menos aferradas a la manufactura, cada vez más ligado a la gestión y con unas nuevas competencias que se detallan en ese capítulo.

Lo mencionado en los dos epígrafes anteriores nos llevó a la necesidad de elegir un código de competencias apropiado para la formación de ingenieros que posibilite la acreditación, que considere las tendencias europeas y americanas, que favorezca la gestión de proyectos, y que sea idóneo para Latinoamérica. Luego de hacer una contextualización a Perú de la codificación elegida, se muestran los métodos pedagógicos que muestran mejores resultados de logros de aprendizaje en la educación superior.

Teniendo la certeza, además, que una Ingeniería Industrial de Perú debe atender las características que la sociedad global exige de los ingenieros industriales de las próximas décadas, vistas en el capítulo dos, es que debemos consideramos indispensable precisar las bases científicas sólidas sobre las que se pueda construir ese modelo educativo que queremos.

Además de considerar necesario que un modelo educativo como el buscado se sustente en sólidas bases científicas, es sustancial tener claro que existen algunos componentes adicionales que no debemos pasar por alto.

Primero debemos determinar el enfoque educativo, o más de uno si fuera necesario, que sea estimulador e integrador de aprendizajes significativos en los alumnos y que permitan que la institución superior les transmita la formación que desde su axiología ha previsto inculcar.

También la planificación es fundamental y este modelo educativo debe emplear un modelo de planificación que permita una paulatina transformación de las formas de hacer considerando la participación de los grupos de interés y permitiendo que los expertos aseguren que los 
lineamientos axiológicos, técnicos, cognitivos y procedimentales fundamentales queden manifiestos en los resultados a alcanzar. Es conveniente elegir un modelo de planificación que haya sido probado de manera exitosa.

Finalmente, será imprescindible definir los aspectos clave de las estrategias y actividades empíricamente posibles y contextualizadas necesarias para aplicar el modelo y que no quede solo en una formulación.

A continuación desarrollaremos las bases científicas que nos permiten precisar las componentes del modelo. Luego de ello se planteará el modelo que consideramos pertinente para la formación en la educación superior y finalmente se mostrará la adecuación del modelo a una aplicación concreta y contextualizada en Perú.

\subsubsection{Formación integral de la persona desde las competencias.}

La educación basada en competencias ayuda a recuperar el genuino sentido del trabajo. Las competencias son para Levy-Leboyer (1996) "Repertorios de comportamientos que algunas personas dominan mejor que otras, lo que las hace eficaces en una situación determinada. Estos comportamientos son observables en la realidad cotidiana del trabajo y en situaciones de test, y ponen en práctica, de forma integrada, aptitudes, rasgos de personalidad y conocimientos adquiridos".

Las competencias llegan a formar parte de la personalidad de un individuo, lo que nos permite conocer cómo podría reaccionar y enfrentar diferentes situaciones laborales. La relación causal implica que la competencia origina o anticipa comportamientos y desempeños; esto permite darnos cuenta quién hace las cosas bien o de forma mediocre, de acuerdo con un criterio general. Según esa definición, hay aspectos que son fácilmente identificables, como el comportamiento o desempeño. Estos comportamientos son el resultado de conocimientos y habilidades, los cuales se pueden conseguir con capacitación, y es lo que la mayoría de los modelos educativos de las universidades han logrado. Sin embargo, la competencia es más que el conjunto de habilidades o destrezas que posee una persona, implica la motivación intrínseca como resultado de un buen desarrollo de la personalidad, de una adecuada escala de valores, del lúcido consentimiento y del autoconocimiento. Estos aspectos son más difíciles de detectar, por lo que normalmente quedan fuera de los modelos educativos, pero son los que responden a las necesidades reales de las empresas. Educar en competencias implica formar personas con iniciativa, proactivos y capaces de resolver conflictos, a la par de la adquisición de conocimientos y habilidades. Es por ello que podemos afirmar que la educación superior con enfoque en competencias es un verdadero proceso de formación integral del alumno (Hernández, 2007).

La noción de formación integral desborda la formación para el ejercicio de una profesión, va a lo humano y social, en este sentido se develan implicaciones de una forma de educar, la formación es integral si considera a la persona del estudiante en su totalidad, además de su potencial cognoscitivo y su capacidad transformadora por medio de su acción profesional. Esto plantea una práctica educativa centrada en la persona y la calificación en lo individual y social, en lo actitudinal y social, en el potencial espiritual y en la capacidad para resolver problemas prácticos de la vida. Una sólida formación básica, el desarrollo de la capacidad de aprendizaje 
en el mismo ambiente de trabajo y el cultivo de valores éticos, son la garantía de que el perfil de egreso será el que mantendrá una visión humana integral significativa y altamente estimulante. Además se ha de tener presente que el proceso de formación que conduce al logro del perfil involucra como actores, centro del proceso, a personas que aprenden y maduran, que tienen voluntad y libertad para comprometerse con valores que sean coherentes con su visión de la vida (Inciarte \& Canquiz; 2007).

Para un hombre debe ser de gran importancia ser formado íntegramente, ser cultivado. El término cultura procede de una metáfora agrícola. La tierra puede ser cultivada o permanecer inculta. Cultura es entonces, cuidado, cultivo del espíritu. Tanto la familia como la escuela y los medios de comunicación impulsan a los estudiantes, sobre todo, a valorar el éxito individual, sin advertir que, como dice Leonardo Polo (1999), "todo éxito es prematuro". En cambio, se les disuade de embarcarse en empresas que les comprometan a servir a los demás, a alcanzar una vida lograda desde la perspectiva ética, que es la única que ofrece valores absolutos. Poder decir tonterías en cinco idiomas parece ser más importante. La propia enseñanza reglada pone todo el énfasis en los procedimientos. Se habla, por ejemplo, de "aprender a aprender". Pero se deja sin contestación -o ni siquiera se formula- la pregunta clave: “¿aprender, qué?”. Los contenidos son lo de menos, se arguye, porque pueden encontrarse en cualquier base de datos. Lo importante es que estos jóvenes, llamados a vivir en la sociedad de la información, dominen las nuevas tecnologías informáticas y telemáticas que van a poner a su disposición inmediata todo el saber disponible en el mundo entero; la inteligencia y el carácter de las personas se manifiestan más claramente en un entramado global de redes ciberespaciales que en un mundo de máquinas y altas chimeneas. Lo que realmente demanda la sociedad que está surgiendo en nuestras manos a comienzos del nuevo milenio es una nueva ciudadanía, mucho más activa y responsable, en la que las personas no se conformen con ser convidados de piedra en el concierto público, sino que ejerciten con energía y decisión su libertad social, su responsabilidad cívica y su creatividad cultural. Los nuevos ciudadanos, quienes habrán de tomar el relevo de la cosa pública dentro de pocos años, tendrán el honor y la carga de configurar ese mundo tan distinto al actual, de una forma hondamente humana. Para ello necesitan aprender una asignatura que no está en los libros de texto ni se puede incluir en los planes de estudio. La formación cívica se adquiere como por ósmosis en la familia, en el colegio, en la Universidad, en las relaciones de parentesco y de vecindad. Esto pone en primer término la necesidad del buen ejemplo. Solo el que conviva con buenos ciudadanos aprenderá a ser un buen ciudadano. En esta disciplina, todos somos maestros y discípulos a un tiempo. Cada uno de nosotros debe pensar: que no sea yo el que les falle (Llano, Alejandro; 2001).

Puesto que la formación en competencias está aún en discusión en las universidades, es conveniente poner cuidadosamente de relieve unos puntos para entender la importancia de acometer el proyecto de diseñar un modelo educativo desde ellas, con el fin de evitar tropiezos que creen frustraciones y con que ellas el fracaso de una apropiada y satisfactoria implantación de un Plan de estudios de una carrera universitaria proveniente de un modelo educativo desde las competencias (Tobón, S; 2008):

1. La formación en competencias aumenta la pertinencia de los programas educativos ya que orienta los aprendizajes de modo que sean acordes con los retos y problemas del contexto 
social, comunitario, profesional, organizacional y disciplinar - investigativo, mediante estudios sistemáticos (como el trabajo en equipo, el estudio de problemas, el registro de comportamientos, el aprendizaje basado en proyectos, etc.), teniendo en cuenta el desarrollo humano sostenible y las necesidades vitales de las personas. Ello permite que los aprendizajes, la enseñanza y la evaluación tengan sentido, no solo para los estudiantes, sino también para los docentes, las instituciones educativas y la sociedad.

2. Gestión de la calidad. El enfoque de las competencias posibilita gestionar la calidad de los procesos de aprendizaje de los estudiantes mediante dos contribuciones: evaluación de la calidad del desempeño (desde el alumno) y evaluación de la calidad de la formación que brinda la institución educativa (desde el profesor).

3. Política educativa internacional. La formación basada en competencias se ha convertido en una política educativa internacional de amplio alcance, que se muestra en los siguientes hechos:

a) contribuciones conceptuales y metodológicas a las competencias por parte de investigadores de diferentes países desde la década de los años sesenta del siglo pasado (véase por ejemplo, Chomsky, 1970; McClelland, 1973).

b) el concepto está presente en las políticas educativas de varias entidades internacionales tales como la UNESCO, la OEI, la OIT, etc. (UNESCO, 1998; OEI, 2010; OIT, 2012).

c) la formación por competencias se ha propuesto como una política clave para la educación superior desde la Conferencia Mundial de Educación Superior (UNESCO, 1998);

d) los procesos educativos de varios países latinoamericanos se están orientando bajo el enfoque de las competencias, tal como está sucediendo en Colombia, México, Chile y Argentina (Bernasconi, 2004; López, 2010).

e) actualmente hay en marcha diversos proyectos internacionales de educación que tienen como base las competencias, tales como el Proyecto Tuning de la Unión Europea (García, M. et al., 2003).

4. Movilidad. El enfoque de las competencias es clave para buscar la movilidad de estudiantes, docentes, investigadores, trabajadores y profesionales entre diversos países, con una articulación en los créditos que permitan un sistema que facilite el reconocimiento de los aprendizajes previos y de la experticia. Será más fácil hacer acuerdos respecto a competencias, desempeños y criterios para evaluarlos, que frente a la diversidad de formas que se han tenido tradicionalmente en educación, tales como destrezas, conocimientos específicos, conocimientos conceptuales, mallas curriculares, etc. Las competencias también facilitan la movilidad entre instituciones de un mismo país, y entre los diversos ciclos de la educación por cuanto representan acuerdos mínimos de aprendizaje (González y Wagenaar, 2003).

Las afirmaciones de los párrafos precedentes establecen claramente la tendencia de formación en competencias en la Educación Superior y las bondades y ventajas que concentran, quedando establecido que esta debe ser la forma de enfrentar la formación en la Ingeniería. 
Ahora se debe decidir cuál enfoque educativo es el más apropiado para la formación en competencias.

Existen diversos enfoques que permiten acometer la formación por competencias: funcionalista, conductual, constructivista y socio-formativo. Se muestra una sucinta descripción de ellos para entenderlos y, luego de una comparación, optar por uno de ellos (Tobón, S. 2013).

El enfoque funcionalista es muy popular en muchos países actualmente. Nace de las NVQ (National Vocational Qualifications) inglesas y busca determinar qué tan funcional es un ser humano en distintos contextos, para ello centra su atención en analizar las funciones laborales y sociales. En este enfoque se trata de definir qué debe hacer una persona en un área de trabajo y con esa base construir el plan de estudios para asegurar que los estudiantes tengan éxito en esas actividades.

El enfoque conductual es resultado de la evolución del modelo conductual y la tecnología educativa. Consiste en orientar la formación de estudiantes a partir de competencias clave que den ventajas competitivas a las organizaciones. Se trata de determinar los atributos que aumentan el éxito de las instituciones y estimularlas en los alumnos.

El enfoque constructivista nace en Francia para cubrir vacíos que dejaba el funcionalista. No se basa en el análisis funcional como aquel, sino en el estudio de dificultades de los procesos laborales. La idea es que los estudiantes formen competencias acordes con las dinámicas empresariales, pero teniendo en cuenta sus personales expectativas. Así, competencias se forman a lo largo de la carrera. La dificultad en este enfoque es que los profesores no logran tener claro cuándo se logra la concreción de las competencias en cada espacio formativo, cayéndose en interminables reuniones de coordinación entre docentes y asistentes y extensos formatos de evaluación no satisfactorios para todos.

El enfoque socio-formativo es un innovador enfoque empleado incipientemente por investigadores europeos y latinoamericanos que busca formación integral y desarrollo de competencias dentro del proyecto de vida y de la sociedad. Se diferencia de los demás en que da gran importancia a la filosofía institucional en la determinación de las competencias específicas por formar. El enfoque socio-formativo tiene en cuenta las demandas y requerimientos del contexto como un para qué orientador en la misión universitaria de formar alumnos, pero no de manera determinista en el proceso (Tobón, S. 2013).

Para Sergio Tobón ${ }^{2}$, en la práctica no hay enfoques que se apliquen de manera pura, lo usual es encontrar contribuciones de varios enfoques en un modelo educativo. Esto es positivo si se realiza con rigor metodológico, pues permite hacer frente a los diversos requerimientos que

\footnotetext{
2 Experto e investigador en educación superior. Doctor (Ph.D.) de la Universidad Complutense de Madrid, en Modelos Educativos y Políticas Culturales en la Sociedad del Conocimiento. Es autor de doce libros, entre los cuales están: “Aprender a emprender" (2001), "Modelo pedagógico basado en competencias" (2002), "Formación basada en competencias, pensamiento complejo, diseño curricular y didáctica" (Varias ediciones, 2008) y "Metodología de gestión curricular una perspectiva socio-formativa" (2013). Conferencista y asesor en aplicación de modelos de formación de competencias en diversas universidades de Bolivia, Chile, Colombia, Ecuador, España, EE.UU., Honduras, México, Perú, Portugal y Venezuela, en: diseño curricular por competencias, establecimiento de ciclos propedéuticos, pensamiento complejo y competencias, estrategias didácticas y procesos de evaluación-certificación de competencias.
} 
tiene una institución educativa en la formación de profesionales. Debe evitarse caer en el diseño de un modelo ecléctico sin articulación como resultado de entretejer distintos enfoques. Pero si dos o más enfoques son complementarios y contribuyen a fortalecer la axiología institucional en la formación de personas, se producen sinergias que permiten alcanzar los perfiles de formación deseados. No es inusual que cuando se toman las competencias únicamente con metodología funcionalista o constructivista, se formen planes de estudio que no son acordes con la filosofía institucional y esto quede de manifiesto al final del proceso de construcción del currículo. Estos enfoques solos también pueden provocar que las partes interesadas al interior de la institución no generen competencias genéricas o específicas con las que hubieran deseado contar porque no fueron detectadas en el análisis funcional o constructivo. También es un riesgo que aparezcan algunas competencias que la institución no considera conveniente estimular en sus alumnos y que sin un filtro adecuado podría verse obligada a alentar, incluso en contra de su propia doctrina.

De los enfoques vistos emplearemos el socio formativo como eje principal en la definición de nuestro modelo educativo porque permite poner de relieve la axiología de la institución que la aplique, toma en consideración los retos y requerimiento del entorno, se preocupa por contribuir al desarrollo socio-económico y se preocupa por la sustentabilidad ambiental y el avance científico y tecnológico. De manera complementaria se utilizará el enfoque funcionalista para asegurar que los alumnos se orienten con éxito hacia las actividades laborales y sociales que mayoritariamente les acogen.

El enfoque socio-formativo sigue un proceso participativo, liderado por la institución y busca formar seres humanos integrales, con un proyecto de vida, con espíritu emprendedor y con idoneidad para enfrentar la vida y los retos profesionales (Tobón, S. 2013).

\subsubsection{Modelos de planificación para la educación superior}

Los enfoques funcional, constructivista y conductual, responden a la creencia moderna que el hombre solo puede conocer y dominar lo que hace, y esto conduce a los conceptos de "acción" y "productividad" tan arraigados en la era posmoderna (Arendt, 1958, citado por Cazorla, A. et al, 2013). Es el enfoque socio-formativo el que implica el ideario de la institución y la conjunta participación de los grupos interesados, tanto ascendente, desde los beneficiarios a la institución, como descendente, de la institución a los usuarios, esto nos obliga a buscar un modelo de planificación que permita esa participación.

Interesa un método que estimule la participación de las personas así como de los grupos interesados, que son quienes conservan la memoria y encaminan la continuidad de las acciones a llevar a cabo a través del diálogo y otros medios dentro de la esfera de la planificación (Holden M., 2008). La búsqueda de una integración entre el conocimiento y la acción se pone de manifiesto y nuestra atención se centra en la aplicación de un modelo de planificación en el que los diferentes actores puedan participar, independientemente del tipo de trabajo, o de las personas dentro de los grupos interesados, su posición, estado o experiencia (Cazorla, A. et al, 2013).

Como afirma Cazorla (2007) citado por Fontana (2012), en las intervenciones pequeñas es más fácil que la gente pueda sentirse responsable a nivel individual cuando participa de un proyecto. 
La participación permite, por tanto, enriquecer la planificación con la atención a aspectos concretos de cada una de las personas afectadas. Sin embargo, es usual que no se establezca un diálogo y un compromiso compartido con las estructuras políticas formales, ni con las diferentes administraciones públicas existentes.

Adolfo Cazorla y coautores (2007) en el libro "Desarrollo rural: Modelos de planificación", menciona que las doce más influyentes tradiciones intelectuales de planificación en los últimos doscientos años han seguido una magnífica labor de integración realizada por John Friedmann en una propuesta de cuatro modelos de planificación: Análisis de políticas, Reforma social, Análisis social y Aprendizaje social, Gráfico 2.1, (Cazorla et al., 2007). Exponemos brevemente cada uno a partir de la detallada explicación hecha en el capítulo tres del libro de Adolfo Cazorla mencionado, para encontrar entre ellos el modelo aplicable a nuestra estrategia de planificación desde el socio-formación.

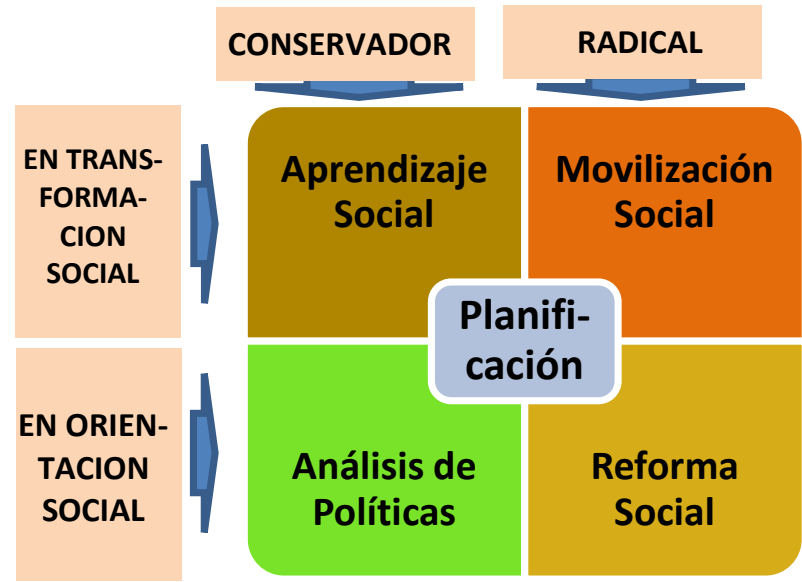

Gráfico 2.1 Integración de Modelos de Planificación.

Fuente: Adaptado de Cazorla et al. 2007.

El primer modelo, Análisis de políticas, insiste en el uso de las teorías científicas y técnicas matemáticas para identificar las mejores soluciones. Es una planificación vertical descendente pero considera los recursos y medios del lugar de actuación. Es empleado en muchos de los proyectos de desarrollo de los países emergentes y su principal defecto es el papel protagónico de los planificadores en el diseño y la acción, con un inadecuado vínculo de comunicación entre planificador y grupos afectados por el cambio.

El Modelo de Reforma Social, en este caso se percibe la planificación como una actividad científica y una de sus principales inquietudes es el uso de paradigmas científicos para informar y limitar las políticas destinadas a la población a lo que considera debe ser lo apropiado (Friedmann, 1991, citado por Cazorla et al. 2007). Es un enfoque descendente de planificación directiva.

El Modelo de Movilización Social, plantea una planificación desde la base primando la voluntad colectiva sobre la del individuo. En este caso son las líneas políticas las que priman sobre la actuación técnica. Es entendida como una lucha entre dirigidos y directores en la que 
los primeros buscan una transformación de lo establecido a través de esa lucha para instaurar un nuevo orden. Es un modelo planificación ascendente.

El Modelo de Aprendizaje Social, para unos es un instrumento que vincula la acción con el conocimiento; para otros una tecnología social muy parecida al Análisis de Políticas. Esto último no es cierto pues el Análisis de Políticas se centra en la toma de decisiones anticipadas y usa la técnica para explicar las consecuencias que de ellas deriven. En esencia el aprendizaje social propugna que la práctica y el conocimiento son procesos correlativos, así uno implica al otro: el conocimiento se deriva de la experiencia, se valida en la práctica y es parte integrante de una acción. Este es un enfoque ascendente.

En el Aprendizaje Social el planificador ya no actuará como experto sino como un articulador de un proceso de aprendizaje que incorpora el conocimiento y experiencia de la población en la creación de las políticas y las decisiones se centran en las personas (Fontana, A. 2012). El término Aprendizaje, en este modelo, se emplea para poner de manifiesto que la participación de los distintos actores y de los planificadores, dará como resultado un mayor conocimiento de los intereses y necesidades de cada uno (Cazorla, A. et al, 2013); entendido así, el aprendizaje se muestra como un proceso que recoge los intereses de los grupos vinculados, permite diseñar las políticas ligadas a esos intereses, y luego de aplicarlas se nutre de los resultados que se van generando, para modificarlas si fuera necesario.

Según Friedman (1993), el aprendizaje social es un proceso complejo, dependiente del tiempo y la experiencia de los actores, que implica, además de la acción en sí misma, estrategia y táctica política, análisis de la realidad, y valores que inspiren y dirijan las acciones y los proyectos (citado por Cazorla et al. 2013). La complejidad reside en que es un modelo bidireccional, se fundamenta en la acción, las personas afectadas se ven involucradas y condiciona la aplicación de políticas. Una breve descripción de estas características se muestra a continuación (Cazorla et al. 2013):

Es bidireccional, produce un aprendizaje tanto en los afectados como en los planificadores. Se rechaza la imposición descendente y se favorece el que los planificadores preguntan a los grupos interesados, se escuchan las respuestas y se actúan en consecuencia. El planificador presenta una propuesta a la población afectada sobre la que se espera un diálogo (Aller y De los Ríos, 1999)

Se fundamenta en la acción, en la planificación no basta el conocimiento experto sino también el experimentado, para poder considerarse un conocimiento completo. De allí la importancia de la consulta a la población afectada, que pasa a convertirse en protagonista a través de la colaboración en la planificación.

Las personas afectadas se ven involucradas, pues el aprendizaje social no puede darse sin el concurso de los actores implicados, de no ser así nos encontraríamos frente a a un proceso en el que el planificador solo extraería conclusiones para sacar conclusiones y mejorar las posibles deviaciones.

Se dice que condiciona la aplicación de políticas, porque las políticas resultantes son fruto de las interacciones entre población y planificadores. 
Sin embargo, en una actuación en un sector como el universitario, no es suficiente contar con los aportes de las partes interesadas, es necesario contar con las normativas del Sistema de Educación Superior, las axiologías institucionales, los estándares internacionales, que hacen que el enfoque ascendente antes mencionado no sea suficiente y se requiera de un enfoque descendente para determinar un modelo de planificación en el que se favorezca la participación de los grupos interesados de la sociedad, de dentro y fuera del sistema universitario formal, pero, sobretodo, tengan espacio la aplicación de la axiología institucional, las normas y políticas hasta los procedimientos y reglamentos.

De los cuatro modelos vistos párrafos arriba, el que mejor se acerca a lo que se desea es el de Análisis de Políticas. Le describimos más ampliamente para entender esta decisión.

El Modelo de Análisis de Políticas se caracteriza por (Cazorla, 2007) ser una planificación desde arriba: desde las autoridades competentes hacia los beneficiarios; se centra en la toma de decisiones, enfatizando en los procesos lógicos y evitando subjetividades en la toma de decisiones porque parte de unas variables básicas establecidas con anterioridad y con arreglo a unos criterios definidos; separa el conocimiento experto y decisor, de modo que el proceso analítico y la decisión se dan en momentos distintos a partir de unos datos justificados y sometiéndose a unos procesos establecidos; los resultados orientan el proceso decisor y la decisión se suele encontrar al nivel más alto, disponiendo al sistema el conocimiento de los efectos de dichas decisiones.

Este modelo no implica el desprecio a los intereses de las partes involucradas en el proceso formativo de la educación, les toma en cuenta, pero se organizan las decisiones a partir de un proceso analítico que involucra los objetivos, valores y normas establecidas con los intereses de los involucrados.

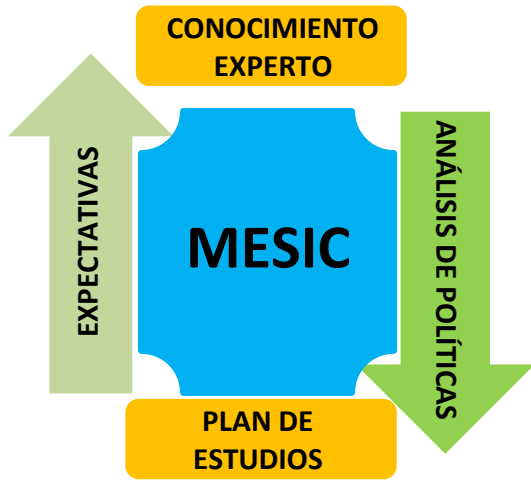

\section{Gráfico 2.2 Modelo de planificación para el MESIC. \\ Fuente: Elaboración propia.}

Por lo visto anteriormente el modelo de planificación apropiado para el MESIC es el de Análisis de Políticas. Con él se conseguirá tener una actuación descendente para lograr, considerando la participación de los grupos interesados y el conocimiento experimentado, una pertinente planificación y contar con un medio apropiado para la aplicación de estándares y normativas del sistema de educación superior e institucionales. Esta planificación resulta apropiada para el enfoque socio-formativo en el proceso de formación en educación superior, en general, y en ingeniería industrial, en particular, pues permitirá vincular la axiología formativa de la institución 
y los estándares nacionales e internacionales con los requerimientos, necesidades y expectativas que tengan los grupos de interés Gráfico 4.2.

\subsubsection{El conocimiento experto y experimentado y la contextualización}

El Modelo de Planificación elegido propicia un proceso abierto de dos características principales: una retroalimentación crítica y una memoria institucional poderosa. Esta apertura requiere de procedimientos participativos, promueve las reuniones abiertas y no las cerradas, e invita a la crítica y el comentario (Friedmann J., 1992), lo que lleva a la necesidad de determinar cómo se componen los grupos que participarán en esos diálogos. La mixtura implica la aplicación de estándares, normas y políticas establecidas con anticipación y estará en la habilidad de los planificadores, lograr un adecuado balance entre las expectativas que se creen y los estándares definidos.

El diálogo que se fomenta producto de la interacción de los actores tiene sus raíces en las diferencias de conocimiento que existe entre ellos. Un primer tipo de actor suele ser una autoridad en una materia concreta y aporta ese conocimiento de forma oficializada por el reconocimiento general que se da a la persona o institución que lo provee; el segundo tiene información basada en la experiencia y el valor que se le asigna radica en su acercamiento a la realidad práctica, contacto en el que ha adquirido una serie de información que se ha integrado, constituyendo una forma de conocimiento. Debe entenderse que el conocimiento no solo es pasivo, sino que presenta una componente activa pues en su acercamiento a la realidad permite construir nuevos saberes que ayudan a entenderla en su totalidad. Estos dos tipos de conocimiento se conocen como Conocimiento experto y Conocimiento experimentado (Cazorla et al. 2013).

Recabar el conocimiento experto y experimentado, requiere de un proceso organizado en el que las partes contribuyen aportando la información necesaria sobre los tópicos de interés que se les plantea.

La aplicación del Modelo Educativo para la Ingeniería Industrial de Perú desde las Competencias (MESIC), requerirá de la aplicación de encuestas, focus groups y reuniones de trabajo con las partes interesadas en el proceso para poder obtener la información relevante de cada uno de los tipos de conocimiento a tener en cuenta, el conocimiento experto y experimentado. Estas actividades dentro del modelo de planificación elegido se convierten en herramientas importantes de recojo de información para el MESIC.

Para poder definir las personas o instituciones que poseen los conocimientos deseados y que coexisten con el espacio educativo en que se quiere influenciar, es necesario definir un ámbito de acción, locoal, nacional, global.

La compleja red de vínculos e interacciones entre los factores sociales, ambientales, culturales y económicos que delimitan, determinan y orientan el desarrollo determinan un contexto en el que se desenvuelve una actividad. Esto comprende los vínculos y las interacciones que se registran en un ámbito de acción local y en relación con los vecinos (global): la economía nacional, la sociedad, la cultura y los contextos mundiales. Ambos tipos de vínculos e interacciones se abordan como procesos evolutivos muy dinámicos, propensos a modificarse 
conforme lo hace la sociedad y el contexto macrosocial en que ésta se encaja (Schejtmann \& Berdegué, 2003). Por ello la importancia de tener en cuenta la contextualización del modelo, pues el conocimiento estará circunscrito a, y será propio de, un ámbito determinado pero estará relacionado dinámicamente con otros ámbitos nacionales y mundiales.

Esta es una concepción holístico-sistémica y dinámico-histórica que caracteriza y da una connotación propia a un lugar. Si bien resulta útil para describir y comprender cabalmente la situación de cada sitio, resulta difícil de abordar en el contexto de los procesos globales de diagnóstico y planificación orientados a la acción. Por esta razón, uno de los desafíos más importantes consiste en controlar la posible proliferación de factores que deben tenerse en cuenta en los análisis, sin que se pierda por ello su orientación holístico-sistémica y dinámicohistórica (Catenacci, 2000).

En este sentido, no parece existir un modelo único o sistema consolidado y unívoco para abordar un problema en un lugar determinado. En cambio, los modelos analíticos que usan el proceso de diagnóstico y planificación implican mucho el contexto y suelen abordar las cuestiones y los problemas más importantes que existen en un ámbito considerando la participación de los actores sociales que deben tomar parte en el diagnóstico (Warren, P. 2001). Un modelo de análisis apropiado debe considerar el diagnóstico, la estratificación de la población involucrada y el grado de participación que tendrán. Con esto se deben definir los grupos de variables fundamentales que deben tomarse en consideración en el análisis, a saber (Cleary, D. 2003):

1. el ámbito sobre el que se actuará y sus características a lo largo del tiempo;

2. estratificación social, determinar los grupos sociales locales y sus diferencias en función de su incidencia sobre el asunto en que se actúa;

3. vinculaciones sociales, es decir las relaciones entre los grupos y las organizaciones o instituciones locales o nacionales que actúan.

Estos grupos de variables se seleccionaron por su capacidad para percibir situaciones perturbadoras entre la sociedad y las instituciones oficiales locales. Se considera que el análisis de la evolución histórica de los cambios que caracterizan las relaciones con el medio ambiente "externo", permite reconocer la evolución general y los principales problemas de que debía ocuparse el proceso de planificación. Esta forma analítica de actuar ayuda a prever los principales riesgos antes de tomar decisiones y emprender acciones, mejora el flujo de comunicaciones entre grupos involucrados e instituciones implicadas y ayuda a controlar la calidad y la efectividad de las medidas adoptadas (Cleary, D. 2003).

Por las razones expuestas en los párrafos precedentes es que optamos por tomar un enfoque de contextualización global en el diseño de un Modelo Educativo para la Ingeniería Industrial de Perú desde las Competencias (MESIC). 


\subsection{PROPUESTA DEL MODELO PARA LA EDUCACIÓN SUPERIOR DE LA INGENIERÍA INDUSTRIAL DE PERÚ DESDE LAS COMPETENCIAS}

El Modelo Educativo de educación superior para la Ingeniería Industrial de Perú desde las Competencias (MESIC) se nutre de los capítulos precedentes, por ello su orientación de formación en competencias respeta el enfoque socio-formativo, con propuestas contextulizadas, basado en una estrategia participativa, contrastando el conocimiento experto y experimentado, considerando las tendencias globales, incluyendo la realidad nacional y sus requerimientos a la ingeniería industrial, y con una codificación de competencias genéricas que asegure la pertinencia de la formación de ingenieros industriales en un contexto global.

Pero un consistente modelo educativo para la educación superior debe responder a su definición, por ello la revisamos.

Para Sergio Tobón, un modelo educativo se define como un conjunto de lineamientos educativos generales que orientan a la institución universitaria en torno a qué tipo de persona formar, para qué sociedad, en qué espacios educativos, con qué filosofía y con qué modelo de gestión de la calidad. Esos son los Aspectos Clave de un modelo educativo (Tobón, S. 2013).

La Tabla 2.2 Aspectos clave del diseño de un Modelo Educativo de Educación Superior (Fin). muestra una adaptación del Cuadro 3.4 del libro "Metodologías de gestión curricular: Una perspectiva socioformativa", del Profesor Sergio Tobón (Tobón, S. 2013), y en ella se describen los Aspectos Clave de un modelo educativo para la educación superior.

\begin{tabular}{|c|c|}
\hline ASPECTO CLAVE & \multicolumn{1}{|c|}{ DESCRIPCIÓN } \\
\hline $\begin{array}{c}\text { ¿Qué tipo de persona } \\
\text { se formará? }\end{array}$ & $\begin{array}{c}\text { Describir el tipo de persona que la institución desea entregar a } \\
\text { la sociedad y con qué grado de participación en ella. }\end{array}$ \\
\hline $\begin{array}{c}\text { ¿Para qué tipo de } \\
\text { sociedad se formará? }\end{array}$ & $\begin{array}{l}\text { Describir la sociedad para la cual se va a formar a docentes, } \\
\text { directivos y estudiantes (puede indicarse la actual y la que se } \\
\text { espera en el futuro. } \\
\text { - Indicar el tipo de vinculación que se espera con la sociedad. }\end{array}$ \\
\hline $\begin{array}{c}\text { ¿Con qué enfoque } \\
\text { educativo se formará? }\end{array}$ & $\begin{array}{l}\text { Indicar el o los enfoques educativos elegidos. } \\
\text { - Indicar los lineamientos fundamentales que de él se } \\
\text { desprenden. }\end{array}$ \\
\hline $\begin{array}{c}\text { ¿Con qué principios } \\
\text { educativos se } \\
\text { formará? }\end{array}$ & $\begin{array}{l}\text { Indicar lineamientos básicos del proceso de aprendizaje, } \\
\text { enseñanza y evaluación. }\end{array}$ \\
\hline $\begin{array}{c}\text { ¿Cuál es el rol de los } \\
\text { docentes }\end{array}$ & $\bullet$ Describir el rol en base al enfoque educativo elegido. \\
\hline $\begin{array}{c}\text { ¿Cuál es el papel de } \\
\text { los estudiantes? }\end{array}$ & $\bullet$ Describir el rol del estudiante en base al enfoque educativo. \\
Debe considerarse la articulación con los docentes
\end{tabular}

Tabla 2.1 Aspectos clave del diseño de un Modelo Educativo de Educación Superior (Continúa)

Fuente: Adaptado de Tobón, 2013. 


\begin{tabular}{|c|c|c|}
\hline $\begin{array}{c}\text { ¿Cómo debe ser la } \\
\text { estructura básica de } \\
\text { los Planes de } \\
\text { estudios? }\end{array}$ & $\begin{array}{l}\text { Estructura básica: ¿Asignaturas? ¿módulos? ¿años? ¿ciclos? } \\
\text { - Lineamientos de los sílabos de las asignaturas. } \\
\text { - Gestión de la calidad del Plan de estudios: ¿cada cuánto se } \\
\text { revisan los programas? ¿quién verificará la calidad de lo } \\
\text { diseñado? } \\
\text { - Mostrar las políticas de gestión del talento humano. }\end{array}$ \\
\hline $\begin{array}{c}\text { ¿Cómo se vinculará } \\
\text { con la sociedad? }\end{array}$ & $\begin{array}{l}\text { Describir de manera general las acciones a emprender con ls } \\
\text { Organizaciones sociales, empresariales y tecnológicas. }\end{array}$ \\
\hline $\begin{array}{c}\text { ¿Cuáles serán los } \\
\text { ejes de la } \\
\text { investigación? }\end{array}$ & $\begin{array}{l}\text { Presentar los lineamientos para la realización de } \\
\text { investigaciones por parte de docentes y alumnos. }\end{array}$ \\
\hline
\end{tabular}

Tabla 2.2 Aspectos clave del diseño de un Modelo Educativo de Educación Superior (Fin). Fuente: Adaptado de Tobón, 2013.

Construir el modelo educativo para los ingenieros industriales en Perú, requerirá que en el diseño se expliciten sus componentes principales: el contexto, un modelo de planificación, un enfoque formativo, una estrategia de participación, y se precise los aspectos clave que componen el modelo (estos provienen de la concepción de modelo que se adopte). En el Gráfico 4.3 se muestran los componentes que juzgamos deben estar presentes en un Modelo educativo para la Educación Superior y que deberán intervenir en el diseño del Modelo Educativo para la Ingeniería Industrial de Perú desde las Competencias (MESIC).

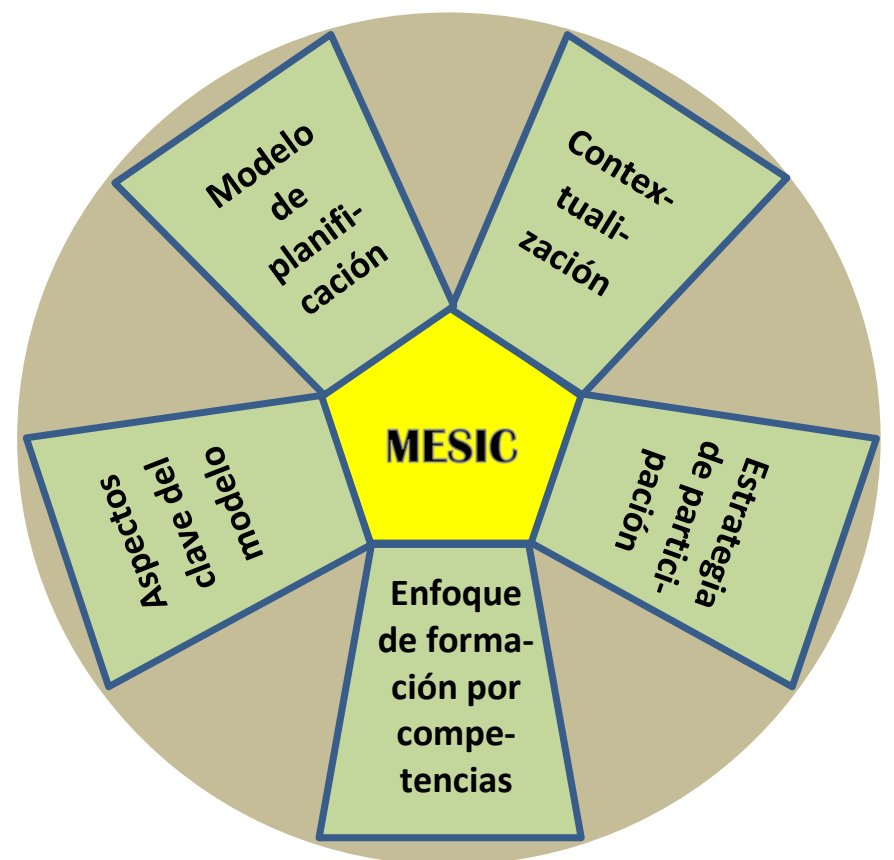

Gráfico 2.3 Propuesta de componentes del Modelo Educativo de Educación Superior. Fuente: Elaboración propia.

Estos componentes definidos de manera general para un modelo educativo de educación superior tienen fuertes interrelaciones que hacen del modelo un cuerpo sólido de herramientas 
empíricamente probadas, con profundas raíces científicas y, aunque complejo en su raíz, de simple entendimiento por el cuidado puesto en su conformación

La forma en que se relacionan estos componentes determina propiamente el Modelo Educativo para la Educación Superior y nos permiten dejar el camino listo para emprender la formulación de MESIC.

En el Gráfico 4.4 se observa los componentes del Modelo y cómo son las interacciones entre ellos, tal como se han definido en los párrafos y capítulos anteriores, mostrando los actores de este tipo de modelos que son: los alumnos, los profesores, los egresados, los expertos que desarrollan la planificación y los empleadores e instituciones vinculadas.

Las relaciones entre componentes son fundamentales.

Los grupos de interés se agrupan en aquellos al interior de la institución universitaria y los que están fuera pero relacionados con ella. En ambos ámbitos se encuentra el conocimiento experto y experimentado que nos interesa recabar para una apropiada aplicación del modelo.

Esa recolección de información se conseguirá con la participación organizada que permitirá el involucramiento activo de los grupos implicados para la definición de las políticas de diseño de los Planes de estudio. Esa interacción debe verificarse dentro de un modelo pedagógico.

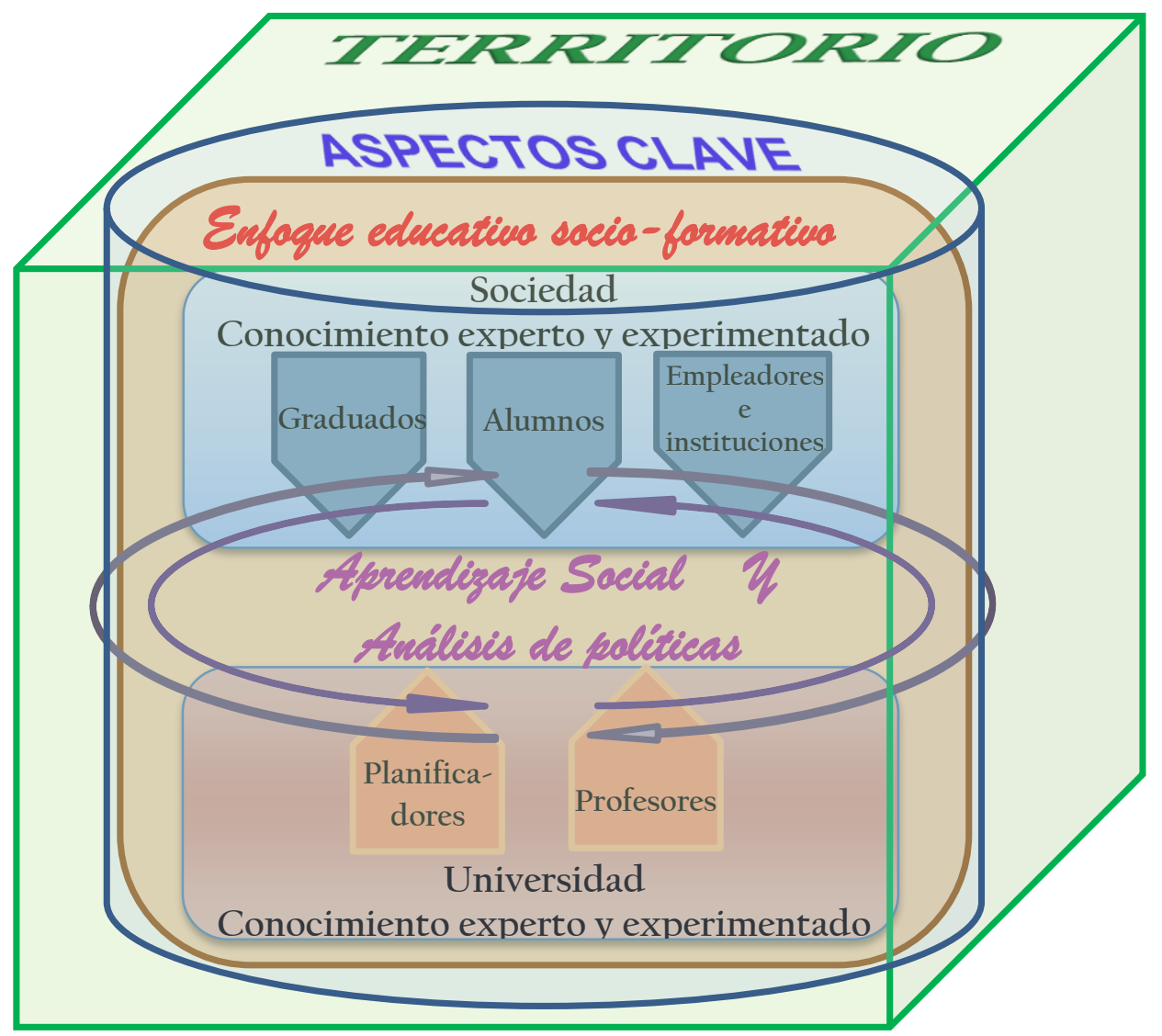

Gráfico 2.4 Propuesta del Modelo Educativo para la Educación Superior desde las competencias. Fuente: Elaboración propia. 
La socio-formación es el modelo que servirá de base ya que es un modelo que favorece decididamente los aprendizajes significativos en competencias y estimula la participación de todos los grupos poniendo mucho énfasis en la axiología institucional; junto con este enfoque se trabajará el funcionalista pues, con los diagnósticos obtenidos de la participación de las partes involucradas, será posible alimentar a la institución universitaria de la información necesaria para determinar los perfiles que se requieren en empresas e instituciones, así como el detalle de habilidades que son necesarias para cumplir con las funciones que se les encomienden.

Tanto la información recabada de expertos y gente con experiencia de los distintos ámbitos educativos como la definición de estrategias pedagógicas y contenidos apropiados desde la socio formación, deben tener una dirección, dirección que debe estar definida por el sistema educativo formal que les acoja. Estos son los aspectos clave del modelo que transversalmente recorren todas las actividades de la gestión educativa. Es en estos aspectos clave donde se encuentran las definiciones institucionales que debe respetar la formación de alumnos y los vínculos con las instituciones y personas externas. Es labor crítica del grupo de expertos planificadores, vincular aquello que se ha obtenido de los grupos interesados e implicados, con la axiología y planes estratégicos de la institución y la nación.

Es en este ámbito en el cual se definen los perfiles de alumnos, las asignaturas, los contenidos, el balance de áreas de conocimiento, la asignación de cargas docentes, las estrategias metodológicas, los objetivos de promoción-retención-deserción, el tipo de créditos a usar y su distribución, la duración de la carrera, las competencias requeridas, etc. En pocos términos, lo que orienta a la institución universitaria a qué tipo de persona formar, para qué sociedad, en qué espacios educativos y con qué filosofía. Pero si no se determinara un ámbito de acción el proyecto de establecer un novedoso Currículo educativo desde las competencias, con todas sus implicancias, podría verse desbordado por la inmensa cantidad de variables a considerar y la variabilidad de contextos.

Consideramos que la aplicación del modelo será posible dentro de un espacio social, económico y geográfico determinado. Establecer el contexto es fundamental y afecta a todos y cada uno de los otros componentes. Al delimitar el ámbito no se está estableciendo un área o porción de realidad física, social o económica que da una connotación propia a un lugar, aislándola del resto de realidades. Lo que se busca es llegar describir y comprender cabalmente la situación de cada sitio, y desentrañar los vínculos y las interacciones que se registran dentro de ese lugar y sus relaciones con los vecinos, incluso de alcance mundial. No debe entenderse el ámbito de acción como una forma de excluir a los que estén fuera del territorio, es todo lo contrario, adquirir la fortaleza de entender la que pasa dentro del ámbito acotado, para poder afianzar las interacciones al interior de él y hacia y con el exterior.

El Modelo Educativo para la Educación Superior desde las competencias así definido, se posiciona como una poderosa herramienta para acometer la complicada gestión curricular en las universidades. 


\subsubsection{Esquema conceptual del MESIC.}

El Modelo para la Educación Superior desde las competencias para el caso de a Ingeniería Industrial de Perú (MESIC) debe considerar que le es aplicable cabalmente el modelo mostrado en el Gráfico 4.4. de este trabajo.

Debe ponerse especial atención en que las competencias genéricas a desarrollar sean apropias para la carrera y estén contextualizadas para afirmar que es aplicable a la ingeniería Industrial de Perú. Puede revisarse lo desarrollado en el Capítulo tres, apartados 3.2 y 3.3.

También debe cuidarse que los aspectos clave, que marcan los demás componentes, sean propios del contexto definido y coherentes con el objetivo de formar en Ingeniería Industrial. Los grupos de interés también deben determinarse atendiendo a este fin.

Así entendido, en el Gráfico 4.5 se muestra el Modelo para la Educación Superior de la Ingeniería Industrial de Perú desde las competencias.

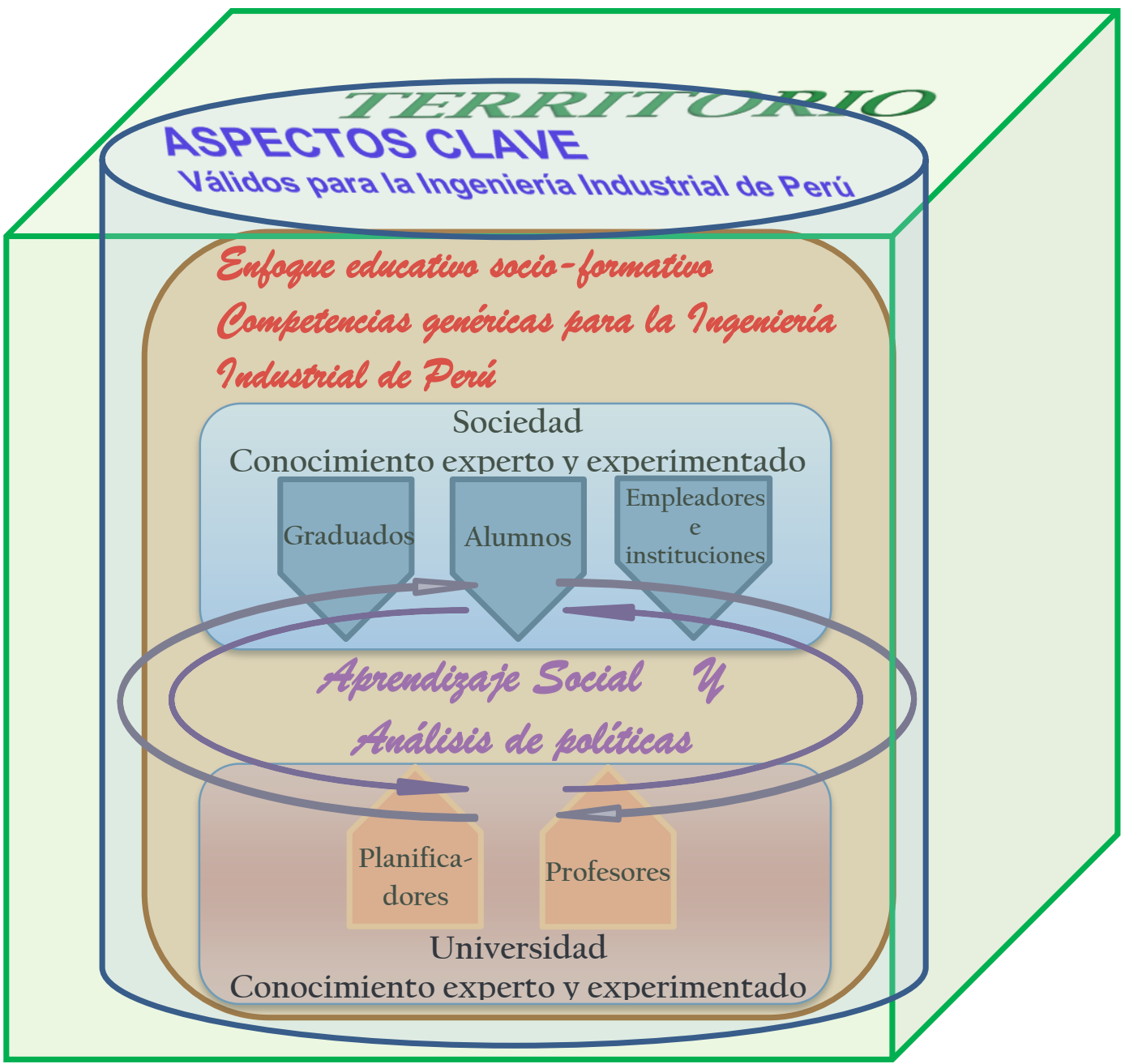

\section{Gráfico 2.5 Propuesta del Modelo para la Educación Superior de la Ingeniería Industrial de Perú desde las competencias. Fuente: Elaboración propia.}

Consideramos que un modelo no está completo sin una adecuada estrategia de aplicación que debe seguir una secuencia clara y proveer de una metodología que contemple los principios determinados por el modelo. 


\subsection{PROPUESTA DE ESTRATEGIA DE APLICACIÓN DEL MODELO}

En el Gráfico 4.6 se aprecia que la estrategia de aplicación del modelo seguirá ocho fases. La primera es partir de la contextualización para seguir con la definición de los aspectos clave en la segunda fase. La tercera implica la planificación desde el Análisis de políticas, esta etapa estará íntimamente relacionada con la siguiente pues la cuarta requiere de los insumos de esta tercera etapa. En la cuarta fase es en la que debemos tener el mayor cuidado e impregnar la axiología, doctrina filosófica o ideario de la institución asegurándonos que es conocida y aceptada por los interesados haciendo uso del enfoque socio-formativo. En la quinta se recogen los requerimientos y opiniones de los usuarios sobre la gestión académica y competencias (duras y blandas) que tienen los grupos de interés determinados partir del conocimiento experto y experimentado; la sexta es encontrar las competencias requeridas, definiendo las metodologías de aprendizajes y las actividades del Plan; la sétima es que expertos trabajen los Planes de estudios; y en la Octava Fase se debe optar por una forma de aseguramiento de la calidad.

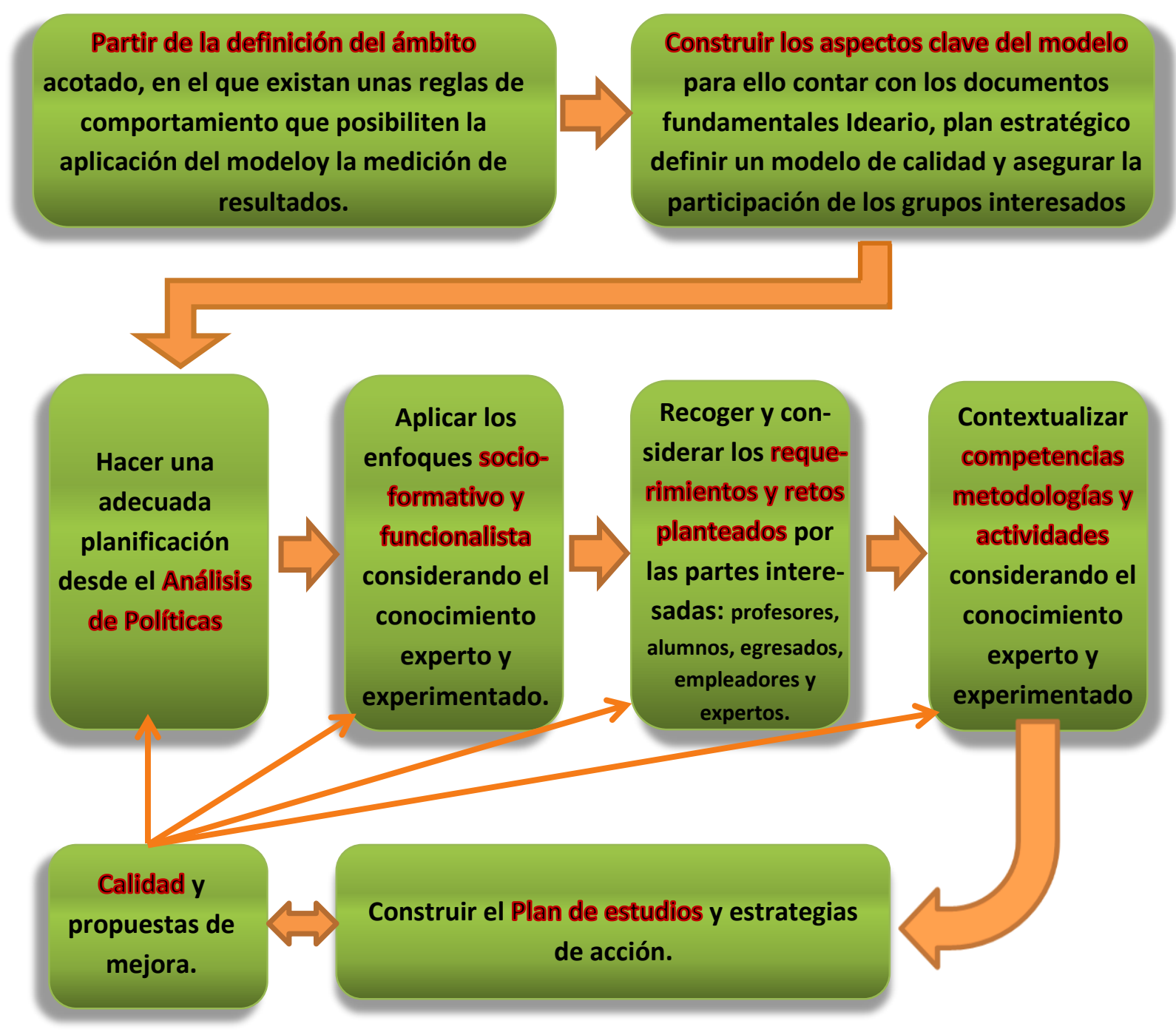

Gráfico 2.6 Estrategia para el diseño de un modelo para la educación superior desde el enfoque socioformativo. Fuente: Elaboración propia. 


\section{Determinación del ámbito.}

$\mathrm{Al}$ definir una estrategia de aplicación es conveniente precisar el objeto sobre el que actuamos, entendiéndose objeto en su acepción de materia o asunto de que se ocupa un estudio o diligencia.

Lo primero es definir el lugar. El lugar debe elegirse y acotarse a una región que puede ser un país o alguna subdivisión política o geográfica dentro de él. En el caso de un Modelo educativo de educación superior se debe tener especial cuidado en la no excesiva heterogeneidad de niveles de autonomía y que existan políticas universitarias comunes uniformes, aceptadas y vigentes al interior de él. Esta referida homogeneidad es importante porque como refiere Gonzalo Sáenz de Buruaga, el ámbito resulta ser un concepto complejo, polifacético, relativo, pluridimensional, ambivalente y, sobre todo, antropocéntrico, del que ciertamente puede decirse que está llamado a ser un reflejo palpable del grado de eficiencia y equidad adquirido por una determina sociedad o grupo humano (Sáenz, 1980). Lo que convierte en crucial la elección del lugar de trabajo, pues si en el lugar que se elija, las disparidades dentro de los grupos son muy grandes o si existen posiciones encontradas irreconciliables o no hay motivación a participar o rebeldía violenta ante las disposiciones, la aplicación de cualquier forma de acción será improductiva.

El segundo Paso debe ser definir los aspectos clave.

\section{Aspectos clave.}

Esta fase de la aplicación debe considerar la delimitación determinada en el paso anterior. Es necesario contar con las características propias de este lugar como: axiología o ideario, y estratificación de la comunidad directamente involucrada.

La definición del ámbito es imprescindible para determinar apropiadamente los grupos de interés, generar espacios de participación, asignar funciones y empoderar a los grupos de expertos que actuarán, definir características o perfiles de alumnos, profesores, ambientes, las asignaturas, el trato con la sociedad, definir las competencias genéricas y específicas pertinentes, fijar metodologías de aprendizaje y establecer formas de control de calidad.

En esta fase es donde se debe responder a las preguntas fundamentales de un modelo educativo. Estos Aspectos Clave surgen de las respuestas a las preguntas ¿Qué tipo de persona se formará?, ¿Para qué tipo de sociedad se formará?, ¿Con qué enfoque educativo se formará?, ¿Con qué principios educativos se formará?, ¿Cuál es el rol de los docentes?, ¿Cuál es el papel de los estudiantes?, ¿En qué escenarios se formará?, ¿Cómo debe ser la estructura básica de los Planes de estudios?, ¿Cómo se vinculará con la sociedad?, ¿Cuáles serán los ejes de la investigación?.

El desarrollo de esta fase es la que da vida al modelo, pues debe responder además, a todas las preguntas que surgen de una adecuada gestión curricular. Igual de importante es definir el Modelo de calidad.

El modelo de calidad es fundamental en esta parte para conocer qué estándares se persiguen y poder diseñar y actuar sobre el modelo con la perspectiva con la que luego será evaluado cuando se apliquen los estándares para el aseguramiento de la calidad. 


\section{Modelo de planificación}

Se empleará el modelo de planificación descendente. Este modelo es apropiado para la aplicación del MESIC, según lo tratado en el Capítulo 4, subdivisión 4.2.1. La estrecha relación que existe entre esta fase y la siguiente hace que en la práctica casi no se evidencie que coexisten, sin embargo es fundamental primero elegir el modelo de planificación y luego empezar a ejecutar las acciones del mismo.

\section{Enfoque educativo}

El enfoque de gestión educativa que se emplee será el socio-formativo complementado con el funcionalista, por las razones expuestas en el Capítulo 4, subdivisión 4.2.1. En la aplicación del enfoque debe ponerse especial atención en compatibilizar los aportes de los grupos interesados con el Ideario institucional y las políticas educativas vigentes. Esta es la fase donde se vinculan claramente los dos modelos de planificación y se atiende al conocimiento experto y al experimentado. Sería poco pertinente que el resultado despreciase los requerimientos que la sociedad y usuarios directos manifiestan tanto como ignorar la axiología institucional o las normas, políticas y estándares existentes.

\section{Estrategia de participación}

Vinculado el enfoque de contextualización con el modelo de planificación ya definido se trabajará la estrategia de diagnóstico, análisis y contrastación del conocimiento experto y del conocimiento experimentado tratados en el Capítulo 4, subdivisión 4.2.3.

En esta fase se definen las estrategias de acción para los pasos siguientes: cómo recoger y considerar los requerimientos y retos planteados por las partes interesadas profesores, alumnos, egresados, empleadores y expertos

\section{Contextualizar las competencias}

En esta fase la importancia recae en contextualizar las competencias que se hayan determinado como las guías aplicables a la formación superior en Latinoamérica, construir las propias competencias genéricas y específicas para el ámbito propuesto, o utilizar un método mixto de aplicación, en el que se amalgamen las adoptadas y las construidas. En nuestro caso emplearemos el tercero de los tres mencionados.

\section{Construcción del Plan de Estudios.}

El grupo de expertos debe tomar las Normas, políticas y reglamentos que inciden en la gestión curricular de la institución, la información recabada de expertos y experimentados, los requerimientos de los grupos de interés y deberán elaborar un Plan de estudios a la especialidad y lugar específico que trate el caso.

\section{Mejora continua.}

Debe definirse el sistema de aseguramiento de la calidad del Plan de estudios y de toda la gestión curricular para mantenerse en una política de mejora continua y hacer posible una acreditación si se diseña bajo estándares establecidos y recomendados por una acreditadora. 
Esta será la estrategia general para construir de un Plan de estudios desde el enfoque socioformativo en nuestro modelo educativo. El siguiente paso es aplicarlo a un caso concreto de Perú. Lo que haremos en el Capítulo 5.

\subsection{CONCLUSIONES DEL CAPÍTULO IV}

Incorporar las competencias en la gestión curricular de la Educación Superior posibilita asegurar la calidad de los procesos de aprendizaje de los estudiantes mediante dos contribuciones de evaluación, la evaluación de la calidad del desempeño en el alumno y evaluación de la calidad de la formación que brinda la institución educativa. Se llega a establecer claramente la tendencia de formación en competencias en la Educación Superior y las bondades y ventajas que concentran, quedando establecido que ésta debe ser la forma de enfrentar la formación en la Ingeniería Industrial de Perú.

Existen diversos enfoques para acometer la gestión educativa desde las competencias, de entre ellos el que mejor se adapta a nuestro Modelo es el socio-formativo, complementado por el funcionalista. El primero por su objetivo de dar prioridad y preponderancia a la axiología institucional en la definición y aplicación del modelo y la segunda por su sesgo claro de formar para tener éxito en el cumplimiento de las funciones propias de los puestos y labores que desempeñaría un egresado en las empresas e instituciones en las que radique.

De entre los 12 Modelos de planificación estudiados y condensados por John Friedmann, analizados y sintetizados por Adolfo Cazorla, el que permite desarrollar una mejor metodología para este trabajo de investigación es el Análisis de Políticas. Su acción descendente de las instituciones a la población afectada fundamentada en la acción, contemplando la participación de las personas afectadas y permitiendo la aplicación de normas, políticas y estándares, es ideal para el diseño y aplicación del modelo.

Un importante componente para el modelo es considerar el conocimiento experto y experimentado. El diálogo que se fomenta producto de la interacción de los actores en una planificación tiene sus raíces en las diferencias de conocimiento que existe entre ellos. Con este enfoque reconocemos que existen dos tipos de conocimiento, el experto atribuido a la autoridad y el experimentado, a la experiencia práctica. Recabarlos requiere de un proceso organizado y de la aplicación de encuestas, focus groups y reuniones de trabajo a las partes interesadas en el proceso. Esto hace de éste un enfoque muy útil y consistente en el levantamiento de información para el modelo.

La definición de un ámbito no solo delimita una porción o espacio de terreno, se centran en la compleja red de vínculos e interacciones entre los factores sociales, ambientales, culturales y económicos que delimitan, determinan y orientan el desarrollo. Esto comprende los vínculos y las interacciones que se registran en un lugar y su relación con ámbitos vecinos. La definición debe contemplar las situaciones perturbadoras entre la sociedad y las instituciones oficiales locales. Se debe reconocer la evolución general y los principales problemas de que debería ocuparse el proceso de planificación. Esta forma analítica de actuar ayuda a prever los principales riesgos antes de tomar decisiones y emprender acciones, mejora el flujo de 
comunicaciones entre grupos involucrados e instituciones implicadas, y ayuda a controlar la calidad y la efectividad de las medidas adoptadas.

Un componente imprescindible en un modelo educativo son los Aspectos Clave pues son los que orientan a la institución universitaria en torno a qué tipo de persona formar, para qué sociedad, en qué espacios educativos, con qué filosofía y con qué modelo de gestión de la calidad. En la definición de ellos se lleva la gestión curricular por un camino u otro.

Los componentes de un Modelo Educativo de Educación Superior desde las competencias deben ser el contexto y sus condiciones, un modelo de planificación, un enfoque formativo, una estrategia de participación, y los aspectos clave que componen el modelo (estos provienen de la concepción de modelo que se adopte y la axiología institucional). Es en el ámbito donde se define el lugar, condiciones y actores implicados; los aspectos clave darán los lineamientos generales de acción en todos los ámbitos; el enfoque educativo desde las competencias será fundamentalmente socio-formativo y definirá la forma de trabajo; la planificación se hará por análisis de políticas, y las decisiones deben tomarrse considerando el conocimiento experto y experimentado.

El Modelo para Educación Superior de la Ingeniería Industrial de Perú desde las Competencias (MESIC) se obtiene cabalmente al considerar las condiciones restrictivas que son un juego de competencias genéricas que permitan formar ingenieros industriales en las características deseadas y que debe imbricarse en un enfoque socio-formativo y en los aspectos clave que deben ser propios de una carrera y una institución, en un ámbito. El modelo así definido es necesario y suficiente para una carrera de educación superior con una gestión curricular desde las competencias y por tanto aplicable al caso de la Ingeniería Industrial de Perú.

Consideramos que un modelo tan complejo como este requiere ser acompañado de una estrategia de aplicación, por lo que se define una de ocho pasos en la que se describe cómo actuar. Se establece una estrategia de aplicación del Modelo para la Educación Superior en una secuencia de pasos que simplifica la tarea de los grupos encargados de definir currículos en las universidades. En el caso de esta investigación se aplica al Perú, y en el Capítulo V puede constatarse la simplicidad y practicidad de su uso.

Teniendo en cuenta las condiciones del Sistema Educativo Superior de Perú, alta variabilidad, poca homogeneidad, autonomía exacerbada y ausencia de liderazgo, se concluye que sería inviable la aplicación de un Modelo en un ámbito tan grande debido a su inestabilidad de condiciones. Teniendo en cuenta la carrera elegida, ingeniería industrial, se optapor definir un ámbito estable y homogéneo en Perú, una institución dispuesta a participar, y se ha considerado como ámbito de acción la Universidad de Piura de Perú.

En el Capítulo V se muestra el caso de aplicación del Modelo educativo para Educación Superior desde las competencias (MESIC) en la Universidad de Piura de Perú en la carrera de Ingeniería Industrial siguiendo la estrategia definida. 


\subsection{REFERENCIAS DEL CAPÍTULO IV}

Aller, J.; De los Ríos, I. (1999). Rozas de Puerto Real: una estrategia de desarrollo sostenible. Madrid: Consejería de Medio Ambiente de la Comunidad de Madrid

Arendt, H. (1958). The human Condition. Chicago: The University of Chicago Press.

Bernasconi, A.; Rojas, F. (2004) Informe sobre la educación superior en Chile 1980 - 2003. Editorial universitaria. Chile.

Catenacci, B. (2000): Local Economic Development Agencies. UNOPS, OIT. Roma: Cooperazione Italiana.

Cazorla, A. (2007). La Innovación para el desarrollo: Modelos de planificación. Obtenido el 7 de enero de 2011, de http://expgrafica.uma.es/Asignaturas/doctorado/ingenieria/ document07/Innovacionparael desarrollo1.pdf

Cazorla, A., De los Ríos, I., \& Salvo, M. (2007). Desarrollo rural: modelos de planificación. Universidad Politécnica de Madrid. Ed. Peninsular. España.

Cazorla, A., De los Ríos, I., \& Salvo, M. (2013). Working With People (WWP) in Rural Development Projects: a Proposal from Social Learning. Cuadernos de Desarrollo Rural, 10 (70), 131-157.

Chomsky, N. (1970). Aspectos de la teoría de la sintaxis. Madrid: Editorial Aguilar.

Cleary, Dervla. (2003). Estrategias enfocadas hacia las personas: Breve estudio bibliográfico y comparativo. Programa de Apoyo a los Modos de Vida Sostenibles (LSP). FAO. ONU.

Fontana, Alejandro. (2012). La Gobernanza en las Políticas de la Cooperación Internacional para el Desarrollo: Análisis y Modelo de Aplicación al Perú. Tesis Doctoral. ETSI Agrónomos. Universidad Politécnica de Madrid.

Friedmann, John. (1991). Planificación en el ámbito público. Colección Estudios. Serie, Administración general. Madrid: Ministerio para las Administraciones Públicas.

Friedmann, John. (1992). Planificación Para el siglo XXI: el desafío del posmodernismo. Revista EURE. Vol XVIII, No 55, pp 79-89. Santiago de Chile.

Friedmann, John. (1993). Toward and non-euclidean mode of planning. Journal of American planning Association. 482. Chicago.

Friedmann, John. (2001). Planificación en el ámbito público: del conocimiento a la acción. Madrid: Ministerio para las Administraciones Públicas.

García, María José; Terrón, Mª José; Blanco, Yolanda. (2010). Desarrollo de Recursos Docentes para la Evaluación de Competencias Genéricas. ReVisión. Vol 3. No 2

González, J., y Wagenaar, R. (2003). Tuning educational structures in Europe. Informe final fase uno. Bilbao: Universidad de Deusto.

Hernández C. Adolfo. (2007). Competencias: modelo de formación integral para el mundo del trabajo. Revista Coepes. Guanajuato. 
Holden, Meg. (2008). Social learning in planning: Seattle's sustainable development codebooks. Progress in Planning, 69 (1), 1-40.

Inciarte, A.; Canquiz L. (2007). Formación Integral y Currículo por Competencias. Facultad de Humanidades y Educación. Universidad del Zulia.

Kemmis, Stephen (1998). El curriculum: más allá de la teoría de la reproducción. Morata. Madrid.

Levy-Leboyer, C. (1996). Gestión de las competencias. Barcelona: Ediciones Gestión 2000.

Llano, Alejandro. (2001). Claves para educar a la generación del Yo. Revista Nuestro Tiempo. Vol 01, 2001

López Segrera, Francisco. (2010). El impacto de la crisis económica mundial en la educación superior mundial y regional. Educación superior y sociedad. Ediciones IESALC. Año 15. Nº 1.

McClelland, D.C. (1973). Testing for competencies rather than intelligence. American Psychologist. No 28, 1-14

McClelland, D.C. (1993). Introduction. En Competence at work. New York: John Wiley and Sons.

Miranda Sara, L. (2012). Ordenamiento territorial: integración de enfoques y contribuciones metodológicas al proceso peruano. Actualidad gubernamental. No 39.

OEI. (2010). 21st Century Skills and Competences for New Millennium Learners in OECD Countries. Instituto de tecnologías educativas. OCDE. OEI. EDU 41.

OIT, (2012). Informe de competencias para el empleo - Orientaciones de política: mejorar sistemas de aprendizaje. Organización Internacional de trabajo.

Polo, Leonardo. (1999). Antropología trascendental. EUNSA. Pamplona. 245 pags.

Schejtman, Alejandro y Berdegué, Julio. (2003). Desarrollo Territorial Rural. En Desarrollo territorial rural en América Latina y el Caribe: manejo sostenible de recursos naturales, acceso a tierras y finanzas rurales. Editado por Rubén G. Echeverría. Ed. del Banco Interamericano de Desarrollo, Washington, D.C.

Sáenz de Buruaga, Gonzalo. (1980). Ciudad y territorio. Revista de ciencia urbana. Núm. 1, 17 $-28$

Strauss, A.; Corbin, J. (1994). Grounded Theory Methodology, An overview. Handbook of Qualitative Research. Sage Publications. New York.

Tobón, Sergio. (2008). La formación basada en competencias en la educación superior: El enfoque complejo. Universidad Autónoma de Guadalajara. México

Tobón, Sergio. (2013). Metodologías de gestión curricular: Una perspectiva socioformativa. Méjico. Ed. Trillas.

UDEP. (1998). IDEARIO. Universidad de Piura. Perú. 
UNESCO, (1998). Declaración Mundial sobre la educación superior en el siglo XXI: Visión y Acción. Visitado el 9 de junio http://www.unesco.org/education/ educprog/wche/declaration_spa.htm

Warren, P. (2001): Reflexiones sobre ordenamiento territorial local e investigación-acción participativa en America Latina. Roma: FAO-SDAA. 
Capítulo V Aplicación del MESIC: Plan de estudios desde las competencias para Ingeniería Industrial en la Universidad Peruana 


\section{INDICE CAPITULO V}

Capítulo V

¿Error! Marcador no definido.

5.1 INTRODUCCIÓN DEL CAPÍTULO V ¡Error! Marcador no definido.

5.2 CONTEXTUALIZACIÓN ¡Error! Marcador no definido.

5.3 ASPECTOS CLAVE: Principios, valores y plan a futuro__ ¡Error! Marcador no definido. 5.4 MODELOS DE PLANIFICACIÓN DE LA ENSEÑANZA ¡Error! Marcador no definido.

5.5 ENFOQUE EDUCATIVO ¡Error! Marcador no definido.

5.6 ESTRATEGIA DE PARTICIPACIÓN ¡Error! Marcador no definido.

5.7 CONTEXTUALIZACIÓN DE COMPETENCIAS ¡Error! Marcador no definido.

5.7.1 Competencias genéricas ¡Error! Marcador no definido.

5.7.1.1 Encuestas a egresados ¡Error! Marcador no definido.

5.7.1.2 Encuestas a alumnos. ¡Error! Marcador no definido.

5.7.1.3 Encuestas a empleadores. iError! Marcador no definido.

5.7.1.4 Interpretación de resultados. ¡Error! Marcador no definido.

5.7.2 Competencias específicas. ¡Error! Marcador no definido.

5.7.2.1 Encuestas a egresados. iError! Marcador no definido.

5.7.2.2 Encuestas a profesores. ¡Error! Marcador no definido.

5.7.2.3 Encuestas a empleadores. ¡Error! Marcador no definido.

5.7.2.4 Interpretación de resultados ¡Error! Marcador no definido.

5.8 DISEÑO DEL PLAN DE ESTUDIOS ¡Error! Marcador no definido.

5.9 ASEGURAMIENTO DE LA CALIDAD ¡Error! Marcador no definido.

5.10 Conclusiones del Capítulo V ¡Error! Marcador no definido.

5.11 Referencias del capítulo V ¡Error! Marcador no definido. 


\section{INDICE DE TABLAS CAPITULO V}

Tabla 5.1 Dimensiones, factores, criterios y estándares para la acreditación de las carreras profesionales universitarias de Ingeniería. Fuente: CONEAU, 2010.

Tabla 5.2 Aspectos clave Modelo para la Educación Superior de la Ingeniería Industrial de Perú desde las Competencias (MESIC). Fuente: Elaboración propia.

Tabla 5.3 Promoción por asignatura en Ciencias Básicas en Ingeniería Industrial de UDEP Fuente: Elaboración propia, a partir de Información del Departamento de Ciencias Básicas de UDEP..........226

Tabla 5.4 Retención de alumnos por ciclo en Ingeniería Industrial de UDEP Fuente: Departamento de Ciencias Básicas de UDEP. .226

Tabla 5.5 Número de ingresantes por ciclo en Ingeniería Industrial en UDEP. .227

Tabla 5.6 Número de egresados y titulados por ciclo en Ingeniería Industrial en UDEP. Fuente:

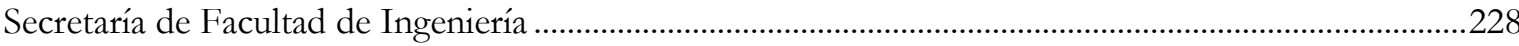

Tabla 5.7 Ranking incompleto de países que participaron en la PISA 2012.

Tabla 5.8 Valores de Alpha de Cronbach para determinar la confiabilidad de una encuesta. Fuente:

Elaboración propia.

Tabla 5.9 Número de egresados por año y ciclo en Ingeniería Industrial en UDEP. Fuente:

Elaboración Propia.

Tabla 5.10 Competencias genéricas más y menos importantes, y más y menos desarrolladas, según egresados de Ingeniería Industrial en UDEP.

Tabla 5.11 Competencias genéricas más y menos importantes, y más y menos desarrolladas, según Profesores de Ingeniería Industrial en UDEP.

Tabla 5.12 Competencias genéricas más y menos importantes, y más y menos desarrolladas, según alumnos de Ingeniería Industrial en UDEP. Fuente: Elaboración Propia.

Tabla 5.13 Competencias genéricas más y menos importantes, y más y menos desarrolladas, según empleadores. Fuente: Elaboración Propia

Tabla 5.14 Competencias específicas propuestas por el grupo planificador. Fuente: Elaboración Propia ¡Error! Marcador no definido.

Tabla 5.15 Resumen de resultados de la contextualización de competencias específicas a la Ingeniería industrial de la UDEP. Fuente: Elaboración propia.....

Tabla 5.16 Asignaturas curriculares de la carrera de Ingeniería Industrial de UDEP. Fuente:

Elaboración propia. .278

Tabla 5.17 Malla curricular de Ingeniería Industrial de UDEP. Fuente: Elaboración propia .279

Tabla 5.18 Asignación de competencias genéricas a asignaturas de la Malla curricular de Ingeniería Industrial de UDEP. Fuente: Elaboración propia.

Tabla 5.19 Asignación de competencias específicas a asignaturas de la Malla curricular de Ingeniería Industrial de UDEP. Fuente: Elaboración propia.

Tabla 5.20 Diseño de actividad de Aprendizaje Basado en Proyectos. Fuente: Elaboración propia....284 
Tabla 5.21 Diseño de actividad de Aprendizaje Basado en Proyectos. Fuente: Adaptación de Tobón, 2013b. . 


\section{INDICE DE GRAFICOS CAPITULO V}

Gráfico 5.1 Localización de Perú. 208

Gráfico 5.2 Localización de Piura 208

Gráfico 5.3 Ideario de la Universidad de Piura. Fuente: UDEP, 1998. 210

Gráfico 5.4 Equipo Central del Plan estratégico de la Facultad de Ingeniería. 211

Gráfico 5.5 Etapa de consolidación con la Decana de la Facultad. 212

Gráfico 5.6 Representantes de alumnos y egresados en el diseño Plan Estratégico. 212

Gráfico 5.7 Anverso del Tríptico del Plan Estratégico de la Facultad de Ingeniería. 213

Gráfico 5.8 Reverso del Tríptico del Plan Estratégico de la Facultad de Ingeniería. 213

Gráfico 5.9 Publicación de los Estándares de calidad para las Ingenierías en Perú. 215

Gráfico 5.10 Modelo de Calidad para la Acreditación de las Ingenierías en Perú. 216

Gráfico 5.11 Situación laboral de egresados 236

Gráfico 5.12 Importancia de las competencias genéricas TuningAL según egresados. 237 Gráfico 5.13 Desarrollo de las competencias genéricas TuningLA en Ingeniería Industrial de UDEP según egresados. 238

Gráfico 5.14 Comparación entre la importancia y nivel de desarrollo de las competencias genéricas TuningLA en Ingeniería Industrial de UDEP según egresados.

Gráfico 5.15 Formación recibida por alumnos de Ingeniería Industrial de UDEP según sus profesores.

Gráfico 5.16 Profesores conocen el concepto de competencias genéricas.

Gráfico 5.17 Importancia de las competencias genéricas TuningAL según los Profesores._242 Gráfico 5.18 Desarrollo de las competencias genéricas TuningLA en Ingeniería Industrial de UDEP según los Profesores.

Gráfico 5.19 Comparación entre la importancia y nivel de desarrollo de las competencias genéricas TuningLA en Ingeniería Industrial de UDEP según Profesores.

Gráfico 5.20 Formación recibida por alumnos de Ingeniería Industrial de UDEP según sus alumnos de último año.

Gráfico 5.21 Alumnos conocen el concepto de competencias genéricas. 245

Gráfico 5.22 Posibilidades de encontrar trabajo según alumnos. 246

Gráfico 5.23 Importancia de las competencias genéricas TuningAL según los alumnos. _ 246 Gráfico 5.24 Desarrollo de las competencias genéricas TuningLA en Ingeniería Industrial de UDEP según los Alumnos.

Gráfico 5.25 Comparación entre la importancia y nivel de desarrollo de las competencias genéricas TuningLA en Ingeniería Industrial de UDEP según los alumnos. 
Gráfico 5.26 Situación laboral de egresados 258

Gráfico 5.27 Egresados conocen el concepto de competencia específica 258

Gráfico 5.28 Importancia asignada por los egresados a las competencia específicas propuestas para Ciencias Básicas. 258

Gráfico 5.29 Promedio de la importancia asignada por los egresados a las competencias específicas propuestas para Ciencias Básicas.

Gráfico 5.30 Importancia asignada por los egresados a las competencias específicas propuestas para Operaciones.

Gráfico 5.31 Promedio de la importancia asignada por los egresados a las competencia específicas propuestas para Operaciones.

Gráfico 5.32 Importancia asignada por los egresados a las competencias específicas propuestas para área Administrativa. 260

Gráfico 5.33 Promedio de la importancia asignada por los egresados a las competencias específicas propuestas para Administrativas. 260

Gráfico 5.34 Importancia asignada por los egresados a las competencias específicas propuestas para el Área de Sistemas.

Gráfico 5.35 Promedio de la importancia asignada por los egresados a las competencias específicas propuestas para Sistemas. 261

Gráfico 5.36 Importancia asignada por los egresados a las competencia específicas propuestas para los cursos Técnicos de Ingeniería.

Gráfico 5.37 Promedio de la importancia asignada por los egresados a las competencias específicas propuestas para Técnica.

Gráfico 5.38 Profesores conocen el concepto de competencia específica

Gráfico 5.39 Importancia asignada por los profesores a las competencias específicas propuestas para Ciencias Básicas. Fuente: 264

Gráfico 5.40 Promedio de la importancia asignada por los profesores a las competencias específicas propuestas para Ciencias Básicas. 264

Gráfico 5.41 Importancia asignada por los profesores a las competencias específicas propuestas para Operaciones.

Gráfico 5.42 Promedio de la importancia asignada por los profesores a las competencias específicas propuestas para Operaciones.

Gráfico 5.43 Importancia asignada por los profesores a las competencias específicas propuestas para área Administrativa. 
Gráfico 5.44 Promedio de la importancia asignada por los profesores a las competencias específicas propuestas para Administrativas.

Gráfico 5.45 Importancia asignada por los profesores a las competencias específicas propuestas para el Área de Sistemas.

Gráfico 5.46 Promedio de la importancia asignada por los profesores a las competencias específicas propuestas para Sistemas.

Gráfico 5.47 Importancia asignada por los profesores a las competencias específicas propuestas para los cursos Técnicos de Ingeniería.

Gráfico 5.48 Promedio de la importancia asignada por los profesores a las competencias específicas propuestas para Técnica.

Gráfico 5.49 Empleadores conocen el concepto de competencia específica 268

Gráfico 5.50 Importancia asignada por los empleadores a las competencias específicas propuestas para Ciencias Básicas.

Gráfico 5.51 Promedio de la importancia asignada por los empleadores a las competencias específicas propuestas para Ciencias Básicas.

Gráfico 5.52 Importancia asignada por los empleadores a las competencias específicas propuestas para Operaciones.

Gráfico 5.53 Promedio de la importancia asignada por los empleadores a las competencias específicas propuestas para Operaciones.

Gráfico 5.54 Importancia asignada por los empleadores a las competencias específicas propuestas para área Administrativa.

Gráfico 5.55 Promedio de la importancia asignada por los empleadores a las competencia específicas propuestas para Administrativas.

Gráfico 5.56 Importancia asignada por los empleadores a las competencias específicas propuestas para el Área de Sistemas.

Gráfico 5.57 Promedio de la importancia asignada por los empleadores a las competencias específicas propuestas para Sistemas.

Gráfico 5.58 Importancia asignada por los empleadores a las competencias específicas propuestas para los cursos Técnicos de Ingeniería

Gráfico 5.59 Promedio de la importancia asignada por los empleadores a las competencias específicas propuestas para Técnica.

Gráfico 5.60 Abordaje del Plan de estudios. Fuente: Adaptación de Tobón, 2013b. 275

Gráfico 5.61 Estructura de la Malla curricular para Ingeniería industrial de UDEP. 277 


\subsection{INTRODUCCIÓN DEL CAPÍTULO V}

En este capítulo final se muestra una aplicación del Modelo para la Educación Superior de la Ingeniería Industrial de Perú desde las competencias: MESIC.

El objetivo principal es mostrar la forma en que se aplica el MESIC y los beneficios que aporta a la construcción de un Plan de estudios y a su apropiada gestión curricular siguiendo las fases de aplicación descritas en la estrategia definida en el Capítulo cuatro. Las fases son:

Fase I: contextualización

Fase II: $\quad$ aspectos clave a partir de los principios, valores y plan a futuro

Fase III: los modelos de planificación de la enseñanza

Fase IV: enfoque educativo

Fase V: estrategia de participación

Fase VI: contextualización de competencias

Fase VII: diseño del Plan de estudios

Fase VIII: aseguramiento de calidad

La determinación del lugar de aplicación del modelo delimita el contexto y define unos escenarios concretos en los que se planifica y desenvuelve la acción del MESIC. El enfoque socio-formativo nos indica que deberá tenerse en cuenta la axiología propia de la institución elegida para poder explicitar los Aspectos Clave. Junto con la axiología, filosofía o ideario de la Universidad de Piura, que es la institución elegida, se considera la planificación a futuro (Plan estratégico) que tiene el Programa Académico de Ingeniería Industrial verificando su coherencia con la propuesta del MESIC. La determinación de los Aspectos Clave, que es el segundo paso de la estrategia, tendrá que respetar e integrarse a estas directrices del Programa Académico de Ingeniería Industrial: el Ideario y el Plan estratégico.

La planificación del diseño curricular basándonos en el Análisis de políticas determina una forma de acción que está presente en toda la aplicación. En el cuarto paso el enfoque educativo, desde las corrientes socio-formativa y funcionalista, permite abarcar la formación integral de los estudiantes respondiendo a los requerimientos de los empleadores. Esta es una efectiva forma de planificación que permite una definición de mallas curriculares basada en el conocimiento experto y tomando en consideración los aportes de las partes ineresadas.

El quinto paso es el manejo de la estrategia participativa y la integración de conocimientos que permitirán la contextualización de las competencias, en un novedoso método participativo de todos los grupos de interés, llegando a conclusiones claras de la priorización de expectativas puestas en la Ingeniería Industrial de la UDEP. Poner en relieve a los grupos de interés utilizando esta estrategia, les empodera académicamente y fortalece los lazos de cooperación.

En el sétima fase, el diseño del Plan de estudios desde las competencias, parte del empleo de un método participativo de asignación, se despliega formas de desarrollo de metodologías activas y se construyen fichas para el desarrollo de competencias y su evaluación, en una propuesta innovadora y de fácil aplicación. En el último paso se pefila con claridad el sistema 
de calidad que debe emplearse para la educación superior de ingeniería en Perú y se concluye que el aseguramiento de la calidad requiere de un trabajo de investigación adicional.

Los cuatro primeros pasos de la metodología han requerido una búsqueda bibliográfica y el análisis y síntesis de la información encontrada para detectar las componentes que permiten definir las líneas principales sobre las que se debe soportar la aplicación del MESIC. En la contextualización de competencias se ha empleado un método cualitativo no probabilístico para la aplicación de encuestas a los cuatro grupos de interés en la formación de ingenieros industriales en Perú: alumnos, profesores, egresados y empleadores, con la finalidad de conocer la aplicabilidad de las competencias TuningAL en el contexto peruano. En tres casos se procedió con muestreo por conveniencia, y en uno de ellos se aplicó el análisis estadístico exhaustivo. También se verificó la confiabilidad de los instrumentos empleados utilizando el Criterio Alpha de Cronbach. Finalmente se analizaron e interpretaron los datos. Similar metodología se emplea para el caso de las competencias específicas. En la definición del Plan de estudios se emplea la metodología de localización, búsqueda, identificación, selección, análisis crítico y descripción de la información referida a la gestión curricular y se aplica al caso.

Finalmnte, tras la aplicación del modelo, se proponen unas líneas de investigación futuras pendientes, como son: el estudio del impacto de los horarios en la adquisición de hábitos y competencias en los estudiantes, la conveniencia de la frecuencia de las evaluaciones y el aseguramiento de la calidad de un proceso formativo en la educación superior peruana. 


\subsection{CONTEXTUALIZACIÓN}

Tal como hemos revisado en el capítulo 2, apartado 2.4.1., la situación de la educación superior en el Perú atraviesa por una crisis, con autonomías institucionales mal entendidas y sin un ente rector operante en los hechos. Esto genera mucha inestabilidad en el sistema. Tal inestabilidad impacta en las universidades e incluso en titulaciones o carreras. Pueden encontrarse severas diferencias entre titulaciones similares de universidades distintas. Tales diferencias están presentes también en formas de gestión, las normas académicas y administrativas e incluso los creditajes. Hasta la designación de autoridades, aunque normada, encuentra marcadas diferencias entre universidades. Ya ha sucedido que siguiendo escrupulosamente el procedimiento y eligiendo a un Rector de manera ajustada a normas, algún estamento universitario, bajo o alto, se resiste a aceptarlo y termina siendo otro quien ocupe su lugar "interinamente" hasta que se hagan nuevas elecciones, con algún o ningún grado de violencia, al amparo de una mal entendida autonomía que linda con el libertinaje. Este escenario incierto indica que en Perú, en estas condiciones, no es posible encarar un Sistema de Educación Superior uniforme, funcional y estable, ya sea porque el sistema no está correctamente normado o porque cada institución, o estamento dentro de ella, hace lo que considera más apropiado; esto nos lleva a la necesidad de acotar un ámbito dentro de Perú para aplicar el Modelo propuesto.

Debemos acotarlo porque las situaciones dinámicas complejas generadas tanto por las continuidades como por los cambios histórico-culturales coexistentes en un territorio, cuando no están exentos de diversos grados de violencia o libertinaje, agregan complejidad e incertidumbre generando una dialéctica de localización. Por ello, debe buscarse la armonía entre las dimensiones social, económica y ambiental del desarrollo (Miranda, 2012).

Por ello decidimos elegir una universidad dentro del sistema universitario peruano, en la que podamos aplicar el modelo y ese será nuestro ámbito. Una universidad donde se imparta la titulación de Ingeniería Industrial dentro de Perú con normas establecidas, con actitud positiva de mejora y características académicas y administrativas relevantes y estables para que los resultados puedan ser válidos y replicables al resto del sistema, si otras universidades lo consideran pertinente.

Elegimos la Universidad de Piura (UDEP). Esta universidad tiene su sede principal fuera de la capital de la República de Perú (ver Gráfico 5.1), al norte, en la Región Piura (Gráfico 5.2), y por su tamaño permitirá aplicar los instrumentos necesarios e incluso probar el modelo educativo con mayor facilidad que una de mayor envergadura.

La Universidad de Piura (UDEP) se encuentra en la ciudad de Piura, capital de la Región Piura. Esta Región está localizada al noroeste del Perú entre los $4^{\circ} 5^{\prime}$ y $6^{\circ} 22^{\prime}$ latitud sur, y $79^{\circ} 00^{\prime}$ y $81^{\circ} 7^{\prime}$ longitud oeste. La ciudad de Piura lo está en $05^{\circ} 12^{\prime} 00^{\prime \prime}$ latitud sur y $80^{\circ} 38^{\prime} 00^{\prime \prime}$ longitud oeste, en zona horaria UT-5:00. La Región limita por el norte con la Región Tumbes y la República del Ecuador, al sur con la Región Lambayeque, al este con la Región de Cajamarca y al oeste con el Océano Pacífico. La Región Piura tiene una superficie de 35,892.49 $\mathrm{Km}^{2}$, equivalente al 3\% del territorio peruano; en la superficie mencionada debe tenerse en cuenta que $1.32 \mathrm{Km}^{2}$ corresponden a la superficie insular oceánica de las islas Isla La Foca e Isla G, 
ubicadas frente a sus costas. La ciudad capital, Piura, se encuentra a veinticinco m.s.n.m.; las otras capitales de provincias costeras de la región no sobrepasan los cien m.s.n.m., y las serranas alcanzan los dos mil setecientos quince m.s.n.m. En la costa piurana la temperatura media de verano es de $35^{\circ} \mathrm{C}$ y la de invierno $16^{\circ} \mathrm{C}$. Las lluvias son escasas y generalmente se presentan entre enero a marzo. La población de la Región proyectada para el año 2015 es un millón ochocientos cuarentaicuatro mil personas, de los cuales novecientos veintiseis mil son hombre y novecientos dieciocho mil son mujeres. Los habitantes de la Provincia Piura son setecientos sesentaicinco mil personas, con trescientos ochentaicinco mil mujeres y trescientos ochenta mil hombres, con una tasa de crecimiento anual de 1.49 (INEI, 2009).

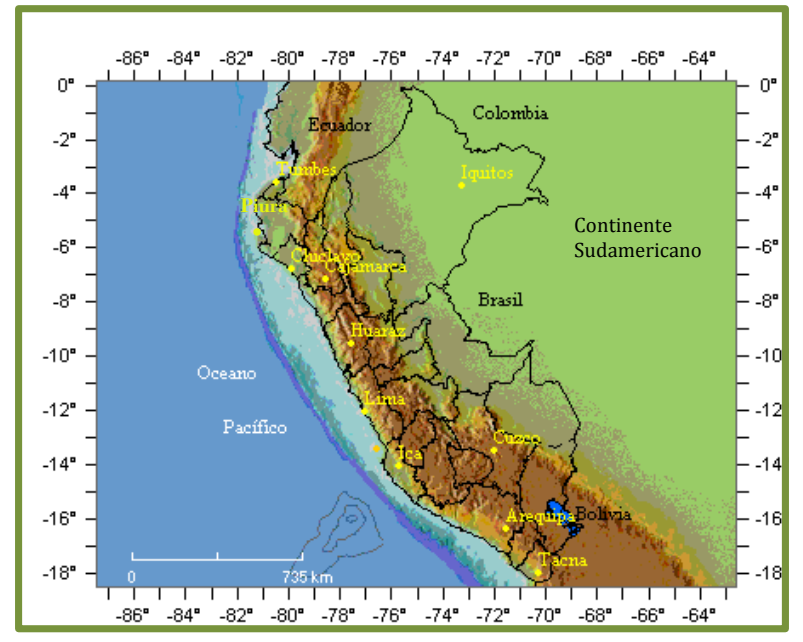

Gráfico 0.1 Localización de Perú.

Fuente: Mundo cartográfico, 2014.

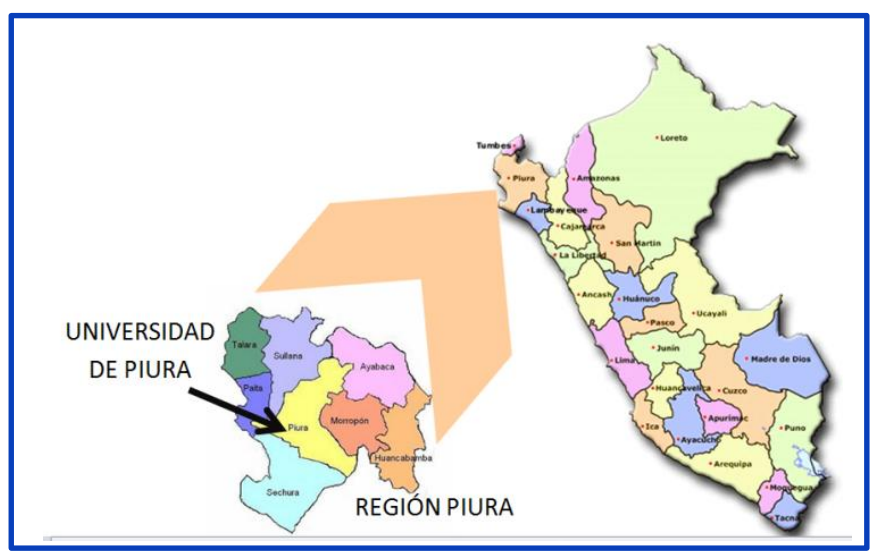

Gráfico 0.2 Localización de Piura

Fuente: Elaboración propia

La Universidad de Piura (UDEP) cuenta más de cinco mil alumnos en el Campus de Piura y más de mil quinientos en el Campus de Lima, distribuidos en seis Facultades y doce Programas Académicos. En la Memoria Anual 2013 se indica que en la UDEP, ese año, se han realizado 
81 trabajos de consultoría y proyectos de investigación, expusieron 200 ponencias en más 150 reuniones científicas, publicaron 52 artículos en revistas científicas y publicaron 32 libros (UDEP, 2013).

En la Facultad de Ingeniería se encuentran los Programas Académicos Ingeniería Industrial y Sistemas, Ingeniería Civil e Ingeniería Mecánica Eléctrica. La Titulación o Programa Académico de la UDEP en que haremos la validación de las competencias seleccionadas recibe el nombre de Ingeniería Industrial y de Sistemas, por el énfasis que se pone en formar a los Ingenieros Industriales en el dominio de las TIC's, programación, manejo de bases de datos, y en la concepción que una industria forma parte de un sistema que a su vez se conforma de subsistemas y que la gestión de ella debe considerar ese enfoque. Este énfasis se soporta en el tradicional cuerpo operatcional-organizacional de la carrera. Este Programa Académico tiene 950 alumnos en los dos Campus y es percibido como competitivo por los empresarios del país, Tabla 2.1 del Capítulo II, figurando entre los cinco primeros lugares en opinión de los empleadores, siendo la única de fuera de la capital nacional en el ranking.

Para abreviar, a partir de este punto al Programa Académico de Ingeniería Industrial y de Sistemas de la Facultad de Ingeniería de la Universidad de Piura le llamaremos, Ingeniería Industrial de la UDEP.

Existe en la Facultad de Ingeniería en general y en Ingeniería Industrial de la UDEP en particular, una marcada actitud de mejora continua y buena disposición a emprender cambios en su rutina administrativa, en planes de estudio, en la búsqueda de enriquecer su práctica académica, la formación de alumnos, la investigación y la proyección a la sociedad, siempre que esté acorde con su axiología plasmada en su Ideario (UDEP, 1998), y con su Plan estratégico (UDEP F.I., 2014).

A partir de ahora deberán considerarse como ámbito de acción los escenarios en los que se desenvuelve la UDEP y como grupos de interés para relevar información, aquellos que se relacionen directa o indirectamente con ella.

La Universidad de Piura en el Norte del Perú se convierte en el espacio contextual apropiado para aplicar el Modelo para la Educación Superior de la Ingeniería Industrial de Perú desde las Competencias (MESIC).

\subsection{ASPECTOS CLAVE: Principios, valores y plan a futuro}

Como se indicó en el Capítulo IV, apartado 4.2, es primordial definir la axiología o ideario, el plan estratégico y un modelo de calidad de la institución antes de definir los aspectos clave del MESSIPC.

\section{E1 IDEARIO de la Universidad de Piura (UDEP).}

Ideario es el conjunto de ideas fundamentales que caracteriza el pensamiento de una colectividad, según el Diccionario de la lengua española, de la Real Academia Española (RAE, 2014), y así se promulga en la Universidad de Piura. 
En la Ceremonia de Apertura del Año Académico 2009, el Rector de ese momento Dr. Antonio Abruña Puyol, señalaba (UDEP, 2009):

"Precisamente porque aspiramos llegar muy alto, sabemos que los cimientos han de ser sólidos y profundos, más aun tratándose de una institución como la Universidad que cuenta sus años por siglos. Mirar el Ideario que enuncia los principios y valores de nuestra peculiar fisonomía institucional será la mejor guía para garantizar la fecundidad de los esfuerzos futuros".

El Ideario de la Universidad de Piura enuncia aquellos principios fundamentales que deben presidir todas sus actuaciones, así como sus relaciones con quienes la integran: profesores, estudiantes, graduados y personas que trabajan en los diferentes Centros (UDEP, 1998). Es en este documento donde se plasma la axiología de la Universidad de Piura y, por ende, se convierte en la fuente axiológica la Ingeniería Industrial de UDEP.

Siendo el Ideario, Gráfico 0.3, el compendio de los valores y principios que orientan el accionar de todos los Centros de la UDEP, los Aspectos Clave del MESIC deben definirse respetando escrupulosamente lo que en él se señala.

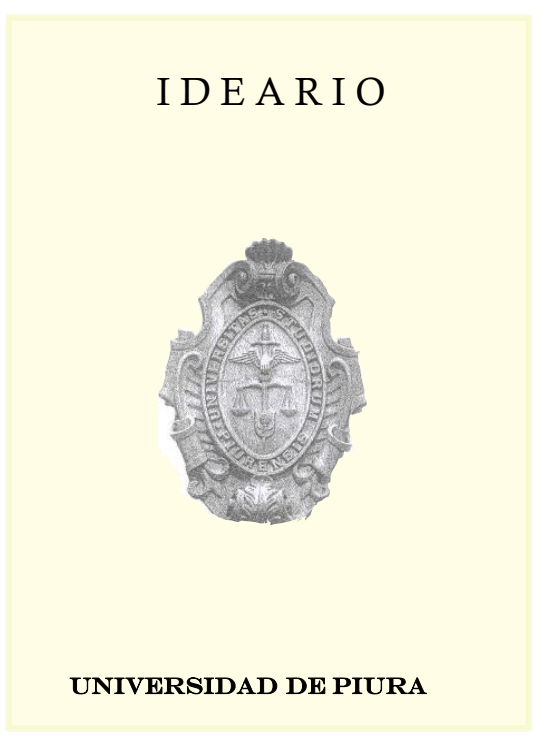

Gráfico 0.3 Ideario de la Universidad de Piura. Fuente: UDEP, 1998.

\section{Plan Estratégico.}

La Facultad de Ingeniería, a la que pertenece Ingeniería Industrial de UDEP, ha concluido el año 2013 su Plan Estratégico para los siguientes cinco años. Este Plan fue elaborado contando con la participación de todos los grupos de interés, conformándose el Equipo central (Core group) con representantes de alumnos, de egresados, de profesores, de administrativos, de empleadores, directivos de la Facultad y como representante de instituciones del medio el Presidente del Colegio de Ingenieros del Perú y ex Ministro de Energía y Minas. En el Gráfico 5.4a el Equipo Central. 


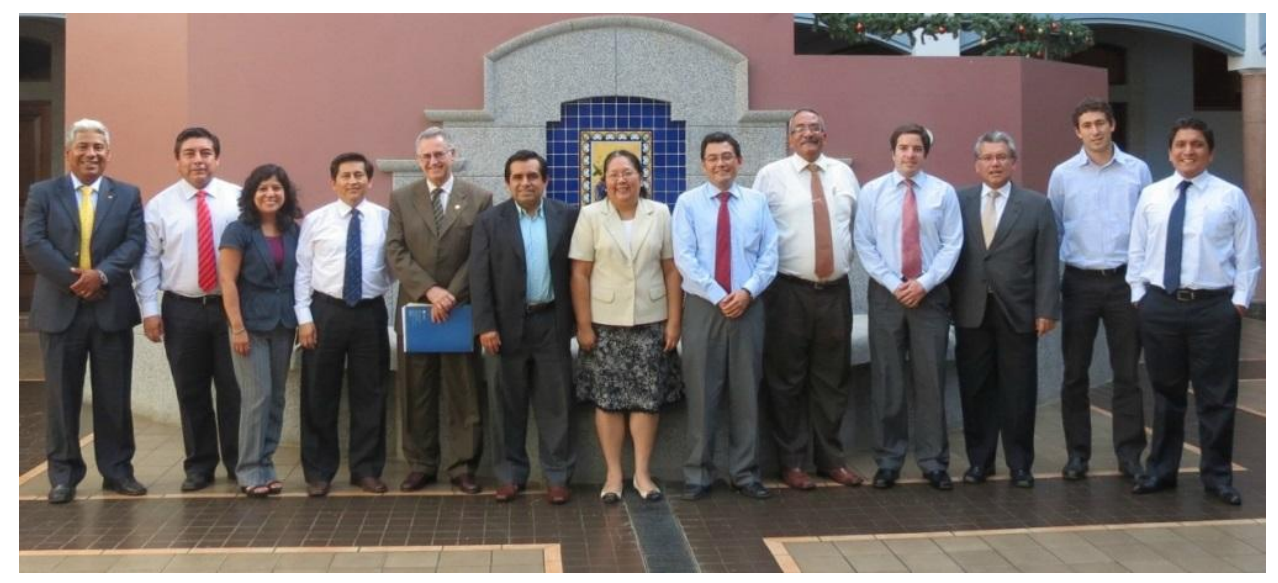

\section{Gráfico 0.4 Equipo Central del Plan estratégico de la Facultad de Ingeniería. Fuente: Archivo de la Pas Decana Ph.D. Ing. Susana Vegas.}

Los temas que surgieron fueron desarrollados por un segundo nivel de planificación que estaba constituido fueron grupos conformados por todos los profesores de la Facultad y un significativo número de administrativos. Los resultados a que se llegaron fueron consolidados por el Equipo Central, con la asesoría y dirección del Dr. Axel Meisen³.

El Ph.D. Axel Misen es un antiguo colaborador de la Facultad de Ingeniería, en particular, y de la Universidad de Piura, en general. Su participación en el Plan estratégico le imprimió un muy experto enfoque con visión global, dada su experiencia en universidades e instituciones de gran prestigio mundial. En el Gráfico 0.5 trabajando la consolidación de información con la Decana de la Facultad de Ingeniería de ese momento, y en el Gráfico 0.6 se observan representantes de alumnos y egresados junto con profesores y directores de programa en un clima de armonía y estrecha cooperación.

\footnotetext{
${ }^{3}$ Axel Meisen, C.M., Ph.D., P.Eng. Eurlng:

Presidente de la Comisión Canadiense para la UNESCO como miembro de la Junta Directiva de la Asociación de Edmonton Opera.

Miembro de la Academia Canadiense de Ingeniería (FCAE), el Instituto Canadiense de Química (FCIC) y el Instituto de Ingenieros de Irlanda (FIEI).

Miembro nombrado de la Orden de Canadá y Grado de Doctor Honoris causa por la Universidad de Waterloo. Former Chair of Foresight, at Alberta Innovates - Technology Futures (AITF). Pas Presidente y Pas Rector de la Memorial University of Newfoundland-Canadá. Pas Decano de Ciencias Aplicadas de la Universidad de Columbia Británica.
} 


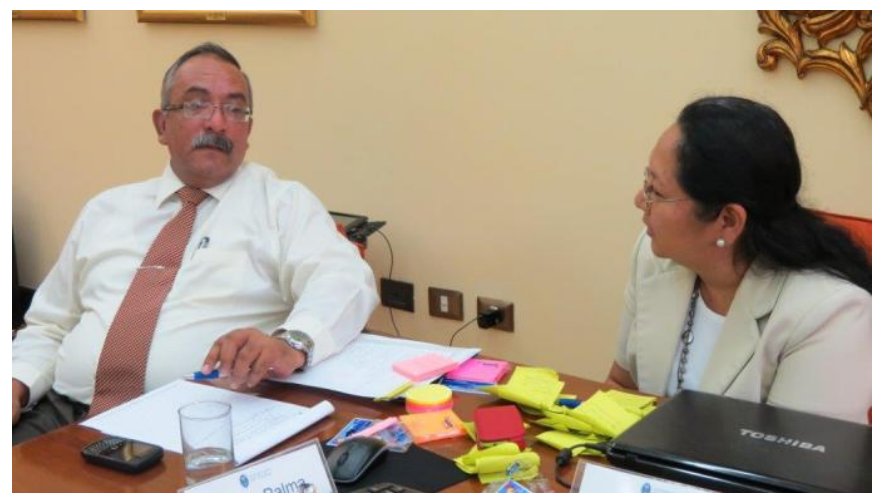

Gráfico 0.5 Etapa de consolidación con la Decana de la Facultad. Fuente: Archivo de la Facultad de Ingeniería de UDEP.

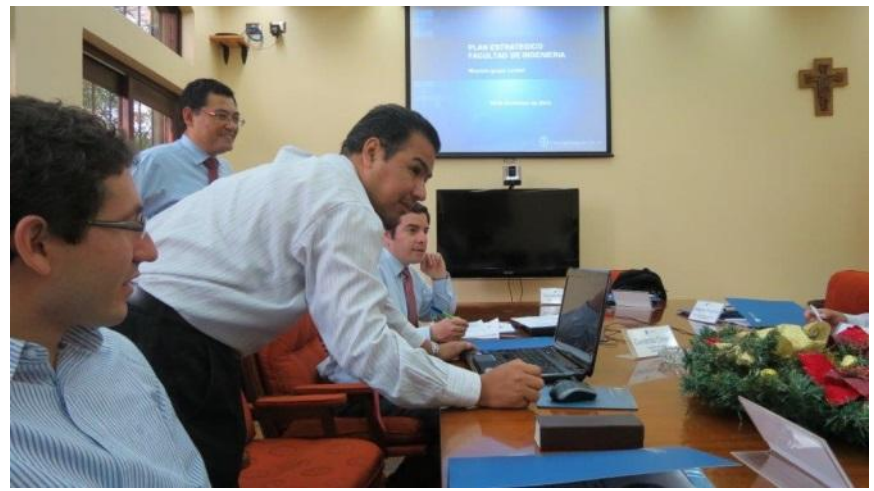

Gráfico 0.6 Representantes de alumnos y egresados en el diseño Plan Estratégico. Fuente: Archivo de la Facultad de Ingeniería de UDEP.

El Plan Estratégico fue planificado y desarrollado siguiendo una estrategia participativa que bajo el modelo del Análisis de políticas, concluyó en un documento que compila en diez puntos prioritarios el horizonte de acción de los próximos cinco años de la Facultad de Ingeniería y, por tanto, de los Programas Académicos que le conforman.

El documento, conciso y concreto, consta de varias páginas que se condensaron en un tríptico de fácil lectura para la distribución entre la comunidad universitaria y grupos de interés. En los Gráfico 0.7 y Gráfico 0.8 se muestra el tríptico 


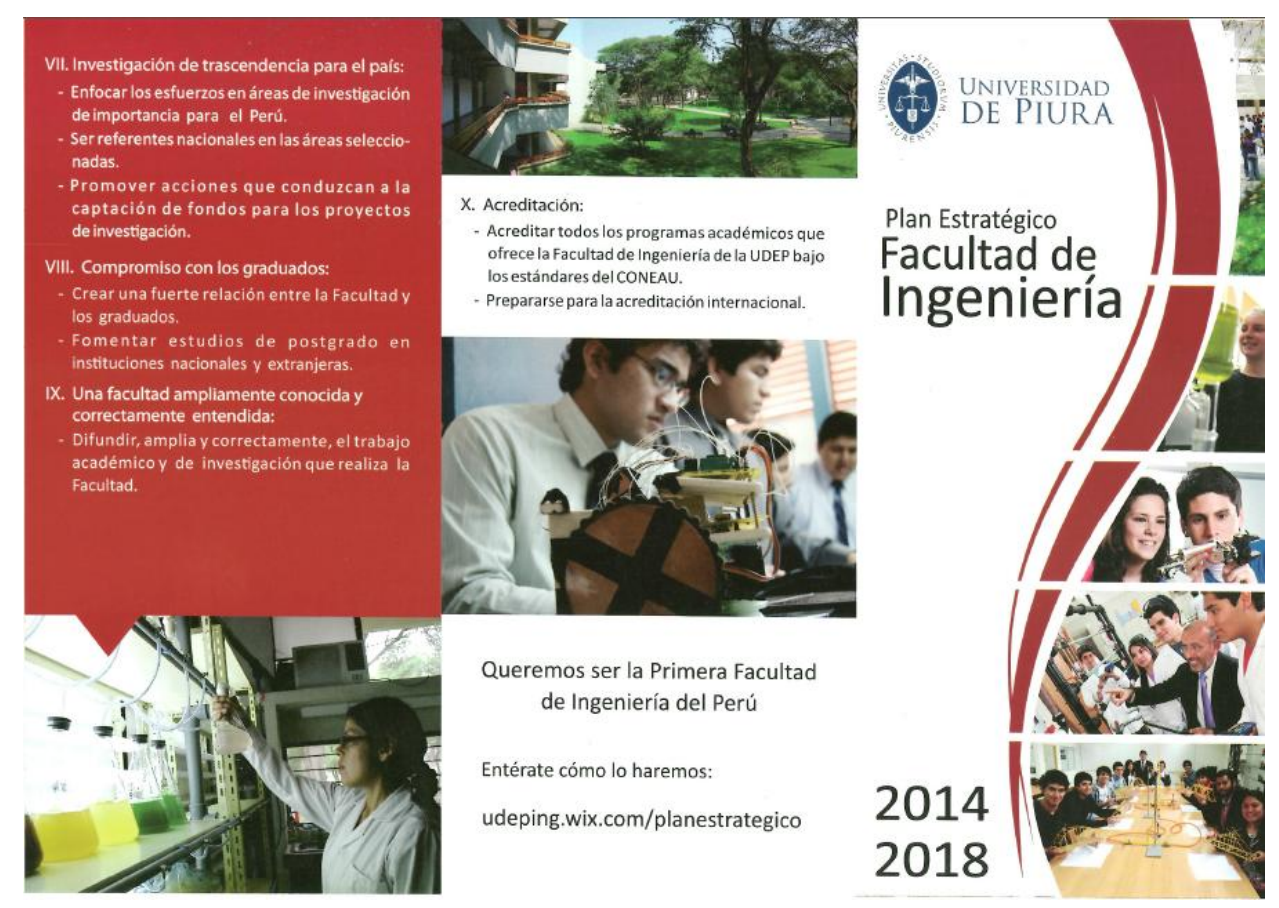

Gráfico 0.7 Anverso del Tríptico del Plan Estratégico de la Facultad de Ingeniería. Fuente: Archivo de la Facultad de Ingeniería de la UDEP.

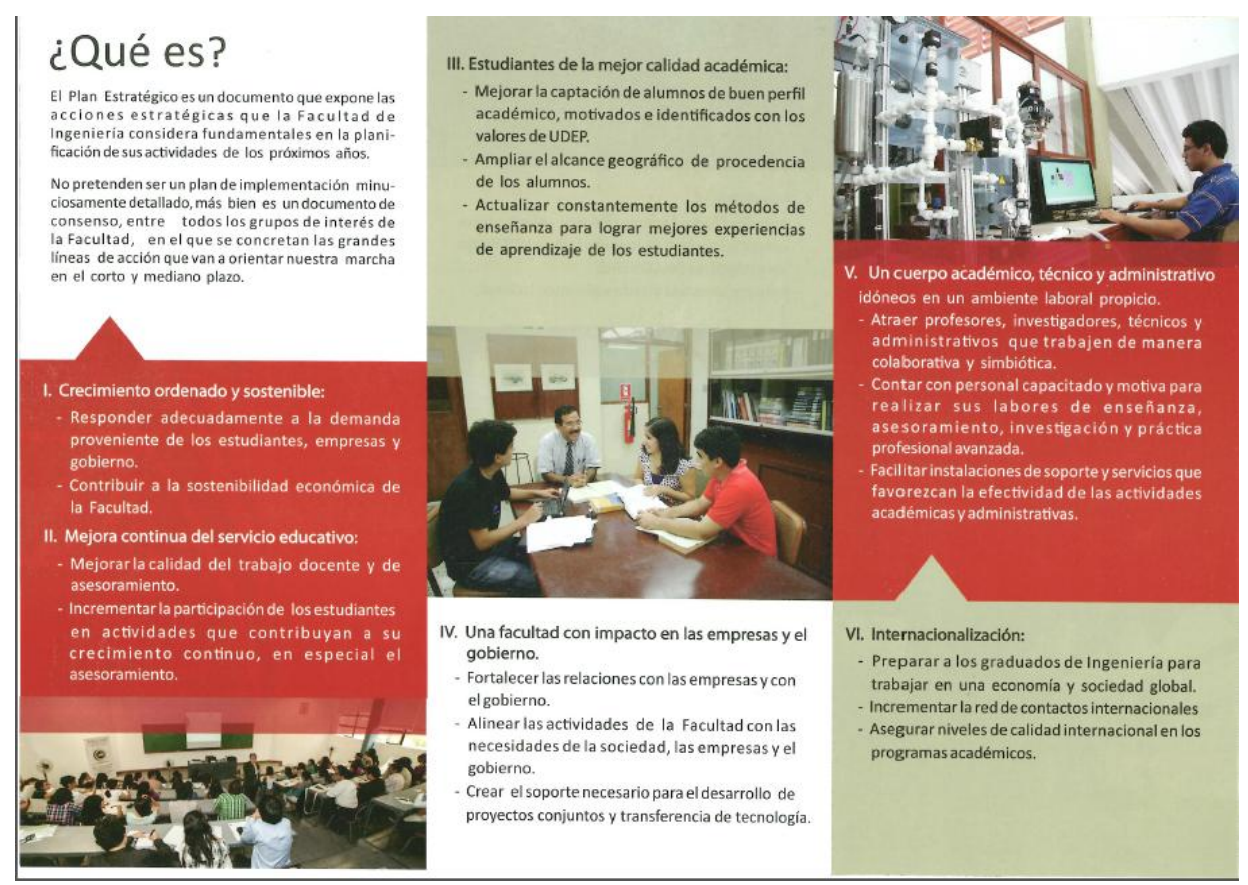

Gráfico 0.8 Reverso del Tríptico del Plan Estratégico de la Facultad de Ingeniería. Fuente: Archivo de la Facultad de Ingeniería de la UDEP.

Con el Ideario y el Plan Estratégico definidos, resta especificar el Modelo de Calidad que acompañe la formación de los alumnos de Ingeniería Industrial de la UDEP, para poder abordar los Aspectos Clave que requiere el MESIC desde los tres aspectos: la axiología, la visión de futuro y la calidad. 


\section{Modelo de Calidad.}

Abordar el aseguramiento de la calidad en educación superior es muy complejo pues el concepto "calidad de la educación superior" es considerado no taxativo. Nicholson (2011), citado por Yamada y coautores (2012), afirma que para muchos estudiosos la falta de acuerdo con el significado de "calidad en la educación superior" sugiere que este concepto, tomado de la actividad empresarial y la economía, es poco adaptable al contexto educativo. La principal razón para esto es que una única visión de la calidad no necesariamente resulta representativa de los variados, y a veces contradictorios, puntos de vista de los grupos de interés (stakeholders) en torno al quehacer educativo.

La cuestión clave es si el concepto de calidad tiene la capacidad de facilitar la perspectiva de todas las partes interesadas, que pueden tener diferentes concepciones de la educación superior (Cullen, Joyce, Hassall y Broadbent, 2003).

El punto es que al intentar determinar si la experiencia educativa ha cumplido con sus expectativas iniciales se encuentra que los estudiantes son más propensos a juzgar la calidad como la capacidad para cumplir con una función, mientras que los profesores tienden a medir la calidad en términos de insumos y productos, tales como fondos para la investigación y la productividad en número de publicaciones, número de cursos impartidos o resultados del aprendizaje de los alumnos. Por el contrario, las partes interesadas externas como el gobierno y la sociedad en general, requieren una calidad asociada a la rentabilidad de las inversiones realizadas; por otra parte, se agrega que los dos pilares de la universidad, investigación y enseñanza, difieren en cuanto a propósito, proceso y resultados. Por todo esto es que se requieren diferentes enfoques de aseguramiento de la calidad en la educación superior (Marshall, 1998). A la luz de esto, no es de extrañar que Harvey y Green (1993) sugieran que la única solución práctica a esta "cuestión filosófica compleja" es reconocer y validar todas estas perspectivas diversas y rechazar la posibilidad de aceptar una definición única de la calidad de educación superior (Yamada et al., 2012).

Lo que haremos será definir un modelo de calidad que atienda los estándares exigidos por el sistema universitario peruano y la acreditación, tan extendida actualmente, y considerar los requerimientos que los grupos de interés hayan hecho y no se contemplen en esos modelos.

El sistema de calidad que estableceremos para esta aplicación del MESIC, entendido como una forma de mejora continua, será el normado por el Estado Peruano para las universidades través de SINEACE, sin olvidar que el tratamiento de este tópico requiere de un enfoque variado e inclusivo de los intereses de todos los interesados.

El SINEACE es el Sistema Nacional de Evaluación, Acreditación y Certificación de la Calidad Educativa, creada el 19 de mayo del 2006 mediante Ley No 28740; el 09 de julio del año 2007 se aprobó su Reglamento con el Decreto Supremo D.S. No 018-2007. Su finalidad es garantizar que las instituciones públicas y privadas brinden un servicio educativo de calidad. Sus principios son: informar sobre los avances y resultados del proceso de certificación, promover cultura de calidad educativa, y velar por la pertinencia y transparencia de procesos (SINEACE, 2014). 
El SINEACE está conformado por tres operadores, uno para la educación básica, IPEBA, uno para la educación superior no universitaria, CONEACES, y uno para la educación superior universitaria CONEAU (SINEACE, 2014).

El CONEAU, Consejo de Evaluación, Acreditación y Certificación de la Calidad de la Educación Superior Universitaria, tiene como misión definir criterios, indicadores y estándares para evaluar la calidad de la formación en las universidades públicas y privadas, y de los profesionales, por medio de procesos de acreditación y certificación. Las consecuencias que derivan de una acreditación de calidad frente al CONEAU son: priorización en la asignación de fondos para investigación, innovación tecnológica y becas; preferencia en la contratación de personal del Estado; respaldo del estado ante donaciones internacionales a la carrera o universidad acreditada; entrega de fondos para ejecutar planes de mejora en busca de nuevas acreditaciones; y mayores posibilidades de obtener trabajos y becas en el extranjero (CONEAU, 2014). Por ello se convierte en el ente rector de la calidad en las universidades peruanas al que conviene ajustar la aplicación del MESIC, pues aunque no es obligatorio, proporciona una herramienta útil para la mejora continua de una institución universitaria además que las bondades que ofrece a quien se acredite le hacen un sistema apetecible.

El año 2010 el CONEAU emitió los "Estándares para la Acreditación de las Carreras Profesionales Universitarias de Ingeniería" que a la fecha no ha sido reglamentada ni es de acatamiento obligatorio, Gráfico 0.9. En él se define el marco estructural, con el que, afirma, promoverá el orden, la sistematización, la evaluación y la autorregulación de las carreras de ingeniería, al facilitar la interacción de los procesos que tienen lugar en la unidad académica y que le permiten el cumplimiento de los compromisos adquiridos por la institución con la sociedad en cuanto al conocimiento creado, los profesionales formados y los servicios entregados a la comunidad, expresados en el número de graduados y titulados por promoción, los proyectos de investigación, extensión universitaria y proyección social realizados, las publicaciones y la percepción de la sociedad sobre la calidad del servicio ofrecido y recibido (CONEAU, 2010).

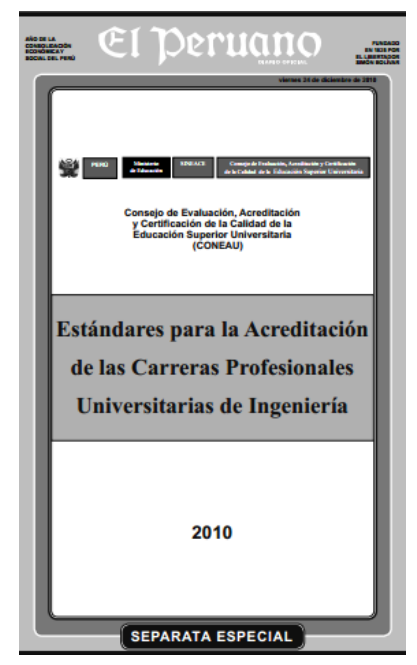

Gráfico 0.9 Publicación de los Estándares de calidad para las Ingenierías en Perú. Fuente: CONEAU, 2010. 
El Modelo de Calidad que se propugna desde el Estado para las carreras de ingeniería se plasma en el documento del CONAU mencionado se aprecia en el Gráfico 0.10. Para las ingenierías consta de 03 dimensiones, 09 factores, 16 criterios y 98 estándares, con sus correspondientes fuentes de verificación referenciales (141 distintas), y 134 indicadores de gestión (Tabla 0.1). Como dimensiones se plantean: la gestión de la carrera profesional, la formación profesional y los servicios de apoyo para la formación profesional; dimensiones que permiten diferenciar los niveles de actuación y facilitan su aplicación sin menoscabo de la importancia de cada factor a evaluar (CONEAU, 2010).

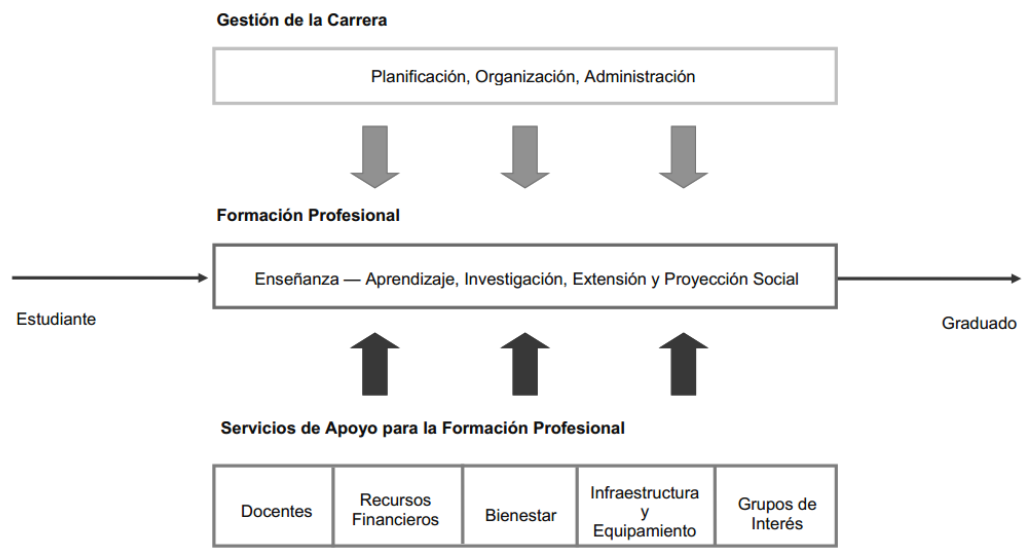

Gráfico 0.10 Modelo de Calidad para la Acreditación de las Ingenierías en Perú. Fuente: CONEAU, 2010.

Los estándares de calidad que correspondan se deben tomar en cuenta en el diseño del Plan de Estudios bajo el enfoque del MESIC como un instrumento de mejora continua. Esto permitirá que en el futuro, en una posible autoevaluación del Programa Académico para la acreditación ante el Estado, sea más fácil cumplir con los estándares pues desde el diseño se planificó pensando cumplir lo solicitado. 


\begin{tabular}{|c|c|c|c|}
\hline DIMENSIÓN & FACTOR & CRITERIO & $\begin{array}{c}\text { No DE }^{\circ} \\
\text { ESTÁNDARES }\end{array}$ \\
\hline \multirow{2}{*}{$\begin{array}{l}\text { Gestión de la } \\
\text { carrera. }\end{array}$} & \multirow{2}{*}{$\begin{array}{l}\text { Planificación, } \\
\text { organización, dirección y } \\
\text { control. }\end{array}$} & Planificación estratégica. & 5 \\
\hline & & $\begin{array}{l}\text { Organización, dirección y } \\
\text { control. }\end{array}$ & 9 \\
\hline \multirow{7}{*}{$\begin{array}{l}\text { Formación } \\
\text { profesional. }\end{array}$} & \multirow{5}{*}{$\begin{array}{l}\text { Enseñanza - } \\
\text { aprendizaje. }\end{array}$} & $\begin{array}{l}\text { Proyecto educativo.- } \\
\text { Curriculo. }\end{array}$ & 14 \\
\hline & & $\begin{array}{l}\text { Estrategias de enseñanza- } \\
\text { aprendizaje. }\end{array}$ & 2 \\
\hline & & $\begin{array}{l}\text { Desarrollo de las actividades } \\
\text { de enseñanza-aprendizaje. }\end{array}$ & 4 \\
\hline & & \begin{tabular}{|l|} 
Evaluación del aprendizaje y \\
acciones de mejora.
\end{tabular} & 2 \\
\hline & & Estudiantes y egresados. & 10 \\
\hline & Investigación. & $\begin{array}{l}\text { Generación y evaluación de } \\
\text { proyectos de investigación. }\end{array}$ & 9 \\
\hline & $\begin{array}{l}\text { Extensión universitaria y } \\
\text { proyección social. }\end{array}$ & \begin{tabular}{|lrr|}
\multicolumn{3}{|l}{ Generación y evaluación de } \\
proyectos & de & extensión \\
universitaria & y & proyección \\
social. & & \\
\end{tabular} & 10 \\
\hline \multirow{7}{*}{$\begin{array}{l}\text { Servicios de } \\
\text { apoyo para la } \\
\text { formación } \\
\text { profesional }\end{array}$} & \multirow{3}{*}{ Docentes. } & Labor de enseñanza y tutoria. & 10 \\
\hline & & Labor de investigación. & 5 \\
\hline & & $\begin{array}{l}\begin{array}{l}\text { Labor de extensión } \\
\text { universitaria y de proyección } \\
\text { social. }\end{array} \\
\end{array}$ & 3 \\
\hline & $\begin{array}{l}\text { Infraestructura y } \\
\text { equipamiento. }\end{array}$ & $\begin{array}{l}\text { Ambientes y equipamiento } \\
\text { para la enseñanza- } \\
\text { aprendizaje, investigación, } \\
\text { extensión universitaria y } \\
\text { proyección social, } \\
\text { administración y bienestar. }\end{array}$ & 3 \\
\hline & Bienestar. & $\begin{array}{l}\text { Implementación de } \\
\text { programas de bienestar. }\end{array}$ & 6 \\
\hline & Recursos financieros. & $\begin{array}{l}\text { Financiamiento de la } \\
\text { implementación de la carrera. }\end{array}$ & 3 \\
\hline & Grupos de Interés. & \begin{tabular}{|l|} 
Vinculación con los grupos de \\
interés.
\end{tabular} & 3 \\
\hline 3 & 9 & 16 & 98 \\
\hline
\end{tabular}

Tabla 0.1 Dimensiones, factores, criterios y estándares para la acreditación de las carreras profesionales universitarias de Ingeniería. Fuente: CONEAU, 2010.

Además, y en paralelo a estas instituciones, la Nueva Ley Universitaria Ley 30220 de julio de 2014, crea la Superintendencia Nacional de Educación Superior Universitaria (SUNEDU) como Organismo Público Técnico Especializado adscrito al Ministerio de Educación, con autonomía técnica, funcional, económica, presupuestal y administrativa, para el ejercicio de sus funciones. La SUNEDU tiene por finalidad el licenciamiento para el servicio educativo superior universitario. Debe entenderse por licenciamiento el procedimiento que tiene como objetivo verificar el cumplimiento de condiciones básicas de calidad para ofrecer el servicio educativo superior universitario y autorizar su funcionamiento. La SUNEDU es también responsable de supervisar la calidad del servicio educativo universitario (Ley Universitaria, 2014).

El artículo 22 de la nueva Ley Universitaria dictamina que "La SUNEDU es la autoridad central de la supervisión de la calidad bajo el ámbito de su competencia, incluyendo el licenciamiento y supervisión de las condiciones del servicio educativo de nivel superior universitario, en razón de lo cual dicta normas y establece procedimientos para asegurar el cumplimiento de las políticas públicas del Sector Educación en materia de su competencia".

También la Ley, en el artículo 30, señala que "El proceso de acreditación de la calidad educativa en el ámbito universitario, es voluntario, se establece en la ley respectiva y se desarrolla a través de normas y procedimientos estructurados e integrados funcionalmente. Los criterios y estándares que se determinen para su cumplimiento, tienen como objetivo mejorar la calidad en el servicio educativo. Excepcionalmente, la acreditación de la calidad de algunas carreras será obligatoria por disposición legal expresa. El crédito tributario por reinversión y otros benefi cios e incentivos que se establezcan, se otorgan en mérito al cumplimiento del proceso de 
acreditación, de acuerdo a la normativa aplicable. La existencia de Institutos de Investigación en las universidades se considera un criterio favorable proceso de acreditación de su calidad".

Siendo el SINEACE una institución independiente del Ministerio de Educación ha mantenido sus funciones y es la que actualmente acrdita los Programas Académicos y Facultades universitarias, a pesar que el SUNEDU, dependiente del Ministerio de Educación en la nueva Ley universitaria, es el ente encargado de centralizar el proceso de acreditación de la calidad educativa en el ámbito universitario. Esta situación lleva a constantes discrepancias entre ambos lo que mantiene a las universidades peruanas a la expectativa de cual será finalmente el ente acreditador estatal. A la fecha el SINEACE sigue acreditando y el SUNEDU se ha dedicado al licenciamiento universitario institucional con el eslogan "Educación con estándares básicos de calidad, que brinde las herramientas necesarias para el desarrollo personal y profesional de los estudiantes".

Dada la situación descrita se optará por seguir el sistema de aseguramiento de calidad ligado a los estándares exigidos por el SINEACE para alcanzar la acreditación nacional.

Definida la axiología, el Plan Estratégico y estándares de calidad, podemos definir los Aspectos Clave del modelo.

\section{Aspectos Clave.}

A partir de la definición de Modelo educativo dada por Tobón, revisada en el Capítulo IV apartado 4.3, en esta parte del trabajo se desarrollan los Aspectos Clave del modelo. Los aspectos clave son: ¿qué tipo de persona se pretende formar? ¿Para qué tipo de sociedad? ¿Con qué enfoque formativo? ¿Con qué principios educativos? ¿Cuál es el rol de los docentes? ¿Cuál es el papel de los estudiantes en el proceso? ¿En qué escenarios? ¿Cómo debe ser la estructura básica de los Planes de estudios? ¿Cómo se vinculará con la sociedad? ¿Cuáles serán las propuestas de investigación para los estudiantes? (Tobón, S. 2010).

De lo trabajado en los capítulos anteriores, contrastando con el Ideario de la Universidad de Piura, su Plan Estratégico y el Modelo de calidad del SINEACE, y contando con la opinión de los expertos de Ingeniería Industrial de la UDEP, los aspectos clave del MESIC son como se muestra en la Tabla 0.2 Aspectos clave Modelo para la Educación Superior de la Ingeniería Industrial de Perú desde las Competencias (MESIC). Fuente: Elaboración propia. 


\begin{tabular}{|c|c|}
\hline $\begin{array}{c}\text { ASPECTO } \\
\text { CLAVE }\end{array}$ & DESCRIPCIÓN \\
\hline $\begin{array}{l}\text { ¿Qué tipo de } \\
\text { persona se } \\
\text { formará? }\end{array}$ & $\begin{array}{l}\text { Personas con formación básica sólida con amplio contenido } \\
\text { humanístico y científico como fundamento indispensable, con } \\
\text { formación integral y preparación profesional de modo que puedan } \\
\text { servir eficazmente a sus conciudadanos y a toda la sociedad } \\
\text { promoviendo el bien común. }\end{array}$ \\
\hline $\begin{array}{l}\text { ¿Para qué tipo de } \\
\text { sociedad se } \\
\text { formará? }\end{array}$ & $\begin{array}{l}\text { Una sociedad progresista y en una línea de ordenamiento cada vez } \\
\text { más justo a partir del trabajo, entendido como uno de los valores } \\
\text { humanos más altos, de sus integrantes. }\end{array}$ \\
\hline $\begin{array}{l}\text { ¿Con qué } \\
\text { enfoque educa- } \\
\text { tivo se formará? }\end{array}$ & $\begin{array}{l}\text { - La Universidad de Piura se guía por los principios derivados de una } \\
\text { concepción cristiana del hombre, de la sociedad y del mundo. } \\
\text { - Tomará el enfoque socio-formativo para el diseño del plan de estudios } \\
\text { en una vigorosa coparticipación con el enfoque funcional. }\end{array}$ \\
\hline $\begin{array}{l}\text { ¿Con qué } \\
\text { principios } \\
\text { educativos se } \\
\text { formará? }\end{array}$ & $\begin{array}{l}\text { - Respeto de la axiología institucional. } \\
\text { - Alto nivel de exigencia académica que estimule los hábitos de estudio } \\
\text { e investigación. } \\
\text { - Los conocimientos y saberes, manteniendo su autonomía legítima, } \\
\text { estarán esclarecidos por la verdades de la fe, en las que se inspirarán } \\
\text { todas las enseñanzas y la investigación, de modo que ambas proyecten } \\
\text { una imagen cierta, cristiana, de la significación y del fin del hombre y } \\
\text { de la realidad entera. } \\
\text { - Formar para desenvolverse con sapiencia en las actividades sociales y } \\
\text { laborales. } \\
\text { - Fomento de la búsqueda de la verdad y ante cuestiones opinables } \\
\text { (políticas, económicas, profesionales, sociales, etc.), lejos de imponer } \\
\text { posiciones, desarrollar su capacidad de juicio y proveerles } \\
\text { conocimientos y criterios para que cada uno forme sus propias } \\
\text { convicciones, en un legítimo pluralismo. } \\
\text { - Fomento de la honradez y entereza necesarias para que cada uno } \\
\text { asuma con responsabilidad personal, las consecuencias de sus } \\
\text { decisiones y actos. }\end{array}$ \\
\hline $\begin{array}{c}\text { ¿Cuál es el rol de } \\
\text { los docentes }\end{array}$ & $\begin{array}{l}\text { - Ejercer sus tareas con dedicación y competencia profesional. } \\
\text { - Distinguirse por su competencia científica y pedagógica; por su } \\
\text { rectitud de vida; por el cumplimiento estricto de sus deberes; y, en } \\
\text { general, por su aptitud para identificarse con los principios del ideario } \\
\text { institucional. }\end{array}$ \\
\hline $\begin{array}{c}\text { ¿Cuál es el papel } \\
\text { de los } \\
\text { estudiantes? }\end{array}$ & $\begin{array}{l}\text { - Servir eficazmente a sus conciudadanos y a toda la sociedad } \\
\text { promoviendo el bien común, y con una conducta que favorezca el } \\
\text { respeto al honor y dignidad de las personas. }\end{array}$ \\
\hline $\begin{array}{l}\text { ¿En qué } \\
\text { escenarios se } \\
\text { formará } \\
\text { (Continúa...) }\end{array}$ & $\begin{array}{l}\text { - Principalmente se empleará la modalidad presencial, coordinando las } \\
\text { visitas a centros de manufactura y servicios, y con requisito de } \\
\text { prácticas laborales como condición de egreso. } \\
\text { - Clima de intensa laboriosidad sin interrupciones ni interferencias por } \\
\text { causas ajenas al quehacer universitario. } \\
\text { - (Continúa...) }\end{array}$ \\
\hline
\end{tabular}

Tabla 0.2 Aspectos clave Modelo para la Educación Superior de la Ingeniería Industrial de 
Perú desde las Competencias (MESIC). Fuente: Elaboración propia.

\begin{tabular}{|c|c|}
\hline $\begin{array}{l}\text { ASPECTO } \\
\text { CLAVE }\end{array}$ & DESCRIPCIÓN \\
\hline $\begin{array}{l}\text { (Continuación) } \\
\text { ¿En qué } \\
\text { escenarios se } \\
\text { formará? }\end{array}$ & $\begin{array}{l}\text { - La vida académica se ha de desenvolver siempre dentro de un régimen } \\
\text { de libertad responsable, de modo que se cree el ambiente necesario } \\
\text { para la mutua cooperación y respeto. } \\
\text { - De respeto a las opiniones y a la legítima libertad de investigación, } \\
\text { entendida como capacidad de esforzarse y comprometerse en la } \\
\text { búsqueda y servicio de la verdad. } \\
\text { - De colaboración mutua y con relaciones interdisciplinarias dentro de } \\
\text { cada Centro y en el conjunto de ellos, pues no son entidades aisladas, } \\
\text { sino partes de un todo para el logro de los fines de la corporación } \\
\text { universitaria. }\end{array}$ \\
\hline $\begin{array}{l}\text { ¿Cómo debe ser } \\
\text { la estructura } \\
\text { básica de los } \\
\text { Planes de } \\
\text { estudios? }\end{array}$ & $\begin{array}{l}\text { - En el Plan de estudios se contemplará: } \\
{ }^{\circ} \text { Los Contenidos curriculares: Velando por su vigencia, la coherencia } \\
\text { con el perfil y balance de creditaje entre áreas. } \\
{ }^{\circ} \text { Evaluación interna: congruencia del Plan con objetivos, integración } \\
\text { con los requisitos, viabilidad de recursos necesarios, requisitos de } \\
\text { permanencia y egreso, y rendimiento, retención y promoción. } \\
\text { ○ } \text { Flexibilidad: actualización con el entorno, posibilidad de concluir en } \\
\text { menos tiempo si el rendimiento es alto, secuenciación de cursos, } \\
\text { coherencia en cada nivel, cursos alternativos. } \\
{ }^{\circ} \text { Con una malla curricular: indicando duración de la carrera, cursos, } \\
\text { creditaje, seriación, coherencia vertical y horizontal. } \\
{ }^{\circ} \text { Sílabos por asignatura: detallados en el Plan. } \\
\text { - Vinculando la teoría con la práctica, con clases magistrales que } \\
\text { deberán incorporar paulatinamente metodologías activas. }\end{array}$ \\
\hline $\begin{array}{l}\text { ¿Cómo se } \\
\text { vinculará con la } \\
\text { sociedad? }\end{array}$ & $\begin{array}{l}\text { - Se vincula con la sociedad: } \\
\text { o Procurando el acceso a cuantos posean la capacidad académica y } \\
\text { humana, con independencia de sus posibilidades económicas, su } \\
\text { origen social, su raza o su religión. } \\
\text { o Realizando una amplia labor de extensión universitaria que } \\
\text { contribuya a la elevación moral, cultural y material de los diversos } \\
\text { sectores sociales. } \\
\text { o Llevando a cabo tareas de servicio a la sociedad en los ámbitos } \\
\text { propios de su actividad docente y científica. } \\
\text { o Manteniéndose abierta a cuantos respeten el Ideario, individuos o } \\
\text { instituciones, del ámbito nacional o mundial, con quienes procurará } \\
\text { mantener relaciones cada vez más intensas de colaboración, } \\
\text { intercambio y mutua ayuda. }\end{array}$ \\
\hline $\begin{array}{c}\text { ¿Cuáles serán los } \\
\text { ejes de la } \\
\text { investigación? }\end{array}$ & $\begin{array}{l}\text { - Impulsar y divulgar la investigación científica en todos los campos, } \\
\text { comenzando por los vinculados más directamente con la promoción } \\
\text { de la calidad de vida de la sociedad regional, nacional e internacional. } \\
\text { - Contar con una sensibilidad atenta a los problemas que se plantean en } \\
\text { la sociedad, para estudiarlos con profundidad científica, sin } \\
\text { desembocar en la acción política partidaria ni en otras tareas ajenas al } \\
\text { fin de la Universidad. }\end{array}$ \\
\hline
\end{tabular}




\section{Tabla 5.2. (Continuación...)}

Estos aspectos clave son fundamentales y deben tenerse en cuenta durante todo el desarrollo de la aplicación del MESIC.

\subsection{MODELOS DE PLANIFICACIÓN DE LA ENSEÑANZA}

Se empleará el modelo de planificación mixto como se ha definido en el capítulo IV apartado 4.2.1. De esta forma serán complementarios el Análisis de Políticas y el Aprendizaje Social y por tanto las directrices serán descendentes y ascendentes.

\section{Enfoque descendente}

Para trabajar el enfoque descendente, o Análisis de Políticas, debemos precisar las normas o líneas que deben respetarse en este diseño:

1. Ley Universitaria. Ley 30220, promulgada en 2014 (Ley universitaria, 2014).

Existen disposiciones concretas a cumplir desde esta Ley, por ejemplo:

"Artículo 2. Ámbito de aplicación. La presente Ley regula a las universidades bajo cualquier modalidad, sean públicas o privadas, nacionales o extranjeras, que funcionen en el territorio nacional".

"Articulo 8. 8.3 Autonomía académica, implica la potestad autodeterminativa para fijar el marco del proceso de enseñanza-aprendizaje dentro de la institución universitaria. Supone el señalamiento de los planes de estudios, programas de investigación, formas de ingreso y egreso de la institución, etc. Es formalmente dependiente del régimen normativo y es la expresión más acabada de la razón de ser de la actividad universitaria".

"Artículo 39. Régimen de estudios. El régimen de estudios se establece en el Estatuto de cada universidad, preferentemente bajo el sistema semestral, por créditos y con currículo flexible. Puede ser en la modalidad presencial, semipresencial o a distancia. El crédito académico es una medida del tiempo formativo exigido a los estudiantes, para lograr aprendizajes teóricos y prácticos. Para estudios presenciales se define un crédito académico como equivalente a un minimo de dieciséis (16) horas lectivas de teoría o el doble de horas de práctica.".

"Articulo 40. Diseño curricular. ... Cada universidad determina en la estructura curricular el nivel de estudios de pregrado, la pertinencia y duración de las prácticas preprofesionales, de acuerdo a sus especialidades. El currículo se debe actualizar cada tres (3) años o cuando sea conveniente, según los avances cientificos y tecnológicos. ... Los estudios de pregrado comprenden los estudios generales y los estudios específicos y de especialidad. Tienen una duración minima de cinco años. Se realizan un máximo de dos semestres académicos por año".

"Artículo 41. Estudios generales de pregrado. Los estudios generales son obligatorios. Tienen una duración no menor de 35 créditos. Deben estar dirigidos a la formación integral de los estudiantes.

"Articulo 42. Estudios especificos y de especialidad de pregrado. Son los estudios que proporcionan los conocimientos propios de la profesión y especialidad correspondiente. El periodo de estudios debe tener una duración no menor de ciento sesenta y cinco (165) créditos." 
2. Se seguirán también los "Estándares para la Acreditación de las Carreras Profesionales Universitarias de Ingeniería” del SINEACE, como un Modelo de Calidad, sabiendo que no son de obligatorio cumplimiento (SINEACE, 2014).

3. Los Aspectos Clave definidos en este modelo.

4. Las tendencias internacionales que han mostrado mayor éxito en la formación de ingenieros y las decisiones estructurales que les llevaron a esos resultados (Conclusiones del Capítulo I y del Capítulo II).

5. IDEARIO de la UDEP (UDEP, 1998).

6. Manual de Organización y Funciones de la UDEP, MOF-UDEP, (SIGA, 2014).

7. Reglamento de Funcionamiento Académico de la UDEP RFAG-UDEP, (SIGA, 2014).

8. Mapa de procesos de la UDEP, MAPRO-UDEP, (SIGA, 2014).

9. Metodología para revisión y actualización de los Planes de Estudio de las carreras de Ingeniería de la Universidad de Piura - 2007 (UDEP 2007).

10. A pesar que la Ley Universitaria asigna a SUNEDU responsabilidades sobre la creación, licenciamiento y aseguramiento de calidad sobre las universidades, este año ha iniciado con el licenciamiento por lo que son otras instituciones las que actúan sobre los otros aspectos. Sufinalidad es "La SUNEDU es responsable del licenciamiento para el servicio educativo superior universitario..., entendiéndose el licenciamiento como verificar el cumplimiento de condiciones básicas de calidad para ofrecer el servicio educativo superior universitario y autorizar su funcionamiento. La SUNEDU es también responsable, en el marco de su competencia, de supervisar la calidad del servicio educativo universitario, incluyendo el servicio brindado por entidades o instituciones que por normativa especifica se encuentren facultadas a otorgar grados y titulos equivalentes a los otorgados por las universidades; así como de fiscalizar si los recursos públicos y los beneficios otorgados por el marco legal a las universidades, han sido destinados a fines educativos y al mejoramiento de la calidad." (Ley universitaria, 2014). En general la acción de la SUNEDU es orientar a las universidades hacia el cumplimiento de la Ley Universitaria.

En este enfoque descendente del modelo de planificación elegido, también debe precisarse el grupo de planificadores que deben llevar a cabo el diseño del Plan de Estudios en la aplicación del Modelo.

El grupo de expertos estará conformado por el Director Académico de Ciencias Básicas, el Director de Programa Académico de Ingeniería Industrial y Sistemas, el Director del Programa Académico de Ingeniería Civil y el Director de Programa Académico de Ingeniería Mecánica Eléctrica. Junto con ellos el Vice Decano Académico y el Jefe de la Oficina de Acreditación de la Facultad. Lo resuelto debe pasar a aprobación del Decano, quien si lo estima pertinente lo enviará al Consejo de Facultad y de ser aprobado pasará al Consejo Superior de la UDEP para su aprobación.

Para el caso de la Ingeniería Industrial de la UDEP, el Director Académico de Ciencias Básicas y el del Programa Académico de Ingeniería Industrial y Sistemas son los principales responsables de hacer cumplir las normas: diseñar perfiles de egreso e ingreso, mallas 
curriculares, líneas académicas, asignaturas en cada línea, contenidos, balanceo de créditos, metodologías a emplear, formas de evaluación, porcentajes de cursos electivos en la carrera, actividades extracurriculares, posibilidades de convalidación o exoneración.

Los Directores de los otros Programas Académicos mencionados, participan para velar por que los cursos de estudios generales o ciencias de la ingeniería, que se comparten en el primer y segundo año de la carrera, no pierdan su enfoque básico y general y también satisfagan los requisitos de sus propias carreras. Esto sucede, además, con algunos cursos de ciclos superiores llamados "comunes".

La metodología es comunicar a los profesores involucrados del proceso y, convocándoles por área de conocimiento y por secciones académicas, se trabaja con ellos el análisis de las asignaturas y del conjunto de asignaturas del área, se revisan las propuestas de cambio si fuera el caso y se define una respuesta. En el caso de cursos que por sus características no tienen incidencia directa en otras asignaturas, salvo como requisito de secuencia, se trata directamente con el profesor del curso y con el Director de Departamento correspondiente.

\section{Enfoque ascendente}

En el enfoque ascendente se precisa contar con los grupos interesados representativos en el diseño y valoración de resultados de una carrera universitaria, en este caso la Ingeniería Industrial de la UDEP.

Los grupos de interés definidos son:

1. Los alumnos de Ingeniería Industrial de la UDEP.

2. Los egresados de Ingeniería Industrial de UDEP.

3. Los Profesores de Ingeniería Industrial de UDEP.

4. Los empleadores, públicos o privados.

5. No se consideran las instituciones estatales reguladoras del sistema universitario, pues dejan total autonomía en este tema a las universidades. Ley Universitaria 30220, artículos 8, 39 y 40. Adicionales a estos se muestran los siguientes artículos en los que se puede aquilatar el grado de libertad universitaria (Ley universitaria, 2014).

Artículo 44. Grados y titulos. Las universidades otorgan los grados académicos de Bachiller, Maestro, Doctor y los titulos profesionales que correspondan, a nombre de la Nación. Las universidades que tengan acreditación reconocida por el organismo competente en materia de acreditación, pueden hacer mención de tal condición en el titulo a otorgar.

Articulo 45. Obtención de grados y títulos. La obtención de grados y titulos se realiza de acuerdo a las exigencias académicas que cada universidad establezca en sus respectivas normas internas. Los requisitos minimos son los siguientes:

45.1 Grado de Bachiller: requiere haber aprobado los estudios de pregrado, así como la aprobación de un trabajo de investigación y el conocimiento de un idioma extranjero, de preferencia inglés o lengua nativa. 
45.2 Titulo Profesional: requiere del grado de Bachiller y la aprobación de una tesis o trabajo de suficiencia profesional. Las universidades acreditadas pueden establecer modalidades adicionales a estas últimas. El título profesional sólo se puede obtener en la universidad en cual se haya obtenido el grado de bachiller.

La información se obtuvo por encuestas, focus group, conversaciones-entrevistas, reuniones de trabajo y análisis de información pública existente. La información resultante llegó al grupo planificador para tejerla en la definición de los planes de estudios.

\section{El resultado}

La información recogida de los grupos de interés enriqueció del diseño de un nuevo Plan de estudios y permitió qu se generasen nuevos aprendizajes en el grupo de expertos para la definición del tipo de profesionales que se desea tener al final del proceso formativo. Estos aprendizajes son valiosos, pues:

- permiten enfocarse mejor en alcanzar los requisitos de su carrera, a los alumnos.

- tener claro los contenidos y competencias alcanzadas en el periodo de formación y los que deben alcanzarse, y por tanto les faltan, a los egresados para tener las competencias profesionales duras y blandas,

- entender mejor la labor que se espera de cada uno y las dificultades que existen para llegar a los perfiles requeridos, a los profesores,

- entender mejor lo que se puede esperar de los nuevos egresados y definir acciones a futuro para alcanzar los resultados que se desean, a los empleadores, y

- entender mejor el contexto interno y externo y las consecuencias que se generan de sus decisiones, a los planificadores.

\subsection{ENFOQUE EDUCATIVO}

$\mathrm{Al}$ enfoque educativo que aplicaremos le hemos denominado mixto, porque coexisten los enfoques socio-formativo, de formación en competencias, y el funcionalista, de habilidades que los empleadores requieren, ver Capítulo 4, apartado 4.2.1. Esto lleva claramente a moldear en los egresados unas características genéricas requeridas por la sociedad en su conjunto y queridas por la institución, además de unas específicas propias de su carrera y requeridas para desempeñarse en los puestos de trabajo en que se desarrollan funciones propias de su especialidad profesional.

Una realidad en los procesos de formación es que para poder realizar aprendizajes complejos se requiere haber adquirido aprendizajes más simples. Esta perspectiva nos puede regresar a dudas sobre si tiene sentido enfocarse en las competencias, pero en la matemática encontramos fácil explicación para las ciencias básicas: no se puede abordar la multiplicación sin la noción de suma. Pero también aplica a la formación especializada, no se puede realizar un cálculo de estimación probabilística de duración de un proyecto sin un conocimiento previo de cálculo y 
uso de variables estadísticas. En los planes de estudio para la formación profesional se diferencian estos dos tramos denominados usualmente ciencias básicas o estudios generales frente a otros de conocimiento aplicado. Roe (2003) sostiene que ésta forma de enfocar un plan de estudios incorpora la perspectiva de una formación en competencias, respetando un proceso de aprendizaje básico, centrado en el conocimiento de diversas disciplinas que posteriormente permitirán la integración de la información en varias competencias genéricas o específicas. En este sentido considera que desde la estructura global de un plan de estudios ambas partes deben quedar claramente formulados. Incluso, de su pensamiento se puede derivar con toda claridad que el perfil de formación profesional puede establecerse determinando los conocimientos, habilidades y actitudes que debe adquirir el estudiante durante su proceso de formación básica y, al mismo tiempo, delimitar los contenidos específicos que singularizan esta especialidad. Vistas de esta manera, las competencias responden a una etapa de integración de la información a partir de problemas que provienen de la realidad, de la práctica profesional. Más aún, en el fondo, esta distinción permite reiterar una visión curricular que organiza la formación profesional en dos tramos: uno de formación básica (ciencias básicas) centrado en la adquisición de los conocimientos y competencias que derivan de las disciplinas clásicas y otro de formación aplicada, centrado en la vinculación de los conocimientos y habilidades adquiridas para enfrentar problemas profesionales reales (Díaz, 2005).

La experiencia que se está promoviendo en varios planes de estudio que incluyen intercambios, prácticas profesionales, estancias formativas en ámbitos laborales, movilidad esudiantil, responde con claridad a esta perspectiva. En este sentido el enfoque mixto es el más prometedor para incorporar el punto de vista de las competencias en el plano curricular (Díaz, 2005).

Estas corrientes son abarcadas por el enfoque socio-formativo y el funcionalista que indican que las acciones a seguir son, primero analizar el contexto y definir los perfiles de egreso y de ingreso de la carrera. En el análisis debe involucrarse a los grupos de interés y considerar los Aspectos Clave definidos en el apartado 5.3 de este capítulo; luego, se definirán las acciones previas a ejecutar antes de aplicar la contextualización de competencias genéricas y construcción de las específicas para poder plantear la malla curricular.

Lo que se busca con la aplicación de estos enfoques es que la institución "trabaje en equipo para generar las condiciones, ambientes y procesos necesarios para que los estudiantes, familias, docentes y directivos posean una sólida formación integral, con las competencias necesarias para afrontar los retos de la realización personal, el tejido social, la recreación, el desarrollo socioeconómico, el conocimiento científico y el equilibrio ambiental” (Tobón, 2010).

Entonces, lo primero es acometer el conocimiento del contexto externo y el contexto interno.

\section{Contexto interno}

Dentro del contexto interno debe verificarse: el rendimiento académico de los estudiantes, el crecimiento de la admisión, las tasas de deserción, egreso y titulación.

Analizando el rendimiento académico de los estudiantes observamos en la Tabla 0.3 Promoción por asignatura en Ciencias Básicas en Ingeniería Industrial de UDEP Fuente: Departamento de Ciencias Básicas de UDEPque en los dos primeros años considerados los años de formación básica 
incluida el ciclo propedéutico, que se explica en el apartado de perfil del ingresante líneas abajo, los resultados de promoción en las asignaturas por ciclo son como se observan.

\begin{tabular}{|c|c|c|c|c|c|}
\hline Ciclo & Sigla & Asignatura & Semestre 1 & Semestre 2 & $\begin{array}{c}\text { Media por ciclo y } \\
\text { por asignatura }\end{array}$ \\
\hline 0 & $\mathrm{FBO}$ & FÍSICA BÁSICA & $54.58 \%$ & $62.40 \%$ & \\
\hline 0 & LLO & LENGUA 0 & $75.05 \%$ & $77.30 \%$ & \\
\hline 0 & $\mathrm{MBO}$ & MATEMÁTICA BÁSICA 0 & $72.50 \%$ & $74.90 \%$ & \\
\hline 0 & MRO & MATEMÁTICA RAZONADA 0 & $73.00 \%$ & $74.11 \%$ & \\
\hline 0 & QBO & QUÍMICA BÁSICA 0 & $57.08 \%$ & $43.42 \%$ & $66.43 \%$ \\
\hline 1 & GAV & GEOMETRÍA ANALÍTICA Y VECTORIAI & $65.39 \%$ & $62.26 \%$ & \\
\hline 1 & GFT & GEOMETRÍA FUNDAMENTAL Y TRIGQ & $74.93 \%$ & $74.30 \%$ & \\
\hline 1 & HIS & HISTORIA DE LA INGENIERÍA & $91.29 \%$ & $91.13 \%$ & \\
\hline 1 & ICS & INTRODUCCIÓN AL CÁLCULO SUPERI & $78.14 \%$ & $75.99 \%$ & \\
\hline 1 & MEU & METODOLOGÍA DEL ESTUDIO UNIVE & $89.88 \%$ & $96.86 \%$ & \\
\hline 1 & $\mathrm{QG1}$ & QUÍMICA GENERAL I & $63.29 \%$ & $70.28 \%$ & $77.75 \%$ \\
\hline 2 & $\mathrm{~A} 1$ & ANÁLISIS MATEMÁTICO I & $67.16 \%$ & $68.67 \%$ & \\
\hline 2 & ALG & ÁLGEBRA LINEAL & $90.37 \%$ & $89.28 \%$ & \\
\hline 2 & DIB & DIBUJO TÉCNICO & $85.11 \%$ & $88.25 \%$ & \\
\hline 2 & F1 & FÍSICA GENERAL I & $67.67 \%$ & $69.93 \%$ & \\
\hline 2 & LYL & LENGUA Y LITERATURA & $89.78 \%$ & $92.22 \%$ & $80.80 \%$ \\
\hline 3 & $\mathrm{~A} 2$ & ANÁLISIS MATEMÁTICO II & $62.73 \%$ & $54.69 \%$ & \\
\hline 3 & $\mathrm{~F} 2$ & FíSICA GENERAL II & $77.85 \%$ & $86.31 \%$ & \\
\hline 3 & FI1 & FILOSOFÍA I & $97.16 \%$ & $85.75 \%$ & \\
\hline 3 & $\mathrm{~PB}$ & PROGRAMACIÓN BÁSICA & $62.45 \%$ & $77.99 \%$ & \\
\hline 3 & PMN & PROGRAMACIÓN Y MÉTODOS NUMÉR & $83.71 \%$ & $84.51 \%$ & \\
\hline 3 & $\mathrm{QG2}$ & QUÍMICA GENERAL II & $72.73 \%$ & $72.30 \%$ & \\
\hline 3 & RGC & REPRESENTACIÓN GRÁFICA EN INGE & $92.18 \%$ & $98.37 \%$ & \\
\hline 3 & RGM & REPRESENTACIÓN GRÁFICA EN INGE & $94.15 \%$ & $90.27 \%$ & $88.90 \%$ \\
\hline 4 & $\mathrm{~A} 3$ & ANÁLISIS MATEMÁTICO III & $80.59 \%$ & $84.66 \%$ & \\
\hline 4 & $\cos$ & COSTOS & $94.80 \%$ & $95.25 \%$ & \\
\hline 4 & EDB & ESTADÍSTICA & $67.40 \%$ & $75.88 \%$ & \\
\hline 4 & EMT & ELECTROMAGNETISMO & $80.12 \%$ & $71.74 \%$ & \\
\hline 4 & ET & MECÁNICA ESTÁTICA & $78.85 \%$ & $62.17 \%$ & \\
\hline 4 & MRA & MECÁNICA RACIONAL & $94.27 \%$ & $98.24 \%$ & \\
\hline 4 & PAV & PROGRAMACIÓN AVANZADA & $83.00 \%$ & $83.38 \%$ & \\
\hline 4 & TL1 & TEOLOGÍA 1 & $93.20 \%$ & $96.59 \%$ & $83.75 \%$ \\
\hline
\end{tabular}

Tabla 0.3 Promoción por asignatura en Ciencias Básicas en Ingeniería Industrial de UDEP Fuente: Departamento de Ciencias Básicas de UDEP

(Elaboración propia)

Si bien los promedios de notas en las asignaturas van en aumento en la medida que se avanza en los ciclos de estudios, las cifras son bastante bajas en el acumulado. Esto no es fácil de apreciar en esta forma de mostrar los datos, pero si se analiza el impacto en la deserción de alumnos, es decir, el porcentaje de alumnos que deben retirarse del sistema por no aprobar las asignaturas de acuerdo a los requisitos establecidos o la variable contraria, la retención que es el porcentaje de alumnos que permanecen en la institución y promueven a los ciclos superiores como consecuencia de satisfacer los requisitos establecidos, se tienen las cifras mostradas en la Tabla 0.4.

\begin{tabular}{|c|c|c|}
\hline Ciclo & $\begin{array}{c}\text { Porcentajes de retención de } \\
\text { estudiantes } \\
\text { (en base a ciclo anterior) }\end{array}$ & $\begin{array}{c}\text { Porcentajes de retención de } \\
\text { estudiantes } \\
\text { (en base a Ciclo 1) }\end{array}$ \\
\hline Ciclo 1 & $100 \%$ & $100 \%$ \\
\hline Ciclo 2 & $91.93 \%$ & $91.93 \%$ \\
\hline Ciclo 3 & $88.78 \%$ & $81.61 \%$ \\
\hline Ciclo 4 & $87.36 \%$ & $71.30 \%$ \\
\hline Ciclo 5 & $93.08 \%$ & $66.37 \%$ \\
\hline Ciclo 6 & $95.95 \%$ & $63.68 \%$ \\
\hline Ciclo 7 & $91.55 \%$ & $58.30 \%$ \\
\hline Ciclo 8 & $98.46 \%$ & $57.40 \%$ \\
\hline Ciclo 9 & $90.63 \%$ & $52.02 \%$ \\
\hline Ciclo 10 & $95.69 \%$ & $49.78 \%$ \\
\hline
\end{tabular}

Tabla 0.4 Retención de alumnos por ciclo en Ingeniería Industrial de UDEP Fuente: Departamento de Ciencias Básicas de UDEP

(Elaboración propia) 
Visto ciclo por ciclo, e incluso año por año, las cifras de retención se ven aceptables y hasta halagadoras, pues de un ciclo a otro la retención es superior al $90 \%$ en todos los casos, excepto en el segundo año en que se acercan mucho a esa cifra por debajo. Sin embargo, al hacer acumulados, se encuentra que al final del proceso solo uno de cada dos de los ingresantes logra culminar su carrera. Por eso el Plan de estudios debe definir estrategias para mejorar estos resultados y se explica por qué el Plan Estratégico dentro del punto prioritario tres "Estudiantes de la mejor calidad académica" plantea aumentar la retención de los alumnos con nuevos métodos de aprendizaje, mejorar el perfil de ingreso y ampliar el horizonte de proveniencia de alumnos.

En la Tabla 0.5 se muestra el número de alumnos ingresantes a Ingeniería Industrial de UDEP durante los últimos seis años. Se puede inducir de los datos mostrados que el número de ingresantes a Ingeniería Industrial de UDEP en Piura se ha mantenido, a pesar que en los últimos años se han abierto sedes de no menos de cuatro universidades que ofrecen esta misma titulación en la ciudad de Piura, adicionándose a las dos que ya existían en la ciudad, y que la propia Facultad de Ingeniería de la UDEP oferta una nueva carrera este año 2014. En el Campus de Lima ha habido un ligero aumento de matrícula. Esto es un buen indicio que ante un exceso de oferta, más variada y más barata, se mantiene la admisión de manera sólida.

\begin{tabular}{|c|c|}
\hline Ciclo & $\begin{array}{c}\text { ingresantes Ing. } \\
\text { Ind. de UDEP }\end{array}$ \\
\hline 2008 I & 100 \\
\hline 2008 II & 28 \\
\hline 2009 I & 100 \\
\hline 2009 II & 32 \\
\hline 2010 I & 113 \\
\hline 2010 II & 34 \\
\hline 2011 I & 102 \\
\hline 2011 II & 13 \\
\hline 2012 I & 98 \\
\hline 2012 II & 6 \\
\hline 2013 I & 106 \\
\hline 2013 II & 19 \\
\hline 2014 I & 107 \\
\hline
\end{tabular}

Tabla 0.5 Número de ingresantes por ciclo en Ingeniería Industrial en UDEP. Fuente: Elaboración Propia

En la Tabla 0.6 se puede observar el número de egresados y titulados de Ingeniería industrial de UDEP por ciclo. 


\begin{tabular}{|c|c|c|}
\hline CICLO & $\begin{array}{c}\text { TOTAL } \\
\text { EGRESADOS }\end{array}$ & TITULADOS \\
\hline $2008-I$ & 11 & 10 \\
\hline $2008-$ II & 49 & 41 \\
\hline $2009-I$ & 15 & 11 \\
\hline $2009-$ II & 39 & 29 \\
\hline $2010-\mathrm{V}$ & 25 & 20 \\
\hline $2010-I$ & 19 & 16 \\
\hline $2010-$ II & 23 & 23 \\
\hline $2011-V$ & 15 & 13 \\
\hline $2011-I$ & 32 & 24 \\
\hline $2011-$ II & 17 & 10 \\
\hline $2012-\mathrm{V}$ & 12 & 9 \\
\hline $2012-I$ & 3 & 4 \\
\hline $2012-$ II & 33 & 10 \\
\hline $2013-\mathrm{V}$ & 16 & 4 \\
\hline $2013-I$ & 16 & 2 \\
\hline $2013-$ II & 19 & 0 \\
\hline & & \\
\hline
\end{tabular}

Tabla 0.6 Número de egresados y titulados por ciclo en Ingeniería Industrial en UDEP. Fuente: Secretaría de Facultad de Ingeniería

Los números que se aprecian en la Tabla 5.6 permiten una comparación entre los números de egresados y titulados por ciclo. Se aprecia que los números se acercan mucho si se comparan las columnas de seis años atrás. Manteniéndose esa paridad hasta el año 2010. El año 2011 hay discretas diferencias entre las columnas y para los años 2012 y 2013 existe una marcada diferencia entre el número de titulados y el número de egresados.

Debe entenderse que las carreras en Perú llevan a cumplir unos requisitos que, al superarlos, otorgan la condición de egresado y Bachiller de la especialidad. Para poder ejercer la profesión se requiere tener un título profesional entregado por la universidad a nombre de la nación peruana y refrendada por SUNEDU. La diferencia entre un egresado o bachiller y un titulado es que el primero terminó sus estudios y todos los requisitos de una carrera, el segundo además, ha obtenido el título profesional.

Las formas de titulación que existen son: sustentar una tesis ante un jurado (como un proyecto de fin de carrera), presentar un trabajo de investigación (esto lo norma cada universidad) y cualquier otra modalidad que establezca cada universidad, esto según la Ley Universitaria peruana (Ley universitaria, 2014).

Las más empleadas son actualmente son el Programa de Titulación Profesional (PAT, forma que se preveía en la anterior Ley Universitaria y ha quedado en el quehacer universitario por las bondades que muestra hasta el año 2019) y la elaboración de una tesis en ese orden. El 2013, en UDEP, se ha normado la posibilidad de titularse a través de una tesis por artículos publicados en bases de datos, pero todavía es de incipiente empleo por los alumnos. En el Plan de estudios se mantendrán estas modalidades. 
Las cifras y las tendencias de entorno nos llevan a concluir que es necesario mejorar la infraestructura existente y ampliar la capacidad de laboratorios y aulas, pues aumentar la retención y mejorar la admisión hará crecer el número de alumnos en todos los niveles y la necesidad de mejorar y aumentar infraestructura.

Además, el Plan de estudios debe enfrentar la necesidad de titulación de los egresados de manera decidida pues, con la rapidez con la que los alumnos son convocados al mundo laboral actualmente, dada la manifiesta escasez de ingenieros bien preparados en el país (Manpower, 2012 y 2013), suelen dejar de lado la elaboración de una tesis, tradicional o por artículos, para ejercer profesionalmente y luego, con el tiempo, solicitan una opción como el PAT para titularse.

Esta opción es recibir cursos de actualización con enfoque laboral durante 85 horas presenciales durante 10 semanas, se evalúan los aprendizajes y si es satisfactorio, se otorga el título. El requisito fundamental para participar de este programa es haberse graduado dos años antes y tener experiencia laboral mínima por ese mismo tiempo en la especialidad.

\section{El contexto externo.}

En el contexto externo es indispensable conocer las tendencias de la carrera en el país y en el extranjero, el posicionamiento de la carrera en el medio nacional y en el exterior, y las posibilidades de empleabilidad.

Todos estos tópicos han sido abordados, analizados y llegado a conclusiones el primer y segundo capítulos de este trabajo de investigación. Tomaremos las conclusiones a las que se llegaron en ellos para el diseño del Plan de estudios.

Ahora nos centraremos en definir el perfil del ingresante y el de egresado a partir de la información de contexto.

\section{Perfil del ingresante.}

Para definir el perfil de ingreso de los alumnos a la Facultad de Ingeniería de UDEP, y por tanto a Ingeniería Industrial de UDEP, en el año 2012 se conformó una Comisión de profesores para evaluar la normativa existente sobre los alumnos que culminaban la educación básica y los resultados obtenidos en los primeros años de estudios en la Facultad, obteniéndose en enero del 2013 el documento de veinticuatro páginas "Perfil del ingresante a la Facultad de Ingeniería y procedimiento de evaluación del perfil del ingresante", Anexo A.

En este documento se perfila claramente dos tipos de competencias requeridas: las aptitudinales y las actitudinales. Las primeras se refieren a los contenidos que debe dominar el ingresante y que son requeridos para superar con éxito los primeros años de estudios universitarios. Las segundas se refieren a las conductas y comportamientos de debe mostrar en su desempeño.

Luego de las entrevistas realizadas, del análisis de las estadísticas de desempeño académico en UDEP y los desastrosos resultados de las tres últimas pruebas PISA (Program for International Student Assessment), que se basa en el análisis del rendimiento de estudiantes a partir de unos exámenes que se realizan cada tres años en varios países con el fin de determinar la valoración 
internacional de los alumnos y en la que el año 2012 Perú ocupó el último lugar, Tabla 0.7, se concluyó que "la mayoría de los jóvenes ingresantes requieren cursar un nivel previo al inicio de los estudios universitarios, a fin de que puedan ser nivelados, y a la vez adquieran el ritmo de vida universitaria requerido" (PISA, 2012). Si bien la última prueba PISA se desarrollo el segundo semestre de 2015, los resultados se comunicarán formalmente en diciembre de 2016.

\begin{tabular}{|c|c|c|c|c|}
\hline Puesto & País & $\begin{array}{c}\text { Matemá- } \\
\text { ticas }\end{array}$ & Lectura & Ciencias \\
\hline 1 & Shanghai-China & 613 & 570 & 580 \\
\hline 2 & Singapur & 573 & 542 & 551 \\
\hline 3 & Hong Kong-China & 561 & 545 & 555 \\
\hline 9 & Suiza & 531 & 509 & 515 \\
\hline 10 & Holanda & 523 & 511 & 522 \\
\hline 11 & Estonia & 521 & 516 & 541 \\
\hline 12 & Finlandia & 519 & 524 & 545 \\
\hline 13 & Canadá & 518 & 523 & 525 \\
\hline 14 & Polonia & 518 & 518 & 526 \\
\hline 15 & Bélgica & 515 & 509 & 505 \\
\hline 16 & Alemania & 514 & 508 & 524 \\
\hline 17 & Vietnam & 511 & 508 & 528 \\
\hline 25 & Francia & 495 & 505 & 499 \\
\hline 26 & OCDE & 494 & 496 & 501 \\
\hline 27 & Reino Unido & 494 & 499 & 514 \\
\hline 31 & Noruega & 489 & 504 & 495 \\
\hline 32 & Portugal & 487 & 488 & 489 \\
\hline 33 & Italia & 485 & 490 & 494 \\
\hline 34 & España & 484 & 488 & 496 \\
\hline 36 & Eslovaquia & 482 & 463 & 471 \\
\hline 37 & Estados Unidos & 481 & 498 & 497 \\
\hline 52 & Chile & 423 & 441 & 445 \\
\hline 53 & Malasia & 421 & 398 & 420 \\
\hline 54 & México & 413 & 424 & 415 \\
\hline 55 & Montenegro & 410 & 422 & 410 \\
\hline 56 & Uruguay & 409 & 411 & 416 \\
\hline 57 & Costa Rica & 407 & 441 & 429 \\
\hline 59 & Brasil & 391 & 410 & 405 \\
\hline 60 & Argentina & 388 & 396 & 406 \\
\hline 66 & Perú & 368 & 384 & 373 \\
\hline
\end{tabular}

Tabla 0.7 Ranking incompleto de países que participaron en la PISA 2012. Fuente: Elaboración Propia

El objetivo principal de continuar con esta estrategia que se aplica desde hace seis años en la Facultad de Ingeniería de UDEP con carácter de obligatoria, es brindar las competencias necesarias para cursar con éxito los estudios en la Facultad de Ingeniería, y por consiguiente disminuir los índices de reprobación y deserción de los primeros semestres. En consecuencia, se instaura como un mecanismo adicional de evaluación del ingresante. Este mecanismo contempla una evaluación de los conocimientos específicos que se requieren para cursar con éxito los Programas Académicos de la Facultad de Ingeniería. El ingresante previo a iniciar sus estudios en los Programas Académicos debe superar la nivelación, y para esto puede optar por tres alternativas: Propedéutico, Introductorio o Examen de Convalidación. Existe un gráfico muy esclarecedor en el Anexo A.

El Propedéutico se cursa en el verano de manera intensiva en siete semanas, si el alumno supera los requisitos ingresa al primer ciclo. Los resultados indican que quienes superan este semestre son los alumnos que traen de la educación básica las competencias ya desarrolladas y los que no lo hacen son quienes requieren alcanzarlas antes de ingresar a los estudios universitarios. Estadísticamente son un 50\%. 
El Introductorio plantea los mismos retos del Propedéutico pero se desarrolla en un semestre académico y en él sí se adquieren los aprendizajes y se desarrollan las competencias que no se tenían, la promoción de alumnos en este caso también suele ser del 50\%. Quienes no logran desarrollarlas en una segunda oportunidad deben dejar la universidad.

El Examen de convalidación es para quienes consideran que sí tienen lo requerido por UDEP y se someten a una entrevista y un único examen para demostrar sus buenas condiciones. Normalmente aprueban la convalidación menos del 10\% de los interesados, ellos inician sus estudios en primer ciclo y los que no lo aprueban van a Introductorio.

Este esquema, tan desacreditado por los académicos que lo revisan por primera vez, es muy bien recibido por alumnos y padres de familia cuando se les explica las razones por las que deben estudiar un verano previo al inicio de clases o todo un semestre antes de iniciar sus estudios de carrera. Incluso muestran su satisfacción al terminar los periodos correspondientes. Existen casos de alumnos que, estando en la carrera en segundo año, se arrepienten de no haber cursado el Introductorio, pues sienten que tendrían más base de conocimientos y otras competencias.

Pero estas bondades no han quedado solo en percepciones. Profesoras de Estadística de UDEP, PhD. Ing. Susana Vegas y Mgtr. Ing Valeria Quevedo, estudiaron el caso y junto con el Prof. Ing. Reynaldo Villar presentaron la ponencia "Statistical approach for measuring the effectiveness of a remedial program for low-achieving undergraduate engineering candidates in Perú" en la " $118^{a}$ ASEE Annual conference and exposition", de la Sociedad Americana para la Educación en Ingeniería, celebrada en Vancouver. En este estudio demuestran, aplicando el Diseño de Regresión Discontinua, que los alumnos que siguen la nivelación tienen un desempeño mejor que aquellos que no lo siguen con 1.5 puntos de promedio más en valores cercanos a la línea de corte, que era el límite entre aprobar o desaprobar (Quevedo, V., 2011).

En el Anexo A encontrará el detalle de las competencias aptitudinales y actitudinales que se espera de un ingresante, la forma de evaluación que se propone desde la Facultad de Ingeniería, la descripción detallada de la propuesta de nivelación antes del inicio de los estudios en Ingeniería industrial de UDEP y los contenidos y estrategia del curso Propedéutico y del Ciclo Introductorio.

\section{Perfil del egresado.}

En reuniones sostenidas el Director del Programa Académico con los responsables de las Secciones académicas de Ingeniería Industrial de UDEP, y estos a su vez recogiendo la información de sus profesores. Considerando la información obtenida de los empleadores y graduados así como evaluando las tendencias locales y externas, el Programa Académico define que un egresado de Ingeniería Industrial de la UDEP como se describe a continuación:

"El Ingeniero Industrial y de Sistemas de la UDEP gestiona y optimiza procedimientos, procesos y operaciones de una empresa. La componente de sistemas le ofrece una mayor versatilidad y visión integral, haciendo más eficiente su labor. Sus habilidades técnicas y de gestión lo convierten en líder de las industrias de hoy. Es capaz de diseñar, gestionar y ejecutar operaciones de manufactura, servicios y proyectos de información. Orienta su actividad 
profesional a los principales sectores productivos, en especial, aquellos que contribuyen al desarrollo nacional".

Esta concisa y determinante redacción del perfil de egresado de la Ingeniería Industrial de la UDEP, nos permite pasar a la siguiente que es definir las estrategias de participación.

\subsection{ESTRATEGIA DE PARTICIPACIÓN}

La noción del conocimiento experto y el conocimiento experimentado tratados en el Capítulo 4, subdivisión 4.2.3, nos lleva establecer una estrategia de trabajo participativa que se debe tener claramente definida en los pasos siguientes.

Consideramos que la participación de los dos grupos, poseedores del conocimiento experto y del conocimiento experimentado, tienen particular relevancia en el desarrollo de un modelo como el MESIC, pues favorece la contemplación simultánea de ambas perspectivas, de manera individual y grupal, durante las diferentes fases de desarrollo de la aplicación del modelo. Sin embargo, debido a factores de tipo contextual, se observa que existen dificultades para lograr una completa y decidida participación de los grupos de interés.

Para evitar dicha dificultad los planificadores deben ser conscientes que deberán afrontarse las dificultades de levantamiento de información, de respuesta a las convocatorias y bajo porcentaje de participación empleando diversas estrategias. Siendo conscientes que algunas de estas posibilidades o todas juntas, sucederán en el avance de la aplicación, se establecen una forma de actuar secuenciada en fases, que permita lograr los resultados esperados.

La primera fase es tener definidos e identificar los grupos de participación. Los grupos de interés ya se mencionaron y definieron en 4.3 y 5.4, los grupos de participación son estos mismos que se pueden aglomerar en alumnos y egresados, en conocimiento experimentado, planificadores y profesores en conocimiento experto y los empleadores en ambos tipos de conocimiento.

La segunda fase debe conseguir generar atención y confianza en los grupos que nos interesa que participen, las acciones desarrolladas deben dirigirse a eso y definir una estructura que apoye la logística y la recolección de información relevante que permita a los planificadores formarse una idea más precisa de la realidad grupal. En esta fase se establecen los pasos a seguir, se distribuye material informativo si es necesario, se plantea un cronograma de actividades y se ejecutan las acciones.

La tercera es emplear el diagnóstico previo que se hizo de lo que podría encontrarse, esto permite no encontrase con sorpresas que puedan truncar el avance de lo planificado. Lo importante es anticipar los problemas que podrían suceder y prever soluciones a esas posibles complicaciones. Puede ser un diagnóstico basado solo en percepciones del grupo planificador, pero aun así permitirán enfrentar la tarea de la participación desde la anticipación de complicaciones de manera más solvente.

La cuarta fase es diseñar los instrumentos que se requerirán en los eventos participativos: los guiones de los focus group, las preguntas de las encuestas, los guiones de las entrevistas. Deben probarse y validarse los instrumentos antes de emplearlos. 
La quinta y última es establecer las condiciones de gestión y ejecución de las metodologías elegidas, seleccionar a las personas que se harán cargo, identificar y convocar a los grupos, y ejecutar las acciones de participación.

Esta es una estrategia que se debe emplear en cada uno de los levantamientos de información que se realiza.

\subsection{CONTEXTUALIZACIÓN DE COMPETENCIAS}

\section{Definición del contexto.}

Para trabajar con las competencias para la formación de ingenieros industriales en Perú, debemos contextualizarlas al territorio acotado que es la Ingeniería Industrial de la UDEP.

Para hacerlo se realizarán encuestas a las partes interesadas en la formación de estos ingenieros industriales. Para cada uno de estos grupos se determinarán, el universo, el tipo de análisis estadístico que se empleará, la muestra que se tomará y la interpretación de resultados.

\section{Metodología de encuestas y encuestas de contextualización.}

Se trata de verificar si el listado de competencias genéricas seleccionado y el de competencias específicas construido, son aceptados como pertinentes por los involucrados: egresados con no más de cinco años fuera de aulas, profesores, alumnos, y empleadores. La razón de no involucrar egresados de mayor antigüedad es porque el ejercicio profesional cambia la percepción de las competencias obtenidas en los estudios de grado, y que se requieren en los primeros años de trabajo, y se confunden con las laborales que son necesarias para mantener un desempeño profesional sostenido en una actividad determinada; no se consideran egresados con mayor antigüedad pues pueden distorsionar la información que se desea. El grupo de expertos planificadores está inmerso en el grupo de profesores pues forman parte de este segmento.

Antes de hacer el análisis de datos es necesario explicar las herramientas que se emplearán para validar los resultados de las encuestas.

Se encuestará a las partes interesadas para conocer el grado de importancia que dan a las competencias, también se medirá el grado de desarrollo alcanzado y otras variables que mediremos y que se explicarán encada caso. Los valores de las variables que se encuentren como resultado de la aplicación de encuestas, requieren que no solo el método empleado sea válido si no que los instrumentos también lo sean y por ello es necesaria una validación formal (Kane MT.; 2001).

Para la validez del método usado se empleará un muestreo no probabilístico por conveniencia y en algún caso la muestra exhaustiva, que es a todos los individuos de una población.

El muestreo no probabilístico por conveniencia es útil cuando no es posible llegar a la población y la muestra se compone de los individuos que sean más asequibles y convenientes para la limitación existente (Cohen, L., et al; 2003). Si bien con este método el investigador no puede afirmar con un preciso grado de confianza que los resultados son representativos de la 
población, la muestra provee información útil que permite responder a preguntas e hipótesis; la muestra puede ser un grupo elegido o individuos disponibles a participar en el estudio (Creswell J.; 2014); incluso, si la población es de características homogéneas, los resultados se pueden extender a la población y puede afirmarse que es generalizable a sujetos similares (McMillan \& Schumacher; 2001).

La muestra exhaustiva no requiere mayor análisis. Es una forma no estructurada y directa de obtener información, que se realiza de individuo en individuo. Apoyarse en dicha técnica permite el sondeo detallado con los sujetos en estudio, y facilita la adquisición y comprensión detallada y completa de la información de los participantes ante el objeto de estudio (Pérez, 2010).

Dentro del proceso de determinación del método de evaluación, además de la validez del método de cálculo, que determina la cuantificación apropiada de la variable a partir de un adecuado método probabilístico o no, debe verificarse la confiabilidad, que alude a si el instrumento mide lo que dice y determina si esta medición es estable en el tiempo.

Según la teoría clásica, la confiabilidad se define como el grado en que un instrumento de varios ítems mide consistentemente una muestra de la población. La medición consistente se refiere al grado en que una medida está libre de errores. El coeficiente de confiabilidad indica la fuerza de la asociación; el coeficiente varía entre -1 y +1 y un valor de 0 indica que no existe relación entre el valor real y el obtenido, mientras que un valor cercano a -1 o a +1 indica una relación muy cercana, negativa o positiva. Un valor positivo indica que las personas con puntaje alto en una aplicación de la encuesta también puntuarán alto en una segunda ocasión. Una confiabilidad negativa indica un error en el cálculo o una terrible inconsistencia de la encuesta. El error se conceptualiza como la diferencia entre el valor observado y el verdadero o respecto a un valor promedio de las mediciones repetidas. La imposibilidad de calcular la varianza de la puntuación verdadera, obliga a que se considere la varianza de la puntuación verdadera igual a 1 menos la varianza del error (Kupermintz H.; 2004).

Uno de los más reconocidos métodos para calcular la confiabilidad es el Coeficiente Alpha de Cronbach. El coeficiente de Cronbach fue descrito en 1951 por Lee J. Cronbach y es un índice usado para medir la confiabilidad de tipo consistencia interna, de una encuesta. Sirve para evaluar la magnitud en que los ítems de un instrumento están correlacionados (Bland JM., et al.; 2002). Esto porque las encuestas pueden ser validadas en forma indirecta basándose en la relación que muestren los ítems que las componen, si éstos presentan una excelente interrelación entre sí, se afirma que tienen buena consistencia interna y por tanto los resultados son confiables sin necesidad de un patrón de referencia (Bland, J.M.; 2002).

Existen muchos coeficientes para medir la confiabilidad de una encuesta a partir de la consistencia interna: El Coeficiente de Angoff-Feldt, El Coeficiente Beta propuesto por Raju, El Coeficiente de Feldt-Glimer, El Coeficiente de Kristof, y otros más, pero todos son variantes del Coeficiente Alpha de Cronbach (Osburn, H. G.; 2000).

La popularización del Coeficiente Alfa de Cronbach se debe a la practicidad de su uso, ya que requiere una sola administración de la prueba. Además, tiene la ventaja de corresponder a la 
media de todos los posibles resultados de la comparación que se hace en el proceso de dividir en mitades una escala (Kwok \& Sharp; 1998).

Existen varias fórmulas para hallar el Coeficiente Alfa de Cronbach. Entre las fórmulas más sofisticadas para averiguar la consistencia interna por Cronbach está la que se plantea a partir de la varianza de cada ítem y la varianza total de las sumas de los ítems (Sánchez \& Gómez; 1998).

La varianza es una medida de variabilidad e indica qué tan dispersos se encuentran los datos. En nuestros casos la varianza de cada ítem indica qué tanto difieren las respuestas de los encuestados a ese ítem, y la varianza total indica qué tan dispersas están las sumas de las respuestas a cada ítem. En la ecuación Ec. 5.1 se muestra cómo se calcula la varianza $S^{2}$, en dónde $n$ es el número de datos en análisis, $\bar{x}$ es el promedio de los datos y $x_{i}$ es cada uno de los valores o datos.

$$
S^{2}=\frac{1}{n} \cdot \sum_{i=1}^{n}\left(\bar{x}-x_{i}\right)^{2}
$$

Así la fórmula para el cálculo del Coeficiente Alpha de Cronbach se muestra en la ecuación Ec. 5.2. Donde $n$ es el número de ítems, $S_{i}{ }^{2}$ la varianza de cada ítem y $S_{\text {tot }}{ }^{2}$ es la varianza de las sumas de las respuestas de cada ítem o varianza total. Así el coeficiente $\alpha$ mide la fiabilidad del test en función de la proporción de varianza total de la prueba debida a la covarianza entre sus partes (ítems) y del número de ítems (o longitud de la prueba) (Ledesma R. et al; 2002)

$$
\propto=\left(\frac{n}{n-1}\right) \cdot\left(1-\frac{\sum S_{i}^{2}}{S_{t o t}^{2}}\right)
$$

Como criterio general, se emplea la Tabla 0.8, para interpretar los resultados alcanzados al aplicar el coeficiente de Cronbach (George, D. et al; 2003: 231):

\begin{tabular}{|l|c|}
\hline Alpha de Cronbach & Confiabilidad \\
\hline Coeficiente $\quad \alpha>0.9$ & es excelente \\
\hline Coeficiente $0.8<\alpha \leq 0.9$ & es buena \\
\hline Coeficiente $0.7<\alpha \leq 0.8$ & es aceptable \\
\hline Coeficiente $0.6<\alpha \leq 0.7$ & es cuestionable \\
\hline Coeficiente $0.5<\alpha \leq 0.6$ & es pobre \\
\hline Coeficiente $\alpha \leq 0.5$ & es inaceptable \\
\hline
\end{tabular}

Tabla 0.8 Valores de Alpha de Cronbach para determinar la confiabilidad de una encuesta. Fuente: Elaboración propia

En las encuestas realizadas a las partes interesadas se aplicará este criterio para evaluar la confiabilidad de la encuesta. 


\subsubsection{Competencias genéricas}

\subsubsection{Encuestas a egresados.}

La encuesta se realizó a egresados de Ingeniería Industrial de UDEP con no más de cinco años desde su egreso. En la Tabla 0.9, se muestran las cantidades de egresados por año y semestre.

\begin{tabular}{|c|c|}
\hline CICLO & $\begin{array}{c}\text { TOTAL } \\
\text { EGRESADOS }\end{array}$ \\
\hline 2007 II & 40 \\
\hline 2008 I & 11 \\
\hline 2008 II & 49 \\
\hline 2009 I & 15 \\
\hline 2009 II & 39 \\
\hline $2010 \mathrm{~V}$ & 25 \\
\hline 2010 I & 19 \\
\hline 2010 II & 23 \\
\hline 2011 V & 15 \\
\hline 2011 I & 32 \\
\hline 2011 II & 17 \\
\hline 2012 V & 12 \\
\hline 2012 I & 3 \\
\hline TOTAL & 300 \\
\hline
\end{tabular}

Tabla 0.9 Número de egresados por año y ciclo en Ingeniería Industrial en UDEP. Fuente: Elaboración Propia

El universo de egresados entre 2007 II y 2012 I es de 300 personas. Dado que este grupo de personas está dispersa por varios continentes, algunos no accesibles incluso estando en Perú por radicar en localidades alejadas, y otros que, siendo accesibles, no responden a intentos de comunicación, hemos decidido optar por un muestreo no probabilístico por conveniencia. La confiabilidad de la aplicación de la encuesta se verificará empleando el Coeficiente Alpha de Cronbach.

La encuesta que se aplicó a mediados de 2012 a 59 de los 300 egresados entre los años 2008 y 2012 se puede revisar en el Anexo B. Los resultados fueron los que mostraremos en los párrafos siguientes.

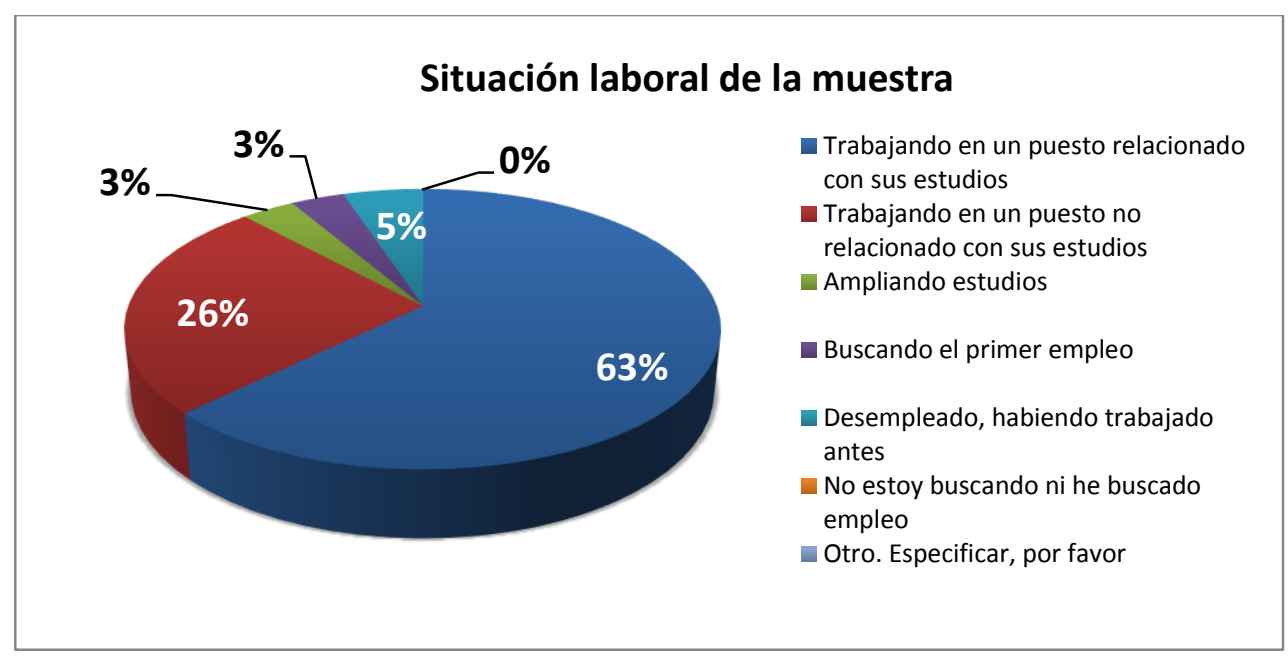

Gráfico 0.11 Situación laboral de egresados Fuente: Elaboración propia 
A la cuestión situación laboral actual, el 63\% de los egresados respondió que se encuentran trabajando en un puesto relacionado con sus estudios de Ingeniería Industrial, 26\% se encuentra trabajando en un puesto no relacionado con sus estudios, $3 \%$ de los encuestados respondieron que están ampliando sus estudios, 3\% buscando su primer empleo y 5\% están desempleados habiendo trabajado antes. Dos de los tres egresados que forman este 5\% final estaban postulando a una formación pos gradual, por ello estaban desempleados, Gráfico 0.7 Anverso del Tríptico del Plan Estratégico de la Facultad de Ingeniería. Fuente: Archivo de la Facultad de Ingeniería de la UDEP. En consecuencia podemos afirmar que el 97\% de los egresados encuestados estaban trabajando en el momento de la encuesta o lo habían hecho.

Todos los encuestados debían conocer qué es una competencia para responder a las preguntas, esa era una condición filtro, por ello se les hizo conocer la definición y a la pregunta de qué era una competencia el resultado fue que 100\% lo sabían.

La encuesta indagó sobre la importancia que el encuestado consideraba tenía cada una de las 27 competencias genéricas TuningAL y el nivel de desarrollo que estimaba habían tenido al finalizar su carrera. Esto debía contestarse en preguntas cerradas en una escala de 1 a 4 que indican nada, poco, bastante, mucho, respectivamente. También se preguntaba de manera abierta si consideraba que faltaba alguna competencia y se pedía que la escribieran en los espacios dejados en blanco.

En el Gráfico 5.8 se muestra la valoración que los encuestados dan a la importancia de las competencias. En él se observa que consideran en todos los casos las competencias mostradas como muy o bastante importantes. La más baja es la 20 Compromiso con la preservación del medio ambiente con $81.3 \%$, y solo $1.69 \%$ de los encuestados considera 6 de ellas nada importantes.

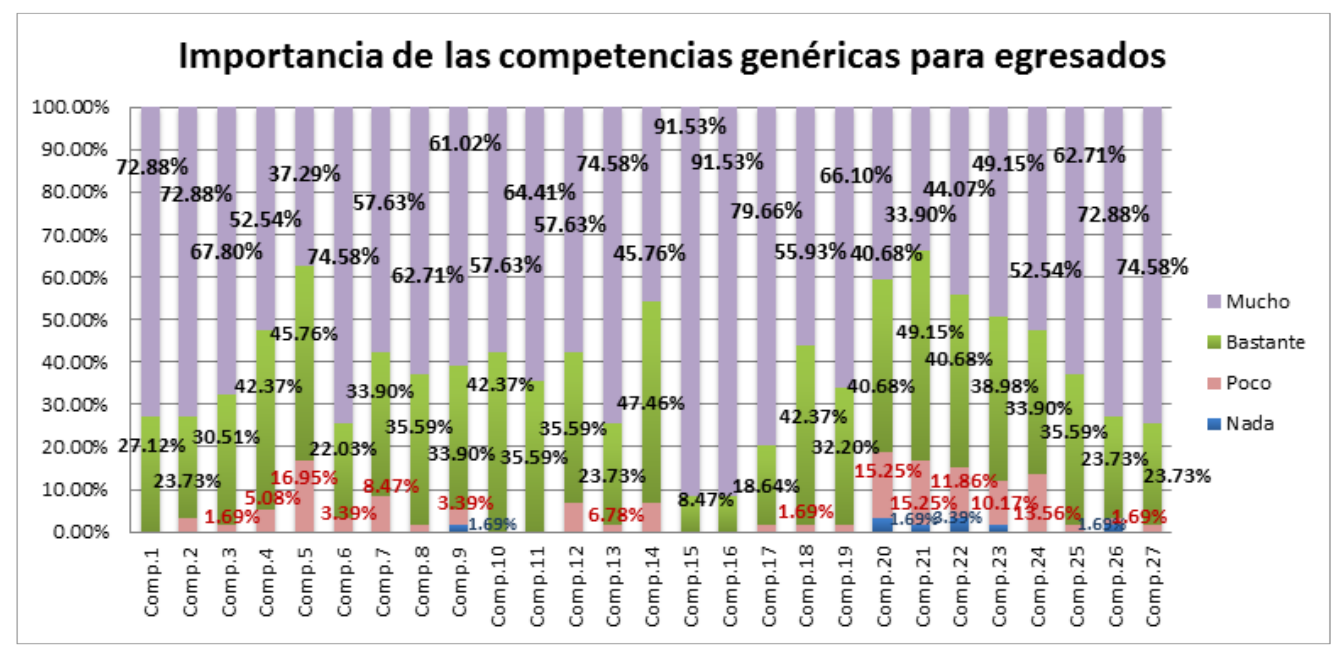

Gráfico 0.12 Importancia de las competencias genéricas TuningAL según egresados. Fuente: Elaboración propia

Las respuestas a la pregunta de cuánto estimaban que se habían desarrollado en su carrera de Ingenieros Industriales se muestran en el Gráfico 0.9 Publicación de los Estándares de calidad para las Ingenierías en Perú. Fuente: CONEAU, 2010.. En él se aprecia que el 75.03\% de los egresados consideran que en promedio han sido mucho o bastante desarrolladas, aunque existen otros 
casos: el 57.7\% opina que la competencia 23, Habilidad para trabajar en contextos internacionales, se ha desarrollado poco o nada, el 45.95\% lo mismo con la competencia 7, Capacidad de comunicación en un segundo idioma, y un 42.5\% lo afirma de la 21 Compromiso con su medio socio-cultural. Deberá ponerse énfasis en estas competencias en el desarrollo de un plan curricular futuro. La media de valoración del nivel de desarrollo alcanzdo para estas competencias es de 2.95 para los egresados.

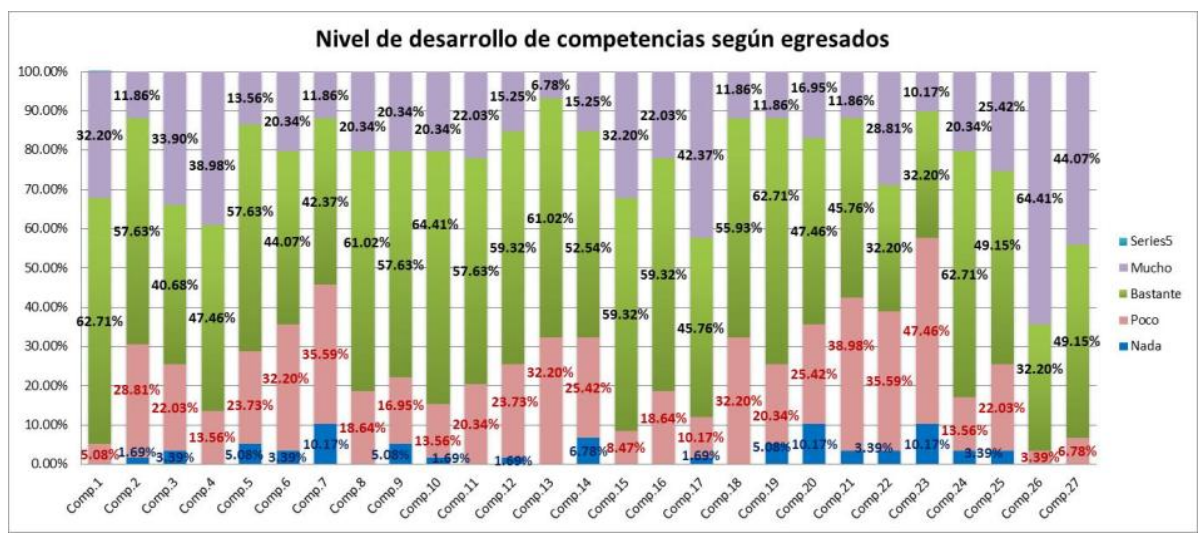

\section{Gráfico 0.13 Desarrollo de las competencias genéricas TuningLA en Ingeniería Industrial de UDEP} según egresados. Fuente: Elaboración propia

En una comparación entre la importancia que se les atribuye a estas competencias genéricas y la percepción de qué tanto se han desarrollado en la época de formación universitaria, Gráfico 5.10, se observa que los egresados señalan que todas las competencias genéricas tienen una importancia por encima de 3.15, siendo cuatro la máxima puntuación, y el promedio alcanzado es de 3.56. De las 27 competencias, 18 están por encima de 3.5. En consecuencia consideran que todas son importantes. Debe señalarse que ninguno de los egresados encuestados sugirió incluir una competencia adicional a las listadas.

En el Gráfico 5.10 se observa que las competencias en que el nivel de desarrollo es muy cercano a la importancia que asignan los egresados son la 26 Compromiso ético, la 4 Conocimientos sobre el área de estudio y la profesión, la 27 Compromiso con la calidad y la 5 Responsabilidad social y compromiso ciudadano. Las que muestran mayor distancia son la 23 Habilidad para trabajar en contextos internacionales, la 7 Capacidad de comunicación en un segundo idioma, la 13 Capacidad para actuar en nuevas situaciones y la 6 Capacidad de comunicación oraly escrita.

En cuanto al desarrollo, solo una competencia (26. Compromiso ético) tiene una media por encima de 3.6, considerando los egresados que son muy cercanos los valores entre la importancia que estiman tienen esta competencia con el nivel de desarrollo alcanzado en la universidad. También es claro que en todos los casos se considera que el nivel de desarrollo está por debajo que el de importancia.

Del Gráfico 5.10, también puede afirmarse que las cinco competencias más importantes para los egresados son las 15, 16, 17, 1 y 27 y las menos importantes, 21, 20, 5, 22, 23. Las más desarrolladas son 26, 27, 17, 1 y 4, las menos desarrolladas 23, 7, 21, 20 y 13. 


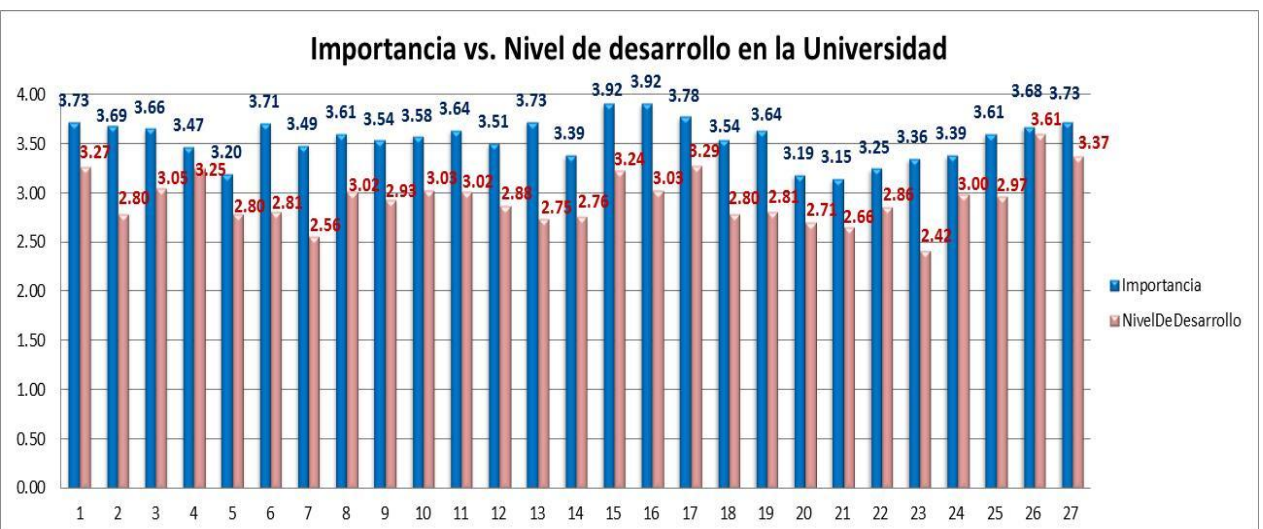

Gráfico 0.14 Comparación entre la importancia y nivel de desarrollo de las competencias genéricas TuningLA en Ingeniería Industrial de UDEP según egresados. Fuente: Elaboración propia

La Tabla 0.10 Competencias genéricas más y menos importantes, y más y menos desarrolladas, según egresados de Ingeniería Industrial en UDEP. Muestra las competencias consideradas más y menos importantes así como las más y menos desarrolladas, según los egresados. Esto nos permite apreciar que consideran como más importantes las competencias técnicas, excepto una, y todas las menos importantes son de contexto y comportamiento. Entre las que estiman más desarrolladas las tres primeras son de comportamiento y las siguientes dos son técnicas; las menos desarrolladas todas son de contexto y comportamiento.

Es claro el sesgo de los egresados a pensar que lo útil es fundamentalmente lo técnico, lo procedimental y que son menos importantes las competencias contextuales y de comportamiento. En el desarrollo de competencias hay balance entre las más desarrolladas pues hay competencias técnicas y no técnicas, en cambio las menos desarrolladas son todas no técnicas.

\begin{tabular}{|l|l|l|l|}
\hline \multicolumn{2}{|c|}{ IMPORTANCIA } & \multicolumn{2}{c|}{ DESARROLLO } \\
\hline Más importancia & Menos importancia & Más desarrollo & Menos desarrollo \\
\hline $\begin{array}{l}\text { 15) Capacidad para } \\
\text { identificar, plantear y } \\
\text { resolver problemas. }\end{array}$ & $\begin{array}{c}\text { 21) Compromiso con su } \\
\text { medio socio-cultural. }\end{array}$ & 26) Compromiso ético. & $\begin{array}{l}\text { 23) Habilidad para } \\
\text { trabajar en contextos } \\
\text { internacionales. }\end{array}$ \\
\hline $\begin{array}{l}\text { 16) Capacidad para } \\
\text { tomar decisiones. }\end{array}$ & $\begin{array}{c}\text { 20) Compromiso con la } \\
\text { preservación del medio } \\
\text { ambiente. }\end{array}$ & $\begin{array}{c}\text { 27) Compromiso con } \\
\text { la calidad. }\end{array}$ & $\begin{array}{l}\text { 7) Capacidad de } \\
\text { comunicación en un } \\
\text { segundo idioma. }\end{array}$ \\
\hline $\begin{array}{l}\text { 17) Capacidad de trabajo } \\
\text { en equipo. }\end{array}$ & $\begin{array}{c}\text { 5) Responsab. Social y } \\
\text { compromiso ciudadano. }\end{array}$ & $\begin{array}{c}\text { 17) Capacidad de } \\
\text { trabajo en equipo. }\end{array}$ & $\begin{array}{l}\text { 21) Compromiso con su } \\
\text { medio socio-cultural. }\end{array}$ \\
\hline $\begin{array}{l}\text { 1) Capacidad de } \\
\text { abstracción, análisis y } \\
\text { síntesis. }\end{array}$ & $\begin{array}{c}\text { 22) Valoración y res-peto } \\
\text { por la diversidad y } \\
\text { multiculturalidad }\end{array}$ & $\begin{array}{l}\text { 1) Capacidad de } \\
\text { abstracción, análisis y } \\
\text { síntesis. }\end{array}$ & $\begin{array}{l}\text { 20) Compromiso con la } \\
\text { preservación del medio } \\
\text { ambiente. }\end{array}$ \\
\hline $\begin{array}{l}\text { 27) Compromiso con la } \\
\text { calidad }\end{array}$ & $\begin{array}{c}\text { 23) Habilidad para } \\
\text { trabajar en contextos } \\
\text { internacionales. }\end{array}$ & $\begin{array}{c}\text { 4) Conocimientos } \\
\text { sobre el área de } \\
\text { estudio y la profesión. }\end{array}$ & $\begin{array}{l}\text { 13) Capacidad para } \\
\text { actuar en nuevas } \\
\text { situaciones. }\end{array}$ \\
\hline
\end{tabular}

Tabla 0.10 Competencias genéricas más y menos importantes, y más y menos desarrolladas, según egresados de Ingeniería Industrial en UDEP.

Fuente: Elaboración Propia 
Para conocer la confiabilidad de la encuesta para la importancia asignada a las competencias, se calculó la varianza de cada competencia y se sumaron estas varianzas hallándose que $\sum S_{i}{ }^{2}=$ 9.223 y al calcular la varianza de las sumas de los puntajes asignados por ítem se encontró que la varianza total era $S_{\text {tot }}{ }^{2}=57.072$. Con estos dos valores se calcula el Coeficiente de Cronbach en la ecuación Ec. 5.2 y se obtiene:

$$
\propto=\left(\frac{27}{27-1}\right) \cdot\left(1-\frac{9.223}{57.072}\right)=0.8706
$$

Se hace lo mismo para hallar la confiabilidad de la encuesta para el desarrollo que los egresados estiman han alcanzado las competencias durante su carrera. La suma de varianzas de ítems fue $\sum S_{i}{ }^{2}=13.752$ y la varianza total era $S_{\text {tot }}{ }^{2}=93.174$. Con estos dos valores se calcula el Coeficiente de Cronbach en la ecuación Ec. 5.2 y se obtiene:

$$
\propto=\left(\frac{27}{27-1}\right) \cdot\left(1-\frac{13.752}{93,17}\right)=0.885
$$

Con estos resultados podemos afirmar que los resultados de las encuestas realizadas tienen buena consistencia interna pues los valores son superiores a 0,8 , por lo que son confiables en un buen nivel, según la Tabla 5.8 .

\subsubsection{Encuestas a profesores.}

La encuesta se realizó al universo de profesores de tiempo completo involucrados en la formación de los estudiantes de Ingeniería Industrial de UDEP; se desempeñan en asignaturas desde el primer semestre al último de esa carrera y ejercían esa función durante el semestre 2012 I.

El total de profesores en ese momento era 27 y respondieron a la encuesta 21 . Los que no participaron fue porque estuvieron de viaje o no enviaron sus respuestas.

El método usado fue un muestreo no probabilístico por conveniencia dada la dificultad de llegar al total de la población y al bajo número de individuos de la población, menor de treinta. Dado el porcentaje encuestado, 78\%, y la condición de homogeneidad de la población (todos profesores de una misma universidad, trabajando a tiempo completo en una misma carrera) los resultados podrán considerarse representativos del universo. Se verificará la confiabilidad del instrumento aplicando el Coeficiente de Cronbach.

La encuesta aplicada se puede ver en el Anexo C.

Las preguntas filtro se emplearon para garantizar la validez de los resultados. Todos los encuestados son profesores de Ingeniería industrial de UDEP, e impartían una asignatura en esa carrera en el semestre de encuesta.

La primera pregunta de investigación ¿Considera usted que las personas a las que enseña en su universidad reciben una formación universitaria adecuada para trabajar en una empresa?, dio los resultados mostrados en el Gráfico 5.11. Los profesores consideran con mayor frecuencia que la formación universitaria ha sido bastante adecuada en un $62 \%$ y muy adecuada en un 33\%. También podemos observar que existe un pequeño porcentaje $(5 \%)$ que le parece que la formación ha sido algo adecuada, siendo la minoría. 


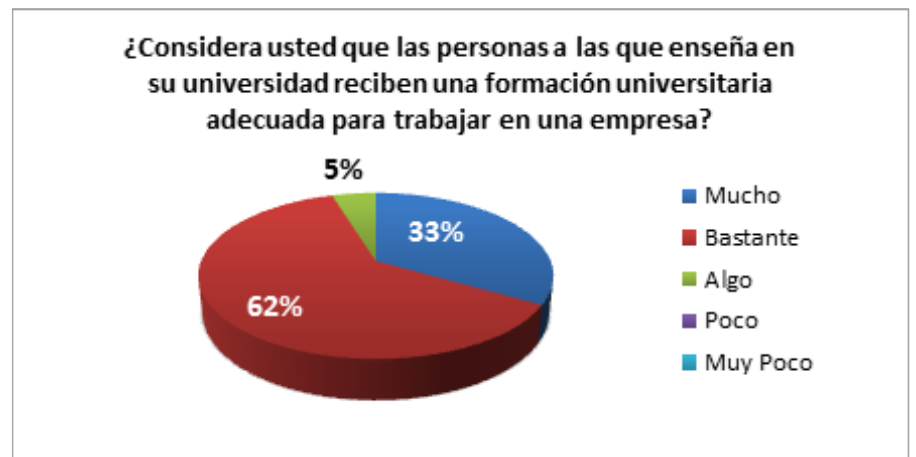

Gráfico 0.15 Formación recibida por alumnos de Ingeniería Industrial de UDEP según sus profesores. Fuente: Elaboración propia

Antes de proceder a aplicar la encuesta se verificó si los profesores conocían el significado de competencia genérica, se les informó al respecto y a modo de filtro se les preguntó si lo sabían, pues diferencias de opinión habrían distorsionado la encuesta. En el Gráfico 5.12 se muestran los resultados.

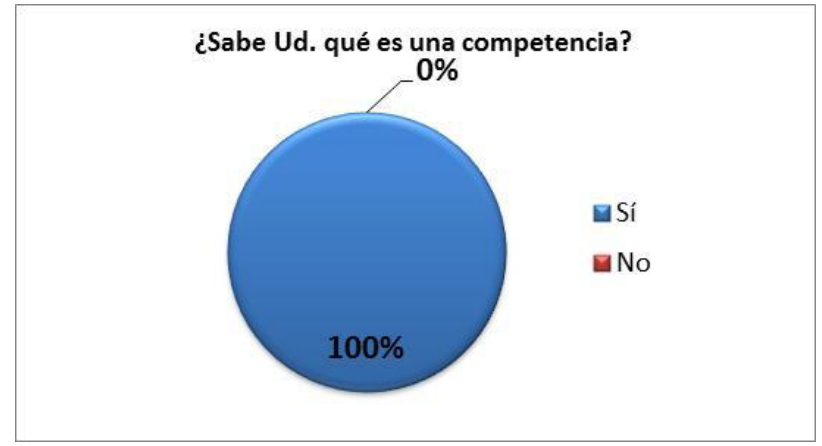

Gráfico 0.16 Profesores conocen el concepto de competencias genéricas.

Fuente: Elaboración propia

La encuesta pide que cada profesor pondere la importancia que considera tiene cada competencia y el nivel de desarrollo que alcanza un alumno en cada una de ellas durante sus estudios.

Los Profesores de Ingeniería Industrial de UDEP afirman que todas las competencias tienen una importancia por encima de 3.24 y el promedio de los valores es de 3.70 cercano al tope máximo 4, que indica mucha importancia. De las 27 competencias, 22 están por encima de 3.5. Una competencia es evaluada por todos los profesores con la máxima puntuación de 4 puntos mucha importancia y fue la 17 Capacidad de trabajo en equipo; la competencia 26, Compromiso ético, tuvo una valoración similar, solo un profesor la calificó de bastante importante, Gráfico 5.13. 


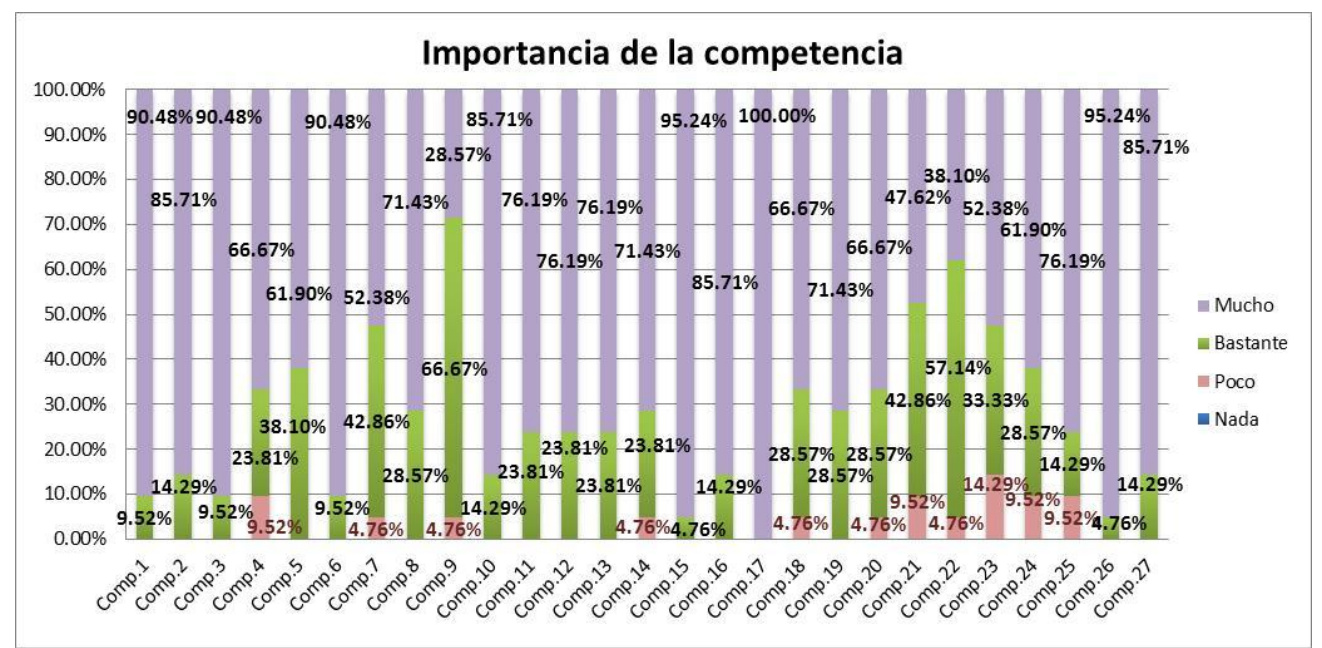

Gráfico 0.17 Importancia de las competencias genéricas TuningAL según los Profesores. Fuente: Elaboración propia

La valoración de los profesores del desarrollo de las competencias en Ingeniería Industrial de UDEP, arroja como promedio de todas 2.86, cercano a bastante desarrollado; se nota una disminución en los resultados de 0.9 respecto de la valoración de importancia (Gráfico 5.14). Todas las competencias se consideran desarrolladas por debajo del nivel de importancia asignado. El Compromiso ético y el Compromiso con la calidad son las más desarrolladas según los profesores. Nueve de las competencias muestran niveles de desarrollo sobre la media de $2.86 \mathrm{y}$ solo una, Compromiso ético, muestra un desarrollo superior a 3.7, que es el valor que dieron en media a la importancia de las competencias.

Se detecta que los profesores, en todos los casos, perciben que el nivel de desarrollo de competencia en Ingeniería Industrial de UDEP está por debajo de la importancia asignada a cada una. Por esto los niveles medios de las mediciones se diferencian 0.9, de 3.7 a 2.8. También se observa en el Gráfico 5.15 que hay competencias que consideran muy desarrolladas respecto al nivel de importancia asignado, con valores muy cercanos: la competencia 26 Compromiso ético, la 27 Compromiso con la calidad y la 4 Conocimientos sobre el área de estudio y la profesión. En las que se aprecia mayor diferencia son la 19 Capacidad de motivar y conducir hacia metas comunes, la 18 Habilidades interpersonales y la 6 Capacidad de comunicación oral y escrita.

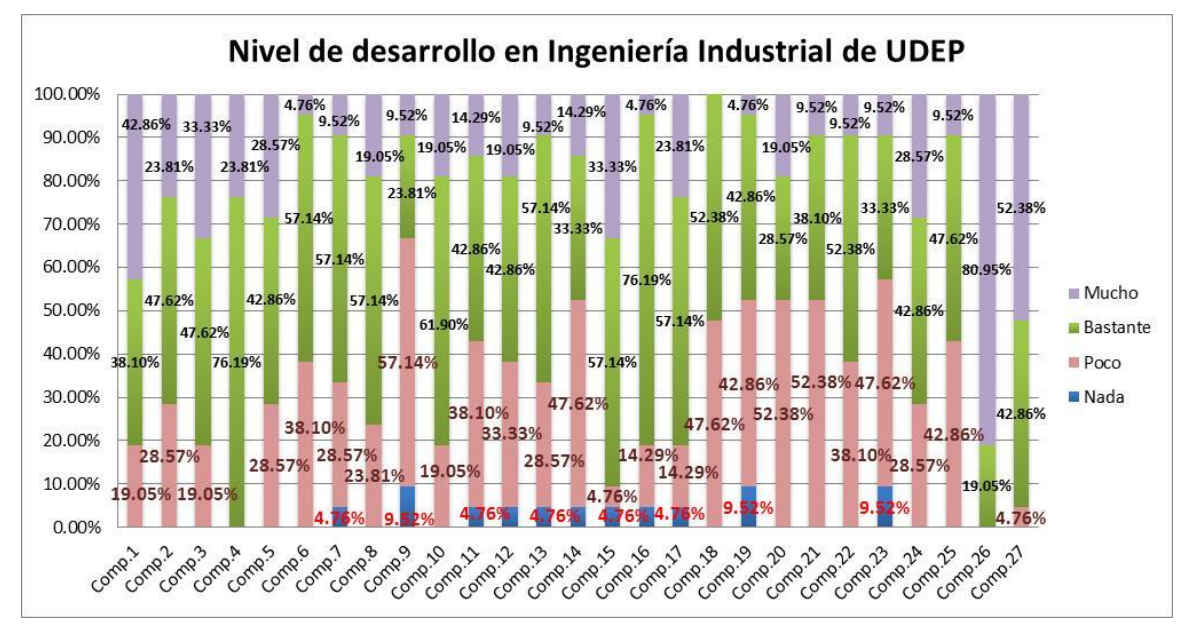

Gráfico 0.18 Desarrollo de las competencias genéricas TuningLA en Ingeniería Industrial de UDEP según los Profesores. Fuente: Elaboración propia 


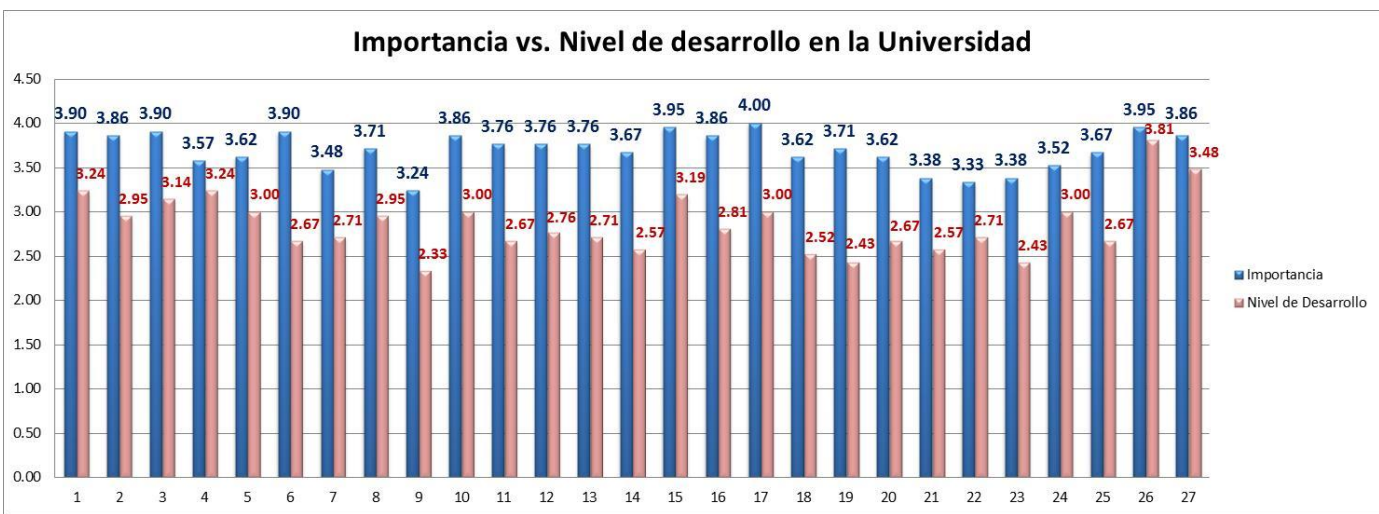

Gráfico 0.19 Comparación entre la importancia y nivel de desarrollo de las competencias genéricas TuningLA en Ingeniería Industrial de UDEP según Profesores. Fuente: Elaboración propia

Del Gráfico 5.15, también puede afirmarse que las cinco competencias más importantes para los profesores son las, 17, 15, 26, y 1,6 y 3 y las menos importantes, 21, 20, 5, 22, 23. Las más desarrolladas son 26, 27, 17, 1 y 4, las menos desarrolladas 23, 7, 21, 20 y 13.

La Tabla 5.11 muestra las competencias consideradas más y menos importantes así como las más y menos desarrolladas, según los profesores. Entre las más importantes existe un balance apropiado entre las competencias técnicas y las de comportamiento o contextuales, en cambio en las menos importantes una es técnica y las demás son de contexto y comportamiento. Entre las que estiman más desarrolladas existe balance entre los tipos de competencias, las menos desarrolladas tienen un marcado sesgo a las de contexto y comportamiento.

\begin{tabular}{|c|c|c|c|}
\hline \multicolumn{2}{|c|}{ IMPORTANCIA } & \multicolumn{2}{|c|}{ DESARROLLO } \\
\hline Más importancia & Menos importancia & Más desarrollo & Menos desarrollo \\
\hline $\begin{array}{l}\text { 17) Capacidad de trabajo } \\
\text { en equipo. }\end{array}$ & $\begin{array}{l}\text { 9) Capacidad de } \\
\text { investigación }\end{array}$ & $\begin{array}{l}\text { 26) Compromiso } \\
\text { ético. }\end{array}$ & $\begin{array}{l}\text { 9) Capacidad de } \\
\text { investigación. }\end{array}$ \\
\hline $\begin{array}{l}\text { 15) Capacidad para } \\
\text { identificar, plantear y } \\
\text { resolver problemas }\end{array}$ & $\begin{array}{l}\text { 22) Valoración y res- } \\
\text { peto por la diversidad } \\
\text { y multiculturalidad. }\end{array}$ & $\begin{array}{l}\text { 27) Compromiso con } \\
\text { la calidad. }\end{array}$ & $\begin{array}{l}\text { 19) Capacidad de } \\
\text { motivar y conducir } \\
\text { hacia metas comunes. }\end{array}$ \\
\hline 26) Compromiso ético. & $\begin{array}{l}\text { 21) Compromiso con } \\
\text { su medio socio- } \\
\text { cultural. }\end{array}$ & $\begin{array}{l}\text { 1) Capacidad de } \\
\text { abstracción, análisis } \\
\text { y síntesis. }\end{array}$ & $\begin{array}{l}\text { 23) Habilidad para } \\
\text { trabajar en contextos } \\
\text { internacionales. }\end{array}$ \\
\hline $\begin{array}{l}\text { 1) Capacidad de } \\
\text { abstracción, análisis y } \\
\text { síntesis. }\end{array}$ & $\begin{array}{l}\text { 23) Habilidad para } \\
\text { trabajar en contextos } \\
\text { internacionales }\end{array}$ & $\begin{array}{l}\text { 4) Conocimientos } \\
\text { sobre el área de es- } \\
\text { tudio y la profesión. }\end{array}$ & $\begin{array}{l}\text { 18) Habilidades } \\
\text { interpersonales. }\end{array}$ \\
\hline $\begin{array}{l}\text { 3) Capacidad para } \\
\text { organizar y planificar } \\
\text { el tiempo. } \\
\text { 6) Capacidad de } \\
\text { comunicación oral y } \\
\text { escrita. }\end{array}$ & $\begin{array}{l}\text { 7) Capacidad de } \\
\text { comunicación en un } \\
\text { segundo idioma. }\end{array}$ & $\begin{array}{l}\text { 15) Capacidad para } \\
\text { identificar, plantear } \\
\text { y resolver } \\
\text { problemas. }\end{array}$ & $\begin{array}{l}\text { 14) Capacidad } \\
\text { creativa. }\end{array}$ \\
\hline
\end{tabular}

Tabla 0.11 Competencias genéricas más y menos importantes, y más y menos desarrolladas, según Profesores de Ingeniería Industrial en UDEP. Fuente: Elaboración Propia

Está claro el balance que los profesores entienden hay entre competencia técnicas de comportamiento y contextuales tanto en las de mayor importancia como de mayor desarrollo; 
pero también está claro que les son menos importantes las de comportamiento y de contexto, y son las que se desarrollan menos que las técnicas.

Para conocer la confiabilidad de la encuesta para la importancia asignada a las competencias, se calculó la varianza de cada competencia y se sumaron estas varianzas hallándose que $\sum S_{i}^{2}=$ 6.49 y al calcular la varianza de las sumas de los puntajes asignados por ítem se encontró que la varianza total era $S_{\text {tot }}{ }^{2}=43.83$. Con estos dos valores se calcula el Coeficiente de Cronbach en la ecuación Ec. 5.2 y se obtiene:

$$
\propto=\left(\frac{27}{27-1}\right) \cdot\left(1-\frac{6.49}{43.83}\right)=0.8847
$$

Se hace lo mismo para hallar la confiabilidad de la encuesta para el desarrollo que los profesores estiman alcanzan los alumnos durante su carrera. La suma de varianzas de ítems fue $\sum S_{i}{ }^{2}=$ 13.343 y la varianza total era $S_{\text {tot }}{ }^{2}=117.29$, Con estos dos valores se calcula el Coeficiente de Cronbach en la ecuación Ec. 5.2 y se obtiene:

$$
\propto=\left(\frac{27}{27-1}\right) \cdot\left(1-\frac{13.343}{117.29}\right)=0.92
$$

Con estos resultados podemos afirmar que las encuestas realizadas tienen buena consistencia interna pues los valores son cercanos a 0.9 , por lo que son confiables en un buen y excelente nivel, respectivamente, según la Tabla 5.8.

\subsubsection{Encuestas a alumnos.}

Para los alumnos se hizo una estratificación y se definieron tres grupos para ser encuestados. El método aplicado fue a población completa en cada caso. El primer grupo se conformó por alumnos de primer año, el segundo por alumnos de tercer año y el último por alumnos de quinto año. Los resultados de los tres grupos fueron muy similares, tanto, que no justifica mostrar los resultados de los tres grupos pues llevan a las mismas conclusiones. Por esta razón mostraremos los resultados de los alumnos de último año, por haber pasado por la mayor parte del proceso formativo, haber realizado prácticas preprofesionales y estando cerca a egresar. Se prefirieron sus resultados por el mayor conocimiento del proceso formativo completo y de la realidad externa.

En el semestre 2012 I estuvieron matriculados 60 alumnos en el último año de carrera y la encuesta se aplicó a los 60 alumnos, en consecuencia la encuesta muestra las opiniones del total de la población llamándose exhaustiva, pues abarca a todas las unidades estadísticas que componen el universo o población. Por ello los resultados son precisos y la certeza es total. A este grupo también se les preguntó sobre la importancia y el nivel de desarrollo de las competencias, Anexo D.

En la encuesta se les preguntó a los estudiantes de último año si ¿consideran que la formación que están recibiendo en Ingeniería Industrial de UDEP es la adecuada? Ellos contestaron según se muestra en el Gráfico 5.16. Consideran que la formación recibida es muy adecuada 10\%, bastante adecuada $80 \%$, y algo adecuado $10 \%$. 


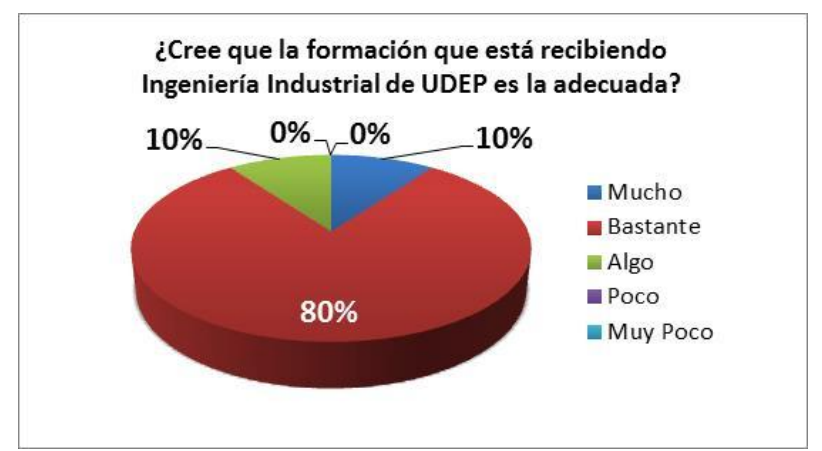

Gráfico 0.20 Formación recibida por alumnos de Ingeniería Industrial de UDEP según sus alumnos de último año. Fuente: Elaboración propia

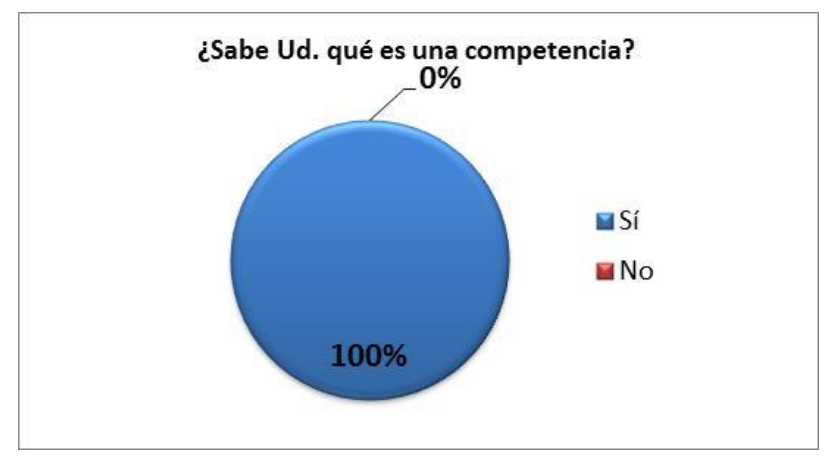

Gráfico 0.21 Alumnos conocen el concepto de competencias genéricas.

Fuente: Elaboración propia

Antes de proceder a aplicar la encuesta se verificó si los alumnos conocían el significado de competencia genérica, se les informó al respecto y a modo de filtro se les preguntó si lo sabían, pues no debía existir una significativa cantidad de alumnos que la ignoraran pues marcadas diferencias de opinión sobre el concepto habrían distorsionado la encuesta. En el Gráfico 5.17 se muestran los resultados. Se observa que a pesar dela información dada algunos alumnos manifestaban desconocer la definición de competencias genéricas. Aun así se les aplicó la encuesta para no perder la condición de encuesta exhaustiva.

Otra pregunta formulada a los estudiantes fue ¿Cómo valora las posibilidades de encontrar trabajo al terminar su carrera profesional? De entre las respuestas muy pocas, pocas, algunas bastantes muchas, los alumnos de último año respondieron en un $65 \%$ que son bastantes las posibilidades de hallarlo, $12 \%$ que son muchas, un $23 \%$ contestaron que algunas. Se concluye que el $77 \%$ de alumnos confía en que encontrará trabajo con bastante o mucha expectativa, ninguno a respondido pocas posibilidades, Gráfico 5.18. 


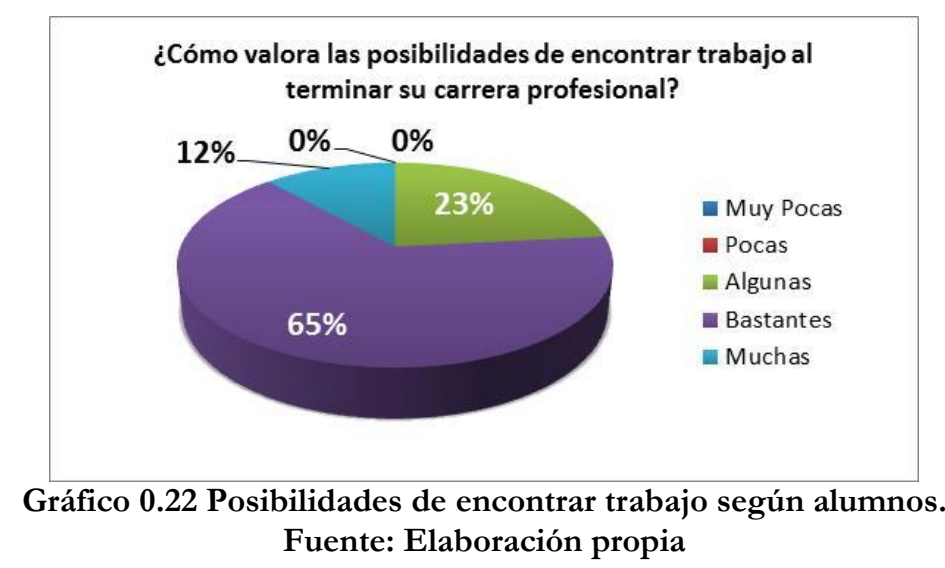

Los alumnos de último año de Ingeniería Industrial de UDEP afirman que todas las competencias tienen una importancia por encima de 3.05 y el promedio de los valores es de 3.50, valor intermedio entre bastante importancia y mucha importancia. De las 27 competencias, 15 están por encima de 3.5. Ninguna competencia fue considerada por todos como muy importante, sin embargo el $81.67 \%$ de alumnos consideraron las competencias 16 Capacidad para tomar decisiones y 2, Capacidad de aplicar los conocimientos en la práctica, como muy importantes, Gráfico 5.19. Las siguientes fueron la competencia 1, Capacidad de abstracción, análisis y sintesis, y la 26, Compromiso ético fueron las siguientes con $76.67 \%$ y $75 \%$.

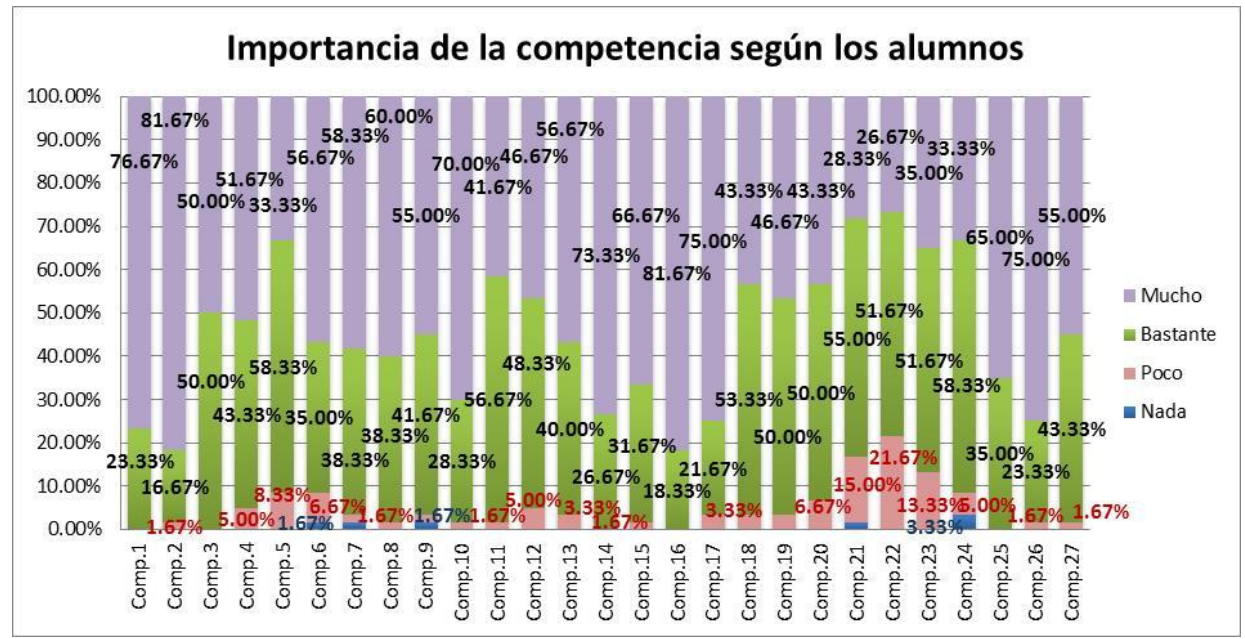

Gráfico 0.23 Importancia de las competencias genéricas TuningAL según los alumnos. Fuente: Elaboración propia

Los alumnos de último año de Ingeniería Industrial de UDEP opinan que durante la carrera han adquirido unas competencias, que al compararlas con las TuningAL mostradas resulta que: en la evaluación de 1 a 4 asignan un nivel de desarrollo del conjunto, en promedio, de 2.79 cercano a bastante desarrolladas; la competencia que más alumnos consideraron como muy desarrollada con 51.67\% fue la 26, Compromiso ético, seguida de la 17, Capacidad de trabajo en equipo con $36.67 \%$, Gráfico 5.20. Las que recibieron la valoración de poco desarrolladas fueron la 23 Habilidad para trabajar en contextos internacionales con $21.67 \%$, y $10 \%$ de los alumnos dijeron que la 7, Capacidad de comunicación en un segundo idioma también fue poco desarrollada. 


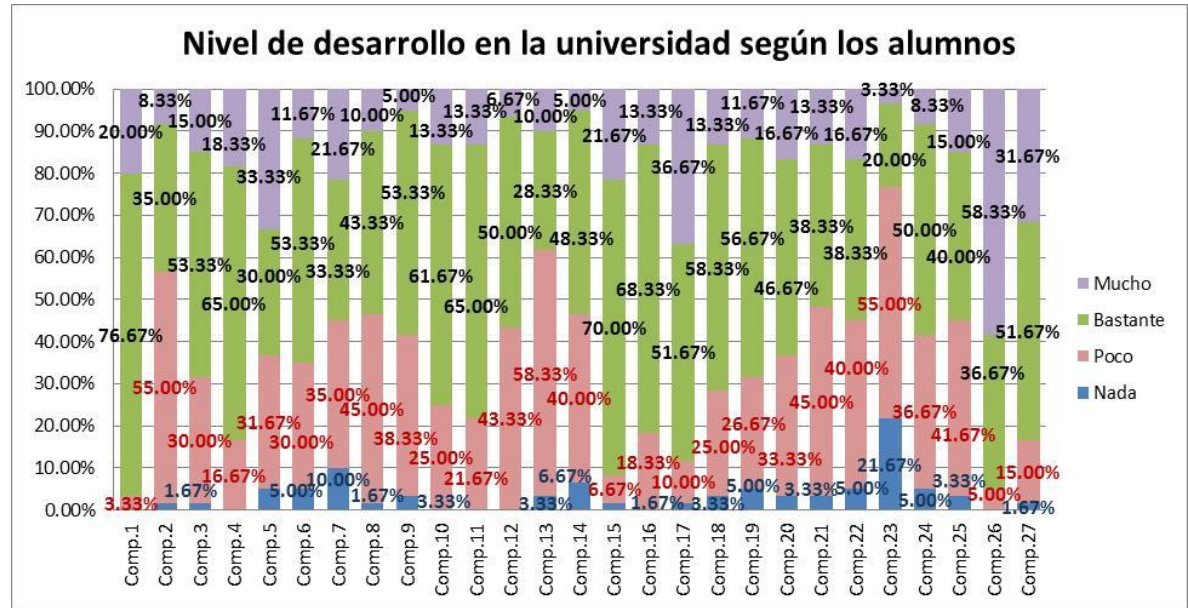

Gráfico 0.24 Desarrollo de las competencias genéricas TuningLA en Ingeniería Industrial de UDEP según los Alumnos. Fuente: Elaboración propia

También los alumnos, en todos los casos, perciben que el nivel de desarrollo de competencia en Ingeniería Industrial de UDEP está por debajo de la importancia asignada por ellos a cada una. Los niveles medios de las mediciones se distancian 0.71 , de 3.5 a 2.79 . Se observa en el Gráfico 5.21 que hay competencias cuyo desarrollo es muy cercano a la importancia dada, la competencia 26 Compromiso ético con 0.2 de diferencia, la 5 Responsabilidad social y compromiso ciudadano con 0.33, y la 27 Compromiso con la calidad con 0.4. En las que se aprecia mayor diferencia son: la 2, Capacidad de aplicar los conocimientos en la práctica con 1.3, la competencia 14, Capacidad creativa, con 1.21, y la 23, Habilidad para trabajar en contextos internacionales, con 1.17 de diferencia.

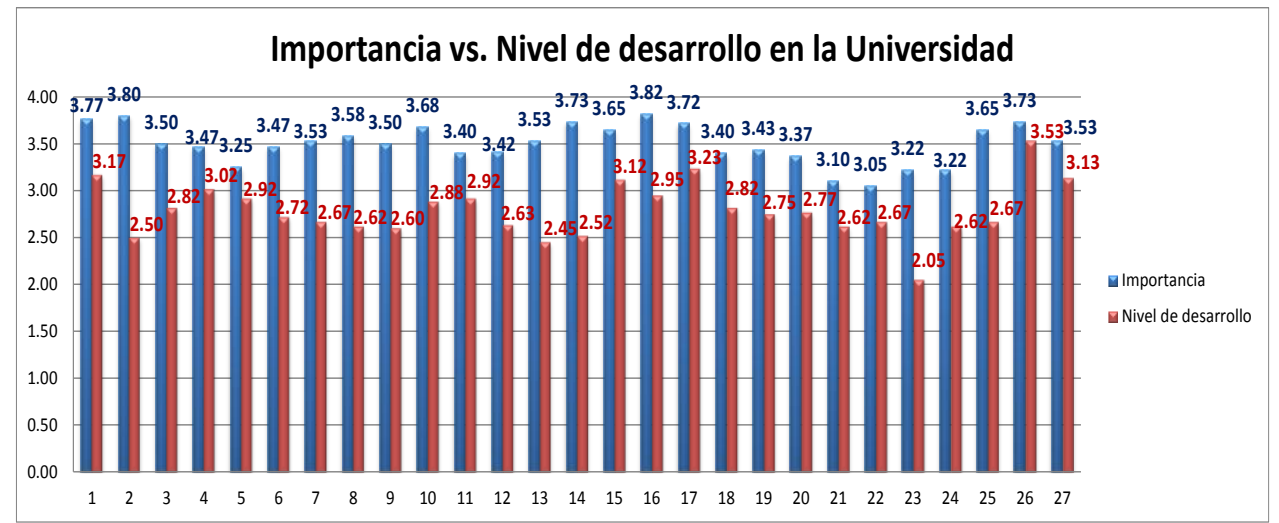

Gráfico 0.25 Comparación entre la importancia y nivel de desarrollo de las competencias genéricas TuningLA en Ingeniería Industrial de UDEP según los alumnos. Fuente: Elaboración propia

Del Gráfico 5.21, también puede afirmarse que las cinco competencias más importantes para los alumnos son las 16, 2, 1, 26 y 17 y las menos importantes, 22, 21, 23, 24 y 5. Las más desarrolladas son 26, 17, 1, 27, y 15, las menos desarrolladas 23, 13, 2, 14 y 21.

La Tabla 5.12 muestra las competencias consideradas más y menos importantes así como las más y menos desarrolladas, según los alumnos. Entre las más importantes existe un desbalance inclinado hacia las competencias técnicas, en cambio en las menos importantes todas son de contexto y comportamiento. Entre las que estiman más desarrolladas existe balance entre las 
competencias contextuales, de comportamiento y técnicas, las menos desarrolladas todas son de contexto y comportamiento.

Queda en evidencia en este cuadro, que para los alumnos las competencias menos importantes y menos desarrolladas son todas de comportamiento y de contexto.

\begin{tabular}{|c|l|l|l|}
\hline \multicolumn{2}{|c|}{ IMPORTANCIA } & \multicolumn{2}{c|}{ DESARROLLO } \\
\hline Más importancia & Menos importancia & Más desarrollo & Menos desarrollo \\
\hline $\begin{array}{l}\text { 16) Capacidad para } \\
\text { tomar decisiones. }\end{array}$ & $\begin{array}{c}\text { 22) Valoración y res- } \\
\text { peto por la diversidad } \\
\text { y multiculturalidad. }\end{array}$ & $\begin{array}{l}\text { 26) Compromiso } \\
\text { ético. }\end{array}$ & $\begin{array}{l}\text { 23) Habilidad para } \\
\text { trabajar en contextos } \\
\text { internacionales. }\end{array}$ \\
\hline $\begin{array}{l}\text { 2) Capacidad de aplicar } \\
\text { los conocimientos en } \\
\text { la práctica }\end{array}$ & $\begin{array}{c}\text { 21) Compromiso con } \\
\text { su medio socio- } \\
\text { cultural. }\end{array}$ & $\begin{array}{l}\text { 17) Capacidad de } \\
\text { trabajo en equipo. }\end{array}$ & $\begin{array}{l}\text { 13) Capacidad para } \\
\text { actuar en nuevas } \\
\text { situaciones. }\end{array}$ \\
\hline $\begin{array}{l}\text { 1) Capacidad de } \\
\text { abstracción, análisis y } \\
\text { síntesis. }\end{array}$ & $\begin{array}{l}\text { 23) Habilidad para } \\
\text { trabajar en contextos } \\
\text { internacionales }\end{array}$ & $\begin{array}{l}\text { 1) Capacidad de } \\
\text { abstracción, análisis } \\
\text { y síntesis. }\end{array}$ & $\begin{array}{l}\text { 2) Capacidad de apli- } \\
\text { car los conocimien- } \\
\text { tos en la práctica }\end{array}$ \\
\hline 26) Compromiso ético. & $\begin{array}{l}\text { 24) Habilidad para } \\
\text { trabajar en forma } \\
\text { autónoma }\end{array}$ & $\begin{array}{l}\text { 27) Compromiso con } \\
\text { la calidad. }\end{array}$ & $\begin{array}{l}\text { 14) Capacidad } \\
\text { creativa. }\end{array}$ \\
\hline $\begin{array}{l}\text { 17) Capacidad de } \\
\text { trabajo en equipo. }\end{array}$ & $\begin{array}{l}\text { 5) Responsabilidad } \\
\text { social y compromiso } \\
\text { ciudadano }\end{array}$ & $\begin{array}{l}\text { 15) Capacidad para } \\
\text { identificar, plantear } \\
\text { y resolver } \\
\text { problemas. }\end{array}$ & $\begin{array}{l}\text { 21) Compromiso con } \\
\text { su medio socio- } \\
\text { cultural. }\end{array}$ \\
\hline
\end{tabular}

Tabla 0.12 Competencias genéricas más y menos importantes, y más y menos desarrolladas, según alumnos de Ingeniería Industrial en UDEP. Fuente: Elaboración Propia

Para conocer la confiabilidad de la encuesta aplicada a los alumnos en la medición de la importancia asignada a las competencias, se calculó la varianza de cada competencia y se sumaron estas varianzas hallándose que $\sum S_{i}{ }^{2}=8.651$ y al calcular la varianza de las sumas de los puntajes asignados por ítem se encontró que la varianza total era $S_{t o t}{ }^{2}=62.796$. Con estos dos valores se calcula el Coeficiente de Cronbach en la ecuación Ec. 5.2 y se obtiene:

$$
\propto=\left(\frac{27}{27-1}\right) \cdot\left(1-\frac{8.651}{62.796}\right)=0.8954
$$

Se hace lo mismo para hallar la confiabilidad de la encuesta para el desarrollo que los alumnos estiman han alcanzado las competencias durante su carrera. La suma de varianzas de ítems fue $\sum S_{i}{ }^{2}=13.339$ y la varianza total era $S_{\text {tot }}{ }^{2}=83.548$, Con estos dos valores se calcula el Coeficiente de Cronbach en la ecuación Ec. 5.2 y se obtiene:

$$
\propto=\left(\frac{27}{27-1}\right) \cdot\left(1-\frac{13.339}{83.548}\right)=0.873
$$

Con estos resultados podemos afirmar que las encuestas realizadas tienen buena consistencia interna pues los valores se encuentran entre 0.8 y 0.9 , por lo que son confiables en un buen nivel, según la Tabla 5.8.

\subsubsection{Encuestas a empleadores.}

El cuarto grupo de interés en la formación de ingenieros lo conforman los empleadores. Dado el alto porcentaje de oferta laboral en los servicios más que en la manufactura, como se ha tratado en el capítulo anterior, se buscó reflejar ese porcentaje en los encuestados. Quedó clara 
una marcada reticencia de los empleadores a responder las encuestas; se pudo encuestar a jefes de recursos humanos de 11 empresas. Una dificultad adicional es que solicitábamos que hubieran tenido y conserven egresados de Ingeniería Industrial de la UDEP entre sus trabajadores, esta era una condición filtro.

El método a usar es de muestreo no probabilístico por conveniencia dada la dificultad de llegar al total de la población y porque era conveniente elegir a las empresas que sabíamos conocen a nuestros egresados. Ya que no existe alternativa de muestreo pues solo puede encuestarse a los empleadores que están accesibles y disponibles, se eligen los individuos de manera no aleatoria sabiendo que puede aplicarse solo en casos en los que no existe otra alternativa (Casal, J. et al; 2003). Se verificará la confiabilidad del instrumento aplicando el Coeficiente de Cronbach.

La encuesta aplicada se puede ver en el Anexo E.

La distribución fue 36\% empresas de manufactura y 64\% de servicios. 45\% de la Región Piura, $45 \%$ de ámbito nacional y una transnacional.

A la pregunta żconsidera que los egresados de Ingeniería Industrial de la Universidad de Piura han recibido una formación universitaria adecuada para trabajar en su empresa? Las respuestas fueron $27.7 \%$ muy de acuerdo, 45.4\% bastante, 18.18 algo y 9\% poco, Gráfico 5.22.

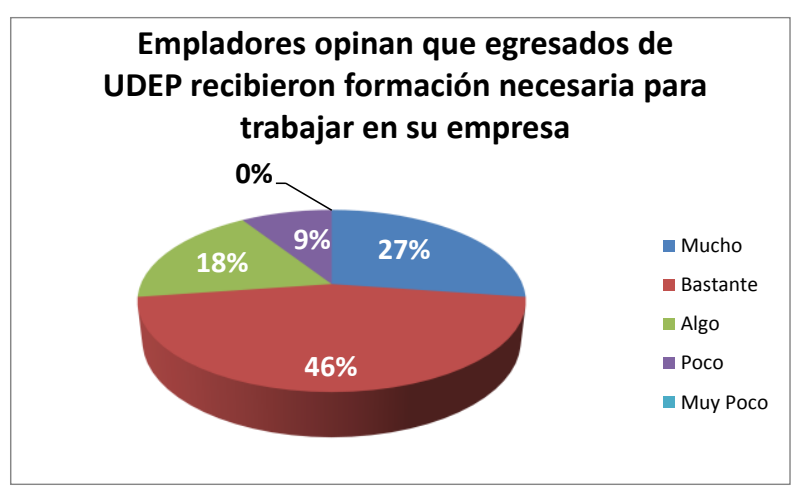

Gráfico 5.26: Formación de egresado de Ingeniería Industrial de UDEP según los empleadores.

Fuente: Elaboración propia

A los encuestados se les explicó la naturaleza de la encuesta y el significado de competencias genéricas y cuál era el objetivo del estudio. Al preguntarles si conocían el significado de competencia genéricas, respondieron que sí Gráfico 5.23 .

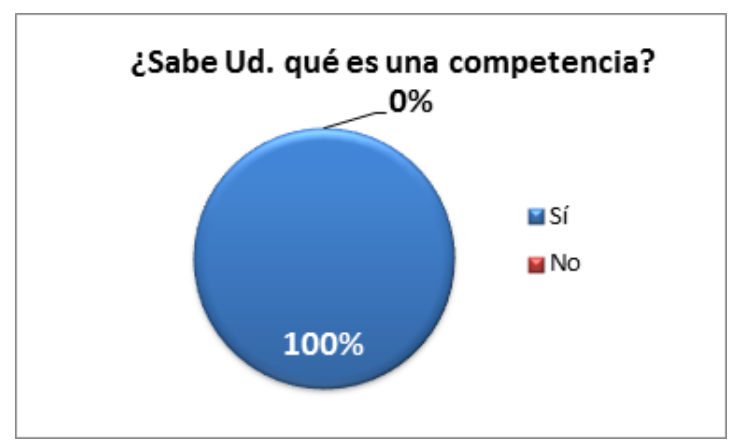

Gráfico 5.27: Dominio del concepto de competencia según los empleadores.

Fuente: Elaboración propia 
Los empleadores afirman que las competencias de TunningAL tienen una importancia en el quehacer de su empresa por encima de 2.82 y el promedio del conjunto es 3.60, valor intermedio entre bastante importancia y mucha importancia. De las 27 competencias, 19 están por encima de 3.5. Las competencias 15 Capacidad para identificar, planteary resolver problemas y 17 Capacidad de trabajo en equipo fueron consideradas por todos como muy importantes Gráfico 5.24. Ningún empleador ha considerado alguna competencia como nada importante. Fueron consideradas poco importantes la 4 Conocimientos sobre el área de estudio y la profesión, la 9 Capacidad de investigación y la 20 Compromiso con la preservación del medio ambiente.

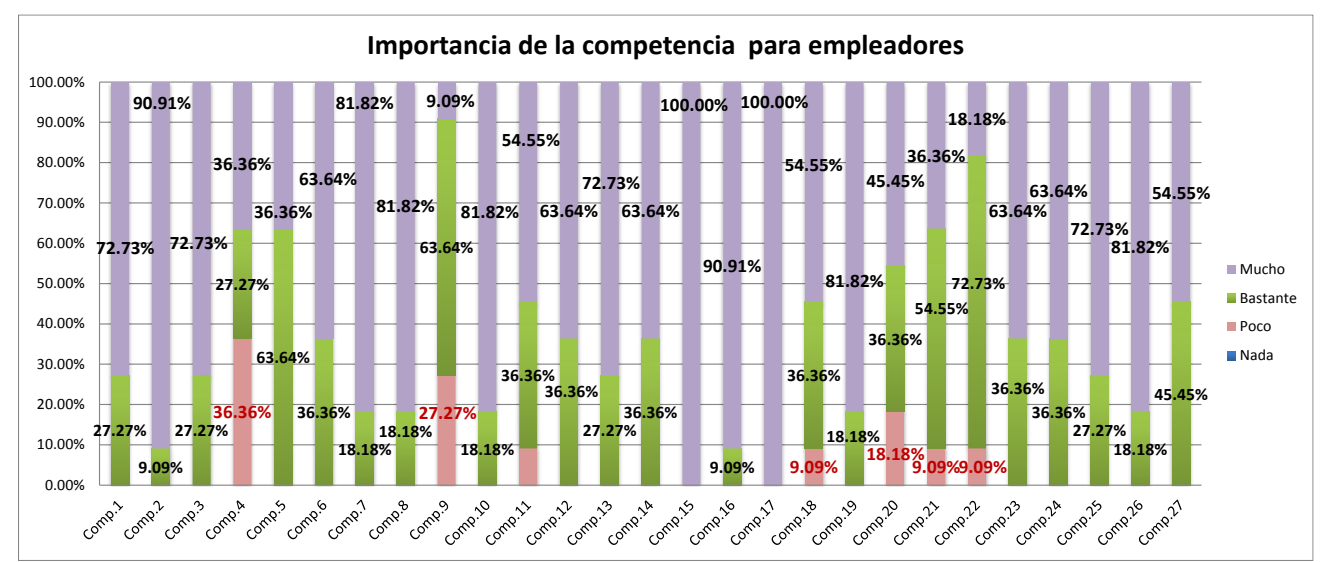

Gráfico 5.28: Importancia de las competencia genéricas TuningAL según los empleadores Fuente: Elaboración propia

En el Gráfico 5.25 se muestra el nivel de desarrollo de las competencias TunningAL que los empleadores perciben en los egresados de Ingeniería Industrial de UDEP. La media de desarrollo del conjunto de competencias es, en promedio, 2.71, valor entre poco y bastante desarrolladas; la competencia que más empleadores consideraron como muy desarrollada con $72.73 \%$ fue la 26, Compromiso ético. Las que recibieron la valoración de poco desarrolladas fueron en mayor magnitud la 21, Compromiso con su medio socio-cultural, $72.73 \%$, y la 18 Habilidades interpersonales con 63.63\%.

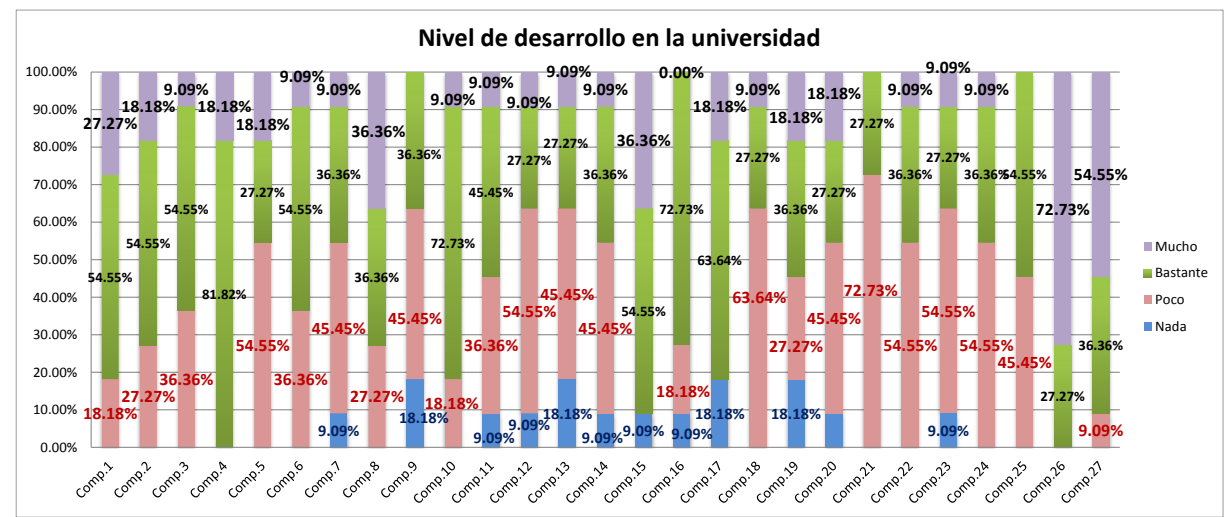

Gráfico 5.29: Desarrollo de las competencia genéricas TuningAL en Ingeniería Industrial de UDEP según los empleadores.

Fuente: Elaboración propia 
En el caso de los empleadores existe una competencia que se considera más desarrollada que el grado de importancia asignada, la 4, Conocimientos sobre el área de estudio y la profesión. En todos los demás casos el desarrollo de la competencia está por debajo de la importancia asignada. Las medias de las asignaciones se diferencian 0.89 , de 3.6 a 2.71. También se observa en el Gráfico 5.26 que hay competencias con desarrollo muy cercano al grado de importancia atribuido por los empleadores, la 26 Compromiso ético, la 27 Compromiso con la calidad. Aquellas en que se aprecia mayor diferencia entre importancia y desarrollo son la 7 Capacidad de comunicación en un segundo idioma con 1.38; la 19 Capacidad de motivary conducir hacia metas comunes, y la 18, Capacidad para tomar decisiones, con 1.27 de diferencia; y la 17, Capacidad de trabajo en equipo, con 1.18.

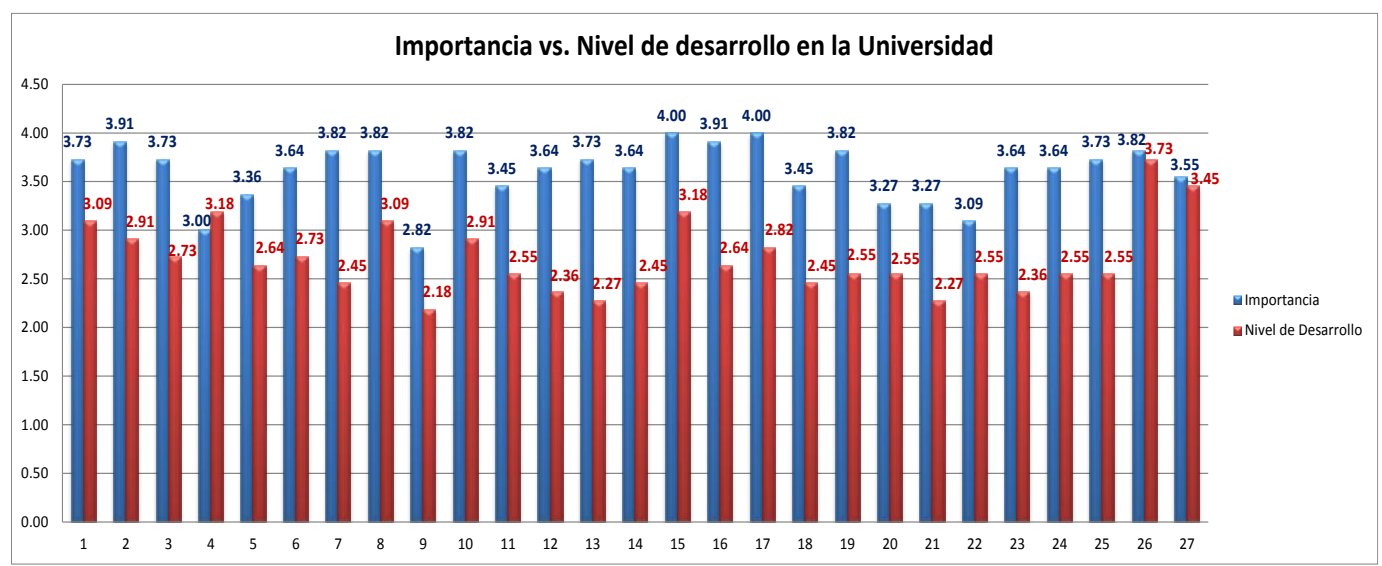

Gráfico 5.30: Comparación entre la importancia y nivel de desarrollo de las competencia genéricas TuningAL en Ingeniería Industrial de UDEP según Empleadores.

Fuente: Elaboración propia

Del Gráfico 5.26, también puede afirmarse que las cinco competencias más importantes para los empleadores son las 15, 17, 2, 16, y cinco competencias en quinto lugar y las menos importantes, 9, 4, 22, 20 y 21. Las más desarrolladas son 26, 27, 15, 4 y, 1 y 8, las menos desarrolladas 9, 21, 13, 12 y 24 .

La Tabla 5.13 muestra las competencias consideradas más y menos importantes así como las más y menos desarrolladas, según los empleadores. Hay balance entre las de comportamiento y contextuales en el caso de las más importantes; entre las menos importantes la mayoría son de contexto y comportamiento. Entre las que estiman más desarrolladas la gran mayoría son técnicas; las menos desarrolladas todas son de contexto y comportamiento. 


\begin{tabular}{|c|c|c|c|}
\hline \multicolumn{2}{|c|}{ IMPORTANCIA } & \multicolumn{2}{|c|}{ DESARROLLO } \\
\hline Más importancia & Menos importancia & Más desarrollo & Menos desarrollo \\
\hline $\begin{array}{l}\text { 15) Capacidad para } \\
\text { identificar, plantear y } \\
\text { resolver problemas. }\end{array}$ & $\begin{array}{l}\text { 9) Capacidad de } \\
\text { investigación. }\end{array}$ & $\begin{array}{l}\text { 26) Compromiso } \\
\text { ético. }\end{array}$ & $\begin{array}{l}\text { 9) Capacidad de } \\
\text { investigación }\end{array}$ \\
\hline $\begin{array}{l}\text { 17) Capacidad de } \\
\text { trabajo en equipo. }\end{array}$ & $\begin{array}{l}\text { 4) Conocimientos } \\
\text { sobre el área de es- } \\
\text { tudio y la profesión. }\end{array}$ & $\begin{array}{l}\text { 27) Compromiso con } \\
\text { la calidad. }\end{array}$ & $\begin{array}{l}\text { 21) Compromiso con } \\
\text { su medio socio- } \\
\text { cultural. }\end{array}$ \\
\hline $\begin{array}{l}\text { 2) Capacidad de aplicar } \\
\text { los conocimientos en } \\
\text { la práctica. }\end{array}$ & $\begin{array}{l}\text { 22) Valoración y } \\
\text { respeto por la } \\
\text { diversidad y } \\
\text { multiculturalidad. }\end{array}$ & $\begin{array}{l}\text { 15) Capacidad para } \\
\text { identificar, plantear } \\
\text { y resolver } \\
\text { problemas. }\end{array}$ & $\begin{array}{l}\text { 13) Capacidad para } \\
\text { actuar en nuevas } \\
\text { situaciones }\end{array}$ \\
\hline \multirow[t]{2}{*}{$\begin{array}{l}\text { 16) Capacidad para } \\
\text { tomar decisiones }\end{array}$} & $\begin{array}{l}\text { 20) Compromiso con } \\
\text { la preservación del } \\
\text { medio ambiente. }\end{array}$ & $\begin{array}{l}\text { 4) Conocimientos } \\
\text { sobre el área de es- } \\
\text { tudio y la profesión. }\end{array}$ & $\begin{array}{l}\text { 12) Capacidad crítica } \\
\text { y autocrítica. }\end{array}$ \\
\hline & $\begin{array}{l}\text { 21) Habilidad para } \\
\text { trabajar en contextos } \\
\text { internacionales. }\end{array}$ & $\begin{array}{l}\text { 1) Capacidad de } \\
\text { abstracción, análisis } \\
\text { y síntesis. } \\
\text { 8) Conocimientos } \\
\text { sobre el área de es- } \\
\text { tudio y la profesión. }\end{array}$ & $\begin{array}{l}\text { 23) Habilidad para } \\
\text { trabajar en contextos } \\
\text { internacionales. }\end{array}$ \\
\hline
\end{tabular}

Tabla 0.13 Competencias genéricas más y menos importantes, y más y menos desarrolladas, según empleadores. Fuente: Elaboración Propia

Queda en evidencia en la Tabla 5.13, que las competencias menos importantes y menos desarrolladas son todas de comportamiento y de contexto.

Para conocer la confiabilidad de la encuesta aplicada a los empleadores para medir la importancia asignada a las competencias, se calculó la varianza de cada competencia y se sumaron estas varianzas hallándose que $\sum S_{i}^{2}=1.343$ y al calcular la varianza de las sumas de los puntajes asignados por ítem se encontró que la varianza total era $S_{t o t}{ }^{2}=10.603$. Con estos dos valores se calcula el Coeficiente de Cronbach en la ecuación Ec. 5.2 y se obtiene:

$$
\propto=\left(\frac{27}{27-1}\right) \cdot\left(1-\frac{1.343}{10.603}\right)=0.907
$$

Se hace lo mismo para hallar la confiabilidad de la encuesta para el desarrollo que los alumnos estiman han alcanzado las competencias durante su carrera. La suma de varianzas de ítems fue $\sum S_{i}{ }^{2}=1.683$ y la varianza total era $S_{\text {tot }}{ }^{2}=16.963$, Con estos dos valores se calcula el Coeficiente de Cronbach en la ecuación Ec. 5.2 y se obtiene:

$$
\propto=\left(\frac{27}{27-1}\right) \cdot\left(1-\frac{1.683}{16.963}\right)=0.935
$$

Con estos resultados podemos afirmar que las encuestas realizadas tienen buena consistencia interna pues los valores en ambos casos son mayores que 0.9 , por lo que son confiables en un excelente nivel, según la Tabla 5.8.

\subsubsection{Interpretación de resultados.}

De los resultados de las encuestas a los grupos interesados en la formación de ingenieros industriales de una universidad de Perú podemos extraer las siguientes conclusiones. 
Todos los grupos de interés valoran la importancia que tienen estas competencias genéricas TuningAL en la formación de Ingenieros industriales Perú con una media superior a 3.5 en una escala de 1 a 4. Esto nos permite afirmar que las competencias TuningAL sí son una codificación de competencias apropiadas para la formación de Ingenieros Industriales en Perú. El grupo que les da mayor importancia son los profesores con 3.7, seguidos de los empleadores con 3.6, en media.

Haciendo una media de los puntajes medios dados por cada grupo de interés con calificaciones de bastante importante y muy importante, se considera como bastante o muy importante a esta codificación de competencias en un $87.1 \%$.

Existen algunas competencias que son consideradas como poco importantes, pero son casos aislados. Los profesores y los empleadores en ningún caso mencionan que alguna competencia sea poco importante. Los egresados mencionan a 6 de ellas en un 1.69\%, y los alumnos a cinco de ellas, en 3.3\% la más mencionada.

Para las preguntas sobre el nivel de desarrollo alcanzado por los estudiantes de Ingeniería Industrial de UDEP el valor asignado por las partes interesadas, en media, fue 2.82, cifra muy cercana a bastante desarrollado. Sin embargo, para todos los grupos las competencias se desarrollan en Ingeniería Industrial de UDEP menos que la importancia que les asignan. En media esa diferencia entre importancia y desarrollo es 0.76. En los empleadores es donde se encuentra que es más grande la diferencia entre importancia asignada y desarrollo alcanzado con un valor de 0.89 .

El grupo que califica más alto el desarrollo de competencias alcanzado en UDEP son los egresados con 2.95 y los que más bajo califican son los empleadores con 2.71 .

$\mathrm{Al}$ evaluar las competencias consideradas como más importantes en los cuatro grupos de interés, entre las cinco más importantes se observa que existen repeticiones. La competencia que se repite como más importante para todos es la 17 Capacidad de trabajo en equipo. Las que se repiten en tres de los cuatro grupos son la 16 Capacidad para tomar decisiones, la 15 Capacidad para identificar, plantear y resolver problemas, y la 1 Capacidad de abstracción, análisis y sintesis. Dos veces se repite la 26 Compromiso ético.

Entre las cinco competencias que se consideran más desarrolladas en los egresados de Ingeniería Industrial de UDEP también hay coincidencias en los cuatro grupos. Las que fueron mencionadas por los cuatro grupos están la 26 Compromiso ético, la 27 Compromiso con la calidad y la 1 Capacidad de abstracción, análisis y sintesis. Mencionadas tres veces la 4, Conocimientos sobre el área de estudio y la profesión, y la 15, Capacidad para identificar, planteary resolver problemas. La 17, Capacidad de trabajo en equipo, aparece dos veces.

Hay mucha coincidencia entre las cinco competencias consideradas más importantes y las cinco consideradas más desarrolladas, por los cuatro grupos de interés, pero debe tenerse en cuenta que no tienen el mismo orden y que el desarrollo es menor que la importancia atribuida a cada una. Cuatro de ellas son comunes a ambas evaluaciones, la 17 Capacidad de trabajo en equipo, 26 Compromiso ético, la 15 Capacidad para identificar, plantear y resolver problemas, y la 1 Capacidad de abstracción, análisis y sintesis. Todas competencias técnicas excepto una. 
Entre las cinco competencias menos desarrolladas mencionadas por los cuatro grupos de interés están: mencionadas cuatro veces la 23, Habilidad para trabajar en contextos internacionales; mencionadas tres veces la 21, Compromiso con su medio socio-cultural y la 13 Capacidad para actuar en nuevas situaciones; mencionadas dos veces la 9, Capacidad de investigación, y la 14 Capacidad creativa. Competencias de contexto y de comportamiento excepto una.

Entre las cinco menos importantes mencionadas por los cuatro grupos figuran: mencionadas cuatro veces la 22, Valoración y respeto por la diversidad y multiculturalidad, y la 21, Compromiso con su medio socio-cultural; mencionada tres veces la 2, Capacidad de aplicar los conocimientos en la práctica; mencionadas dos veces la 9, Capacidad de investigación, la 20, Compromiso con la preservación del medio ambiente, y la 5, Responsabilidad socialy compromiso ciudadano. Que son dos técnicas y tres de contexto y comportamiento.

Queda muy claro que las competencias consideradas más importantes y más desarrolladas por los cuatro grupos son marcadamente técnicas, en cambio las menos importantes y menos desarrolladas son marcadamente técnicas y de comportamiento.

\subsubsection{Competencias específicas.}

Luego de confirmar que las competencias genéricas elegidas se contextualizan bien con el territorio elegido: la Ingeniería Industrial de la UDEP en Perú, debemos construir el elenco de competencias específicas para esta carrera. En el año 2012 en reuniones con miembros seleccionados de los grupos de interés, se identificaron unas competencias específicas que debían validarse antes de aplicarlas. La validación de estas competencias genéricas debía seguir el mismo procedimiento que la contextualización de las competencias genéricas.

Dentro del grupo de planificación se decidió que los grupos de interés de los que era relevante recabar información en esta etapa eran los egresados, los profesores y los empleadores. A los alumnos no se les incluye en esta muestra de resultados, aunque sí se tienen sus respuestas, pues no se podía saber el sesgo que contendrían sus valoraciones al responder qué se requiere en el ejercicio profesional, dado que es una realidad que aún no conocen. Solo podrían tener nociones aquellos que hubieran hecho prácticas preprofesionales. El problema era no poder saber si respondían en base a experiencias propias, suposiciones, o a que aún se encontraban cursando asignaturas y fuese un premio o un castigo a los docentes o contenidos, es decir, si pesaría más su incipiente experiencia de trabajo o su realidad académica actual. Por ello se dejó de lado la información tomada a los alumnos.

Se detallaron las competencias, se agruparon por las secciones y se elaboró el cuadro que se muestra en la Tabla 5.14: 


\section{Habilidad / Competencia Específica}

\section{Competencias Específicas de Formación Básica}

1.1 Capacidad para la resolución de los problemas matemáticos que puedan plantearse en la ingeniería

1.2 Comprensión y dominio de los conceptos básicos sobre las leyes generales de la mecánica, termodinámica, ondas y electromagnetismo y su aplicación para la resolución de problemas propios de la ingeniería

1.3 Capacidad para comprender y aplicar los principios básicos de la química general

1.4 Capacidad de visión espacial y conocimiento de las técnicas de representación gráfica, geometría métrica y geometría descriptiva

1.5 Capacidad de comprender y analizar escritos en idioma español

1.6 Capacidad de escribir y hablar con corrección en idioma español.

1.7 Capacidad de comunicarse empleando medios audiovisuales.

1.8 Comprende la naturaleza y realidad del hombre, y su desarrollo social.

1.9 Conoce los principios fundamentales que organizan y orientan el conocimiento de la realidad, así como el correcto obrar humano

1.10 Conoce a Dios, sus atributos y perfecciones a la luz de los principios de la razón y por verdades reveladas. Sabe aplicar este conocimiento a las acciones humanas.

1.11 Conoce y domina los métodos y técnicas de estudio apropiadas.

1.12 Capacidad de trabajar y comunicarse con corrección en un entorno multidisciplinar y multilingüe (sobre todo en español e inglés)

\section{Competencias específicas de operaciones}

2.1 Conocimientos de diseño y organización de plantas industriales, diseño y mejora de procesos productivos y de servicios, control estadístico de procesos y gestión de la calidad.

2.2 Comprensión y dominio de métodos cuantitativos, algoritmos, optimización, redes y grafos, teoría de colas, toma de decisiones, modelado, simulación y validación, en el ámbito de los sistemas industriales, económicos y sociales.

2.3 Comprensión y dominio de los sistemas de producción, la planificación y el control de la producción, la gestión de la cadena de suministro, la gestión de stocks, la gestión de mantenimiento.

2.4 Conocimientos de estudio del trabajo, métodos y tiempos.

2.5 Conocimientos aplicados de planificación estratégica

2.6 Comprensión y dominio de la gestión integrada de la calidad, seguridad, el medioambiente y la prevención de riesgos laborales.

2.7 Conocimientos básicos de la organización de los sistemas de producción y fabricación.

2.8 Conocimientos de cambio tecnológico y estrategia empresarial, innovación en la empresa, la competitividad industrial e innovación, los sistemas regionales y nacionales de innovación, la política tecnológica y patrones de innovación.

2.9 Conocimientos sobre planificación y desarrollo de nuevos productos y procesos

2.10 Conoce el tipo de trabajo a realizar en una empresa en el ámbito de la Ingeniería Industrial.

2.11 Capacidad de dirección de proyectos en Ing. Industrial

Tabla 5.14: Competencias específicas propuestas por el grupo planificador.

Fuente: Elaboración Propia 


\section{Habilidad / Competencia Específica}

2.12 Capacidad para la redacción, firma y desarrollo de proyectos vinculados a la Ingeniería Industrial

2.13 Conocimientos y capacidades para organizar y gestionar proyectos. Conoce la estructura organizativa y las funciones de una oficina de proyectos.

2.14 Capacidad de analizar y valorar el impacto medioambiental y social de las soluciones técnicas

\section{Competencias específicas administrativas}

3.1 Conocimiento adecuado del concepto de empresa, marco institucional y jurídico de la empresa. Organización y gestión de empresas.

3.2 Conocimientos de marketing y comercialización de productos y servicios.

3.3 Comprensión y dominio de la organización del trabajo y el factor humano, valoración de puestos de trabajo, conocimientos de derecho mercantil y laboral.

3.4 Comprensión y dominio de técnicas de gestión financiera y de costes, análisis de inversiones, estudios de viabilidad, finanzas, análisis de mercados.

3.5 Conocimientos de la empresa y el modelo microeconómico, la competitividad estratégica y estructura del mercado, el entorno y las políticas macroeconómicas.

3.6 Emprende y fomenta iniciativas empresariales

3.7 Tiene conocimientos aplicados de organización de empresas.

\section{Competencias específicas en sistemas}

4.1 Conocimientos básicos sobre el uso y programación de los ordenadores, sistemas operativos, bases de datos y programas informáticos con aplicación en ingeniería.

4.2 Conocimientos de sistemas de gestión para la organización y dirección de empresas, sistemas de información y gestión integrada ERP

4.3 Iniciativa para proponer ideas y alternativas innovadoras para la mejora de los sistemas productivos y organizativos

4.4 Conoce lenguajes de programación apropiados para la ejecución y control de procesos.

\section{Competencias específicas técnicas}

5.1 Conocimientos de termodinámica aplicada y transmisión de calor. Principios básicos y su aplicación a la resolución de problemas de ingeniería

5.2 Conocimientos de los principios básicos de la mecánica de fluidos y su aplicación a la resolución de problemas en el campo de la ingeniería. Cálculo de tuberías, canales y sistemas de fluidos.

5.3 Conocimiento de los fundamentos de ciencia, tecnología y química de materiales. Comprender la relación entre la microestructura, la síntesis o procesado y las propiedades de los materiales.

5.4 Conocimiento y utilización de los principios de teoría de circuitos y máquinas eléctricas.

5.5 Conocimientos de los fundamentos de la electrónica.

5.6 Conoce sobre fundamentos de automatismos y métodos de control

5.7 Conocimiento de los principios de teoría de máquinas y mecanismos.

5.8 Conocimientos básicos de los sistemas de producción y fabricación.

5.9 Conocimiento y utilización de los principios de resistencia de materiales

5.10 Conocimientos básicos y aplicación de tecnologías medioambientales y sostenibilidad

Tabla 5.14: Continuación... 
Se hizo una primera muestra del listado de competencias entre algunos profesores y egresados para ajustar posibles deficiencias en la ubicación de las competencias, o si se debía incluir, excluir o modificar alguna antes de hacer las encuestas. En esta fase se presentaron solo dos propuestas y ambas provinieron de profesores.

La primera provino de una ingeniera profesora de filosofía de la Facultad, con más de treinta años formando ingenieros, quien propuso modificar la competencia específica 1.8 "Comprende la naturaleza y realidad del hombre, y su desarrollo social" por el texto "Conoce la naturaleza del hombre y la raíz de su dignidad. Sabe ponerse en el lugar del otro (empatía) cuando dirige y planifica el trabajo de modo que contribuya al mejoramiento personal de los otros". Modificación que se estudió e incluyó en los textos de las encuestas enviadas.

También se recibió la sugerencia de incluir una competencia de parte de un joven profesor del área de operaciones quien sugería la inclusión una en el área de sistemas. La propuesta fue consultada con profesores del área e indicaron que ya estaba implícita en las mostradas por lo que no era necesario acceder a lo solicitado.

Se hicieron las modificaciones y se aplicaron las encuestas que se muestran en los Anexos F, G y H. Los resultados se muestran en los párrafos siguientes.

\subsubsection{Encuestas a egresados.}

La encuesta se realizó a egresados de Ingeniería Industrial de UDEP con no más de cinco años desde su egreso. En la Tabla 5.9 se mostraron las cantidades de egresados por año y semestre.

El universo de egresados entre 2007 II y 2012 I es de 300 personas. Dada la dispersión y dificultades de participación con este que este grupo de interés, hemos decidido optar por un muestreo no probabilístico por conveniencia. La confiabilidad de la aplicación de la encuesta se verificará empleando el Coeficiente Alpha de Cronbach.

La encuesta que se aplicó a mediados de 2012 a 41 de los 300 egresados entre los años 2007 y 2012 se puede revisar en el Anexo F. Los resultados fueron los que mostraremos en los párrafos siguientes.

A la cuestión situación laboral actual el 54\% de los egresados respondió que se encuentran trabajando en un puesto relacionado con sus estudios de Ingeniería Industrial, 41\% se encuentra trabajando en un puesto no relacionado con sus estudios y $5 \%$ de los encuestados respondieron que están ampliando sus estudios. Podemos afirmar que el 95\% de los egresados encuestados estaban trabajando en el momento de la encuesta, el 5\% restante ya lo habían hecho y estudiaba para escalar posiciones, Gráfico 5.27. 


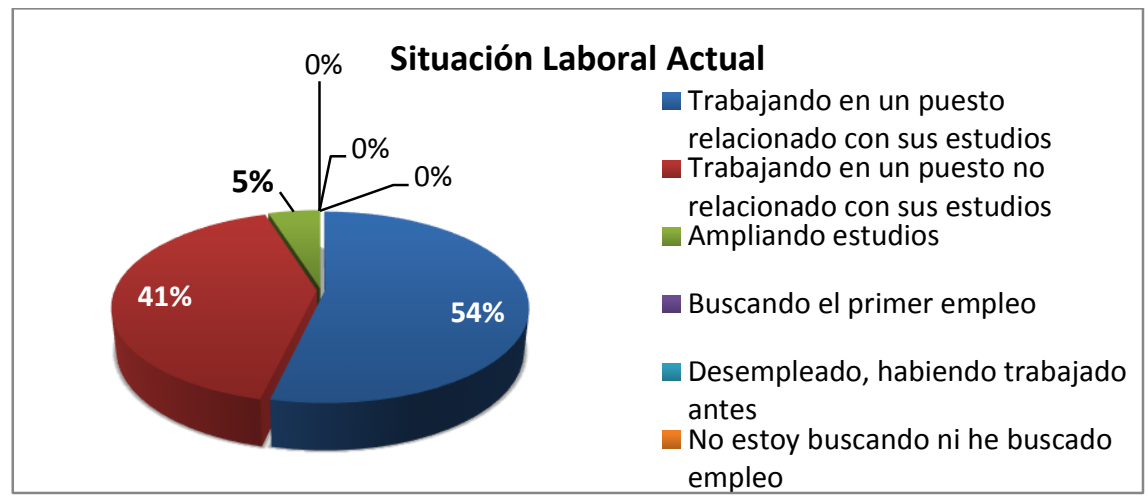

Gráfico 0.31 Situación laboral de egresados Fuente: Elaboración propia

Todos los encuestados debían conocer qué es una competencia específica para responder a las preguntas, esa era una condición filtro, por ello se les hizo conocer la definición y a la pregunta de si sabían qué era una competencia específica el resultado es que $100 \%$ de los datos evaluados afirmaban que lo sabían, Gráfico 5.28 .

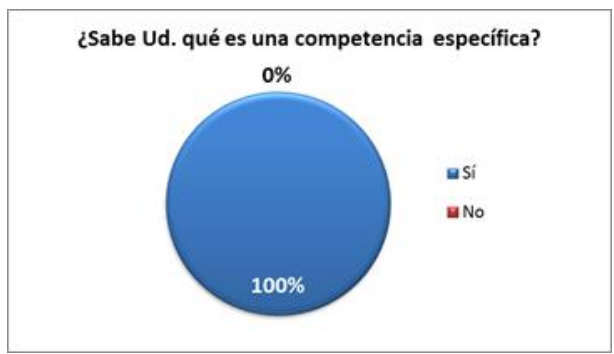

Gráfico 0.32 Egresados conocen el concepto de competencia específica Fuente: Elaboración propia

La encuesta indagó sobre la importancia que el encuestado consideraba tenía cada una de las competencias específicas diseñadas en la formación de ingenieros industriales de la UDEP. Esto debía contestarse en preguntas cerradas en una escala de 1 a 4 que indican nada, poco, bastante, mucho, respectivamente. También se preguntaba de manera abierta si consideraba que faltaba o si se debía eliminar alguna competencia y se pedía que la escribieran en los espacios dejados en blanco. Ninguno de los encuestados sugirió esto, ni modificaciones a las mostradas.

En el Gráfico 5.29 se muestra la valoración que los encuestados dan a la importancia de las competencias de Ciencias Básicas y en el Gráfico 5.30 el promedio de cada una.

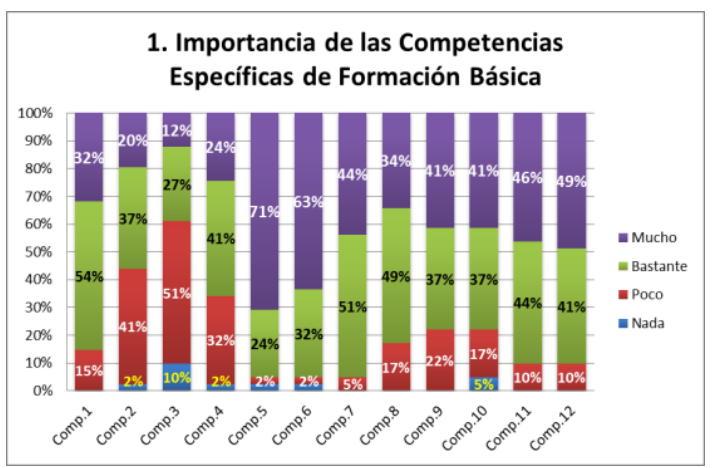

Gráfico 0.33 Importancia asignada por los egresados a las competencia específicas propuestas para Ciencias Básicas. Fuente: Elaboración propia 
En el Gráfico 5.30 se observa que la más baja es la 1.3 "Capacidad para comprender y aplicar los principios básicos de la química general", las mejor evaluadas son la 1.5 "Capacidad de comprender y analizar escritos en idioma español" y la 1.6 "Capacidad de escribiry hablar con corrección en idioma español”. En el Gráfico 5.29 se ve que solo la competencia 1.3 tiene un $10 \%$ de encuestados que creen que no tiene ninguna importancia. En los demás casos menos del 5\% de los encuestados piensa que alguna competencia no tiene ninguna importancia. La media de importancia asignada a este grupo e competencias específicas es 3.17 en una escala de uno a cuatro, asignándole los egresados a estas competencias específicas una calificación entre bastante y muy importante.

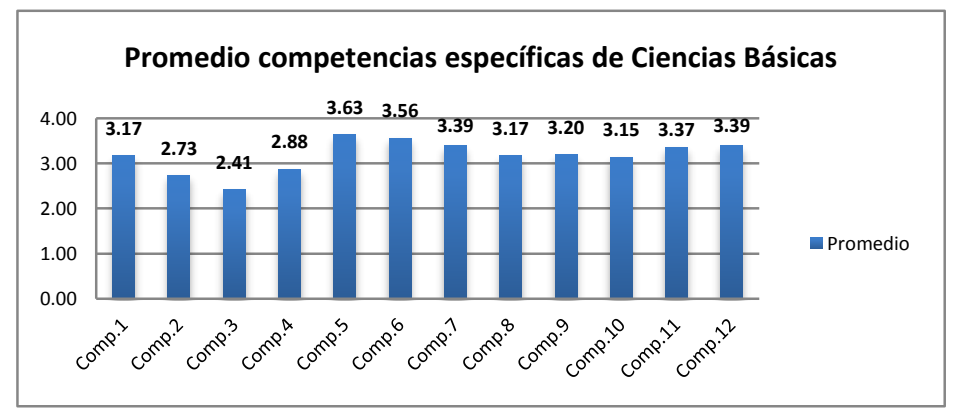

Gráfico 0.34 Promedio de la importancia asignada por los egresados a las competencias específicas propuestas para Ciencias Básicas. Fuente: Elaboración propia

En el Gráfico 5.31 se muestra la valoración que los egresados dan a la importancia de las competencias específicas propuestas para el Área de Operaciones y en el Gráfico 5.32 el promedio de cada una. En él se observa que consideran en todos los casos las competencias mostradas como muy o bastante importantes. Ninguna de estas competencias es evaluada por ningún egresado como nada importante.

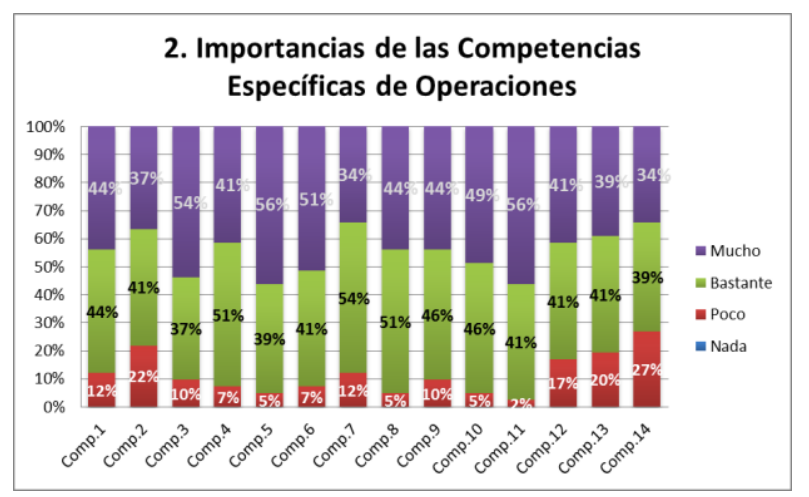

Gráfico 0.265 Importancia asignada por los egresados a las competencias específicas propuestas para Operaciones. Fuente: Elaboración propia

En el Gráfico 5.32 puede apreciarse que la más baja de las competencias es la 2.14 "Capacidad de analizary valorar el impacto medioambiental y social de las soluciones técnicas” y la más alta la 2.11 "Capacidad de dirección de proyectos en Ingeniería Industrial seguida de la 2.5 Conocimientos aplicados de planificación estratégica”. Los graduados valoran en media con 3.34 la importancia delas competencias de operaciones, asignándole la valoración entre bastante y muy importante a este grupo de competencias. 


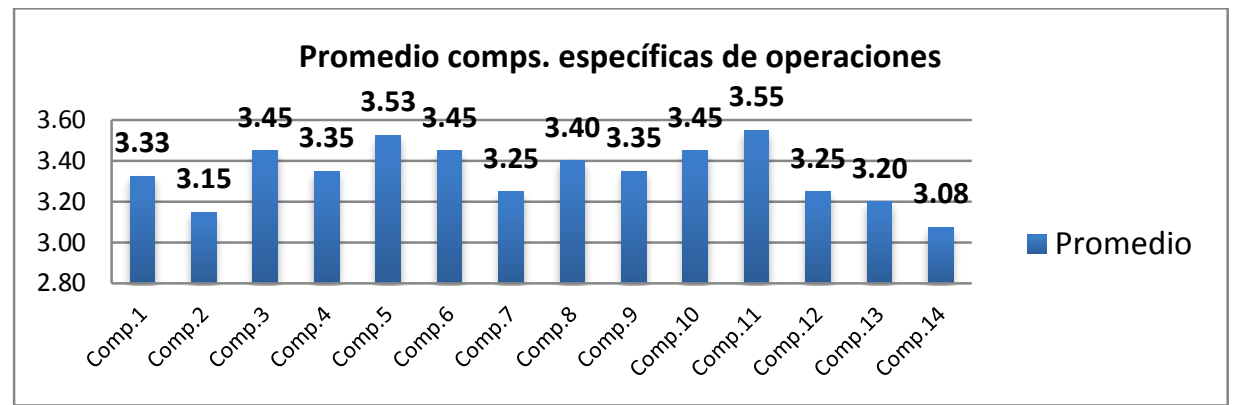

Gráfico 0.276 Promedio de la importancia asignada por los egresados a las competencia específicas propuestas para Operaciones. Fuente: Elaboración propia

En el Gráfico 5.33 se muestra la valoración que los egresados dan a la importancia de las competencias específicas propuestas para el Área de Administración y en el Gráfico 5.34 el promedio de cada una. En el primero se observa que en media son consideradas en un $83 \%$ como bastante o muy importantes. Solo la competencia 3.7 Tiene conocimientos aplicados de organización de empresas es considerada en un 7\% como nada importante y las demás tienen valoración de nada importantes en menos de $5 \%$.

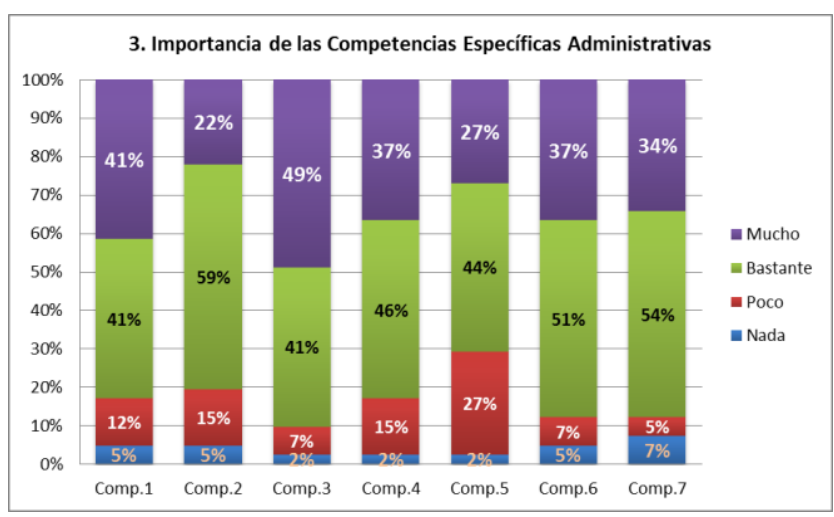

Gráfico 0.37 Importancia asignada por los egresados a las competencias específicas propuestas para área Administrativa. Fuente: Elaboración propia

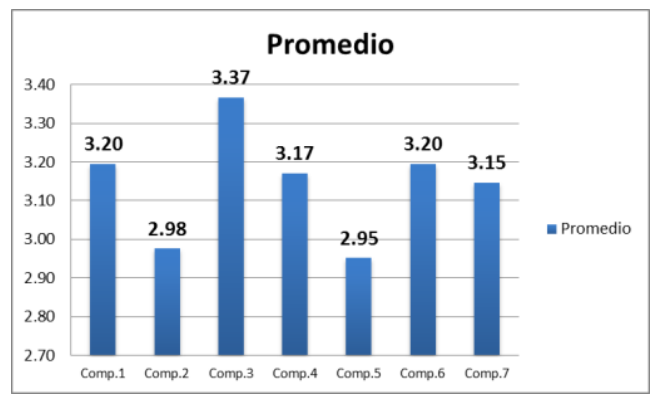

Gráfico 0.28 Promedio de la importancia asignada por los egresados a las competencias específicas propuestas para Administrativas. Fuente: Elaboración propia

En el Gráfico 5.34 puede apreciarse que la más baja importancia dada a una competencia de este bloque recae en la 3.5 Conocimientos de la empresa y el modelo microeconómico, la competitividad estratégica y estructura del mercado, el entorno y las políticas macroeconómicas. La más alta la 3.3 Comprensión y dominio de la organización del trabajo y el factor humano, valoración de puestos de trabajo, junto con la 3.6 Emprende y fomenta iniciativas empresariales y la 3.1 Conocimiento adecuado del 
concepto de empresa, marco institucional y juridico de la empresa. Organización y gestión de empresas. Los graduados valoran en media con 3.15 la importancia delas competencias administrativas, dándole al grupo la valoración una entre bastante y muy importante.

En el Gráfico 5.35 se muestra la valoración que los egresados dan a la importancia de las competencias específicas propuestas para el Área de Sistemas y en el Gráfico 5.36 el promedio de cada una. En el primero se observa que en media las tres primeras son consideradas como muy y bastante importantes por el $89.3 \%$ de los graduados y la competencia 4.4 es considerada como bastante o muy importantes por solo el 58\%. Solo la competencia 4.4 Conoce lenguajes de programación apropiados para la ejecución y control de procesos es considerada como nada importante por el $2 \%$ de egresados.

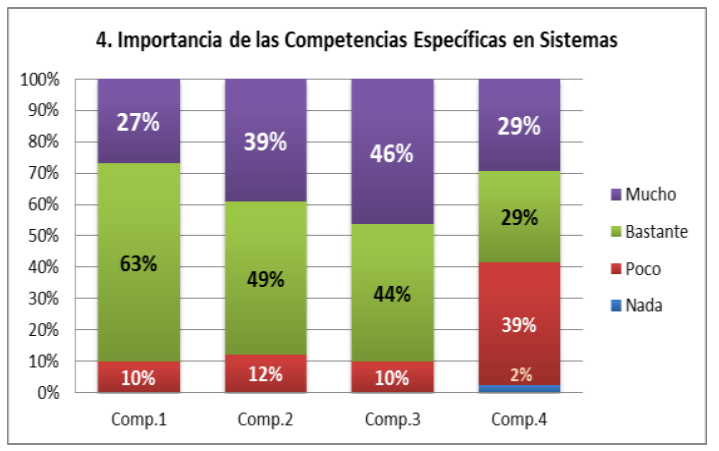

Gráfico 0.299 Importancia asignada por los egresados a las competencias específicas propuestas para el Ârea de Sistemas. Fuente: Elaboración propia

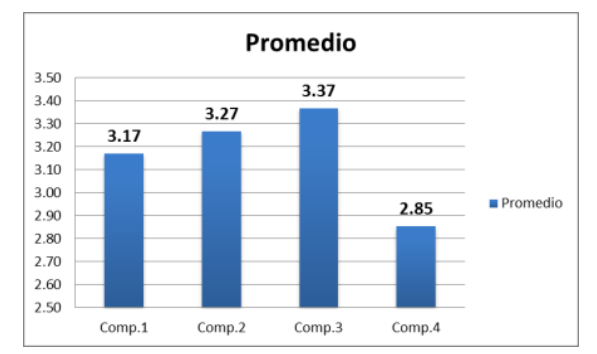

Gráfico 0.40 Promedio de la importancia asignada por los egresados a las competencias específicas propuestas para Sistemas. Fuente: Elaboración propia

En el Gráfico 5.36 se ve que la más baja importancia dada a una competencia de Sistemas recae en la 4.4 Conoce lenguajes de programación apropiados para la ejecución y control de procesos y la más alta la 4.3 Iniciativa para proponer ideas y alternativas innovadoras para la mejora de los sistemas productivos y organizativos, junto con la 4.2 Conocimientos de sistemas de gestión para la organización y dirección de empresas, sistemas de información y gestión integrada ERP. Los graduados valoran en media con 3.165 la importancia delas competencias de Sistemas asignándole así al grupo una valoración entre muy y bastante importante como a los anteriores.

En el Gráfico 5.37 se muestra la valoración que los egresados dan a la importancia de las competencias específicas propuestas para el Área de Técnicas de Ingeniería y en el Gráfico 5.38 el promedio de cada una. En el primero se observa que en media las competencias son percibidas como muy o bastante importantes en un $58.2 \%$, por el $41.8 \%$ de los encuestados son valoradas como poco o nada importantes. Son consideradas como nada importantes, por el $12 \%$ de los graduados la 5.7 Conocimiento de los principios de teoría de máquinas y mecanismos y 
por el $10 \%$ las competencias 5.4 y 5.5 Conocimiento y utilización de los principios de teoría de circuitos y máquinas eléctricas y Conocimientos de los fundamentos de la electrónica.

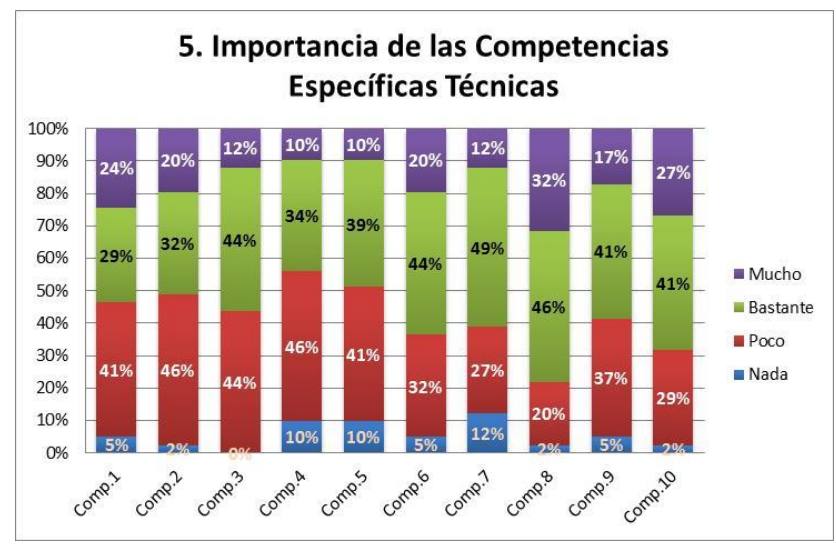

Gráfico 0.41 Importancia asignada por los egresados a las competencia específicas propuestas para los cursos Técnicos de Ingeniería. Fuente: Elaboración propia

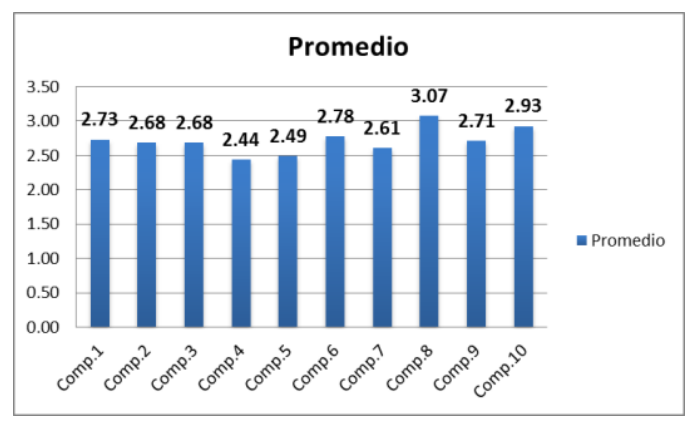

Gráfico 0.30 Promedio de la importancia asignada por los egresados a las competencias específicas propuestas para Técnica. Fuente: Elaboración propia

Puede afirmarse del Gráfico 5.38 que la más baja importancia dada a una competencia del Área Técnica recae en la 5.4 Conocimiento y utilización de los principios de teoría de circuitos y máquinas eléctricas y la más, alta la 5.8 Conocimientos básicos de los sistemas de producción y fabricación seguida de la 5.10 Conocimientos básicos y aplicación de tecnologías medioambientales y sostenibilidad. Los graduados valoran en media con 2.71 la importancia de las competencias del Área Técnica asignándole al grupo una calificación entre poco y bastante importante.

Para conocer la confiabilidad de la encuesta aplicada a los graduados para medir la importancia asignada a las competencias específicas, se calculó la varianza de cada competencia y se sumaron estas varianzas hallándose que $\sum S_{i}{ }^{2}=25.13$ y al calcular la varianza de las sumas de los puntajes asignados por ítem se encontró que la varianza total era $S_{t o t}{ }^{2}=161.72$. Con estos dos valores se calcula el Coeficiente de Cronbach en la ecuación Ec. 5.2 y se obtiene:

$$
\propto=\left(\frac{47}{47-1}\right) \cdot\left(1-\frac{25.13}{161.72}\right)=0.86
$$

Con valor de Alpha de Cronbach podemos afirmar que los resultados de las encuestas sobre competencias específicas realizadas a los graduados tienen buena consistencia interna pues los valores son superiores a 0,8 , por lo que son confiables en un buen nivel, según la Tabla 5.8. 


\subsubsection{Encuestas a profesores.}

La encuesta se realizó al universo de profesores de tiempo completo involucrados en la formación de los estudiantes de Ingeniería Industrial de UDEP, que se desempeñan en asignaturas desde el primer semestre al último de esa carrera y ejercieron la docencia durante el semestre $2012 \mathrm{I}$.

El total de profesores en ese momento era 27 y respondieron a la encuesta 22 . Los que no participaron fue porque por distintas razones.

El método usado fue un muestreo no probabilístico por conveniencia dada la dificultad de llegar al total de la población y al bajo número de individuos de la población, menor de treinta. Dado el porcentaje encuestado, 81.5\%, y la condición de homogeneidad de la población (todos profesores de una misma universidad, trabajando a tiempo completo en una misma carrera) los resultados podrán considerarse representativos del universo. Se verificará la confiabilidad del instrumento aplicando el Coeficiente de Cronbach.

Todos los profesores encuestados debían conocer qué es una competencia específica para responder a las preguntas, esa era una condición filtro, por ello se les hizo conocer la definición y a la pregunta de si sabían qué era una competencia específica el resultado es que 100\% de los datos evaluados afirmaban que lo sabían, Gráfico 5.39.

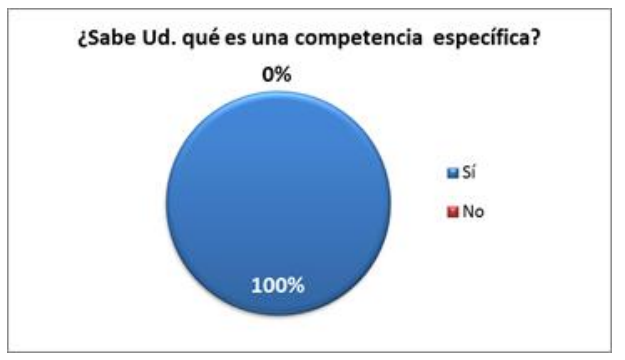

Gráfico 0.4331 Profesores conocen el concepto de competencia específica Fuente: Elaboración propia

La encuesta indagó sobre la importancia que cada profesor consideraba tenía cada una de las competencias específicas diseñadas en la formación de ingenieros industriales de la UDEP. Esto debía contestarse en preguntas cerradas en una escala de 1 a 4 que indican nada, poco, bastante, mucho, respectivamente. También se preguntaba de manera abierta si consideraba que faltaba o si se debía eliminar alguna competencia y se pedía que la escribieran en los espacios dejados en blanco. Ninguno de los encuestados sugirió esto, ni modificaciones a las mostradas.

En el Gráfico 5.40 se muestra la valoración que los encuestados dan a la importancia de las competencias de Ciencias Básicas y en el Gráfico 5.41 el promedio de cada una. El 91.5\% de los profesores califican, en media, estas competencias como bastante o muy importantes. Solo las competencias 1.2 y 1.3 son consideradas como nada importantes por un $5 \%$ de los docentes: 1.3 Capacidad para comprender y aplicar los principios básicos de la química general y 1.2 Comprensión y dominio de los conceptos básicos sobre las leyes generales de la mecánica, termodinámica, ondas y electromagnetismo y su aplicación para la resolución de problemas propios de la ingeniería. 


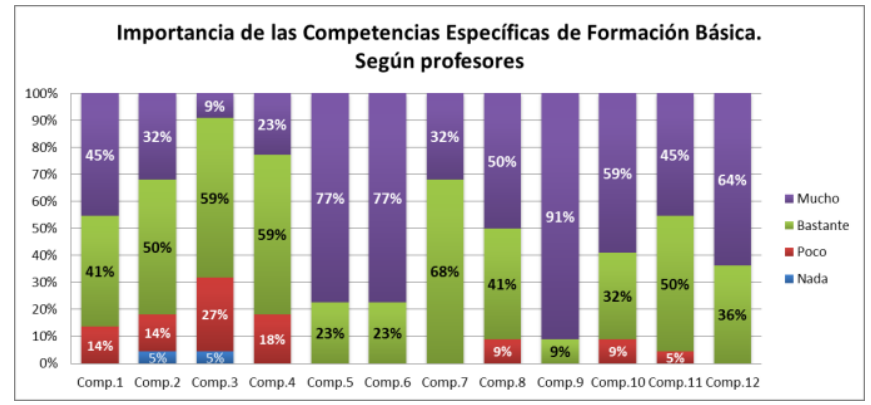

Gráfico 0.44 Importancia asignada por los profesores a las competencias específicas propuestas para Ciencias Básicas. Fuente: Elaboración propia

En el Gráfico 5.41 se observa que la más baja es la 1.3 "Capacidad para comprender y aplicar los principios básicos de la química general”, las mejor evaluadas son la 1.9 Conoce los principios fundamentales que organizan y orientan el conocimiento de la realidad, asi como el correcto obrar bumano, junto con la 1.5 "Capacidad de comprender y analizar escritos en idioma español" y la 1.6 “Capacidad de escribiry hablar con corrección en idioma español”. La media de importancia asignada a este grupo e competencias específicas es 3.41 en una escala de uno a cuatro, asignándole los egresados a estas competencias específicas una calificación entre bastante y muy importantes.

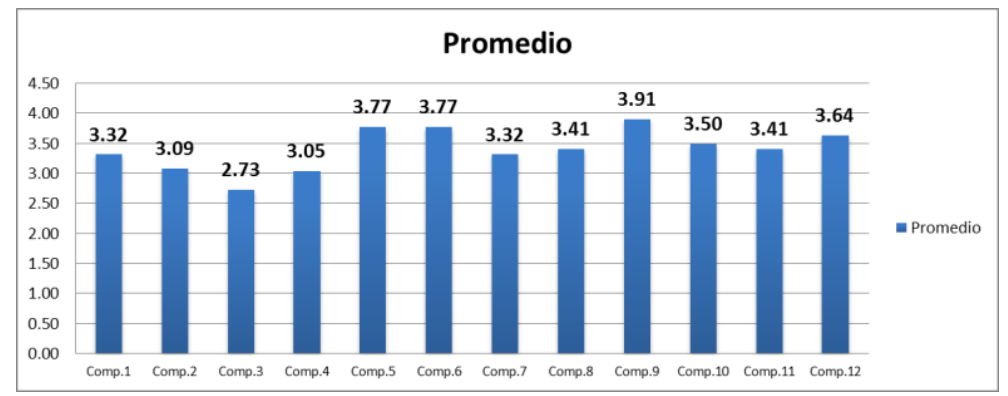

Gráfico 0.45 Promedio de la importancia asignada por los profesores a las competencias específicas propuestas para Ciencias Básicas. Fuente: Elaboración propia

En el Gráfico 5.42 se muestra la valoración que los profesores dan a la importancia de las competencias específicas propuestas para el Área de Operaciones y en el Gráfico 5.43 el promedio de cada una. Se observa que ninguna competencia ha sido evaluada como nada importante y la media de evaluación entre bastante y muy importante para este grupo de competencias es $93.7 \%$.

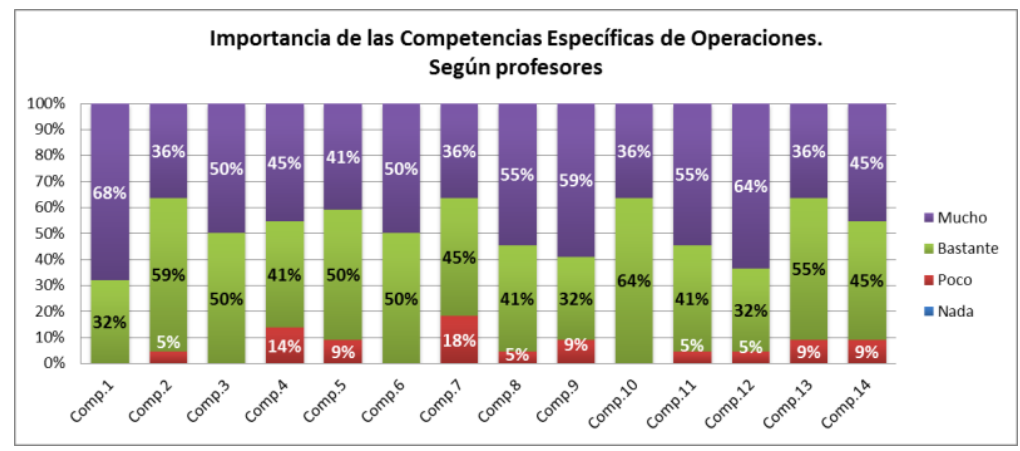

Gráfico 0.46 Importancia asignada por los profesores a las competencias específicas propuestas para Operaciones. Fuente: Elaboración propia 
En el Gráfico 5.43 puede apreciarse que la más baja de las competencias es la 2.7 "Conocimientos básicos de la organización de los sistemas de producción y fabricación” y la más alta la 2.1 "Conocimientos de diseño y organización de plantas industriales, diseño y mejora de procesos productivos y de servicios, control estadístico de procesos y gestión de la calidad”. Los profesores valoran en media con 3.42 la importancia de las competencias de operaciones, asignándole la valoración entre bastante y muy importante a este grupo de competencias.

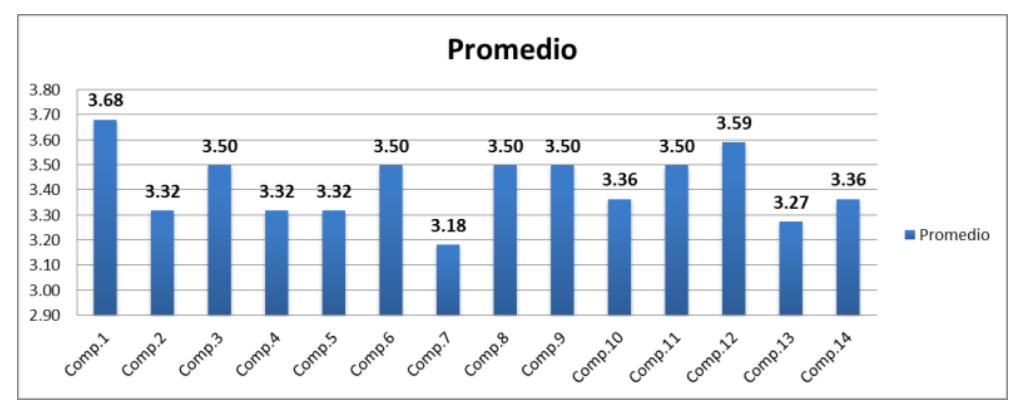

Gráfico 0.47 Promedio de la importancia asignada por los profesores a las competencias específicas propuestas para Operaciones. Fuente: Elaboración propia

En el Gráfico 5.44 se muestra la valoración que los profesores dan a la importancia de las competencias específicas propuestas para el Área de Administración y en el Gráfico 5.45 el promedio de cada una. En el primero se observa que en media son consideradas en un $79.7 \%$ como bastante o muy importantes. Ninguna es considerada nada importante por los profesores.

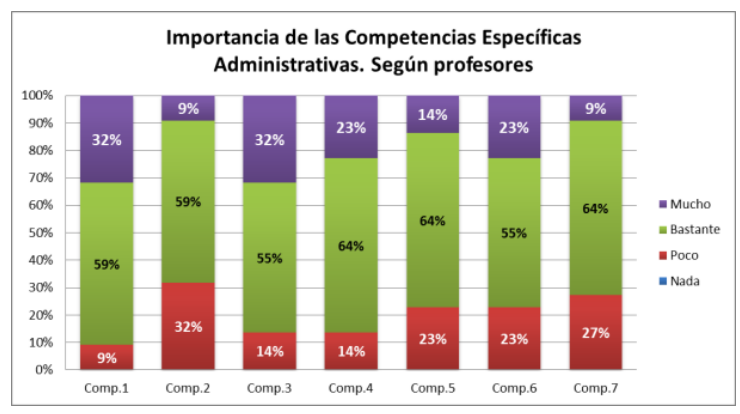

Gráfico 0.48 Importancia asignada por los profesores a las competencias específicas propuestas para área Administrativa. Fuente: Elaboración propia

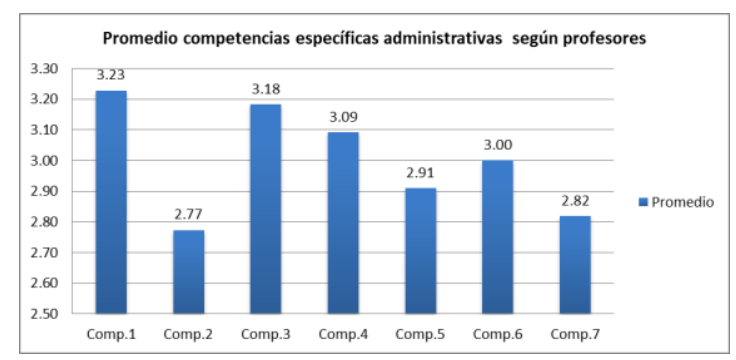

Gráfico 0.329 Promedio de la importancia asignada por los profesores a las competencias específicas propuestas para Administrativas. Fuente: Elaboración propia

En el Gráfico 5.45 puede apreciarse que la más baja importancia dada a una competencia de este bloque recae en la 3.2 Conocimientos de marketing y comercialización de productos y servicios. La más alta la 3.1 Conocimiento adecuado del concepto de empresa, marco institucional y jurídico de la empresa. Organización y gestión de empresas, seguida de la 3.3 Comprensión y dominio de la organización del trabajo 
y el factor humano, valoración de puestos de trabajo. Los profesores valoran en media con 3.00 la importancia delas competencias administrativas, dándole al grupo la valoración de bastante importante.

En el Gráfico 5.46 se muestra la valoración que los profesores dan a la importancia de las competencias específicas propuestas para el Área de Sistemas y en el Gráfico 5.47 el promedio de cada una. En el primero se observa que en media las tres primeras son consideradas como muy y bastante importantes por el $92.3 \%$ de los profesores y la competencia 4.4 es considerada como bastante o muy importantes por solo el $45 \%$. Ninguna de estas competencias es considerada como nada importante.

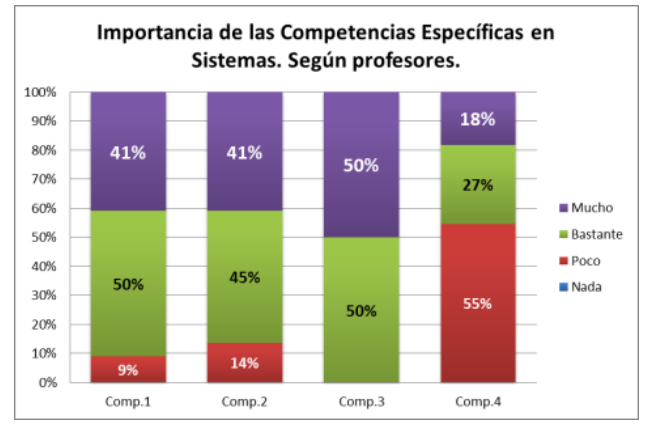

Gráfico 0.50 Importancia asignada por los profesores a las competencias específicas propuestas para el Área de Sistemas. Fuente: Elaboración propia

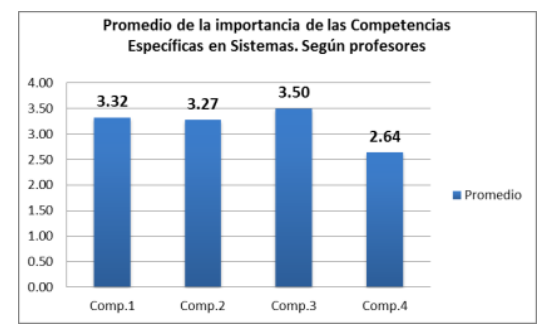

Gráfico 0.331 Promedio de la importancia asignada por los profesores a las competencias específicas propuestas para Sistemas. Fuente: Elaboración propia

En el Gráfico 5.4 se ve que la más baja importancia dada a una competencia de Sistemas recae en la 4.4 Conoce lenguajes de programación apropiados para la ejecución y control de procesos y la más alta la 4.3 Iniciativa para proponer ideas y alternativas innovadoras para la mejora de los sistemas productivos y organizativos. Los profesores valoran en media con 3.18 la importancia delas competencias de Sistemas asignándole así al grupo una valoración entre muy y bastante importante como a los anteriores.

En el Gráfico 5.48 se muestra la valoración que los profesores dan a la importancia de las competencias específicas propuestas para el Área de Técnicas de Ingeniería y en el Gráfico 5.49 el promedio de cada una. En el primero se observa que en media las competencias son percibidas como muy o bastante importantes en un $52.9 \%$, en consecuencia el $47.1 \%$ de los encuestados las valora como poco o nada importantes. Son consideradas como nada importantes, por el 5\% de los profesores la 5.1, 5.2, 5.3, 5.7 y 5.9. Es importante señalar que la 
competencia 5.9 Conocimiento y utilización de los principios de resistencia de materiales fue considera como bastante o muy importante por el $91 \%$ de los profesores.

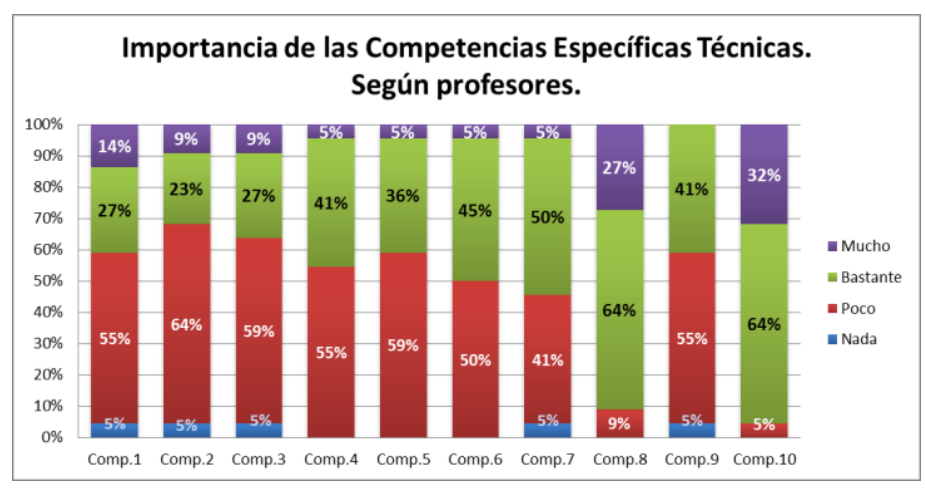

Gráfico 0.5234 Importancia asignada por los profesores a las competencias específicas propuestas para los cursos Técnicos de Ingeniería. Fuente: Elaboración propia

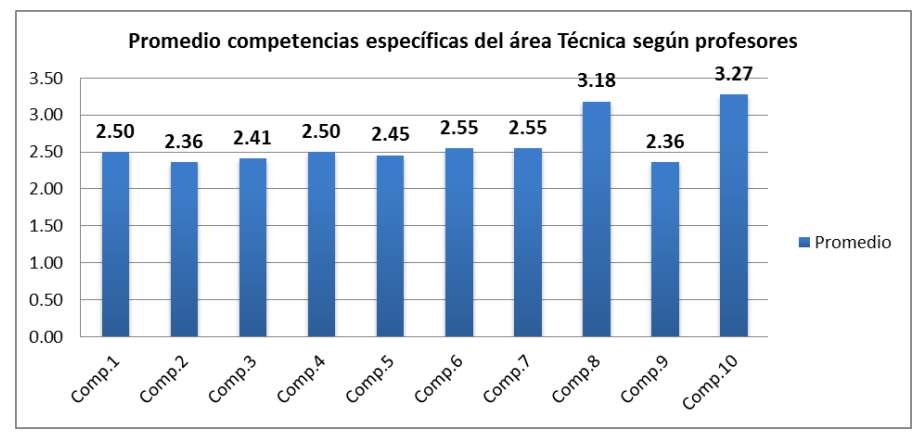

Gráfico 0.35 Promedio de la importancia asignada por los profesores a las competencias específicas propuestas para Técnica. Fuente: Elaboración propia

Puede afirmarse del Gráfico 5.49 que a las competencias del Área Técnica se les da una importancia cercana o inferior a 2.5 excepto en dos casos que son los de mayor valoración: la competencia la 5.10 Conocimientos básicos y aplicación de tecnologías medioambientales y sostenibilidad y la 5.8 Conocimientos básicos de los sistemas de producción y fabricación Los profesores valoran en media con 2.61 la importancia de las competencias del Área Técnica asignándole al grupo una calificación entre poco y bastante importante.

Para conocer la confiabilidad de la encuesta aplicada a los profesores para medir la importancia asignada a las competencias específicas, se calculó la varianza de cada competencia y se sumaron estas varianzas hallándose que $\sum S_{i}{ }^{2}=17.33$ y al calcular la varianza de las sumas de los puntajes asignados por ítem se encontró que la varianza total era $S_{t o t}{ }^{2}=82.41$. Con estos dos valores se calcula el Coeficiente de Cronbach en la ecuación Ec. 5.2 y se obtiene:

$$
\propto=\left(\frac{47}{47-1}\right) \cdot\left(1-\frac{17.33}{82.41}\right)=0.81
$$

Con valor de Alpha de Cronbach podemos afirmar que los resultados de las encuestas sobre competencias específicas realizadas a los graduados tienen buena consistencia interna pues los valores son superiores a 0,8 , por lo que son confiables en un buen nivel, según la Tabla 5.8. 


\subsubsection{Encuestas a empleadores.}

El tercer grupo de interés en la formación de Ingeniería Industrial de la UDEP lo conforman los empleadores. Se pudo encuestar a jefes de recursos humanos de 11 empresas que hubieran tenido y conserven egresados de Ingeniería Industrial de la UDEP entre sus trabajadores, esta era una condición filtro.

El método a usar es de muestreo no probabilístico por conveniencia dada la dificultad de llegar al total de la población y porque era conveniente elegir a las empresas que sabíamos conocen a nuestros egresados. Ya que no existe alternativa de muestreo pues solo puede encuestarse a los empleadores que están accesibles y disponibles, se eligen los individuos de manera no aleatoria sabiendo que puede aplicarse solo en casos en los que no existe otra alternativa (Casal, J. et al; 2003). La distribución fue 36\% empresas de manufactura y 64\% de servicios. 45\% de la Región Piura, $45 \%$ de ámbito nacional y una transnacional. Se verificará la confiabilidad del instrumento aplicando el Coeficiente de Cronbach.

La encuesta aplicada se puede ver en el Anexo H.

Todos los empleadores encuestados debían conocer qué es una competencia específica para responder a las preguntas, esa era una condición filtro, por ello se les hizo conocer la definición y a la pregunta de si sabían qué era una competencia específica el resultado es que $100 \%$ de los datos evaluados afirmaban que lo sabían, Gráfico 5.50. También todos respondieron que sí trabajan o han trabajado con Ingenieros industriales de la UDEP.

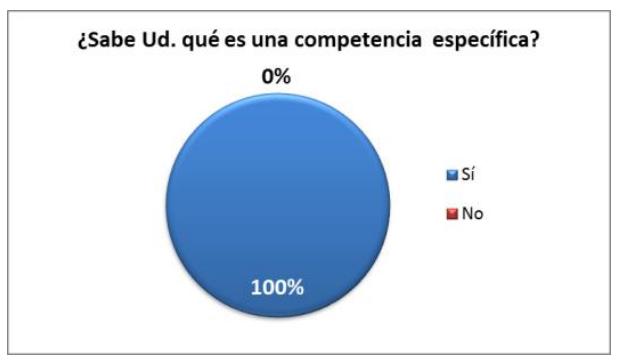

Gráfico 0.54 Empleadores conocen el concepto de competencia específica Fuente: Elaboración propia

La encuesta indagó sobre la importancia que cada empleador consideraba tenía cada una de las competencias específicas diseñadas en la formación de ingenieros industriales de la UDEP. Esto debía contestarse en preguntas cerradas en una escala de 1 a 4 que indican nada, poco, bastante, mucho, respectivamente. También se preguntaba de manera abierta si consideraba que faltaba o si se debía eliminar alguna competencia y se pedía que la escribieran en los espacios dejados en blanco. Ninguno de los encuestados sugirió esto, ni modificaciones a las mostradas.

En el Gráfico 5.51 se muestra la valoración que los encuestados dan a la importancia de las competencias de Ciencias Básicas y en el Gráfico 5.52 el promedio de cada una. El 80.9\% de los empleadores califican, en media, estas competencias como bastante o muy importantes. Solo las competencias 1.10 y 1.3 son consideradas como nada importantes por un $18 \%$ y $9 \%$ de los empleadores respectivamente: 1.10 Conoce a Dios, sus atributos y perfecciones a la luz de los 
principios de la razón y por verdades reveladas. Sabe aplicar este conocimiento a las acciones humanas y 1.3 Capacidad para comprender y aplicar los principios básicos de la química general.

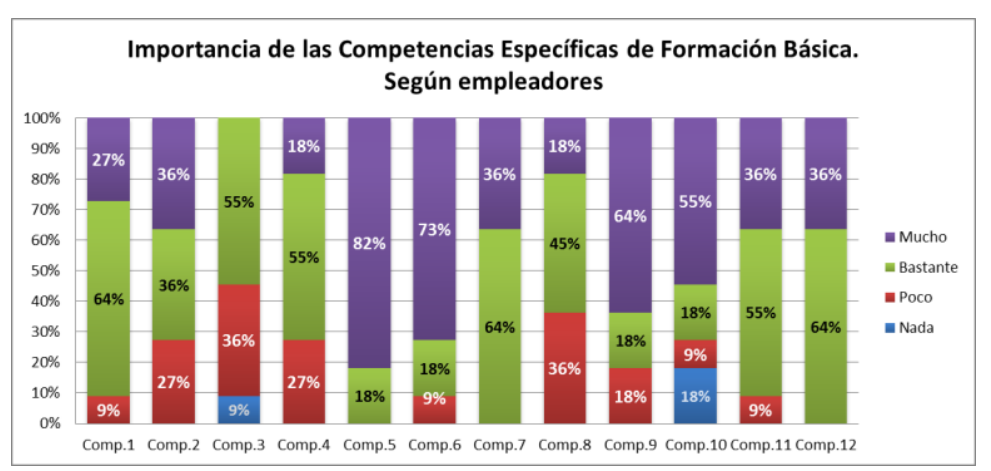

Gráfico 0.365 Importancia asignada por los empleadores a las competencias específicas propuestas para Ciencias Básicas. Fuente: Elaboración propia

En el Gráfico 5.52 se observa que la más baja es la 1.3 "Capacidad para comprender y aplicar los principios básicos de la química general", las mejor evaluadas son la 1.5 "Capacidad de comprender y analizar escritos en idioma español" y la 1.6 "Capacidad de escribiry hablar con corrección en idioma español". La media de importancia asignada a este grupo e competencias específicas es 3.2 en una escala de uno a cuatro, asignándole los empleadores a estas competencias específicas una calificación entre bastante y muy importantes.

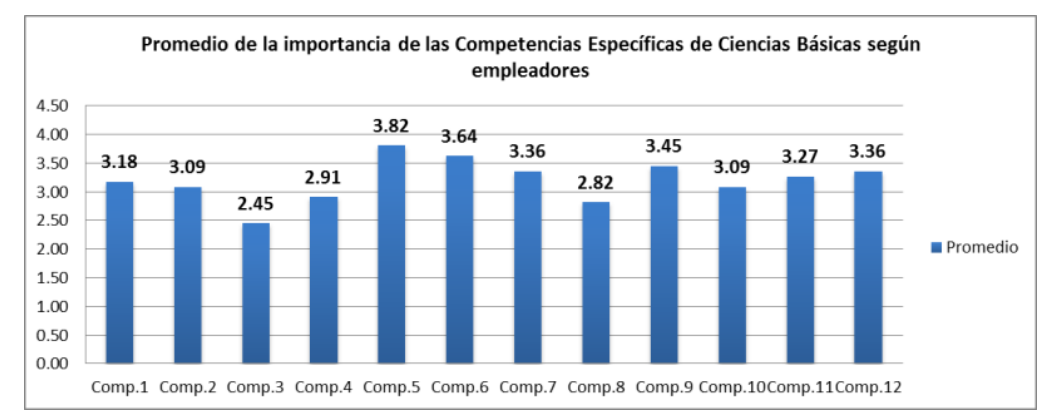

Gráfico 0.376 Promedio de la importancia asignada por los empleadores a las competencias específicas propuestas para Ciencias Básicas. Fuente: Elaboración propia

En el Gráfico 5.53 se muestra la valoración que los empleadores dan a la importancia de las competencias específicas propuestas para el Área de Operaciones y en el Gráfico 5.54 el promedio de cada una. Se observa que ninguna competencia ha sido evaluada como nada importante y la media de evaluación entre bastante y muy importante para este grupo de competencias es $85.86 \%$. Las competencias específicas 2.6 y 2.10 fueron evaluadas por el $100 \%$ de empleadores como muy o bastante importante: 2.6 Comprensión y dominio de la gestión integrada de la calidad, seguridad, el medioambiente y la prevención de riesgos laborales, 2.10 Conoce el tipo de trabajo a realizar en una empresa en el ámbito de la Ingeniería Industrial. 


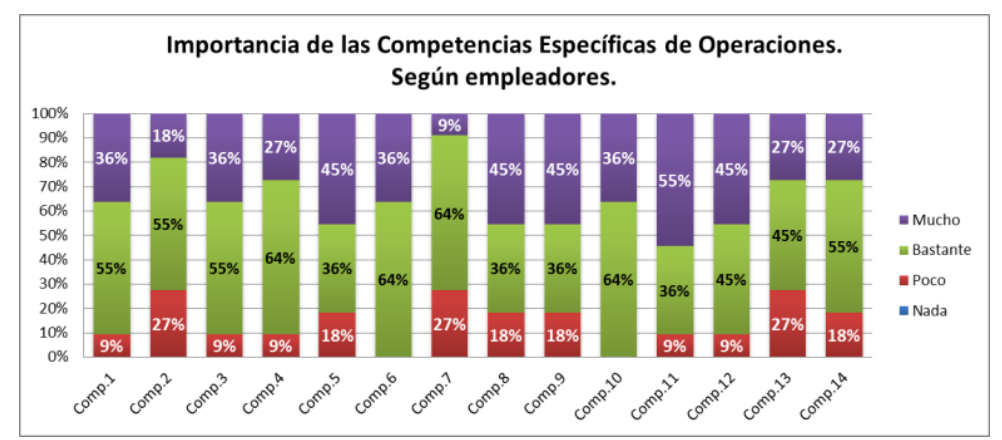

Gráfico 0.387 Importancia asignada por los empleadores a las competencias específicas propuestas para Operaciones. Fuente: Elaboración propia

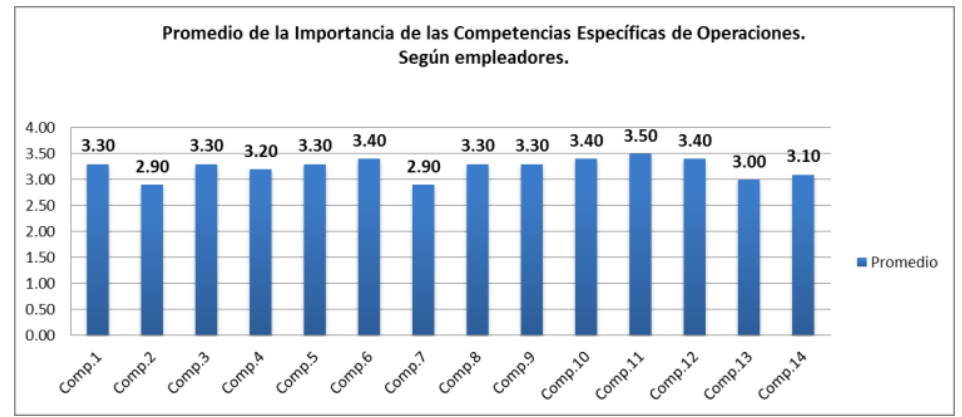

Gráfico 0.398 Promedio de la importancia asignada por los empleadores a las competencias específicas propuestas para Operaciones. Fuente: Elaboración propia

En el Gráfico 5.54 puede apreciarse que la más baja de las competencias es la 2.7 "Conocimientos básicos de la organización de los sistemas de producción y fabricación” junto con la 2.9 "Conocimientos sobre planificación y desarrollo de nuevos productos y procesos". La mejor evaluada la 2.11 "Capacidad de dirección de proyectos en Ing. Industrial". Los empleadores valoran en media con 3.24 la importancia de las competencias de operaciones, asignándole la valoración entre bastante y muy importante a este grupo de competencias.

En el Gráfico 5.55 se muestra la valoración que los empleadores dan a la importancia de las competencias específicas propuestas para el Área de Administración y en el Gráfico 5.56 el promedio de cada una. En el primero se observa que en media son consideradas en un $80.71 \%$ como bastante o muy importantes. El 19.29\% de los empleadores considera poco o nada importante estas competencias.

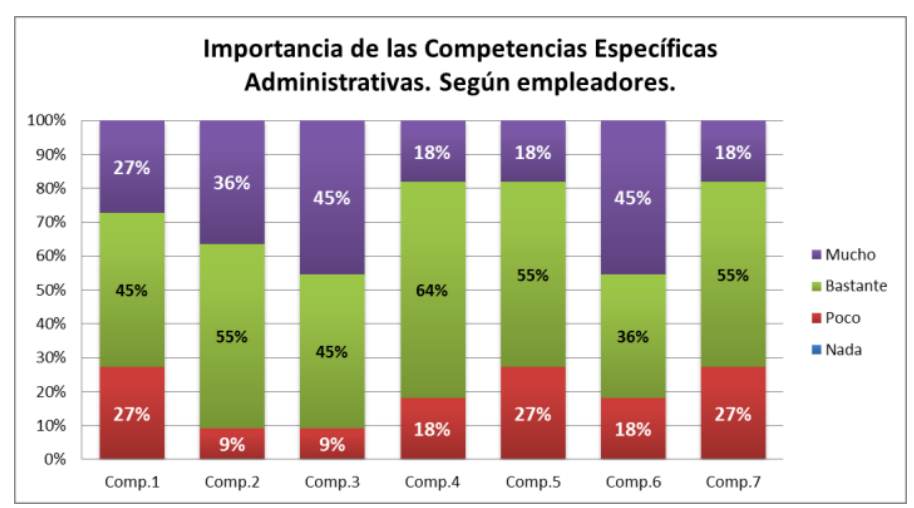

Gráfico 0.409 Importancia asignada por los empleadores a las competencias específicas propuestas para área Administrativa. Fuente: Elaboración propia 


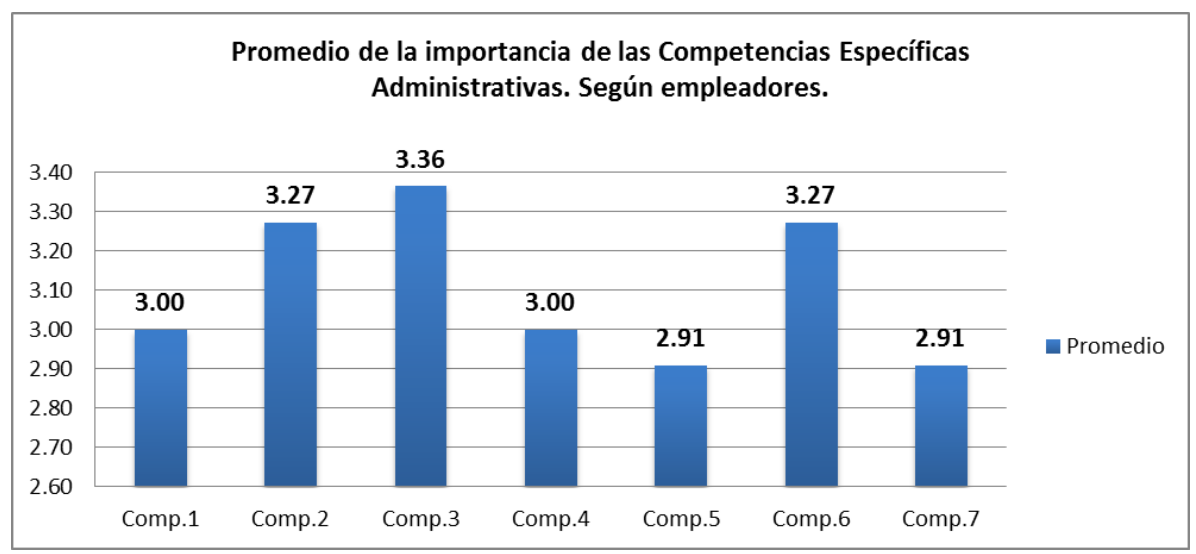

Gráfico 0.60 Promedio de la importancia asignada por los empleadores a las competencia específicas propuestas para Administrativas. Fuente: Elaboración propia

En el Gráfico 5.56 puede apreciarse que la más baja importancia dada a una competencia de este bloque recae en las competencias 3.5 y 3.7 con 2.91 puntos de 4 en media, 3.5 "Conocimientos de la empresa y el modelo microeconómico, la competitividad estratégica y estructura del mercado, el entorno y las políticas macroeconómicas" y 3.7 "Tiene conocimientos aplicados de organización de empresas". La más alta la 3.3 Comprensión y dominio de la organización del trabajo y el factor humano, valoración de puestos de trabajo. Los empleadores valoran en media con 3.1 la importancia delas competencias administrativas, dándole al grupo la valoración entre bastante y muy importante.

En el Gráfico 5.57 se muestra la valoración que los profesores dan a la importancia de las competencias específicas propuestas para el Área de Sistemas y en el Gráfico 5.58 el promedio de cada una. En el primero se observa que en media las tres primeras son consideradas como muy y bastante importantes por el $79 \%$ de los empleadores y la competencia 4.4 es considerada como bastante o muy importantes por solo el 45\%. Ninguna de estas competencias es considerada como nada importante.

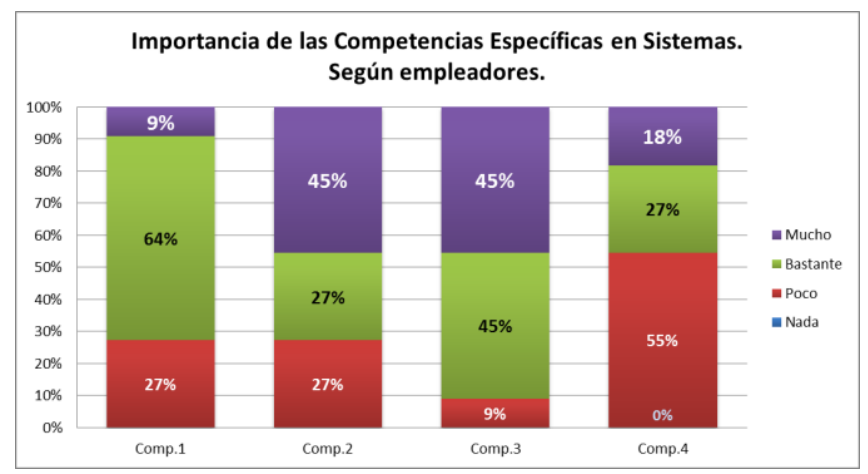

Gráfico 0.411 Importancia asignada por los empleadores a las competencias específicas propuestas para el Área de Sistemas. Fuente: Elaboración propia

En el Gráfico 5.58 se ve que la más baja importancia dada a una competencia de Sistemas recae en la 4.4 Conoce lenguajes de programación apropiados para la ejecución y control de procesos y la más 
alta la 4.3 Iniciativa para proponer ideas y alternativas innovadoras para la mejora de los sistemas productivos y organizativos. Los empleadores valoran en media con 3.00 la importancia delas competencias de Sistemas asignándole así al grupo una valoración de bastante importante.

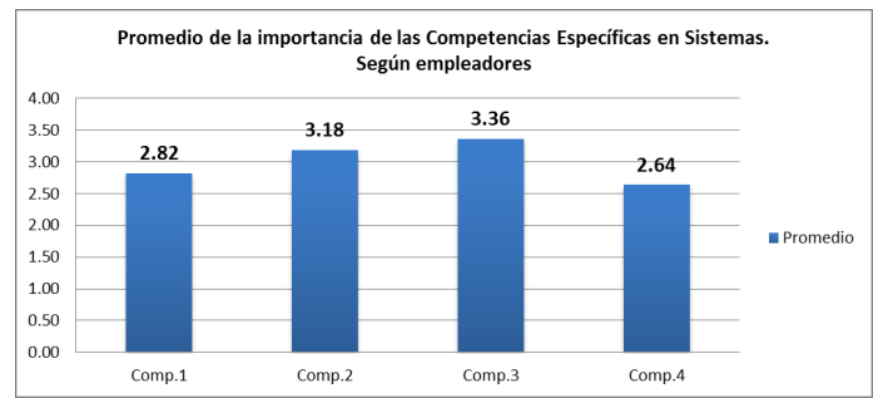

Gráfico 0.42 Promedio de la importancia asignada por los empleadores a las competencias específicas propuestas para Sistemas. Fuente: Elaboración propia

En el Gráfico 5.59 se muestra la valoración que los empleadores dan a la importancia de las competencias específicas propuestas para el Área de Técnicas de Ingeniería y en el Gráfico 5.60 el promedio de cada una. En el primero se observa que en media las competencias son percibidas como muy o bastante importantes en un 55\%, en consecuencia el $45 \%$ de los encuestados las valora como poco o nada importantes. Son consideradas como nada importantes, por el 9\% de los empleadores la 5.1, y 5.4. Es importante señalar que el $91 \%$ de los empleadores considera que la competencia 5.10 es muy o basta importante, 5.10 "Conocimientos básicos y aplicación de tecnologías medioambientales y sostenibilidad".

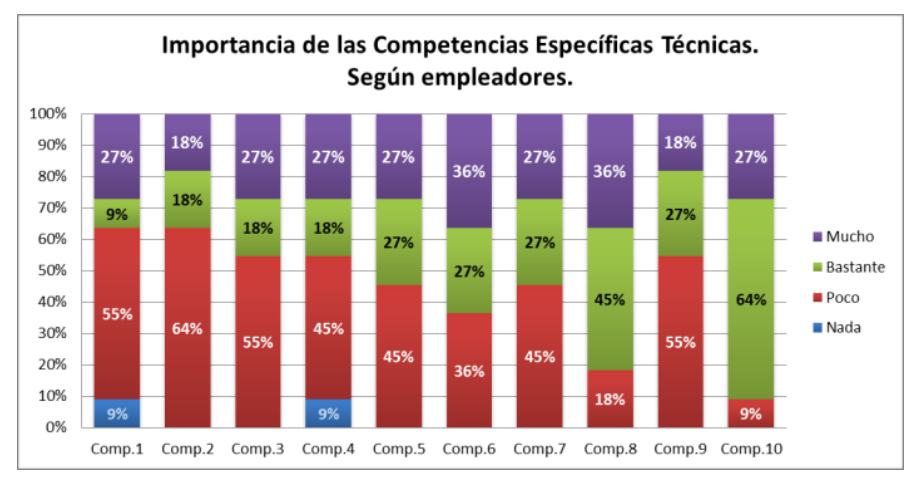

Gráfico 0.63 Importancia asignada por los empleadores a las competencias específicas propuestas para los cursos Técnicos de Ingeniería. Fuente: Elaboración propia

Puede afirmarse del Gráfico 5.60 que entre las competencias del Área Técnicas de la Ingeniería se les da una menor importancia, con 2.55, a las competencias 5.1 y 5.2, 5.1 "Conocimientos de termodinámica aplicada y transmisión de calor. Principios básicos y su aplicación a la resolución de problemas de ingeniería" y 5.2 "Conocimientos de los principios básicos de la mecánica de fluidos y su aplicación a la resolución de problemas en el campo de la ingeniería. Cálculo de tuberías, canales y sistemas de fluidos". Las competencias técnicas mejor evaluadas fueron la 5.10 y la 5.8. La 5.10 es "Conocimientos básicos y aplicación de tecnologías medioambientales y sostenibilidad" y la 5.8 "Conocimientos básicos de los sistemas de producción y fabricación”. Los empleadores valoran en 
media con 2.81 la importancia de las competencias del Área Técnica asignándole al grupo una calificación entre poco y bastante importante.

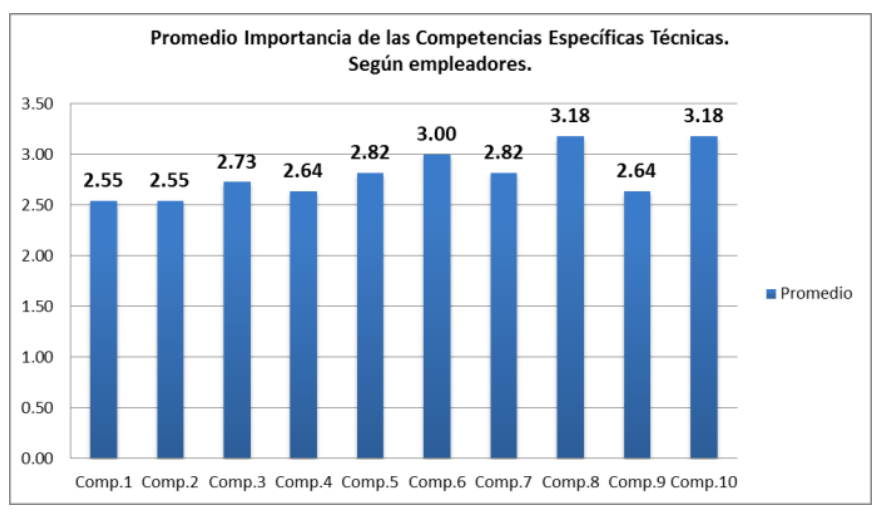

Gráfico 0.6443 Promedio de la importancia asignada por los empleadores a las competencias específicas propuestas para Técnica. Fuente: Elaboración propia

Para conocer la confiabilidad de la encuesta aplicada a los empleadores para medir la importancia asignada a las competencias específicas, se calculó la varianza de cada competencia y se sumaron estas varianzas hallándose que $\sum S_{i}{ }^{2}=21.6$ y al calcular la varianza de las sumas de los puntajes asignados por ítem se encontró que la varianza total era $S_{t o t}{ }^{2}=72.7$. Con estos dos valores se calcula el Coeficiente de Cronbach en la ecuación Ec. 5.2 y se obtiene:

$$
\propto=\left(\frac{47}{47-1}\right) \cdot\left(1-\frac{21.6}{72.7}\right)=0.72
$$

Con valor de Alpha de Cronbach podemos afirmar que los resultados de las encuestas sobre competencias específicas realizadas a los empleadores tienen buena consistencia interna pues los valores son superiores a 0,7 por lo que son confiables en un aceptable nivel, según la Tabla 5.8 .

\subsubsection{Interpretación de resultados}

En la Tabla 0.15 se muestra un resumen de resultados de las encuestas aplicadas a los grupos de interés con la finalidad de contextualizar las competencias específicas propuestas para la Ingeniería Industrial de la UDEP.

Del análisis de resultados se puede afirmar que los tres grupos de interés coinciden en su valoración de la importancia de los grupos de competencias específicas. Consideran las más importantes las competencias del Área de Operaciones, aunque para profesores y empleadores los dos grupos de competencias tienen igual importancia si consideramos que las diferencias son mínimas. Les siguen muy de cerca las del Área de Ciencias Básicas, en tercer lugar las del Área de Sistemas, en cuarto las del Área Administrativa. También entre las competencias de Sistemas y Administrativas existe un virtual empate por la cercanía de puntajes. Los interesados consideran el grupo de menor importancia a las competencias de Técnicas de la Ingeniería, estas sí por una marcada diferencia. 


\begin{tabular}{|c|c|c|c|c|}
\hline & Competencias específicas & Graduados & Profesores & Empleadores \\
\hline \multirow{5}{*}{$\begin{array}{c}\text { Media de } \\
\text { valoración por } \\
\text { grupo de } \\
\text { interesados }\end{array}$} & Ciencias Básicas & 3.17 & 3.41 & 3.2 \\
\hline & A. Operaciones & 3.34 & 3.42 & 3.24 \\
\hline & A. Administrativa & 3.15 & 3 & 3.1 \\
\hline & A. Sistemas & 3.16 & 3.18 & 3 \\
\hline & A. técnicas de ingeniería & 2.71 & 2.61 & 2.81 \\
\hline \multirow{5}{*}{$\begin{array}{c}\text { Competencias } \\
\text { mejor } \\
\text { valoradas }\end{array}$} & Ciencias Básicas & 1.5 y 1.6 & $1.9,1.5$ y 1.6 & 1.5 y 1.6 \\
\hline & A. Operaciones & 2.11 y 2.5 & 2.1 & 2.11 \\
\hline & A. Administrativa & 3.6 y 3.1 & 3.1 y 3.3 & 3.3 \\
\hline & A. Sistemas & 4.3 y 4.2 & 4.3 & 4.3 \\
\hline & A. técnicas de ingeniería & 5.8 y 5.10 & 5.10 y 5.8 & 5.10 y 5.8 \\
\hline \multirow{5}{*}{$\begin{array}{c}\text { Competencias } \\
\text { peor } \\
\text { valoradas }\end{array}$} & Ciencias Básicas & 1.3 & 1.3 & 1.3 \\
\hline & A. Operaciones & 2.14 & 2.7 & 2.7 y 2.9 \\
\hline & A. Administrativa & 3.5 & 3.2 & 3.5 y 3.7 \\
\hline & A. Sistemas & 4.4 & 4.4 & 4.4 \\
\hline & A. técnicas de ingeniería & 5.4 & 5.2 y 5.9 & 5.1 y 5.2 \\
\hline
\end{tabular}

Tabla 0.14 Resumen de resultados de la contextualización de competencias específicas a la Ingeniería industrial de la UDEP. Fuente: Elaboración propia

Lo obtenido en el párrafo anterior coincide con lo descrito en el segundo Capítulo de este trabajo como tendencia internacional, que los ingenieros industriales cada vez están menos llamados a desenvolverse en el ámbito de la manufactura (competencias técnicas de la ingeniería), y más en el de los servicios (competencias de operaciones), con más responsabilidades humanas, sociales y medioambientales (competencias básicas: formación humanística).

Las competencias mejor valoradas y peor valoradas por los tres grupos de interés se aprecian claramente en la Tabla 5.15 y las coincidencias son tomadas en cuenta en el momento de definir la incidencia que debe tenerse en unas competencias u otras al desarrollar el Plan de Estudios.

\subsection{DISEÑO DEL PLAN DE ESTUDIOS}

En el diseño del Plan de estudios se deben considerar todos los aspectos desarrollados previamente en esta estrategia de aplicación del MESIC.

Un Plan de estudios es el agrupamiento de objetivos, estrategias, métodos, contenidos y prácticas que, con determinado orden, han de cursarse para cumplir un ciclo de estudios u obtener un título (RAE, 2014).

Existen muchos enfoques para el diseño de Planes de Estudio en Educación superior. En este caso seguiremos la metodología del enfoque socio-formativo y nos apoyamos en la construcción clásica prevista en el documento "Metodología para revisión y actualización de 
los Planes de Estudio de las carreras de Ingeniería de la Universidad de Piura - 2007" (UDEP, 2007).

En este paso de la construcción curricular es cuando se ponen realmente de manifiesto las bondades del modelo seguido. Haber trabajado con el MESIC no solo facilita la confección del Plan de Estudios, le da solidez a la aplicación y a la toma de decisiones, pues las preguntas que surgen en los planificadores en esta parte del desarrollo curricular, ya han sido respondidas por el MESIC para la Ingeniería Industrial de la UDEP, desde las competencias.

Los pasos del diseño Plan de estudios clásico son (Diaz B. et al., 1995):

- Análisis previo: Donde se analizan las características, condiciones y tendencias del contexto social, político y económico.

- Diseño curricular: Se especifican fines y objetivos, se explicita el enfoque educativo y se muestran los principios en los que debe basarse el nuevo currículo.

- Aplicación curricular: Determina la forma y medios para poner en práctica lo diseñado.

- Seguimiento curricular: se evalúa la eficacia, eficiencia y efectividad de lograr los fines propuestos.

El enfoque socio-formativo enriquece esta forma de proceder como se muestra en el Gráfico 5.61., incluye estos pasos e inserta nuevos como el carácter participativo o la gestión de competencias, en una adptació de lo propuesto por Sergio Tobón (2013b).

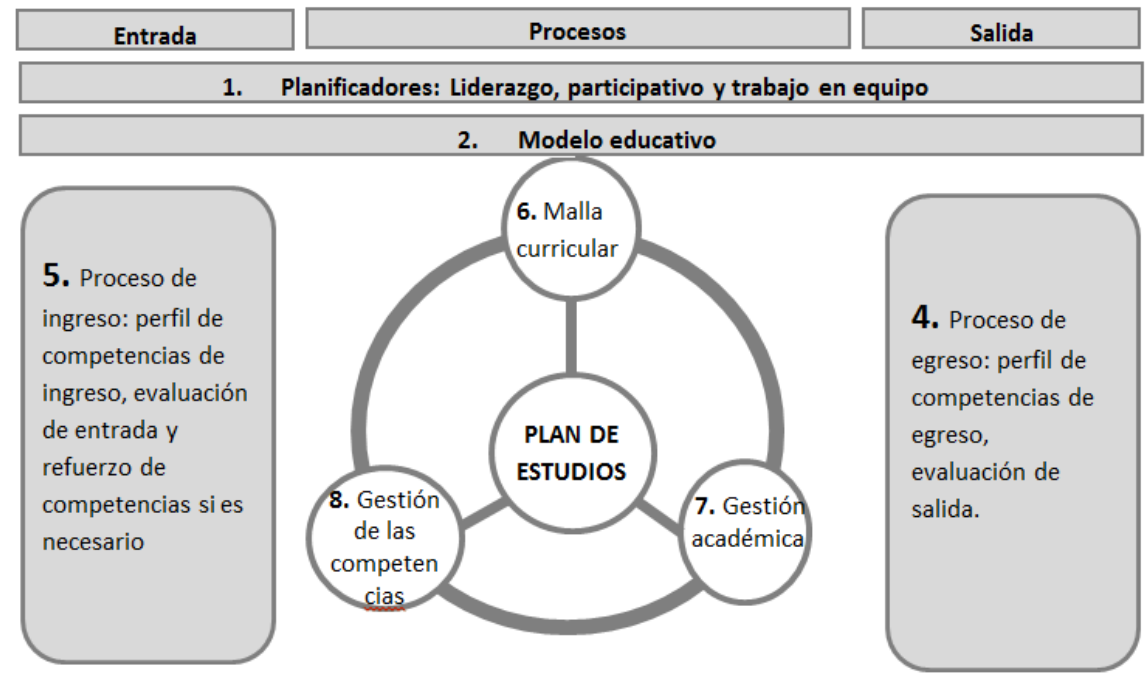

3. Estudio del contexto social, cultural, ambiental, empresarial, laboral, profesional y económico.

Gráfico 0.445 Abordaje del Plan de estudios. Fuente: Adaptación de Tobón, 2013b.

Para la forma de diseño de Plan de estudios propuesto desde la socio-formación, ya contamos claramente definidos los puntos uno, dos, tres, cuatro y cinco, que ya se desarrollaron en los apartados 5.2, 5.3 , 5.4, 5.5 y 5.6, y pueden revisarse en esos apartados. Solo falta definir los procesos del diseño curricular que los tomaremos de esta propuesta pues pertenece al enfoque elegido: malla curricular, gestión académica y gestión de las competencias. 


\section{Malla curricular.}

A partir del perfil de egreso para los ingenieros industriales de la UDEP definido en 5.5, que se obtuvo a partir de considerar lo que se requiere para resolver los problemas del entorno, las áreas en que puede laborar, las posibles ubicaciones, y la formación íntegra que se desea tengan los egresados, se definen los contenidos, la organización de dichos contenidos y su estructuración.

Lo primero que se realizó fue determinar los conocimientos y habilidades requeridos para alcanzar el perfil de egresado definido. Esto se hizo con la participación de los docentes de las áreas académicas del Programa Académico, y contrastando con la información de tendencias de la ingeniería industrial en el mundo desarrollados en los capítulos uno y dos y con la información del contexto externo cercano provisto por los empleadores y egresados.

Luego se determinó la organización de estos contenidos por asignaturas en una definición mixta de currículo. Es decir, pensando en un avance secuencial de los contenidos, sin perder el enfoque cruzado de simultaneidad de asignaturas, lo que lleva a una definición temporal con balanceo de créditos por periodo de tiempo asignado. Para nuestro caso, por semestres.

Las primeras decisiones tomadas fueron:

1. La carrera durará cinco años como lo estipula la Ley Universitaria. En caso deba nivelarse algún alumno, cursará el semestre Introductorio. Quienes muestren los conocimientos y competencias requeridos irá al primer ciclo de la carrera.

2. Se ha hecho una serie de cálculos, en varios casos, de la carga de las asignaturas con y sin horas prácticas, y se ha determinado que la relación horas presenciales contra horas de trabajo efectivo es 2. Esto quiere decir que un crédito presencial, en el caso de Ingeniería Industrial de UDEP, equivale a 2 créditos comparables con los ECTS del EEES.

3. El currículo se construirá sobre la base de créditos que determinan el número de horas presenciales del alumno a los que a partir de este momento se les llamará créditos. A los créditos comparables con los ECTS les llamaremos CLAR o Créditos Latinoamericanos de Referencia.

4. Se dará una formación humana integral a lo largo de toda la carrera respondiendo al Ideario y Plan estratégico de 5.3 y a las tendencias vistas en el capítulo 2.

5. Se respetarán los Aspectos Clave definidos en 5.3.

6. Se tendrá una formación con contenidos humanísticos, administrativos y sociales, en concordancia con lo visto en el Capítulo 2 y Capítulo 3.

7. Las metodologías requieren actualización y sin abandonar las clases magistrales ni el aprendizaje basado en ejercicios y problemas, entraremos a manejar el aprendizaje basado en proyectos, el trabajo en equipos y el aprendizaje basado en problemas. Atendiendo a lo tratado en el Capítulo cuatro.

8. Debe considerarse el perfil de ingreso y poner medios para nivelar a los ingresantes que no tengan las competencias requeridas según lo desarrollado en 5.5.

9. La malla curricular consta de 221 créditos en total. Estos se distribuirán atendiendo a la importancia asignada a las áreas en las encuestas: las dos primeras áreas son ciencias 
Básicas y Operaciones, se considera las ciencias básicas con mayor carga pues allí se desarrollan los cursos de formación humana y consideramos que es importante que los alumnos reciban cada semestre al menos un curso de humanidades. Luego se encuentran las competencias administrativas y en cuarto lugar las tecnologías de la ingeniería, pues son indispensables para mantener el perfil de ingeniero, considerar pocos créditos en esta área, desnaturalizaría la especialidad de "ingeniería". El que ocupará el siguiente lugar en la asignación de créditos es Sistemas. La distribución será:

- 82 créditos en Ciencias Básicas. Esto incluye matemáticas, física, química, programación básica, estadística básica, estos durante los dos primeros años de carrera, y formación humanística que se imparte cada semestre a lo largo de toda la carrera.

- 47 créditos en el Área de Operaciones: 28 en Operaciones y 19 en Investigación de Operaciones.

- 33 en el Área de Ciencias Económicas y Administrativas

- 33 créditos en el Área de Tecnologías de la Ingeniería.

- 22 créditos en Sistemas de Información.

- 4 créditos electivos.

Con las decisiones adoptadas y definidos los contenidos las Áreas de conocimiento de la carrera, se estructura la Malla curricular como se muestra en el Gráfico 5.62. En este gráfico se observa el Área de Ciencias Básicas en los dos primeros años y a continuación las cuatro áreas de conocimientos restantes, con una línea adicional, la de Humanidades, que perteneciendo a Ciencias Básicas, se desarrolla a lo largo de toda la carrera para sostener la formación integral de la persona y su enfoque más humano y social.

\begin{tabular}{|c|c|c|c|c|c|c|c|c|c|c|}
\hline \multicolumn{11}{|c|}{ CICLOS } \\
\hline INTRODUCTORIO & 1 & II & III & IV & $\mathbf{v}$ & VI & VII & VIII & IX & $\underline{x}$ \\
\hline \multirow{6}{*}{ NIVELACIÓN } & \multirow{4}{*}{\multicolumn{3}{|c|}{ CIENCIAS BÁSICAS }} & \multicolumn{7}{|c|}{ A. DE TÉCNICAS DE LA ING. } \\
\hline & & & & \multicolumn{7}{|c|}{ A. DE SISTEMAS } \\
\hline & & & & \multicolumn{7}{|c|}{ A. DE OPERACIONES } \\
\hline & & & & \multicolumn{7}{|c|}{ A. DE ADMINISTRATIVAS } \\
\hline & \multicolumn{10}{|c|}{ HUMANIDADES } \\
\hline & \multicolumn{10}{|c|}{ ELECTIVOS - REQUISITOS DE MATRÍCULA } \\
\hline
\end{tabular}

Gráfico 0.456 Estructura de la Malla curricular para Ingeniería industrial de UDEP. Fuente: Elaboración propia.

Hecha la estructura se definen las asignaturas. Cada una tiene un sílabo en el que debe plasmarse la gestión del curso, desde los objetivos hasta la forma de evaluación.

El sílabo es el resultado de reuniones entre profesores del área para asegurar que los contenidos no sean innecesariamente repetidos y que la profundidad con que se traten sea la requerida por las asignaturas siguientes. Esta es una planificación vertical pues verifica la secuencia y la construcción de aprendizajes y competencias en el desarrollo de la carrera. 
La otra forma de construcción, adicional a la anterior es horizontal. Los profesores se reúnen por cursos del mismo nivel y plantean la carga que dejarán en el semestre así se constata que el alumno no exceda de la carga prevista: 21 créditos en promedio por semestre, es decir, 42 horas de trabajo semanal real en promedio. Las asignaturas de la carrera se describen en el Tabla 5.16.

\begin{tabular}{|c|c|c|c|}
\hline Área & Ciclo & Asignatura & Sigla \\
\hline \multirow{27}{*}{$\begin{array}{l}\text { Cicencias } \\
\text { básicas }\end{array}$} & 0 & Matemática Básica & MBO \\
\hline & 0 & Matemática Razonada & MRO \\
\hline & 0 & Lengua Básica & LBO \\
\hline & 0 & Física Básica & FBO \\
\hline & 0 & Química general básica & QG0 \\
\hline & 1 & Introducción al cálculo superior & ICS \\
\hline & 1 & Gemetría analítica vectorial & GAV \\
\hline & 1 & Geometría métrica fundamental & GFT \\
\hline & 1 & Química general 1 & QG1 \\
\hline & 1 & Metodología de estudio univ. & MEU \\
\hline & 1 & Historia de la ingeniería & HIS \\
\hline & 2 & Dibujo técnico & DIB \\
\hline & 2 & Algebra lineal & ALG \\
\hline & 2 & Análisis matemático 1 & $\mathrm{~A} 1$ \\
\hline & 2 & Física general 1 & F1 \\
\hline & 2 & Lengua y Literatura & LYL \\
\hline & 3 & Análisis matemático 2 & $\mathrm{~A} 2$ \\
\hline & 3 & Física general 2 & F2 \\
\hline & 3 & Química general 2 & QG2 \\
\hline & 3 & Filosofía 1 & FI1 \\
\hline & 4 & Teología 1 & TL1 \\
\hline & 7 & Filosofía 2 & $\mathrm{FI} 2$ \\
\hline & 5 & Teología 2 & TL2 \\
\hline & 6 & Teología 3 & TL3 \\
\hline & 8 & Doctrina Social & DS \\
\hline & 9 & Deontología para ingenieros & DE \\
\hline & 10 & Redacción técnica & RT \\
\hline
\end{tabular}

\begin{tabular}{|c|c|c|c|}
\hline Área & Ciclo & Asignatura & Sigla \\
\hline \multirow{9}{*}{ Opera-ciones } & 4 & Estadística Básica & EDB \\
\hline & 5 & Estadística Aplicada & EDA \\
\hline & 5 & Investigación de Operaciones 1 & 01 \\
\hline & 6 & Investigación de Operaciones 2 & 02 \\
\hline & 7 & Diseño de Operaciones & DOP \\
\hline & 8 & Gestión de Operaciones & GOP \\
\hline & 9 & Estrategia de Operaciones & EOP \\
\hline & 10 & Proyectos & PRY \\
\hline & 10 & Tecnología de Fabricación & TFA \\
\hline \multirow{8}{*}{$\begin{array}{c}\text { Adminis- } \\
\text { trativas }\end{array}$} & 4 & Costos & $\cos$ \\
\hline & 5 & Administración & ADM \\
\hline & 6 & Economía & ECO \\
\hline & 7 & Finanzas & FIN \\
\hline & 8 & Investigación de Mercado & $\mathrm{IMD}$ \\
\hline & 9 & Iniciativa Empresarial & IEM \\
\hline & 10 & Relaciones y psicología industrial & RP \\
\hline & 10 & Sistemas Empresariales & SEM \\
\hline \multirow{5}{*}{ Sistemas } & 3 & Programación Básica & PB \\
\hline & 4 & Programación Avanzada & PAV \\
\hline & 7 & Análisis y Diseño de Sistemas & ADS \\
\hline & 8 & Bases de Datos & $\mathrm{BD}$ \\
\hline & 9 & Tecnologías de Internet & TIN \\
\hline \multirow{7}{*}{$\begin{array}{c}\text { Técnicas de } \\
\text { ingeniería }\end{array}$} & 4 & Mecánica Racional & MRA \\
\hline & 5 & Mecánica de Fluidos & MF \\
\hline & 6 & Tecnología Energética & TEN \\
\hline & 6 & Tecnología Eléctrica 1 & TE1 \\
\hline & 7 & Tecnología Eléctrica 2 & TE2 \\
\hline & 8 & Tecnología de Procesos & TPR \\
\hline & 9 & Tecnología Ambiental & TAM \\
\hline
\end{tabular}

Tabla 0.15 Asignaturas curriculares de la carrera de Ingeniería Industrial de UDEP. Fuente: Elaboración propia.

Por Área de conocimientos se asigna la secuencia de asignaturas de acuerdo a los contenidos definidos y sus requisitos.

En la Tabla 5.17 se muestra la Malla curricular de la carrera de Ingeniería de UDEP. En ella se puede ver la secuencia de los cursos, el número de créditos por semestre, el Área de conocimiento a que pertenece y el número de créditos por asignatura. Los requisitos adicionales de las asignaturas no se muestran para no complicar la muestra de la aplicación del MESIC. 


\begin{tabular}{|c|c|c|c|c|c|c|c|c|c|c|c|c|c|c|c|c|c|c|c|c|}
\hline \multicolumn{21}{|c|}{ CICLOS } \\
\hline 0 & \multicolumn{2}{|c|}{1} & \multicolumn{2}{|c|}{ ॥ } & \multicolumn{2}{|c|}{ III } & \multicolumn{2}{|c|}{ IV } & \multicolumn{2}{|c|}{ v } & \multicolumn{2}{|c|}{ vi } & \multicolumn{2}{|c|}{ VII } & \multicolumn{2}{|c|}{ VIII } & \multicolumn{2}{|c|}{ IX } & \multicolumn{2}{|c|}{$x$} \\
\hline \multirow{6}{*}{$\begin{array}{l}\text { Semestre } \\
\text { de nivela- } \\
\text { ción } \\
\text { cuando } \\
\text { corres- } \\
\text { ponda }\end{array}$} & ICS & 4 & A1 & 6 & A2 & 6 & MRA & 5 & MF & 5 & TE1 & 5 & TE2 & 5 & TPR & 4 & TAM & 4 & TFA & 6 \\
\hline & GFT & 4 & DIB & 4 & PB & 4 & PAV & 4 & EDA & 6 & TEN & 5 & ADS & 5 & BD & 5 & TIN & 4 & SEM & 4 \\
\hline & GAV & 4 & ALG & 5 & QG2 & 5 & EDB & 4 & 01 & 5 & 02 & 4 & DOP & 6 & GOP & 6 & EOP & 6 & PYT & 4 \\
\hline & QG1 & 5 & F1 & 5 & F2 & 5 & $\cos$ & 5 & ADM & 4 & ECO & 4 & FIN & 4 & IMD & 4 & IEM & 4 & RP & 4 \\
\hline & HIS & 3 & LYL & 3 & FI1 & 3 & TL1 & 3 & TL2 & 3 & TL3 & 3 & FL2 & 3 & DS & 2 & DE & 1 & RT & 3 \\
\hline & MEU & 1 & & & AEX & 1 & & & & & & & & & & & ELEC & 4 & & \\
\hline 0 & \multicolumn{2}{|c|}{21} & \multicolumn{2}{|c|}{23} & \multicolumn{2}{|c|}{24} & \multicolumn{2}{|c|}{21} & \multicolumn{2}{|c|}{23} & \multicolumn{2}{|c|}{21} & \multicolumn{2}{|c|}{23} & \multicolumn{2}{|c|}{21} & \multicolumn{2}{|c|}{23} & \multicolumn{2}{|c|}{21} \\
\hline
\end{tabular}

Ciencias Básicas: matemáticas y empíricas.

Ciencias Básicas: Humanidades

Operaciones

Técnicas de la Ingeniería

Administrativas

Sistemas

Tabla 0.16 Malla curricular de Ingeniería Industrial de UDEP. Fuente: Elaboración propia.

Definidas las asignaturas, es necesario aplicar las competencias contextualizadas en 5.7 dentro de las asignaturas correspondientes. Esto lo hizo el comité de expertos con la participación de los docentes involucrados en cada caso y tomando en consideración los aportes de los grupos interesados.

En el Tabla 5.18 se puede visualizar la asignación de competencias genéricas. Los cursos se pueden apreciar en la columna de la izquierda y las competencias en la fila superior que se corresponden con las mostradas en la Tabla 3.4. 


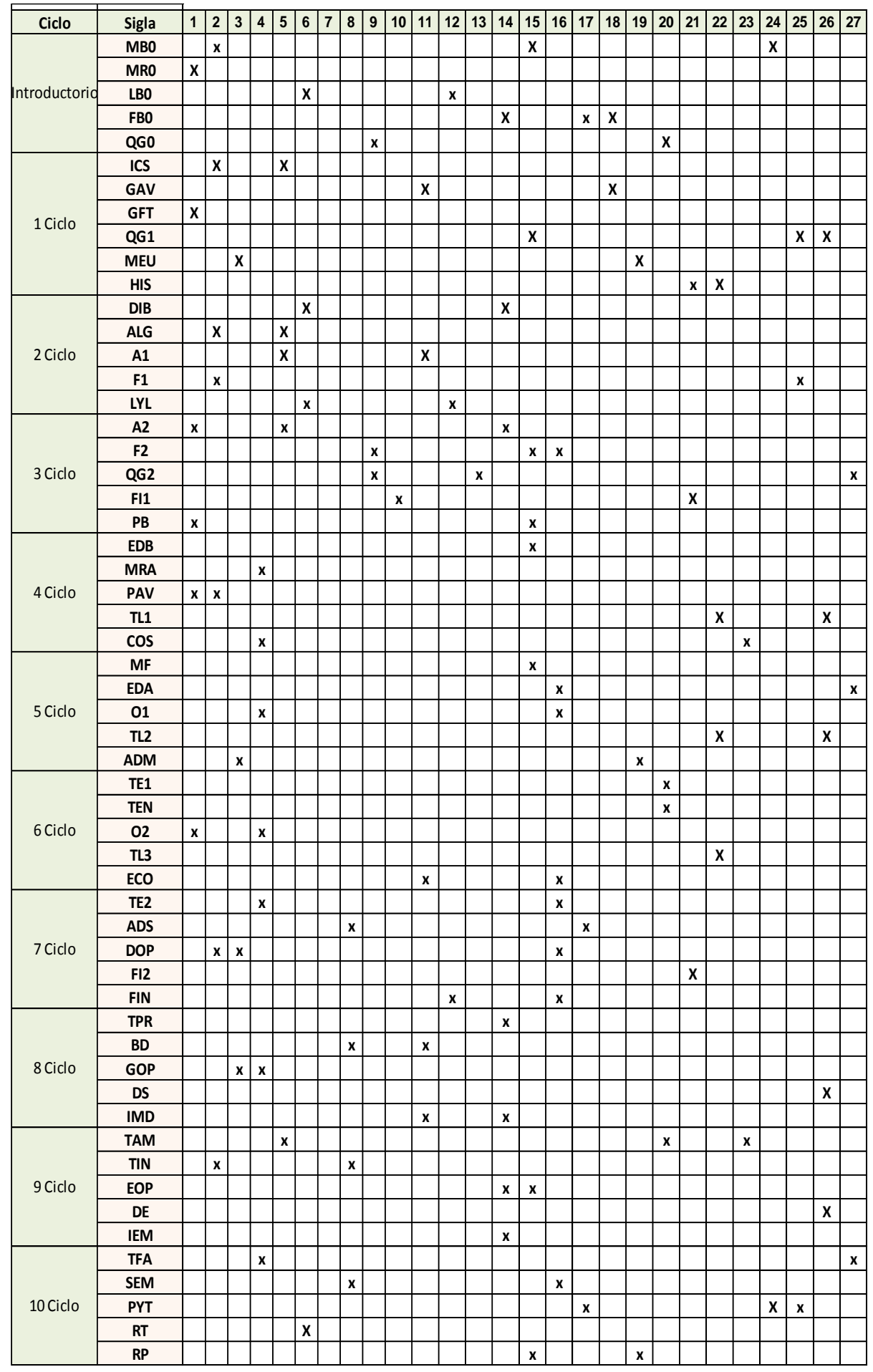

Tabla 0.17 Asignación de competencias genéricas a asignaturas de la Malla curricular de Ingeniería Industrial de UDEP. Fuente: Elaboración propia. 
En la Tabla 5.19 se muestra la asignación de las competencias específicas a los cursos de la Malla curricular de Ingeniería Industrial de la UDEP.

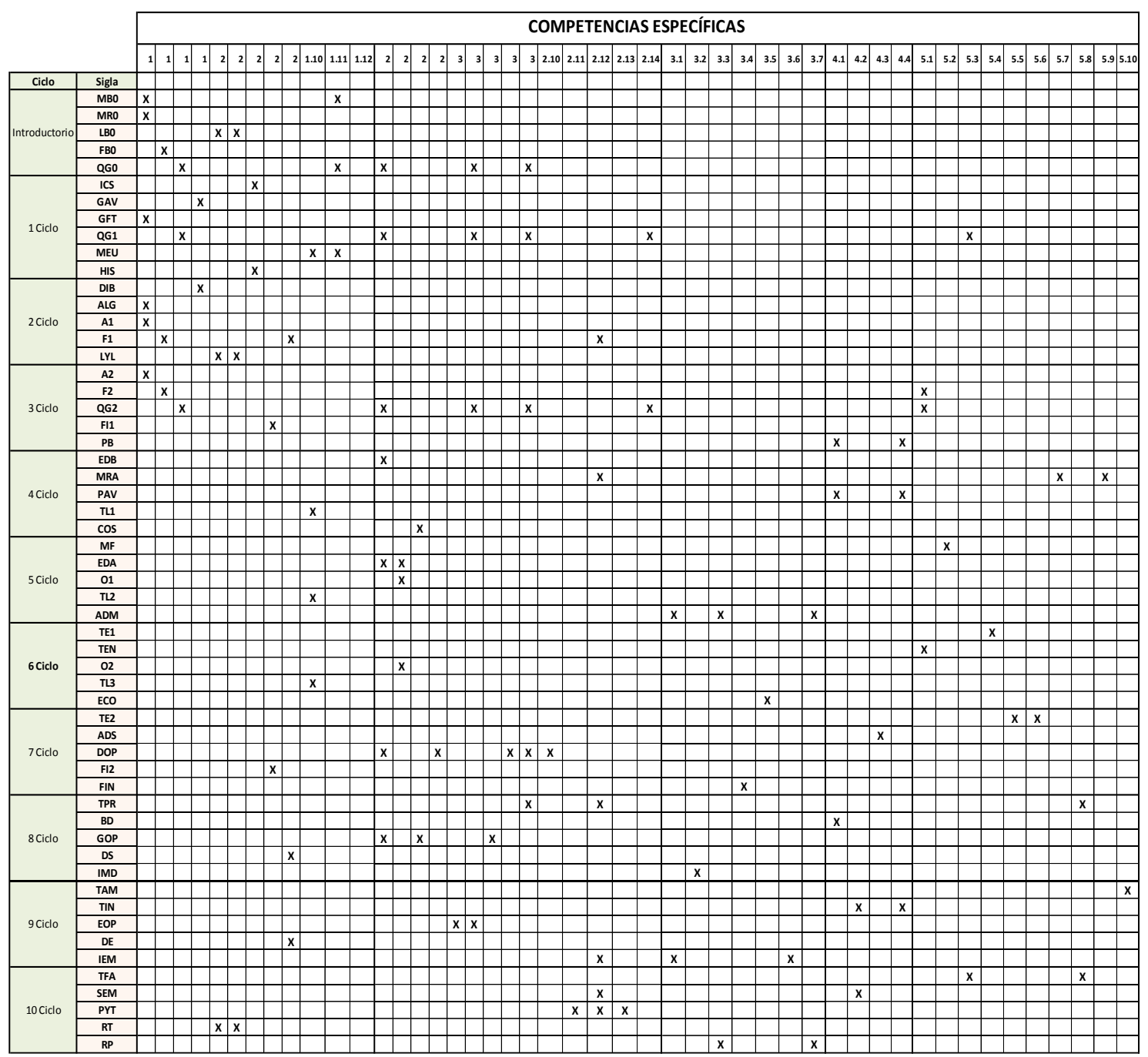

Tabla 0.18 Asignación de competencias específicas a asignaturas de la Malla curricular de Ingeniería Industrial de UDEP. Fuente: Elaboración propia.

En estas asignaciones de competencias tanto genéricas como específicas, se ha cuidado que ninguna competencia quede sin ser desarrollada y aquellas que merecen mayor interés sean tratadas más de una vez durante el transcurso de la carrera. También se ha cuidado que las asignaturas no queden cargadas de competencias genéricas, y las específicas si pueden abundar en razón de la naturaleza de los contenidos.

\section{Gestión académica}

La gestión académica se compone de las políticas necesarias para llevar adelante la malla curricular con las competencias asignadas y hacer realidad el modelo planteado. Esto implica tener clara la gestión administrativa y la gestión de la formación integral del alumno. 
Los procedimientos y políticas de gestión académica están claramente normadas en el Reglamento de Funcionamiento Académico General (RFAG) de la Universidad de Piura (SIGA, 2014).

Además del RFAG, se deben respetar los formatos de los sílabos de los cursos, en los que se detalla la forma cómo se procederá en cada uno de ellos. En ellos se describe la fundamentación del curso, los objetivos generales, los contenidos, las competencias, las estrategias metodológicas, la forma de evaluación y la bibliografía. Ver Anexo I donde se muestra el sílabo completo de un curso.

Los horarios también deberán ajustarse a una adecuada distribución en función de las características de los alumnos. Como estrategia, para fortalecer la formación de los alumnos menores y favorecer la mejora del perfil de ingreso, se ha definido que los horarios de clases de los alumnos de Ciencias Básicas, dos primeros años de carrera, serán de 9 a.m. a 1 p.m. y sus evaluaciones son de 7:15 a.m. a 8.45 a.m. Para los alumnos de asignaturas superiores las clases serán de 3 p.m. a 7 p.m. y sus evaluaciones de 1 p.m a 3 p.m. Los sondeos realizados a la fecha han mostrado una gran aceptación por parte del alumnado. El horario ha ayudado a que los alumnos menores puedan disponer de las tardes para el estudio diario de las evaluaciones de primeras horas del día, y a los mayores les favorece tener las mañanas libres para dedicarlas al estudio en casa o la investigación; a los de último año les ayuda a poder trabajar medio tiempo en empresas que se los permita. No se ha hecho un análisis cuantitativo del impacto en los resultados, siendo un tema de investigación pendiente.

La decisión de mejorar las competencias de primeros años llevó a una serie de reflexiones que concluyeron en que los alumnos carecían de hábitos de estudio y de actitudes, por ello se ha decidido que las evaluaciones en primer año sean diarias mientras que en los otros cursos son quincenales o de mayor periodo de espaciamiento. Esto ha traído muy buenos comentarios de parte de los padres de familia y de los propios alumnos que ven en esto una forma de lograr más fácilmente las competencias y alcanzar los aprendizajes iniciales requeridos. Este también es un tema de investigación pendiente que estamos convencidos mostrará los buenos resultados.

Las metodologías de Aprendizaje basado en Proyectos y Trabajo en Equipos, entre otros, que se desarrollan en el transcurso de la carrera, han servido para desarrollar las competencias apropiadas. Esto puede apreciarse en la ponencia "Improving generic skills among engineering students through project-based learning in a project management course", presentado en el 120th ASEE (American Society for Engineering Education) Annual Conference and Exposition. En esta ponencia se puede verificar cómo los estudiantes son capaces de mejorar las competencias de dirección de proyectos desde una línea de referencia al inicio hasta, la medición final, empleando las metodologías mencionadas en la asignatura Proyectos.

La estrategia no solo es hacerlo en ese curso, resultados similares, salvando las distancias pues es una asignatura de primer año, se observa en Física 1 con su estrategia de desarrollar un proyecto a lo largo del ciclo, cumpliendo con las tendencias descritas en el capítulo dos, en las que se sugiere iniciar el aprendizaje de proyectos desde los primeros años de formación en ingeniería. 


\section{Gestión de las competencias.}

Insertar las competencias ha sido relativamente sencillo, pues siguiendo el modelo ya estaban contextualizadas y aceptadas por todos los grupos de interés y en la asignación se cuenta con la participación de los profesores involucrados.

El problema es cómo gestiona las competencias el profesor. Está claro que las competencias específicas han venido desarrollándolas y ahora lo que se le pide es hacerlo con nuevas metodologías, para lo que se está llevando a cabo un plan de capacitación de docentes en estas formas de aprendizaje activo moderno. Contrario a lo que se preveía, ha generado entusiasmo en los profesores quienes están dispuestos a trabajar con ellas. En una reunión sostenida con los seis encargados de las Áreas de conocimientos de Ingeniería Industrial de UDEP en abril de 2014, tres de ellos afirmaron estar dispuestos a emplearlas ellos mismos en sus cursos y aseguraron que algunos de sus profesores también lo harían.

La estrategia de aplicación de competencias no es por imposición. En el "Seminario Taller Internacional: Diseño de planes de estudio y proyectos para desarrollar competencias" llevado a cabo en Lima por la Universidad Nacional de Ingeniería (UNI) para reunir a las carreras de ingeniería del país y debatir sobre el tema, en octubre de 2013, el Dr. Sergio Tobón (2013b), quien tiene amplia experiencia en el desarrollo de esta metodología en Chile, Argentina, Estados Unidos, Panamá, Colombia, etc. afirmó enfáticamente que esta metodología funciona por afinidad y no por imposición. El fracaso registrado en algunos lugares es justamente debido a la imposición. Deben plantearse los currículos y los sílabos, pero la implantación debe ser negociada con cada profesor, uno a uno, pues si el profesor no está convencido de las bondades del uso de las competencias y que es necesario cambiar radicalmente el estilo de trabajo, las consecuencias sobre el alumno pueden ser devastadoras. El otro riesgo que surge de la imposición es la frustración en la que cae buena parte del cuerpo docente al encontrarse frente a una metodología que no domina y que le significa mucho más trabajo, para ellos innecesario, viendo además que los resultados son peores que los que se obtenían con el método tradicional.

Por lo mencionado anteriormente se iniciará con un grupo el grupo de profesores que estén dispuestos a desarrollar esta metodología y se integrarán poco a poco los demás docentes. En primer año de carrera, primer y segundo ciclo, todos los profesores están dispuestos a iniciarlo, así que con la puesta en funcionamiento el próximo semestre de este Plan de estudios ocho profesores de ciencias básicas y cuatro de especialidad iniciarían el trabajo curricular desde las competencias.

Las competencias específicas suelen ser desarrolladas en el quehacer del curso, pues siempre han estado presentes y con el solo cambio de metodología, que no es simple, se pueden mejorar los resultados. Las competencias genéricas requieren una mayor atención pues al ser transversales se corre el riesgo que todos las consideren ajenas a su propia asignatura.

Un ejemplo de nueva metodología para la adquisición de competencias específicas es el Aprendizaje basado en proyectos. Con las capacitaciones que reciben ahora los docentes, son capaces de diseñar eventos en el aula con las nuevas metodologías para mejorar los aprendizajes de los contenidos clásicos. En la Tabla 5.20 se muestra uno de los eventos diseñados el semestre 2013 II para la asignatura de Dirección de Operaciones (DOP). Este tipo de diseño es 
sumamente útil para los docentes y los alumnos, pues se planifica lo que sucederá y en la columna de "productos de los alumnos" se determinan las formas de evaluación y los entregables.

Los docentes ya fueron capacitados en varias técnicas distintas, lo que se considera fundamental para la aplicación del MESIC.

ACTIVIDAD DE APRENDIZAJE BASADO EN PROYECTOS

Martín Palma Lama

Proyecto: Determinar la capacidad de producción de un bien, en una jornada laboral, con tiempos estandarizados.

\begin{tabular}{|c|c|c|c|c|c|c|}
\hline Sesión & $\begin{array}{c}\text { Etapas, pasos, } \\
\text { actividades }\end{array}$ & $\begin{array}{l}\text { Descripción detallada de las } \\
\text { actividades }\end{array}$ & Tiempo & $\begin{array}{l}\text { Productos de los } \\
\text { alumnos }\end{array}$ & $\begin{array}{l}\text { Materiales } \\
\text { requeridos }\end{array}$ & $\begin{array}{c}\text { Actividades/ } \\
\text { productos fuera del aula }\end{array}$ \\
\hline $\begin{array}{l}\text { Sesión } 1 \\
31 / 10 / 13\end{array}$ & $\begin{array}{l}\text { Explicación de lo que se } \\
\text { requerirá para llevar } \\
\text { adelante su proyecto }\end{array}$ & $\begin{array}{l}\text { El profesor indicará que se desarrollará } \\
\text { el tema de Estudios de tiempos a través } \\
\text { de un proyecto. El será determinarel } \\
\text { impacto en el costo que tiene planificar } \\
\text { con el tiempo real que tomaría un } \\
\text { operario al realizar una actividad } \\
\text { repetitiva para satisfacer un pedido de } \\
\text { fabricación de un determinado número } \\
\text { de piezas, a hacerlo con el tiempo } \\
\text { cronometrado. El proyecto tendrá el } \\
\text { peso de dos prácticas. } \\
\text { El profesor pedirá a los alumnos que } \\
\text { formen tres grupos de } 4 \text { personas cada } \\
\text { uno (aula de } 12 \text { alumnos). Los grupos } \\
\text { deben tener un integrante del primer } \\
\text { tercio del cuadro de mérito, uno del } \\
\text { segundoy uno deltercero. (Soncadetes } \\
\text { de la Escuela Naval) } \\
\text { El profesor explica que deberán } \\
\text { investigar sobre la duración real de } \\
\text { actividades de manufactura en la } \\
\text { determinación de costos de operación } \\
\text { de una planta. También debenconocer } \\
\text { de definiciónde actividades, divisiónen } \\
\text { elementos, forma de cronometradosy } \\
\text { sobre todo la diferencia entre tiempos } \\
\text { cronometrałlos, valorados y } \\
\text { estandarizados. } \\
\text { Los alumnos deberán determinarel } \\
\text { impacto de una actividad en un pedido } \\
\text { de fabricación que exige la repetición de } \\
\text { la actividad. } \\
\text { Diseñar un evento que sea repetitivo, de } \\
\text { varios pas os, que deberán construiry } \\
\text { experimentarrepetidamente. Medir }\end{array}$ & $2 \mathrm{hr}$ & $\begin{array}{l}\text { Lista del grupo. } \\
\text { Dominio del uso de } \\
\text { cronómetros (deben } \\
\text { descubrirlo) } \\
\text { Preguntas para dilucidar } \\
\text { dudas sobre el trabajo. } \\
\text { Determinación deltiempo } \\
\text { medio de los elementos } \\
\text { medidos } \\
\text { Deberán traer a la } \\
\text { siguiente clase la } \\
\text { definición deltipo de } \\
\text { cronometrado, de } \\
\text { valoracióny } \\
\text { estandarización. Valdrá } \\
\text { 1/4 de la nota total del } \\
\text { proyecto. }\end{array}$ & $\begin{array}{l}\text { Diapositivas } \\
\text { explicativas de } \\
\text { como se hace lo } \\
\text { que seles está } \\
\text { pidiendo. }\end{array}$ & $\begin{array}{l}\text { Búsqueda y acercamiento a la } \\
\text { teoría del impacto de los } \\
\text { tiempos en el costeo de la } \\
\text { manufactura. } \\
\text { Conocimiento a formas de } \\
\text { cronometrado, } \\
\text { estandarizacióny valoración. }\end{array}$ \\
\hline
\end{tabular}

Tabla 0.19 Diseño de actividad de Aprendizaje Basado en Proyectos. Fuente: Elaboración propia.

\begin{tabular}{|c|c|c|c|c|c|}
\hline $\begin{array}{l}\text { Absolución de inquietudes } \\
\text { Simulación de caso parecido } \\
\text { a lo solicitado }\end{array}$ & $\begin{array}{l}\text { repetidamente el tiempo por el método } \\
\text { que elegirán, deberán normalizarloy } \\
\text { estandarizarlo de las formas elegidas. } \\
\text { Tendrán que explicar cómo han elegido } \\
\text { las asignaciones arbitrarias de } \\
\text { porcentajes de descansoy los } \\
\text { argumentos considerados para esa } \\
\text { elección. Es fundamental que lleven a la } \\
\text { siguiente clase (1 semana des pués)los } \\
\text { materiales necesarios para realizar de } \\
\text { manera repetitiva la actividad diseñada. } \\
\text { El profesor pedirá que se formulen las } \\
\text { preguntas sobre el tema y las abs olverá. } \\
\text { En caso no se produjeraninducirá su } \\
\text { formulación. } \\
\text { Los alumnos experimentarán una de las } \\
\text { formas de medición de tiempos con la } \\
\text { filmación de un ejemplo. Tomarán } \\
\text { tiempos, calcularán la media y se darán } \\
\text { inquietudes de fatiga, cronometrado } \\
\text { consecutivo, acumulación de tareas. }\end{array}$ & & & & \\
\hline Diseño del evento & $\begin{array}{l}\text { Los alumnos se reunirán en grupo y } \\
\text { escogeránuna actividad que les permita } \\
\text { realizar una operación repetitiva de } \\
\text { varios elementos, debe poder dividirse } \\
\text { en elementos. La actividad no debe } \\
\text { durar más de } 3 \text { minutos, debe tener más } \\
\text { de } 7 \text { elementos }\end{array}$ & $1 \mathrm{hr}$ & $\begin{array}{l}\text { Actividad dividible en } \\
\text { elementos a construir en } \\
\text { casa. Primeray } \\
\text { modificable división en } \\
\text { elementos. (1/4 puntaje } \\
\text { total) }\end{array}$ & $\begin{array}{l}\text { Lista de mérito de } \\
\text { los cadetes. }\end{array}$ & $\begin{array}{l}\text { Aprendizaje de lectura para } \\
\text { realizar correctamenteel } \\
\text { evento. } \\
\text { En casa deben preparar el } \\
\text { material de la actividad a } \\
\text { realizar en clase. P. ej: armar } \\
\text { un lego sencillo; doblar hojas, } \\
\text { ensobrar, etiquetar, colocar } \\
\text { sellosy agrupar; etc. }\end{array}$ \\
\hline
\end{tabular}

Tabla 5.20: Diseño de actividad de Aprendizaje Basado en Proyectos. Fuente: Elaboración propia. 


\begin{tabular}{|c|c|c|c|c|c|c|}
\hline & $\begin{array}{l}\text { Preparación del material } \\
\text { Asignación de tareas } \\
\text { Determinación del número } \\
\text { de mediciones, toma de } \\
\text { tiemposy valoración }\end{array}$ & $\begin{array}{l}\text { Cada grupo de alumnos preparará el } \\
\text { material para realizar repetidamente la } \\
\text { actividad diseñada. } \\
\text { Asignarán tareas a cada miembro del } \\
\text { grupo. Uno de ellos debe ser quien } \\
\text { cronometre y tome nota de tiempos y } \\
\text { valoraciones. Una vez listos realizarán } \\
\text { pruebas de mediciones. } \\
\text { Los alumnos de cada grupo harán } 10 \\
\text { mediciones para determinar los tiempos } \\
\text { medios. } \\
\text { Con los tiempos medios y la fórmula } \\
\text { para 95\% de confianza y } 5 \% \text { de error se } \\
\text { determinará el número de veces que } \\
\text { deben medirla actividad para determinar } \\
\text { el tiempo normal. }\end{array}$ & $1 \mathrm{hr} 30 \mathrm{~min}$ & \begin{tabular}{|l|} 
Tabla de resultados de \\
pruebas iniciales. \\
Lista de mediciones de los \\
10 primeros eventos con \\
la media de ellos. \\
Número de eventos a \\
medir
\end{tabular} & \begin{tabular}{|l} 
Material de la \\
actividad constrido \\
en casa y traído a \\
clase porlos \\
grupos. \\
Tres cronómetros. \\
Tablas para anotar \\
datos. \\
Calculadoras.
\end{tabular} & \\
\hline & $\begin{array}{l}\text { Tomar tiempos con sus } \\
\text { valoraciones } \\
\text { Fijar tiempos suplementarios }\end{array}$ & $\begin{array}{l}\text { Se tomarán los tiempos de todos los } \\
\text { eventos y en cada uno se colocará la } \\
\text { valoración correspondiente. } \\
\text { Se rotarán los puestos cuatro veces } \\
\text { para que cada uno tome tiempos y } \\
\text { valore. } \\
\text { Se discutirá en grupo la asignación de } \\
\text { tiempos suplementarios como } \\
\text { porcentaje y se asignará una cantidad. } \\
\text { Se determinará cuál de los grupos de } \\
\text { medida se consideran mejores y se } \\
\text { adoptarán como los finales. } \\
\text { Determinarán el tiempo estandarizado } \\
\text { de esa actividad con el grupo de datos } \\
\text { seleccionado. } \\
\text { Calcularán cuántas veces pueden hacer } \\
\text { esa tarea en una jornada de ocho horas } \\
\text { y calcularán cuántas veces requiere } \\
\text { repetirse, por cuántas personas para } \\
\text { satisfacer el pedido de compra hechoy } \\
\text { programaránla producción. }\end{array}$ & $1 \mathrm{hr} 30 \mathrm{~min}$ & \begin{tabular}{|l|} 
Número de veces que se \\
puede esperar se pueda \\
realizar la operación en un \\
día \\
Lista de tiemposy \\
valoraciones de todos los \\
eventos para cada \\
integrante del grupo. \\
Lista de tiemposy \\
valoraciones seleccionado \\
como mejor. \\
Tiempo suplementario a \\
asignar. \\
Tiempo estandarizado de \\
la actividad \\
Estos cálculos valdrán $1 \%$ \\
del puntaje.
\end{tabular} & $\begin{array}{l}\text { Material de la } \\
\text { actividad traído de } \\
\text { casa. } \\
\text { Tres cronómetros. } \\
\text { Tablas para anotar } \\
\text { datos. } \\
\text { Calculadoras. }\end{array}$ & $\begin{array}{l}\text { Preparar un informe de lo } \\
\text { realizado, indicando: cuellos } \\
\text { de botella, momentos de } \\
\text { mayores dificultades, } \\
\text { características del trabajador } \\
\text { típico, fundamentar por qué } \\
\text { se eligíó ese grupo de } \\
\text { mediciones y no los otros } \\
\text { tres. Debe ser consensuado y } \\
\text { firmado por los cuatro. } \\
\text { Deberán calcular el tiempo } \\
\text { requerido para satisfacer el } \\
\text { pedido solicitado, cómo se } \\
\text { acomoda esto en los turnos } \\
\text { de trabajo, número de días } \\
\text { totales involucrados. Deberá } \\
\text { compararlo con el calculo a } \\
\text { partir del tiempo medido in } \\
\text { valorar y mostrarán } \\
\text { conclusiones. El informe } \\
\text { valdrá } 1 \% \text { del puntaje total. }\end{array}$ \\
\hline
\end{tabular}

\section{Tabla 5.20: Continuación.}

Las competencias genéricas requieren otra estrategia. La idea es que la competencia se enfrente desde la definición de un problema real del entorno, dentro del contexto definido. La competencia a satisfacer es la que ya está escrita en el sílabo de la asignatura y lo que se requiere es asociarla a un problema del entorno definiendo los criterios y las evidencias que se desean recabar. Luego deben indicarse las actividades y los recursos para alcanzar esas evidencias (Tobón 2013b).

Lo primero debe ser identificar un problema concreto para una competencia genérica de una asignatura concreta. En las Tablas 5.22a, 5.22b y 5.22c, se muestran las plantillas que es conveniente confeccionar al trabajar el desarrollo de aprendizajes por desarrollo de competencias genéricas. Por ejemplo: en el curso de Química la competencia genérica 15. Capacidad para identificary resolver problemas.

\section{PROYECTO REAL - DESARROLLO DE COMPETENCIAS}

\begin{tabular}{|c|c|}
\hline $\begin{array}{l}\text { Programa: Ingeniería Industrial de UDEP } \\
\text { Situación real: La química de los alimentos. }\end{array}$ & $\begin{array}{ll}\text { Semestre: II } & \text { Asignatura: QG1 } \\
\text { Duración: } 3 \text { meses. } & \text { Docente: }\end{array}$ \\
\hline \multicolumn{2}{|c|}{ Competencia a formar: 15. Capacidad para identificar y resolver problemas. } \\
\hline \multicolumn{2}{|c|}{$\begin{array}{l}\text { Problema real: ¿Cómo elaborar un producto alimenticio acorde con procesos de la química, cumpliendo con las normas } \\
\text { de calidad. }\end{array}$} \\
\hline \multicolumn{2}{|c|}{$\begin{array}{l}\text { Transversalidad con: Estadística aplicada, investigación de operaciones 1, economía, tecnología eléctrica 2, dirección de } \\
\text { operaciones y finanzas. }\end{array}$} \\
\hline $\begin{array}{l}\text { Criterios } \\
\text { Sabe planificar un problema de acuerdo a la metodología } \\
\text { del marco lógico. } \\
\text { Ejecuta las acciones de acuerdo a lo planificado } \\
\text { Participa en el trabajo colaborativo de acuerdo a una meta. } \\
\text { Demuestra sentido de trabajo para satisfacer necesidades de } \\
\text { producción de alimentos de acuerdo a normas químicas. } \\
\text { Argumenta positivamente los resultados hallados. }\end{array}$ & $\begin{array}{l}\text { Evidencias } \\
\text { Documento de definición del problema, alcances y } \\
\text { consecuencias. } \\
\text { Informes de avance del trabajo con los resultados } \\
\text { alcanzados. Son tres, uno al final de cada mes. } \\
\text { Registro del trabajo colaborativo }\end{array}$ \\
\hline
\end{tabular}


En la Tabla 5.21a se muestra el diseño de la actividad identificando un problema real y definiendo los pasos a seguir y las evidencias que se espera alcancen los alumnos. Esta es una ficha que prepara al profesor y estimula a los alumnos para que se comprometan con resolver ese caso. Si no hay receptividad puede buscarse en conjunto uno nuevo, pero el docente define íntegramente esta plantilla.

\begin{tabular}{|c|c|c|}
\hline ACTIVIDADES & EVIDENCIAS & RECURSOS \\
\hline $\begin{array}{l}\text { Conformación de equipos de cinco integrantes. } \\
\text { Documento de definición, alcances y consecuencias del problema. } \\
\text { Visualizar la meta: Alimentos que cumplen normas. } \\
\text { Cada uno de los integrantes comprende lo realizado por el grupo }\end{array}$ & $\begin{array}{l}\text { Documento de } \\
\text { definición, alcances y } \\
\text { consecuencias del } \\
\text { problema }\end{array}$ & $\begin{array}{l}\text { Manuales de } \\
\text { composición química } \\
\text { de alimentos. } \\
\text { Marco lógico } \\
\text { Libro de Química }\end{array}$ \\
\hline $\begin{array}{l}\text { Ejecución del proyecto por tres meses. } \\
\text { Comprensión y refuerzo de la teoría inicial. } \\
\text { Afianzar el trabajo con laboriosidad, motivación y corregir errores. } \\
\text { Informe de participación }\end{array}$ & $\begin{array}{l}\text { Registro del trabajo } \\
\text { colaborativo. } \\
\text { Informes de avances }\end{array}$ & $\begin{array}{ll}\text { Escalas } & \mathrm{de} \\
\text { evaluación. } & \end{array}$ \\
\hline $\begin{array}{l}\text { Preparación del informe final del proyecto en equipo. } \\
\text { Presentación del informe al resto del aula y docente. } \\
\text { Evaluar logros y errores cometidos. } \\
\text { Docente refuerza los aspectos clave desarrollados }\end{array}$ & $\begin{array}{l}\text { Informe final. } \\
\text { Presentación pública. }\end{array}$ & $\begin{array}{l}\text { Mapas de evaluación } \\
\text { y soportes } \\
\text { informáticos. }\end{array}$ \\
\hline
\end{tabular}

Tabla 5.21b: Planificación de actividad de Aprendizaje Basado en Proyectos. Fuente: Adaptación de Tobón, 2013b.

La Tabla 5.21b es preparada por los alumnos y revisada por el profesor hasta que queden conformes ambos con lo detallado en ella. En esta ficha se definen claramente las tareas o actividades concretas a ejecutar y los entregables o evidencias evaluables a las que se debe llegar. Cerrada esta ficha, los alumnos deben proceder con lo acordado y el docente es quien debe vigilar el avance.

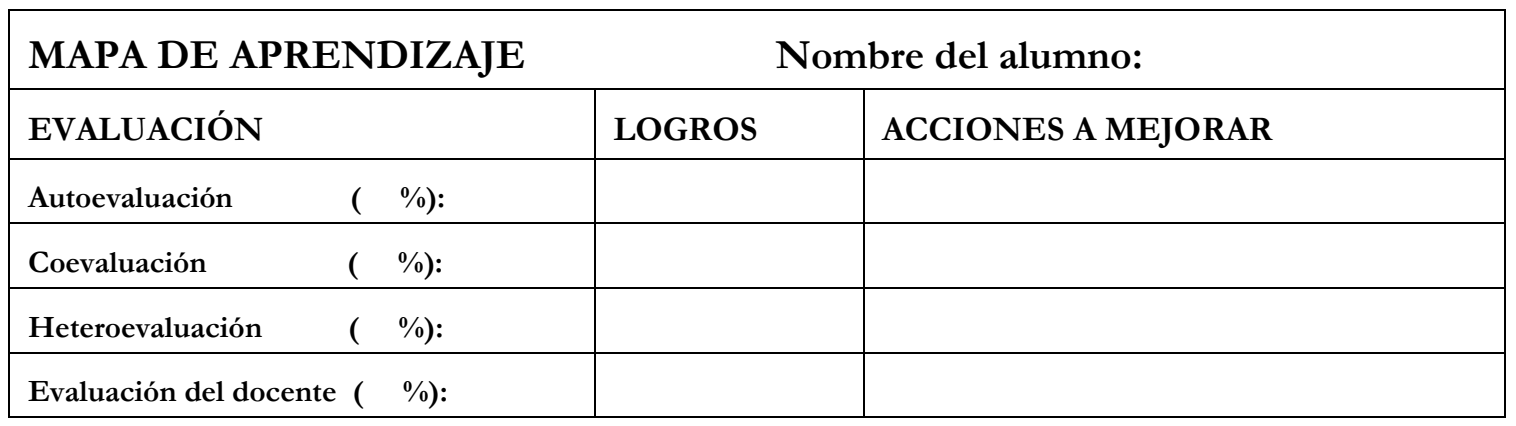

Tabla 5.21c: Evaluación de las competencias genéricas. Fuente: Adaptación Tobón 2013b.

El muy difícil problema de evaluar las competencias queda resuelto con la ficha mostrada en la Tabla 5.21c, pues acordados los entregables o evidencias en la Tabla 22b, en una ficha como la de la Tabla 22c se registran las evaluaciones entregadas por cada uno de los ejecutantes del trabajo, a sí mismo, por sus compañeros de equipo, por el reto de alumnos del aula que participaron de la sustentación del trabajo y por el docente. Existen unas ponderaciones a cada componente que el docente debe definir con anticipación y la nota es resultado de la media ponderada. También quedan registrados para el docente, y se le entrega una copia al alumno, los logros alcanzados y las acciones a mejorar. 


\subsection{ASEGURAMIENTO DE LA CALIDAD}

El proceso de aseguramiento de la calidad de la aplicación del MESIC recae en el sistema de calidad del CONEAU para las instituciones universitarias, como se ha descrito en el apartado 5.3 .

En rasgos generales, deben cumplirse los estándares de calidad mostrados en 5.3 y reunir la información suficiente para que el CONEAU verifique si se satisface lo requerido. Luego de conseguir la información necesaria sobre el proceso, si el Programa Académico quisiera tener certificación de calidad, debe iniciar una autoevaluación en base a una matriz proporcionada y elaborada por el CONEAU.

El Programa deberá satisfacer un conjunto de indicadores y estándares que le permitirá tener un informe detallado de sus deficiencias y defectos. En base a este informe, se establece un plan de mejora, el cual debe implementarse lo más pronto posible. Luego de levantar las recomendaciones, el Programa puede solicitar la evaluación externa, proceso realizado por instituciones reconocidas por el SINEACE y el CONEAU (Ver 5.3).

Las evaluadoras van a la universidad y constatan todo aquello que dice su plan de mejora y realizan una serie de acciones antes de elaborar un nuevo informe, indicando en él cuál es el estado de situación de lo que han encontrado.

Si se deseara la acreditación, ese documento es evaluado por el CONEAU, órgano que determina si la universidad merece la acreditación. De ser positivo este resultado, el Consejo Superior del SINEACE ratificará esta decisión, otorgando la acreditación a la carrera. Aunque no se deseara la acreditación, los resultados del informe sirven como un sistema de aseguramiento de la calidad del proceso académico.

Este proceso, puede tardar cerca de dos años.

Si bien planteamos la estrategia de aseguramiento de calidad a seguir, la ejecución de las normas del CONEAU exceden los alcances de este trabajo.

\subsection{CONCLUSIONES DEL CAPÍTULO V}

La estrategia de aplicación del Modelo para la Educación Superior de la Ingeniería Industrial de Perú desde las competencias MESIC facilita la acción de los planificadores curriculares, ordena la secuencia de pasos y vuelve en una tarea muy ordenada el difícil proceso de definir un Plan de Estudios y la respectiva gestión curricular para las ingenierías.

Acotar claramente un territorio para poder realizar un trabajo de planificación es fundamental y queda demostrado en la aplicación de este modelo. Se refuerza la idea que debe buscarse la armonía entre las dimensiones social, económica y cultural del ambiente territorial y estas a su vez en equilibrio con un territorio físico. Ello lleva a que debe definirse un territorio donde la aplicación pueda realizarse sin indiferencia ni violencia, por lo que se restringe de un caótico sistema de educación superior nacional a una universidad donde los procesos puedan desarrollarse. 
Los Aspectos Clave en el MESIC son fundamentales, pues se convierten en el ámbito en el que debe fluir el modelo. En este elenco de respuestas se plasman los principios de la institución y su visión de sí misma a futuro; permiten delinear el proceso de definición de contenidos y de balanceo de áreas de conocimiento, pues se basa en la axiología institucional y el plan estratégico, siendo un cuerpo de conocimientos sólido y válido para la subsecuente planificación curricular.

Si bien el MESIC es un modelo que se fundamenta sustancialmente en el Análisis de políticas para la planificación, la componente del Aprendizaje social ha permitido no solo recabar información, si no estimular la participación de los grupos interesados para construir con ellos parte del Plan de estudios, empoderándoles en la toma de decisiones y logrando compromisos con el resultado mostrado.

Para la contextualización de las competencias genéricas se utilizaron muestreos por conveniencia y exhaustivas, o de saturación; se comprobó la confiabilidad de los instrumentos haciendo análisis de Cronbach corroborándose que en todos los casos eran confiables.

Todos los grupos de interés valoran positivamente la importancia que tienen estas competencias genéricas TuningAL en la formación de Ingenieros industriales. Haciendo una media de los puntajes medios dados por cada grupo de interés, se encuentra que el $87.1 \%$ considera bastante importante y muy importante a esta codificación de competencias. Esto nos permite afirmar que las competencias TuningAL sí son una codificación de competencias apropiadas para la formación de Ingenieros Industriales en Perú.

Ninguno de los individuos encuestados en los cuatro grupos de interés incluyó una competencia adicional a las mostradas como genéricas dentro de las TuningAL a pesar de habérseles indicado en las encuestas que podían hacerlo.

Se encuentra mucha coincidencia entre las cinco competencias genéricas consideradas más importantes y las cinco consideradas más desarrolladas, por los cuatro grupos de interés, pero debe tenerse en cuenta que, en media, el desarrollo de competencias es valorado con menor puntaje que la importancia atribuida a cada una.

Queda establecido que las competencias genéricas consideradas más importantes y más desarrolladas por los cuatro grupos son marcadamente técnicas, en cambio las menos importantes y menos desarrolladas son marcadamente contextuales y de comportamiento.

Las competencias específicas propuestas han sido ampliamente aceptadas por los grupos de interés haciendo apenas una modificación entre todos los encuestados y no agregando ni eliminando ninguna de las definidas por los planificadores en ningún caso.

Una correcta gestión de un currículo por competencias pasa por la activa, voluntaria y comprometida participación de los docentes. No es posible tener resultados de la aplicación de un currículo o un sílabo por competencias si el docente no se ha comprometido con la nueva metodología ni con el objetivo que se pretende alcanzar. Del grado de implicación y dedicación que el docente muestre dependerá el grado en que los estudiantes logren aprendizajes significativos que además sean personal y socialmente valiosos, y que se revelen en competencias integradas en sus realidades humana, profesional y social. 
La gestión curricular es posible desde el MESIC y quedan algunas líneas abiertas para seguir con la investigación en este campo: ¿cómo influyen los horarios en la adquisición de competencias y hábitos?; ¿qué tan importante es la frecuencia de evaluaciones escritas clásicas y la adquisición de hábitos anexa a ellas en la adquisición de competencias? ¿'son solo formativas o solo miden la adquisición de aprendizajes?; y finalmente ¿cómo debe ser un sistema de aseguramiento de calidad académico desde la primera matrícula del alumno hasta la adquisición de su título profesional?

\subsection{REFERENCIAS DEL CAPÍTULO V}

Bland J. M., Altman D. G. (2002). Validating scales and indexes. British Medical Journal. Vol 24: 606-607.

Casal, J., Mateu E. (2003). Tipos de muestreo. Revista de Epidemiología y Medicina Preventiva. Vol 1: 3-7.Consultado el 02 de junio de 2014 en http://www.mat.uson.mx/ ftapia/Lecturas $\% 20$ Adicionales $\% 20(\mathrm{C} \% \mathrm{C} 3 \% \mathrm{~B} 3 \mathrm{mo} \% 20$ dise $\%$ C3\%B1 ar\%20una $\% 20$ encuesta)/TiposMuestreo1.pdf.

Cohen, L., Manion, L. \& Morrison, K. (2003). Research methods in education. (5ª edición). Londres, Reutledge Farmer.

Creswell, John W. (2014). Research Design: Qualitative, Quantitative, and Mixed Methods Approaches. University of Nebraska, Lincoln. SAGE Publications, Inc. (4 $4^{a}$ edición ISBN: 9781452226101).

Cullen, J., Joyce, J., Hassal, T., \& Broadbent, M. (2003). Quality in higher education: From monitoring to management. Quality Assurance in Education. Vol 11, $\mathrm{N}^{\mathrm{o}}(1)$ : 5-14.

CONEAU. (2010). Estándares para la Acreditación de las Carreras Profesionales Universitarias de Ingeniería. Consejo de Evaluación, Acreditación y Certificación de la Calidad de la Educación Superior Universitaria (CONEAU)

CONEAU. (2014). Consejo de Evaluación, Acreditación y Certificación de la calidad de la Educación Superior Universitaria. República del Perú. Visitado el 18 de junio de 2014. www.coneau.gob.pe

Díaz, Angel. (2005). El enfoque de competencias en la educación ¿Una alternativa o un disfraz de cambio? Revista Perfiles Educativos. UNAM.

Díaz Barriga, F, Lule, M. Rojas, S. y Saad, S. (1995). Metodología de Diseño Curricular para la Educación Superior. México. Trillas.

Gob.Pe. (2014). Ley 23733. Ley Universitaria. Congreso de la República del Perú. Visitado por última vez el 24 de junio de 2014 en http://www.peru.gob.pe/docs/PLANES/10402/PLAN_10402_Ley\%20Universitaria_20 10.pdf

Harvey, L.; Green, D. (1993). Defining quality. Assessment and Evaluationin Higher Education. Vol. $18 \mathrm{~N}^{\circ}$ 1: 9-3 
INEI. (2009). Perú: Estimaciones y proyecciones de población por sexo según departamento, provincia y distrito. Boletín Especial N 18. Dirección Técnica de Demografía e Indicadores Sociales del Instituto Nacional de Estadística e Informática (INEI). ISBN 2009-15501.

Kane MT. (2001). Current concepts in validity theory. Journal of Educational Measurement; vol. 38: 319-342.

Kupermintz H. (2004). On the reliability of categorically scored examinations. Journal of Educational Measurement. Vol 41:193-204.

Kwok W.C.C, Sharp, D. J. (1998). A review of construct measurement issues in behavioral accounting research. Journal of Accounting Literature. Elsevier Vol. 17: 137-174.

Ledesma R., Molina G., Valero P. (2002). Análisis de consistencia interna mediante Alfa de Cronbach: un programa de gráficos dinámicos. Psico UFE. Universidad de Sao Francisco. Brasil. Vol 7: 143.152.

Ley universitaria. (2014). Ley 30220. Ley Universitaria. Congreso de la Repúplica del Perú. http://www.sunedu.gob.pe/nueva-ley-universitaria-30220-2014/. Visitado el 3 de enero de 2016.

Manpower (2012). Estudio ManpowerGroup sobre escasez de Talento. Resultados. Manpower Perú.

Manpower. (2013). Encuesta de Expectativas de Empleo. Manpower Perú.

Marshall, SJ. (1998). Professional development and quality in higher education institutions of the 21st century. Australian Journal of Education. Vol. 42, No 3: 321-334

McMillan, J. H., \& Schumacher, S. (2001). Research in education: A conceptual introduction. (5th Ed.). New York: Longman.

Nicholson, Karen (2011) Quality Assurance in Higher Education: A Review of the Literature. Council of Ontario Universities Degree Level Expectations Project. McMaster University, Canada

Osburn, H. G. (2000). Coefficient alpha and related internal consistency reliability coefficients. Psychol Methods. Vol 5: 343-355.

Pérez S., Rigoberto. (2010). Nociones Básicas de Estadística. Universidad de Oviedo. Segunda edición.

PISA. (2012). PISA 2012 results. OECD. http://www.oecd.org/pisa/keyfindings/pisa-2012results.htm. Visitado por última vez el 16 de diciembre de 2015.

RAE. (2014). Diccionario de la Lengua española. Real Academia Española. http:// www.rae.es/obras-academicas/diccionarios/diccionario-de-la-lengua-espanola Visitado el 18 de junio de 2014.

ROE, R. (2003). ¿Qué hace competente a un psicólogo? Papeles del Psicólogo. Revista del Colegio Oficial de Psicólogos. Núm. 83. 
Sánchez R; y Gómez C. (1998). Conceptos básicos sobre validación de escalas. Revista Colombiana de Psiquiatría.. Vol 27: 21 - 30.

SIGA. (2014). Sistema Integrado de Gestión Administrativa. Universidad de Piura. Visitado por última vez el 20 de junio de 2014 en https://sigadocentes.udep.edu.pe/siga/ administracion/gestionDocumentos/DocumentosInfo.seam?logic $=$ and\&cid $=11849$

SINEACE. (2014). Sistema Nacional de Evaluación, Acreditación y Certificación de la Calidad Educativa. República del Perú. http://www.sineace.gob.pe/. Visitado el 18 de junio de 2014.

Tobón, S. (2010). Proyectos formativos: aprendizaje y evaluación de competencias. Méjico. Book Mart.

Tobón, S. (2013b). Diseño de planes de estudio y proyectos para desarrollar competencias. Seminario Taller Internacional. Universidad Nacional de Ingeniería. Perú.

UDEP. (1998). IDEARIO. Universidad de Piura. Perú. Visitado por última vez el 24 de junio de 2014 en http://udep.edu.pe/ideario.html

UDEP. (2007). Metodología para revisión y actualización de los Planes de Estudio de las carreras de Ingeniería de la Universidad de Piura - 2007. Facultad de Ingeniería. Universidad de Piura.

UDEP. (2009). Discursos de apertura y Lecciones inaugurales. Universidad de Piura. Visitado por última vez el 17 de junio de 2014. http://beta.udep.edu.pe /apertura/ discurso-delrector-dr-antonio-abruna-puyol-apertura-del-ano-academico-del-2009/

UDEP. (2013). Memoria Anual 2012. Universidad de Piura.

UDEP F.I. (2014). Plan estratégico de la Facultad de Ingeniería 2014 - 2018. Universidad de Piura. Visitado por última vez el 24 de junio de 2014 en http://udeping.wix.com/planestrategico\#!que-es/c13qh

Quevedo, V., Vegas, S., \& Villar, R. (2011). Statistical approach for measuring the effectiveness of a remedial program for low-achieving undergraduate engineering candidates in Peru. In American Society for Engineering Education. American Society for Engineering Education.

Yamada, G.; Castro, J.; \& Rivera, M. (2012). Educación Superior en el Perú: Retos para el Aseguramiento de la Calidad. Estudio del SINEACE encargado a los especialistas. SINEACE. 
Capítulo VI

\section{Conclusiones}


- Se ha logrado diseñar un modelo educativo para la ingeniería industrial de Perú que facilita a los estudiantes la adquisición de competencias que les permiten, al egresar, desempeñarse profesionalmente con suficiencia técnica, con integridad personal, respeto por el entorno y con competencias para la dirección de proyectos en un contexto internacional. La formación integral ha sido comprendida en el modelo, lo que les permite afrontar los retos del contexto, uniendo al logro de metas personales a su contribución con el desarrollo social, tecnológico y ambiental de Perú.

- El modelo ha logrado integrar la escencia de la identidad de la universidad latinoamericana, las tendencias internacionales, las competencias que se exigen a un graduado de ingeniería industrial en el mundo laboral globalizado, con metodologías de planificación, enfoques educativos y modernas formas de gestión curricular en una sólida propuesta de gestión curricular que se aplica a un caso de una universidad peruana, con éxito.

- Para lograr este modelo, a lo largo del trabajo de investigación se han ido definiendo tópicos muy importantes para perfilarlo. El Modelo para la Educación Superior de la Ingeniería Industrial de Perú desde las Competencias (MESIC) ha requerido, en su conformación, consolidar los siguientes temas que se han argumentado a lo largo del trabajo:

- La identidad de la universidad latinoamericana encuentra su lugar en la universidad europea, hispánica, salmantina y boloñesa, particularmente en el enfoque napoleónico. Junto con esa identidad se presenta una realidad distinta: la universidad anglosajona, que desde su inicio, presenta significativas diferencias con la hispana - continental: la forma de gobierno (de profesores o de alumnos), las formas de aprendizaje y su evolución.

- En la definición de cualquier actuación que busque acercar la educación superior de Latinoamérica al EEES o al anglosajón debe considerarse que el crecimiento acelerado actual define corrientes que deben tenerse en cuenta, entre todas, la más importante es considerar la triple hélice: universidad-industria-sociedad para la definición de modelos educativos.

- La educación superior universitaria en el Perú tiene tendencias hacia la diversificación de la oferta, una mejor estructura, una organización competitiva y una mayor homogeneidad. Los indicadores de estas tendencias coinciden con el entorno latinoamericano y permiten establecer una visión común hacia dónde se deben dirigir las universidades peruanas, y es encaminarse como el Espacio Europeo de Educación Superior con miras a lograr características de la universidad norteamericana.

- Muy importante ha sido encontrar evidencias que el conocimiento, los procesos, la ciencia y la técnica pueden trasladarse de un territorio a otro con posibilidades de alcanzar resultados exitosos en nuevas regiones. En esas experiencias se ha verificado que las sociedades exitosas tienen más dificultad para cambiar y mantener su ventaja, y las sociedades atrasadas y con menos éxito son más propensas a adaptarse y progresar. Por esto es posible aplicar en Perú experiencias y tendencias exitosas en otros medios con altas posibilidades de éxito. 
- Una característica decisiva de la universidad norteamericana es la presencia de respaldo financiero a la educación superior tecnificada, logrando contundentes resultados si es sostenido en el tiempo. Se basa en dar un fuerte soporte a los laboratorios y en la convicción que debían egresar grandes números de ingenieros con el "nivel adecuado", sin demasiada sofisticación científica ni soberbiamente inteligentes, convirtiéndolos en el motor del desarrollo científico y tecnológico de sus países.

- La autonomía universitaria existente en Perú, no ha contribuido a una homogenización de planes de estudios en Ingeniería Industrial, pues cada universidad puede establecer el Plan más apropiado, según sus intereses. No existen directivas en cuanto a asignaturas, contenidos o cantidad de horas mínimas por área de conocimiento y carrera, así los planes de estudio de una misma titulación pueden diferir drásticamente entre universidades. Entonces, decidimos elegir una universidad destacada en Ingeniería para aplicar el modelo y luego poder replicarlo en el resto de universidades peruanas que lo deseen.

- La similitud con la universidad europea y la definición del Espacio Europeo de Educación Superior ha llevado a la necesidad de contar con una codificación de competencias genéricas que, sin restarle importancia a las técnicas, deben considerar el desarrollo de habilidades contextuales y de comportamiento, en un enfoque holístico, indispensable para el egresado de educación superior actual.

- Luego de comparaciones entre variados códigos de competencias se encuentra que la codificación de competencias TuningAL puede: satisfacer las exigencias de acreditación internacional, generar condiciones de gestión de proyectos, ser apropiadas para la formación en ingeniería y ser compatibles con los requerimientos de la educación superior latinoamericana.

- Las competencias genéricas son un contexto del aprendizaje de la ingeniería y no su contenido, que seguirá estando constituido por las competencias específicas de las distintas materias. Para poder transmitir las competencias genéricas a los alumnos, debe diseñarse un modelo educativo que estimule su adquisición y un Plan de estudios para la formación de ingenieros que incluya unas competencias específicas para su especialidad y contexto.

- Existen diversos enfoques para acometer la gestión educativa desde las competencias, de entre ellos el que mejor se adapta a nuestro Modelo es el socio-formativo, complementado por el funcionalista. Laplanificación del modelo se ha realizado bajo un enfoque de Análisis de políticas, fuertemente complementado con el aprendizaje social. Esta bidireccionalidad fundamentada en la acción, contemplando la participación de las personas afectadas y permitiendo la aplicación de normas, políticas y estándares, es ideal para el diseño y aplicación del modelo.

- El diálogo que se fomenta producto de la interacción de los actores en una planificación tiene sus raíces en las diferencias de conocimiento que existe entre ellos, la autoridad de unos y la experiencia práctica de otros permiten identificar el conocimiento experto y 
experimentado que deben recabarse con instruentos confiables para nutrir el proceso de diseño curricular. A esto debe sumarse que es necesario definir el contexto de acción y lo haremos desde un enfoque territorial, teniendo en cuenta que los enfoques territoriales no solo delimitan una porción o espacio de terreno, se centran en la compleja red de vínculos e interacciones entre los factores sociales, ambientales, culturales y económicos que delimitan, determinan y orientan el desarrollo en un territorio.

- Un componente imprescindible en un modelo educativo son los Aspectos Clave pues son los que orientan que orientan a la institución universitaria en torno a qué tipo de persona formar, para qué sociedad, en qué espacios educativos, con qué filosofía y con qué modelo de gestión de la calidad. Esta definición requiere de un profundo conocimiento de la axiología institucional y su visión de futuro. Estas definiciones llevan la gestión curricular por un camino u otro.

- Con esas definiciones encontradas, analizadas y sintetizadas, se ha conformado el Modelo Educativo para la Educación Superior de la Ingeniería Industrial de Perú desde las competencias (MESIC) concluyendo que sus componentes deben ser el territorio y sus condiciones, un modelo de planificación, un enfoque formativo, una estrategia de participación, y los aspectos clave (estos provienen de la concepción de modelo que se adopte y la axiología institucional). Es el territorio quien define el lugar, condiciones y actores implicados; los aspectos clave darán los lineamientos generales de acción en todos los ámbitos; el enfoque educativo desde las competencias será quien defina las fuentes y formas de trabajo; la planificación se hará por aprendizaje social y análisis de políticas, y las decisiones deben tomarrse considerando el conocimiento experto y experimentado.

- Consideramos que un modelo tan complejo como este requiere ser acompañado de una estrategia de aplicación, por lo que se define una de ocho fases que describe cómo actuar:

- Fase I: contextualización del territorio

- Fase II: aspectos clave a partir de los principios, valores y plan a futuro

- Fase III: los modelos de planificación de la enseñanza

- Fase IV: enfoque educativo

- Fase V: estrategia de participación

- Fase VI: contextualización de competencias

- Fase VII: diseño del Plan de estudios

- Fase VIII: aseguramiento de calidad

- La estrategia de aplicación del MESIC facilita la acción de los planificadores curriculares, ordena la secuencia de pasos y vuelve en una tarea muy ordenada y secunecial el difícil proceso de definir un Plan de Estudios y la respectiva gestión curricular para las ingenierías.

- En la contextualización de las competencias se comprobó la confiabilidad de los instrumentos de recolección de información, haciendo análisis de Cronbach corroborándose que en todos los casos eran confiables. Ninguno de los individuos encuestados en los cuatro grupos de interés incluyó una competencia adicional a las mostradas ni eliminó alguna, a pesar de habérseles indicado en las encuestas que podían hacerlo. 
- Es claro que una correcta gestión de un currículo por competencias pasa por la activa, voluntaria y comprometida participación de los docentes. No es posible tener resultados de la aplicación de un currículo o un sílabo por competencias si el docente no se ha comprometido con la nueva metodología ni con el objetivo que se pretende alcanzar. Del grado de implicación y dedicación que el docente muestre dependerá el grado en que los estudiantes logren aprendizajes significativos que además sean personal y socialmente valiosos, y que se revelen en competencias integradas en sus realidades humana, profesional y social.

- Si bien es cierto puede afirmarse que la aplicación está hecha para un caso particular y que cada institución presenta diferencias saltantes que no permiten enfrentar los procesos de la misma manera, la forma en que se ha construido el MESIC le permite una gran versatilidad y estamos seguros puede aplicarse a distintas instituciones e incluso, siguiendo la metodología desarrollada, puede tenerse modelos similares para realidades muy distintas a la peruana.

- La gestión curricular es posible desde el MESIC y tras la aplicación que se ha hecho, se proponen unas líneas de investigación futuras pendientes, como son: el estudio del impacto de los horarios en la adquisición de hábitos y competencias en los estudiantes, la conveniencia de la frecuencia de las evaluaciones y el aseguramiento de la calidad de un proceso formativo en la educación superior peruana

- Otra línea de investigación abierta es estudiar si al realizar este tipo de gestión curricular el tiempo que le demandará al docente universitario encarar este proceso, no irá en desmedro de su actividad investigadora. Se podrán lograr egresados con gran preparación en competencias específicas y con competencias genéricas que les hagan pensar reflexiva, lógoca y creativamente, con capacidad para el trabajo en equipo y el desarrollo de proyectos, pero la gran dusa actual es quiénes harán el trabajo investigador, ¿quedará reservado esto para algunos pocos? ¿es ese el fin de una universidad y responde a los requerimientos sociales? 
Capítulo VII

Bibliografía general 
Abarca Fernández, Ramón. (2007). Modelos pedagógicos, educativos, de exelencia e instrumentales y construcción dialógica. Universidad Católica Santa María. Perú. pp 8.

ABET (2009). Criteria for Accrediting Engineering Programs. Engineering Accreditation Commission. Effective for evaluations during the 2010-2011 accreditation cycle. See http://www.abet.org/forms.shtml\#For_Engineering_Programs_Only

ABET (2012). Criteria for Accrediting Engineering Programs. Effective for reviews during the 2013-2014 accreditation cycle. Engineering Accreditation Commission. ABET 2012. Visto por última vez en mayo de 2014 en http://www.abet.org/uploadedFiles/ Accreditation/Accreditation_Step_by_Step/Accreditation_Documents/Current/2013__2014/eac-criteria-2013-2014.pdf

ABET; EUR-ACE. (2007). Criteria for Accrediting Engineering Programs. Engineering Accreditation Commission.abet. U.S.A.

Ackoff, Russel. 1987. Scientific method: optimizing applied research decisions. New York. Editorial Jhon Wiley and sons.

Adell Segura, J. \& Castañeda Quintero, L. (2010) Los Entornos Personales de Aprendizaje (PLEs): una nueva manera de entender el aprendizaje. En Roig Vila, R. \& Fiorucci, M. (Eds.). Stumenti di ricerca per l'innovaziones e la qualità in ámbito educativo. Le Tecnologie dell'informazione e della Comunicaziones e l'interculturalità nella scuola. Alcoy: Marfil Roma. Università degli studi

Aguirre Beltrán, Gonzalo. (1960). Estructura y función de la universidad latinoamericana. Revista La Educación. Unión Panamericana Núm. 18. Año V, Washington, D.C. pp. 36-55.

Aguirre Beltrán, Gonzalo. (1961). La universidad latinoamericana y otros ensayos. Xalapa, 1961. Editorial Universidad Veracruzana. pp. 2-3.

Albornoz, Orlando. (1972. Ideología y política en la universidad latinoamericana. Instituto Societas. Caracas, 1972, pp. 113-118-119.

Aller, J.; De los Ríos, I. (1999). Rozas de Puerto Real: una estrategia de desarrollo sostenible. Madrid: Consejería de Medio Ambiente de la Comunidad de Madrid

Alvarez, María. (2005). Panorama laboral del ingeniero industrial egresado de universidades ubicadas en el departamento de Lima - Perú. Tesis de grado. Universidad Nacional Mayor de San Marcos. Perú.

América Economía. (2013). Ranking 2013 Perú: las mejores universidades. América economía http://rankings.americaeconomia.com/mejores-universidades-peru-2013/ingenieriaindustrial/. Visitado por última vez el 22 -05-2014

Anderson, G., Boud, D., Sampson, J. (1996). Learning contracts. A practical guide. RoutledgeFalmer. Londres.

ANECA. (2005). Ingeniero De Organización Industrial. Libro blanco de titulaciones de grado de ingeniería de la rama industrial: Capítulo V. http://www.aneca.es/ activin/activin_conver_LLBB_indus.asp. 
Arendt, H. (1958). The human Condition. Chicago: The University of Chicago Press.

Arocena, Rodrigo; y Sutz, Judith. (2000). La Universidad Latinoamericana del Futuro: Tendencias - Escenarios - Alternativas. Unión de Universidades de América Latina, UDUAL. México 2000.

Ashby, Erick; 1958. Technology and the academics: An essay on universities and the scientific revolution. Última edición Macmillan, Londres y Nueva Yorew York). ID: 101-188-916.

Attwell, G. (2007). The Personal Learning Environments - the future of eLearning? eLearning Papers, Vol. 2 No. 1. ISSN 1887-1542. http://www.elearningeuropa.info/ files /media/media11561.pdf

Augustine, N.; Vest, C. (1994). Engineering Education for A Changing World. Joint Project by the Engineering Deans Council and the Corporate Roundtable of the American Society for Engineering Education. ASEE, 1994.

Baker, D.P.; Day, R.; Salas, E. (2006). Teamwork as an Essential Component of High-Reliability Organizations. HSR: Health Services Research. Vol. 41, No 4: 1576-1598

Barroso, Luciana; Morgan, Jim; (2009). Project Enhanced Learning: Addressing ABET Outcomes and Linking the Curriculum. Journal of professional issues in engineering education and practice. ASCE. Jan. 2009, pp $11-20$.

Benjamin, Harold R. (1965). Higher Education in the American Republics. N. Y. McGraw-Hill. pp. 12-13, 35 y 45-48.

Bennett, James. (2004). The Anglosphere Challenge: Why the English-Speaking Nations Will Lead the Way in the Twenty-First Century. Rowman \& Littlefield. 352 pp, ISBN 0-7425$3332-8$

Bernasconi, A.; Rojas, F. (2004) Informe sobre la educación superior en Chile 1980 - 2003. Editorial universitaria. Chile.

Black, K.M. (1994). An Industry View of Engineering Education. Journal of the Engineering Education, Vol, $83 \mathrm{~N}^{\circ}$ 1: $15-18$.

Bland J. M., Altman D. G. (2002). Validating scales and indexes. British Medical Journal. Vol 24: 606-607.

BLS (2012).

Bragós, R, Alarcón E., Cabrera M., Calveras A., Comellas J., O’Callaghan J., Pegueroles J., Prat L., Sáez, G., Sardá J., Sayrol, E. (2010). Proceso de inserción de competencias genéricas en los nuevos planes de estudios de grado de la ETSETB de acuerdo al modelo CDIO. IX Congreso de tecnologías aplicadas a la enseñanza de la electrónica. Madrid 2010.

Brown, L., Nietupski, J. y Hamre-Nieupski, S. (2007). Criterios de funcionalidad última. Suports. Vol. 11, $\mathrm{N}^{\mathrm{o}} 1$

Brunner, José Joaquín. (2008). Educación Superior en América Latina: elementos para un enfoque comparativo. Conferencia Regional de educación superior 2008. IESALC (Instituto 
Internacional para la Educación Superior en América Latina y Caribe). UNESCO. Cartagena de Indias 2008.

Canós, Lourdes, García, José; García,Julio; Marin. (2009). Competencias profesionales y perfil del Ingeniero de Organización ante el Espacio Europeo de Educación Superior. Actas del Congreso. IV Congreso Cibersociedad, 2009. Visitado por última vez en junio de 2013 http://www.cibersociedad.net/congres2009/es/coms/eixos/

Casal, J., Mateu E. (2003). Tipos de muestreo. Revista de Epidemiología y Medicina Preventiva. Vol 1: 3-7.Consultado el 02 de junio de 2014 en http://www.mat.uson.mx/ ftapia/Lecturas $\% 20$ Adicionales $\% 20(\mathrm{C} \% \mathrm{C} 3 \%$ B3mo $\% 20$ dise $\%$ C3\%B1 ar\%20una \%20encuesta)/TiposMuestreo1.pdf.

Catenacci, B. (2000): Local Economic Development Agencies. UNOPS, OIT. Roma: Cooperazione Italiana.

Cazorla, A. (2007). La Innovación para el desarrollo: Modelos de planificación. Obtenido el 7 de enero de 2011, de http://expgrafica.uma.es/Asignaturas/doctorado/ingenieria/ document07/Innovacionparael desarrollo1.pdf

Cazorla, A., De los Ríos, I., \& Salvo, M. (2007). Desarrollo rural: modelos de planificación. Universidad Politécnica de Madrid. Ed. Peninsular. España.

Cazorla, A., De los Ríos, I., \& Salvo, M. (2013). Working With People (WWP) in Rural Development Projects: a Proposal from Social Learning. Cuadernos de Desarrollo Rural, 10 (70), 131-157.

CE IP/12/1233. (2012). "La Comisión presenta la nueva estrategia Replantear la Educación". Comisión Europea. Comunicado de prensa IP/12/1233. Bruselas, Estraburgo, noviembre 2012.

CE IP/12/394. (2012). Comunicación a los Ministros del Proceso de Bolonia: la reforma de la educación superior es clave para el empleo y el crecimiento. Comisión Europea. Comunicado de prensa IP/12/394, del 25/04/2012.

Censo universitario. (2010). II Censo Nacional Universitario 2010 ). Instituto Nacional de Estadística (INEI). http://www.coneau.gob.pe/noticias/ii-censo/Exposicion_Jefe _INEI.pdf

Cepal. (2010). Anuario estadístico de América Latina y el Caribe. Comisión económica para América Latina y el Caribe. ONU 2010. p 24.

Cepeda Juan; Sánchez Alfredo; Verástegui Jesús. (2006). Proceso de Bolonia: Enseñanzas y Cooperación entre las Instituciones de Educación Superior Mexicanas y sus Homólogas Europeas. Memorias del 3er Congreso Internacional sobre Docencia. p 376

Chen, C.; Jiang, B. C.; Hsu, K. (2005). An empirical study of industrial engineering and management curriculum reform in fostering students' creativity. European Journal of Engineering Education, 30 (2): 191-202. 
Chinnowsky, P., Brown, H., Szajnman, A. \& Realph, A. (2006) Developing knowledge landscapes through project-based learning. Journal of Professional Issues in Engineering Education and Practice, 132(2), (118-125).

Chomsky, N. (1970). Aspectos de la teoría de la sintaxis. Madrid: Editorial Aguilar.

Cleary, Dervla. (2003). Estrategias enfocadas hacia las personas: Breve estudio bibliográfico y comparativo. Programa de Apoyo a los Modos de Vida Sostenibles (LSP). FAO. ONU.

Cohen, L., Manion, L. \& Morrison, K. (2003). Research methods in education. (5ª edición). Londres, Reutledge Farmer.

Colburn, Forrest D. (2002). Latin America at the End of Politics. Princeton University Press. ISBN 0691091811.

CONEAU. (2010). Estándares para la Acreditación de las Carreras Profesionales Universitarias de Ingeniería. Consejo de Evaluación, Acreditación y Certificación de la Calidad de la Educación Superior Universitaria (CONEAU)

CONEAU. (2012). Estándares de calidad para la acreditación de las carreras profesionales universitarias de ingeniería. Tomo IX. CONEAU

CONEAU. (2014). Consejo de Evaluación, Acreditación y Certificación de la calidad de la Educación Superior Universitaria. República del Perú. Visitado el 18 de junio de 2014. www.coneau.gob.pe

Congreso de la República del Perú. (2006). Ley 28740 Ley del Sistema Nacional de evaluación, acreditación y certificación de la calidad de la educación. Título II, Artículo 18. Cuninggim, Merriman. 1969. The Integrity of the University. Educational Record, Vol 2. p 39. Cita de Clark Kerr.

Cotterell, Arthur .2000. Historia de las civilizaciones antiguas. Tomo 1. Editorial Crítica, Provenza. Barcelona.

Crawley, E. F; Malmqvist, J.; Östlund, S.; Brodeur, D. (2007). Rethinking engineering education: the CDIO approach. (2007) Springer Science.

Crawley, Edward F.. (2001). The CDIO Syllabus. A Statement of Goals for Undergraduate Engineering Education. http://www.cdio.org

Crawley, Edward; Jianzhong, Cha; Malmqvist, Johan; Brodeur Doris; (2008). The context of engineering education. Proceedings of the 4th International CDIO Conference, Hogeschool Gent, Belgium. June 2008.

Creswell, John W. (2014 ). Research Design: Qualitative, Quantitative, and Mixed Methods Approaches. University of Nebraska, Lincoln. SAGE Publications, Inc. (4a edición ISBN: 9781452226101).

Cullen, J., Joyce, J., Hassal, T., \& Broadbent, M. (2003). Quality in higher education: From monitoring to management. Quality Assurance in Education. Vol 11, No(1): 5-14.

Cuninggim, Merrimon. (1969). The Integrity of the University. Educational Record. USA 
De los Ríos, I.; Guerrero, D. \& Díaz-Puente, JM. (2008). Las competencias profesionales: marco conceptual y modelos internacionales. Actas II Jornadas Internacionales UPM sobre Innovación Educativa y Convergencia Europea 2008 (INECE'08).

De los Ríos, Ignacio; Cazorla, Adolfo; Díaz-Puente, José; Yagüe, José. (2010). Aprendizaje basado en la ingeniería del proyecto de educación superior: dos décadas de las competencias docentes en entornos reales. Procedia Social and Behavioral Sciences (2010), (1368 - 1378). Science direct, 2010

De Miguel Fernández, E., (2005). Introducción a la gestión (management).Valencia: Editorial de la Universidad Politécnica de Valencia. ISBN 8497057503

De Miguel, M. (2005). Modalidades de enseñanza centradas en el desarrollo de competencias: Orientaciones para promover el cambio metodológico en el Espacio Europeo de Educación Superior. Madrid: Ediciones Universidad de Oviedo.

\section{Desarrollo peruano. (2012). E1 Perú en el Ranking Latinoamericano: Crecimiento}

Acumulado del PBI en el Siglo XXI. http://desarrolloperuano.blogspot. com.es /2012/04/el-peru-en-el-ranking-latinoamericano.html

Díaz Barriga, F, Lule, M. Rojas, S. y Saad, S. (1995). Metodología de Diseño Curricular para la Educación Superior. México. Trillas.

Díaz, Angel. (2005). El enfoque de competencias en la educación ¿ Una alternativa o un disfraz de cambio? Revista Perfiles Educativos. UNAM.

Downey, G., \& Lucena, J. (2004). Knowledge and professional identity in engineering: Codeswitching and the metrics of progress. History and Technology, 20(4), 393-420.

Dukhan, N. (2008). Implementation of service-learning in engineering and its impact on students' attitudes and identity. European Journal of Engineering Education, 33(1), 21-31.

Eiroa, Jorge J. (1994). La prehistoria: paleolítico y neolítico. Ediciones Akal. Madrid

Eliot, Matt; Turns, Jennifer. (2011). Constructing Professional Portfolios: Sense-Making and Professional Identity Development for Engineering Undergraduates. Journal of Engineering Education. October 2011, Vol. 100, No. 4, pp. 630-654

Elsayed, E.A.. (1999). Industrial Engineering Education: A Prospective. European Journal of Engineering Education, volumen 24, $\mathrm{N}^{\circ} 4$, pp. 415-421.

Escobar, Jaime. (1999). Historia de las universidades. Revista Medicina. Academia Nacional de Medicina de Colombia. Vol. 21 No. 1 (49), Marzo 1999.

European Commission. (2014). Vacancies, hirings and job prospects. Employment, Social Affairs \& Inclusion. European Vacancy Monitor. Volumen No. 12 / Febrero 2014. ISSN: 1977-3897

Felder, RM; Woods, DR; Stice JE; Rugarcia, A. (2000). The Future of Engineering Education II: Teaching Methods that Work. Chemical Engineering Education, v. 34, 1, 2000 pp. 2639. 
Felder, R.M.; Brent, R.; (2003). Designing and Teaching Courses to Satisfy the ABET Engineering Criteria. Journal of the engineering Education. 92(1), 7-25.

Felder, Richard; Brent, Rebecca. (2004) The ABC's of engineering education ABET, Bloom's taxonomy, cooperative learning, and so on. Proceedings of the 2004 American Society for Engineering Education Annual Conference \& Exposition.

\section{Fernández Lamarra, Norberto. (2005). Hacia la convergencia de los sistemas de} educación superior en América Latina. OEI - Revista Iberoamericana de Educación. Número 35.

Ferrer, Thaís; Pelekais, Cira de. (2004) Tendencias gerenciales y la gestión universitaria”. Revista de Ciencias Sociales. Universidad del Zulia, Venezuela. Enero-abril 2004, vol X, número 001. pp. 148-163.

Figuera, Juan Ramón, 2007. Análisis del pasado de la Ingeniería de Organización en España para mantener su competitividad en el futuro. International Conference on Industrial Engineering \& Industrial Management - CIO 2007. Innovation in Education and Professional Skills p.p 931- 940.

Fontana, Alejandro. (2012). La Gobernanza en las Políticas de la Cooperación Internacional para el Desarrollo: Análisis y Modelo de Aplicación al Perú. Tesis Doctoral. ETSI Agrónomos. Universidad Politécnica de Madrid.

Fortea, Miguel Ángel. (2009). Metodologías didácticas para la Enseñanza/Aprendizaje de competencias. Formació professorat de la Unitat de Suport Educatiu. Universitat Jaume I.

Friedmann, John. (1991). Planificación en el ámbito público. Colección Estudios. Serie, Administración general. Madrid: Ministerio para las Administraciones Públicas.

Friedmann, John. (1992). Planificación Para el siglo XXI: el desafío del posmodernismo. Revista EURE. Vol XVIII, No 55, pp 79-89. Santiago de Chile.

Friedmann, John. (1993). Toward and non-euclidean mode of planning. Journal of American planning Association. 482. Chicago.

Friedmann, John. (2001). Planificación en el ámbito público: del conocimiento a la acción. Madrid: Ministerio para las Administraciones Públicas.

Fundora Herrera, Gilberto. (2010). La educación superior avanzada: Calidad, Equidad y Pertinencia: Tasas de Coberturas Terciarias en América Latina y el Caribe. Pedagogía Universitaria Vol. XV. № 1. 2010. Ministerio de Educación Superior, Cuba.

Gacel-Ávila, Jocelyne. (2006). Calidad y educación sin fronteras. Apertura pp 76- 91. Jalisco, México

Gallwey, T. J. (1992). Europe needs Industrial Engineering degrees in order to enhance its conpetitiveness. European Journal of Engineering Education. 17(1): pp. 51-57.

García A., Lupe; Meza B., Aníbal; Sarria J., César; et al. (2010. Principios, lineamientos, y programa: propuesta para la gestión del gobierno 2004 - 2007 de la UNMSM, Lima, Perú. Revista IIPSI. Vol. 13. N 1. 2010. 273 - 282 
García Borrajero, N.H. (2010). Breve cronología del conocimiento científico-técnico desde la antigüedad hasta la ingeniería industrial. Contribuciones a las Ciencias Sociales, octubre 2010. www.eumed.net/rev/cccss/10/

García, F.J., y. Fortea, M.A. (2006). Ficha metodológica de contrato didáctico o contrato de aprendizaje. Coordinada por Universitat Jaume I. Generalitat Valenciana.

García, María José; Terrón, Ma José; Blanco, Yolanda. (2010). Desarrollo de Recursos Docentes para la Evaluación de Competencias Genéricas. ReVisión. Vol 3. No 2

Gazzola, Ana Lucía; Didriksson Axel. (2008). Tendencias de la Educación Superior en América Latina y el Caribe. IESALC-UNESCO. Caracas. ISBN: 978-958-98546-2-4

Gob.Pe. (2014). Ley 23733. Ley Universitaria. Congreso de la República del Perú. Visitado por última vez el 24 de junio de 2014 en http://www.peru.gob.pe/docs/PLANES/10402/PLAN_10402_Ley\%20Universitaria_20 10.pdf

González G., Ignacio. (1966). Estructura de la universidad latinoamericana. Grupo Universitario Latinoamericano de Estudio para la Reforma y Perfeccionamiento de la Educación (GULERPE). Segunda Reunión. 1966. Universidad del Valle, Colombia. Carvajal y Cía. Colombia. 23-26.

González Prats, Alfredo. (1991). "La edad del cobre en Mesopotamia (5500-3000 aC)". Universidad de Alicante. España.

González, J., y Wagenaar, R. (2003). Tuning educational structures in Europe. Informe final fase uno. Bilbao: Universidad de Deusto.

Graubard, Stephen R. (1968). Notes on Higher Education. Mimeographed Boston, American Academy of Arts and Sciences. Abril de 1968. pp 16-17.

Grupo de opinión. (2007). Encuesta sobre demanda de profesionales en la empresa. Grupo de opinión pública de la Universidad de Lima. Setiembre octubre 2007. http://www.ulima.edu.pe/webulima. nsf/default/4BE58345536E B3BC05256E630017BCED/\$file/bemp9.pd

Guerrero, Dante. (2011). Modelo de aprendizaje y certificación en competencias en la dirección de proyectos de desarrollo sostenible. Tesis Doctoral. Universidad Politécnica de Madrid. ETSI Agrónomos.

Guerrero, Dante; De los Ríos, Ignacio. (2013). Modelos internacionales de competencias profesionales. DYNA: Ingeniería e industria, 88 (3), 266-270.

Hansen, Joergen. (2004). International Engineering Students in Cross-cultural, Interdisciplinary Teams. International Conference on Engineering Education and Research "Progress Through Partnership". Ostrava, pp 523 - 527.

Harvey, L.; Green, D. (1993). Defining quality. Assessment and Evaluationin Higher Education. Vol. 18 No $1: 9-3$ 
Hernández C. Adolfo. (2007). Competencias: modelo de formación integral para el mundo del trabajo. Revista Coepes. Guanajuato.

Hicks Philips E. (2002) Ingeniería industrial y administración. CECSA, Editorial 27. México, Distrito Federal:.

Hobsbawn, Erich (1994). The age of the extremes. History of de world, 1914 - 1941. Pantheon books. New York. USA.

Hobsbawn, Erich (1996). The age of the capital. 1848 - 1875. Vintage books. New York. USA.

Holden, Meg. (2008). Social learning in planning: Seattle's sustainable development codebooks. Progress in Planning, 69 (1), 1-40.

Hutchins, Robert M. (1967). The Issues. The University in America Congress. Santa Bárbara, Calif. Center for the Study of Democratic Institutions. 1967. p. 5.

IIE. (2011). Visitado en abril 2012. http://arisecenter.eng.fiu.edu/iie_latino/.

Imbernón, F.; et al. (1999). La educación en el siglo XXI. Los retos del futuro inmediato. 1999. Biblioteca de Aula, Barcelona, págs. 101 - 114]

Inciarte, A.; Canquiz L. (2007). Formación Integral y Currículo por Competencias. Facultad de Humanidades y Educación. Universidad del Zulia.

INEI. (2009). Perú: Estimaciones y proyecciones de población por sexo según departamento, provincia y distrito. Boletín Especial N 18. Dirección Técnica de Demografía e Indicadores Sociales del Instituto Nacional de Estadística e Informática (INEI). ISBN 2009-15501.

INEI. (2012). Perú en cifras. Instituto Nacional de Estadística e Informática. http://www.inei.gob.pe/

INEI. (2014). Informe Técnico Evolución de la Pobreza 2009-2013. INEI Perú. Lima, mayo 2014

IPMA (International Project Management Association). (2009). Nacional Competence Baseline. V3.0, Revisión 3.1. Asociación Española de Ingeniería de Proyectos. Valencia (2009). AEIPRO.

Jackson, H.; Tarhini, K.; Zapalska, A.; Zelmanowitz, S. (2010). Strategies to Infuse Global Perspectives and Industrial Collaboration in Engineering Education. 40th ASEE/IEEE Frontiers in Education Conference. October2010 Washington, DC

Johnson, D; Johnson, R. y Smith, K. (1997). El Aprendizaje Cooperativo Regresa a la Universidad; Qué Evidencia Existe de que Funciona. Universidad de Minnesota.

Kane MT. (2001). Current concepts in validity theory. Journal of Educational Measurement; vol. 38: 319-342.

Kaplan, Marcos (1996). Universidad nacional, sociedad y desarrollo. Asociación nacional de universidades e instituciones de educación superior, ANUIES. Dirección de servicios editoriales. México. ISBN 968-6297-98-7 
Kemmis, Stephen (1998). El curriculum: más allá de la teoría de la reproducción. Morata. Madrid.

Khan, Salman.. (2012). Why Long Lectures Are Ineffective?. Time Ideas, 2 de octubre. Visitado por última vez el 06 de junio de 2014 en http://ideas.time.com/2012/10/02/why- lecturesare-ineffective/

Kupermintz H. (2004). On the reliability of categorically scored examinations. Journal of Educational Measurement. Vol 41:193-204.

Kwok W.C.C, Sharp, D. J. (1998). A review of construct measurement issues in behavioral accounting research. Journal of Accounting Literature. Elsevier Vol. 17: 137-174.

Ledesma R., Molina G., Valero P. (2002). Análisis de consistencia interna mediante Alfa de Cronbach: un programa de gráficos dinámicos. Psico UFE. Universidad de Sao Francisco. Brasil. Vol 7: 143.152.

Lemasson, J.P. y Chiappe M. (1998). La investigación universitaria en América Latina, CRESALC, Caracas

Levy-Leboyer, C. (1996). Gestión de las competencias. Barcelona: Ediciones Gestión 2000.

Ley universitaria. (2014). Ley 30220. Ley Universitaria. Congreso de la Repúplica del Perú. http://www.sunedu.gob.pe/nueva-ley-universitaria-30220-2014/. Visitado el 3 de enero de 2016.

Llano, Alejandro. (2001). Claves para educar a la generación del Yo. Revista Nuestro Tiempo. Vol 01, 2001

Lobato F., Clemente. (2006). Estudio y trabajo autónomo del estudiante. En De Miguel D., Mario (coord.) Metodologías de enseñanza y aprendizaje para el desarrollo de competencias. Alianza Editorial. Madrid: 191-223.

Lockard, Craig A. (2010). The sea Common to All: Maritime frontiers, Port cities, and Chinese Traders in the Southeast Asian Age of Commerce, ca. 1400-1750. Journal of World History, Jun2010, Vol. 21 Issue 2, pp. 219-247.

López Segrera, Francisco. (2007). Transformación Mundial de la Educación Superior Universidad de Guadalajara. 26, 316

López Segrera, Francisco. (2010). El impacto de la crisis económica mundial en la educación superior mundial y regional. Educación superior y sociedad. Ediciones IESALC. Año 15. No 1.

López Segrera, Francisco. (2011). Tendencias de la educación superior en América Latina y el Caribe: Un estudio comparado. Universidad de Guadalajara.

Loui, M. C. (2005). Ethics and the development of professional identities of engineering students. Journal of Engineering Education, 94(4), 383-390.

Luján-Mora, Sergio. (2013) Revista de Docencia Universitaria. Vol.11 (Número especial, 2013), 279-300. ISSN: $1887-4592$ 
Lynch, N. (2013). La autonomía universitaria. Otra mirada. Página web http://www.otramirada.pe/content/la-autonomía-universitaria , visitada por última vez el 20-052014.

Maffioli, Francesco; Augusto, Giuliano. (2003). Tuning engineering education into the European higher education orchestra. European Journal of the Engineering Education. (pp $251,273)$

Malo, Salvador. (2004). El proyecto 6x4 UEALC. Seis profesiones en cuatro ejes. CENEVAL, México.

Manpower (2012). Estudio ManpowerGroup sobre escasez de Talento. Resultados. Manpower Perú.

Manpower. (2013). Encuesta de Expectativas de Empleo. Manpower Perú.

Marín -García, J.A.; Garcia-Sabater, J.P.; Miralles, C.; Rodríguez, A.; Andrés, C., (2008), La Ingeniería de Organización en un entorno educativo globalizado: reflexiones y propuestas para la Universidad Española. II International Conference on Industrial Engenieering and industrial management. XII Congreso de Ingeniería de Organización. Burgos, pp. 817-826.

Marin-Garcia, J.; Garcia-Sabater, J; Perello-Marin, R; Canos-Daros, L. (2009). Propuesta de competencias para el Ingeniero de Organización en el contexto de los nuevos planes de estudio. Intangible Capital, 2009

Markes, I. (2006). A review of literatura on employability skills needs in engineering. European Journal of Engineering Education. 31(6): pp 637-650.

Marquès Graells, Pere. (2000). Los docentes: Funciones, roles, competencias necesarias, formación. Universidad autónoma de Barcelona. UAB 2000

Marshall, SJ. (1998). Professional development and quality in higher education institutions of the 21st century. Australian Journal of Education. Vol. 42, No 3: 321-334

Martínez Moya, Armando. (2005). De la Universidad Colonial a la Universidad Napoleónica. Revista Historia de la Educación Latinoamericana - RHELA. Vol. 7, año 2005, 257 - 272

Martinez, C.; Calvet P., D.; Pons, O.; Tura, M.; (2007). Inserción laboral de las titulaciones de la subárea de tecnologías avanzadas de producción. International conference on Industrial engineering and Industrial Management. II International Conference on Industrial Engenieering and industrial management. XII Congreso de Ingeniería de Organización. Burgos, pp 985-992

Mazzilli, Sueli. (1996): "Ensino, pesquisa, extensao: uma associaçao contraditótia", Tesis doctoral, Universidad Federal de San Carlos, Brasil.

McClelland, D.C. (1973). Testing for competencies rather than intelligence. American Psychologist. No 28, 1-14

McClelland, D.C. (1993). Introduction. En Competence at work. New York: John Wiley and Sons. 
McMillan, J. H., \& Schumacher, S. (2001). Research in education: A conceptual introduction. (5th ed.). New York: Longman.

Menacho Chiok, Luis Pedro. (2007). Historia de la educación superior y de posgrado. Oficina de Trámite Documentario y Archivo - OTDA. MIMDES. Perú.

Mereddu Torres, César (2006). Pragmatismo, ética y carrera académica en la educación superior. Reencuentro 45, México. Pp. 8-16

Miranda Sara, L. (2012). Ordenamiento territorial: integración de enfoques y contribuciones metodológicas al proceso peruano. Actualidad gubernamental. $\mathrm{N}^{\circ} 39$.

Monzón, Ricardo. (2014). Perú segundo país de Sudamérica con más universidades. http://peru21.pe/noticias-de-conafu-105859?href=nota_tag, visitado por última vez el 2005-2014

Mureddu, César. (1994). Educación y universidad: el modelo francés de universidad moderna. ITAM, 1994.

Narez Melgoza, Erika. (2011). Influencia de los países anglosajones en el mundo globalizado. http://lessonplansandtips.blogspot.com.es/2011/09/influencia-de-lospaises-anglosajones.html

NCSES, (2012). National Center for Science and Engineering Statistics. Science and Engineering Degrees: 1966-2008. Detailed Statistical Tables NSF 11-316. National Science Foundation, 2011. Arlington, Virginia, USA.

Nicholson, Karen (2011) Quality Assurance in Higher Education: A Review of the Literature. Council of Ontario Universities Degree Level Expectations Project. McMaster University, Canada

NRC (1985). National Research Council. Engineering Education and Practice in the United States. National Academy Press. Washington DC.

O’Connor, K., Amos, D., Bailey, T., Garrison, L., Lichtenstein, G., Loshbaugh, H., \& ... Stevens, R. (2007). Sponsorship: Engineering's tacit gatekeeper. Proceedings of the 2007 American Society of Engineering Education Conference, Honolulu, HI.

OECD. (2011). Education at a Glance 2011: OECD Indicators. Organization for Economic Cooperation and Development. 2011.

OEI. (2010). 21st Century Skills and Competences for New Millennium Learners in OECD Countries. Instituto de tecnologías educativas. OCDE. OEI. EDU 41.

Ogliastri, Enrique. (2008). Tendencias en la universidad europea. Editorial Tiempo. Colombia OIT. (2010). Políticas salariales en tiempos de crisis. Informe mundial sobre salarios 2010/2011. Santiago de Chile, Organización Internacional del Trabajo, 2010. p 16.

OIT. (2011. Panorama Laboral 2011: América Latina y el Caribe. Oficina Regional de la OIT para América Latina y el Caribe. pp 48, 49, 51 
OIT. (2012). Informe de competencias para el empleo - Orientaciones de política: mejorar sistemas de aprendizaje. Organización Internacional de trabajo.

OIT. (2012). Informe Mundial sobre Salarios 2012-13: Los salarios y el crecimiento equitativo. Conditions of Work and Employment Branch(TRAVAIL). ISBN: 978-92-2-126236-7

Olvera, René B. (2009). Educación Superior en América Latina y el Proceso de Bolonia: Alcances y Desafíos. REMO: Volumen VI, Número 16 México, Enero-Abril de 2009. pp $50-58$

Ortega y Gasset, José. (1964) Meditación de la Técnica. Obras Completas; Revista de Occidente, Madrid, 1964, 6 a ed., Vol. V, p. 304.

Osburn, H. G. (2000). Coefficient alpha and related internal consistency reliability coefficients. Psychol Methods. Vol 5: 343-355.

Pant, Ira; Baroudi, Bassam. (2008). Project management education: The human skills imperative. International Journal of Project Management. 26 (2008). (124-128). Science Direct.

Paoli, Ugo Enrico. (1944). La vida en la Roma antigua. Iberia. Barcelona. España.

Pérez S., Rigoberto. (2010). Nociones Básicas de Estadística. Universidad de Oviedo. Segunda edición.

Pérez, Carlota. (2000. La reforma educativa ante el cambio de paradigma. Revista EUREKA, Pág. 61. Universidad Católica Andrés Bello, Caracas, 2000.

Pérez-Estevez, Antonio. (2004). LA universidad venezolana: de la colonia a la crisis actual Revista internacional de filosofía iberoamericana y teoría social. Año 9. N²7. Pp 97-101.

PISA. (2012). PISA 2012 results. OECD. http://www.oecd.org/pisa/keyfindings/pisa-2012results.htm. Visitado por última vez el 16 de diciembre de 2015.

Pister, K.S.. (1993). A Context for Change in Engineering. Journal of Engineering Education, Vol. 82, No. 2: 66-69.

Poblete R., Manuel. (2007). Evaluación de competencias en la educación superior. Preguntas clave que sobre evaluación de competencias se hacen los profesores. Tentativas de respuesta. III Jornadas Universitarias de Innovación y Calidad "Buenas Prácticas Académicas". Bilbao.

Poblete, M. \& Gracía, A. (2007). Desarrollo de competencias y créditos transferibles: experiencia multidisciplinar en el contexto universitario. Ediciones Mensajero. Universidad Deusto. Bilbao.

Polo, Leonardo. (1993). Quién es el Hombre. Servicio de Publicaciones de la Universidad de Piura. p. 112. Primera edición.

Polo, Leonardo. (1999). Antropología trascendental. EUNSA. Pamplona. 245 pags.

Popper Karl R., et al. 1978. La lógica de las ciencias sociales. México. Editorial Grijalbo.

Prados, J.W. (1997). The Editor's Page: Engineering Criteria 2000-A Change Agent for Engineering Education. Journal of Engineering Education. Vol. 86, No. 4. 
Prados, John. (1998). Engineering Education in the United States: Past, Present, and Future. International Conference on Engineering Education. Proceedings of ICEE'98, pp. 17 - 20.

Prince, M., \& Felder, R. (2006). Inductive Teaching and Learning Methods: Definitions, Comparisons, and Research Bases. Journal of Engineering Education , 123-138.

Proyecto Tuning (2007). Reflexiones y perspectivas de la Educación Superior en América Latina. Informe Final - Proyecto Tuning - América Latina. 2004-2007 http://tuning.unideusto.org/tuningal.

Proyecto Tuning. (2007). Reflexiones y perspectivas de la Educación Superior en América Latina. Informe Final. Proyecto Tuning - América Latina. 2004

Pujolàs, Pere. (2012). Aulas inclusivas y aprendizaje cooperativo. Educatio Siglo XXI. Vol. 30 $\mathrm{N}^{\circ}$ 1: 89-112.

Quevedo, V., Vegas, S., \& Villar, R. (2011). Statistical approach for measuring the effectiveness of a remedial program for low-achieving undergraduate engineering candidates in Peru. In American Society for Engineering Education. American Society for Engineering Education.

Quiroz Chueca, Francisco. (2001). De la Colonia a la República independiente. Barcelona. Editorial Lexus. pp 165.

RAE. (2005). Diccionario Panhispánico de dudas. Real Academia Española. Asociación de academias de lengua española. Ed. Santillana. ISBN 9788429406238. Octubre 2005. Primera edición.

RAE. (2014). Diccionario de la Lengua española. Real Academia Española. http:// www.rae.es/obras-academicas/diccionarios/diccionario-de-la-lengua-espanola Visitado el 18 de junio de 2014.

Rama, Claudio. (2006a). La Tercera Reforma de la educación superior en América Latina. Educación, Lenguaje y Sociedad. Vol. IV No 4 (Diciembre 2006). Fondo de Cultura Económica. pp 195-200

Rama, Claudio. (2006b). La metamorfosis de la educación superior. Informe final sobre la educación superior en américa Latina y el Caribe 2000-2005. IESALC. UNESCO. pp 11 15.

Rama, Claudio. (2010). Seminario de doctorado. Doctorado de Ciencias de la Educación. Escuela de comando y Estado Mayor del Ejército de Bolivia. Universidad Militar de las Fuerzas Armadas de Bolivia. http://www.slideshare.net/claudiorama/historia-de-laeducacin-superior-tendencias-y-nuevos-retos-en-amrica-latina

Ribeiro, Darcy. (1971). La universidad latinoamericana. Editorial Universitaria, Santiago de Chile. p. 107.

Rivero García, Luis (2005). El crédito ECTS y la nueva estructura universitaria. Comisión Andaluza para el EEES. Universidad de Cádiz. 
Robles Ortiz, Elmer. (2006). Origen de las universidades más antiguas del Perú. Revista Historia de la Educación Latinoamericana, año 2006/vol. 8. Universidad Pedagógica y Tecnológica de Colombia. pp. 35-48

Roco, Mihail; Tomellini, Renzo. (2002).Revolutionary Opportunities \& Societal Implications. 3rd Joint EC - NSF Workshop on Nanotechnology. Istituto Nazionale per la Fisica della Materia. Lecce (Italy), February 2002.

Rodríguez Cruz, Agueda María. (2005). La Universidad de Salamanca en Hispanoamérica”. Salamanca, Ediciones Universidad de Salamanca, 2005.

Rodríguez-Gómez, Roberto. (1999). La universidad latinoamericana en la encrucijada del siglo XXI Revista Iberoamericana de Educación.21 (1999): 55-77.

ROE, R. (2003). ¿Qué hace competente a un psicólogo? Papeles del Psicólogo. Revista del Colegio Oficial de Psicólogos. Núm. 83.

Rojas, Raúl. 2013. "Guía para realizar investigaciones sociales”. México. Editorial Plaza y Valdés, p.p. 37-38.

Romero H., Omar; Muñoz, David; Romero H., Sergio (2006). Introducción a la ingeniería. Un enfoque industrial. International Thompsom editores. México. ISBN 9706865551

Romero, F. (2003). El perfil del ingeniero industrial generalista en el nuevo espacio europeo. Jornada: El Ingeniero Superior Industrial en el Nuevo Espacio Europeo. Universitat Jaume I. Mayo 2003. http://www.cinei.uji.es/estud_ perfil/docs/Jornada16mayo/Presentacion \%20F.Romero.pdf

Rosario, Jimmy. (2006). El Internet Herramienta de Innovación para la Educación a Distancia 5to. Congreso Internacional de Educación Superior. La Habana, Cuba.

Rousseau, V., Aube, C., Savoie, A. (2006). Teamwork behaviors: A review and an integration of frameworks. Small Group Research. Vol. 37 No 5: 540-570.

Rubia Avi, Mariano; Marbán Prieto, José. (2006). El papel de las nuevas tecnologías en el desarrollo de proyectos piloto de innovación docente. Revista Latinoamericana de tecnología educativa. Vol 5. $\mathrm{N}^{\circ}$ 2. 301 - 308

Sáenz de Buruaga, Gonzalo. (1980). Ciudad y territorio. Revista de ciencia urbana. Núm. 1, 17 $-28$

San Marcos, 2013. Universidad Nacional Mayor de San Marcos. Facultad de Ingeniería Industrial. http://industrial.unmsm.edu.pe/es.resena_historica.php Visitado el cinco de junio de 2013.

Sánchez Ferrer, Leonardo. (1996). Políticas de reforma universitaria en España: 1983-1993. Tesis Doctoral. Univ. de Salamanca.

Sánchez R; y Gómez C. (1998). Conceptos básicos sobre validación de escalas. Revista Colombiana de Psiquiatría.. Vol 27: 21- 30.

Sánchez, Luis Alberto. (1969). La universidad latinoamericana. Editorial universitaria de San Carlos de Guatemala. 6-11, 19. 
Santamaría, Rocío. (2001). La Unión de Universidades de América Latina: 51 años en la historia de la educación superior latinoamericana. Revista universidades $\mathrm{N}^{\circ} 21$. UDUAL.

Saravia G., Ana María; Amorim, Luisa F. (2009). Influencia de la ingeniería en el desarrollo comercial de la humanidad. Edad antigua. Revista Lámpsakos. Fundación universitaria Luis Amigó. No 2, 2009, págs. 79-89. ISSN 2145-4086.

Sarton, George. (1970). Historia de la ciencia: la ciencia antigua durante la edad de oro griega. Vol. 1. Eudeba.

Schejtman, Alejandro y Berdegué, Julio. (2003). Desarrollo Territorial Rural. En Desarrollo territorial rural en América Latina y el Caribe: manejo sostenible de recursos naturales, acceso a tierras y finanzas rurales. Editado por Rubén G. Echeverría. Ed. del Banco Interamericano de Desarrollo, Washington, D.C.

Schwartzman, S. (1979): Formaçao de comunidade científica no Brasil. FINEP. Río de Janeiro. Brasil.

Shuman, Larry J.; et al. (2002.) The future of engineering education. 32 ${ }^{\text {nd }}$ ASEE/IEEE: Frontiers in Education Conference. November 6 - 9,2002, Boston.

Shuman, Larry J.; et al. (2005.)The ABET Professional Skills - Can TheyBe Taught? Can They Be Assessed? Journal of Engineering Education, 94(1), pp. 41-56, 2005.

Shuman, Larry; Atman, Cynthia; Eschembach, Elizabeth; Evans, Don; FelderR, Richard; Imbrie, P. K.; Mc Gourty, Jack; Miller Ronald; Richards Larry; Smith, Karl; Soulsbi, Eric; Waller, Alisha and Yokomoto, Charles. (2002). The future of engineering education.. $32^{\circ}$ ASEE/IEEE Frontiers in Education Conference. pp T4A-1 - T4A-15

Sierra, Javier; Cabezuelo, Francisco. (2009). Post periodismo y formación en competencias digitales bajo el paraguas de Bolonia. I Congreso Internacional de la Sociedad Latina de Comunicación Social. Universidad de La Laguna.

SIGA. (2014). Sistema Integrado de Gestión Administrativa. Universidad de Piura. Visitado por última vez el 20 de junio de 2014 en https://sigadocentes.udep.edu.pe/siga/ administracion/gestionDocumentos $/$ DocumentosInfo.seam?logic $=$ and\&cid $=11849$

SINEACE. (2014). Sistema Nacional de Evaluación, Acreditación y Certificación de la Calidad Educativa. República del Perú. http://www.sineace.gob.pe/. Visitado el 18 de junio de 2014.

SIR-SCHIMAGO. (2011). SIR World Report 2011: Regional Supplements. Revisado junio 2012. http://www.scimagoir.com/pdf/sir_2011_world_report.pdf.

Smerdon, E., (2000). An Action Agenda for Engineering Curriculum Innovation. 11th IEEEUSA Biennial Careers Conference, San Jose, Cal., Nov. 2 and 3, 2000. Visitado por última vez en junio de 2013, http://www.ieeeusa.org/careercon/proceeding/esmerdon.pdf.

Smerdon, E., (2000). An Action Agenda for Engineering Curriculum Innovation. 11th IEEEUSA Biennial Careers Conference, San Jose, Cal., Nov. 2 and 3, 2000. Visto por última vez en junio 2013, http://www.ieeeusa.org/careercon/proceeding/esmerdon.pdf. 
Smith, K.A.; Prados, JW. (2000) Academic Bookshelf. Journal of Engineering Education, v. 89, 4, October, 2000.

Stevens, M. J., \& Campion, M. A. (1994). The knowledge, skill, and ability requirements for teamwork: Implications for human resource management. Journal of Management. Vol. 20: 503-530.

Strauss, A.; Corbin, J. (1994). Grounded Theory Methodology, An overview. Handbook of Qualitative Research. Sage Publications. New York.

Suarez A., B. (2004). Las enseñanzas técnicas del espacio europeo de educación superior. Universidad Politécnica de Cataluña. http://www.porto.ucp.pt/feg/bolonha/docs/ Reflectir_bolonha/sems/c1/01_bs.pdf

Thompson Reuters. (2011). The world university rankings 2010-2011. Inglaterra. http://www.timeshighereducation.co.uk/world-university-rankings/2010-2011/top200.html

Tobón, Sergio. (2008). La formación basada en competencias en la educación superior: El enfoque complejo. Universidad Autónoma de Guadalajara. México

Tobón, S. (2010). Proyectos formativos: aprendizaje y evaluación de competencias. Méjico. Book Mart.

Tobón, S. (2013b). Diseño de planes de estudio y proyectos para desarrollar competencias. Seminario Taller Internacional. Universidad Nacional de Ingeniería. Perú.

Tobón, Sergio. (2013). Metodologías de gestión curricular: Una perspectiva socioformativa. Méjico. Ed. Trillas.

Toloza, María del Pilar. (2006). Hacia la Movilidad Estudiantil en la Integración Latinoamericana a partir de la Experiencia Europea. OBREA/UELARO. Buenos Aires.

Tonso, K. (2006a). Student engineers and engineering identity: Campus engineer identities as figured world. Cultural Studies of Science Education, 1(2), 273-307.

Tonso, K. (2006b). Teams that work: Campus culture, engineer identity, and social interactions. Journal of Engineering Education, 95(1), 210-229.

Torrelles C., Coiduras, J., Isus, S., Carrera X., París, G. y Cela, J. (2011). Competencia de trabajo en equipo: definición y categorización. Profesorado, Revista de currículum y formación del profesorado. Vol. 15, No 3: 329-344

Trabajando Perú, 2013. Tendencias en el mercado laboral peruano en el 2012. htpp://trabajando.com/peru/382-tendencias-en-el-mercado-laboral-peruano-en-2012. trabajando.com. Revisado el 27 de mayo de 2013.

Tünnennann Bernheim, Carlos. (1998). La reforma universitaria de Córdoba. Educación Superior y Sociedad. Vol. 9, N 1, 103-127, 1998.

Tünnennann, Carlos. (2003). La universidad ante los retos del siglo XXI. Universidad autónoma de Yucatán. 42 - 48 
Tünnermann Bemheim, Carlos. (2006). Desarrollo histórico de la Universidad en América Latina: Desde las primeras fundaciones universitarias hasta la universidad republicana. Buenos Aires. pp 64 - 72

U. Perú: Universidad Perú. (2012). http://www.universidadperu.com/ingenieria-industrialperu.php Consultada en abril de 2012.

UDEP. (1998). IDEARIO. Universidad de Piura. Perú. Visitado por última vez el 24 de junio de 2014 en http://udep.edu.pe/ideario.html

UDEP. (2007). Metodología para revisión y actualización de los Planes de Estudio de las carreras de Ingeniería de la Universidad de Piura - 2007. Facultad de Ingeniería. Universidad de Piura.

UDEP. (2009). Discursos de apertura y Lecciones inaugurales. Universidad de Piura. Visitado por última vez el 17 de junio de 2014. http://beta.udep.edu.pe /apertura/ discurso-delrector-dr-antonio-abruna-puyol-apertura-del-ano-academico-del-2009/

UDEP. (2013). Memoria Anual 2012. Universidad de Piura.

UDEP F.I. (2014). Plan estratégico de la Facultad de Ingeniería 2014 - 2018. Universidad de Piura. Visitado por última vez el 24 de junio de 2014 en http://udeping.wix.com/planestrategico\#!que-es/c13qh

UNESCO, (1998). Declaración Mundial sobre la educación superior en el siglo XXI: Visión y Acción. Visitado el 9 de junio http://www.unesco.org/education/ educprog/wche/declaration_spa.htm

UNESCO. (2009). Compendio Mundial de Educación 2009. Instituto de Estadística de UNESCO.

UNESCO. (2010). Compendio Mundial de Educación 2010, Instituto de Estadística de UNESCO. pp.160-170.

UNI, 2013. Universidad Nacional de Ingeniería. Facultad de Ingeniería Industrial y de Sistemas. http://www.uni.edu.pe/sitio/academico/facultades/industrial/. Visitado el cinco de junio de 2013.

UNIVERSIA, 2013. http://estudios-internacionales.universia.net/uk/sistema-educativo/ estructura.html. Consultado el 25 de mayo de 2013.

UPM. (2009). El contrato de aprendizaje. Guías rápidas sobre nuevas tecnologías- Servicio de Innovación Educativa. Universidad Politécnica de Madrid.

UVa. (2006). Método de casos. Universidad Politécnica de Valencia. Visitado el 16 de Junio de 2014, de Espacio interuniversitario de recursos para el EEES: http://www.recursos eees.uji.es/fichas/fm3.pdf

Uva: Universidad de Valladolid, 2010. Graduado en Ingeniería de Organización Industrial. Escuela de Ingenierías Industriales, Versión 2, 2010.7 - 9. Programa Verifica - ANECA.

Valcárcel, Carlos Daniel (1975). Historia de la educación. Lima. Editorial Educación, p 88. 
Vessuri, Henne. (1996). Pertinencia de la educación superior latinoamericana a finales del siglo XX. Revista Nueva Sociedad Nro. 146 Noviembre-Diciembre 1996, pp. 102-107.

Villanueva P., María E. (2013). Evaluación del trabajo adicional de resolución de problemas de matemática. VII Congreso Iberoamericano de Educación Matemática CIBEM. Uruguay. Actas del VII CIBEM (ISSN 2301-0797).

Waggoner. George R. (1971). La educación superior en los Estados Unidos y en Latinoamérica. University Press of Kansas. Vol 2. 1971. Lawrence, KS.

Warren, P. (2001): Reflexiones sobre ordenamiento territorial local e investigación-acción participativa en America Latina. Roma: FAO-SDAA.

Wei, James. (2005). Engineering education for a post-industrial world. Technology in Society. Elsevier Ltd. Vol. 27 pp. 123-132.

Weinberg, Gregorio. (2001). Ilustración a la reforma universitaria. Ideas y protagonistas. Santillana, Buenos Aires. p 46.

World Bank. (2011). Perú Data. http://www.bancomundial.org/es/country/peru

Xiang-Yun, D. (2006). Gendered practices of constructing an engineering identity in a problem based learning environment. European Journal of Engineering Education, 31(1), 35-42.

Yamada, G.; Castro, J.; \& Rivera, M. (2012). Educación Superior en el Perú: Retos para el Aseguramiento de la Calidad. Estudio del SINEACE encargado a los especialistas. SINEACE.

Yániz, C. (2003). Sistemas y métodos de aprendizaje. Seminario Internacional: Orientaciones pedagógicas para la convergencia Europea de Educación Superioi. Universidad de Deusto. Bilbao 2003.

Zambrano, J.; Velázquez, Rodrigo; Sáenz Fabiola. (2009). Tendencias de la educación en ingeniería. Avances investigación en ingeniería. Revista del Centro de Investigaciones. Facultad de Ingeniería de la Universidad Libre.

Zambrano, S. y Alvarado, F. (2011). Surgimiento y evolución de la ingeniería industrial. Revista In Vestigium Ire. Vol 4, 19-28 
ANEXOS 
ANEXO A

PERFIL DEL INGRESANTE A INGENIERÍA INDUSTRIAL DE LA UNIVERSIDAD DE PIURA 


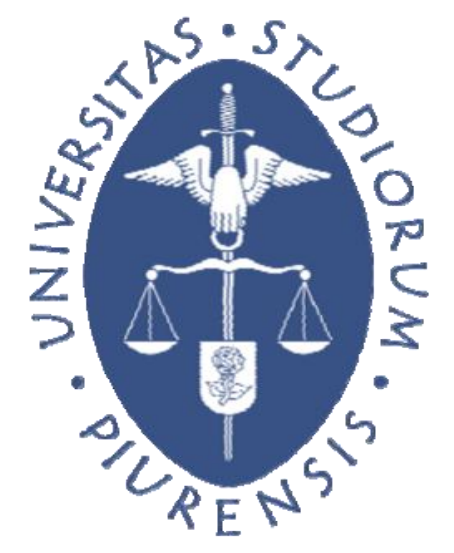

\section{PERFIL DEL INGRESANTE A LA FACULTAD DE INGENIERÍA Y PROCEDIMIENTO DE EVALUACION DEL PERFIL DEL INGRESANTE}




\section{ÍNDICE}

PARTE A

PERFIL DEL INGRESANTE 3

PARTE B

PROCEDIMIENTO DE EVALUACIÓN DEL PERFIL DEL INGRESANTE_6

PARTE C

INDICADORES PROPUESTOS 9

ANEXO

INGRESO CONTINUA DE UNIVERSIDAD DE PIURA 10

CONTENIDO DE LAS ASIGNATURAS DEL CURSO PROPEDÉUTICO EN INGENIERIA. 16 
Universidad de Piura

Facultad de Ingeniería

Documentos del ingresante 


\section{A. PERFIL DEL INGRESANTE}

\section{PERFIL DEL INGRESANTE}

Para poder afrontar con éxito los retos de los estudios universitarios, un admitido a los Programas Académicos de la Facultad de Ingeniería de la Universidad de Piura, debe haber desarrollado una serie de competencias y adquirido ciertos conocimientos.

El perfil del ingresante establece de manera precisa las competencias compuestas por conocimientos, habilidades, actitudes; y en general, los aprendizajes requeridos para desenvolverse en la carrera universitaria de la Facultad de Ingeniería.

Las competencias están organizadas de acuerdo a dos aspectos: el actitudinal y el aptitudinal.

A continuación se presenta una descripción de las competencias relacionadas al aspecto actitudinal (adaptación del Diseño Curricular Nacional 2009-DCN) y aptitudinal.

\section{COMPETENCIAS DEL ASPECTO ACTITUDINAL}

La competencia relacionada con la ÉTICA y la MORAL, le sirve al alumno para construir juicios de valor, los cuales formarán parte de su personalidad, permitiéndole actuar con una actitud positiva frente a las diferencias culturales, ideológicas y filosóficas.

La competencia relacionada con la DEMOCRACIA, se evidencia cuando el alumno es respetuoso de las reglas básicas de convivencia. La democracia la asume como una participación activa y responsable en todos los espacios en que se requiere su presencia e iniciativa. Asimismo, la demuestra en las diferentes situaciones donde se generan consensos y toma decisiones con otros.

La competencia relacionada con el pensamiento CRÍTICO Y REFLEXIVO, es una habilidad que se identifica cuando el alumno hace uso de manera constante del pensamiento divergente. Esta habilidad se evidencia cuando el alumno sabe analizar reflexivamente distintas situaciones, argumentando sus opiniones y se encuentra apto para discrepar, cuestionar y emitir juicios críticos.

La competencia relacionada con el pensamiento CREATIVO E INNOVADOR, se adquiere cuando al presentarse un problema, el alumno busca soluciones, alternativas y estrategias originales a los retos de su vida, orientándolas hacia el bien común e individual, en un marco de libertad. Es potencialmente innovador frente a la producción de conocimientos en distintos contextos.

La competencia relacionada con la SENSIBILIDAD y la SOLIDARIDAD, se evidencia cuando el alumno integra sus afectos en su actuar cotidiano y en su pensamiento reflexivo y es capaz de reaccionar tanto ante la injusticia, el dolor, la pobreza; como ante la alegría, la belleza, los descubrimientos y el avance de la humanidad. Respeta la vida y la naturaleza evitando su destrucción y defiende los derechos humanos de los más vulnerables.

La competencia relacionada con la TRASCENDENCIA, se evidencia cuando el alumno busca dar un sentido a su existencia y a su actuar, ubicándose como parte de una historia mayor de la humanidad. 
La competencia relacionada con la COMUNICACIÓN, se demuestra cuando el alumno expresa lo que piensa y siente con libertad en diferentes lenguajes y contextos. Asimismo, comprende mensajes e ideas diversas, sabe dialogar siendo capaz de escuchar a otros e interpretar diversos lenguajes simbólicos.

La competencia relacionada con la EMPATÍA y la TOLERANCIA, se evidencia en el alumno, cuando se pone en el lugar del otro para entender las motivaciones, intereses y puntos de vista distintos. Asume como riqueza la diversidad humana, respetándose a sí mismo y respetando al otro, entendiendo y comprendiendo a aquellos que son diferentes racial, sexual, cultural y religiosamente.

La competencia relacionada con la ORGANIZACIÓN, ayuda al alumno a organizar la información; planificar su tiempo y actividades, haciendo compatibles diversas dimensiones de su vida personal y social. Le permite planificar anticipadamente su accionar, con la finalidad de tomar mejores decisiones oportuna y eficazmente.

La competencia relacionada con la PROACTIVIDAD, le permite al alumno enfrentar con energía y seguridad, decisiones sobre situaciones diversas. Además, le ayuda a conjugar variables y factores para llegar a soluciones adecuadas. Se pone de manifiesto cuando el alumno constantemente se adelanta a los hechos; siendo diligente, independiente y teniendo iniciativa propia.

La competencia relacionada con la AUTONOMÍA, se hace evidente cuando el alumno actúa de manera acertada y de acuerdo con su propio criterio. Además, es capaz de asumir con responsabilidad las consecuencias de sus actos y el cuidado de sí mismo.

La competencia relacionada con la FLEXIBILIDAD, se hace evidente cuando el alumno es capaz de asumir diferentes situaciones de manera libre. Esta capacidad le permite poseer versatilidad de adaptación al cambio permanentemente.

La competencia relacionada con la RESOLUCIÓN DE PROBLEMAS, implica que el alumno comprenda los problemas identificando la información relevante para su solución. Esta habilidad le permite mantener el control de lo que hace, aplicando y adaptando diversas estrategias, así como también evaluando los resultados obtenidos.

La competencia relacionada con la INVESTIGACIÓN E INFORMACIÓN, se refiere a la capacidad que tiene el alumno para buscar y manejar información actualizada, significativa y diversa de manera organizada. El alumno está preparado para analizar, comparar y construir nuevos conocimientos a partir de la información proporcionada. Además, es capaz de hacer conjeturas e interesarse por resolver diversos problemas de la vida diaria y de la ciencia, haciendo uso de las tecnologías de la información y la comunicación.

La competencia relacionada con la COOPERACIÓN, se hace evidente cuando el alumno tiene la capacidad de enfrentar de manera efectiva y compartida una tarea, o resolver diversas situaciones conjuntamente con otras personas.

La competencia relacionada EMPRENDIMIENTO, se demuestra cuando el alumno asume iniciativas individuales o colectivas para solucionar problemas que tienen relación con su proyecto de vida. 


\section{COMPETENCIAS DEL ASPECTO APTITUDINAL}

Opera conforme a reglas aprendidas.

Fija información recién aprendida y lo aplica de inmediato.

Estima valores sin realizar cálculos

Estima el valor de verdad de proposiciones.

Descubre relaciones implícitas en el problema planteado.

Compara magnitudes e infiere conclusiones a partir de un enunciado.

Transforma palabras en símbolos y viceversa.

Traduce de una forma simbólica a otra (lee gráficos, interpreta diagramas, opera con símbolos).

Comprende y organiza la información dada, produce una solución y evalúa el resultado obtenido en relación al problema planteado.

Evalúa la situación problemática que se le presenta usando todas las habilidades anteriores mencionadas.

Posee un dominio léxico que le permite determinar el valor semántico de las palabras.

Posee competencia textual / Mantiene la coherencia y cohesión de textos.

Usa las palabras adecuadas para unir y relacionar elementos gramaticales.

Produce textos con claridad, orden y coherencia.

Organiza la información de un discurso, identificando las ideas principales, las ideas secundarias, así como las relaciones que establecen unas y otras.

Interpreta lo que lee, construye nuevos significados

Establece relaciones entre lo que lee y su experiencia y con informaciones anteriores.

Es capaz de una actitud crítica. 


\section{B. PROCEDIMIENTO DE EVALUACIÓN DEL PERFIL DEL INGRESANTE}

La evaluación del postulante tiene como objetivo seleccionar a los candidatos idóneos para estudiar la carrera profesional de Ingeniería en alguna de sus especialidades. Por ello, la Facultad de Ingeniería de la Universidad de Piura, establece varias características que deben reunir las personas que desean estudiar Ingeniería, entre las cuales destacan las siguientes:

\section{PERFIL ACTITUDINAL}

Se considera que las competencias actitudinales no pueden ser evaluadas simplemente con test psicotécnicos, psicológicos o con una simple entrevista formal. Este tipo de competencias deben ser evaluadas durante un período de tiempo, ya que los comportamientos que demuestren tener los estudiantes durante las situaciones de aprendizaje y la interacción con los demás agentes educativos, permitirá a los docentes verificar en qué nivel han sido adquiridas.

Por lo indicado en el párrafo anterior, las competencias deben ser logradas por el ingresante durante la Educación Básica Regular (EBR). Estas deben ser alcanzadas a través de los niveles educativos de esta modalidad y son garantizadas mediante la certificación que otorga el Sistema Educativo Peruano (Certificado de Estudios y Certificado de Conducta).

Adicionalmente durante el primer año de estudios en los Programas Académicos de la Facultad de Ingeniería, se realiza una evaluación y reforzamiento del Perfil actitudinal de los ingresantes.

Los docentes asesores evalúan las competencias, utilizando generalmente la técnica de la observación, apoyados en el sistema de tutoría. Ellos tienen a cargo la orientación de cada uno de los estudiantes asesorados, registran la información en el Sistema de Gestión Académica. El asesor orienta al estudiante para que identifique sus limitaciones y fortalezas. Con ello se busca que el estudiante logre desarrollar y consolidar sus competencias, perfeccionándolas y logrando un mayor nivel.

Las sugerencias y ayudas se proporcionan a través del Sistema de Tutoría de la Universidad de Piura. Los registros que se van creando con las entrevistas tienen un carácter confidencial y solo son conocidos por el estudiante y el asesor.

\section{PERFIL APTITUDINAL MATEMÁTICO-VERBAL}

Desde la creación de la carrera en el año 1969 hasta la actualidad, se ha considerado importante evaluar la condición en que ingresan los alumnos a la facultad de Ingeniería. Producto de ello, se ha ido cambiando la forma de admisión a la Universidad y los estudios en el primer año de la carrera.

Desde el año 2002 en la Universidad de Piura, se introdujo un cambio en la modalidad de admisión, y se da paso al concepto de ingreso o admisión continua, validado por el Departamento de Evaluación de la Universidad de Piura, y que actualmente constituye el medio de selección de los candidatos a las diferentes carreras profesionales que ofrece la Universidad de Piura.

La admisión continua, es un sistema de evaluación académica permanente, mediante el cual el postulante puede ser admitido a la carrera de su elección a través de los exámenes programados a lo largo del año.

La universidad ofrece dos tipos de vacantes: ordinaria y subvencionada.

La vacante ordinaria es aquella otorgada a postulantes de las modalidades de Test de Aptitup Académico (TAA), Prueba de Aptitud Escolar (PAE), Certificación UDEP (CU), Bachilleraro Internacional (IB), Tercio Superior (TS) o Premio Excelencia (PE). A los ingresantes bajo vacante 
ordinaria, la Oficina de Pensiones les evalúa su situación socioeconómica a fin de asignarle la escala correspondiente de pensión académica, cabe señalar que de este modo se subvenciona parte de los costos a los jóvenes que no cuenten con los recursos necesarios para pagar la pensión académica regular.

La vacante subvencionada es aquella otorgada solo a postulantes de alto rendimiento escolar y cuyos padres carecen de la capacidad económica suficiente para asumir la pensión mínima de una vacante ordinaria. Solo se puede acceder a una vacante subvencionada mediante el examen denominado "Concurso de Becas y Semibecas".

\section{CONOCIMIENTOS ESPECIFICOS DE LOS PROGRAMAS ACADÉMICOS DE LA FACULTAD DE INGENIERÍA}

Durante los años previos a 2005, se observó que los índices de reprobación y deserción de alumnos en los primeros ciclos en la Facultad de Ingeniería se incrementaron; esto debido a que muchos de los jóvenes ingresantes no contaban con el nivel académico, ni el ritmo de vida necesario para empezar una carrera universitaria.

Esto debido a muchos factores, entre ellos: la falta de preparación académica en los colegios secundarios y el sistema de admisión universitario, que permite a un alumno ingresar medio año antes a la universidad, trayendo como consecuencia una despreocupación en su exigencia académica y personal.

En reunión de claustro de profesores se abordó este tema, designando una comisión para que realice una evaluación y elabore una propuesta. Para cumplir con este encargo, la comisión consideró conveniente solicitar la opinión de los docentes de la Facultad, en cuanto a los temas que debería dominar un joven ingresante (competencia del aspecto aptitudinal); los resultados de esta solicitud se detallan a continuación:

\begin{tabular}{|l|}
\hline Contenidos requeridos \\
\hline Algebra Básica \\
Algebra Booleana \\
Aritmética Básica \\
Comprensión de lectura \\
Física Básica \\
Geometría Básica \\
Matemática \\
Ortografía \\
Química Básica \\
Razonamiento Matemático \\
Razonamiento Verbal \\
Redacción Técnica \\
Trigonometría Básica \\
\hline
\end{tabular}

Analizando los resultados obtenidos y tomando en cuenta las estadísticas del desempeño académico de los alumnos ingresantes, se llegó a la conclusión que la mayoría de los jóvenes ingresantes requieren cursar un nivel previo al inicio de los estudios universitarios, a fin de que puedan ser nivelados, y a la vez adquieran el ritmo de vida universitaria requerido.

El objetivo principal de esta propuesta es brindar a los jóvenes ingresantes, las competencias necesarias para cursar con éxito los estudios 
en la Facultad de Ingeniería, y por consiguiente disminuir los índices de reprobación y deserción de los primeros semestres. En consecuencia, se instaura como un mecanismo adicional de evaluación del ingresante.

Este mecanismo de evaluación del ingresante contempla una evaluación de los conocimientos específicos que se requieren para cursar con éxito los Programas Académicos de la Facultad de Ingeniería. El ingresante previo a iniciar sus estudios en los Programas académicos debe superar la nivelación, y para esto puede optar por tres opciones: Propedéutico, Introductorio o Examen de Convalidación.

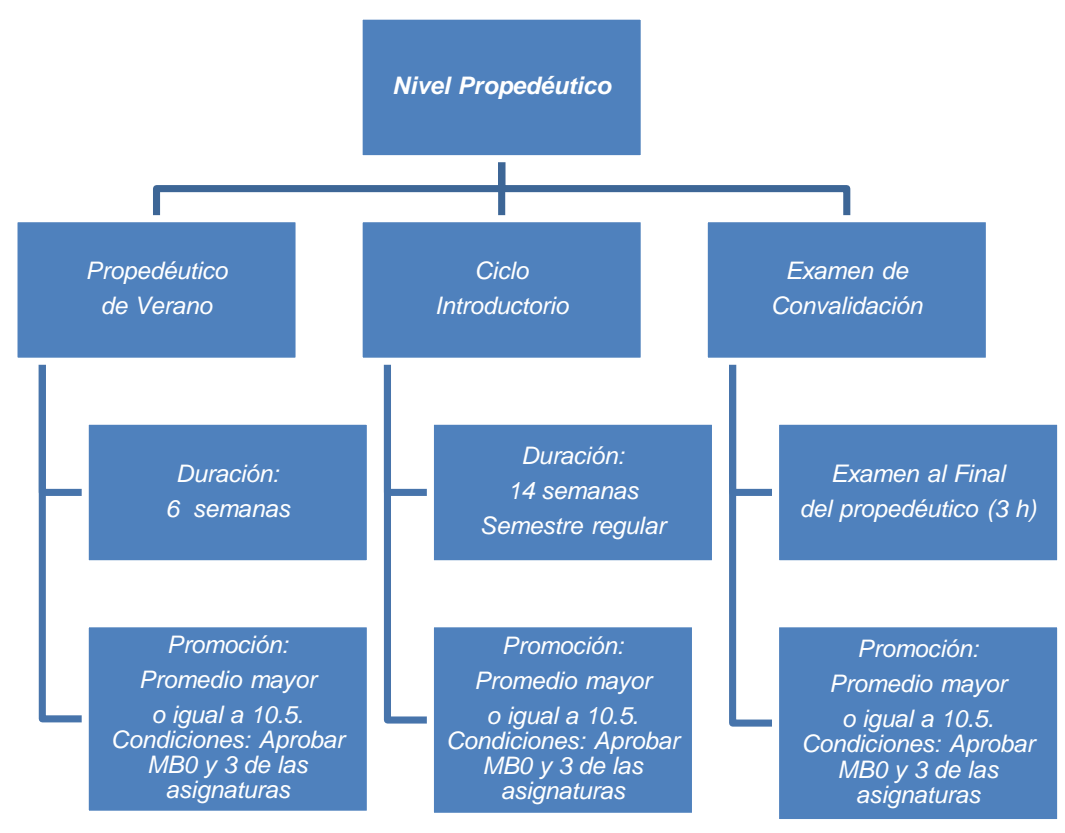

\section{INDICADORES}

Los indicadores que nos permiten llevar a cabo una mejor gestión del perfil de ingresante son los siguientes:

- Ratios del Número de Postulantes al Programa Académico, por modalidad: (NP)

$$
(\mathbf{N P})_{\mathbf{M}}=\left(\frac{\text { Número de Postulantes al Prog.Académico por cada modalidad }}{\text { Número total de Postulantes al Prog.Académico }}\right) \times \mathbf{1 0 0}
$$


- Porcentaje de Ingresantes al Programa Académico (PI):

$$
(\mathbf{P I})=\left(\frac{\text { Número de Ingresantes al Prog.Académico }}{\text { Número total de Postulantes al Prog.Académico }}\right) \times \mathbf{1 0 0}
$$

- Porcentaje de Ingresantes al Programa Académico matriculados (PM):

$$
(\mathbf{P M})=\left(\frac{\text { Número de Ingresantes al Prog.Académico matriculados }}{\text { Número total de Postulantes al Prog.Académico }}\right) \times \mathbf{1 0 0}
$$

- Porcentaje de Ingresantes Matriculados que superan la nivelación (PMP) en el primer intento:

$$
(\mathbf{P M P})=\left(\frac{\text { Número de Ingresantes al Prog.Académico aprobados en nivelación }}{\text { Número total de matriculados en nivelación o convalidación }}\right) \times \mathbf{1 0 0}
$$

Nota: Se considera aquellos que superan satisfactoriamente el ciclo propedéutico o el ciclo introductorio, en el primer intento, de acuerdo con los parámetros establecidos. Se considera incluso aquellos que intentan la convalidación.

- Puntaje promedio de admisión logrado por los ingresantes matriculados (PPA) i por Programa Académico, reportado en base vigesimal.

- Puntaje promedio de nivelación logrado por los ingresantes matriculados (PPN) i por Programa Académico, reportado en base vigesimal.

Nota: Se considera aquellos alumnos matriculados en el ciclo propedéutico o el ciclo introductorio, en el primer intento,

- Porcentaje de aprobación por asignatura en la nivelación (PA)

Nota: Se considera aquellos alumnos matriculados en el ciclo propedéutico o el ciclo introductorio, en el primer intento.

- Porcentaje de deserción (PD) en nivelación

$$
(P D)=\left(\frac{\text { Número de Ingresantes al Prog.Académico matriculados y deciden cambio de Facultad }}{\text { Número total de matriculados en nivelación o convalidación }}\right) \times \mathbf{1 0 0}
$$


ANEXO B CONTEXTUALIZACIÖN DE COMPETENCIAS GENÉRICAS: ENCUESTA PARA EGRESADOS 


\section{CUESTIONARIO PARA EGRESADOS}

A continuación se presentan una serie de cuestiones que tienen que ver con las competencias y habilidades que pueden ser importantes para el buen desempeño de la ingeniería industrial. Por favor, conteste a cada una de las preguntas. Las respuestas pueden ser de gran utilidad para la mejora de la planificación de su carrera de cara a los futuros alumnos.

Agradecemos sinceramente su colaboración.

\section{PREGUNTAS FILTRO}

1. ¿Hace cuántos años culminó sus estudios universitarios?

$$
\text { —1 - } 5 \text { años _6 - } 10 \text { años O más (Terminar) }
$$

2. Nombre del título:

(Si es distinto a Ingeniería Industrial TERMINE aquí la encuesta)

3. Situación laboral actual:
a. Trabajando en un puesto relacionado con sus estudios
b. Trabajando en un puesto no relacionado con sus estudios
c. Ampliando estudios
d. Buscando el primer empleo
e. Desempleado, habiendo trabajado antes
f. No estoy buscando ni he buscado empleo
g. Otro. Especificar, por favor:

\section{PREGUNTAS DE LA INVESTIGACIÓN}

4. ¿Cree que la formación que ha recibido en la universidad ha sido la adecuada?
1. Mucho

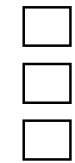
4. Poco
2. Bastante
5. Nada
3. Algo

5. ¿Cómo valora las posibilidades de encontrar trabajo al terminar su carrera?
1. Muy pocas

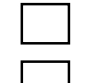
4. Bastantes
2. Pocas
5. Muchas
3. Algunas

6. ¿Sabe Ud. qué es una competencia genérica?
1. Sí
2. No
Terminar) 
Una competencia es "Una combinación dinámica de atributos que describen los resultados del aprendizaje de un determinado programa, o cómo los estudiantes serán capaces de desenvolverse al final del proceso educativo“. [Proyecto Tuning, 2003, p. 280)].

Para cada una de las competencias que se presentan a continuación, indique por favor:

$\checkmark$ La importancia que, en su opinión, tiene la competencia o habilidad para el ejercicio de su profesión.

$\checkmark$ El nivel en que cree que la habilidad o competencia se ha desarrollado durante sus estudios en su universidad.

Puede utilizar los espacios en blanco para incluir alguna otra competencia que considere importante y que no aparece en el listado o tachar la que le parece inapropiada

Utilice, por favor, la siguiente escala:

\begin{tabular}{|c|c|c|c|}
\hline $1=$ nada & $2=$ poco & $3=$ bastante & $4=$ mucho \\
\hline
\end{tabular}

\begin{tabular}{|c|c|c|}
\hline Habilidad / Competencia & Importancia & $\begin{array}{c}\text { Nivel } \\
\text { desarrollado } \\
\text { en la } \\
\text { Universidad }\end{array}$ \\
\hline 1) Capacidad de abstracción, análisis y síntesis. & 1234 & 1234 \\
\hline 2) Capacidad de aplicar los conocimientos en la práctica. & 1234 & 1234 \\
\hline 3) Capacidad para organizar y planificar el tiempo. & 1234 & 1234 \\
\hline 4) Conocimientos sobre el área de estudio y la profesión. & 1234 & 1234 \\
\hline 5) Responsabilidad social y compromiso ciudadano. & 1234 & 1234 \\
\hline 6) Capacidad de comunicación oral y escrita. & 1234 & 1234 \\
\hline 7) Capacidad de comunicación en un segundo idioma. & 1234 & 1234 \\
\hline $\begin{array}{l}\text { 8) Habilidades en el uso de las tecnologías de la } \\
\text { información y de la comunicación. }\end{array}$ & 1234 & 1234 \\
\hline 9) Capacidad de investigación. & 1234 & 1234 \\
\hline Habilidad / Competencia & Importancia & $\begin{array}{c}\text { Nivel } \\
\text { desarrollado } \\
\text { en la } \\
\text { Universidad } \\
\end{array}$ \\
\hline $\begin{array}{l}\text { 10) Capacidad de aprender y actualizarse } \\
\text { permanentemente. }\end{array}$ & 1234 & 1234 \\
\hline $\begin{array}{l}\text { 11) Habilidades para buscar, procesar y analizar } \\
\text { información procedente de fuentes diversas. }\end{array}$ & 1234 & 1234 \\
\hline
\end{tabular}




\begin{tabular}{|c|c|c|}
\hline 12) Capacidad crítica y autocrítica. & 1234 & 1234 \\
\hline 13) Capacidad para actuar en nuevas situaciones. & 1234 & 1234 \\
\hline 14) Capacidad creativa. & 1234 & 1234 \\
\hline $\begin{array}{l}\text { 15) Capacidad para identificar, plantear y resolver } \\
\text { problemas. }\end{array}$ & 1234 & 1234 \\
\hline 16) Capacidad para tomar decisiones. & 1234 & 1234 \\
\hline 17) Capacidad de trabajo en equipo. & 1234 & 1234 \\
\hline 18) Habilidades interpersonales. & 1234 & 1234 \\
\hline $\begin{array}{l}\text { 19) Capacidad de motivar y conducir hacia metas } \\
\text { comunes. }\end{array}$ & 1234 & 1234 \\
\hline 20) Compromiso con la preservación del medio ambiente. & 1234 & 1234 \\
\hline 21) Compromiso con su medio socio-cultural. & 1234 & 1234 \\
\hline $\begin{array}{l}\text { 22) Valoración y respeto por la diversidad y } \\
\text { multiculturalidad. }\end{array}$ & 1234 & 1234 \\
\hline 23) Habilidad para trabajar en contextos internacionales. & 1234 & 1234 \\
\hline 24) Habilidad para trabajar en forma autónoma. & 1234 & 1234 \\
\hline 25) Capacidad para formular y gestionar proyectos. & 1234 & 1234 \\
\hline 26) Compromiso ético. & 1234 & 1234 \\
\hline 27) Compromiso con la calidad. & 1234 & 1234 \\
\hline 28) $\ldots \ldots \ldots$ & 1234 & 1234 \\
\hline 29) & 1234 & 1234 \\
\hline
\end{tabular}

Muchas gracias por su colaboración. 
ANEXO C CONTEXTUALIZACIÓN DE COMPETENCIAS GENÉRICAS: ENCUESTA PARA PROFESORES 


\section{CUESTIONARIO PARA PROFESORES}

A continuación se presentan una serie de cuestiones que tienen que ver con las competencias y babilidades que pueden ser importantes para el buen desempeño de su profesión. Por favor, conteste a cada una de las preguntas. Las respuestas pueden ser de gran utilidad para la mejora de la planificación de su carrera de cara a los futuros alumnos.

Marque, en cada pregunta, la respuesta que considere más oportuna.

Agradecemos sinceramente su colaboración.

\section{PREGUNTAS FILTRO}

1. ¿Trabaja en la Universidad de Piura?

1. Sí

2. No (TERMINAR)

2. ¿Enseña una asignatura de Ingeniería Industrial?

1. Sí

2. No (TERMINAR)

3. Número de asignaturas que imparte:

\section{PREGUNTAS DE LA INVESTIGACIÓN}

4. ¿Considera usted que las personas a las que enseña en su universidad reciben una formación universitaria adecuada para trabajar en una empresa?
1. Mucho
2. Bastante
3. Algo
4. Poco
5. Muy poco

5. ¿Sabe Ud. qué es una competencia?
1. Sí
2. No 


\section{VALORACIÓN DE LAS COMPETENCIAS GENÉRICAS}

Una competencia es "Una combinación dinámica de atributos -con respecto al conocimiento y su aplicación a las actitudes y responsabilidades- que describen los resultados del aprendizaje de un determinado programa, o cómo los estudiantes serán capaces de desenvolverse al final del proceso educativo". [Proyecto Tuning. Informe final, fase I. (González y Wagenaar, 2003, p. 280)].

Para cada una de las competencias que se presentan a continuación, indique por favor:

$\checkmark$ La importancia que, en su opinión, tiene la competencia o habilidad para el ejercicio de la profesión.

$\checkmark$ El nivel en que cree que la habilidad o competencia se ha desarrollado durante su enseñanza en su universidad.

Puede utilizar los espacios en blanco para incluir alguna otra competencia que considere importante y que no aparece en el listado, tache aquella que considera no debe ser desarrollada.

Utilice, por favor, la siguiente escala:

\begin{tabular}{|l|l|l|l|}
\hline $1=$ nada & $2=$ poco & $3=$ bastante & $4=$ mucho \\
\hline
\end{tabular}

Por favor en cada caso borre el número que considera el más apropiado al item

\begin{tabular}{|l|r|r|}
\hline \multicolumn{1}{|c|}{ Habilidad / Competencia } & Importancia & $\begin{array}{c}\text { Nivel } \\
\text { desarrollado } \\
\text { en la } \\
\text { Universidad }\end{array}$ \\
\hline 1) Capacidad de abstracción, análisis y síntesis. & 1234 & 1234 \\
\hline 2) Capacidad de aplicar los conocimientos en la práctica. & 1234 & 1234 \\
\hline 3) Capacidad para organizar y planificar el tiempo. & 1234 & 1234 \\
\hline 4) Conocimientos sobre el área de estudio y la profesión. & 1234 & 1234 \\
\hline 5) Responsabilidad social y compromiso ciudadano. & 1234 & 1234 \\
\hline 6) Capacidad de comunicación oral y escrita. & 1234 & 1234 \\
\hline
\end{tabular}

\begin{tabular}{|c|c|c|}
\hline Habilidad / Competencia & Importancia & $\begin{array}{c}\text { Nivel } \\
\text { desarrollado } \\
\text { en la } \\
\text { Universidad }\end{array}$ \\
\hline 7) Capacidad de comunicación en un segundo idioma. & 1234 & 1234 \\
\hline
\end{tabular}




\begin{tabular}{|c|c|c|}
\hline $\begin{array}{l}\text { 8) Habilidades en el uso de las tecnologías de la } \\
\text { información y de la comunicación. }\end{array}$ & 1234 & 1234 \\
\hline 9) Capacidad de investigación. & 1234 & 1234 \\
\hline $\begin{array}{l}\text { 10) Capacidad de aprender y actualizarse } \\
\text { permanentemente. }\end{array}$ & 1234 & 1234 \\
\hline $\begin{array}{l}\text { 11) Habilidades para buscar, procesar y analizar } \\
\text { información procedente de fuentes diversas. }\end{array}$ & 1234 & 1234 \\
\hline 12) Capacidad crítica y autocrítica. & 1234 & 1234 \\
\hline 13) Capacidad para actuar en nuevas situaciones. & 1234 & 1234 \\
\hline 14) Capacidad creativa. & 1234 & 1234 \\
\hline $\begin{array}{l}\text { 15) Capacidad para identificar, plantear y resolver } \\
\text { problemas. }\end{array}$ & 1234 & 1234 \\
\hline 16) Capacidad para tomar decisiones. & 1234 & 1234 \\
\hline 17) Capacidad de trabajo en equipo. & 1234 & 1234 \\
\hline 18) Habilidades interpersonales. & 1234 & 1234 \\
\hline $\begin{array}{l}\text { 19) Capacidad de motivar y conducir hacia metas } \\
\text { comunes. }\end{array}$ & 1234 & 1234 \\
\hline $\begin{array}{l}\text { 20) Compromiso con la preservación del medio } \\
\text { ambiente. }\end{array}$ & 1234 & 1234 \\
\hline 21) Compromiso con su medio socio-cultural. & 1234 & 1234 \\
\hline $\begin{array}{l}\text { 22) Valoración y respeto por la diversidad y } \\
\text { multiculturalidad. }\end{array}$ & 1234 & 1234 \\
\hline 23) Habilidad para trabajar en contextos internacionales. & 1234 & 1234 \\
\hline 24) Habilidad para trabajar en forma autónoma. & 1234 & 1234 \\
\hline
\end{tabular}

\begin{tabular}{|c|c|c|}
\hline Habilidad / Competencia & Importancia & $\begin{array}{c}\text { Nivel } \\
\text { desarrollado } \\
\text { en la } \\
\text { Universidad }\end{array}$ \\
\hline 25) Capacidad para formular y gestionar proyectos. & 1234 & 1234 \\
\hline 26) Compromiso ético. & 1234 & 1234 \\
\hline 27) Compromiso con la calidad. & 1234 & 1234 \\
\hline 28) $\ldots \ldots \ldots \ldots \ldots \ldots \ldots$ & 1234 & 1234 \\
\hline
\end{tabular}




\begin{tabular}{|c|c|c|}
\hline 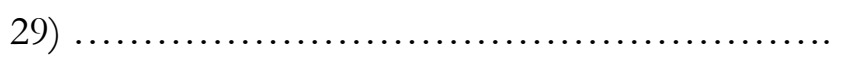 & 1234 & 1234 \\
\hline 30) $\ldots \ldots \ldots \ldots \ldots \ldots \ldots$ & 1234 & 1234 \\
\hline
\end{tabular}

Muchas gracias por su colaboración. 
ANEXO D CONTEXTUALIZACIÓN DE COMPETENCIAS GENÉRICAS:

ENCUESTA PARA ALUMNOS 


\section{CUESTIONARIO PARA ALUMNOS DE PREGRADO}

A continuación se presentan una serie de cuestiones que tienen que ver con las competencias y habilidades que pueden ser importantes para un buen desempeño cuando ejerzan su profesión. Por favor, conteste a cada una de las preguntas. Las respuestas pueden ser de gran utilidad para la mejora de la planificación de su carrera.

Marque, en cada pregunta, la respuesta que considere más oportuna.

Agradecemos sinceramente su colaboración.

\section{PREGUNTAS FILTRO}

1. Ciclo en que cursa sus estudios:

-1 a 2 ciclo $\quad 5$ a 6 ciclo $\quad 9$ a 10 ciclo

2. Nombre del título que obtendrá:

(Sino pertenece a la rama de Ingeniería Industrial TERMINAR)

\section{PREGUNTAS DE LA INVESTIGACIÓN}

3. ¿Cree que la formación que está recibiendo en la universidad es la adecuada?
1. Mucho
4. Poco
2. Bastante
5. Nada
3. Algo

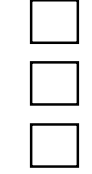

4. ¿Cómo valora las posibilidades de encontrar trabajo al terminar su carrera profesional?
1. Muy pocas
4. Bastantes
2. Pocas
5. Muchas
3. Algunas

5. ¿Sabe Ud. qué es una competencia?
1. Sí
2. No $\square$

VALORACIÓN DE LAS COMPETENCIAS GENÉRICAS 
Una competencia es "Una combinación dinámica de atributos que describen los resultados del aprendizaje de un determinado programa, o cómo los estudiantes serán capaces de desenvolverse al final del proceso educativo". [Proyecto Tuning. Informe final, fase I. (González y Wagenaar, 2003, p. 280)].

Para cada una de las competencias que se presentan a continuación, indique por favor:

$\checkmark$ La importancia que, en su opinión, tiene la competencia o habilidad para el ejercicio de su profesión.

$\checkmark$ El nivel en que cree que la habilidad o competencia se ha desarrollado durante sus estudios en su universidad.

Puede utilizar los espacios en blanco para incluir alguna otra competencia que considere importante y que no aparece en el listado.

Utilice, por favor, la siguiente escala:

\begin{tabular}{|l|l|l|l|}
\hline $1=$ nada & $2=$ poco & $3=$ bastante & $4=$ mucho \\
\hline
\end{tabular}

\begin{tabular}{|c|c|c|}
\hline Habilidad / Competencia & Importancia & $\begin{array}{c}\text { Nivel } \\
\text { desarrollado } \\
\text { en la } \\
\text { Universidad }\end{array}$ \\
\hline 1) Capacidad de abstracción, análisis y síntesis. & 1234 & 1234 \\
\hline 2) Capacidad de aplicar los conocimientos en la práctica. & 1234 & 1234 \\
\hline 3) Capacidad para organizar y planificar el tiempo. & 1234 & 1234 \\
\hline 4) Conocimientos sobre el área de estudio y la profesión. & 1234 & 1234 \\
\hline 5) Responsabilidad social y compromiso ciudadano. & 1234 & 1234 \\
\hline 6) Capacidad de comunicación oral y escrita. & 1234 & 1234 \\
\hline 7) Capacidad de comunicación en un segundo idioma. & 1234 & 1234 \\
\hline $\begin{array}{l}\text { 8) Habilidades en el uso de las tecnologías de la información } \\
\text { y de la comunicación. }\end{array}$ & 1234 & 1234 \\
\hline 9) Capacidad de investigación. & 1234 & 1234 \\
\hline 10) Capacidad de aprender y actualizarse permanenten & 1234 & 1234 \\
\hline
\end{tabular}

\begin{tabular}{|l|r|r|}
\hline \multicolumn{1}{|c|}{ Habilidad / Competencia } & Importancia & $\begin{array}{c}\text { Nivel } \\
\text { desarrollado } \\
\text { en la } \\
\text { Universidad }\end{array}$ \\
\hline $\begin{array}{l}\text { 11) Habilidades para buscar, procesar y analizar } \\
\text { información procedente de fuentes diversas. }\end{array}$ & 1234 & 1234 \\
\hline 12) Capacidad crítica y autocrítica. & 1234 & 1234 \\
\hline
\end{tabular}




\begin{tabular}{|c|c|c|}
\hline 13) Capacidad para actuar en nuevas situaciones. & 1234 & 1234 \\
\hline 14) Capacidad creativa. & 1234 & 1234 \\
\hline $\begin{array}{l}\text { 15) Capacidad para identificar, plantear y resolver } \\
\text { problemas. }\end{array}$ & 1234 & 1234 \\
\hline 16) Capacidad para tomar decisiones. & 1234 & 1234 \\
\hline 17) Capacidad de trabajo en equipo. & 1234 & 1234 \\
\hline 18) Habilidades interpersonales. & 1234 & 1234 \\
\hline $\begin{array}{l}\text { 19) Capacidad de motivar y conducir hacia metas } \\
\text { comunes. }\end{array}$ & 1234 & 1234 \\
\hline 20) Compromiso con la preservación del medio ambiente. & 1234 & 1234 \\
\hline 21) Compromiso con su medio socio-cultural. & 1234 & 1234 \\
\hline $\begin{array}{l}\text { 22) Valoración y respeto por la diversidad y } \\
\text { multiculturalidad. }\end{array}$ & 1234 & 1234 \\
\hline 23) Habilidad para trabajar en contextos internacionales. & 1234 & 1234 \\
\hline 24) Habilidad para trabajar en forma autónoma. & 1234 & 1234 \\
\hline 25) Capacidad para formular y gestionar proyectos. & 1234 & 1234 \\
\hline 26) Compromiso ético. & 1234 & 1234 \\
\hline 27) Compromiso con la calidad. & 1234 & 1234 \\
\hline 28) $\ldots \ldots \ldots \ldots \ldots \ldots \ldots \ldots \ldots \ldots \ldots \ldots \ldots$ & 1234 & 1234 \\
\hline 29) $\ldots \ldots \ldots$ & 1234 & 1234 \\
\hline 30) $\ldots \ldots$ & 1234 & 1234 \\
\hline
\end{tabular}

Muchas gracias por su colaboración. 
ANEXO E CONTEXTUALIZACIÓN DE COMPETENCIAS GENÉRICAS: ENCUESTA PARA EMPLEADORES 


\section{CUESTIONARIO PARA EMPLEADORES}

A continuación se presentan una serie de cuestiones que tienen que ver con las competencias y habilidades que pueden ser importantes para el buen desempeño de la profesión de (incluir el área). Por favor, conteste a cada una de las preguntas. Sus respuestas serán muy valiosas para la mejora de la planificación de los estudios de futuros alumnos de esta área.

Marque, en cada pregunta, la respuesta que considere más oportuna.

Agradecemos sinceramente su colaboración

\section{PREGUNTAS FILTRO}

1. ¿Usted tiene a cargo a personal que pertenezca a la rama de Ingeniería Industrial y que provenga de la Universidad de Piura?

1. Sí

2. No (TERMINAR)

\section{PREGUNTAS DE LA INVESTIGACIÓN}

2. Nombre de la empresa u organización (si lo desea):

3. Puesto o cargo de la persona que responde:

4. Rubro al que pertenece su empresa:

5. ¿Considera que provienen de Ingeniería Industrial de la Universidad de Piura han recibido una formación universitaria adecuada para trabajar en su empresa?

1. Mucho

2. Bastante

3. Algo

4. Poco

5. Muy poco

6. ¿Sabe Ud. qué es una competencia?

1. Sí

2. No 
Una competencia es "Una combinación dinámica de atributos -con respecto al conocimiento y su aplicación, a las actitudes y responsabilidades- que describen los resultados del aprendizaje de un determinado programa, o cómo los estudiantes serán capaces de desenvolverse al final del proceso educativo". Proy. Tuning, 2003].

Para cada una de las competencias que se presentan a continuación, indique por favor:

$\checkmark$ La importancia que, en su opinión, tiene la competencia o habilidad para el trabajo en su organización;

$\checkmark$ El nivel en que cree que la habilidad o competencia se ha desarrollado en los programas de la universidad en el área de (incluir aquí el área).

Puede utilizar los espacios en blanco para incluir alguna otra competencia que considere importante y que no aparece en el listado.

Utilice, por favor, la siguiente escala:

$$
1=\text { nada }
$$

$$
2=\text { poco }
$$$$
3 \text { = bastante }
$$$$
4=\text { mucho }
$$

Si responde a mano marque el número con una equis $(\mathrm{X})$, si lo hace digitalmente

\begin{tabular}{|c|c|c|}
\hline Habilidad / Competencia & Importancia & $\begin{array}{c}\text { Nivel } \\
\text { desarrollado } \\
\text { en la } \\
\text { Universidad }\end{array}$ \\
\hline 1) Capacidad de abstracción, análisis y síntesis. & 1234 & 1234 \\
\hline 2) Capacidad de aplicar los conocimientos en la práctica. & 1234 & 1234 \\
\hline 3) Capacidad para organizar y planificar el tiempo. & 1234 & 1234 \\
\hline 4) Conocimientos sobre el área de estudio y la profesión. & 1234 & 1234 \\
\hline 5) Responsabilidad social y compromiso ciudadano. & 1234 & 1234 \\
\hline 6) Capacidad de comunicación oral y escrita. & 1234 & 1234 \\
\hline 7) Capacidad de comunicación en un segundo idioma. & 1234 & 1234 \\
\hline $\begin{array}{l}\text { 8) Habilidades en el uso de las tecnologías de la información y } \\
\text { de la comunicación. }\end{array}$ & 1234 & 1234 \\
\hline 9) Capacidad de investigación. & 1234 & 1234 \\
\hline Habilidad / Competencia & Importancia & $\begin{array}{c}\text { Nivel } \\
\text { desarrollado } \\
\text { en la } \\
\text { Universidad } \\
\end{array}$ \\
\hline 10) Capacidad de aprender y actualizarse permanentemente. & 1234 & 1234 \\
\hline $\begin{array}{l}\text { 11) Habilidades para buscar, procesar y analizar información } \\
\text { procedente de fuentes diversas. }\end{array}$ & 1234 & 1234 \\
\hline
\end{tabular}
borre aquel número que considere la situación más apropiada a esa competencia. 


\begin{tabular}{|c|c|c|}
\hline 12) Capacidad crítica y autocrítica. & 1234 & 1234 \\
\hline 13) Capacidad para actuar en nuevas situaciones. & 1234 & 1234 \\
\hline 14) Capacidad creativa. & 1234 & 1234 \\
\hline 15) Capacidad para identificar, plantear y resolver problemas. & 1234 & 1234 \\
\hline 16) Capacidad para tomar decisiones. & 1234 & 1234 \\
\hline 17) Capacidad de trabajo en equipo. & 1234 & 1234 \\
\hline 18) Habilidades interpersonales. & 1234 & 1234 \\
\hline 19) Capacidad de motivar y conducir hacia metas comunes & 1234 & 1234 \\
\hline 20) Compromiso con la preservación del medio ambiente. & 1234 & 1234 \\
\hline 21) Compromiso con su medio socio-cultural. & 1234 & 1234 \\
\hline 22) Valoración y respeto por la diversidad y multiculturalidad. & 1234 & 1234 \\
\hline 23) Habilidad para trabajar en contextos internacionales. & 1234 & 1234 \\
\hline 24) Habilidad para trabajar en forma autónoma. & 1234 & 1234 \\
\hline 25) Capacidad para formular y gestionar proyectos. & 1234 & 1234 \\
\hline 26) Compromiso ético. & 1234 & 1234 \\
\hline 27) Compromiso con la calidad. & 1234 & 1234 \\
\hline 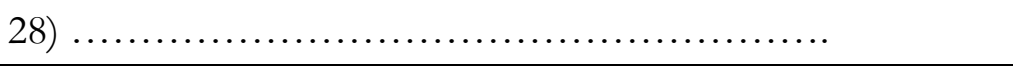 & 1234 & 1234 \\
\hline 29) $\ldots .$. & 1234 & 1234 \\
\hline
\end{tabular}

\section{Muchas gracias por su colaboración.}


ANEXO F CONTEXTUALIZACIÓN DE COMPETENCIAS ESPECÍFICAS: ENCUESTA PARA EGRESADOS 


\section{CUESTIONARIO PARA EGRESADOS}

A continuación se presentan una serie de cuestiones relacionadas con las competencias y habilidades especificas que pueden ser importantes para el buen desempeño profesional de la ingeniería industrial. Por favor, responda a cada una de las preguntas iniciales. Luego llene los casilleros de la tabla adjunta. Sus respuestas serán de gran utilidad para la mejora de la planificación de su carrera de cara a los futuros alumnos.

Agradecemos sinceramente su colaboración.

\section{PREGUNTAS FILTRO}

1. ¿Hace cuántos años culminó sus estudios universitarios?

-1 - 5 años

-6 - 10 años

_ Más de 10 años (Terminar)

2. Situación laboral actual:

h. Trabajando en un puesto relacionado con sus estudios

i. Trabajando en un puesto no relacionado con sus estudios

j. Ampliando estudios

k. Buscando el primer empleo

1. Desempleado, habiendo trabajado antes

m. No estoy buscando ni he buscado empleo

n. Otro. Especificar, por favor:

\section{VALORACIÓN DE LAS COMPETENCIAS ESPECÍFICAS}

Las competencias específicas de una carrera son los saberes y técnicas propias de un ámbito profesional, están más centradas en el «saber profesional», el «saber hacer» y el «saber guiar», que se distinguen de las genéricas que se centran en el "saber ser" y "saber estar". (Corominas, 2001)

Para cada una de las competencias que se presentan a continuación, indique por favor la importancia que, en su opinión, tiene la competencia o habilidad para el ejercicio profesional de la ingeniería industrial.

Puede utilizar los espacios en blanco para incluir alguna otra competencia que considere importante y que no aparece en el listado. 
Utilice, por favor, la siguiente escala:

\begin{tabular}{|c|c|c|c|c|}
\hline $1=$ nada & $2=$ poco & 3 = bastante & $4=$ mucho & \\
\hline \multicolumn{4}{|c|}{ Habilidad / Competencia Específica } & Importancia \\
\hline \multicolumn{5}{|c|}{ 1. Competencias Específicas de Formación Básica } \\
\hline \multicolumn{4}{|c|}{$\begin{array}{l}\text { 1.1 Capacidad para la resolución de los problemas matemáticos que puedan } \\
\text { plantearse en la ingeniería }\end{array}$} & \\
\hline \multicolumn{4}{|c|}{$\begin{array}{l}\text { 1.2 Comprensión y dominio de los conceptos básicos sobre las leyes generales } \\
\text { de la mecánica, termodinámica, ondas y electromagnetismo y su aplicación } \\
\text { para la resolución de problemas propios de la ingeniería }\end{array}$} & \\
\hline \multicolumn{4}{|c|}{$\begin{array}{l}\text { 1.3 Capacidad para comprender y aplicar los principios básicos de la química } \\
\text { general }\end{array}$} & \\
\hline \multicolumn{4}{|c|}{$\begin{array}{l}\text { 1.4 Capacidad de visión espacial y conocimiento de las técnicas de representación } \\
\text { gráfica, geometría métrica y geometría descriptiva }\end{array}$} & \\
\hline \multicolumn{4}{|c|}{ 1.5 Capacidad de comprender y analizar escritos en idioma español } & \\
\hline \multicolumn{4}{|c|}{ 1.6 Capacidad de escribir y hablar con corrección en idioma español. } & \\
\hline \multicolumn{4}{|c|}{ 1.7 Capacidad de comunicarse empleando medios audiovisuales. } & \\
\hline \multicolumn{4}{|c|}{$\begin{array}{l}\text { 1.8 Conoce la naturaleza del hombre y la raíz de su dignidad. Sabe ponerse en el } \\
\text { lugar del otro (empatía) cuando dirige y planifica el trabajo, de modo que } \\
\text { contribuya al mejoramiento personal de los otros. }\end{array}$} & \\
\hline \multicolumn{4}{|c|}{$\begin{array}{l}\text { 1.9 Conoce los principios fundamentales que organizan y orientan el } \\
\text { conocimiento de la realidad, así como el correcto obrar humano }\end{array}$} & \\
\hline \multicolumn{4}{|c|}{$\begin{array}{l}\text { 1.10 Conoce a Dios, sus atributos y perfecciones a la luz de los principios de la } \\
\text { razón y por verdades reveladas. Sabe aplicar este conocimiento a las } \\
\text { acciones humanas. }\end{array}$} & \\
\hline \multicolumn{4}{|c|}{ 1.11 Conoce y domina los métodos y técnicas de estudio apropiadas. } & \\
\hline \multicolumn{4}{|c|}{$\begin{array}{l}\text { 1.12 Capacidad de trabajar y comunicarse con corrección en un entorno } \\
\text { multidisciplinar y multilingüe (sobretodo en español e inglés) }\end{array}$} & \\
\hline \multicolumn{4}{|c|}{ 2. Competencias específicas de operaciones } & \\
\hline \multicolumn{4}{|c|}{$\begin{array}{l}\text { 2.1 Conocimientos de diseño y organización de plantas industriales, diseño y } \\
\text { mejora de procesos productivos y de servicios, control estadístico de } \\
\text { procesos y gestión de la calidad. }\end{array}$} & \\
\hline \multicolumn{4}{|c|}{$\begin{array}{l}\text { 2.2 Comprensión y dominio de métodos cuantitativos, algoritmos, optimización, } \\
\text { redes y grafos, teoría de colas, toma de decisiones, modelado, simulación y } \\
\text { validación, en el ámbito de los sistemas industriales, económicos y sociales. }\end{array}$} & \\
\hline
\end{tabular}




\begin{tabular}{|c|c|}
\hline Habilidad / Competencia Específica & Importancia \\
\hline $\begin{array}{l}\text { 2.3 Comprensión y dominio de los sistemas de producción, la planificación y el } \\
\text { control de la producción, la gestión de la cadena de suministro, la gestión } \\
\text { de stocks, la gestión de mantenimiento. }\end{array}$ & \\
\hline 2.4 Conocimientos de estudio del trabajo, métodos y tiempos. & \\
\hline 2.5 Conocimientos aplicados de planificación estratégica & \\
\hline $\begin{array}{l}\text { 2.6 Comprensión y dominio de la gestión integrada de la calidad, seguridad, el } \\
\text { medioambiente y la prevención de riesgos laborales. }\end{array}$ & \\
\hline $\begin{array}{l}\text { 2.7 Conocimientos básicos de la organización de los sistemas de producción y } \\
\text { fabricación. }\end{array}$ & \\
\hline $\begin{array}{l}\text { 2.8 Conocimientos de cambio tecnológico y estrategia empresarial, innovación } \\
\text { en la empresa, la competitividad industrial e innovación, los sistemas } \\
\text { regionales y nacionales de innovación, la política tecnológica y patrones de } \\
\text { innovación. }\end{array}$ & \\
\hline $\begin{array}{l}\text { 2.9 Conocimientos sobre planificación y desarrollo de nuevos productos y } \\
\text { procesos }\end{array}$ & \\
\hline $\begin{array}{l}\text { 2.10Conoce el tipo de trabajo a realizar en una empresa en el ámbito de la } \\
\text { Ingeniería Industrial. }\end{array}$ & \\
\hline 2.11Capacidad de dirección de proyectos en Ing. Industrial & \\
\hline $\begin{array}{l}\text { 2.12Capacidad para la redacción, firma y desarrollo de proyectos vinculados a la } \\
\text { Ingeniería Industrial }\end{array}$ & \\
\hline $\begin{array}{l}\text { 2.13Conocimientos y capacidades para organizar y gestionar proyectos. Conoce } \\
\text { la estructura organizativa y las funciones de una oficina de proyectos. }\end{array}$ & \\
\hline $\begin{array}{l}\text { 2.14Capacidad de analizar y valorar el impacto medioambiental y social de las } \\
\text { soluciones técnicas }\end{array}$ & \\
\hline 3. Competencias específicas administrativas & \\
\hline $\begin{array}{l}\text { 3.1 Conocimiento adecuado del concepto de empresa, marco institucional y } \\
\text { jurídico de la empresa. Organización y gestión de empresas. }\end{array}$ & \\
\hline 3.2 Conocimientos de marketing y comercialización de productos y servicios. & \\
\hline $\begin{array}{l}\text { 3.3 Comprensión y dominio de la organización del trabajo y el factor humano, } \\
\text { valoración de puestos de trabajo, conocimientos de derecho mercantil y } \\
\text { laboral. }\end{array}$ & \\
\hline $\begin{array}{l}\text { 3.4 Comprensión y dominio de técnicas de gestión financiera y de costes, } \\
\text { análisis de inversiones, estudios de viabilidad, finanzas, análisis de } \\
\text { mercados. }\end{array}$ & \\
\hline
\end{tabular}




\begin{tabular}{|c|c|}
\hline Habilidad / Competencia Específica & Importancia \\
\hline 3.6 Emprende y fomenta iniciativas empresariales & \\
\hline 3.7 Tiene conocimientos aplicados de organización de empresas. & \\
\hline 4. Competencias específicas en sistemas & \\
\hline $\begin{array}{l}\text { 4.1 Conocimientos básicos sobre el uso y programación de los ordenadores, sistemas } \\
\text { operativos, bases de datos y programas informáticos con aplicación en ingeniería. }\end{array}$ & \\
\hline $\begin{array}{l}\text { 4.2 Conocimientos de sists. de gestión para la organización y dirección de empresas, } \\
\text { sistemas de información y gestión integrada ERP }\end{array}$ & \\
\hline $\begin{array}{l}\text { 4.3 Iniciativa para proponer ideas y alternativas innovadoras para la mejora de los } \\
\text { sistemas productivos y organizativos }\end{array}$ & \\
\hline $\begin{array}{l}\text { 4.4 Conoce lenguajes de programación apropiados para la ejecución y control de } \\
\text { procesos. }\end{array}$ & \\
\hline 5. Competencias específicas técnicas & \\
\hline $\begin{array}{l}\text { 5.1 Conocimientos de termodinámica aplicada y transmisión de calor. Principios } \\
\text { básicos y su aplicación a la resolución de problemas de ingeniería }\end{array}$ & \\
\hline $\begin{array}{l}\text { 5.2 Conocimientos de los principios básicos de la mecánica de fluidos y su aplicación a } \\
\text { la resolución de problemas en el campo de la ingeniería. Cálculo de tuberías, } \\
\text { canales y sistemas de fluidos. }\end{array}$ & \\
\hline $\begin{array}{l}\text { 5.3 Conocimiento de los fundamentos de ciencia, tecnología y química de materiales. } \\
\text { Comprender la relación entre la microestructura, la síntesis o procesado y las } \\
\text { propiedades de los materiales. }\end{array}$ & \\
\hline $\begin{array}{l}5.4 \text { Conocimiento y utilización de los principios de teoría de circuitos y máquinas } \\
\text { eléctricas. }\end{array}$ & \\
\hline 5.5 Conocimientos de los fundamentos de la electrónica. & \\
\hline 5.6 Conoce sobre fundamentos de automatismos y métodos de control & \\
\hline 5.7 Conocimiento de los principios de teoría de máquinas y mecanismos. & \\
\hline 5.8 Conocimientos básicos de los sistemas de producción y fabricación. & \\
\hline 5.9 Conocimiento y utilización de los principios de resistencia de materiales & \\
\hline $\begin{array}{l}\text { 5.10Conocimientos básicos y aplicación de tecnologías medioambientales y } \\
\text { sostenibilidad }\end{array}$ & \\
\hline
\end{tabular}


Si desea agregar o eliminar una competencia específica, puede hacerlo en estos espacios. Si desea modificar alguna, puede hacerlo colocando el número de la de origen y la modificación.

\begin{tabular}{|l|}
\hline \\
\hline \\
\hline \\
\hline \\
\hline \\
\hline
\end{tabular}

Muchas gracias por su colaboració 
ANEXO G CONTEXTUALIZACIÓN DE COMPETENCIAS ESPECÍFICAS: ENCUESTA PARA PROFESORES 


\section{CUESTIONARIO PARA ACADEMICOS}

A continuación se presentan una serie de cuestiones relacionadas con las competencias y habilidades especificas que pueden ser importantes para el buen desempeño profesional de la ingeniería industrial. Por favor, coloque el número que en su opinión debe ir en cada casillero, siguiendo las indicaciones siguientes. Sus respuestas serán de gran utilidad para la mejora de la planificación de su carrera de cara a los futuros alumnos.

Agradecemos sinceramente su colaboración.

\section{VALORACIÓN DE LAS COMPETENCIAS ESPECÍFICAS}

Las competencias específicas de una carrera son los saberes y técnicas propias de un ámbito profesional, están más centradas en el «saber profesional», el «saber hacer» y el «saber guiar», que se distinguen de las genéricas que se centran en el "saber ser" y "saber estar". (Corominas, 2001)

Para cada una de las competencias que se presentan a continuación, indique por favor la importancia que, en su opinión, tiene la competencia o habilidad para el ejercicio profesional de la ingeniería industrial. Hágalo colocando el número que considere conveniente en la celda de la columna de la derecha, para cada caso.

Puede utilizar los espacios en blanco al final de la tabla para incluir alguna otra competencia que considere importante y que no aparece en el listado.

\section{Pregunta filtro}

1. ¿Conoce usted qué es una competencia específica?<smiles>C1C[SiH2]1</smiles>

Si la respuesta no fuese SÍ por favor no responda el formulario. Muchas gracias.

Utilice, por favor, la siguiente escala:

\begin{tabular}{|l|l|l|l|}
$1=$ nada & $2=$ poco & $3=$ bastante & $4=$ mucho \\
\hline
\end{tabular}




\section{\begin{tabular}{l|l|l|l}
$1=$ nada & $2=$ poco & $3=$ bastante & $4=$ mucho
\end{tabular}}

\begin{tabular}{|c|c|}
\hline Habilidad / Competencia Específica & Importancia \\
\hline 6. Competencias Específicas de Formación Básica & \\
\hline $\begin{array}{l}\text { 1.1 Capacidad para la resolución de los problemas matemáticos que puedan } \\
\text { plantearse en la ingeniería }\end{array}$ & \\
\hline $\begin{array}{l}\text { 1.2 Comprensión y dominio de los conceptos básicos sobre las leyes generales } \\
\text { de la mecánica, termodinámica, ondas y electromagnetismo y su aplicación } \\
\text { para la resolución de problemas propios de la ingeniería }\end{array}$ & \\
\hline $\begin{array}{l}\text { 1.3 Capacidad para comprender y aplicar los principios básicos de la química } \\
\text { general }\end{array}$ & \\
\hline $\begin{array}{l}\text { 1.4 Capacidad de visión espacial y conocimiento de las técnicas de } \\
\text { representación gráfica, geometría métrica y geometría descriptiva }\end{array}$ & \\
\hline 1.5 Capacidad de comprender y analizar escritos en idioma español & \\
\hline 1.6 Capacidad de escribir y hablar con corrección en idioma español. & \\
\hline 1.7 Capacidad de comunicarse empleando medios audiovisuales. & \\
\hline $\begin{array}{l}\text { 1.8 Conoce la naturaleza del hombre y la raíz de su dignidad. Sabe ponerse en el } \\
\text { lugar del otro (empatía) cuando dirige y planifica el trabajo de modo que } \\
\text { contribuya al mejoramiento personal de los otros. }\end{array}$ & \\
\hline $\begin{array}{l}\text { 1.9 Conoce los principios fundamentales que organizan y orientan el } \\
\text { conocimiento de la realidad, así como el correcto obrar humano }\end{array}$ & \\
\hline $\begin{array}{l}\text { 1.10 Conoce a Dios, sus atributos y perfecciones a la luz de los principios de la } \\
\text { razón y por verdades reveladas. Sabe aplicar este conocimiento a las } \\
\text { acciones humanas. }\end{array}$ & \\
\hline 1.11 Conoce y domina los métodos y técnicas de estudio apropiadas. & \\
\hline $\begin{array}{l}\text { 1.12 Capacidad de trabajar y comunicarse con corrección en un entorno } \\
\text { multidisciplinar y multilingüe (sobre todo en español e inglés) }\end{array}$ & \\
\hline 7. Competencias específicas de operaciones & \\
\hline $\begin{array}{l}\text { 2.1 Conocimientos de diseño y organización de plantas industriales, diseño y } \\
\text { mejora de procesos productivos y de servicios, control estadístico de } \\
\text { procesos y gestión de la calidad. }\end{array}$ & \\
\hline $\begin{array}{l}\text { 2.2 Comprensión y dominio de métodos cuantitativos, algoritmos, } \\
\text { optimización, redes y grafos, teoría de colas, toma de decisiones, } \\
\text { modelado, simulación y validación, en el ámbito de los sistemas } \\
\text { industriales, económicos y sociales. }\end{array}$ & \\
\hline $\begin{array}{l}\text { 2.3 Comprensión y dominio de los sistemas de producción, la planificación y el } \\
\text { control de la producción, la gestión de la cadena de suministro, la gestión } \\
\text { de stocks, la gestión de mantenimiento. }\end{array}$ & \\
\hline
\end{tabular}




\begin{tabular}{|c|c|}
\hline Habilidad / Competencia Específica & Importancia \\
\hline 2.4 Conocimientos de estudio del trabajo, métodos y tiempos. & \\
\hline 2.5 Conocimientos aplicados de planificación estratégica & \\
\hline $\begin{array}{l}\text { 2.6 Comprensión y dominio de la gestión integrada de la calidad, seguridad, el } \\
\text { medioambiente y la prevención de riesgos laborales. }\end{array}$ & \\
\hline $\begin{array}{l}\text { 2.7 Conocimientos básicos de la organización de los sistemas de producción y } \\
\text { fabricación. }\end{array}$ & \\
\hline $\begin{array}{l}\text { 2.8 Conocimientos de cambio tecnológico y estrategia empresarial, innovación } \\
\text { en la empresa, la competitividad industrial e innovación, los sistemas } \\
\text { regionales y nacionales de innovación, la política tecnológica y patrones de } \\
\text { innovación. }\end{array}$ & \\
\hline $\begin{array}{l}\text { 2.9 Conocimientos sobre planificación y desarrollo de nuevos productos y } \\
\text { procesos }\end{array}$ & \\
\hline $\begin{array}{l}\text { 2.10Conoce el tipo de trabajo a realizar en una empresa en el ámbito de la } \\
\text { Ingeniería Industrial. }\end{array}$ & \\
\hline 2.11Capacidad de dirección de proyectos en Ing. Industrial & \\
\hline $\begin{array}{l}\text { 2.12Capacidad para la redacción, firma y desarrollo de proyectos vinculados a la } \\
\text { Ingeniería Industrial }\end{array}$ & \\
\hline $\begin{array}{l}\text { 2.13Conocimientos y capacidades para organizar y gestionar proyectos. Conoce } \\
\text { la estructura organizativa y las funciones de una oficina de proyectos. }\end{array}$ & \\
\hline $\begin{array}{l}\text { 2.14Capacidad de analizar y valorar el impacto medioambiental y social de las } \\
\text { soluciones técnicas }\end{array}$ & \\
\hline 8. Competencias específicas administrativas & \\
\hline $\begin{array}{l}\text { 3.1 Conocimiento adecuado del concepto de empresa, marco institucional y } \\
\text { jurídico de la empresa. Organización y gestión de empresas. }\end{array}$ & \\
\hline 3.2 Conocimientos de marketing y comercialización de productos y servicios. & \\
\hline $\begin{array}{l}\text { 3.3 Comprensión y dominio de la organización del trabajo y el factor humano, } \\
\text { valoración de puestos de trabajo, conocimientos de derecho mercantil y } \\
\text { laboral. }\end{array}$ & \\
\hline $\begin{array}{l}\text { 3.4 Comprensión y dominio de técnicas de gestión financiera y de costes, } \\
\text { análisis de inversiones, estudios de viabilidad, finanzas, análisis de } \\
\text { mercados. }\end{array}$ & \\
\hline $\begin{array}{l}\text { 3.5 Conocimientos de la empresa y el modelo microeconómico, la } \\
\text { competitividad estratégica y estructura del mercado, el entorno y las } \\
\text { políticas macroeconómicas. }\end{array}$ & \\
\hline
\end{tabular}




\begin{tabular}{|c|c|}
\hline Habilidad / Competencia Específica & Importancia \\
\hline 3.6 Emprende y fomenta iniciativas empresariales & \\
\hline 3.7 Tiene conocimientos aplicados de organización de empresas. & \\
\hline 9. Competencias específicas en sistemas & \\
\hline $\begin{array}{l}\text { 4.1 Conocimientos básicos sobre el uso y programación de los ordenadores, sistemas } \\
\text { operativos, bases de datos y programas informáticos con aplicación en ingeniería. }\end{array}$ & \\
\hline $\begin{array}{l}\text { 4.2 Conocimientos de sists. de gestión para la organización y dirección de empresas, } \\
\text { sistemas de información y gestión integrada ERP }\end{array}$ & \\
\hline $\begin{array}{l}\text { 4.3 Iniciativa para proponer ideas y alternativas innovadoras para la mejora de los } \\
\text { sistemas productivos y organizativos }\end{array}$ & \\
\hline $\begin{array}{l}\text { 4.4 Conoce lenguajes de programación apropiados para la ejecución y control de } \\
\text { procesos. }\end{array}$ & \\
\hline 10. Competencias específicas técnicas & \\
\hline $\begin{array}{l}\text { 5.1 Conocimientos de termodinámica aplicada y transmisión de calor. Principios } \\
\text { básicos y su aplicación a la resolución de problemas de ingeniería }\end{array}$ & \\
\hline $\begin{array}{l}\text { 5.2 Conocimientos de los principios básicos de la mecánica de fluidos y su aplicación a } \\
\text { la resolución de problemas en el campo de la ingeniería. Cálculo de tuberías, } \\
\text { canales y sistemas de fluidos. }\end{array}$ & \\
\hline $\begin{array}{l}\text { 5.3 Conocimiento de los fundamentos de ciencia, tecnología y química de materiales. } \\
\text { Comprender la relación entre la microestructura, la síntesis o procesado y las } \\
\text { propiedades de los materiales. }\end{array}$ & \\
\hline $\begin{array}{l}\text { 5.4 Conocimiento y utilización de los principios de teoría de circuitos y máquinas } \\
\text { eléctricas. }\end{array}$ & \\
\hline 5.5 Conocimientos de los fundamentos de la electrónica. & \\
\hline 5.6 Conoce sobre fundamentos de automatismos y métodos de control & \\
\hline 5.7 Conocimiento de los principios de teoría de máquinas y mecanismos. & \\
\hline 5.8 Conocimientos básicos de los sistemas de producción y fabricación. & \\
\hline 5.9 Conocimiento y utilización de los principios de resistencia de materiales & \\
\hline $\begin{array}{l}\text { 5.10Conocimientos básicos y aplicación de tecnologías medioambientales y } \\
\text { sostenibilidad }\end{array}$ & \\
\hline
\end{tabular}

Si desea agregar o eliminar una competencia específica, puede indicarlo en estos espacios. Si desea modificar alguna, puede hacerlo colocando el número de la de origen y la modificación. 


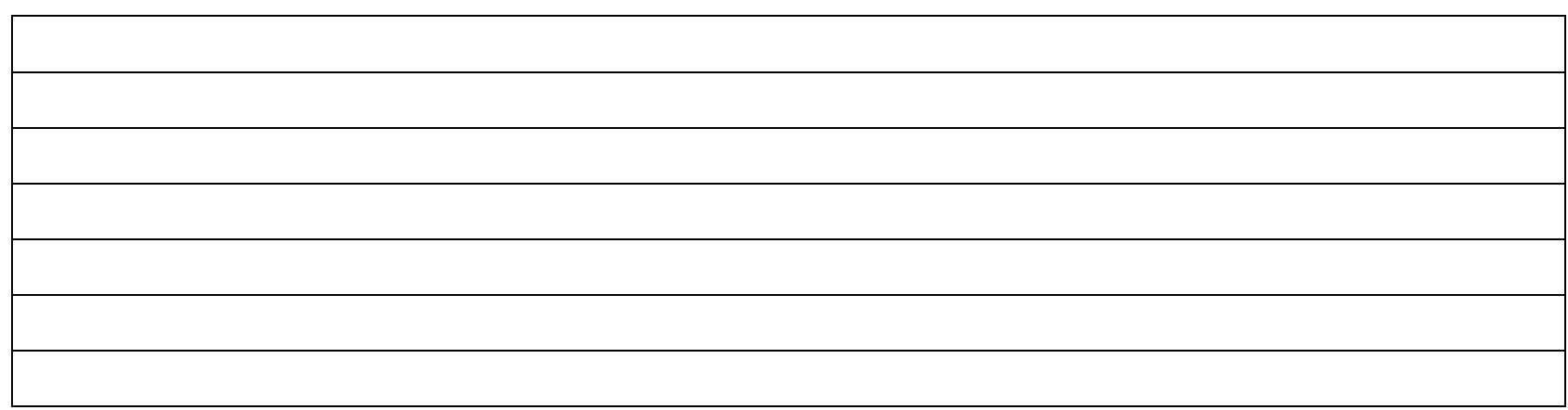

Muchas gracias por su colaboración. 
ANEXO H

CONTEXTUALIZACIÓN DE COMPETENCIAS ESPECÍFICAS:

ENCUESTA PARA EMPLEADORES 


\section{CUESTIONARIO PARA EMPLEADORES}

A continuación se presentan una serie de cuestiones relacionadas con las competencias y habilidades específicas que pueden ser importantes para el buen desempeño profesional de la ingeniería industrial. Por favor, coloque el número que en su opinión debe ir en cada casillero, siguiendo las indicaciones siguientes. Sus respuestas serán de gran utilidad para la mejora de la planificación de la carrera.

Agradecemos sinceramente su colaboración.

\section{PREGUNTA FILTRO}

1. ¿Conoce usted qué s una competencia específica?

$\square$ Sí

Si su respuesta es distinta a Sí, por favor, no responda la encuesta.

2. ¿Han trabajado o trabajan en su empresa egresados de la carrera de ingeniería industrial de la UDEP?

$\square$ Sí

Si su respuesta es distinta a Sí, por favor, no responda la encuesta.

\section{VALORACIÓN DE LAS COMPETENCIAS ESPECÍFICAS}

Las competencias específicas de una carrera son los saberes y técnicas propias de un ámbito profesional, están más centradas en el «saber profesional», el «saber hacer» y el «saber guiar», que se distinguen de las genéricas que se centran en el "saber ser" y "saber estar". (Corominas, 2001)

Para cada una de las competencias que se presentan a continuación, indique por favor la importancia que, en su opinión, tiene la competencia o habilidad para el ejercicio profesional de la ingeniería industrial. Hágalo colocando el número que considere conveniente en la celda de la columna de la derecha, para cada caso.

Puede utilizar los espacios en blanco al final de la tabla para incluir alguna otra competencia que considere importante y que no aparece en el listado.

\section{Utilice, por favor, la siguiente escala:}

\begin{tabular}{l|l|l|l}
$1=$ nada & $2=$ poco & $3=$ bastante & $4=$ mucho
\end{tabular}




\section{\begin{tabular}{l|l|l|l}
$1=$ nada & $2=$ poco & $3=$ bastante & $4=$ mucho
\end{tabular}}

\begin{tabular}{|c|c|}
\hline Habilidad / Competencia Específica & Importancia \\
\hline 3. Competencias Específicas de Formación Básica & \\
\hline $\begin{array}{l}\text { 1.1 Capacidad para la resolución de los problemas matemáticos que puedan } \\
\text { plantearse en la ingeniería }\end{array}$ & \\
\hline $\begin{array}{l}\text { 1.2 Comprensión y dominio de los conceptos básicos sobre las leyes generales } \\
\text { de la mecánica, termodinámica, ondas y electromagnetismo y su aplicación } \\
\text { para la resolución de problemas propios de la ingeniería }\end{array}$ & \\
\hline $\begin{array}{l}\text { 1.3 Capacidad para comprender y aplicar los principios básicos de la química } \\
\text { general }\end{array}$ & \\
\hline $\begin{array}{l}\text { 1.4 Capacidad de visión espacial y conocimiento de las técnicas de } \\
\text { representación gráfica, geometría métrica y geometría descriptiva }\end{array}$ & \\
\hline 1.5 Capacidad de comprender y analizar escritos en idioma español & \\
\hline 1.6 Capacidad de escribir y hablar con corrección en idioma español. & \\
\hline 1.7 Capacidad de comunicarse empleando medios audiovisuales. & \\
\hline $\begin{array}{l}\text { 1.8 Conoce la naturaleza del hombre y la raíz de su dignidad. Sabe ponerse en el } \\
\text { lugar del otro (empatía) cuando dirige y planifica el trabajo, de modo que } \\
\text { contribuya al mejoramiento personal de los otros. }\end{array}$ & \\
\hline $\begin{array}{l}\text { 1.9 Conoce los principios fundamentales que organizan y orientan el } \\
\text { conocimiento de la realidad, así como el correcto obrar humano }\end{array}$ & \\
\hline $\begin{array}{l}\text { 1.10 Conoce a Dios, sus atributos y perfecciones a la luz de los principios de la } \\
\text { razón y por verdades reveladas. Sabe aplicar este conocimiento a las } \\
\text { acciones humanas. }\end{array}$ & \\
\hline 1.11 Conoce y domina los métodos y técnicas de estudio apropiadas. & \\
\hline $\begin{array}{l}\text { 1.12 Capacidad de trabajar y comunicarse con corrección en un entorno } \\
\text { multidisciplinar y multilingüe (sobretodo en español e inglés) }\end{array}$ & \\
\hline 4. Competencias específicas de operaciones & \\
\hline $\begin{array}{l}\text { 2.1 Conocimientos de diseño y organización de plantas industriales, diseño y } \\
\text { mejora de procesos productivos y de servicios, control estadístico de } \\
\text { procesos y gestión de la calidad. }\end{array}$ & \\
\hline $\begin{array}{l}\text { 2.2 Comprensión y dominio de métodos cuantitativos, algoritmos, } \\
\text { optimización, redes y grafos, teoría de colas, toma de decisiones, } \\
\text { modelado, simulación y validación, en el ámbito de los sistemas } \\
\text { industriales, económicos y sociales. }\end{array}$ & \\
\hline $\begin{array}{l}\text { 2.3 Comprensión y dominio de los sistemas de producción, la planificación y el } \\
\text { control de la producción, la gestión de la cadena de suministro, la gestión } \\
\text { de stocks, la gestión de mantenimiento. }\end{array}$ & \\
\hline
\end{tabular}




\begin{tabular}{|c|c|}
\hline Habilidad / Competencia Específica & Importancia \\
\hline 2.4 Conocimientos de estudio del trabajo, métodos y tiempos. & \\
\hline 2.5 Conocimientos aplicados de planificación estratégica & \\
\hline $\begin{array}{l}\text { 2.6 Comprensión y dominio de la gestión integrada de la calidad, seguridad, el } \\
\text { medioambiente y la prevención de riesgos laborales. }\end{array}$ & \\
\hline $\begin{array}{l}\text { 2.7 Conocimientos básicos de la organización de los sistemas de producción y } \\
\text { fabricación. }\end{array}$ & \\
\hline $\begin{array}{l}\text { 2.8 Conocimientos de cambio tecnológico y estrategia empresarial, innovación } \\
\text { en la empresa, la competitividad industrial e innovación, los sistemas } \\
\text { regionales y nacionales de innovación, la política tecnológica y patrones de } \\
\text { innovación. }\end{array}$ & \\
\hline $\begin{array}{l}\text { 2.9 Conocimientos sobre planificación y desarrollo de nuevos productos y } \\
\text { procesos }\end{array}$ & \\
\hline $\begin{array}{l}\text { 2.10Conoce el tipo de trabajo a realizar en una empresa en el ámbito de la } \\
\text { Ingeniería Industrial. }\end{array}$ & \\
\hline 2.11Capacidad de dirección de proyectos en Ing. Industrial & \\
\hline $\begin{array}{l}\text { 2.12Capacidad para la redacción, firma y desarrollo de proyectos vinculados a la } \\
\text { Ingeniería Industrial }\end{array}$ & \\
\hline $\begin{array}{l}\text { 2.13Conocimientos y capacidades para organizar y gestionar proyectos. Conoce } \\
\text { la estructura organizativa y las funciones de una oficina de proyectos. }\end{array}$ & \\
\hline $\begin{array}{l}\text { 2.14Capacidad de analizar y valorar el impacto medioambiental y social de las } \\
\text { soluciones técnicas }\end{array}$ & \\
\hline 5. Competencias específicas administrativas & \\
\hline $\begin{array}{l}\text { 3.1 Conocimiento adecuado del concepto de empresa, marco institucional y } \\
\text { jurídico de la empresa. Organización y gestión de empresas. }\end{array}$ & \\
\hline 3.2 Conocimientos de marketing y comercialización de productos y servicios. & \\
\hline $\begin{array}{l}\text { 3.3 Comprensión y dominio de la organización del trabajo y el factor humano, } \\
\text { valoración de puestos de trabajo, conocimientos de derecho mercantil y } \\
\text { laboral. }\end{array}$ & \\
\hline $\begin{array}{l}\text { 3.4 Comprensión y dominio de técnicas de gestión financiera y de costes, } \\
\text { análisis de inversiones, estudios de viabilidad, finanzas, análisis de } \\
\text { mercados. }\end{array}$ & \\
\hline $\begin{array}{l}\text { 3.5 Conocimientos de la empresa y el modelo microeconómico, la } \\
\text { competitividad estratégica y estructura del mercado, el entorno y las } \\
\text { políticas macroeconómicas. }\end{array}$ & \\
\hline
\end{tabular}




\begin{tabular}{|c|c|}
\hline Habilidad / Competencia Específica & Importancia \\
\hline 3.6 Emprende y fomenta iniciativas empresariales & \\
\hline 3.7 Tiene conocimientos aplicados de organización de empresas. & \\
\hline 6. Competencias específicas en sistemas & \\
\hline $\begin{array}{l}\text { 4.1 Conocimientos básicos sobre el uso y programación de los ordenadores, } \\
\text { sistemas operativos, bases de datos y programas informáticos con } \\
\text { aplicación en ingeniería. }\end{array}$ & \\
\hline $\begin{array}{l}\text { 4.2 Conocimientos de sists. de gestión para la organización y dirección de } \\
\text { empresas, sistemas de información y gestión integrada ERP }\end{array}$ & \\
\hline $\begin{array}{l}\text { 4.3 Iniciativa para proponer ideas y alternativas innovadoras para la mejora de } \\
\text { los sistemas productivos y organizativos }\end{array}$ & \\
\hline $\begin{array}{l}\text { 4.4 Conoce lenguajes de programación apropiados para la ejecución y control } \\
\text { de procesos. }\end{array}$ & \\
\hline 7. Competencias específicas técnicas & \\
\hline $\begin{array}{l}\text { 5.1 Conocimientos de termodinámica aplicada y transmisión de calor. } \\
\text { Principios básicos y su aplicación a la resolución de problemas de } \\
\text { ingeniería }\end{array}$ & \\
\hline $\begin{array}{l}\text { 5.2 Conocimientos de los principios básicos de la mecánica de fluidos y su } \\
\text { aplicación a la resolución de problemas en el campo de la ingeniería. } \\
\text { Cálculo de tuberías, canales y sistemas de fluidos. }\end{array}$ & \\
\hline $\begin{array}{l}\text { 5.3 Conocimiento de los fundamentos de ciencia, tecnología y química de } \\
\text { materiales. Comprender la relación entre la microestructura, la síntesis o } \\
\text { procesado y las propiedades de los materiales. }\end{array}$ & \\
\hline $\begin{array}{l}\text { 5.4 Conocimiento y utilización de los principios de teoría de circuitos y } \\
\text { máquinas eléctricas. }\end{array}$ & \\
\hline 5.5 Conocimientos de los fundamentos de la electrónica. & \\
\hline 5.6 Conoce sobre fundamentos de automatismos y métodos de control & \\
\hline 5.7 Conocimiento de los principios de teoría de máquinas y mecanismos. & \\
\hline 5.8 Conocimientos básicos de los sistemas de producción y fabricación. & \\
\hline 5.9 Conocimiento y utilización de los principios de resistencia de materiales & \\
\hline $\begin{array}{l}\text { 5.10Conocimientos básicos y aplicación de tecnologías medioambientales y } \\
\text { sostenibilidad }\end{array}$ & \\
\hline
\end{tabular}

Si desea agregar o eliminar una competencia específica, puede hacerlo en estos espacios. Si desea modificar alguna, puede hacerlo colocando el número de la de origen y la modificación. 


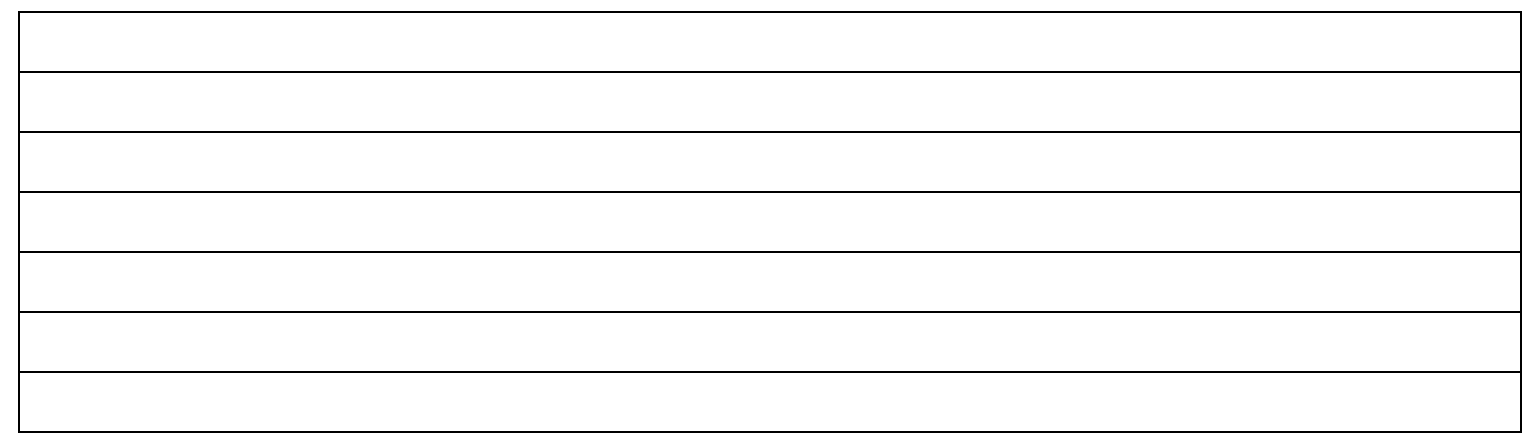

Muchas gracias por su colaboración. 
ANEXO I SILABO DE ASIGNATURA 


\section{FACULTAD(ES) DE INGENIERIA.}

PROGRAMA(S) ACADEMICO(S) DE INGENIERIA INDUSTRIAL Y DE SISTEMAS, INGENIERIA MECANICO ELECTRICA, INGENIERIA CIVIL, ARQUITECTURA.

\section{DATOS INFORMATIVOS}

Asignatura

Sigla

Sección

$\mathrm{N}^{\circ}$ créditos

Semestre

Profesor(es)
FÍSICA GENERAL I

F1

A

5

2014-I

Fernandez Curay, Roxana Ofelia.

\section{SUMILLA}

El desarrollo del presente curso tendrá un carácter eminentemente didáctico - práctico, basado en la introducción de los conceptos más importantes de la física general, con un grado de formalización y claridad conceptual adecuado al nivel del desarrollo intelectual del alumno. El estudiante ha de desarrollar una capacidad de raciocinio y de análisis riguroso de los hechos, al mismo tiempo con flexibilidad mental para adaptarse a los cambios que ocasiona la introducción de nuevas tecnologías.mación General siendo de carácter teórico-práctico

\section{FUNDAMENTACION}

El curso de Física 1 aborda el aspecto cognitivo (conocimiento), aspecto afectivo (valores, intereses) y su interacción con el medio que nos rodea.??

El curso en lo posible trata que el alumno pierda el temor las ciencias 'básicas, evitando en lo posible de que no solo se dedique al aspecto cuantitativo sino también al cualitativo. Para lograr esto se intenta primero conocer al grupo y poder observar las deficiencias que traen del colegio, para lo cual se elaboran una serie de estrategias que permita poder llegar a ellos y poder lograr los objetivos deseados.??

Entre los test que se vienen utilizando para conocer al grupo y llegar a observar dichas dificultades tenemos:?
a) Test de estilos de aprendizaje??
b) Test de pre-conceptos de la mecánica??

\section{OBJETIVOS GENERALES}

1. 1. Al final de la asignatura el alumno será capaz de entender con claridad y consistencia conceptual las cuestiones básicas de la Física, desarrollando la capacidad de raciocinio y de 
análisis de los hechos.?

2. 2. Al final del la asignatura el alumno será capaz de expresar la relación-interacción entre fenómenos físicos, químicos, matemáticos y biológicos, hasta encontrar una relación de dichos fenómenos con su entorno.?

\section{CONTENIDOS}

Unidad 1: Cinemática de la partícula

$\mathbf{N}^{\circ}$

Tema

1

recorrido, vector posición y vector

desplazamiento, relatividad al

movimiento

Movimiento en una dimensión:

velocidad media e instantánea

2 Movimiento con aceleración constante. Caída libre Movimiento Parabólico .

3 Movimiento Relativo. Movimiento acelración variable

Unidad 2: Leyes de Newton y aplicaciones para una partícula

$\mathbf{N}^{\circ}$

Tema

Semana

3

4

2 Newton. Fuerzas de contacto: normal y de rozamiento

Unidad 3: Equilibrio

$\mathbf{N}^{\circ}$

Tema

1 Momento de fuerza respecto de un eje y par de fuerzas. Fuerzas equivalentes

2 Traslado de pares a un mismo o distinto plano Diagrama de cuerpo
Semana Fecha de la sesión

5

6

2014-03-31

2014-04-14
Fecha de la sesión

2014-03-10

2014-03-17

2014-03-24
2.0

1.0

Horas de Horas de sesiones sesiones teóricas practicas

$4.0 \quad 2.0$

$4.0 \quad 2.0$

Horas de Horas de sesiones sesiones teóricas practicas

$2.0 \quad 1.0$

$4.0 \quad 2.0$

Horas de Horas de sesiones sesiones teóricas practicas

2.0

2.0

4.0

2.0 
libre y análisis de equilibrio en el plano

3 Estabilidad del equillibrio y centros de gravedad. Reacciones

Unidad 4: Trabajo y energía. Conservación

$\mathbf{N}^{\circ}$

\section{Tema}

Trabajo realizado por una fuerza

1 constante y variable Teorema de energia Cinética: energía cinética

Concepto de energía potencial de

2 fuerzas conservativas Fuerzas no conservativas

Ley de conservacíon de la energía.

3 Resolución de ejercicios usando los teoremas de trabajo vs energía

\section{Semana Fecha de la sesión}

8

9

2014-05-19

2014-05-19

9
Horas de Horas de sesiones sesiones teóricas practicas

4.0

Horas de Horas de sesiones sesiones teóricas practicas

internas e externas Cantidad de 10

2014-05-26 cantidad de movimiento

Impulso. Colisiones elásticas,inelástica

2 y plástica en una dimensión, 11

2014-06-09

Unidad 6: Sólido Rígido. Definición del momento angular

$\mathbf{N}^{\circ}$

\section{Tema}

Equilibrio estático de un cuerpo

1 rígido, sentido físico de un sólido rígido

Momento angular de una partícula y

2

relación con la cantidad de

movimiento Momento angular de un sistema de partículas

3 Momento angular del sólido rígido, conservación

\section{Semana Fecha de la sesión}

2014-06-02

sesiones sesiones teóricas practicas 
Semana

Fecha de la sesión

Horas de Horas de sesiones sesiones teóricas practicas

Postulados de Einstein.

Consecuencias del principio de

relatividad y principales alcances de la

13

2014-06-16

2.0

2.0

Física Cuántica

\section{COMPETENCIAS A DESARROLLAR}

Competencias Genéricas

Capacidad de aplicar los conocimientos en la práctica.

Capacidad de formular y gestionar proyectos.

Competencias específicas

Comprensión y dominio de los conceptos básicos sobre las leyes generales de la mecánica, termodinámica, ondas y electromagnetismo y su aplicación para la resolución de problemas propios de la ingeniería

Conoce los principios fundamentales que organizan y orientan el conocimiento de la realidad, así como el correcto obrar humano

Capacidad para la redacción, firma y desarrollo de proyectos vinculados a la Ingeniería Industrial

\section{ESTRATEGIAS METODOLÓGICAS}

1. Aprendizaje Basado en Problemas/Aprendizaje Basado en Proyectos

2. Debate

3. Exposición

4. Lluvia de ideas

5. Mapas conceptuales

6. Prácticas de laboratorio

7. Seminarios y mesas redondas

8. Simulación

9. Técnica de panel

\section{EVALUACION}

Para el curso de física 1 los criterios de evaluación serán:? 
- Durante el semestre se realizarán 04 prácticas de laboratorio, el promedio de las mismas tendrán peso 1 para la calificación final. De cada laboratorio se presentará un informe final, en el que se incluye la redacción formal del mismo.?

- Se realizará 04 ABP durante todo el semestre, el cual será desarrollado en forma grupal, se evaluará en aula y los informes de los mismos, teniendo peso de una práctica calificada .?

La evaluación en cuanto a prácticas calificadas y exámenes, será de acuerdo al cronograma de la Facultad.?

- El alumno podrá eliminar la nota más desfavorable de las prácticas calificadas, excepto la práctica de laboratorio, o la práctica del trabajo final, que no podrá anular?

\section{Tabla resumen}

\begin{tabular}{|c|c|c|c|c|c|}
\hline $\mathbf{N}^{\circ}$ & Descripción & Tipo evaluación & \multicolumn{2}{|c|}{ PesoAnulabl } & e Fecha \\
\hline 1 & Práctica 1 & Práctica & 1 & Sí & 21-03-2014 \\
\hline 2 & Práctica 2 & Práctica & 1 & Sí & $28-03-2014$ \\
\hline 3 & Práctica 3 & Práctica & 1 & Sí & 04-04-2014 \\
\hline 4 & Práctica 4 & Práctica & 1 & Sí & 11-04-2014 \\
\hline 5 & Práctica 6(grupal) & Práctica & 1 & No & 23-04-2014 \\
\hline 6 & Práctica 5 & Práctica & 1 & Sí & 25-04-2014 \\
\hline 7 & Práctica 7 & Práctica & 1 & Sí & 23-05-2014 \\
\hline 8 & Práctica 8 & Práctica & 1 & Sí & $30-05-2014$ \\
\hline 9 & Práctica 10 & Práctica & 1 & No & $16-06-2014$ \\
\hline 10 & Práctica 9 (grupal 3) & Práctica & 1 & No & $16-06-2014$ \\
\hline 11 & Examen 1 & Examen & 3 & Sí & $10-05-2014$ \\
\hline 12 & Examen 2 & Examen & 3 & Sí & $27-06-2014$ \\
\hline 13 & Laboratorio 1 & Laboratorio & 1 & No & 06-03-2014 \\
\hline 14 & Laboratorio 2 & Laboratorio & 1 & No & 06-03-2014 \\
\hline 15 & Laboratorio 3 & Laboratorio & 1 & No & 06-03-2014 \\
\hline 16 & Laboratorio 4 & Laboratorio & 1 & No & 06-03-2014 \\
\hline
\end{tabular}




$\begin{array}{lllll}17 \text { Laboratorio Promedio } & \text { Laboratorio } & 1 & \text { No } & \text { 02-04-2014 } \\ 18 \text { Sustitutorio/Aplazado 1Sustitutorio/Aplazado } & 3 & \text { Sí } & \text { 06-03-2014 }\end{array}$

\section{Temas por evaluación}

\section{Práctica 1}

No se han definido los temas que se evaluarán

\section{Práctica 2}

No se han definido los temas que se evaluarán

\section{Práctica 3}

No se han definido los temas que se evaluarán

\section{Práctica 4}

No se han definido los temas que se evaluarán

\section{Práctica 6(grupal)}

No se han definido los temas que se evaluarán

\section{Práctica 5}

No se han definido los temas que se evaluarán

\section{Práctica 7}

No se han definido los temas que se evaluarán

\section{Práctica 8}

No se han definido los temas que se evaluarán

\section{Práctica 10}

No se han definido los temas que se evaluarán

\section{Práctica 9 (grupal 3)}

No se han definido los temas que se evaluarán

\section{Examen 1}

No se han definido los temas que se evaluarán

\section{Examen 2}

No se han definido los temas que se evaluarán

\section{Laboratorio 1}

No se han definido los temas que se evaluarán

\section{Laboratorio 2}

No se han definido los temas que se evaluarán

\section{Laboratorio 3}


No se han definido los temas que se evaluarán

Laboratorio 4

No se han definido los temas que se evaluarán

Laboratorio Promedio

No se han definido los temas que se evaluarán

Sustitutorio/Aplazado 1

No se han definido los temas que se evaluarán

\section{BIBLIOGRAFIA}

\section{Bibliografía Básica}

1. 1. Sears Semasky, Física Universitario

2. 2. Tipler, Física, vol. I y II, Ed. Reverté 1995

\section{Bibliografía Avanzada}

1. 1. M. J. Shove, Física Clásica y moderna 